MARIANA VIVOLO AUN

ESTUDO DA REMOÇÃO DE NITROGÊNIO VIA NITRITO E VIA NITRATO EM SISTEMAS DE LODO ATIVADO ALIMENTADOS POR DESPEJO COM ELEVADA CONCENTRAÇÃO DE FENOL 


\section{ESTUDO DA REMOÇÃO DE NITROGÊNIO VIA NITRITO E VIA NITRATO EM SISTEMAS DE LODO ATIVADO ALIMENTADOS POR DESPEJO COM ELEVADA CONCENTRAÇÃO DE FENOL}

Tese apresentada à Escola Politécnica da Universidade de São Paulo para obtenção do título de Doutor em Engenharia 


\section{ESTUDO DA REMOÇÃO DE NITROGÊNIO VIA NITRITO E VIA NITRATO EM SISTEMAS DE LODO ATIVADO ALIMENTADOS POR DESPEJO COM ELEVADA CONCENTRAÇÃO DE FENOL}

Tese apresentada à Escola Politécnica da Universidade de São Paulo para obtenção do título de Doutor em Engenharia

Área de Concentração:

Engenharia Hidráulica e Sanitária

Orientador:

Pedro Alem Sobrinho 


\section{FICHA CATALOGRÁFICA}

\section{Aun, Mariana Vivolo}

Estudo da remoção de nitrogênio via nitrito e via nitrato em sistemas de lodo ativado alimentados por despejo com elevada concentração de fenol / M.V. Aun. -- São Paulo, 2007. 224p.

Tese (Doutorado) - Escola Politécnica da Universidade de São Paulo. Departamento de Engenharia Hidráulica e Sanitária.

1. Águas residuárias 2. Nitrificação 3. Desnitrificação I. Universidade de São Paulo. Escola Politécnica. Departamento de Engenharia Hidráulica e Sanitária II. t. 
Ao meu marido Abílio e a meu filho Felipe, pelo amor, carinho e compreensão; aos meus pais, irmãos e sobrinhos, preciosos companheiros e amigos de sempre. 


\section{AGRADECIMENTOS}

Ao Prof. Dr. Pedro Alem Sobrinho, pela orientação do trabalho, apoio profissional e amizade durante todos esses anos de convívio;

à Prof ${ }^{\mathrm{a}}$ Dra. Dione Mari Morita, pelas grandes contribuições que tanto engrandecem os trabalhos desta Escola;

ao colega e amigo Luciano Matos Queiroz, que me ajudou durante todo o desenvolvimento da pesquisa, desde a fase experimental até as preciosas sugestões para o enriquecimento da tese;

à colega de pós-graduação Mailer, pela grande colaboração no Laboratório durante os últimos meses de operação dos sistemas;

à FAPESP - Fundação de Amparo à Pesquisa do Estado de São Paulo, pelo financiamento do projeto de pesquisa;

à CAPES - Coordenação de Aperfeiçoamento de Pessoal de Nível Superior, pela bolsa de estudos oferecida;

do curso;

a meu marido Abílio e a meu filho Felipe, por todo o carinho e compreensão ao longo

a meus pais Wilson e Flávia; meus irmãos Adriana, Cristiane, Veridiana, Giovana, Giuliana e Marcelo; meus sobrinhos Tiago e Camilo; e meus cunhados e cunhada pela colaboração, paciência, apoio e ótimos conselhos dados;

aos colegas de pós-graduação da área de Hidráulica e Sanitária, Lúcia, Adriana, Ricardo, Carlos, Ruy, Gilberto e Diego, pelo estímulo e convivência amiga;

aos funcionários do Laboratório de Saneamento da EPUSP, Fábio e Laerte, e a todos os funcionários do CTH, especialmente Sr. Adhemar, pela preciosa colaboração prestada na fase experimental; colaboração e incentivo;

aos funcionários e professores do PHD-EPUSP, que sempre deram toda a e enfim, a todos aqueles que direta ou indiretamente contribuíram para a realização desta tese. 


\section{RESUMO}

Efluentes com grandes concentrações de fenol e nitrogênio amoniacal apresentam grande potencial poluidor ao meio ambiente. Exemplo deste tipo de despejo é o da unidade de coqueria da indústria siderúrgica que apresenta em termos quantitativos os fenóis como os principais constituintes orgânicos. Constituintes inorgânicos também estão presentes neste tipo de despejo e são principalmente cianeto, tiocianato, sulfato e nitrogênio amoniacal, sendo que a concentração deste último pode atingir níveis de centenas de miligramas por litro. No Estado de São Paulo, para atendimento às legislações em vigor - Decreto Estadual 8468/76 e Resolução CONAMA 357/05 - em termos de nitrogênio amoniacal e fenóis, as fontes poluidoras devem atender aos limites de emissão de $20 \mathrm{mg} \mathrm{N} / \mathrm{L}$ para nitrogênio amoniacal total e $0,5 \mathrm{mg} \mathrm{C}_{6} \mathrm{H}_{5} \mathrm{OH} / \mathrm{L}$ para índice de fenóis, e além disso, devem atender a classificação do corpo d'água. Após resultados bem sucedidos de pesquisas realizadas anteriormente no Departamento de Engenharia Hidráulica e Sanitária da EPUSP objetivando remoção de compostos fenólicos e nitrogênio amoniacal, presentes em uma água residuária sintética de coqueria, através de nitrificação/desnitrificação do afluente em sistemas de lodo ativado, idealizou-se a presente pesquisa objetivando promover a nitrificação/desnitrificação de um despejo similar contendo altas concentrações de fenol $(1000 \mathrm{mg} / \mathrm{L})$ e nitrogênio amoniacal (500 a $1000 \mathrm{mgN} / \mathrm{L}$ ) em sistema piloto de lodo ativado de lodo único, com duas concepções distintas: parcial ("P") a nitrito (ou "nitritação/desnitritação") em um primeiro caso, somente com fonte interna de carbono para a desnitrificação, e total ("T") num segundo caso, com fontes interna e externa de carbono. Além disso, também foi objetivo comparar os resultados obtidos do sistema piloto "P" com um sistema em bateladas seqüenciais operado paralelamente para remoção de nitrogênio via nitrito. A pesquisa permitiu concluir que o sistema contínuo, em virtude de seu regime operacional, não foi eficiente para remoção de nitrogênio via nitrito por não favorecer a manutenção de amônia livre na fase aeróbia em concentrações inibitórias aos microrganismos oxidadores de nitrito, já que segundo os resultados satisfatórios do sistema em bateladas seqüenciais, a existência de amônia livre e o $\mathrm{pH}$ se mostraram os principais parâmetros que regem o acúmulo de nitrito no reator. Apesar disso, o sistema apresentou resultados satisfatórios quanto à desnitrificação com fenol como fonte de carbono sendo que, durante toda a operação do sistema, o efluente final apresentou concentrações de fenol desprezíveis. Resumindo, o sistema contínuo só se mostrou adequado para remoção de nitrogênio via nitrato, ao passo que o sistema em batelada favoreceu a remoção via nitrito. Quanto ao sistema "T", que visava nitrificação/desnitrificação completa com fontes interna e externa de carbono, os resultados permitiram concluir que, apesar do etanol ser utilizado com eficiência pelas bactérias heterotróficas para promover a desnitrificação, seu uso como fonte externa de carbono não foi adequado em sistema de lodo único. Isto porque os microrganismos deixaram de utilizar o fenol na desnitrificação passando a utilizar somente o etanol, provocando acúmulo de fenol e desequilíbrio do sistema. Sendo assim, concluiu-se que o uso de etanol como fonte externa de carbono para a desnitrificação só seria recomendável em reator anóxico em separado, ou seja, em sistema de dois lodos e não de lodo único, como o da presente pesquisa.

Palavras-chave: Nitrito. Nitrato. Lodo Ativado. Fenol. 


\begin{abstract}
Wastewaters containing high phenol and ammonium concentrations present a great pollutant potential to the environment. An example of this kind of effluent is the discharge of coke-plants, which presents, quantitatively, the phenols as the main organic compound. Inorganic compounds are also present in these wastewaters and are mainly cyanide, thiocyanate, sulphate and ammonium, the last one being able to achieve hundreds of milligrammes per litre. In Sao Paulo State, there are two legislations to be accomplished, State Decree 8468/76 and CONAMA Resolution 357/05 that stand that the polluters must accomplish the discharge limits of $20 \mathrm{mg} \mathrm{N} / \mathrm{L}$ to total ammonium nitrogen and $0,5 \mathrm{mg} \mathrm{C}_{6} \mathrm{H}_{5} \mathrm{OH} / \mathrm{L}$ to phenols, as well as accomplish the waterbody classification. The present research was planned after well succeded results of former researches in EPUSP's Hydraulic and Sanitation Engineering Department aiming to remove phenolic compounds and ammonium from a synthetic coke-plant wastewater, by nitrification/denitrification of the influent in activated sludge plants. The main purpose of this work was to remove nitrogen of a similar wastewater containing high phenol $(1000 \mathrm{mg} / \mathrm{L})$ and ammonium $(500$ a $1000 \mathrm{mgN} / \mathrm{L})$ concentrations in two activated sludge pilot plants (single sludge): a partial one ("P") to remove nitrite (or "nitritation/denitritation") in the first case, only with internal carbon source for the denitrification, and a total one ("T") in a second case, with internal and external carbon sources. It was also aim of this work to compare the results obtained by the Partial ("P") pilot system with a parallel batch sequence reactor operated to remove nitrogen via nitrite. The research concluded that the continuos system, due to its operational characteristic, was not efficient to remove nitrogen via nitrite that does not favor the maintenance of free ammonia in the oxic phase in inhibitory concentrations to the nitrite oxidizers, as according to the wellsucceeded batch system, the existance of free ammonia and the $\mathrm{pH}$ have been the main parameters to raise the nitrite accumulation in the reactor. Nevertheless, the system presented satisfactory results to the denitrification with phenol as carbon source and, during the whole experimental work, the final effluent just showed despicable phenol concentrations. Summing up, continuos system was just adequate to remove nitrogen via nitrate, while the batch system favored its removal via nitrite. Due to the Total ("T") system which aims to complete nitrification/denitrification with internal and external carbon sources, the results showed that, despite ethanol having been successfully used by the heterotrophic bacteria to denitrification, its use as external carbon source was not adequate in single sludge system, because the microorganisms do not use phenol in denitrification, just using ethanol, causing phenol accumulation and unbalance of the system. Therefore, it was concluded that the use of ethanol as external carbon source to denitrification would be recommended only in anoxic separated reactor, i.e., in a double sludge system and not in a single sludge one, as this research.
\end{abstract}

Keywords: Nitrite. Nitrate. Activated Sludge. Phenol. 


\section{LISTA DE FIGURAS}

Figura 1 - Esquema dos principais produtos obtidos pela destilação do carvão e sua distribuição percentual.

Figura 2 - Etapas da biodegradação dos fenol com rompimento do anel benzênico nas posições orto e meta.

Figura 3 - Relação de inibição aos organismos nitrificantes por amônia e ácido nitroso.

Figura 4 - Variação do número de oxidação de nitrogênio nos processos de nitrificação e desnitrificação.

Figura 5 - $\quad$ O processo Wurhmann para remoção de nitrogênio......

Figura 6 - O processo modificado de Ludzack-Ettinger de remoção de nitrogênio.... 45

Figura 7 - O processo Bardenpho de remoção de nitrogênio. 47

Figura 8 - Esquema experimental do sistema CFID.

Figura 9 - Taxa de crescimento das Nitrosomonas e Nitrobacter em função da temperatura e tempo de residência.

Figura 10 - Esquema geral das instalações piloto.

Figura 11 - Caixa de alimentação. Na parte superior, pode-se visualizar a haste do misturador e o funil para introdução dos reagentes para preparo da água residuária

Figura 12 - Vista do painel de controle e bancada do sistema PARCIAL (P).............. 75

Figura 13 - Vista do painel de controle e bancada do sistema TOTAL (T)................ 76

Figura 14 - Vista geral dos sistemas piloto em paralelo: à direita o sistema Parcial (P) e à esquerda, o Total $(\mathrm{T})$

Figura 15 - Reator aeróbio do sistema PARCIAL ainda na fase de adaptação da biomassa, portanto sem controle e diminuição da aeração e sem agitador mecânico.

Figura 16 - Reator aeróbio do sistema PARCIAL, agora com controle de aeração e agitador mecânico instalado, evitando-se assim a decantação do lodo no fundo do reator. Mais ao fundo, o decantador secundário e seu motor do raspador de lodo

Figura 17 - Vista do sistema TOTAL: em primeiro plano o reator anóxico pré-D; no centro o reator aeróbio e ao fundo, o anóxico pós-D. 
Figura 18 - Procedimento diário de leitura de vazões.

Figura 19 - Vista geral da ETE piloto; em primeiro plano, os decantadores e suas respectivas bombas de deslocamento positivo para retorno de lodo.

Figura 20 - Vista geral das instalações piloto em um plano superior: primeiramente, o sistema PARCIAL e, mais ao fundo, o TOTAL.

Figura 21 - Esquema dos pontos de amostragem.

Figura 22 - Seqüência cronológica das etapas do ciclo de tratamento do sistema em batelada.

Figura 23 - Variação do pH do Sistema TOTAL (T) ao longo da primeira fase da pesquisa, com fração anóxica de 39\%.

Figura 24 - Variação da temperatura do Sistema TOTAL (T) ao longo da primeira fase da pesquisa, com fração anóxica de 39\%.

Figura 25 - Variação da concentração de OD do reator aeróbio do Sistema TOTAL (T) ao longo da primeira fase da pesquisa, com fração anóxica de 39\%....

Figura 26 - Concentração de sólidos em suspensão totais e voláteis do Sistema TOTAL (T) ao longo da primeira fase da pesquisa, com fração anóxica de $39 \%$.

Figura 27 - Alcalinidade observada nas unidades do Sistema TOTAL (T) ao longo da primeira fase da pesquisa, com fração anóxica de 39\%.

Figura 28 - Comportamento do nitrogênio amoniacal do Sistema TOTAL (T) ao longo da primeira fase da pesquisa, com fração anóxica de 39\%.

Figura 29 - Comportamento do nitrito e nitrato do Sistema TOTAL (T) ao longo da primeira fase da pesquisa, com fração anóxica de 39\%

Figura 30 - Eficiência de remoção de nitrogênio amoniacal no reator aeróbio e no sistema ao longo da primeira fase da pesquisa para o Sistema TOTAL (T), com fração anóxica de 44\%.

Figura 31 - Análise estatística de nitrogênio amoniacal do afluente e decantador do Sistema TOTAL (T), com concentração afluente da ordem de $500 \mathrm{mgN} / \mathrm{L}$, durante a primeira fase da pesquisa, com fração anóxica de $39 \%$.

Figura 32 - Análise estatística dos compostos oxidados de nitrogênio do Sistema TOTAL (T), com concentração afluente de nitrogênio amoniacal da ordem de $500 \mathrm{mgN} / \mathrm{L}$, durante a primeira fase da pesquisa, com fração anóxica de $39 \%$.

Figura 33 - Comportamento da DBO do Sistema TOTAL (T) ao longo da primeira fase da pesquisa, com fração anóxica de 39\%. 
Figura 34 - Comportamento do fenol do Sistema TOTAL (T) ao longo da primeira fase da pesquisa, com fração anóxica de 39\%.

Figura 35 - Relação A/M e taxa de utilização de substrato para o reator anóxico pré-D do Sistema TOTAL (T) ao longo da primeira fase da pesquisa, com fração anóxica de 39\%

Figura 36 - Análise estatística dos compostos fenólicos nas unidades do Sistema TOTAL (T), quando as concentrações afluentes de nitrogênio amoniacal eram de $500 \mathrm{mgN} / \mathrm{L}$, durante a primeira fase da pesquisa, com fração anóxica de 39\%

Figura 37 - Eficiência de remoção de fenol no reator anóxico pré-D e no sistema na primeira fase da pesquisa, com fração anóxica de 39\%, para o Sistema TOTAL (T).

Figura 38 - Variação do pH do Sistema TOTAL (T) ao longo da segunda fase da pesquisa, com fração anóxica de $49 \%$.

Figura 39 - Variação da temperatura do Sistema TOTAL (T) ao longo da segunda fase da pesquisa, com fração anóxica de $49 \%$.

Figura 40 - Variação da concentração de OD do reator aeróbio do Sistema TOTAL (T) ao longo da segunda fase da pesquisa, com fração anóxica de $49 \%$.

Figura 41 - Concentração de sólidos em suspensão totais e voláteis do Sistema TOTAL (T) ao longo da segunda fase da pesquisa, com fração anóxica de $49 \%$.

Figura 42 - Alcalinidade observada nas unidades do Sistema TOTAL (T) ao longo da segunda fase da pesquisa, com fração anóxica de $49 \%$

Figura 43 - Comportamento do nitrogênio amoniacal do Sistema TOTAL (T) ao longo da segunda fase da pesquisa, com fração anóxica de $49 \%$

Figura 44 - Comportamento do nitrito e nitrato do Sistema TOTAL (T) ao longo da segunda fase da pesquisa, com fração anóxica de $49 \%$.

Figura 45 - Eficiência de remoção de nitrogênio amoniacal no reator aeróbio e no sistema ao longo da segunda fase da pesquisa, com fração anóxica de $49 \%$, para o Sistema TOTAL (T).

Figura 46 - Análise estatística de nitrogênio amoniacal para o Sistema TOTAL (T), com concentração afluente da ordem de $500 \mathrm{mg}$ N/L, durante a segunda fase da pesquisa, com fração anóxica de $49 \%$.

Figura 47 - Análise estatística dos compostos oxidados de nitrogênio para o Sistema TOTAL (T), quando as concentrações afluentes de nitrogênio amoniacal eram de $500 \mathrm{mgN} / \mathrm{L}$, durante a segunda fase da pesquisa, com fração anóxica de $49 \%$ 
Figura 48 - Comportamento da DBO do Sistema TOTAL (T) ao longo da segunda fase da pesquisa, com fração anóxica de $49 \%$.

Figura 49 - Comportamento do fenol do Sistema TOTAL (T) ao longo da segunda fase da pesquisa, com fração anóxica de $49 \%$.

Figura 50 - Relação A/M e taxas de utilização de substrato para o reator anóxico pré-D do Sistema TOTAL (T) ao longo da segunda fase da pesquisa, com fração anóxica de $49 \%$

Figura 51 - Eficiência de remoção de fenol no reator anóxico pré-D e no sistema ao longo da segunda fase da pesquisa, com fração anóxica de 49\%, para o Sistema TOTAL (T)

Figura 52 - Análise estatística dos compostos fenólicos para o Sistema TOTAL (T), quando a concentração afluente de nitrogênio amoniacal era de $500 \mathrm{mgN} / \mathrm{L}$, durante a segunda fase da pesquisa, com fração anóxica de $49 \%$.

Figura 53 - Variação do pH do Sistema PARCIAL (P) ao longo da primeira fase da pesquisa, com fração anóxica de $23 \%$.

Figura 54 - Variação da temperatura do Sistema PARCIAL (P) ao longo da primeira fase da pesquisa, com fração anóxica de 23\%.

Figura 55 - Variação da concentração de OD do reator aeróbio do Sistema PARCIAL (P) ao longo da primeira fase da pesquisa, com fração anóxica de $23 \%$.

Figura 56 - Alcalinidade observada nas unidades do Sistema PARCIAL (P) ao longo da primeira fase da pesquisa, com fração anóxica de $23 \%$.

Figura 57 - Concentração de sólidos em suspensão totais e voláteis do Sistema PARCIAL (P) ao longo da primeira fase da pesquisa, com fração anóxica de $23 \%$

Figura 58 - Comportamento do nitrogênio amoniacal do Sistema PARCIAL (P) ao longo da primeira fase da pesquisa, com fração anóxica de 23\%.

Figura 59 - Comportamento do nitrito e nitrato do Sistema PARCIAL (P) ao longo da primeira fase da pesquisa, com fração anóxica de 23\%.

Figura 60 - Relação $\mathrm{N}-\mathrm{NO}_{2}{ }^{-} /\left(\mathrm{N}_{-} \mathrm{NO}_{2}{ }^{-}+\mathrm{N}-\mathrm{NO}_{3}{ }^{-}\right)$nos reatores anóxico e aeróbio do Sistema PARCIAL (P) ao longo da primeira fase da pesquisa, com fração anóxica de $23 \%$.

Figura 61 - Comportamento do pH e dos compostos nitrogenados no reator aeróbio do Sistema PARCIAL (P) ao longo da primeira fase da pesquisa, com fração anóxica de $23 \%$ 
Figura 62 - Eficiência de remoção de nitrogênio amoniacal no reator aeróbio e no sistema ao longo da primeira fase da pesquisa, com fração anóxica de 23\%, para o Sistema PARCIAL (P)

Figura 63 - Análise estatística do nitrogênio amoniacal no Sistema PARCIAL (P), para os resultados com concentração afluente de $500 \mathrm{mgN} / \mathrm{L}$, durante a primeira fase da pesquisa, com fração anóxica de $23 \%$

Figura 64 - Análise estatística dos compostos oxidados de nitrogênio no Sistema PARCIAL (P), para os resultados com concentração afluente de nitrogênio amoniacal de $500 \mathrm{mgN} / \mathrm{L}$, durante a primeira fase da pesquisa, com fração anóxica de $23 \%$.

Figura 65 - Análise estatística da relação $\mathrm{N}-\mathrm{NO}_{2}{ }^{-} /\left(\mathrm{N}-\mathrm{NO}_{2}{ }^{-}+\mathrm{N}-\mathrm{NO}_{3}{ }^{-}\right)$nos reatores anóxico e aeróbio do Sistema PARCIAL (P), para os resultados com concentração afluente de nitrogênio amoniacal de $500 \mathrm{mgN} / \mathrm{L}$, durante a primeira fase da pesquisa, com fração anóxica de $23 \%$

Figura 66 - Comportamento da DBO do Sistema PARCIAL (P) ao longo da primeira fase da pesquisa, com fração anóxica de $23 \%$.

Figura 67 - Comportamento do fenol do Sistema PARCIAL (P) ao longo da primeira fase da pesquisa, com fração anóxica de $23 \%$.

Figura 68 - Relação A/M e taxas de utilização de substrato no reator anóxico do Sistema PARCIAL (P) ao longo da primeira fase da pesquisa, com fração anóxica de $23 \%$.

Figura 69 - Eficiência na remoção de fenol no reator anóxico e no sistema ao longo da primeira fase da pesquisa, com fração anóxica de 23\%, para o Sistema PARCIAL (P).

Figura 70 - Análise estatística dos compostos fenólicos para o Sistema PARCIAL (P), para os resultados com concentração afluente de nitrogênio amoniacal de $500 \mathrm{mgN} / \mathrm{L}$, na primeira fase da pesquisa, com fração anóxica de $23 \%$

Figura 71 - Variação do pH do Sistema PARCIAL (P) ao longo da segunda fase da pesquisa, com fração anóxica de $41 \%$.

Figura 72 - Variação da temperatura do Sistema PARCIAL (P) ao longo da segunda fase da pesquisa, com fração anóxica de $41 \%$

Figura 73 - Variação da concentração de OD do reator aeróbio do Sistema PARCIAL (P) ao longo da segunda fase da pesquisa, com fração anóxica de $41 \%$.

Figura 74 - Concentração de sólidos em suspensão totais e voláteis do Sistema PARCIAL (P) ao longo da segunda fase da pesquisa, com fração anóxica de $41 \%$ 
Figura 75 - Alcalinidade observada nas unidades do Sistema PARCIAL (P) ao longo da segunda fase da pesquisa, com fração anóxica de $41 \%$.

Figura 76 - Comportamento do nitrogênio amoniacal do Sistema PARCIAL (P) ao longo da segunda fase da pesquisa, com fração anóxica de $41 \%$.

Figura 77 - Comportamento do nitrito e nitrato do Sistema PARCIAL (P) ao longo da segunda fase da pesquisa, com fração anóxica de $41 \%$.

Figura 78 - Relação $\mathrm{N}-\mathrm{NO}_{2}{ }^{-} /\left(\mathrm{N}-\mathrm{NO}_{2}{ }^{-}+\mathrm{N}-\mathrm{NO}_{3}{ }^{-}\right)$nos reatores anóxico e aeróbio do Sistema PARCIAL (P) ao longo da segunda fase da pesquisa, com fração anóxica de $41 \%$.

Figura 79 - Comportamento do $\mathrm{pH}$ e dos compostos nitrogenados no reator aeróbio do Sistema PARCIAL (P) ao longo da segunda fase da pesquisa, com fração anóxica de 41\%.

Figura 80 - Eficiência de remoção de nitrogênio amoniacal no reator aeróbio e no sistema ao longo da segunda fase da pesquisa, com fração anóxica de $41 \%$, para o Sistema PARCIAL (P)....

Figura 81 - Análise estatística da relação $\mathrm{N}-\mathrm{NO}_{2}{ }^{-} /\left(\mathrm{N}-\mathrm{NO}_{2}{ }^{-}+\mathrm{N}-\mathrm{NO}_{3}{ }^{-}\right)$nos reatores do Sistema PARCIAL (P), quando as concentrações afluentes de nitrogênio amoniacal eram de $500 \mathrm{mgN} / \mathrm{L}$, durante a segunda fase da pesquisa, com fração anóxica de $41 \%$

Figura 82 - Análise estatística do nitrogênio amoniacal no Sistema PARCIAL (P), quando as concentrações afluentes eram de $500 \mathrm{mgN} / \mathrm{L}$ ao longo da segunda fase da pesquisa, com fração anóxica de 41\%.

Figura 83 - Análise estatística dos compostos oxidados de nitrogênio no Sistema PARCIAL (P), quando as concentrações afluentes de nitrogênio amoniacal eram de $500 \mathrm{mgN} / \mathrm{L}$, durante a segunda fase da pesquisa, com fração anóxica de $41 \%$.

Figura 84 - Comportamento da DBO do Sistema PARCIAL (P) ao longo da segunda fase da pesquisa, com fração anóxica de $41 \%$.

Figura 85 - Comportamento do fenol do Sistema PARCIAL (P) ao longo da segunda fase da pesquisa, com fração anóxica de $41 \%$.

Figura 86 - Relações A/M e taxas de utilização de substrato no reator anóxico do Sistema PARCIAL (P) ao longo da segunda fase da pesquisa, com fração anóxica de $41 \%$.

Figura 87 - Eficiência de remoção de fenol no reator anóxico e no sistema ao longo da segunda fase da pesquisa, com fração anóxica de 41\%, para o Sistema PARCIAL (P). 
Figura 88 - Análise estatística dos compostos fenólicos no Sistema PARCIAL (P), quando as concentrações afluentes de nitrogênio amoniacal eram de $500 \mathrm{mgN} / \mathrm{L}$, durante a segunda fase da pesquisa, com fração anóxica de $41 \%$

Figura 89 - Perfis temporais das concentrações de $\mathrm{N}_{-} \mathrm{NO}_{2}{ }^{-}, \mathrm{N}-\mathrm{NO}_{3}{ }^{-}$, fenol, $\mathrm{N}_{-} \mathrm{NH}_{3}$ no conteúdo do reator - Ciclo 05 ( $\mathrm{pH}$ na etapa aeróbia $\cong 8,3$; $\mathrm{T} \cong 33^{\circ} \mathrm{C}$ ) Etapa 01 do Sistema em Bateladas Seqüenciais

Figura 90 - Perfis temporais de $\mathrm{pH}$ e OD no conteúdo do reator - Ciclo 05 Etapa 01 do Sistema em Bateladas Seqüenciais

Figura 91 - Perfis temporais das concentrações de $\mathrm{N}_{-} \mathrm{NO}_{2}{ }^{-}, \mathrm{N}-\mathrm{NO}_{3}{ }^{-}$, fenol, $\mathrm{N}^{-} \mathrm{NH}_{3}$ no conteúdo do reator - Ciclo 02 - Etapa 02 (pH na etapa aeróbia $\cong 8,3$; $\mathrm{T} \cong 25^{\circ} \mathrm{C}$ ) do Sistema em Bateladas Seqüenciais.

Figura 92 - Perfis temporais de pH e OD no conteúdo do reator - Ciclo 02 Etapa 02 do Sistema em Bateladas Seqüenciais.

Figura 93 - Perfil temporal de ORP no conteúdo do reator - Ciclo 02 - Etapa 02 do Sistema em Bateladas Seqüenciais

Figura 94 - Perfis temporais das concentrações de $\mathrm{N}^{-\mathrm{NO}_{2}}{ }^{-}, \mathrm{N}-\mathrm{NO}_{3}{ }^{-}$, fenol, $\mathrm{N}^{-} \mathrm{NH}_{3}$ no conteúdo do reator - Ciclo 02 - Etapa 03 ( $\mathrm{T} \cong 25^{\circ} \mathrm{C}$; $\mathrm{pH}$ na etapa aeróbia $\cong 8,3$ ) do Sistema em Bateladas Seqüenciais

Figura 95 - Perfis temporais de pH e OD no conteúdo do reator - Ciclo 02 Etapa 03 do Sistema em Bateladas Seqüenciais. 


\section{LISTA DE TABELAS}

Tabela 1 - Características de alguns despejos de coquerias ou similares.................... 09

Tabela 2 - Produtos químicos utilizados para preparação da água residuária sintética.

Tabela 3 - $\quad$ Plano de amostragem para monitoramento dos sistemas piloto.

Tabela 4 - Condições operacionais utilizadas durante toda a operação das ETE piloto.

Tabela 5 - Resumo dos resultados dos experimentos em batelada da Etapa 01 (nitrogênio amoniacal afluente $=200 \mathrm{mgN} / \mathrm{L}$ )

Tabela 6 - Resumo dos resultados dos experimentos em batelada da Etapa 02 (nitrogênio amoniacal afluente $=300 \mathrm{mgN} / \mathrm{L}$ )

Tabela A.1- Resultados do Monitoramento do Sistema TOTAL ("T") na Fase de Aclimatação.

Tabela A.2- Resultados do Monitoramento do Sistema PARCIAL ("P") na Fase de Aclimatação.

Tabela B.1- Resultados do Monitoramento do Sistema TOTAL ("T") das Análises de DQO.

Tabela B.2- Resultados do Monitoramento do Sistema PARCIAL ("P") das Análises de DQO.

Tabela C.1- Resultados do Monitoramento Diário do Sistema TOTAL ("T") na $1^{\mathrm{a}}$ Fase na Pesquisa.

Tabela C.2- Resultados do Monitoramento Diário do Sistema TOTAL ("T") na $2^{\mathrm{a}}$ Fase na Pesquisa.

Tabela D.1- Resultados do Monitoramento Diário do Sistema PARCIAL ("P") na $1^{\mathrm{a}}$ Fase na Pesquisa.

Tabela D.2- Resultados do Monitoramento Diário do Sistema PARCIAL ("P") na $2^{\mathrm{a}}$ Fase na Pesquisa.

Tabela E.1- Resultados do Monitoramento Semanal do Sistema TOTAL ("T") na $1^{\text {a }}$ Fase na Pesquisa.

Tabela E.2- Resultados do Monitoramento Semanal do Sistema TOTAL ("T") na $2^{\text {a }}$ Fase na Pesquisa. 
Tabela F.1- Resultados do Monitoramento Semanal do Sistema PARCIAL ("P") na $1^{\mathrm{a}}$ Fase na Pesquisa.

Tabela F.2- Resultados do Monitoramento Semanal do Sistema PARCIAL ("P") na $2^{\mathrm{a}}$ Fase na Pesquisa. 


\section{LISTA DE ABREVIATURAS E SIGLAS}

ANAMMOX $^{\circledR}$

AER

Afl.

Alcalin.

ANOX

APHA

art.

AWWA

CETESB

$\mathrm{cm}$

CONAMA

COT

$\mathrm{CTH}$

DBO

dec.

DQO

Efic.

EPA

EPUSP

eq.

ETE

FISH

g

h

HP

$\mathrm{kg}$

L
Anaerobic Ammonium Oxidation

reator aeróbio

afluente

Alcalinidade

reator anóxico

American Public Health Association

artigo

American Water Works Association

Companhia de Tecnologia de Saneamento Ambiental

centímetro

Conselho Nacional do Meio Ambiente

Carbono Orgânico Total

Centro Tecnológico de Hidráulica

Demanda Bioquímica de Oxigênio

Decantador

Demanda Química de Oxigênio

Eficiência

Environmental Protection Agency

Escola Politécnica da Universidade de São Paulo

equação

Estação de Tratamento de Efluentes

Fluorescence in situ hybridization

grama

hora

Horse Power - unidade de potência

kilograma

litro 
metro

Máx.

máximo

mg

miligrama

Mín.

mínimo

$\mathrm{mL}$

mililitro

$\mathrm{mm}$

milímetro

$\mathrm{mV}$

milivolts

$\mu \mathrm{g}$

micrograma

NAT

Nitrogênio Amoniacal Total (íon amônio + amônia livre)

NKT

Nitrogênio Kjeldahl Total

OD

Oxigênio Dissolvido

ORP

potencial de óxido-redução

"P”

PAHs

Sistema Parcial

Hidrocarbonetos aromáticos polinucleares

$\mathrm{pH}$

Potencial Hidrogeniônico

PHD

Departamento de Engenharia Hidráulica e Sanitária

pós-D

reator anóxico de pós-desnitrificação

pré-D

reator anóxico de pré-desnitrificação

ret.

retorno de lodo

rpm

rotação por minuto

SBR

SHARON $^{\circledR}$

Sequencing Batch Reactor

SND

Single Rector High Activity Ammonia Removal Over Nitrite

Simultaneous Nitrification/Denitrification

SS

Sólidos em Suspensão

SST

Sólidos em Suspensão Totais

SSV

Sólidos em Suspensão Voláteis

“T”

Sistema Total

TDE

taxa de desnitrificação específica

temp.

temperatura

USP

Universidade de São Paulo 
UV

WEF
Ultra Violeta

Water Environment Federation 


\section{LISTA DE SÍMBOLOS}

\begin{tabular}{|c|c|}
\hline $\mathrm{A}-\mathrm{A} / \mathrm{O}$ & sistema anaeróbio, anóxico e aeróbio \\
\hline$A_{1}-A_{2}-O$ & sistema anaeróbio, anóxico e aeróbio \\
\hline $\mathrm{A} / \mathrm{M}$ & relação Alimento/Microrganismo \\
\hline${ }^{\circ} \mathrm{C}$ & graus Celsius \\
\hline $\mathrm{C}_{6} \mathrm{H}_{5} \mathrm{OH}$ & fórmula molecular do Fenol \\
\hline $\mathrm{CaCO}_{3}$ & carbonato de cálcio \\
\hline $\mathrm{CH}_{3} \mathrm{OH}$ & fórmula molecular do Metanol \\
\hline $\mathrm{C}_{\mathrm{x}} \mathrm{H}_{\mathrm{y}} \mathrm{O}_{\mathrm{z}}$ & fórmula geral para material orgânico \\
\hline $\mathrm{CN}^{-}$ & cianeto \\
\hline $\mathrm{C} / \mathrm{N}$ & relação carbono/nitrogênio \\
\hline $\mathrm{CO}_{2}$ & gás carbônico \\
\hline $\mathrm{CO}_{3}^{2-}$ & íon carbonato \\
\hline $\mathrm{DBO}_{5,20}$ & Demanda Bioquímica de Oxigênio de 5 dias a $20{ }^{\circ} \mathrm{C}$ \\
\hline DQO/N & relação DQO/nitrogênio \\
\hline $\mathrm{e}^{-}$ & elétron livre \\
\hline $\mathrm{H}^{+}$ & cátion hidrogênio \\
\hline $\mathrm{HCO}_{3}^{-}$ & íon bicarbonato \\
\hline $\mathrm{H}_{2} \mathrm{O}$ & fórmula molecular da água \\
\hline $\mathrm{HNO}_{2}$ & ácido nitroso \\
\hline $\mathrm{Ka}$ & constante de ionização do ácido nitroso na condição de equilíbrio \\
\hline $\mathrm{Kb}$ & constante de ionização da amônia na condição de equilíbrio \\
\hline Kw & constante de ionização da água \\
\hline $\mathrm{N}$ & Nitrogênio \\
\hline $\mathrm{N}_{2}$ & gás Nitrogênio \\
\hline N-amon & Nitrogênio amoniacal \\
\hline $\mathrm{NH}_{3}$ & Amônia livre / Nitrogênio amoniacal não ionizado \\
\hline $\mathrm{NH}_{4}^{+}$ & íon amônio / Nitrogênio amoniacal ionizado \\
\hline $\mathrm{NH}_{2} \mathrm{OH}$ & Hidroxilamina não ionizada ou livre \\
\hline $\mathrm{NH}_{3} \mathrm{OH}^{+}$ & Hidroxilamina ionizada \\
\hline NO & óxido nítrico \\
\hline
\end{tabular}




$\begin{array}{ll}\mathrm{NO}_{2}{ }^{-} & \text {Nitrito } \\ \mathrm{NO}_{3}{ }^{-} & \text {Nitrato } \\ \mathrm{NOx} & \text { Nitrito + Nitrato } \\ \mathrm{N}_{2} \mathrm{O} & \text { óxido nitroso } \\ \mathrm{O} & \text { átomo de Oxigênio } \\ \mathrm{O}_{2} & \text { molécula de Oxigênio } \\ \mathrm{OH}^{-} & \text {hidroxila } \\ \mathrm{Q} & \text { vazão } \\ \mathrm{Qa} & \text { vazão afluente } \\ \mathrm{T} & \text { temperatura } \\ \theta & \text { coeficiente de temperatura } \\ \phi & \text { diâmetro } \\ \mathrm{U} & \text { taxa de utilização de substrato }\end{array}$




\section{ÍNDICE}

1. INTRODUÇÃO

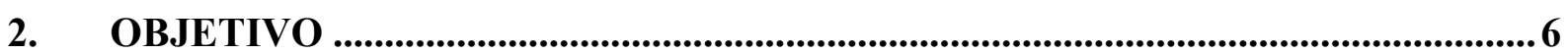

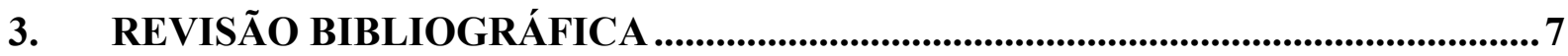

3.1. Poluentes Presentes em Despejos Líquidos de Coquerias ........................................... 7

3.2. Necessidade de Tratamento frente a Legislação..........................................................10

3.3. Técnicas de Tratamento Utilizadas para Despejos de Coquerias e Similares.....13

3.4. Remoção de Nitrogênio em Sistemas Biológicos...........................................................22

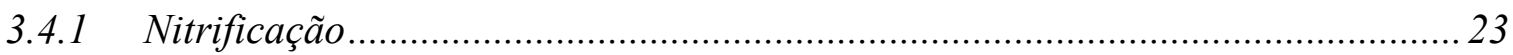

3.4.1.1 Fatores Ambientais que Influenciam a Nitrificação .......................................26

3.4.1.2 Requisitos de Oxigênio e Alcalinidade para a Nitrificação ..............................31

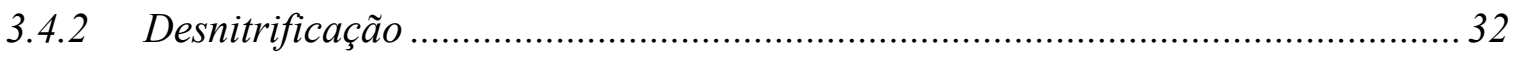

3.4.2.1 Condições Necessárias para o Desenvolvimento da Desnitrificação ..............36

3.4.2.2 Vantagens Obtidas com o Desenvolvimento da Desnitrificação ..................... 40

3.4.2.3 Sistemas Biológicos que Favorecem a Desnitrificação .................................... 42

3.4.3 Formas Alternativas de Remoção de Nitrogênio .................................................49

3.4.3.1 Processo ANAMMOX ${ }^{\circledR}$ - Anaerobic Ammonium Oxidation ...........................50

3.4.3.2 Sistema SND - Simultaneous Nitrification/Denitrification …………...............5 52

3.4.3.3 Nitrificação/Desnitrificação Parcial...............................................................5

3.4.3.4 Associações desses Processos Alternativos de Remoção de Nitrogênio ........63

4. METODOLOGIA...................................................................................................66

4.1 Água Residuária ............................................................................................................68

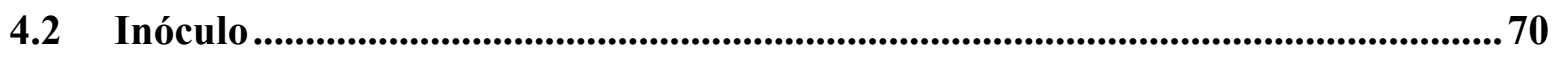

4.3 Instalações Experimentais .......................................................................................70

4.4 Adaptação do Lodo Biológico ...............................................................................80

4.5 Operação e Monitoramento das Instalações Piloto..................................................... 82

4.6 Operação do Sistema em Bateladas Seqüenciais..........................................................85

5. APRESENTAÇÃO E DISCUSSÃO DOS RESULTADOS ........................................87

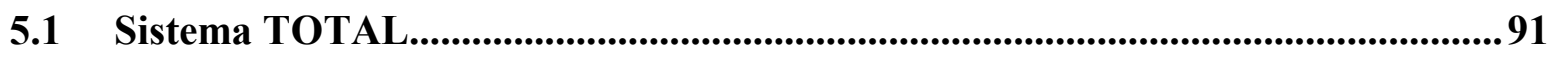

5.1.1 Primeira Fase - Fração Anóxica de 39\%........................................................91

5.1.1.1 Monitoramento Diário do Sistema TOTAL na Primeira Fase.........................91

5.1.1.2 Monitoramento Semanal do Sistema TOTAL na Primeira Fase .................... 94

5.1.2 Segunda Fase - Fração Anóxica de 49\%....................................................... 106 
5.1.2.1 Monitoramento Diário do Sistema TOTAL na Segunda Fase...... 106

5.1.2.2 Monitoramento Semanal do Sistema TOTAL na Segunda Fase 109

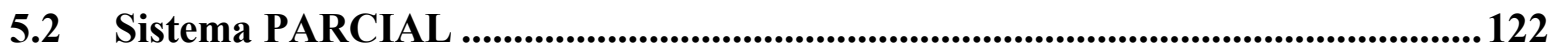

5.2.1 Primeira Fase - Fração Anóxica de 23\% ......................................................... 122

5.2.1.1 Monitoramento Diário do Sistema PARCIAL na Primeira Fase.................. 122

5.2.1.2 Monitoramento Semanal do Sistema PARCIAL na Primeira Fase .............. 126

5.2.2 Segunda Fase - Fração Anóxica de 41\%........................................................ 138

5.2.2.1 Monitoramento Diário do Sistema PARCIAL na Segunda Fase.................. 139

5.2.2.2 Monitoramento Semanal do Sistema PARCIAL na Segunda Fase ............. 143

5.3 Resultados Obtidos com o Sistema em Bateladas Seqüenciais .......................... 157

5.3.1 Primeira Etapa dos Experimentos em Bateladas Seqüenciais........................... 158

5.3.2 Segunda Etapa dos Experimentos em Bateladas Seqüenciais ............................ 162

5.3.3 Terceira Etapa dos Experimentos em Bateladas Seqüenciais ............................ 165

5.4 Comparação entre os Resultados Obtidos com o Sistema PARCIAL e o Reator

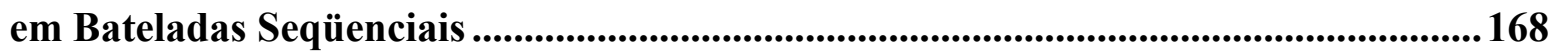

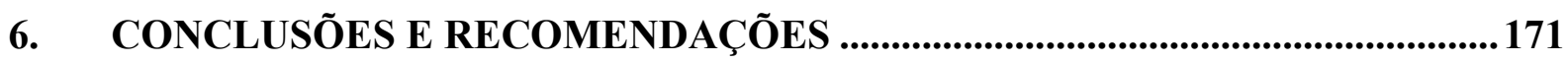

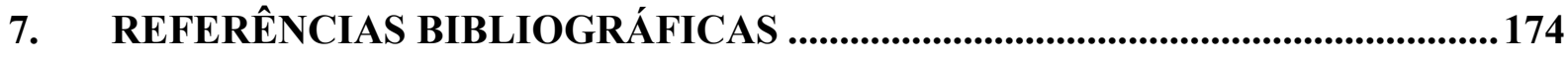

APÊNDICES:

APÊNDICE A - RESULTADOS DO MONITORAMENTO NA FASE DE ACLIMATAÇÃO DA BIOMASSA...................................................................184

APÊNDICE B - RESULTADOS DAS ANÁLISES DE DQO OBTIDOS EM TODAS AS

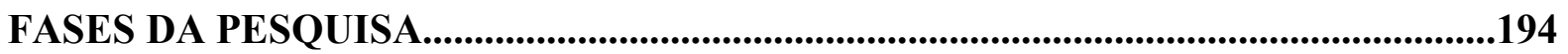

APÊNDICE C - RESULTADOS DO MONITORAMENTO DIÁRIO DO SISTEMA

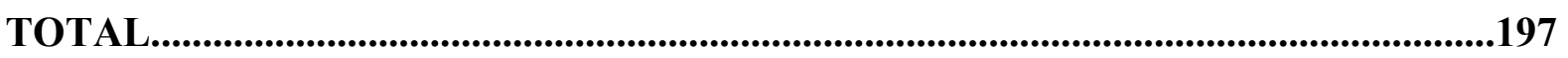

APÊNDICE D - RESULTADOS DO MONITORAMENTO DIÁRIO DO SISTEMA

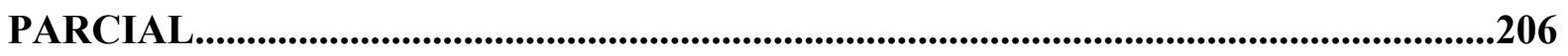

APÊNDICE E - RESULTADOS DO MONITORAMENTO SEMANAL DO SISTEMA TOTAL

APÊNDICE F - RESULTADOS DO MONITORAMENTO SEMANAL DO SISTEMA PARCIAL 


\section{INTRODUÇÃO}

Efluentes com grandes concentrações de fenol e nitrogênio amoniacal apresentam grande potencial poluidor ao meio ambiente. Exemplo deste tipo de despejo é o da unidade de coqueria da indústria siderúrgica que apresenta em termos quantitativos os fenóis como os principais constituintes orgânicos. Outros compostos orgânicos incluem os compostos heterocíclicos contendo nitrogênio, oxigênio e enxofre, e hidrocarbonetos aromáticos polinucleares - PAHs, que são cumulativos, recalcitrantes e dificilmente biodegradáveis, porém esses outros orgânicos presentes em concentrações bem menores.

Tem-se notícia de que alguns dos compostos fenólicos presentes em águas residuárias são tóxicos às células podendo desnaturar proteínas. Também se sabe que vários hidrocarbonetos aromáticos polinucleares são potencialmente carcinogênicos (YI; YIBO; HUIMING, 1994). Assim, torna-se fundamental a remoção destes compostos orgânicos das águas residuárias, para se reduzir o prejuízo ao meio ambiente.

Constituintes inorgânicos também estão presentes neste tipo de despejo e são principalmente cianeto, tiocianato, sulfato e nitrogênio amoniacal, sendo que a concentração deste último pode atingir níveis de centenas de miligramas por litro (ZHANG et al., 1998).

O caso específico do nitrogênio amoniacal é bastante preocupante por diversos fatores, mas principalmente pela toxicidade da amônia. De uma forma geral, o nitrogênio pode ser encontrado nas águas naturais nas formas de nitrogênio orgânico, amoniacal, nitrito e nitrato. As duas primeiras chamam-se formas reduzidas e as duas últimas formas oxidadas. Os compostos de nitrogênio são nutrientes para processos biológicos sendo caracterizados como macronutrientes, pois depois do carbono, o nitrogênio e também o fósforo são os elementos exigidos em maiores quantidades pelas células. 
Especificamente no estado de São Paulo, quase todas as bacias hidrográficas estão comprometidas em termos de presença de nitrogênio amoniacal e/ou fósforo acima dos limites legais aceitos pela legislação no que se refere à classificação dos corpos d'água (CETESB, 2006).

De maneira geral, as fontes poluidoras estão sujeitas a duas legislações, a federal e a estadual (quando existente), devendo sempre prevalecer a mais restritiva. Em São Paulo, a primeira é regulamentada pelo Decreto Estadual 8468 (SÃO PAULO, 1976) e a segunda estabelecida pela Resolução CONAMA N³57 (BRASIL, 2005). Com relação a nitrogênio amoniacal e compostos fenólicos, a Resolução CONAMA 357/05 estipula padrões de emissão em corpos d'água para fontes poluidoras de até $20 \mathrm{mg} \mathrm{N} / \mathrm{L}$ para nitrogênio amoniacal total e até $0,5 \mathrm{mg} \mathrm{C}_{6} \mathrm{H}_{5} \mathrm{OH} / \mathrm{L}$ para índice de fenóis. O Decreto Estadual 8468/76, por sua vez, impõe limites de até $0,5 \mathrm{mg} / \mathrm{L}$ e 5,0 mg/L para lançamento de compostos fenólicos em corpos d'água (art. 18) e em sistemas públicos de esgotos (art. 19A), respectivamente.

Alguns processos de tratamento possibilitam a remoção de nitrogênio amoniacal, mas este é oxidado a nitrito e este último, a nitrato. Assim, o efluente final sai com níveis bastante elevados de nitrato.

Os nitratos são tóxicos, sendo que em adultos, concentrações muito elevadas podem provocar dores de cabeça e diarréia entre outros sintomas. Recém-nascidos podem ser acometidos por metaemoglobinemia, que é letal, pois o nitrato se reduz a nitrito na corrente sangüínea, que compete pelo uso do oxigênio livre, tornando o sangue do bebê azul, provocando asfixia (FELLENBERG, 1980). Assim, tanto o nitrato quanto o nitrito não são padrões de emissão, entretanto são padrões de classificação de corpos d'água, sendo $10 \mathrm{mg} \mathrm{N}-\mathrm{NO}_{3}{ }^{-} / \mathrm{L}$ e $1 \mathrm{mg} \mathrm{N}-\mathrm{NO}_{2}{ }^{-} / \mathrm{L}$, respectivamente, os valores máximos permitido pelo CONAMA 357/05 para as águas classe 1, 2 e 3, além de serem padrões de potabilidade, conforme a Portaria 518 do Ministério da Saúde (BRASIL, 2004). 
Águas residuárias de coquerias, bem como outros efluentes contendo altas concentrações de nitrogênio amoniacal como, por exemplo, resíduos agrícolas (PRAKASAM; LOEHR, 1972), efluentes da indústria farmacêutica (GUPTA; SHARMA, 1996), líquidos percolados provenientes de aterros sanitários (MOSER, 2003), já foram tratados biologicamente com remoção de nitrogênio de maneira eficaz. No mais, efluentes de coquerias são despejos que naturalmente apresentam altas temperaturas $\left(>28^{\circ} \mathrm{C}\right)$, o que favorece esse tipo de tratamento.

Pesquisas anteriores utilizaram sistemas biológicos para remover nitrogênio amoniacal e/ou compostos fenólicos de águas residuárias de coquerias ou similares, podendo citar-se entre elas, Kostenbader \& Flecksteiner (1969), Anthonisen et al. (1976) e Da Costa (1999). Outros pesquisadores, como Melcer; Nutt (1985), Yibo; Min; Yi (1991), Yi; Yibo; Huiming (1994), Lee; Park (1998), Zhang et al. (1998), Aun (2001), Dombroski (2003), com o objetivo de reduzir nitrato a nitrogênio gasoso, utilizaram-se de reatores anóxicos para remover nitrogênio presente em despejos de coquerias, tendo o fenol como principal fonte de carbono.

Após resultados bem sucedidos de trabalhos realizados anteriormente no Departamento de Engenharia Hidráulica e Sanitária (PHD) da Escola Politécnica da Universidade de São Paulo (EPUSP) objetivando remoção de fenol, benzeno, tolueno, xileno, naftaleno e nitrogênio amoniacal, presentes em uma água residuária sintética de coqueria, através de nitrificação e desnitrificação do afluente, idealizou-se a presente pesquisa objetivando promover a desnitrificação de um despejo similar contendo altas concentrações de nitrogênio amoniacal e compostos fenólicos em sistema piloto de lodo ativado de lodo único, com duas concepções distintas: total (“T”) num primeiro caso, com fontes interna e externa de carbono para a desnitrificação, e parcial ("P”) em um segundo caso (“"nitritação/desnitritação"), somente com fonte interna de carbono. 
A água residuária da presente pesquisa diferiu das pesquisas anteriores pois os compostos orgânicos benzeno, tolueno, xileno, naftaleno não foram utilizados, tendo em vista que estes não apresentaram problemas para o tratamento nos trabalhos anteriores, além de não serem objetivo da presente pesquisa.

O primeiro sistema era composto de um reator aeróbio, além de dois reatores anóxicos, um antes e o outro depois do aeróbio, e por fim um decantador secundário, com retorno de lodo do decantador secundário ao primeiro reator anóxico, além de reciclo interno de lodo do reator aeróbio também ao primeiro reator anóxico. Nesta concepção, como era de se esperar que as bactérias desnitrificantes presentes no primeiro reator anóxico consumissem praticamente toda a matéria orgânica (fenol) presente no afluente para promover a desnitrificação, no segundo reator anóxico foi adicionada uma fonte externa de matéria orgânica (etanol) para a desnitrificação, em virtude desta ser de fácil obtenção e baixo custo.

O segundo sistema piloto proposto era constituído de um reator anóxico, seguido de um reator aeróbio com aeração controlada e um decantador secundário, com retorno de lodo do decantador para o reator anóxico, além de reciclo interno de lodo do aeróbio para o anóxico. Nesta concepção, objetivou-se diminuir o consumo de energia necessário ao sistema através do controle da oxigenação do reator aeróbio $\left(\mathrm{OD}<1,0 \mathrm{mgO}_{2} / \mathrm{L}\right)$, além da manutenção de demais condições operacionais para promover a nitrificação parcial a nitrito (ou “nitritação") do efluente, passando deste último diretamente a nitrogênio gasoso em ambiente anóxico. Esse sistema parece de grande interesse tendo em vista que, durante todo o período de desenvolvimento da pesquisa, praticamente não foram encontrados trabalhos anteriores de remoção de nitrogênio pela via simplificada em sistema contínuo, mas somente em reatores em batelada.

Paralelamente aos sistemas piloto de lodo ativado, a pesquisa também contou com a operação de um reator em batelada para tratamento da mesma água residuária, visando a 
remoção de nitrogênio via nitrito e seus resultados puderam ser comparados aos obtidos com o sistema contínuo "P" que também visou a nitritação/desnitritação. A operação do reator em batelada foi objeto do trabalho realizado por Queiroz (2006), como parte integrante dessa linha de pesquisas do Departamento de Engenharia Hidráulica e Sanitária da EPUSP. 


\section{OBJETIVO}

O objetivo geral da presente pesquisa foi avaliar a remoção de nitrogênio via nitrito e via nitrato de despejo contendo elevadas concentrações de nitrogênio amoniacal e compostos fenólicos, em duas diferentes concepções de sistemas piloto de lodo ativado de lodo único, utilizando fontes interna (fenol) e externa (etanol) de carbono para a desnitrificação.

Como objetivos específicos, pretendeu-se:

- avaliar a influência de variáveis operacionais como concentração de oxigênio dissolvido, pH e taxa de recirculação de lodo para verificação de quais regeriam os sistemas e promoveriam o desenvolvimento desses fenômenos mencionados;

- avaliar a influência da fração anóxica como parâmetro de projeto dos sistemas;

- determinar as taxas de remoção de nitrogênio nas diferentes configurações;

- comparar os resultados obtidos no sistema de lodo ativado piloto visando “nitritação/desnitritação" com um sistema operado paralelamente em batelada para remoção de nitrogênio via nitrito. 


\section{REVISÃO BIBLIOGRÁFICA}

\subsection{Poluentes Presentes em Despejos Líquidos de Coquerias}

O coque é o combustível redutor usual para a redução do minério de ferro a ferro-gusa. Apesar do aparecimento de processos de redução direta do minério, a boa resistência do coque metalúrgico e a modernização dos processos de operação fazem com que os altos-fornos levem inúmeras vantagens sobre qualquer outro processo de produção de aço.

A produção do coque permite obter gases e inúmeros subprodutos formados pela destilação do carvão betuminoso ou mineral (BRAILE; CAVALCANTI, 1993). A Figura 1 ilustra esquematicamente os principais produtos obtidos pela destilação do carvão.

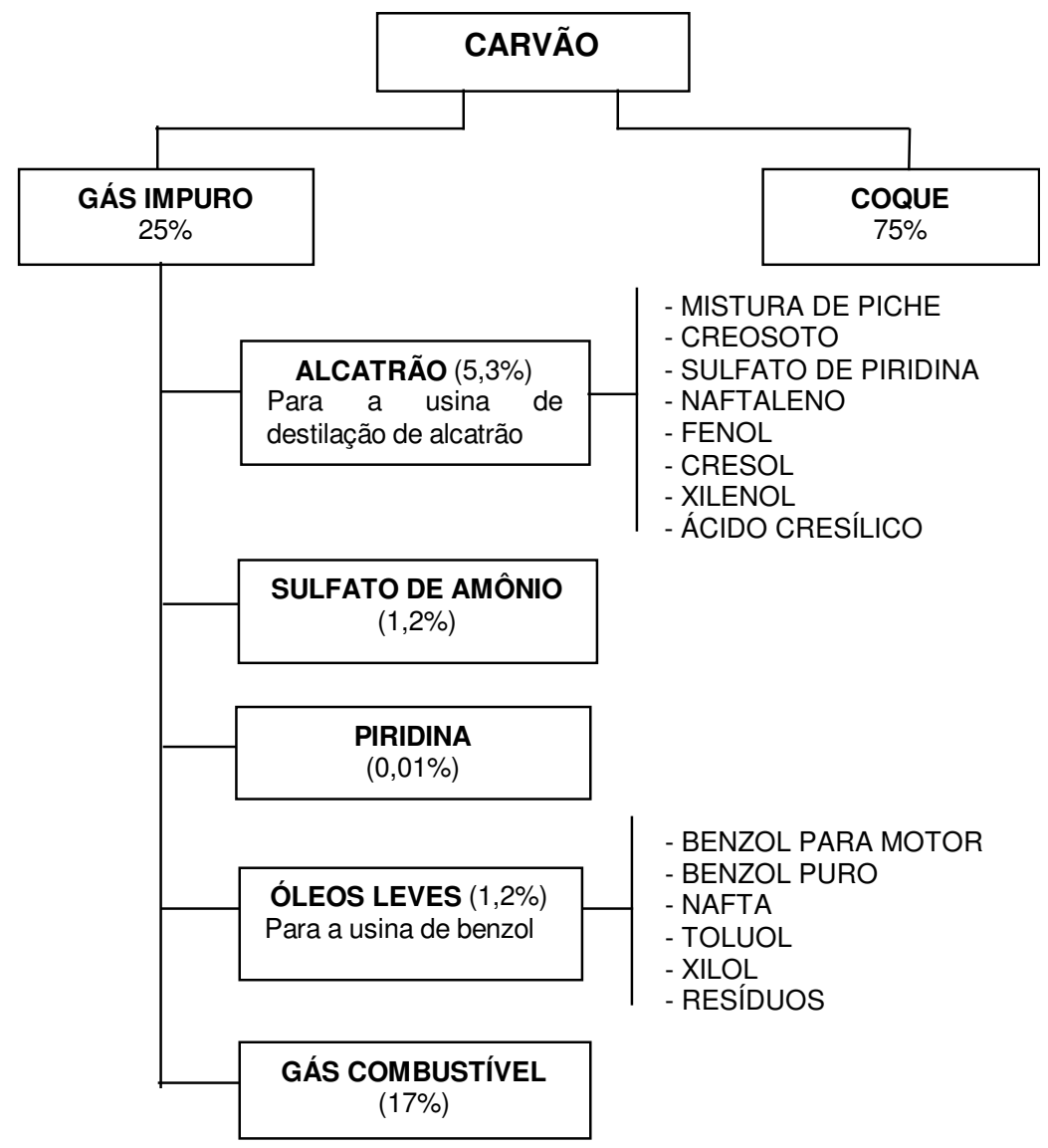

Figura 1 - Esquema dos principais produtos obtidos pela destilação do carvão e sua distribuição percentual

Fonte: ARAUUJO, 1997 
Águas residuárias de coquerias são geralmente uma composição de licor residual amoniacal, despejos da planta de óleos leves e vários gases em quantidades menores, todos gerados no setor de sub-produtos da coqueria. Os contaminantes presentes nestas águas incluem amônia, cianetos, tiocianatos, fenóis e outras substâncias orgânicas como os aromáticos mono e policíclicos contendo nitrogênio, oxigênio e enxofre, e hidrocarbonetos aromáticos polinucleares (YIBO; MIN; YI, 1991).

As águas amoniacais correspondem às águas de condensação produzidas no resfriamento do gás destilado. Elas contêm a maior parte do nitrogênio do carvão em forma de hidróxido de amônio e seus sais, como carbonatos e, em menor grau, sulfatos e cloretos.

Os despejos de coquerias apresentam uma série de poluentes presentes que são listados como poluentes prioritários segundo a EPA (2007), podendo-se citar dentre eles cianeto, fenol, tolueno, benzeno, naftaleno.

Os cianetos possivelmente se constituem nos compostos de maior toxidez encontrados nas águas amoniacais, quando na forma dissociada. Leduc et al. (1982) apud Hartmann (2004) observaram toxicidade aguda para diferentes espécies de peixes em concentrações entre 20 e $1000 \mu \mathrm{g} \mathrm{CN} / \mathrm{L}$. Muitas vezes águas residuárias contêm cianetos totais em concentrações até mais elevadas, porém na forma complexada que não apresenta tanta toxidez.

Os fenóis são os contaminantes orgânicos dominantes em águas residuárias de conversão de carvão e de processos de cozimento de carvão, sendo que eles geralmente colaboram com 40 a $80 \%$ da DQO total do despejo (GANCZARCZYK, 1983 apud KINDZIERSKI; FEDORAK; HRUDEY, 1991; NEUFELD, 1984 apud KINDZIERSKI; FEDORAK; HRUDEY, 1991; GIABBAI et al., 1985 apud KINDZIERSKI; FEDORAK; HRUDEY, 1991). Dependendo de sua concentração, o fenol pode provocar os seguintes efeitos em sistemas biológicos de tratamento por lodo ativado: redução na remoção de DQO e 
DBO, inibição da nitrificação, dificuldades na separação dos sólidos e modificação das propriedades de compactação do lodo (BITTON, 1994).

A Tabela 1 exemplifica a composição de alguns despejos de coquerias ou similares.

Tabela 1 - Características de alguns despejos de coquerias ou similares

\begin{tabular}{|c|c|c|}
\hline Constituintes & Concentração & Referência \\
\hline DQO $\left(\mathrm{mg} \mathrm{O}_{2} / \mathrm{L}\right)$ & $\begin{array}{c}958 \\
3000 \\
525-810 \\
500-1500 \\
400-1300 \\
1240-1850 \\
1500-1800 \\
700-2000\end{array}$ & $\begin{array}{l}\text { FANG; YEONG (1993) } \\
\text { FITTIPALDO; MILLS; WONG-CHONG (1997) } \\
\text { GHOSE (2004) } \\
\text { LEE; PARK (1998) } \\
\text { LI; SUN; LI (2005) } \\
\text { YI; YIBO; HUIMING (1994) } \\
\text { YIBO; MIN; YI (1991) } \\
\text { ZHANG et al. (1998) }\end{array}$ \\
\hline $\begin{array}{l}\text { Compostos fenólicos } \\
(\mathrm{mg} / \mathrm{L})\end{array}$ & $\begin{array}{c}\leq 2500 \\
600 \\
219 \\
81-123 \\
900-1040 \\
900-5000 \\
200-500 \\
170-232 \\
138-160 \\
100-200\end{array}$ & $\begin{array}{l}\text { BARTON; HAMMER; KENNEDY (1978) } \\
\text { FITTIPALDO; MILLS; WONG-CHONG (1997) } \\
\text { GANCZARCZYK (1979) } \\
\text { GHOSE (2004) } \\
\text { KINDZIERSKI; FEDORAK; HRUDEY (1991) } \\
\text { KOSTENBADEN; FLECKSTEINER (1969) } \\
\text { LEE; PARK (1998) } \\
\text { LI; SUN; LI (2005) } \\
\text { YI; YIBO; HUIMING (1994) } \\
\text { YIBO; MIN; YI (1991) }\end{array}$ \\
\hline Amônia (mg N-NH$/ \mathrm{L}$ ) & $\begin{array}{c}94 \\
337-562 \\
700-1000 \\
230-668 \\
220-250 \\
300-700\end{array}$ & $\begin{array}{l}\text { FANG; YEONG (1993) } \\
\text { GHOSE (2004) } \\
\text { LEE; PARK (1998) } \\
\text { LI; SUN; LI (2005) } \\
\text { YIBO; MIN; YI (1991) } \\
\text { ZHANG et al. (1998) }\end{array}$ \\
\hline Cianeto (mg CN/L) & $\begin{array}{c}10-50 \\
30 \\
8-20 \\
10-20 \\
30-35 \\
1,8-4,4 \\
5-21\end{array}$ & $\begin{array}{l}\text { BARTON; HAMMER; KENNEDY (1978) } \\
\text { FITTIPALDO; MILLS; WONG-CHONG (1997) } \\
\text { GHOSE (2004) } \\
\text { LEE; PARK (1998) } \\
\text { LI; SUN; LI (2005) } \\
\text { YI; YIBO; HUIMING (1994) } \\
\text { YIBO; MIN; YI (1991) }\end{array}$ \\
\hline Tiocianato $\left(\mathrm{mg} \mathrm{SCN}^{-} / \mathrm{L}\right)$ & $\begin{array}{l}100-300 \\
194 \\
50-100 \\
142-187 \\
190-210\end{array}$ & $\begin{array}{l}\text { BARTON; HAMMER; KENNEDY (1978) } \\
\text { GANCZARCZYK (1979) } \\
\text { LEE; PARK (1998) } \\
\text { YI; YIBO; HUIMING (1994) } \\
\text { YIBO; MIN; YI (1991) }\end{array}$ \\
\hline Benzeno (mg COT/L) & 11 & YI; YIBO; HUIMING (1994) \\
\hline Tolueno (mg COT/L) & 28 & LEE; PARK (1998) \\
\hline Naftaleno (mg COT/L) & $\begin{array}{l}50 \\
6,5\end{array}$ & $\begin{array}{l}\text { YI; YIBO; HUIMING (1994) } \\
\text { ZHANG et al. (1998) }\end{array}$ \\
\hline Piridina (mg COT/L) & $\begin{array}{c}11 \\
2,6-7,7\end{array}$ & $\begin{array}{l}\text { YI; YIBO; HUIMING (1994) } \\
\text { ZHANG et al. (1998) }\end{array}$ \\
\hline Sulfeto (mg S $\left.{ }^{2-} / \mathrm{L}\right)$ & $\begin{array}{l}\leq 700 \\
65-78\end{array}$ & $\begin{array}{l}\text { BARTON; HAMMER; KENNEDY (1978) } \\
\text { LI; SUN; LI (2005) }\end{array}$ \\
\hline
\end{tabular}


Kostenbader; Flecksteiner (1969) relataram que a concentração dos contaminantes presentes em águas residuárias de coquerias é função da temperatura de cozimento e do carvão cozido utilizado e que, como regra geral, aumentos na temperatura de cozimento resultam em concentrações mais baixas de fenol e mais altas de cianeto.

As indústrias siderúrgicas brasileiras são, na maioria, da década de 1950, portanto bastante antigas. A legislação ambiental vem forçando as indústrias a desenvolverem processos de produção de aço mais limpos e eficientes; ao mesmo tempo, a competição com materiais substitutos está forçando as produtoras de aço a investirem em tecnologias de melhor qualidade e mais econômicas (EPA, 1995).

Assim, como as coquerias são vistas como as maiores causadoras de poluição ambiental, a prevenção está focada em duas áreas: redução nas emissões dos fornos a coque e desenvolvimento de técnicas de fabricação de ferro sem coque. Mesmo não tendo sido largamente desenvolvidos em escala comercial, estes dois processos podem vir a promover uma substancial redução na emissão de gases e nas descargas de águas residuárias em comparação com os processos atuais. As tecnologias que não utilizam coque substituem-no por carvão nos fornos a vapor, eliminando a necessidade de se ter uma coqueria. Essas tecnologias têm um enorme potencial para a redução da poluição gerada durante o processo de fabricação de aço, mas o investimento requerido nesses casos é bastante significativo (EPA, 1995).

\subsection{Necessidade de Tratamento frente a Legislação}

No Estado de São Paulo, o lançamento em corpos d'água dos principais componentes tóxicos gerados pelas indústrias está sujeito a duas legislações, sendo a primeira regulamentada pelo Decreto Estadual n ${ }^{0} 8.468$ (SÃO PAULO, 1976), artigo 18, e a segunda 
estabelecida pela Resolução n. 357 do CONAMA (BRASIL, 2005), artigo 34, sempre prevalecendo o padrão mais restritivo.

Além de padrões de lançamento, a Resolução CONAMA 357/05 prevê o atendimento ao padrão do corpo d'água receptor que inclui cada curso d'água em uma classe em função de seus usos preponderantes. Cada uma destas classes pressupõe uma certa qualidade a ser mantida no corpo d'água.

Assim, os efluentes devem atender também os padrões do corpo receptor para a sua respectiva classe, já que há diluição dos mesmos no corpo d'água; além disso, caso o atendimento aos padrões do corpo receptor seja demonstrado através de estudos ambientais, o poluidor pode solicitar ao órgão ambiental um relaxamento nos padrões de lançamento.

Segundo as legislações em vigor, para padrões de lançamento, são aceitos os seguintes valores máximos admissíveis:

- $\quad$ nitrogênio amoniacal total < $20 \mathrm{mg} \mathrm{N} / \mathrm{L}$ (CONAMA 357/05);

- $\quad$ cianeto total < 0,2 $\mathrm{mg} \mathrm{CN}^{-} / \mathrm{L}$ (CONAMA 357/05 e Decreto Estadual 8468/76);

- $\quad$ fenóis $<0,5 \mathrm{mg} \mathrm{C}_{6} \mathrm{H}_{5} \mathrm{OH} / \mathrm{L}$ (CONAMA 357/05 e Decreto Estadual 8468/76).

O caso específico de cianetos é bastante polêmico, já que seu grau de toxidez é bastante elevado quando se encontra na forma dissociada, sendo bem menos tóxico na forma combinada.

Para se ter uma idéia, o caso de fenóis é tão importante que concentrações tão pequenas como $2 \mu \mathrm{g} / \mathrm{L}$ são suficientes para causar problemas de sabor e odor em águas de abastecimento tratadas com cloro devido à formação de clorofenóis. Desta maneira, em águas potáveis, a concentração de fenóis deve ser inferior a $1 \mu \mathrm{g} / \mathrm{L}$ (ALEM SOBRINHO; GARCIA JR., 1983).

Quanto às formas oxidadas de nitrogênio, essas não são padrões de lançamento de efluentes, entretanto são padrões de classificação de corpos d'água, sendo os valores máximos 
admissíveis para nitrato e nitrito, $10 \mathrm{mg} \mathrm{N} / \mathrm{L}$ e 1,0 $\mathrm{mg} \mathrm{N} / \mathrm{L}$, respectivamente, em águas doces das Classes 1, 2 e 3 (CONAMA 357/05), além de serem padrões de potabilidade, conforme a Portaria 518 do Ministério da Saúde (BRASIL, 2004).

Além dos parâmetros anteriormente mencionados, bastante relevantes no caso específico de indústrias siderúrgicas, há que se ressaltar o atendimento ao lançamento para a demanda bioquímica de oxigênio que, principalmente no Estado de São Paulo, é um parâmetro de controle bastante usado pelas autoridades para fiscalização de empresas poluidoras. Segundo o Decreto Estadual 8468/76, a $\mathrm{DBO}_{5,20}$ do efluente final deve ser menor do que $60 \mathrm{mg} \mathrm{O}_{2} / \mathrm{L}$, podendo até ser maior do que esse valor, desde que a empresa comprove haver eficiência de remoção de DBO no sistema de tratamento superior a 80\%.

Outros estados da União também utilizam o parâmetro DQO para controle do lançamento de efluentes de fontes poluidoras, mas no caso específico de São Paulo, esse não é mencionado na legislação, apesar de ser um importante parâmetro para controle operacional de estações de tratamento de efluentes.

Além dos padrões de lançamento anteriormente mencionados, o art. 34 da Resolução CONAMA 357/05 também menciona que os efluentes não poderão causar ou possuir potencial para causar efeitos tóxicos aos organismos aquáticos no corpo receptor, de acordo com os critérios de toxicidade estabelecidos pelo órgão ambiental competente e que esses critérios devem se basear em ensaios ecotoxicológicos padronizados, utilizando organismos aquáticos e realizados no efluente.

Especificamente no Estado de São Paulo, o lançamento de compostos tóxicos deve atender à Resolução de 22/2/2000 da Secretaria do Meio Ambiente que determina qual deve ser a diluição do efluente no corpo receptor para que não ocorra toxicidade à biota. Além disso, a Resolução frisa que a CETESB deve determinar quais organismos devem ser 
utilizados nos testes de toxicidade e quais os métodos de ensaio, bem como deve definir qual o limite de toxicidade estabelecido para cada efluente (SÃO PAULO, 2000).

Face aos problemas de saúde pública e ao atendimento às legislações vigentes, torna-se indispensável o estudo e a pesquisa relacionados a despejos tóxicos gerados em indústrias e seus respectivos tratamentos.

\subsection{Técnicas de Tratamento Utilizadas para Despejos de Coquerias e Similares}

A eficiência do tratamento biológico de despejos de coquerias e similares, onde os compostos fenólicos são alguns dos principais poluentes, baseia-se em grande parte na remoção de fenóis.

A degradação destes compostos ocorre pela ação de vários microrganismos que atacam seus anéis benzênicos utilizando enzimas distintas. Segundo Neujahr; Varga (1970) apud Lalai; Mura (1989), em valores baixos de $\mathrm{pH}$, certos fungos, como por exemplo Aspergillus niger, podem degradar o fenol parcialmente através do rompimento do anel benzênico na posição orto após sua transformação em catecol. Por outro lado, Watkin (1986) apud Leite (1997) cita que determinadas espécies de bactérias, como Pseudomonas sp, Nocardia sp, Acinetobacter sp, Alcaligenes sp só podem degradar o catecol pelo rompimento na posição meta. Tais caminhos metabólicos envolvem sistemas enzimáticos distintos sendo sujeitos a diferentes formas de inibição (Figura 2). 


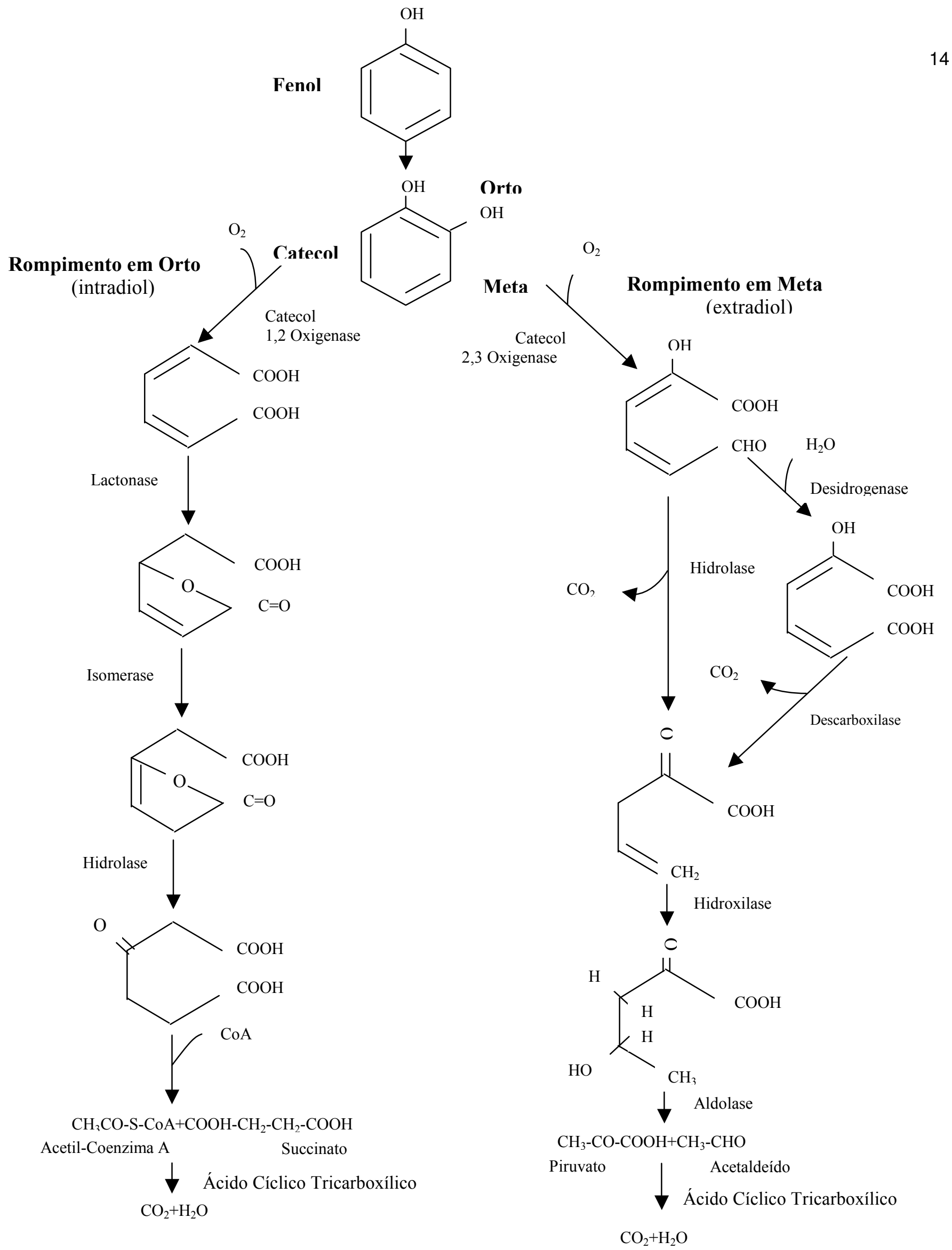

Figura 2 - Etapas da biodegradação do fenol com rompimento do anel benzênico nas posições orto e meta

Fonte: WATKIN, 1986 apud LEITE, 1997 
Apesar de normalmente as bactérias provocarem o rompimento do anel benzênico na posição meta, enquanto fungos e leveduras degradam o catecol pelo rompimento na posição orto, existem bactérias que quebram o anel na posição orto e leveduras, na posição meta (CERNIGLIA, 1992; KANG; PARK, 1997; YANG \& HUMPHREY, 1975 apud VILLAS BÔAS, 1999; ZACHE \& REHM, 1989 apud VILLAS BÔAS, 1999; KOTTURI et al., 1991 apud VILLAS BÔAS, 1999; KUKOR \& OLSEN, 1991 apud VILLAS BÔAS, 1999; HINTEREGGER et al., 1992 apud VILLAS BÔAS, 1999; EHRT et al., 1995 apud VILLAS BÔAS, 1999; BASTOS et al., 1997 apud VILLAS BÔAS, 1999; MUTZEL et al., 2004).

Ahamad \& Kunhi (1996) afirmaram que apesar das Pseudomonas serem bactérias que normalmente provocam a ruptura do benzeno na posição meta, as Pseudomonas stutzeri SPC2 isoladas em sua pesquisa provocaram a degradação do fenol pela ruptura na posição orto.

Kang e Park (1997) mencionaram que a degradação seqüencial de fenol e cianeto pôde ser alcançada por uma interação comensal entre as bactérias degradadoras de fenol (isoladas de uma água residuária de coqueria, identificadas como do gênero das Pseudomonas) e as degradadoras de cianeto (da espécie Pseudomonas fluorescens).

Com o uso da espectroscopia de UV, os pesquisadores afirmaram que as bactérias degradadoras de fenol atuavam supostamente na ruptura na posição meta, produzindo rapidamente intermediários não tóxicos que eram utilizados como fonte de carbono pelas bactérias degradadoras de cianeto para seu crescimento. Com essa interação comensal, $500 \mathrm{mg} / \mathrm{L}$ de fenol e $26 \mathrm{mg} / \mathrm{L}$ de cianeto foram completamente degradados em 40 horas em reator em batelada. Porém, os pesquisadores também afirmaram que, para uma abordagem mais prática, seria melhor o uso de um sistema contínuo de duplo estágio para degradação do fenol e do cianeto. 
Tratamentos de águas residuárias que podem remover efetivamente os fenóis incluem: oxidação (PATTERSON, 1975 apud KINDZIERSKI; FEDORAK; HRUDEY, 1991), adsorção (GANCZARCZYK, 1983 apud KINDZIERSKI; FEDORAK; HRUDEY, 1991), extração com solvente (GREMINGER et al., 1982 apud KINDZIERSKI; FEDORAK; HRUDEY, 1991), sistemas biológicos aeróbios (GALLAGHER \& MAYER, 1985 apud KINDZIERSKI; FEDORAK; HRUDEY, 1991) e combinações destes (HUMENICK \& SHELLENBERGER, 1986 apud KINDZIERSKI; FEDORAK; HRUDEY, 1991). Os processos de oxidação e adsorção normalmente se mostram bastante eficientes para baixas concentrações de fenol. Para altas concentrações, sistemas biológicos são geralmente recomendados.

Segundo Morita (1993), os principais mecanismos de remoção dos poluentes perigosos nos sistemas de tratamento biológico aeróbio são: volatilização, adsorção na biomassa e a biodegradação, sendo que o principal mecanismo de remoção de compostos fenólicos é a biodegradação.

Yibo; Min; Yi (1991) citaram que a presença de compostos orgânicos refratários e biologicamente inibidores como hidrocarbonetos poliaromáticos e compostos heterocíclicos contendo nitrogênio em águas residuárias de coquerias faz do lodo ativado um processo que mantém um residual alto de DQO, mesmo sendo aceitável na remoção de compostos fenólicos e DBO. Segundo os autores, a tentativa de se utilizar um sistema biológico convencional de tratamento para reduzir elevados níveis de nitrogênio amoniacal não teve muito sucesso, sendo que processos anaeróbios estavam recebendo cada vez mais atenção no tratamento de águas residuárias de conversão de carvão.

Segundo Yibo; Min; Yi (1991), o despejo da coqueria de uma indústria de ferro e aço chinesa recebia pré-tratamento por extração do solvente, arraste com ar, separação gravitacional e flotação, seguindo então para um sistema de lodo ativado de duplo estágio, 
com tempos de aeração de 14 e 34 horas, respectivamente, para o primeiro e segundo estágios, não sendo mencionada a idade do lodo do sistema. Este sistema foi considerado satisfatório para a remoção de compostos fenólicos, cianetos e DBO, mas deixava um residual alto de DQO, sendo também bastante ineficiente na redução de nitrogênio amoniacal durante os cinco anos de operação.

A proposta de estudo dos pesquisadores foi o desenvolvimento de um sistema eficiente e viável para que os padrões de descarga na China atingissem níveis de $200 \mathrm{mgO}_{2} / \mathrm{L}$ para a DQO e $25 \mathrm{mgN} / \mathrm{L}$ para nitrogênio amoniacal. Para tanto, o experimento da pesquisa foi conduzido em duas etapas: a primeira, investigando-se os efeitos do tratamento anaeróbio na biotratabilidade da água residuária de coqueria através de testes em batelada e, a segunda, utilizando-se um sistema de fluxo contínuo em escala de laboratório operado por um longo período de tempo.

Os resultados da pesquisa mostraram que a DQO e o nitrogênio amoniacal efluentes de um sistema A-A/O (anaeróbio, anóxico e aeróbio) podiam ser inferiores a $78 \mathrm{mgO}_{2} / \mathrm{L}$ e 4,7 mgN/L respectivamente, quando suas concentrações afluentes eram maiores que $1200 \mathrm{mgO}_{2} / \mathrm{L}$ e $240 \mathrm{mg} / \mathrm{L}$, para um tempo de detenção hidráulico de 36 horas. O tratamento anaeróbio mostrou-se capaz de degradar parcialmente compostos orgânicos biorefratários, melhorando a tratabilidade da água residuária e promovendo fontes de carbono para a desnitrificação no reator anóxico. Além disso, o nitrogênio total da água residuária foi removido em $49 \%$.

Zhang et al. (1998) estudaram o tratamento de águas residuárias de coqueria utilizando um sistema anaeróbio-anóxico-aeróbio $\left(\mathrm{A}_{1}-\mathrm{A}_{2}-\mathrm{O}\right)$ de biofilme fixo de fluxo ascendente com todos os reatores preenchidos com meio semi-flexível construído com anéis plásticos e fios de fibra sintética. Este sistema mostrou-se eficiente na redução de nitrogênio amoniacal e DQO, sendo que o efluente apresentou concentrações de amônia de 3,1 mgN/L e 
DQO de $114 \mathrm{mgO}_{2} / \mathrm{L}$ e eficiências de remoção de 98,8\% e 92,4\% respectivamente, quando o tempo de detenção hidráulico total do sistema foi de 31,6 horas. O tempo de detenção celular não foi citado no artigo.

Testes em batelada também foram realizados nesse estudo cujos resultados mostraram que despejos de coqueria após tratamento anaeróbio tinham maior biodegradabilidade quando comparados com tratamento anóxico. Os compostos orgânicos complexos e de alto peso molecular eram removidos com maior eficiência pelo tratamento anaeróbio em comparação com o tratamento anóxico, enquanto que, com relação aos fenóis biodegradáveis, essa eficiência de remoção era menor. Isto porque no estágio anaeróbio, os compostos orgânicos com estruturas complicadas e de alto peso molecular podiam ser parcialmente convertidos em compostos orgânicos mais facilmente biodegradáveis. Assim fontes de carbono mais adequadas ficavam disponíveis para suprir a necessidade das bactérias desnitrificantes no estágio anóxico.

Yi; Yibo; Huiming (1994) citaram em seu artigo que a biodegradabilidade de contaminantes orgânicos em águas residuárias de coquerias são muito diferentes dependendo de suas estruturas químicas. Segundo os autores, a maioria dos compostos fenólicos como fenol, cresol e fenóis alquílicos é facilmente biodegradável e a eficiência de sua remoção pode alcançar 99\% com um tempo de aeração de 12 a 24 horas num sistema de lodo ativado convencional com idade do lodo de 100 dias, enquanto que compostos heterocíclicos e hidrocarbonetos aromáticos polinucleares são comparativamente menos biodegradáveis.

Estes pesquisadores observaram que processos de tratamento biológico comumente utilizados para purificação de despejos de coquerias não eram eficientes na remoção de compostos orgânicos refratários e que a concentração de DQO e hidrocarbonetos aromáticos polinucleares (PAHs) em efluentes tratados normalmente não atendia aos padrões de descarga, já que estes últimos são bastante restritivos em países desenvolvidos. Além 
disso, o tratamento pelo sistema de lodo ativado convencional podia ter dificuldades na remoção de amônia e nitrogênio total, pois esses despejos apresentavam alta concentração de nitrogênio amoniacal.

Assim, Yi; Yibo; Huiming (1994) realizaram testes em batelada e sistemas em fluxo contínuo, tanto em escala laboratorial quanto piloto. Os métodos de pré-tratamento utilizados na pesquisa foram radiação ultravioleta, ozonização, acidificação anaeróbia e processo anaeróbio. Todos estes métodos apenas tratavam a água parcialmente, sendo que os sistemas de fluxo contínuo selecionados para o experimento possuíam as etapas anóxica e aeróbia como etapa principal do tratamento.

O pré-tratamento anaeróbio, além de degradar parcialmente os compostos orgânicos mais dificilmente biodegradáveis melhorando a biotratabilidade do despejo, promovia fontes de carbono adequadas para a desnitrificação no reator anóxico. O efluente anaeróbio entrava na fase anóxica, na qual os compostos orgânicos da água residuária eram usados como doadores de elétrons para reduzir $\mathrm{NO}_{3}^{-}$e $\mathrm{NO}_{2}^{-}$a $\mathrm{N}_{2} \mathrm{O}$ e $\mathrm{N}_{2}$ através da desnitrificação, e os compostos orgânicos residuais eram quase completamente removidos na fase aeróbia posterior.

O sistema anaeróbio-anóxico-aeróbio $(\mathrm{A}-\mathrm{A} / \mathrm{O})$ mostrou-se bastante eficiente na remoção de compostos orgânicos biorefratários da água residuária de coqueria utilizada, com as vantagens de ter baixo custo, economizar energia e ser de mais fácil operação, quando comparado aos pré-tratamentos com radiação ultravioleta e ozonização.

Yi; Yibo; Huiming (1994) puderam concluir que a DQO efluente podia atender aos padrões de descarga com o uso do sistema A-A/O e que este sistema mostrou-se não somente eficiente na remoção de DQO e compostos poli e heterocíclicos como também de nitrogênio amoniacal, além do controle de nitrogênio total. 
Lee e Park (1998), fazendo uma revisão da literatura, encontraram diversos trabalhos indicando que alguns dos compostos presentes em águas residuárias de coquerias eram inibidores da nitrificação e da desnitrificação. Melcer e Nutt (1988) apud Lee e Park (1998) relataram que um sistema biológico duplo de leito fluidizado apresentava ótima eficiência na remoção de amônia quando as concentrações de amônia presentes num despejo de coqueria pré-tratado eram relativamente baixas.

Entretanto, Lee e Park (1998) trabalharam com um despejo com alta concentração de amônio (de até $1000 \mathrm{mg} \mathrm{N} / \mathrm{L}$ ), e a maioria dos compostos de carbono presentes era hidrocarbonetos aromáticos que, segundo Hutchins et al. (1991), não eram fontes de carbono adequadas para a desnitrificação. Além disso, o despejo também continha cianeto (até $20 \mathrm{mgCN}^{-} / \mathrm{L}$ ) que era conhecido por inibir a enzima nitrato redutase, a enzima chave na desnitrificação (PAINTER, 1977 apud LEE; PARK, 1998). Vários artigos foram encontrados mostrando que a nitrificação poderia ser inibida por fenol, pela maioria dos PAHs, por cianetos e tiocianatos (BLUM; SPEECE, 1991; GLANCER et al., 1994; HOCKENBURY; GRADY, 1977 apud LEE; PARK, 1998) e esses compostos constituíam a maior parte dos compostos presentes na água residuária estudada por Lee e Park (1998).

Assim, a pesquisa realizada pelos autores objetivou propor um sistema de remoção biológica de nitrogênio evitando a ocorrência de todos os problemas de inibição mencionados. O esquema constava primeiramente de um estágio aerado de remoção de matéria carbonácea, onde eram removidos os compostos inibidores; em seguida, um estágio de nitrificação, no qual o lodo era recirculado do decantador para o reator aeróbio onde era mantido um tempo de retenção de sólidos de aproximadamente 60 dias e finalmente, um estágio de desnitrificação num reator anóxico (nível de OD inferior a $0,05 \mathrm{mgO}_{2} / \mathrm{L}$ ) com adição externa de carbono (acetato de sódio). Além do fenol outras fontes de carbono contribuíam para a DQO afluente como o cresol e o tolueno. A concentração de amônia era 
elevada, entre 700 e $1000 \mathrm{mgN} / \mathrm{L}$; o fenol variava entre 200 e $500 \mathrm{mg} / \mathrm{L}$ e a DQO, entre 500 e $1500 \mathrm{mgO}_{2} / \mathrm{L}$.

Os resultados mostraram que a razão média de DQO removida: $\mathrm{N}_{-} \mathrm{NO}_{3}{ }^{-}$ desnitrificado foi de 3,6, um pouco inferior aos valores de 4 e 6 , encontrados por Henze (1991) e Isaacs et al. (1994). Lee e Park (1998) ainda afirmaram que esta razão se constitui num importante parâmetro no que se refere à desnitrificação e que ela é variável de acordo com o tipo de microrganismo desnitrificante, compostos carbonáceos e condições de operação. A partir desta relação foi possível determinar a carga ótima de carbono externo adicionado para um tempo de detenção hidráulico de 4 dias. Além disso, observou-se que o sistema proposto removeu mais de $95 \%$ da DQO e da amônia presentes no despejo de coqueria estudado.

Em seus estudos com reatores desnitrificantes em batelada e de fluxo contínuo, Eiroa et al. (2005) observaram que, nos ensaios em batelada, o fenol era inteiramente consumido em concentrações de 30 a $180 \mathrm{mg} / \mathrm{L}$ e que, para concentrações superiores a $360 \mathrm{mg} / \mathrm{L}$, o processo desnitrificante era inibido. Já no experimento contínuo, os pesquisadores relataram que foram obtidas eficiências de remoção de fenol superiores a 90\% quando as concentrações afluentes estiveram entre 27 e $755 \mathrm{mg} / \mathrm{L}$; entretanto, quando os autores trabalharam com concentrações afluentes de $1010 \mathrm{mg} / \mathrm{L}$, a taxa de desnitrificação decresceu em virtude de inibição causada pelo fenol.

Da Costa (1999) operou dois sistemas piloto de lodo ativado de lodo único tratando despejo sintético de coqueria no Centro Tecnológico de Hidráulica localizado na Cidade Universitária da USP e observou boas eficiências na nitrificação e degradação do fenol quando utilizou inóculo proveniente do lodo de retorno de um sistema biológico de tratamento de uma indústria petroquímica. 
Posteriormente, Dombroski (2003) utilizando despejo similar (com concentrações afluentes de fenol e nitrogênio amoniacal de $1000 \mathrm{mg} / \mathrm{L}$ e $750 \mathrm{mgN} / \mathrm{L}$, respectivamente) e inóculo proveniente da mesma indústria trabalhou com os sistemas piloto originalmente utilizados por Da Costa (1999), porém introduziu reatores anóxicos antes dos aeróbios para promover a desnitrificação do despejo, utilizando o fenol presente no afluente como fonte de carbono para a desnitrificação. O estudo permitiu concluir que o fenol podia ser utilizado como fonte de carbono pelos microrganismos desnitrificantes, já que foram obtidas eficiências de remoção de fenol nos reatores anóxicos superiores a 99\%.

Aun (2001), trabalhando com o inóculo proveniente dos sistemas piloto de Dombroski (2003) e com o mesmo tipo de despejo, para verificar as taxas de decaimento de nitrato desses sistemas em testes realizados em reator de bancada, observou que a relação A/M (alimento/microrganismo) mais segura sem haver acúmulo de fenol no reator foi a de 0,10 kg fenol/kg SSV.dia, sendo que com concentrações de nitrato inferiores a $10 \mathrm{mg} \mathrm{N}-\mathrm{NO}_{3}{ }^{-} / \mathrm{L}$ no reator, o fenol passava a acumular. As taxas de desnitrificação observadas para essa relação A/M permaneceram entre 0,04 e $0,06 \mathrm{~kg} \mathrm{~N}-\mathrm{NO}_{3}{ }^{-} / \mathrm{kg} \mathrm{SSV}^{-d i a}$.

\subsection{Remoção de Nitrogênio em Sistemas Biológicos}

O material nitrogenado em águas residuárias compõe-se principalmente de nitrogênio amoniacal (não ionizado, $\mathrm{NH}_{3}$ e ionizado, $\mathrm{NH}_{4}{ }^{+}$) e nitrogênio orgânico (uréia, aminoácidos e outras substâncias orgânicas com o grupo amino). Ocasionalmente ocorrem traços de formas oxidadas do nitrogênio, nitrito $\left(\mathrm{NO}_{2}{ }^{-}\right)$e principalmente, nitrato $\left(\mathrm{NO}_{3}{ }^{-}\right)$. A soma da concentração de nitrogênio orgânico e amoniacal é chamada de nitrogênio Kjeldahl total ou NKT (VAN HAANDEL; MARAIS, 1999; VON SPERLING, 1997). 
No sistema de lodo ativado, é possível a ocorrência de vários processos que modificam a forma do material nitrogenado podendo ocorrer reações de amonificação/assimilação, nitrificação e desnitrificação.

Na reação de amonificação, o nitrogênio orgânico é convertido em amoniacal, enquanto que na assimilação, ocorre o inverso.

Levando-se em consideração que o nitrogênio amoniacal em pH próximo de 7,0 terá predominantemente a forma iônica $\left(\mathrm{NH}_{4}{ }^{+}\right)$, tem-se (VAN HAANDEL; MARAIS, 1999):

$$
\mathrm{RNH}_{2}+\mathrm{H}_{2} \mathrm{O}+\quad \mathrm{H}_{\text {amonificação }}^{\text {assimilação }} \Leftrightarrow \stackrel{\mathrm{ROH}}{\Leftrightarrow}+\mathrm{NH}_{4}^{+}
$$

\subsubsection{Nitrificação}

Em sistemas aeróbios de tratamento biológico, o processo de nitrificação é realizado por microrganismos autótrofos quimiossintetizantes (ou quimioautótrofos), para os quais o gás carbônico é a principal fonte de carbono e a energia é obtida através da oxidação de um substrato inorgânico, a amônia, a formas mineralizadas (VON SPERLING, 1997).

A nitrificação é realizada por gêneros distintos de bactérias autotróficas que oxidam o nitrogênio amoniacal a nitrato. Durante a primeira fase, o nitrogênio amoniacal é convertido em nitrito para em seguida ser transformado em nitrato. Geralmente, as bactérias do gênero Nitrosomonas sp são as responsáveis pela oxidação da amônia a nitrito e as bactérias do gênero Nitrobacter $s p$ por oxidarem o nitrito a nitrato. Pode-se dizer que ambos os gêneros, Nitrosomonas sp e Nitrobacter $s p$, somente desenvolvem atividade bioquímica na presença de oxigênio dissolvido, isto é, são aeróbios obrigatórios. 
Embora esses sejam os gêneros mais conhecidos de bactérias que promovem a oxidação do nitrogênio amoniacal a nitrato, diversos outros já foram identificados até hoje. Schramm et al. (1998) mencionaram que nem o gênero de bactérias Nitrosomonas sp nem tampouco o Nitrobacter $s p$ foram observados na oxidação de amônia a nitrito e de nitrito a nitrato, respectivamente, em sua pesquisa utilizando reator de leito fluidizado nitrificante. Os autores afirmam terem identificado pela técnica de hibridização fluorescente in situ (FISH fluorescence in situ hybridization) que as oxidantes de amônia a nitrito predominantes foram do grupo Nitrosospira $s p$, ao passo que as oxidantes de nitrito a nitrato mostraram-se predominantemente do grupo Nitrospira sp.

Burrell; Keller e Blackall (1998) foram os primeiros a relatar a presença de bactérias Nitrospira sp oxidantes de nitrito em sistemas de tratamento de águas residuárias, fato que até então, segundo os autores, era desconhecido.

Painter (1970) apud Randall; Barnard; Stensel (1992) relacionou outros gêneros de bactérias autotróficas capazes de obter energia da oxidação do amônio como Nitrosococcus sp, Nitrospira sp, Nitrosocyctis sp e Nitrosoglea $s p$, e da oxidação do nitrito, como o Nitrocystis sp.

Pode-se dizer que as reações típicas da nitrificação podem ser expressas por (VON SPERLING, 1997):

$\begin{array}{lll}2 \mathrm{NH}_{4}{ }^{-} \mathrm{N}+3 \mathrm{O}_{2} & \rightarrow & 2 \mathrm{NO}_{2}^{-}-\mathrm{N}+4 \mathrm{H}^{+}+2 \mathrm{H}_{2} \mathrm{O}+\text { Energia } \\ 2 \mathrm{NO}_{2}{ }^{-} \mathrm{N}+\mathrm{O}_{2} & \rightarrow & 2 \mathrm{NO}_{3}{ }^{-} \mathrm{N}+\text { Energia }\end{array}$

$\mathrm{NH}_{4}^{+}-\mathrm{N}+2 \mathrm{O}_{2} \quad \rightarrow \quad \mathrm{NO}_{3}^{-}-\mathrm{N}+2 \mathrm{H}^{+}+\mathrm{H}_{2} \mathrm{O}+$ Energia

Das reações apresentadas, pode-se observar que há um consumo de oxigênio livre (demanda nitrogenada) e também liberação de $\mathrm{H}^{+}$, ou seja, há um consumo de alcalinidade do meio e, sendo assim, possivelmente ocorre redução do pH (VON SPERLING, 1997). 
A energia liberada nessas reações é usada pelos microrganismos nitrificantes na síntese de compostos orgânicos a partir de fontes de carbono inorgânico, como dióxido de carbono, bicarbonato e carbonato.

A taxa de crescimento dos microrganismos nitrificantes é bem lenta e bastante inferior a dos microrganismos responsáveis pela estabilização da matéria carbonácea. Assim, em um sistema de tratamento biológico em que se objetiva a nitrificação, o tempo de residência celular ou idade do lodo deve ser tal que propicie o desenvolvimento das bactérias nitrificantes, antes que elas sejam varridas do sistema. O sistema é controlado, portanto, pelo organismo de crescimento mais lento, no caso, as Nitrosomonas $s p$. As bactérias do gênero Nitrobacter $s p$ têm uma taxa de crescimento mais rápida, razão pela qual quase não se observa acúmulo de nitrito nesses sistemas (VON SPERLING, 1997).

Segundo Knowles et al. (1965) apud Nowak et al. (1999), a taxa de crescimento máximo específico das bactérias do gênero Nitrobacter sp é significantemente maior do que a das Nitrosomonas $s p$ a temperaturas entre 10 e $20^{\circ} \mathrm{C}$, e portanto, normalmente não ocorre o acúmulo de nitrito durante o processo de nitrificação em sistemas de tratamento de esgotos municipais em operação em regiões de clima moderado.

Uma revisão feita por Focht e Chang (1975) apud Randall; Barnard; Stensel (1992) indicou que a nitrificação heterotrófica também seria possível com diversos gêneros de bactérias, fungos e actinomicetos; entretanto sua relevância seria discutível quanto às quantidades de nitrato geradas pelos microrganismos heterotróficos, já que as taxas de nitrificação autotrófica seriam cerca de dez vezes maiores. 


\subsubsection{Fatores Ambientais que Influenciam a Nitrificação}

Os fatores ambientais que influenciam a taxa de crescimento dos organismos nitrificantes e, conseqüentemente, a taxa de oxidação da amônia são: pH, temperatura, oxigênio dissolvido e a presença de substâncias tóxicas ou inibidoras (VON SPERLING, 1997).

Segundo Brond e Sund (1994), o problema básico relacionado à nitrificação em águas residuárias industriais com alto teor de amônia refere-se ao fato da própria amônia ser tóxica aos microrganismos nitrificantes. Segundo eles, o processo de nitrificação é dependente do $\mathrm{pH}$, das concentrações de amônia $\left(\mathrm{NH}_{3}\right)$ e de ácido nitroso $\left(\mathrm{HNO}_{2}\right)$ que são capazes de inibir as bactérias nitrificantes. Brond e Sund (1994) ainda afirmaram que, no caso específico de despejos de coquerias, alguns dos compostos presentes na água residuária são extremamente tóxicos às nitrificantes, como é o caso por exemplo do fenol, cianeto, tiocianato, sulfeto e amônia.

Segundo Anthonisen et al. (1976), os efeitos inibitórios da amônia e do nitrito estão diretamente relacionados às concentrações das formas não ionizadas e como as concentrações dessas duas formas são dependentes do pH da solução, a amônia livre (não ionizada) é o principal composto inibidor em $\mathrm{pH}$ alto $(>8,0)$, enquanto o ácido nitroso não ionizado é o principal inibidor em $\mathrm{pH}$ baixo.

Em relação ao pH, o gráfico apresentado na Figura 3 indica em que condições os organismos nitrificantes são inibidos pela presença de amônia livre $\left(\mathrm{NH}_{3}\right)$ e ácido nitroso $\left(\mathrm{HNO}_{2}\right)$. 


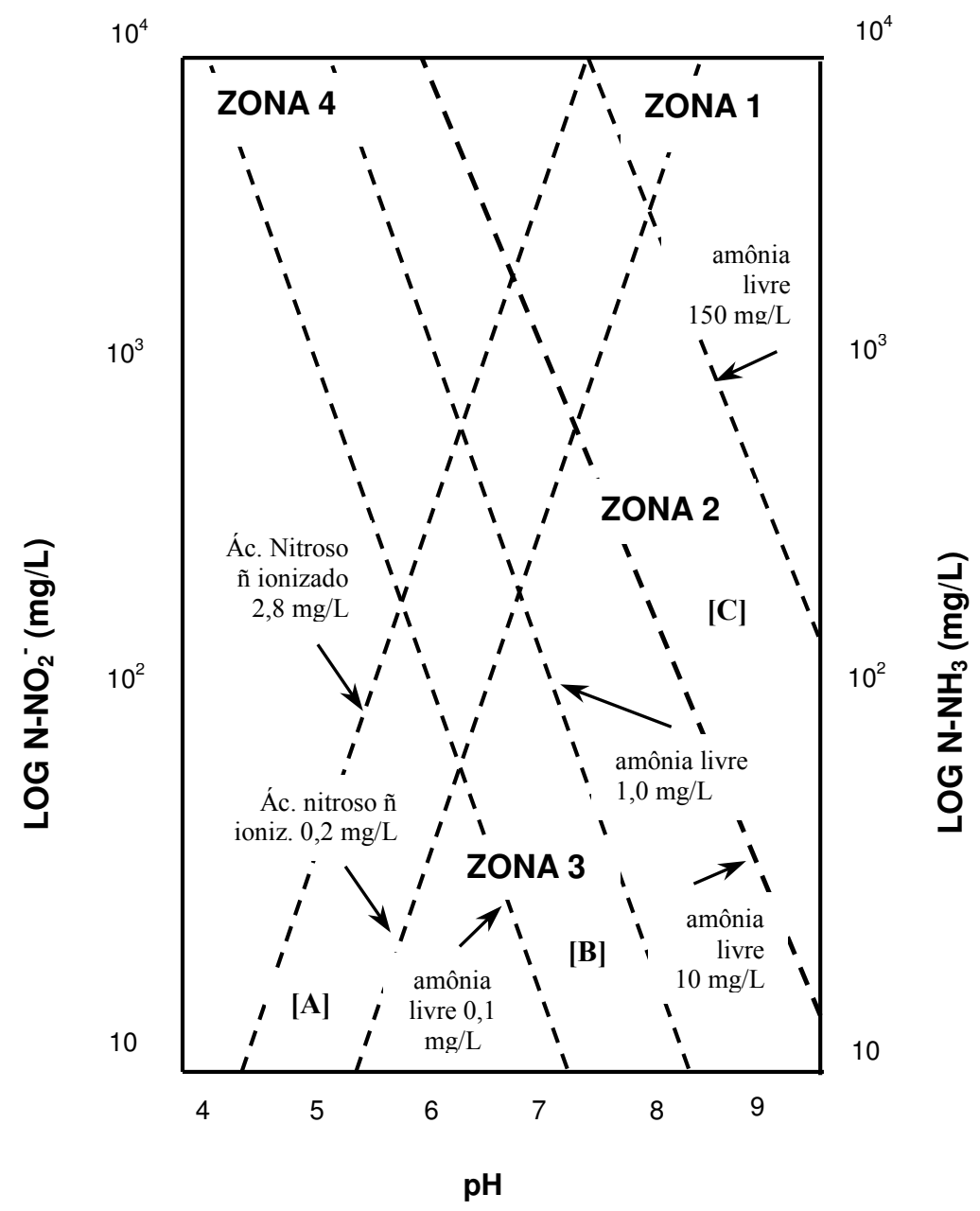

Figura 3 - Relação de inibição aos organismos nitrificantes por amônia e ácido nitroso Fonte: ANTHONISEN et al., 1976

Do gráfico apresentado por Anthonisen et al. (1976), pode-se concluir que, na Zona 1, a concentração de amônia livre é tão elevada que provoca inibição de ambos os gêneros Nitrosomonas $s p$ e Nitrobacter $s p$, conseqüentemente não há nitrificação e a amônia acumula no sistema. Em concentrações inferiores de amônia, pode ocorrer inibição do gênero Nitrobacter sp e o nitrito acaba acumulando (Zona 2). Em concentrações ainda menores de amônia livre, nenhum dos gêneros é inibido e provavelmente haverá nitrificação completa (Zona 3). Pode ocorrer também inibição da nitrificação pelo ácido nitroso e a Zona 4 representa esta condição. 
Anthonisen et al. (1976) concluíram de seus experimentos que concentrações de amônia livre que inibem as bactérias oxidadoras de amônia são maiores que aquelas que inibem as oxidadoras de nitrito e que a faixa de inibição das bactérias oxidadoras de amônia seria de 10 a $150 \mathrm{mg} \mathrm{NH}_{3} / \mathrm{L}$, ao passo que a inibição das oxidadoras de nitrito ocorreria em concentrações de amônia livre de 0,1 a 1,0 $\mathrm{mg} \mathrm{NH}_{3} / \mathrm{L}$. Os pesquisadores ainda reportaram que concentrações de 0,2 a $2,8 \mathrm{mg} \mathrm{HNO}_{2} / \mathrm{L}$ de ácido nitroso também poderiam inibir a nitrificação.

Dado que o equilíbrio entre o íon amônio e amônia livre pode ser expresso pela reação (05), Anthonisen et al. (1976) propuseram as equações (06) e (07) relacionando as concentrações de amônia livre e ácido nitroso não ionizado, com o pH do meio aquoso:

$\mathrm{NH}_{4}^{+}+\mathrm{OH}^{-} \leftrightarrow \mathrm{NH}_{3}+\mathrm{H}_{2} \mathrm{O}$

Amônialivre $\left(\mathrm{mgNH}_{3} / L\right)=\frac{17 \cdot N A T \times 10^{p H}}{14 \cdot K b / K w+10^{p H}}$

sendo

NAT = Nitrogênio amoniacal total (íon amônio + amônia livre) (mg N/L)

$\mathrm{Kb}=10^{-9,24}=$ constante de ionização da amônia no equilíbrio a $20^{\circ} \mathrm{C}$

$\mathrm{Kw}=0,69 \times 10^{-14}=$ constante de ionização da água a $20^{\circ} \mathrm{C}$

$\mathrm{Kb} / \mathrm{KW}=\mathrm{e}^{(6.344 /(273+\mathrm{T}))}$

$\mathrm{T}=$ Temperatura em ${ }^{\circ} \mathrm{C}$

Ácidonitrosolivre $\left(\mathrm{mgHNO}_{2} / \mathrm{L}\right)=\frac{46 \times \mathrm{N}-\mathrm{NO}_{2}^{-}(\mathrm{mg} / \mathrm{L})}{14 . \mathrm{Ka} \times 10^{p H}}$

sendo

$\mathrm{Ka}=\mathrm{e}^{(-2300 / 273+\mathrm{T})}$

$\mathrm{Ka}=$ constante de ionização do ácido nitroso no equilíbrio 
Em seus estudos realizados em sistemas piloto de lodo ativado tratando despejo sintético de coqueria, Da Costa (1999) observou como faixa ideal de pH para a nitrificação entre 6,8 a 7,2 .

Nos estudos realizados por Duisberg e Buehrer (1954) apud Anthonisen et al. (1976), os efeitos da temperatura na concentração de amônia livre foram bastante significativos, sendo que esta concentração a $30^{\circ} \mathrm{C}$ se apresentou duas vezes maior do que a $20^{\circ} \mathrm{C}$, para o mesmo pH e mesma concentração de nitrogênio amoniacal total.

Kim et al. (2007) realizaram testes em batelada utilizando lodo proveniente de um tanque de aeração de uma planta em escala real tratando despejo de coqueria de uma indústria siderúrgica coreana, para avaliação dos fatores que provocariam a instabilidade do processo de nitrificação no verão. Os autores estudaram a influência dos seguintes parâmetros: pH, temperatura, nutrientes e poluentes presentes.

Os estudos mostraram que a taxa de nitrificação era maior no verão $\left(38^{\circ} \mathrm{C}\right)$ do que na primavera ou outono $\left(29^{\circ} \mathrm{C}\right)$ e que os efeitos tóxicos do cianeto, fenol e tiocianato na nitrificação eram reduzidos com o aumento da temperatura. Entretanto, experimentos utilizando reator contínuo mostraram que a taxa de redução na eficiência de nitrificação era maior a $38^{\circ} \mathrm{C}$ do que a $29^{\circ} \mathrm{C}$. Os pesquisadores concluíram que a instabilidade do processo de nitrificação em escala real no verão se devia principalmente à lavagem das bactérias nitrificantes do sistema devido ao rápido crescimento de microrganismos concorrentes a temperaturas mais elevadas sob concentrações maiores de fenol e tiocianato.

A existência de substâncias tóxicas ou inibidoras também pode ser um fator determinante para um fraco desempenho da nitrificação. Randall e Buth (1984) estudaram o efeito combinado da temperatura e da toxicidade de níquel na nitrificação, sendo que os pesquisadores puderam concluir que a presença de níquel é mais tóxica aos microrganismos formadores de nitrato do que aos formadores de nitrito e que a presença desse composto 
poderia resultar no aumento das concentrações de nitrito em sistemas de lodo ativado. Eles também concluíram que os efeitos inibitórios do níquel na nitrificação eram maiores a temperaturas de $14^{\circ} \mathrm{C}$ do que a $17^{\circ} \mathrm{C}$ ou a $30^{\circ} \mathrm{C}$ e, portanto, haveria um efeito inibitório sinergético entre a temperatura e a toxicidade do níquel para a nitrificação.

Mota et al. (2005) estudaram os efeitos da extensão dos períodos de aeração e não-aeração na remoção de nitrogênio em cinco reatores em paralelo operados com aeração intermitente. As bactérias Nitrosomonas sp e Nitrosococcus mobilis foram as oxidantes de amônia predominantes em todos os reatores, enquanto a oxidante de nitrito dominante foi a Nitrospira $s p$, embora também tenham sido observadas Nitrosospira sp e Nitrobacter $s p$ em menores quantidades. Os reatores operados com tempos de aeração mais curtos (30 minutos) mostraram os maiores níveis de Nitrosospira sp e aqueles operados com os períodos anóxicos mais longos (3 e 4 horas) mostraram os menores níveis de Nitrobacter sp. As bactérias oxidantes de nitrito se mostraram mais sensíveis do que as de amônia a longos períodos não aerados. No reator com o período não-aerado mais longo, de 4 horas, foi observada nitrificação parcial seguida de desnitrificação via nitrito, ao passo que os demais reatores removeram nitrogênio via nitrificação e desnitrificação tradicional a nitrato.

Nogueira e Melo (2006) estudaram a competição entre as bactérias Nitrobacter sp e Nitrospira sp na oxidação de nitrito em sistemas de lodo ativado. Os autores puderam observar uma predominância de Nitrobacter sp sobre a Nitrospira sp, na qual eles explicaram ter ocorrido em virtude das elevadas concentrações de nitrito, sendo que as Nitrobacter $s p$ poderiam ter inibido as Nitrospira $s p$.

Com relação à concentração de oxigênio dissolvido do meio, a EPA (1993) recomenda que o OD mínimo seja de 2,0 $\mathrm{mgO}_{2} / \mathrm{L}$, embora outros autores mencionem que concentrações bem inferiores a essa já seriam suficientes para ocorrer a nitrificação. Barnes e Bliss (1983) apud Von Sperling (1997) afirmam que abaixo de $0,2 \mathrm{mgO}_{2} / \mathrm{L}$ a nitrificação não 
se processa, ao passo que Downing (1978) apud Von Sperling (1997) recomenda que o OD não seja inferior a $0,5 \mathrm{mgO}_{2} / \mathrm{L}$.

De seus estudos em laboratório, Schoberl e Engel (1964) apud Randall; Barnard; Stensel (1992) relataram que as taxas de nitrificação para as Nitrosomonas sp eram independentes em concentrações de oxigênio dissolvido maiores do que $1,0 \mathrm{mg} \mathrm{O}_{2} / \mathrm{L}$, ao passo que para as Nitrobacter sp, as mesmas só não eram afetadas para OD acima de $2,0 \mathrm{mgO}_{2} / \mathrm{L}$.

Por outro lado, Wuhrman (1963) apud Randall; Barnard; Stensel (1992) afirmou que as taxas de nitrificação não eram afetadas em concentrações de OD entre 4,0 e $7,0 \mathrm{mgO}_{2} / \mathrm{L}$, mas que as taxas a $1,0 \mathrm{mgO}_{2} / \mathrm{L}$ eram de $90 \%$ daquelas obtidas em concentrações de OD maiores. Nagel e Haworth (1969) apud Randall; Barnard; Stensel (1992) relataram que as taxas de nitrificação em sistemas de lodo ativado dobravam quando as concentrações de OD aumentavam de 1,0 para $3,0 \mathrm{mgO}_{2} / \mathrm{L}$.

\subsubsection{Requisitos de Oxigênio e Alcalinidade para a Nitrificação}

Observando-se a equação 04, que é a reação global da nitrificação, nota-se que 1 mol de nitrogênio amoniacal requer 2 moles de oxigênio para sua oxidação, ou seja, 4,57 $\mathrm{kg} \mathrm{O} 2$ são requeridos para $1 \mathrm{~kg}$ de $\mathrm{N}$ (peso molecular de $\mathrm{N}=14 \mathrm{~g} / \mathrm{mol}$ e do $\left.\mathrm{O}_{2}=64 \mathrm{~g} / \mathrm{mol} ; 64 / 14=4,57\right)$. Sendo assim, a oxidação de $1 \mathrm{mgNH}_{4}{ }^{+}-\mathrm{N} / \mathrm{L}$ consome $4,57 \mathrm{mgO}_{2} / \mathrm{L}$ (VON SPERLING, 1997).

Da mesma reação, observa-se que 1 mol de $\mathrm{NH}_{4}{ }^{+}-\mathrm{N}$ produz 2 moles de $\mathrm{H}^{+}$. Como cada mol de $\mathrm{H}^{+}$consome 1 mol de $\mathrm{HCO}_{3}^{-}$(bicarbonato), então os 2 moles de $\mathrm{H}^{+}$gerados na nitrificação irão consumir 2 moles de $\mathrm{HCO}_{3}{ }^{-}$. Em termos de concentração, $1 \mathrm{mg} \mathrm{NH}{ }_{4}{ }^{-} \mathrm{N} / \mathrm{L}$ consome $8,7 \mathrm{mg} \mathrm{HCO}_{3}{ }^{-} / \mathrm{L}$. No cálculo da alcalinidade, para as faixas usuais de $\mathrm{pH}$, pode-se 
dizer que os termos correspondentes a $\mathrm{OH}^{-}$e $\mathrm{CO}_{3}{ }^{2-}$ são desprezíveis e, sendo assim, simplificadamente, pode-se dizer que a alcalinidade é a concentração de bicarbonatos (em $\mathrm{mg} / \mathrm{L}$ ) dividido por 1,2. Conseqüentemente, os $8,7 \quad \mathrm{mgHCO}_{3}{ }^{-} / \mathrm{L}$ correspondem a $8,7 / 1,2=7,1 \mathrm{mg} / \mathrm{L}$ de alcalinidade e, portanto, a oxidação de $1 \mathrm{mgNH}_{4}{ }^{+}-\mathrm{N} / \mathrm{L}$ consome 7,1 mg/L de alcalinidade (VON SPERLING, 1997).

Do que foi exposto em termos de redução de $\mathrm{pH}$ do meio e consumo de alcalinidade, pode-se concluir que haverá uma redução da taxa de nitrificação, caso o pH decaia muito além da faixa ideal para a nitrificação e, portanto, é necessária a adição de um alcalinizante para a manutenção do $\mathrm{pH}$ na faixa desejada.

\subsubsection{Desnitrificação}

A desnitrificação é um processo de respiração na ausência de oxigênio livre, no qual o nitrato (ou nitrito) serve como aceptor de elétrons. $\mathrm{O}$ nitrato, $\mathrm{NO}_{3}{ }^{-}$, é reduzido a óxido nitroso, $\mathrm{N}_{2} \mathrm{O}$, e então a nitrogênio gasoso, $\mathrm{N}_{2}$, que escapa para a atmosfera (TIEDJE, 1988 apud BITTON, 1994). Ela é a redução biológica de nitrato (ou nitrito) para nitrogênio molecular tendo-se material orgânico como redutor. Admitindo-se uma fórmula geral $\mathrm{C}_{\mathrm{x}} \mathrm{H}_{\mathrm{y}} \mathrm{O}_{\mathrm{z}}$ para material orgânico, a reação de redução e de oxidação pode ser escrita como (VAN HAANDEL; MARAIS, 1999):

Oxidação: $\quad \mathrm{C}_{\mathrm{x}} \mathrm{H}_{\mathrm{y}} \mathrm{O}_{\mathrm{z}}+(2 \mathrm{x}-\mathrm{z}) \mathrm{H}_{2} \mathrm{O} \rightarrow \mathrm{xCO}_{2}+(4 \mathrm{x}+\mathrm{y}-2 \mathrm{z}) \mathrm{H}^{+}+(4 \mathrm{x}+\mathrm{y}-2 \mathrm{z}) \mathrm{e}^{-}$

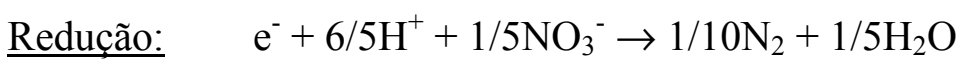

Redox: $\quad \mathrm{C}_{\mathrm{x}} \mathrm{H}_{\mathrm{y}} \mathrm{O}_{\mathrm{z}}+(4 \mathrm{x}+\mathrm{y}-2 \mathrm{z}) / 5 \mathrm{H}^{+}+(4 \mathrm{x}+\mathrm{y}-2 \mathrm{z}) / 5 \mathrm{NO}_{3}{ }^{-} \rightarrow \mathrm{xCO}_{2}+1 / 5(2 \mathrm{x}+3 \mathrm{y}-2 \mathrm{z}) \mathrm{H}_{2} \mathrm{O}+$ $1 / 10(4 x+y-2 z) N_{2}$ 
O nitrato prontamente substitui o oxigênio como aceptor final de elétrons. A diferença está na transferência de elétrons dos citocromos, onde a enzima redutase específica é substituída pela enzima redutase de nitrato, a qual catalisa a transferência final de elétrons para o nitrato ao invés do oxigênio (EKAMA; MARAIS, 1997). Estudos de culturas puras de organismos desnitrificantes indicaram que a presença de oxigênio dissolvido impede a formação da enzima necessária para a transferência final de elétrons para o nitrato (CHANG; MORRIS, 1972 apud EKAMA; MARAIS, 1997).

Segundo Payne (1981) apud Copp; Dold (1998), a desnitrificação é essencialmente um processo de quatro etapas:

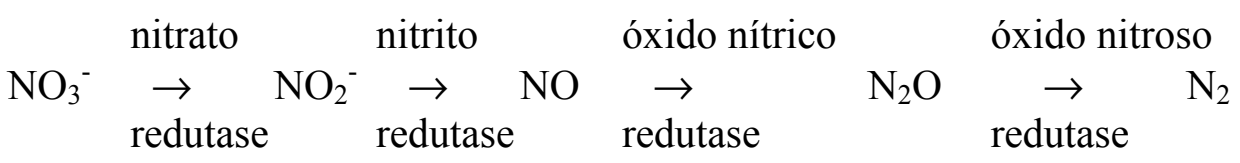

Cada etapa pode ser representada por uma reação onde $\mathrm{e}^{-}$representa os elétrons transferidos do substrato orgânico conforme as equações a seguir:

$$
\begin{aligned}
& 4 \mathrm{e}^{-}+2 \mathrm{NO}_{3}^{-}+4 \mathrm{H}^{+} \rightarrow 2 \mathrm{NO}_{2}^{-}+2 \mathrm{H}_{2} \mathrm{O} \\
& 2 \mathrm{e}^{-}+2 \mathrm{NO}_{2}^{-}+4 \mathrm{H}^{+} \rightarrow 2 \mathrm{NO}+2 \mathrm{H}_{2} \mathrm{O} \\
& 2 \mathrm{e}^{-}+2 \mathrm{NO}+2 \mathrm{H}^{+} \rightarrow \mathrm{N}_{2} \mathrm{O}+\mathrm{H}_{2} \mathrm{O} \\
& 2 \mathrm{e}^{-}+\mathrm{N}_{2} \mathrm{O}+2 \mathrm{H}^{+} \rightarrow \mathrm{N}_{2}+\mathrm{H}_{2} \mathrm{O}
\end{aligned}
$$

Combinando-se estas quatro, obtém-se a reação de desnitrificação completa:

$10 \mathrm{e}^{-}+2 \mathrm{NO}_{3}^{-}+12 \mathrm{H}^{+} \rightarrow \mathrm{N}_{2}+6 \mathrm{H}_{2} \mathrm{O}$

ou

$\mathrm{e}^{-}+1 / 5 \mathrm{NO}_{3}{ }^{-}+6 / 5 \mathrm{H}^{+} \rightarrow 1 / 10 \mathrm{~N}_{2}+3 / 5 \mathrm{H}_{2} \mathrm{O}$

De forma similar, a reação para redução de $\mathrm{O}_{2}$ é:

$\mathrm{e}^{-}+1 / 4 \mathrm{O}_{2}+\mathrm{H}^{+} \rightarrow 1 / 2 \mathrm{H}_{2} \mathrm{O}$ 
Das duas reações anteriores, conclui-se que:

$1 / 5$ mol de nitrato $\equiv 1 / 4$ mol de oxigênio

$14 / 5{\mathrm{~g} \mathrm{~N}-\mathrm{NO}_{3}}^{-} \equiv 32 / 4 \mathrm{~g}$ de oxigênio

$1{\mathrm{~g} \mathrm{~N}-\mathrm{NO}_{3}}^{-} \equiv 2,86 \mathrm{~g}$ de oxigênio

Segundo Van Haandel e Marais (1999), 2/3 da DQO consumida nos sistemas de tratamento de efluentes é sintetizada, enquanto $1 / 3$ é oxidada, consumindo oxigênio na

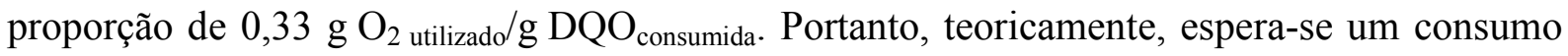
de substrato durante a desnitrificação igual a:

$\mathrm{DQO}_{\text {consumida }}=\mathrm{mg} \mathrm{N}-\mathrm{NO}_{3}{ }^{-}$reduzido $\mathrm{x} 2,86 / 0,33=8,6 \mathrm{mg} \mathrm{DQO} / \mathrm{mg} \mathrm{N}^{-\mathrm{NO}_{3}}{ }^{-}$removido

A desnitrificação é realizada pelas bactérias heterotróficas e autotróficas. As bactérias heterotróficas requerem uma fonte de carbono para seu crescimento e metabolismo celular, que pode ser encontrada como DBO solúvel no esgoto ou sinteticamente como metanol, etanol, ácido acético. Estas bactérias são encontradas no tratamento de esgotos e são responsáveis pela desnitrificação que pode ocorrer em decantadores primários, secundários e em zonas anóxicas de reatores de lodo ativado. As bactérias autotróficas, por sua vez, obtêm sua energia do hidrogênio e do enxofre, e como fonte de carbono, o dióxido de carbono da água. Elas crescem muito mais lentamente e, normalmente, suas velocidades de reprodução impedem que estas bactérias tenham maior contribuição na desnitrificação (UPTON; FERGUSSON; SAVAGE, 1993).

Tem sido descrita uma grande variedade de bactérias capazes de promover a desnitrificação, no entanto, não tem sido verificada capacidade semelhante de algas e fungos. Payne (1981) apud Randall; Barnard; Stensel (1992) cita Achromobacter sp, Acinetobacter sp, Agrobacterium sp, Alcaligenes sp, Arthrobacter sp, Bacillus sp, Chromobacterium sp, 
Corynebacterium sp, Flavobacterium sp, Hypomicrobium sp, Moraxella sp, Neisseria sp, Paracoccus sp, Propionibacterium sp, Pseudomonas sp, Rhizobium sp, Rhodopseudomonas $s p$, Spirillum $s p$ e Vibrio $s p$ entre os gêneros de organismos heterotróficos capazes de promover a desnitrificação. Além desses, Gayle et al. (1989) apud Randall; Barnard; Stensel (1992) incluem nesta lista Halobacterium sp e Methanomonas sp. A maioria dessas bactérias pode utilizar oxigênio tão bem quanto nitrato e algumas delas podem também promover a fermentação na ausência de nitrato ou oxigênio.

Em relação à desnitrificação autotrófica, as bactérias utilizam dióxido de carbono ou bicarbonato como fonte de carbono ao invés de carbono orgânico. As bactérias desnitrificantes Paracoccus e Thiobacillus denitrificans utilizam hidrogênio e compostos reduzidos de enxofre respectivamente, como doadores de elétrons durante a desnitrificação. Ambos podem crescer heterotroficamente se uma fonte de carbono orgânico estiver presente (GAYLE et al., 1989 apud RANDALL; BARNARD; STENSEL, 1992).

As Pseudomonas sp são as bactérias desnitrificantes mais comumente encontradas em sistemas biológicos de tratamento. Algumas das espécies não reduzem nitrato, mas iniciam a desnitrificação com o nitrito. Certas espécies também acumulam óxido nitroso como produto final ao invés do nitrogênio gasoso. Foi demonstrado que as Pseudomonas sp utilizam um grande número de compostos orgânicos incluindo metanol, carboidratos, ácidos orgânicos, álcoois, benzoatos e outros compostos aromáticos (PAYNE, 1981 apud RANDALL; BARNARD; STENSEL, 1992).

Carlson e Ingraham (1983) fizeram uma comparação entre os microrganismos Pseudomonas stutzeri, Pseudomonas aeruginosa e Paracoccus denitrificans quanto à desnitrificação. Os autores observaram que, embora os três tenham promovido a redução de nitrato a nitrogênio gasoso, eles o fizeram a diferentes taxas e em alguns casos acumularam compostos intermediários. A pesquisa dos autores mostrou que a Pseudomonas stutzeri 
produziu somente gás nitrogênio, ao passo que a Pseudomonas aeruginosa e a Paracoccus denitrificans também produziram óxido nitroso, sendo que sob certas condições a Pseudomonas aeruginosa produziu até mais óxido nitroso do que nitrogênio gasoso.

Os pesquisadores também puderam observar que a Pseudomonas stutzeri e a Paracoccus denitrificans rapidamente reduziam nitrato, nitrito e óxido nitroso e foram capazes de crescer anaerobicamente quando nenhum desses óxidos de nitrogênio estava presente no meio. Por outro lado, a Pseudomonas aeruginosa reduziu esses compostos bem mais lentamente, além de não ter sido capaz de crescer anaerobicamente. Além disso, a redução de óxido nítrico e óxido nitroso pela Pseudomonas aeruginosa foi extremamente susceptível à inibição pelo nitrito. Assim, Carlson e Ingraham (1983) puderam concluir que a Pseudomonas aeruginosa não era a espécie mais adequada para promover a desnitrificação.

\subsubsection{Condições Necessárias para o Desenvolvimento da Desnitrificação}

Existem quatro condições básicas para que o processo de desnitrificação se desenvolva (VAN HAANDEL; EKAMA; MARAIS, 1981):

1. presença de nitrato (ou nitrito);

2. ausência de oxigênio dissolvido;

3. massa bacteriana capaz de aceitar nitrato (ou nitrito) como aceptor de elétrons;

4. presença de um doador de elétrons adequado (fonte de energia).

No caso de esgotos sanitários, segundo Van Haandel e Marais (1999), a concentração de nitrato tem pouca influência sobre a taxa de desnitrificação, e sendo assim, quando a concentração de nitrato é maior que $0,5 \mathrm{mgN}^{-\mathrm{NO}_{3}}{ }^{-} / \mathrm{L}$, então a taxa de desnitrificação independe da concentração de nitrato. Já a EPA (1993) afirma que quando as concentrações 
de nitrato são superiores a 1 ou $2 \mathrm{mgN}^{-\mathrm{NO}_{3}}{ }^{-} / \mathrm{L}$, então essas não têm influência sobre a taxa de desnitrificação.

Entretanto, Aun (2001) e Dombroski (2003), em suas pesquisas com água residuária sintética de coqueria, observaram a necessidade da manutenção da concentração mínima de $10 \mathrm{mgN}-\mathrm{NO}_{3}{ }^{-} / \mathrm{L}$ e $15 \mathrm{mgN}-\mathrm{NO}_{3}{ }^{-} / \mathrm{L}$, respectivamente, para não haver acúmulo de fenol no reator anóxico e, conseqüentemente, redução na taxa de desnitrificação ou até inibição do processo desnitrificante.

O oxigênio dissolvido tem efeito inibitório sobre a desnitrificação. Carlson (1972) apud Ekama; Marais (1997) verificou a remoção de 100\% de nitrato à concentração de oxigênio dissolvido igual a zero, enquanto que para concentração de oxigênio dissolvido igual a $0,2 \mathrm{mgO}_{2} / \mathrm{L}$, a desnitrificação obtida não foi significativa. Vale lembrar que em um reator anóxico de mistura completa, mesmo se a concentração de oxigênio dissolvido for mínima, qualquer aporte de oxigênio será utilizado preferencialmente pela biomassa, reduzindo a massa de nitrato passível de desnitrificação no reator.

Metcalf \& Eddy (1991) apresentam uma correção para a taxa de desnitrificação na qual a taxa decresce linearmente com o aumento da concentração de oxigênio dissolvido, atingindo zero quando este é igual a $1,0 \mathrm{mgO}_{2} / \mathrm{L}$.

A maioria das bactérias heterotróficas que se desenvolve no sistema de lodo ativado pode usar tanto oxigênio dissolvido como nitrato para oxidar o material orgânico. Experimentalmente, estabeleceu-se que um lodo gerado sob condições aeróbias, quando sujeito a um ambiente anóxico na presença de material orgânico, demonstra imediatamente a capacidade de usar nitrato como oxidante e continua a desnitrificar sem variação mensurável da reatividade do lodo enquanto a condição anóxica persistir (VAN HAANDEL; MARAIS, 1999). 
A oxidação de compostos carbonáceos com nitrato como aceptor de elétrons proporciona a energia requerida pelos heterotróficos facultativos para a síntese de novas células e respiração endógena. O doador de elétrons constitui a fonte de energia (EKAMA; MARAIS, 1997). As fontes de energia necessárias para a desnitrificação foram caracterizadas como: (a) fonte de energia não presente na água residuária, isto é, uma fonte de energia externa carbonácea (por exemplo, metanol, etanol, acetona, ácido acético); (b) fonte de energia presente no afluente, isto é, fonte de energia interna e (c) fonte de energia gerada no sistema pela liberação de material celular de organismos mortos, isto é, fonte de energia autogerada (VAN HAANDEL; EKAMA; MARAIS, 1981).

Diversas foram as fontes de energia carbonácea já utilizadas para promover a desnitrificação. Henze (1989) apud Pochana; Keller (1999) comparou as taxas de desnitrificação utilizando muitos componentes orgânicos como fonte de carbono e encontrou que a taxa com esgoto sanitário seria aproximadamente $1 / 3$ do valor obtido com ácido acético ou metanol. Tam et al. (1992) apud Pochana; Keller (1999) e Gerber et al. (1986) apud Pochana; Keller (1999), por sua vez, comparando acetato, metanol e glicose, encontraram que o acetato foi o que forneceu as mais altas taxas de desnitrificação, seguido pelo metanol e pela glicose nesta ordem.

Constantin e Fick (1997) estudaram a influência das fontes de carbono na taxa de desnitrificação de uma água residuária industrial com alta concentração de nitrato $\left(7.100 \mathrm{mgNO}_{3}{ }^{-} / \mathrm{L}\right.$, ou seja, aproximadamente $\left.1.600 \mathrm{mgN}^{-N^{2}}{ }_{3}^{-} / \mathrm{L}\right)$ além de muitos outros componentes inorgânicos, através da comparação entre dois substratos: etanol e ácido acético. Dois reatores anóxicos eram alimentados em fluxo contínuo, um utilizando etanol e o outro, ácido acético, como fontes de carbono. Nos dois casos, a desnitrificação foi completa; entretanto os experimentos mostraram que o desenvolvimento dos microrganismos foi maior com o uso do etanol, mas no caso do ácido acético, a taxa específica de desnitrificação foi 
maior, o que pode ser explicado pelo fato do ácido acético ser uma fonte de carbono diretamente assimilável, já que o etanol, primeiramente, deveria ser transformado em acetato.

Tam, Wong e Leung (1992) examinaram os efeitos de três fontes de carbono exógenas na remoção de nutrientes inorgânicos num processo simples de nitrificação/desnitrificação. Metanol, glicose e acetato de sódio foram adicionados como fontes externas de carbono no estágio anóxico em concentrações equivalentes a valores de DQO teóricos de 100 e $200 \mathrm{mgO}_{2} / \mathrm{L}$. Entre os três substratos estudados, o acetato de sódio se mostrou a fonte de carbono mais efetiva, seguido do metanol e da glicose.

Santos (2003) utilizou reatores desnitrificantes em batelada em escala de bancada para comparar o desempenho de metanol, etanol e gás metano como doadores de elétrons. Todos os três compostos se mostraram capazes de promover a desnitrificação completa, sendo que o etanol apresentou-se como o mais eficiente doador de elétrons dentre os compostos experimentados.

Para que a desnitrificação ocorra numa alta taxa, além das condições indispensáveis anteriormente mencionadas, Francis e Callahan (1975) apud Bode; Seyfried; Kraft (1987) citam ainda que a faixa favorável de pH para a desnitrificação é de 7,5 a 8,5 e que a conversão de nitrato para nitrito é menos sensível a quedas de $\mathrm{pH}$ do que a conversão de nitrito a nitrogênio gasoso. Segundo algumas curvas apresentadas pela EPA (1993), em valores de pH abaixo de 6,0 e acima de 8,0, as taxas de desnitrificação diminuem bastante, sendo que como tendência geral, entre 7,0 e 7,5 estaria a máxima taxa, decrescendo de maneira aproximadamente linear com a redução e com o aumento de $\mathrm{pH}$.

Além do pH, Van Haandel e Marais (1999) citam que a temperatura é uma condição ambiental fundamental para que ocorra a desnitrificação e que a taxa de desnitrificação aumenta com o aumento da temperatura até um valor ótimo de $40^{\circ} \mathrm{C}$. Segundo 
Barnes e Bliss (1983) apud Von Sperling (1997), a reação de desnitrificação ocorre em uma ampla faixa de temperatura, de 0 a $50^{\circ} \mathrm{C}$, sendo que entre 35 e $50^{\circ} \mathrm{C}$ estaria seu valor ótimo.

A influência da temperatura em sistemas biológicos pode ser expressa como uma função típica de Arrhenius (VON SPERLING, 1997):

$\mathrm{TDE}_{\mathrm{T}}=\mathrm{TDE}_{20} \cdot \theta^{(\mathrm{T}-20)}$

na qual,

$\mathrm{TDE}_{\mathrm{T}}=$ taxa de desnitrificação específica em uma temperatura $\mathrm{T}\left(\mathrm{mg} \mathrm{N}-\mathrm{NO}_{3}{ }^{-} / \mathrm{mg} \mathrm{SSV}^{\mathrm{d}}\right)$

$\mathrm{TDE}_{20}=$ taxa de desnitrificação específica na temperatura $20^{\circ} \mathrm{C}\left(\mathrm{mg} \mathrm{N}-\mathrm{NO}_{3}{ }^{-} / \mathrm{mg} \mathrm{SSV} \mathrm{d}\right)$

$\mathrm{T}=$ temperatura do líquido $\left({ }^{\circ} \mathrm{C}\right)$

$\theta=$ coeficiente de temperatura

A literatura apresenta faixas bastante amplas para o coeficiente de temperatura $\theta$. Arceivala (1981) apud Von Sperling (1997) menciona valores entre 1,15 a 1,20. EPA (1993) lista valores que variam de 1,03 a 1,20, com predominância de valores próximos a 1,08. Metcalf \& Eddy (1991) utilizam o valor de 1,09.

Além da temperatura e do $\mathrm{pH}$, a presença de substâncias inibidoras ou tóxicas também pode influenciar a taxa de desnitrificação. Porém, como as bactérias nitrificantes, em geral, são bem mais sensíveis à presença destas substâncias do que as bactérias heterotróficas responsáveis pela desnitrificação, caso haja a presença de tais substâncias, a desnitrificação não deverá ocorrer, pelo simples fato da nitrificação ter sido inibida primeiramente (EPA, 1993).

\subsubsection{Vantagens Obtidas com o Desenvolvimento da Desnitrificação}

Os processos biológicos capazes de reduzir nitrato a nitrogênio gasoso permitem algumas vantagens em relação aos sistemas onde ocorre apenas a nitrificação. 
Quanto ao consumo de oxigênio, pode-se observar que na nitrificação o número de oxidação do nitrogênio em amônia -3 aumenta para +5 no nitrato através da transferência de 8 elétrons por átomo de nitrogênio (vide Figura 4) que são aceitos pelo oxigênio, sendo necessários quatro átomos (duas moléculas) de oxigênio para tal, diminuindo o número de oxidação do oxigênio de 0 para -2 na reação. Portanto, na nitrificação, para 1 mol de amônia há um consumo de oxigênio de $64 / 14=4,57 \mathrm{mg} \mathrm{O}_{2} / \mathrm{mg} \mathrm{N}$.

$\mathrm{Na}$ desnitrificação, o oxidante nitrato (número de oxidação +5 ) é reduzido a nitrogênio molecular (número de oxidação 0), havendo portanto uma transferência de 5 elétrons por átomo de nitrogênio. Assim, dos 8 elétrons liberados pelo nitrogênio amoniacal na sua oxidação para nitrato, 5 são recuperados quando o nitrato é reduzido a nitrogênio molecular. Dessa forma uma fração de $5 / 8=0,625$ do consumo de oxigênio necessário para a nitrificação $\left(4,57 \mathrm{mg} \mathrm{O}_{2} / \mathrm{mg} \mathrm{N}\right)$ pode ser recuperada como "oxigênio equivalente" na desnitrificação, isto é, $0,625 \times 4,57=2,86 \mathrm{mg} \mathrm{O}_{2} / \mathrm{mg} \mathrm{N}$. Pode-se concluir que na remoção de nitrogênio há um consumo líquido de 4,57 - 2,86=1,71 mg O $2 / \mathrm{mg} \mathrm{N}$ (VAN HAANDEL; MARAIS, 1999).

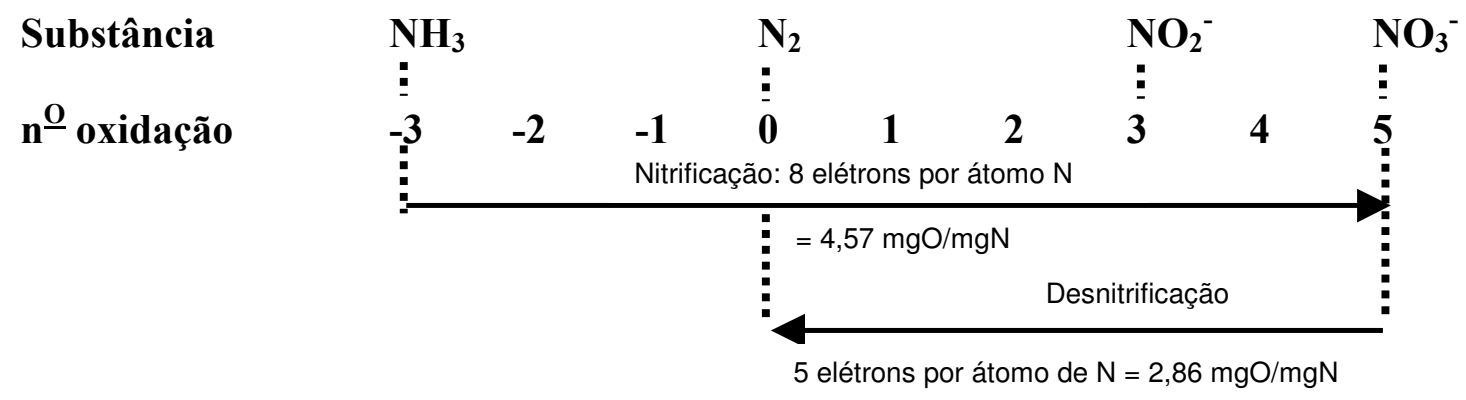

Figura 4 - Variação do número de oxidação de nitrogênio nos processos de nitrificação e desnitrificação Fonte: VAN HAANDEL; MARAIS, 1999

Em suma, para a nitrificação, 4,57 $\mathrm{mg} \mathrm{O}_{2} / \mathrm{mg} \mathrm{N}$ são requeridos; mas para a desnitrificação, 2,86 $\mathrm{mg} \mathrm{O}_{2} / \mathrm{mg} \mathrm{N}$ podem ser recuperados, isto é, com a desnitrificação $63 \%$ 
da demanda de oxigênio para nitrificação pode ser recuperada se for alcançada a desnitrificação completa.

Em relação à alcalinidade, quando o nitrato é reduzido a nitrogênio gás, tem-se um aumento na alcalinidade do sistema. Da estequiometria, para $1 \mathrm{mg} \mathrm{N}$ de nitrato desnitrificado, 3,57 mg de alcalinidade de $\mathrm{CaCO}_{3}$ é produzida. No processo de nitrificação, 7,14 mg de alcalinidade de $\mathrm{CaCO}_{3}$ é consumida para cada $1 \mathrm{mg} \mathrm{N}$ de amônia nitrificada. Com a desnitrificação, metade da alcalinidade consumida na nitrificação pode ser recuperada (EKAMA; MARAIS, 1997).

Outra vantagem observada quando ocorre a desnitrificação no reator é a diminuição da probabilidade desta ocorrer no decantador secundário. Isto porque, o efluente do reator de lodo ativado com nitrificação, ao atingir o decantador, permanece um tempo no mesmo e, sob condições elevadas de temperatura e dependendo do tempo de detenção do lodo no decantador, pode ser criada uma condição favorável para a desnitrificação. Isto significa que os nitratos formados no reator são reduzidos a nitrogênio gasoso, produzindo bolhas de gás nitrogênio que aderem ao lodo, dificultando sua sedimentação e arrastando-o à superfície. O lodo sai com o efluente, deteriorando a qualidade do mesmo em termos de SS e DBO e diminuindo a quantidade de biomassa do sistema (VON SPERLING, 1997).

\subsubsection{Sistemas Biológicos que Favorecem a Desnitrificação}

Upton, Fergusson e Savage (1993) utilizaram um sistema piloto de crescimento aderido desnitrificante incorporado num filtro de areia, onde os mecanismos de remoção de nitrogênio eram os mesmos que ocorrem em zonas anóxicas de crescimento em suspensão. Os microrganismos cresciam em superfícies fixas (areia ou similar) e convertiam o nitrogênio oxidado no esgoto em nitrogênio gasoso sob condições anóxicas. Para acelerar as reações de 
desnitrificação, uma fonte de carbono (normalmente o metanol) era adicionada ao efluente nitrificado a fim de fornecer a energia requerida pelos microrganismos desnitrificantes. A reação de desnitrificação, com o uso do metanol como fonte de carbono suplementar, pode ser expressa como (BODE; SEYFRIED; KRAFT, 1987):

$5 \mathrm{CH}_{3} \mathrm{OH}+6 \mathrm{NO}_{3}{ }^{-} \rightarrow 5 \mathrm{CO}_{2}+7 \mathrm{H}_{2} \mathrm{O}+3 \mathrm{~N}_{2}+6 \mathrm{OH}^{-}$

Upton, Fergusson e Savage (1993) concluíram em seus estudos que foi alcançada remoção de $85 \%$ de nitrogênio quando o metanol foi adicionado como fonte de carbono.

Ha e Ong (2007) operaram um filtro biológico parcialmente aerado de 2,5 m de comprimento, com um meio filtrante composto de areia com duas diferentes granulometrias, visando remoção de DQO e nitrogênio. O filtro foi operado com as zonas anaeróbia, anóxica e aerada a temperatura de $23^{\circ} \mathrm{C}$, sendo que nas zonas anaeróbia e anóxica a areia possuía diâmetro de $10 \mathrm{~mm}$, enquanto que na zona aerada a areia era de $5 \mathrm{~mm}$ de diâmetro.

Os experimentos demonstraram que o sistema pôde ser operado com um tempo de retenção hidráulico de 3 dias com taxas de recirculação de 200 e 300\% obtendo-se eficiências de remoção de DQO e amônia maiores do que $96 \%$, além de eficiência de $75 \%$ de remoção de nitrogênio total.

Bart, Brenner e Lewis (1969) apud Van Haandel; Marais (1999) foram os primeiros a sugerir a desnitrificação com uma fonte externa de material orgânico. O processo por eles desenvolvido compunha-se de três reatores biológicos em série, os dois primeiros aeróbios e o último anóxico, cada um seguido de um decantador, recebendo portanto o nome de sistema de três lodos. Esta denominação referia-se à separação física de cada processo biológico: remoção de material orgânico, nitrificação e desnitrificação, tendo-se em cada reator um lodo diferente. Como o efluente da segunda etapa (nitrificação) encontrava-se essencialmente livre de material orgânico biodegradável, este passou a ser adicionado ao 
terceiro reator, usando-se geralmente metanol. O sistema mostrou-se bastante eficiente, entretanto seu custo de construção e operação foi bastante elevado, não somente pelo fato de possuir três reatores e três decantadores, mas também pela necessidade de se adicionar uma fonte externa de material orgânico.

Assim, outros processos começaram a ser pesquisados usando-se o próprio material orgânico para a redução biológica de nitrato com apenas um lodo (sistema de lodo único), alternando-se, ora em ambiente aeróbio (nitrificação) ora anóxico (desnitrificação). Esta alternância pôde ser realizada através de interrupções periódicas de aeração num único reator ou através de uma divisão do reator em pelo menos duas partes, tendo-se no mínimo um reator continuamente aerado e outro, permanentemente anóxico, enquanto o lodo circulava entre esses reatores.

Wuhrmann (1964) apud Van Haandel; Marais (1999) foi o primeiro pesquisador a colocar em operação um sistema de lodo único com desnitrificação. O afluente entrava no primeiro reator onde ocorria a nitrificação juntamente com a remoção de quase todo o material orgânico biodegradável. O efluente nitrificado passava para o segundo reator onde se mantinha mistura completa com lodo em suspensão, mas sem aeração. Neste reator anóxico chamado de reator de pós-desnitrificação (pós-D) ocorria a redução de nitrato tendo-se como redutor, o material orgânico não-metabolizado no reator aeróbio e material orgânico oriundo do decaimento do lodo ativo no reator anóxico. O conteúdo do reator pós-D passava por um decantador, de onde o lodo era recirculado para o reator aeróbio (Figura 5). 


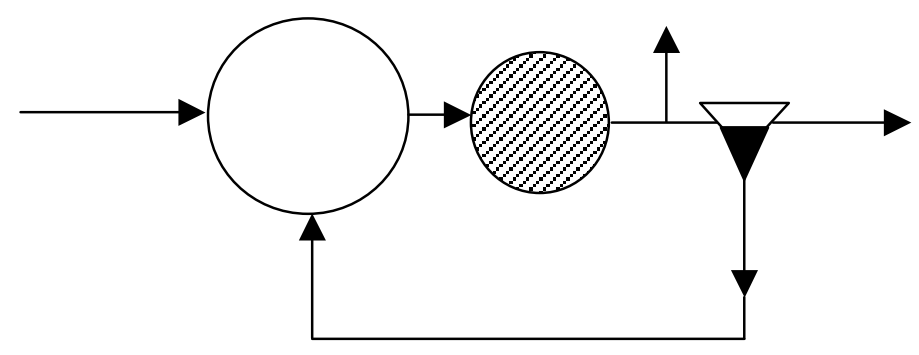

Figura 5 - O processo Wurhmann para remoção de nitrogênio Fonte: EKAMA; MARAIS, 1997

A taxa de desnitrificação no sistema de Wuhrmann era baixa já que a concentração de material biodegradável existente no reator pós-D era pequena. No sistema proposto por Ludzack \& Ettinger (1962) apud Van Haandel; Marais (1999), posteriormente melhorado por Barnard (1973) apud Van Haandel; Marais (1999), foram utilizados dois reatores em série, sendo o primeiro anóxico e o segundo, aeróbio. O nitrato formado no segundo reator era recirculado, em parte, diretamente para o primeiro reator ou junto com o lodo de retorno do decantador. Este primeiro reator recebeu a denominação de reator de prédesnitrificação (pré-D) por possuir o reator anóxico antes do aeróbio (Figura 6).

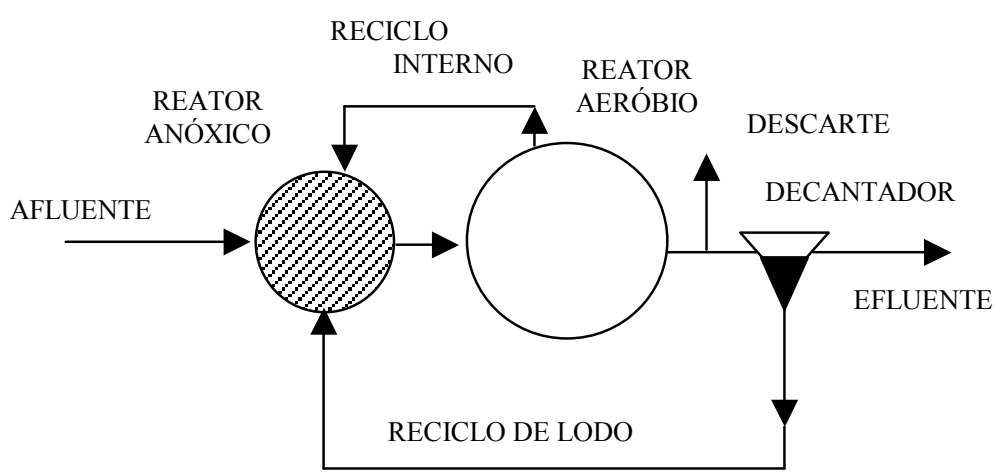

Figura 6 - O processo modificado de Ludzack-Ettinger de remoção de nitrogênio Fonte: EKAMA; MARAIS, 1997 
O sistema de Ludzack \& Ettinger permitia uma taxa de desnitrificação mais elevada do que o sistema de Wuhrmann, pois a concentração de material biodegradável no reator anóxico era mais alta. Uma limitação do sistema pré-D é que a desnitrificação completa é impossível, já que parte do nitrato formado no reator aeróbio não é recirculada para o anóxico sendo descarregada diretamente com o efluente. Deste modo, a eficiência de remoção de nitrato depende da taxa de recirculação do reator aeróbio para o anóxico.

Barnard (1973) apud Ekama; Marais (1997) sugeriu o sistema Bardenpho que permitia combinar as vantagens dos dois sistemas anteriores. Este sistema era constituído de três reatores, sendo o primeiro e o terceiro, anóxicos e o segundo, aeróbio. No primeiro reator, grande parte do nitrato era removida a uma taxa elevada, sendo que o nitrato era ali introduzido através do reciclo interno do lodo nitrificado do segundo reator e pela recirculação do decantador. No terceiro reator, o nitrato remanescente era então removido, produzindo um efluente com baixos teores de nitrato (Figura 7).

No sistema Bardenpho, é comum a utilização de um quarto reator aeróbio denominado reator de reaeração, menor que os demais, entre o reator pós-D e o decantador final, evitando-se assim que o lodo fique muito tempo sem oxigênio e possibilitando manter um ambiente aeróbio no decantador (e no efluente). Essa opção visa a remoção de bolhas de nitrogênio eventualmente formadas no decantador que poderiam prejudicar a eficiência da separação sólido-líquido (flotação) (VAN HAANDEL; MARAIS, 1999).

Vários sistemas com essa configuração já foram testados em escalas piloto e real e demonstraram uma alta eficiência na remoção de nitrogênio (METCALF \& EDDY, 1991; EKAMA; MARAIS, 1997; VAN HAANDEL; MARAIS, 1999). 


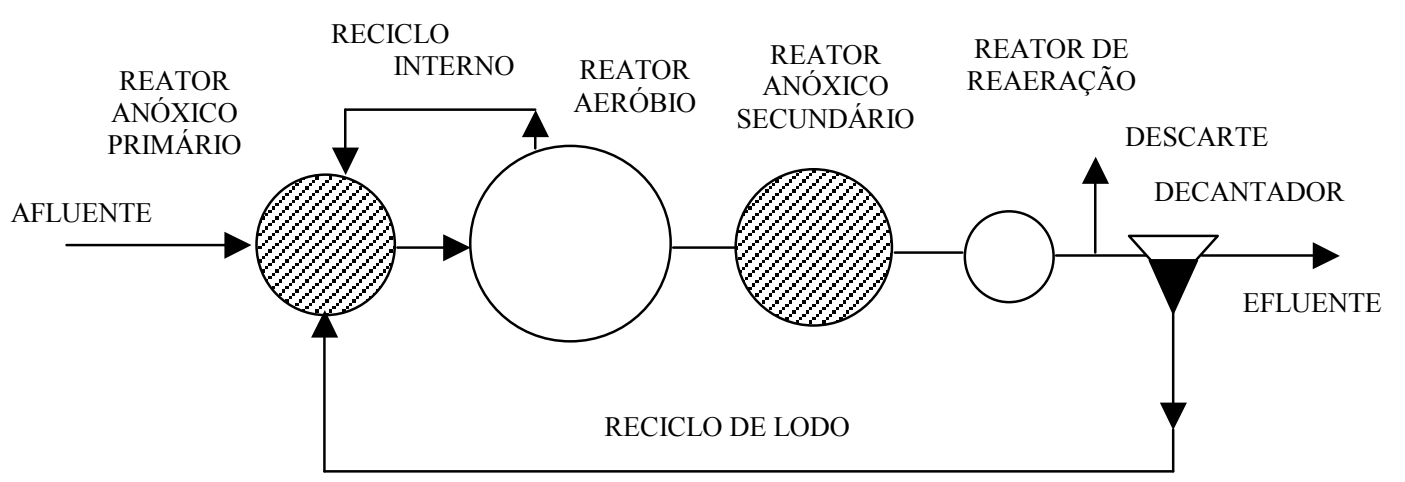

Figura 7 - O processo Bardenpho de remoção de nitrogênio Fonte: EKAMA; MARAIS, 1997

Argaman (1986) propôs um sistema com alimentação contínua e períodos com aeração e decantação alternados (sistema CFID). Foram utilizadas três unidades em escala laboratorial, as quais foram denominadas $\mathrm{X}, \mathrm{Y}$ e Z. Cada um dos três sistemas compunha-se de um reator de capacidade 25 litros, alimentado continuamente de água residuária sintética contendo uma mistura 1:1 de glicose e acetato de sódio, além de cloreto de amônio, bicarbonato de sódio, ortofosfato de potássio e uma série de micronutrientes essenciais. Durante a aeração, as unidades eram misturadas por um agitador mecânico e a injeção de ar era feita por pedras difusoras porosas. Durante a decantação, o sobrenadante era descartado por uma linha efluente equipada com uma válvula solenóide. O agitador mecânico, a válvula solenóide de ar comprimido e a válvula solenóide do efluente eram controlados por um timer para obtenção do ciclo de operação desejado (Figura 8). 


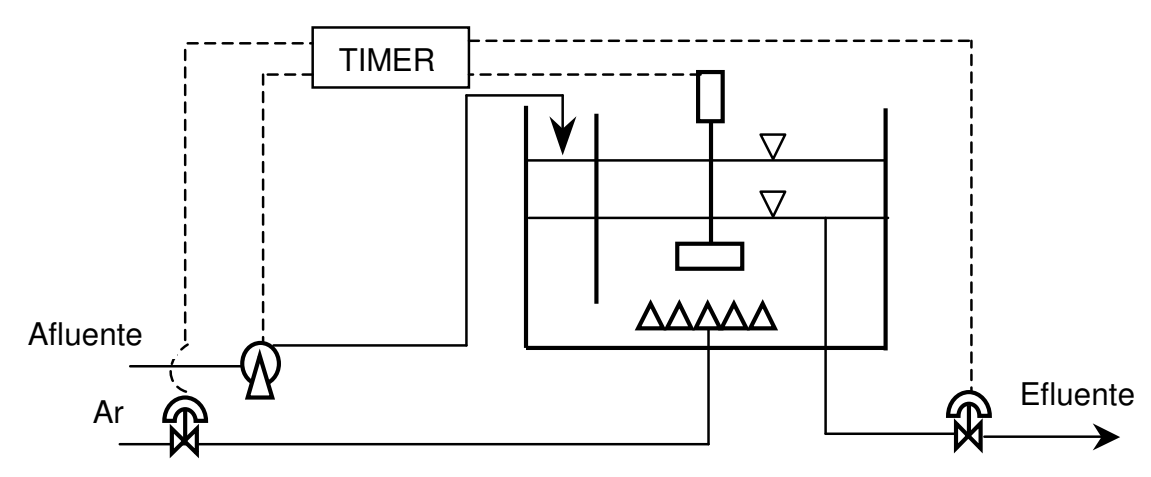

\section{Figura 8 - Esquema experimental do sistema CFID Fonte: ARGAMAN, 1986}

O estudo permitiu concluir que a taxa específica de desnitrificação do sistema CFID era similar àquela encontrada num sistema de fluxo contínuo. Além disso, os dados não mostraram efeitos adversos, alternando-se exposições do lodo a condições aeróbias e anóxicas, sendo que não foi necessário um tempo significativo de adaptação tanto para a nitrificação quanto para a desnitrificação.

Além dos processos biológicos de remoção de nitrogênio, Metcalf \& Eddy (1991) ainda citam alguns processos físico-químicos, como separação de amônia por arraste com ar, cloração ao breakpoint e troca iônica, que não são objetos da presente pesquisa e, portanto, não serão aqui abordados. No caso de águas residuárias de coquerias, um dos processos bastante utilizados é o de remoção de amônia por arraste com ar, seguido de tratamento físico-químico para complexação dos cianetos e tratamento biológico aeróbio para remoção de matéria orgânica biodegradável. No Brasil, ainda são poucos os sistemas visando nitrificação/desnitrificação. 


\subsubsection{Formas Alternativas de Remoção de Nitrogênio}

Pesquisas mais recentes sobre a remoção biológica de nitrogênio mostraram que, apesar de normalmente determinados gêneros de bactérias autotróficas oxidarem a amônia a nitrito e outras, posteriormente a nitrato, e de bactérias heterotróficas reduzirem nitrato a nitrito, e este a nitrogênio gasoso, tendo-se material orgânico como redutor, nem sempre isso ocorre, sendo possível também outras formas alternativas de remoção de nitrogênio.

Mais recentemente, uma nova gama de processos microbiológicos foi descrita e investigada: desnitrificação aeróbia (ROBERTSON; KUENEN, 1984; ROBERTSON; KUENEN, 1990; VAN LOOSDRECHT; JETTEN, 1998; PAI; CHONG; CHEN, 1999; JOO; HIRAI; SHODA, 2005; LI et al., 2006; BLAGODATSKY et al., 2006), nitrificação heterotrófica (ROBERTSON; KUENEN, 1990; VAN LOOSDRECHT; JETTEN, 1998; JOO; HIRAI; SHODA, 2005; BLAGODATSKY et al., 2006), nitrificação/desnitrificação simultâneas (ou SND-Simultaneous Nitrification/Denitrification) (YOO, et al., 1999; POCHANA; KELLER, 1999), oxidação anaeróbia de amônio (MULDER et al., 1995; STROUS et al., 1997; JETTEN et al.; 1998), nitrificação/desnitrificação pela via curta ou parcial ("nitritação/desnitritação") (TURK; MAVINIC, 1987; TURK; MAVINIC, 1989a; TURK; MAVINIC, 1989b; SURMACZ-GÓRSKA; CICHON; MIKSCH, 1997; LAI et al., 2004; DANIEL, 2005; IAMAMOTO, 2006; QUEIROZ, 2006), ou combinações destes (YOO et al., 1999; SLIEKERS et al., 2002; FUX; SIEGRIST, 2004; GIBBS et al., 2004). A desnitrificação autotrófica também seria possível tendo o enxofre elementar como doador de elétrons, mas o enxofre precisaria ser adicionado (KUAI; VERSTRAETE, 1999), exceto no caso de águas residuárias que o contenham. 
Alguns desses processos poderiam explicar a ocorrência de perdas de nitrogênio ainda não compreendidas em determinados tratamentos de águas residuárias (VAN LOOSDRECHT; JETTEN, 1998).

\subsubsection{Processo ANAMMOX ${ }^{\circledR}$ - Anaerobic Ammonium Oxidation}

$\mathrm{Na}$ última década, descobriu-se que certas bactérias, da ordem das Planctomycetales, eram capazes de remover simultaneamente amônia e nitrito sob condições anóxicas ainda não muito bem entendidas. Neste processo, a amônia e o nitrito eram convertidos a nitrogênio gasoso, com a produção de biomassa do dióxido de carbono (JETTEN et al., 1998; STROUS et al., 1999). Pynaert et al. (2003) mencionaram serem as bactérias Kuenenia stuttgartiensis as dominantes da comunidade Planctomycetales e as maiores responsáveis prováveis pela oxidação anóxica de amônio.

Van der Graaf et al. (1990) apud Mulder et al. (1995), e posteriormente, Mulder et al. (1995) descreveram a descoberta de um processo anaeróbio no qual o nitrogênio amoniacal era utilizado como doador de elétrons para a desnitrificação, processo este que foi patenteado como ANAMMOX $^{\circledR}$ (Anaerobic Ammonium Oxidation), ou seja, Oxidação Anaeróbica de Amônio. Eles afirmaram que embora o termo correto para denominá-lo seria "anóxico" ao invés de “anaeróbico", eles preferiram chamá-lo pelo termo genérico.

Neste processo, foi observado desaparecimento de $\mathrm{NH}_{4}{ }^{+}$de um reator de leito fluidizado desnitrificante tratando efluente de um reator metanogênico. Tanto o consumo de nitrato quanto o de amônio aumentaram com a concomitante produção de gás. A evidência para esta oxidação anaeróbica de amônio foi baseada nos balanços de nitrogênio e potencial redox em experimentos de fluxo contínuo. Os autores mencionaram que o processo foi operado a potencial redox de $200 \mathrm{mV}$. Eles também afirmaram que para oxidação de 5 moles 
de amônio, 3 moles de nitrato eram requeridos, resultando na formação de 4 moles de gás nitrogênio.

A reação que estaria envolvida no processo ANAMMOX ${ }^{\circledR}$ foi expressa como (MULDER et al., 1995):

$5 \mathrm{NH}_{4}^{+}+3 \mathrm{NO}_{3}^{-} \rightarrow 4 \mathrm{~N}_{2}+9 \mathrm{H}_{2} \mathrm{O}+2 \mathrm{H}^{+}$

Jetten et al. (1998) observaram que bactérias aeróbias oxidantes de amônia da espécie Nitrosomonas eutropha eram capazes de reduzir nitrito ou dióxido de nitrogênio com hidroxilamina ou amônio como doador de elétrons sob condições anóxicas.

Strous et al. (1998) sugeriram a possibilidade da ocorrência de um processo de desnitrificação autotrófica, no qual as bactérias presentes no sistema ANAMMOX $^{\circledR}$ poderiam estar envolvidas. A amônia seria convertida parcialmente a nitrito (eq. 22) por microrganismos “oxidante-aeróbio-amoniacais-oxigênio-limitantes" e, na seqüência, microrganismos oxidantes de amônia anaeróbios converteriam amônia e nitrito a nitrogênio gasoso (eq. 23). Combinados, estes sistemas poderiam ser descritos pela equação (24).

$$
\begin{aligned}
& 1 \mathrm{NH}_{3}+1,5 \mathrm{O}_{2} \rightarrow 1 \mathrm{NO}_{2}^{-}+\mathrm{H}_{2} \mathrm{O}+\mathrm{H}^{+} \\
& 1 \mathrm{NH}_{3}+1,32 \mathrm{NO}_{2}^{-}+\mathrm{H}^{+} \rightarrow 1,02 \mathrm{~N}_{2}+0,26 \mathrm{NO}_{3}^{-}+2 \mathrm{H}_{2} \mathrm{O} \\
& 1 \mathrm{NH}_{3}+0,85 \mathrm{O}_{2} \rightarrow 0,11 \mathrm{NO}_{3}^{-}+0,44 \mathrm{~N}_{2}+0,14 \mathrm{H}^{+}+1,43 \mathrm{H}_{2} \mathrm{O}
\end{aligned}
$$

Toh e Ashbolt (2002) desenvolveram um sistema com atividade autotrófica oxidante anaeróbia de amônio para remoção de altas concentrações de nitrogênio de uma água residuária sintética de coqueria. $\mathrm{O}$ fenol era a principal fonte de carbono da água estudada, o qual era adicionado gradualmente de 50 a $550 \mathrm{mg} / \mathrm{L}$ no meio enriquecido com bactérias ANAMMOX $^{\circledR}$. 
Após 15 meses de adaptação e operação, com novas seleções e enriquecimentos de culturas do meio, o sistema demonstrou altas taxas de remoção de amônio e nitrito, mesmo com concentrações de fenol de até $330 \mathrm{mg} / \mathrm{L}$. Os pesquisadores concluíram então que a oxidação anaeróbia de amônio era resistente a altas concentrações de fenol e que isso significava que esse processo possuía potencial para tratamento de despejos de coqueria.

\subsubsection{Sistema SND - Simultaneous Nitrification/Denitrification}

O termo nitrificação e desnitrificação simultâneas (SND - Simultaneous Nitrification/Denitrification) define um processo no qual duas reações separadas ocorrem concomitantemente no mesmo reator. Sendo assim, esse sistema elimina a necessidade de se ter tanques separados, como nos processos tradicionais de tratamento, simplificando o projeto das estações e reduzindo-se custos. Mais recentemente, alguns autores já relataram pesquisas bem sucedidas utilizando esse método (SURMACZ-GÓRSKA; CICHON; MIKSCH, 1997; POCHANA; KELLER, 1999).

Alguns dos estudos realizados reportaram que o sistema SND pode ser explicado pela difusão restrita do oxigênio dentro do floco biológico (BECCARI et al., 1992; GORONSZY; DEMOULIN; NEWLAND, 1997; POCHANA; KELLER, 1999; THIRD; NEWLAND; CORD-RUWISCH, 2003). Outros alegam que certos microrganismos têm a capacidade de promover a desnitrificação sob condições aeróbias (ROBERTSON; KUENEN, 1984; PAI; CHONG; CHEN, 1999; PATUREAU et al., 2001). Embora o mecanismo exato da SND ainda não seja tão claro, há evidências da ocorrência da desnitrificação sob condições de oxigenação do meio (POCHANA; KELLER, 1999). 
Robertson et al. (1989) apud Stüven; Bock (2001) mencionaram que embora a desnitrificação ocorra preferencialmente sob condições anóxicas, a desnitrificação aeróbia também seria possível.

Em seus estudos com bactérias desnitrificantes Thiosphaera pantotropha, Robertson e Kuenen (1984) observaram que estes microrganismos eram capazes de utilizar simultaneamente nitrato e oxigênio como aceptor final de elétrons na respiração. Esse fenômeno denominado desnitrificação aeróbia foi descoberto em culturas mantidas a concentrações de oxigênio dissolvido com até 90\% de saturação de ar. Enzimas características da desnitrificação foram encontradas mesmo em organismos não expostos ao nitrato.

Pai, Chong e Chen (1999) observaram que três bactérias desnitrificantes (DCB T6, DCB T23 e DCB T25) foram capazes de obter energia pela conversão de nitrato a nitrogênio gasoso tanto na ausência quanto na presença de oxigênio. Além disso, eles puderam observar que a taxa de desnitrificação da bactéria DCB T6 não havia sido afetada pela presença de oxigênio, o mesmo não acontecendo com as demais.

Os experimentos de Pochana e Keller (1999) tiveram por objetivo determinar as condições e processos que favoreceriam a ocorrência da SND. Para tanto, os pesquisadores operaram reatores seqüenciais em batelada (SBRs) sob condições controladas utilizando uma água residuária proveniente da primeira lagoa anaeróbia de uma estação de tratamento de efluentes de um abatedouro.

A pesquisa permitiu alcançar até $95 \%$ de remoção de nitrogênio total pela nitrificação/desnitrificação simultânea. Pochana e Keller (1999) puderam concluir que a fonte de carbono e as concentrações de oxigênio dissolvido eram alguns dos parâmetros mais importantes do processo.

Li et al. (2006) isolaram três novas bactérias chamadas de HS-03, HS-043 e HS-047 de diferentes ecossistemas que foram capazes de promover a desnitrificação aeróbia. 
Os autores investigaram o comportamento dessas espécies em sistemas de tratamento de águas residuárias sob condições aeróbias. Todas as três foram capazes de remover mais do que $98 \%$ do nitrato presente em 12 a 24 horas adicionando-se uma fonte externa de carbono e baixas concentrações de ferro e molibdato. Os mecanismos atuantes foram analisados em nível molecular. Os resultados do fenótipo e genótipo das bactérias analisadas comprovaram que a HS-03 e a HS-047 pertenciam aos grupos Pseudomonas stutzeri e Pseudomonas pseudoalcaligenes, respectivamente, ao passo que a HS-043 foi identificada como Delftia acidovorans, cuja atividade desnitrificante ainda não havia sido explorada.

Stüven e Boch (2001) relataram em sua pesquisa que um dos problemas associados à nitrificação tradicional e a nitrificação/desnitrificação simultâneas era a produção de óxido nitroso como composto intermediário. Os autores também mencionaram que a taxa de produção de NO nesses processos é dependente dos microrganismos envolvidos, da composição do meio e da taxa de oxidação de amônia.

\subsubsection{Nitrificação/Desnitrificação Parcial}

Nos anos 70, Murray et al. (1975) apud Pollice; Tandoi; Lestingi (2002) observaram que era possível a ocorrência de taxas mais altas de desnitrificação com o nitrito como aceptor de elétrons ao invés do nitrato. A oxidação parcial do $\mathrm{NH}_{4}^{+}$a $\mathrm{NO}_{2}^{-}$e a subseqüente redução deste a nitrogênio molecular $\left(\mathrm{N}_{2}\right.$ gás) foi vista como uma caminho mais curto, bastante favorável técnica e economicamente, especialmente para o tratamento de efluentes com altas concentrações de amônia ou baixas relações C/N (MURRAY et al., 1975 apud POLLICE; TANDOI; LESTINGI, 2002; TURK; MAVINIC, 1987; TURK; MAVINIC, 1989a; MOSQUERA-CORRAL et al., 2005). 
As principais vantagens da nitrificação parcial em relação à completa seriam uma menor demanda de oxigênio (até $25 \%$ de economia na aeração), até aproximadamente $40 \%$ de redução dos substratos orgânicos requeridos para a desnitrificação heterotrófica (vide reações apresentadas a seguir), menor produção de lodo (até aproximadamente $40 \%$ ) e aumento da velocidade de desnitrificação (TURK; MAVINIC, 1987; LAI et al., 2004; AKERMAN, 2005).

$$
\begin{aligned}
& \mathrm{NH}_{4}^{+}+\mathbf{1 , 5} \mathrm{O}_{2} \rightarrow \mathrm{NO}_{2}{ }^{-}+\mathrm{H}_{2} \mathrm{O}+2 \mathrm{H}^{+} \\
& \mathrm{NH}_{4}{ }^{+}+\mathbf{2} \mathrm{O}_{2} \rightarrow \mathrm{NO}_{3}{ }^{-}+\mathrm{H}_{2} \mathrm{O}+2 \mathrm{H}^{+}
\end{aligned}
$$

\section{$\uparrow 25 \%$ de economia de aeração}

$$
\begin{aligned}
& 6 \mathrm{NO}_{2}^{-}+3 \mathrm{CH}_{3} \mathrm{OH}+3 \mathrm{CO}_{2} \rightarrow 3 \mathrm{~N}_{2}+3 \mathrm{H}_{2} \mathrm{O}+6 \mathrm{HCO}_{3}^{-} \\
& 6 \mathrm{NO}_{3}^{-}+\mathbf{5} \mathrm{CH}_{3} \mathrm{OH}+\mathrm{CO}_{2} \rightarrow 3 \mathrm{~N}_{2}+7 \mathrm{H}_{2} \mathrm{O}+6 \mathrm{HCO}_{3}^{-}
\end{aligned}
$$

\section{个 40\% menos substratos orgânicos requeridos}

Em longo prazo, o processo revela-se estável; submetendo o sistema a temperaturas maiores do que $30^{\circ} \mathrm{C}$ e valores de $\mathrm{pH}$ maiores do que 7, os organismos nitrito-oxidantes têm menores taxas de crescimento do que os amônio-oxidantes (HELLINGA et al., 1997 apud POLLICE; TANDOI; LESTINGI, 2002; HELLINGA et al., 1998). Sob estas condições, foi possível selecionar biomassas capazes de nitrificar parcialmente a nitrito operando no tempo de residência celular médio no tanque de aeração, isto é, na idade do lodo.

Estas considerações levaram ao recente desenvolvimento do processo patenteado como SHARON ${ }^{\circledR}$ (Single Reactor High Activity Ammonia Removal Over Nitrite) para oxidação parcial de amônio a nitrito (MULDER; VAN KEMPEN, 1997 apud POLLICE; 
TANDOI; LESTINGI, 2002; JETTEN; VAN LOOSDRECHT, 1998 apud POLLICE;

TANDOI; LESTINGI, 2002). As principais características deste processo seriam altas temperaturas operacionais $\left(30-35^{\circ} \mathrm{C}\right)$ e idades do lodo muito baixas (1-3 dias), ou ainda, ausência de recirculação de lodo (tempo de retenção celular = tempo de detenção hidráulico).

Esse processo é embasado na teoria de que, apesar de normalmente as Nitrobacter converterem rapidamente nitrito a nitrato, em altas temperaturas, elas teriam uma taxa de crescimento bem mais lenta que as Nitrosomonas (vide Figura 9), por isso a oxidação iria até nitrito (HELLINGA, et al., 1997 apud VERSTRAETE; PHILIPS, 1998).

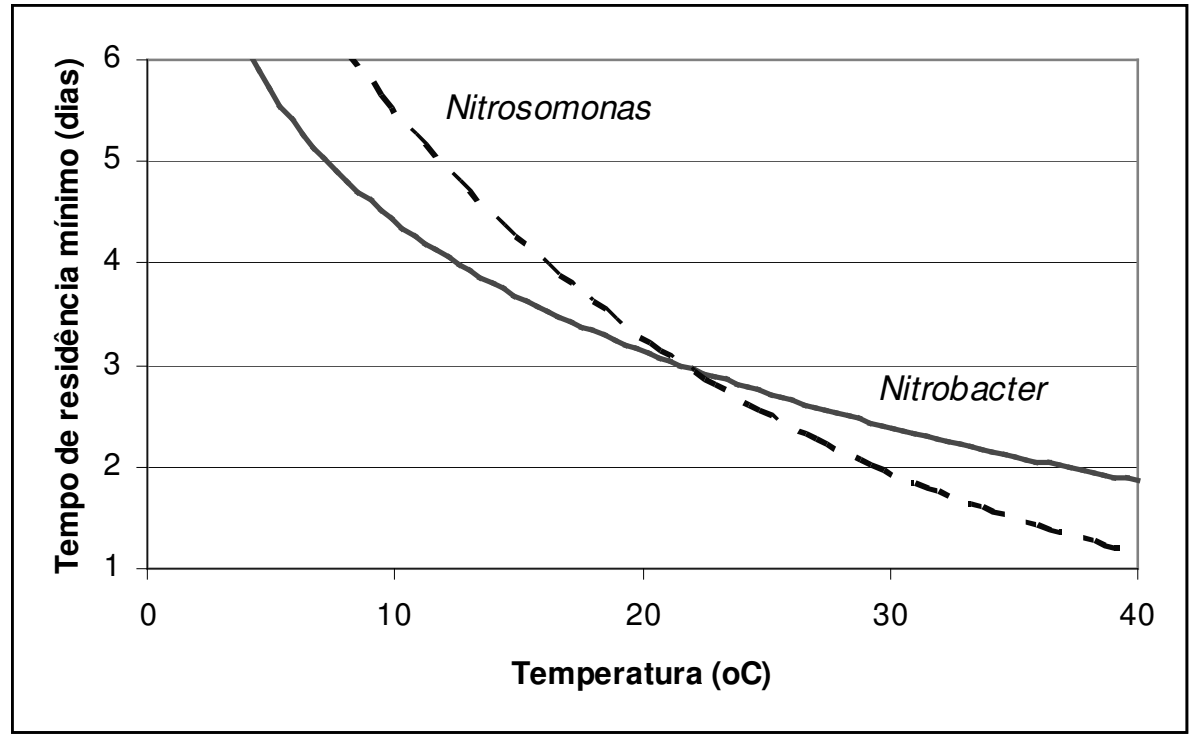

Figura 9 - Taxa de crescimento das Nitrosomonas e Nitrobacter em função da temperatura e tempo de residência Fonte: MULDER; VAN KEMPEN, 1997 apud VERSTRAETE; PHILIPS, 1998

Nessa linha de pesquisas, Pollice, Tandoi e Lestingi (2002) realizaram testes de nitrificação em dois reatores em escala de laboratório operados sob aeração contínua e intermitente, respectivamente. Em ambos os sistemas, a temperatura foi mantida a $32^{\circ} \mathrm{C}$ e o pH regulado para 7,2. Os resultados mostraram que a nitrificação parcial a nitrito foi obtida de modo estável sob limitação de oxigênio, independentemente da idade do lodo utilizada. 
Mosquera-Corral et al. (2005) estudaram os efeitos do acetato e de diferentes sais presentes no afluente ao reator SHARON ${ }^{\circledR}$. Quando o acetato foi adicionado, concentrações de até 0,2 g COT/L não manifestaram efeitos significativos na oxidação da amônia a nitrito; entretanto valores superiores a $0,3 \mathrm{~g} \mathrm{COT} / \mathrm{L}(\mathrm{C} / \mathrm{N}=0,3 \mathrm{~g} / \mathrm{g})$ resultaram na competição entre os microrganismos heterotróficos e autotróficos, com um efeito bastante prejudicial a esses últimos. Os resultados indicaram que o decréscimo na atividade de oxidação da amônia era devido à competição pelos substratos entre esses dois grupos de bactérias.

Lai et al (2004) pesquisaram a remoção de amônio via nitrito (“nitritação/desnitritação") em reatores em bateladas seqüenciais (SBR) em escalas piloto e de laboratório, tratando efluentes com concentração de nitrogênio amoniacal da ordem de 1.000 a $1.400 \mathrm{mgN} / \mathrm{L}$.

No experimento de bancada, após 25 dias de operação, observou-se a razão $\mathrm{N}-\mathrm{NO}_{2}{ }^{-} / \mathrm{N}_{\text {total }}$ acima de $50 \%$. No $44^{\circ}$ dia de "nitritação" estável, introduziu-se o processo de desnitrificação com paradas na aeração e introdução de DQO externa (solução de etanol de 1-4\%). Neste mesmo experimento, a concentração de oxigênio dissolvido foi reduzida de 2,0-3,0 $\mathrm{mg} \mathrm{O}_{2} / \mathrm{L}$, durante a partida do sistema, para 1,1-1,3 $\mathrm{mg} \mathrm{O}_{2} / \mathrm{L}$, quando foi introduzida a “desnitritação" no experimento.

Os resultados do experimento em escala piloto mostraram que a oxidação da amônia a nitrito era um processo seguro, já que nos 330 dias de experimentação o acúmulo de nitrato em nenhum momento mostrou-se um problema.

Todos os experimentos de Lai et al. (2004), tanto em escala piloto quanto de bancada, indicaram excelentes reduções nas concentrações de nitrogênio, sendo que nos experimentos em bancada, para a concentração afluente de $1.200 \mathrm{mgN} / \mathrm{L}$, foi alcançada de 96 a 98\% de remoção de nitrogênio amoniacal total, com um tempo de detenção hidráulica de apenas 1,1 dia e taxa de remoção de $1,05 \mathrm{~kg} \mathrm{~N} / \mathrm{m}^{3}$.dia. Já nos experimentos em escala piloto, 
as taxas de remoção de nitrogênio foram de aproximadamente $1,2 \mathrm{~kg} \mathrm{~N} / \mathrm{m}^{3}$.dia com um tempo de detenção hidráulico de 0,88 dia. As relações DQO/N requeridas na planta piloto estiveram na faixa de 1,6 a $1,9 \mathrm{~kg}$ DQO $/ \mathrm{kg} \mathrm{N}$ removido.

Lai et al. (2004) apresentaram também as reações que mostram o processo combinado de "nitritação" e "desnitritação" com metanol como fonte de carbono:

Nitritação: $\mathrm{NH}_{4}^{+}+1,5 \mathrm{O}_{2}+2 \mathrm{HCO}_{3}^{-} \rightarrow \mathrm{NO}_{2}^{-}+3 \mathrm{H}_{2} \mathrm{O}+2 \mathrm{CO}_{2}$

Desnitritação: $\mathrm{NO}_{2}^{-}+0,5 \mathrm{CH}_{3} \mathrm{OH}+0,5 \mathrm{CO}_{2} \rightarrow+0,5 \mathrm{~N}_{2}+0,5 \mathrm{H}_{2} \mathrm{O}+\mathrm{HCO}_{3}^{-}$

Sarfaraz et al. (2004) e posteriormente Queiroz (2006) apresentaram as reações da desnitrificação completa e curta, tendo fenol como fonte de carbono para os microrganismos desnitrificantes:

Desnitrificação: $28 \mathrm{NO}_{3}^{-}+5 \mathrm{C}_{6} \mathrm{H}_{5} \mathrm{OH} \rightarrow 14 \mathrm{~N}_{2}+30 \mathrm{CO}_{2}+28 \mathrm{OH}^{-}+\mathrm{H}_{2} \mathrm{O}$

Desnitritação: $25 \mathrm{NO}_{2}^{-}+3 \mathrm{C}_{6} \mathrm{H}_{5} \mathrm{OH} \rightarrow 12,5 \mathrm{~N}_{2}+18 \mathrm{CO}_{2}+16 \mathrm{OH}^{-}+\mathrm{H}_{2} \mathrm{O}$

Da estequiometria, tem-se que a quantidade de fenol requerida para a desnitrificação completa de $1 \mathrm{~mol}$ de nitrato a $1 \mathrm{~mol}$ de nitrogênio gasoso é de 0,179 mol. Em massa, para a redução de $1 \mathrm{~g} \mathrm{NO}_{3}^{-}$, são necessários $0,270 \mathrm{~g}$ de fenol. $\mathrm{Na}$ "desnitritação", a redução de 1 mol de nitrito requer 0,120 mol de fenol ou, em massa, a redução de $1 \mathrm{~g} \mathrm{NO}_{2}^{-}$ requer $0,245 \mathrm{~g}$ de fenol.

Fdz-Polanco, Villaverde e Garcia (1996) estudaram os efeitos combinados da temperatura, $\mathrm{pH}$ e concentração de amônio no fenômeno do acúmulo de nitrito na nitrificação a partir de um filtro biológico aerado de fluxo ascendente. Os autores observaram que em condições de não inibição por amônia livre, em valores baixos de $\mathrm{pH}$ e temperatura, e em altas concentrações de amônio, a atividade relativa dos microrganismos oxidantes de amônia era maior do que os oxidantes de nitrito ocorrendo, portanto, acúmulo de nitrito no sistema. 
Bae et al. (2002) investigaram os fatores ambientais que afetariam o acúmulo de nitrito em reatores nitrificantes. O trabalho dos pesquisadores concluiu que as condições operacionais ótimas para a obtenção desse acúmulo foram em $\mathrm{pH}=8$, temperatura de $30^{\circ} \mathrm{C}$ e concentração de oxigênio dissolvido de $1,5 \mathrm{mgO}_{2} / \mathrm{L}$.

Wu et al. (2006) observaram acúmulo de nitrito em um sistema em escala piloto de pré-desnitrificação. Foram analisados diversos fatores para a obtenção dos parâmetros chave para a ocorrência do acúmulo de nitrito.

Os autores puderam concluir que o oxigênio dissolvido era o parâmetro chave para ocorrer o acúmulo de nitrito, pois quando esse foi mantido a $0,5 \mathrm{mg} \mathrm{O}_{2} / \mathrm{L}$ observou-se grande acúmulo de nitrito, entretanto quando o OD foi aumentado para $1,5 \mathrm{mg} \mathrm{O}_{2} / \mathrm{L}$, praticamente não foram observadas concentrações significativas.

Balmelle et al. (1992), por sua vez, afirmaram que, dentre os parâmetros pesquisados para a obtenção dos fatores responsáveis pelo acúmulo de nitrito, os parâmetros chave que se destacaram foram a amônia livre e a temperatura.

Surmacz-Górska, Cichon e Miksch (1997) afirmaram que é a amônia livre o parâmetro chave para a inibição das espécies de bactérias Nitrobacter e que, portanto, possibilita a nitrificação curta. Eles afirmaram que a presença de amônia livre depende das altas concentrações de nitrogênio amoniacal na água residuária e de seu pH e que, portanto, é o pH do afluente o parâmetro decisivo na inibição da atividade das oxidantes de nitrito. Os pesquisadores afirmaram ainda que o controle da reação da fase aerada do tratamento garantiu a concentração de amônia livre entre 1 e $6 \mathrm{mg} \mathrm{NH} / \mathrm{L}$ e que ao mesmo tempo a concentração de ácido nitroso não excedeu $0,04 \mathrm{mg} \mathrm{HNO}_{2} / \mathrm{L}$. Essas condições permitiram que a nitrificação fosse significativamente encurtada e as concentrações de nitrito puderam alcançar até $300 \mathrm{mg} \mathrm{N}-\mathrm{NO}_{2}{ }^{-} / \mathrm{L}$. A taxa de nitrificação obtida foi da ordem de $0,06 \mathrm{~g} \mathrm{~N} / \mathrm{g}$ SS.dia. 
Em seus experimentos em reatores de lodo ativado em escala de bancada tratando líquidos percolados de aterros sanitários, Akerman (2005) estudou diferentes condições operacionais para obter quais aquelas que proporcionariam a oxidação da amônia preferencialmente a nitrito. Akerman (2005) mencionou que esse processo já havia sido utilizado em plantas em escala real (podendo-se citar as estações de tratamento de Utrecht, Rotterdam, Zwolle e Beverwijk, todas localizadas na Holanda), principalmente para tratamento de sobrenadantes de digestores, entretanto que a experiência com chorumes ainda era limitada. Outros objetivos do trabalho foram obter uma partida rápida do sistema, eficiência na oxidação de amônio de 80 a 90\% e "nitritação" completa.

$\mathrm{O}$ autor mencionou que os parâmetros que poderiam ser controlados para favorecer a nitrificação curta eram a concentração de amônio, tempo de residência, pH, temperatura, concentração de oxigênio dissolvido e presença de elementos tóxicos.

Akerman (2005) concluiu que o decréscimo de temperatura não foi fator determinante para inibir o acúmulo de nitrito e favorecer a nitratação, e que altas concentrações de amônia livre são o fator limitante para a capacidade de oxidação do sistema. Não houve indicação de inibição por ácido nitroso.

$\mathrm{O}$ autor mencionou ainda que os melhores resultados foram observados para o percolado não diluído (embora a partida rápida do sistema só tenha sido possível com o uso de chorume diluído), com concentrações afluentes de nitrogênio amoniacal de $1200 \mathrm{mgN} / \mathrm{L}$, com taxas de oxidação de amônia de 70\%, "nitritação" completa e concentrações de nitrato desprezíveis. As condições operacionais observadas nessas situações foram $\mathrm{pH}=7,5$, $\mathrm{OD}=2,0 \mathrm{mgO}_{2} / \mathrm{L}$, temperatura de $25^{\circ} \mathrm{C}$ e tempo de retenção hidráulico de 3,5 dias. Akerman (2005) pôde concluir que a "nitritação" mostrou um decréscimo no volume requerido pelo sistema, além de importante economia nos custos operacionais com aeração e com adição de carbono para a desnitrificação. 
A pesquisa realizada por Zdradek (2005) objetivou estudar dois dos fatores hipotéticos que promoveriam o acúmulo de nitrito em reatores descontínuos SBR, sendo o primeiro através da lavagem das bactérias oxidadoras de nitrito e o segundo via limitação da disponibilidade de oxigênio dissolvido do meio.

O autor observou grande dificuldade na obtenção de nitrito utilizando a estratégia de lavagem das bactérias oxidadoras de nitrito do sistema, ao passo que, nos experimentos operados com aumento da limitação de oxigênio dissolvido, as concentrações de nitrito obtidas foram bastante significativas.

Daniel (2005) utilizou reator de leito fixo preenchido com biomassa imobilizada em espuma de poliuretano, operado em bateladas seqüenciais e alimentado com substrato sintético com concentrações de nitrogênio amoniacal de 40, 125, 250 e $500 \mathrm{mgN} / \mathrm{L}$ e observou que, para todas as concentrações de nitrogênio estudadas, o nitrito foi a forma oxidada predominante ao longo de todo o período de operação, sendo que esse se mostrou um processo estável de remoção de nitrogênio.

Iamamoto (2006) operou reator em batelada com biomassa suspensa submetido a etapas alternadas anóxicas e aeróbias em uma mesma batelada, com o objetivo de remover nitrogênio amoniacal em diferentes concentrações $(125,250$ e $500 \mathrm{mgN} / \mathrm{L})$. O autor manteve ciclos anóxico/aeróbio de $2 \mathrm{~h} / 2 \mathrm{~h}$ e concentração de aproximadamente de $2 \mathrm{mgO}_{2} / \mathrm{L}$ de oxigênio dissolvido no reator no período aeróbio.

O autor observou que, para a concentração de $125 \mathrm{mgN} / \mathrm{L}$ de nitrogênio amoniacal, o nitrato foi o principal produto da nitrificação, com $87 \%$ de eficiência de remoção de nitrogênio. Na condição de $250 \mathrm{mgN} / \mathrm{L}$, essa eficiência foi de $84 \%$, com predominância de nitrito como forma oxidada, sendo que também foi observada a ocorrência de nitrificação e desnitrificação simultâneas durante os dois primeiros ciclos aeróbios. Na condição de $500 \mathrm{mgN} / \mathrm{L}$, as condições de $2 \mathrm{mgO}_{2} / \mathrm{L}$ de $\mathrm{OD}$ e aeração intermitente a cada 2 horas não 
foram suficientes para promover a remoção total de nitrogênio amoniacal, sendo que foram feitas alterações para ciclos de 2 horas anóxico e 9 horas aeróbio, com concentração média de OD de $2,8 \mathrm{mgO}_{2} / \mathrm{L}$, o que resultou em eficiências de remoção de nitrogênio de $94 \%$, com predominância de nitrito como forma oxidada.

Queiroz (2006) operou reator em bateladas seqüenciais (SBR) tratando despejo sintético com fenol como única fonte de carbono orgânico e obteve predominância de nitrito como forma oxidada na nitrificação para as três concentrações afluentes de nitrogênio amoniacal experimentadas: 200, 300 e $500 \mathrm{mgN} / \mathrm{L}$. As eficiências de remoção de nitrogênio variaram de 89 a $97 \%$.

As melhores condições de operação observadas no experimento ao final da etapa aeróbia foram: $\mathrm{pH}=8,3$, concentração mínima de amônia livre $>0,3 \mathrm{mg} \mathrm{NH} / \mathrm{L}$, concentração de oxigênio dissolvido de $1,0 \mathrm{mgO}_{2} / \mathrm{L}$ e tempo de residência hidráulico de 3 dias. As taxas de nitrificação específica obtidas variaram entre 0,01 e 0,05 kg N-NH$/ 2 g$ SSV.dia. O autor ainda afirmou que concentrações de amônia livre da ordem de 16 mg NH $3 / \mathrm{L}$ e de ácido nitroso entre 0,001 e 0,009 mg $\mathrm{HNO}_{2} / \mathrm{L}$ não inibiram a oxidação biológica.

Quanto à etapa anóxica dos experimentos de Queiroz (2006), as taxas de “desnitritação" obtidas compreenderam valores entre 0,01 e $0,05 \mathrm{~kg} \mathrm{~N}-\mathrm{NO}_{2}{ }^{-} / \mathrm{kg} \mathrm{SSV}$ dia e as eficiências de remoção do nitrogênio oxidado variaram entre 97 e 100\%. O fenol, em concentrações afluentes de $1000 \mathrm{mg} \mathrm{C}_{6} \mathrm{H}_{5} \mathrm{OH} / \mathrm{L}$, mostrou-se uma fonte de carbono capaz de promover a "desnitritação", com eficiências de remoção que variaram de 37 a 67\%.

Entretanto, alguns autores citaram um dos problemas na formação de nitrito, que seria o aparecimento da hidroxilamina, que é um produto intermediário das bactérias que oxidam amônia a nitrito.

A hidroxilamina existe em duas formas: não ionizada ou livre $\left(\mathrm{NH}_{2} \mathrm{OH}\right)$ ou ionizada $\left(\mathrm{NH}_{3} \mathrm{OH}^{+}\right)$. A reação de dissociação na água é representada por: 


$$
\mathrm{NH}_{3} \mathrm{OH}^{+}+\mathrm{H}_{2} \mathrm{O} \leftrightarrow \mathrm{NH}_{2} \mathrm{OH}+\mathrm{H}_{3} \mathrm{O}^{+}
$$

Yang e Alleman (1992) relacionaram a taxa de crescimento das concentrações de nitrito em culturas isoladas de lodo ativado com a adição de hidroxilamina livre $\left(\mathrm{NH}_{2} \mathrm{OH}\right)$ e não com a concentração de amônia livre $\left(\mathrm{NH}_{3}\right)$, nem com baixas concentrações de oxigênio dissolvido.

Noophan, Figueroa e Munakata-Marr (2004) estudaram e modelaram matematicamente a inibição causada pela hidroxilamina na oxidação do nitrito. Os pesquisadores mantiveram o pH entre 7,4 e 8,4 e a concentração de nitrogênio amoniacal em $100 \mathrm{mgN} / \mathrm{L}$. A atividade das bactérias que oxidam nitrito foi completamente inibida para dosagens de hidroxilamina de 7,0 e 8,9 mg/L para valores de $\mathrm{pH}$ de 8,4 e 7,6, respectivamente. Os autores afirmam que baixas concentrações de hidroxilamina $(0,35$ a $5,5 \mathrm{mg} / \mathrm{L}$ ) podem inibir completamente a oxidação do nitrito, mas não causam efeito nas bactérias que oxidam amônia, nem nas heterotróficas que realizam a desnitrificação.

\subsubsection{Associações desses Processos Alternativos de Remoção de Nitrogênio}

Yoo et al. (1999) propuseram um sistema com um único reator com aeração e decantação intermitentes para investigar alguns dos parâmetros chave de controle para a remoção de nitrogênio de dois tipos de água residuária sintética, cuja principal fonte de carbono era o acetato, através da nitrificação/desnitrificação simultâneas via nitrito. O processo induzia a nitritação, enquanto a nitratação era eficientemente suprimida, sendo que a desnitrificação iniciava a partir do nitrito. Os parâmetros de maior importância para a efetividade da SND via nitrito foram: (a) a mínima e máxima concentração de oxigênio dissolvido durante o período de aeração (sendo a concentração ótima ao final do período 
aerado em torno de 2,0 a 2,5 $\mathrm{mgO}_{2} / \mathrm{L}$ para a remoção do nitrogênio); (b) o tamanho de um ciclo e da aeração por ciclo, se beneficiando da defasagem de tempo (lag-time) que as oxidantes de nitrito são retardadas em relação às oxidantes de amônia, quando ocorre o ajuste da condição anóxica/anaeróbia para a aeróbia; e (c) o contato entre os sólidos em suspensão da biomassa no reator e a água residuária sob a condição anóxica/anaeróbia.

Para ambas as águas residuárias estudadas, a eficiência média de remoção de DQO alcançou aproximadamente 95\%, além de ótimas eficiências de remoção de nitrogênio, da ordem de $90 \%$.

Os cálculos realizados por Turk e Mavinic (1986) apud Gibbs et al. (2004) indicaram que o sistema SND via nitrito possui potencial para atingir $40 \%$ de redução da demanda de DQO para a desnitrificação e $63 \%$ maior taxa de desnitrificação quando comparado ao SND via nitrato.

Sliekers et al. (2002) propuseram um reator de simples estágio para remoção autotrófica completa de nitrogênio amoniacal. O reator foi partido anoxicamente após inoculação com biomassa proveniente de sistema ANAMMOX ${ }^{\circledR}$. Em seguida, fornecia-se oxigênio ao reator e desenvolveu-se uma população nitrificante. O oxigênio permaneceu como fator limitante ao processo, mantendo-o no limite de detecção de $0,3 \%$ de saturação de ar (equivalente a $0,02 \mathrm{mgO}_{2} / \mathrm{L}$ ). $\mathrm{O} \mathrm{pH}$ do reator foi mantido em 7,8.

Bactérias do gênero Nitrosomonas sp convertiam parcialmente nitrogênio amoniacal a nitrito e as bactérias $\mathrm{ANAMMOX}^{\circledR}$ convertiam a mistura amônia e nitrito principalmente a gás nitrogênio. No reator, não foram detectadas bactérias oxidantes de nitrito aeróbias. O potencial desnitrificante da biomassa permaneceu abaixo dos limites de detecção do método utilizado. A amônia foi principalmente convertida a $\mathrm{N}_{2}(85 \%)$ e o restante $(15 \%)$ foi recuperado como $\mathrm{NO}_{3}^{-}$, fato que os autores mencionaram já sendo de se esperar num sistema combinado ANAMMOX ${ }^{\circledR} /$ nitrificação parcial, já que o nitrato produzido seria 
proveniente da atividade das bactérias $\mathrm{ANAMMOX}^{\circledR}$ sob condições anóxicas, e não aeróbias. Os autores ainda mencionaram não ter sido necessária adição de fonte externa de carbono para o desenvolvimento da desnitrificação autotrófica.

Van Dongen, Jetten e van Loosdrecht (2001) estudaram o tratamento de águas residuárias ricas em amônio através da combinação do processo SHARON ${ }^{\circledR}$ (nitrificação parcial a nitrito) com o ANAMMOX $^{\circledR}$ (oxidação anóxica de amônio). Os autores mencionaram que o sistema proposto estava parcialmente implantado na estação de tratamento de águas residuárias Dokhaven de Rotterdam, na Holanda. A amônia (1.000 a $1.500 \mathrm{mg} \mathrm{NH}_{4}^{-}-\mathrm{N} / \mathrm{L}$ ) era removida pela oxidação parcial do amônio a nitrito, para em seguida o nitrito ser desnitrificado com o amônio como doador de elétrons. Com a combinação dos dois processos, os autores mencionaram que os requerimentos de oxigênio para a remoção de nitrogênio eram reduzidos em $60 \%$, bem como não era necessária adição de fonte de carbono, além de haver menor produção de lodo.

Fux e Siegrist (2004) afirmaram, em sua pesquisa comparativa entre sistemas SBR (“Sequencing Batch Reactor”) de eliminação de nitrogênio clássico com nitrificação autotrófica/desnitrificação heterotrófica e de nitritação/ANAMMOX ${ }^{\circledR}$, que esse segundo processo permite uma economia de cerca de 50 a $60 \%$ do oxigênio requerido para aeração, além de não ser necessária adição de fonte externa de carbono.

Os pesquisadores ainda mencionaram como grande vantagem desse processo que a desnitrificação heterotrófica clássica de nitrato a nitrogênio gasoso compreende a passagem pelas vias intermediárias óxido nítrico $(\mathrm{NO})$ e óxido nitroso $\left(\mathrm{N}_{2} \mathrm{O}\right)$ e que, com a utilização do sistema ANAMMOX ${ }^{\circledR}$, estes dois sub-produtos intermediários são detectados em concentrações quase desprezíveis. 


\section{METODOLOGIA}

A presente pesquisa consistiu na operação de dois sistemas piloto de lodo ativado de lodo único em paralelo, para tratamento de despejo sintético contendo elevadas concentrações de nitrogênio amoniacal e fenol, visando remoção de nitrogênio via nitrificação/desnitrificação total e parcial, com fontes interna (fenol presente no afluente) e externa (etanol adicionado) de carbono para a desnitrificação, e de um sistema em batelada para a remoção de nitrogênio via nitrito.

Este tipo de água residuária já fora objeto de estudos anteriores do Departamento de Hidráulica e Sanitária da Escola Politécnica da USP, bem como o inóculo utilizado na presente pesquisa, primeiramente sendo utilizado por Da Costa (1999) para avaliação de sua tratabilidade e, posteriormente, por Dombroski (2003) para avaliação da nitrificação e desnitrificação deste efluente com elevadas concentrações de fenol e nitrogênio amoniacal.

Para dar continuidade a esta linha de pesquisas, a proposta foi o estudo de dois sistemas contínuos de lodo ativado, sendo que um deles visa a obtenção da nitrificação/desnitrificação total, com fontes interna e externa de carbono para a desnitrificação, e o outro, da nitritação/desnitritação, com fenol como única fonte de carbono para a desnitritação. O primeiro foi denominado de sistema TOTAL ou "T" e o segundo, de sistema PARCIAL ou "P". Paralelamente aos sistemas de lodo ativado, a pesquisa também contou com a operação de um sistema em batelada, que fora objeto do trabalho de Queiroz (2006), objetivando promover a remoção de nitrogênio da mesma água residuária, via nitrito, permitindo assim uma comparação entre os resultados obtidos em sistema contínuo (sistema "P") e em sistema em batelada pela via simplificada.

Sendo assim, pretendeu-se avaliar a influência de variáveis operacionais como concentração de oxigênio dissolvido, $\mathrm{pH}$, fração anóxica e taxa de recirculação de lodo para 
verificação de quais regeriam os sistemas e promoveriam o desenvolvimento desses fenômenos mencionados.

O sistema TOTAL foi operado com concentrações de oxigênio dissolvido na etapa aerada que variaram de 1,5 a $5,0 \mathrm{mgO}_{2} / \mathrm{L}$; o $\mathrm{pH}$ foi controlado ao longo da pesquisa entre 6,5 e 7,5; as frações anóxicas utilizadas foram de 39\% na primeira metade da pesquisa e de 49\%, na segunda metade; a razão de recirculação de lodo variou de 4 a 12 vezes ao longo de toda a operação do sistema, sendo que essa foi alterada em função do acúmulo de fenol observado no reator anóxico de pré-desnitrificação. Ainda pelo mesmo fator, no início da operação, só foi utilizada recirculação de lodo do fundo do decantador secundário para o reator anóxico pré-D, sendo que no decorrer da pesquisa, em virtude de limitação da bomba de retorno de lodo, instalou-se outra bomba para possibilitar o reciclo interno do tanque aeróbio desse sistema também para o anóxico pré-D, aumentando assim o afluxo das formas oxidadas de nitrogênio nesse reator.

O sistema PARCIAL foi operado com concentrações de oxigênio dissolvido no reator aeróbio que variaram de 0,0 a 5,0 $\mathrm{mgO}_{2} / \mathrm{L}$. Essa ampla faixa deveu-se principalmente a dois fatores: o primeiro em virtude de não se conhecer a faixa ideal para favorecer o acúmulo de nitrito e, em segundo, pois grande parte da pesquisa foi feita sem o controlador automático de oxigenação do meio. $\mathrm{O}$ pH foi controlado ao longo da pesquisa, sendo que foi adotada uma faixa bem ampla, entre 5,5 e 9,0, para se observar qual aquela que favoreceria o acúmulo de nitrito no sistema. As frações anóxicas utilizadas foram de $23 \%$, na primeira metade da pesquisa, e de 41\%, na segunda metade. Da mesma forma e pelos mesmos fatores mencionados para o sistema TOTAL, a taxa de recirculação de lodo variou de 3,5 a 11 vezes ao longo de toda a operação do sistema. Também nesse caso, no início só foi utilizada recirculação de lodo do fundo do decantador para o reator anóxico e, posteriormente, nos 
meses finais da pesquisa, instalou-se outra bomba para o reciclo do tanque aeróbio para o anóxico.

A idade do lodo de ambos os sistemas foi elevada, bem superior a 100 dias, tendo em vista que não foi possível o descarte de lodo dos mesmos em nenhuma das fases da pesquisa. Como a taxa de crescimento dos microrganismos era muito lenta, não foi observado crescimento da biomassa suficiente que justificasse um descarte de lodo programado. Portanto, para se evitar grande perda de sólidos com os descartes, as únicas retiradas de lodo ocorreram nas coletas de amostras para monitoramento dos sistemas (além das perdas de sólidos no efluente final).

Não foi feito controle rigoroso da temperatura nos reatores; apenas foram utilizados termostatos/aquecedores para manutenção da mesma acima de $25^{\circ} \mathrm{C}$ visando a não inibição da nitrificação.

Não foi utilizado potencial redox para monitoramento dos sistemas contínuos tendo em vista que o mesmo se apresenta praticamente constante ao longo de toda a operação, só mostrando alguma variação quando se observa alguma anomalia ou desequilíbrio operacional, não sendo representativos seus resultados para esse tipo de sistema. No caso do sistema em batelada, o sensor de ORP passou a ser utilizado no decorrer da operação, porém também não mostrou valores representativos para ser adotado como parâmetro operacional.

\section{1 Água Residuária}

A água residuária sintética utilizada foi similar àquelas utilizadas nas pesquisas que precederam a presente (DA COSTA, 1999; AUN, 2001; DOMBROSKI, 2003) e apresentou a seguinte composição: 
Tabela 2 - Produtos químicos utilizados para preparação da água residuária sintética

\begin{tabular}{lc}
\hline \multicolumn{1}{c}{ Produtos químicos } & Concentração (mg/L) \\
\hline Fenol & 1000 \\
Cloreto de amônio & $1900 / 2870$ \\
Sulfato de manganês & 53 \\
Cloreto de cálcio & 53 \\
Ferrocianeto de potássio & 133 \\
Sulfato de magnésio & 330 \\
Fosfato de potássio bibásico & 200 \\
\hline
\end{tabular}

Entretanto, diferentemente das pesquisas anteriores mencionadas, os compostos orgânicos naftaleno, benzeno, tolueno e xileno não foram adicionados em virtude desses não serem objeto da presente pesquisa e terem demonstrado não interferirem no tratamento.

Vale ressaltar que foram estudadas duas concentrações afluentes de cloreto de amônio, tendo em vista que os efluentes das unidades de coqueria não mais apresentam concentrações de nitrogênio amoniacal tão elevadas quanto antigamente, já que boa parte delas reduz esse composto em unidades anteriores ao tratamento biológico propriamente dito, como é o caso das unidades de arraste de amônia com ar (BROND; SUND, 1994; SUTTON; HURVID; HOEKSEMA, 1999). Sendo assim, além da concentração de nitrogênio amoniacal de $750 \mathrm{mgN} / \mathrm{L}$ utilizada nos trabalhos anteriores mencionados, estudou-se também concentração da ordem de $500 \mathrm{mgN} / \mathrm{L}$.

É importante mencionar que, apesar dos cloretos apresentarem interferências consideráveis em diversas determinações analíticas, quando se estudou a composição do despejo (DA COSTA, 1999), poucas eram as alternativas de sais amoniacais possíveis de serem utilizados e, portanto, verificou-se que outros sais apresentariam mais problemas e dificuldades, como por exemplo baixa solubilidade, sendo praticamente inviáveis para o 
preparo da água residuária, o que levou à adoção da utilização do cloreto de amônio na composição do despejo.

Tendo em vista que as pesquisas precursoras (DA COSTA, 1999; DOMBROSKI, 2003) já utilizaram a composição dessa água residuária sem a adição de micronutrientes, adotou-se a mesma premissa para a presente pesquisa e estes também não foram adicionados.

\subsection{Inóculo}

O inóculo utilizado é proveniente do lodo de retorno do sistema de tratamento biológico de efluentes líquidos de uma indústria petroquímica, tendo em vista que este já apresentou resultados satisfatórios quando foi utilizado anteriormente no tratamento desse tipo de despejo nas pesquisas de Da Costa (1999) e Dombroski (2003).

Após aquisição do lodo, esse foi então submetido a um processo de adaptação para tratamento do despejo sintético, objeto da presente pesquisa.

Entretanto, diferentemente das pesquisas anteriores, após início da operação do sistema com esse inóculo, obteve-se a informação de que a indústria tinha passado a utilizar em seu sistema de tratamento o composto "DOSFOLAT", que é a base de ácido fólico, objetivando menor produção de lodo. Sendo assim, a biomassa não foi exatamente a utilizada pelos autores mencionados, sendo que esse pode ter sido o fator principal para a demora e dificuldades em sua adaptação.

\subsection{Instalações Experimentais}

Os dois sistemas piloto de lodo ativado foram instalados em paralelo no laboratório do Centro Tecnológico de Hidráulica (CTH) situado na Universidade de São 
Paulo. Os procedimentos analíticos foram realizados no Laboratório de Saneamento da Escola Politécnica da USP.

O sistema piloto PARCIAL ou "P" era composto de um reator anóxico, seguido de um reator aeróbio com aeração controlada e um decantador secundário, com retorno de lodo de fundo do decantador para o reator anóxico, além de recirculação interna de lodo do reator aeróbio para o anóxico (vide Figura 10).

É importante ressaltar que no início da pesquisa não foi utilizado reciclo do aeróbio para o anóxico, sendo que o lodo e o nitrato só eram retornados para o ambiente anóxico através da bomba de retorno do decantador secundário para o anóxico. Entretanto, em virtude de dificuldades operacionais no que diz respeito à capacidade da bomba de deslocamento positivo de retorno de lodo, no decorrer da pesquisa procedeu-se à instalação de uma bomba de recirculação interna do reator aeróbio para o anóxico, dando maior flexibilidade ao sistema no que concerne à taxa de reciclo de lodo e de nitrato.

O reator anóxico era dotado de agitador mecânico, visando manter os sólidos em suspensão. $\mathrm{O}$ pH do reator aeróbio era mantido por equipamento integrado para dosagem de solução alcalinizante (bombas dosadoras) acoplado a medidor/controlador de $\mathrm{pH}$. Esses equipamentos também foram utilizados no caso do sistema TOTAL.

A aeração do reator aeróbio era garantida por difusores do tipo usado em aquário (pedras porosas), dispersando ar na massa líquida. O controle da oxigenação era feito com medidor e controlador de OD (marca Yokogawa) acoplado a válvula proporcional de vazão (marca Festo), sendo que esses só foram utilizados da metade dos experimentos até seu término. Em virtude da baixa aeração nesse reator, também foi utizado misturador evitando a sedimentação dos sólidos no fundo do tanque.

Tanto para o sistema PARCIAL como para o TOTAL, o decantador era dotado de dispositivo para remoção automática do lodo com estrutura metálica capaz de limpar suas 
paredes, acionada por um conjunto moto-redutor com capacidade de variação de rotação de 2 a $10 \mathrm{rpm}$.

Quanto ao sistema TOTAL ou “T”, esse era composto de um reator aeróbio, além de dois reatores anóxicos, um a montante (pré-D) e o outro a jusante (pós-D) do aeróbio (este último também dotado de separação para reaeração), e por fim um decantador secundário, com retorno de lodo de fundo do decantador secundário ao primeiro reator anóxico, além da recirculação interna do reator aeróbio ao primeiro reator anóxico (da mesma forma que no PARCIAL, essa última utilizada apenas no decorrer da pesquisa). Como mencionado anteriormente, esse tipo de sistema ficou conhecido como Bardenpho (EKAMA; MARAIS, 1997).

Nesta concepção, como era de se esperar que as bactérias desnitrificantes presentes no reator pré-D consumissem praticamente toda a matéria orgânica existente no afluente (fenol) promovendo a desnitrificação, no reator pós-D, instalou-se uma bomba peristáltica multicanal para adição de etanol, com a função de promover fonte de material carbonáceo para a desnitrificação, visando alcançar menores concentrações de nitrato no efluente final.

A adoção do etanol como fonte externa de carbono foi em virtude dessa ser de fácil obtenção no mercado, além de apresentar baixo custo.

Ainda em relação ao sistema TOTAL, para evitar que o lodo permanecesse muito tempo em ambiente anóxico favorecendo sua suspensão no decantador secundário, deteriorando a qualidade do efluente final e lavando a biomassa do sistema, procedeu-se a instalação de um septo no reator anóxico de pós-desnitrificação para separar uma parte de seu conteúdo, deixando aproximadamente dois terços em ambiente anóxico, com apenas misturador para evitar decantação do lodo, e o outro terço em ambiente aerado, utilizando-se para tanto bomba de aquário e pedras porosas para a difusão do oxigênio no meio líquido. 
O tanque de armazenamento do afluente aos dois sistemas tinha capacidade máxima de 162 litros (volume útil 150 L), era dotado de agitador mecânico evitando sedimentação dos reagentes no fundo e tampa hermética contendo um funil para a introdução e preparo da água residuária.

O fornecimento de ar aos sistemas era feito por um compressor de ar de potência $10 \mathrm{HP}$, que também alimentava outras instalações piloto existentes no CTH.

Uma caixa de 500 litros de capacidade era utilizada para armazenamento e preparo de solução alcalinizante, no caso bicarbonato de sódio a $50 \mathrm{~g} / \mathrm{L}$.

Além dos equipamentos constantemente instalados nos sistemas (agitadores, bombas, medidores/controladores de $\mathrm{pH}$ e $\mathrm{OD}$, termostatos), alguns equipamentos de monitoramento diário ou de uso temporário também foram utilizados.

Como o monitoramento diário incluía leitura de $\mathrm{pH}$, temperatura e oxigênio dissolvido de todos os reatores, além da medição de vazões, assim os equipamentos utilizados diariamente foram: medidor de $\mathrm{pH}$, termômetro, oxímetro e cronômetro.

Em algumas fases da pesquisa, foi necessária a utilização de timer temporariamente para algumas bombas, visando a diminuição de sua vazão, tendo em vista que muitas vezes a vazão mínima da bomba era bem maior do que a necessária no sistema, a exemplo do reciclo interno, da adição de etanol (sistema TOTAL) e da bomba de aquário, para a parte aerada do reator anóxico pós-D do sistema TOTAL.

O esquema das instalações piloto é apresentado na Figura 10. As fotos apresentadas nas Figuras 11 a 20 ilustram os experimentos realizados no Centro Tecnológico de Hidráulica. 


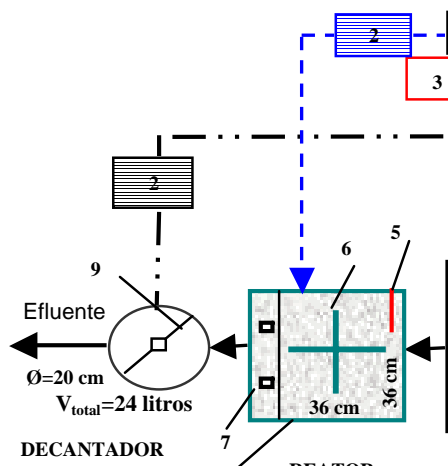

$\mathrm{h}_{\text {totel }}=77 \mathrm{~cm} /$ REATOR

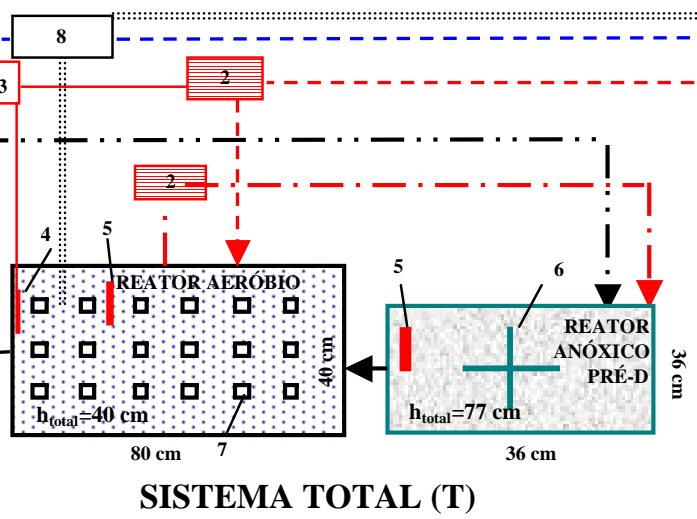

SISTEMA PARCIAL (P)
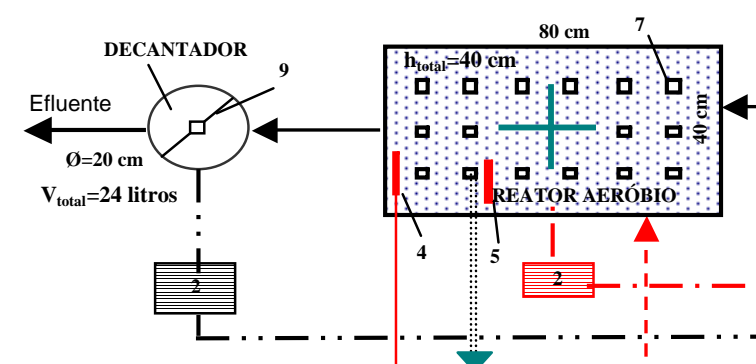

a

C REATOR AERÓBIO

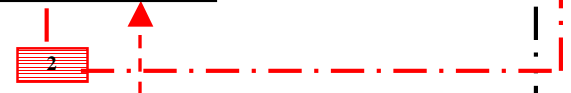

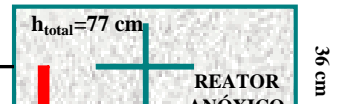

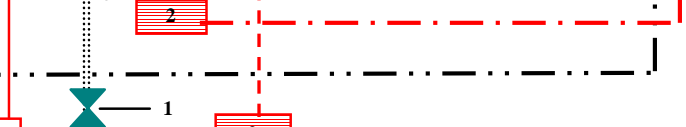
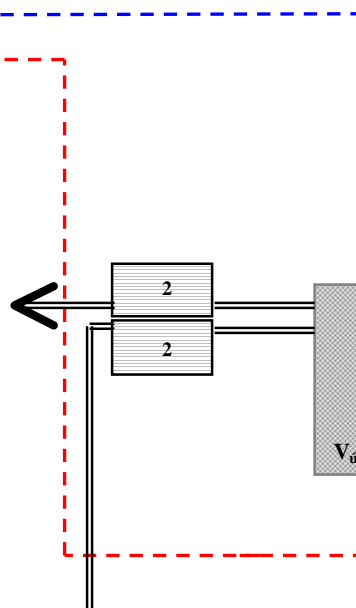

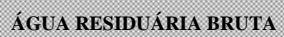
1.10

1. 1. 150 . itiros

ETANOL

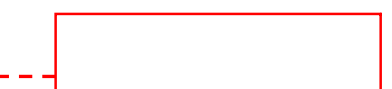

SOLUÇÃO ALCALINIZANTE

$\mathrm{V}_{\text {utili }}=\mathbf{5 0 0}$ litros

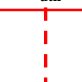

1
-
1

\section{Legenda:}

ב Água residuária bruta

- - - Retorno do reator aeróbio para o reator anóxico

\section{- - - Recirculação do lodo

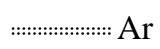

Figura 10 - Esquema geral das instalações piloto

\begin{tabular}{ll|}
\hline 1 - Válvula/Controlador OD & 6 - Agitador mecânico \\
2 - Bomba & 7 - Difusor de ar \\
3 - Controlador de $\mathrm{pH}$ & 8 - Distribuidor de ar \\
4 - Eletrodo de $\mathrm{pH}$ & 9 - Removedor de lodo \\
5 - Controlador de temperatura & 10 - Filtro de ar
\end{tabular}

1 - Válvula/Controlador OD

7 - Difusor de ar

9 - Removedor de

5 - Controlador de temperatura

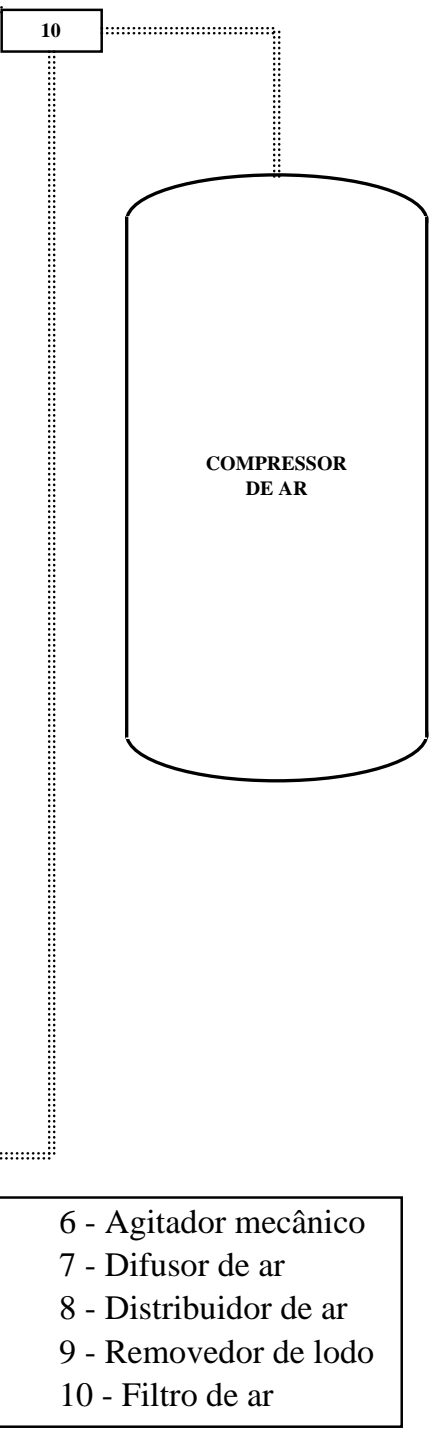




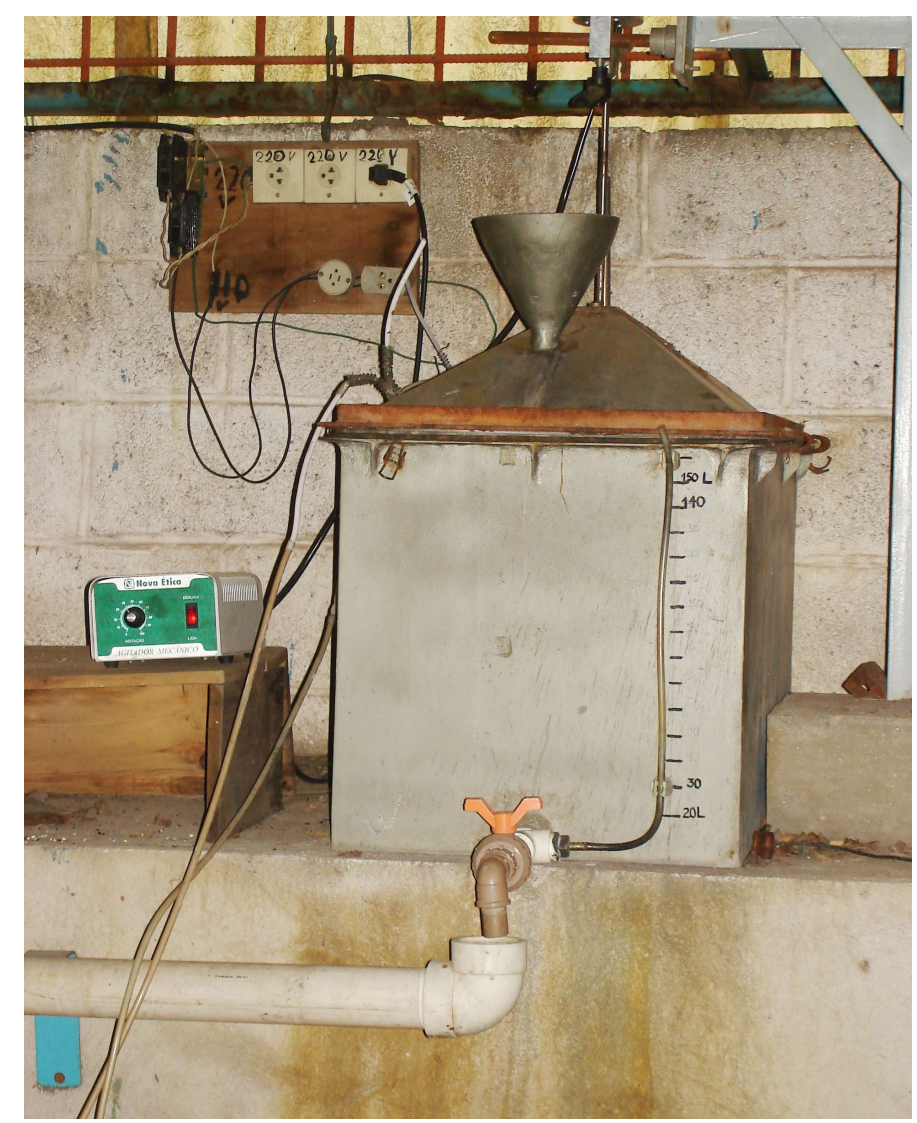

Figura 11 - Caixa de alimentação. Na parte superior, pode-se visualizar a haste do misturador e o funil para introdução dos reagentes para preparo da água residuária.

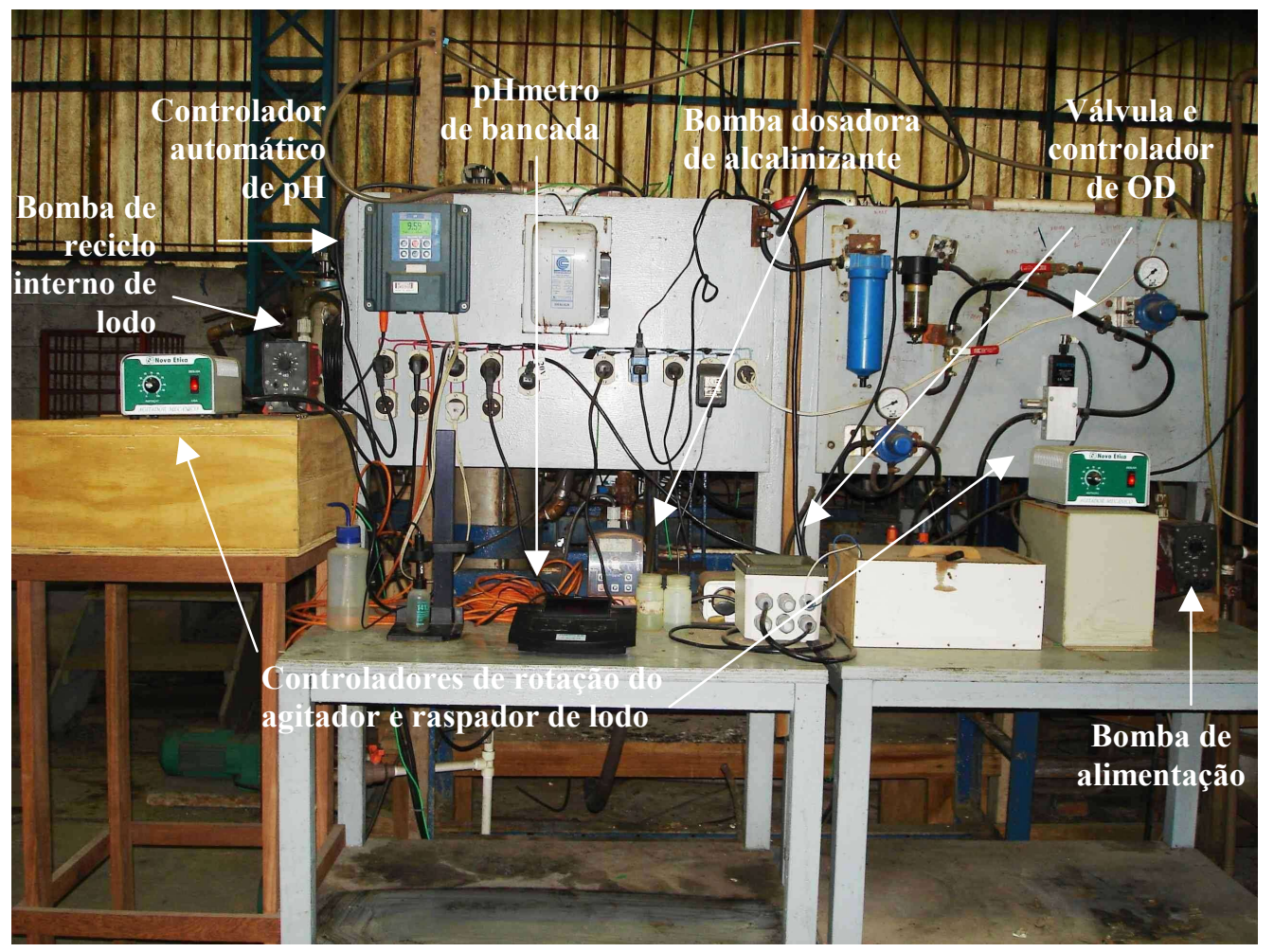

Figura 12 - Vista do painel de controle e bancada do sistema PARCIAL (P) 


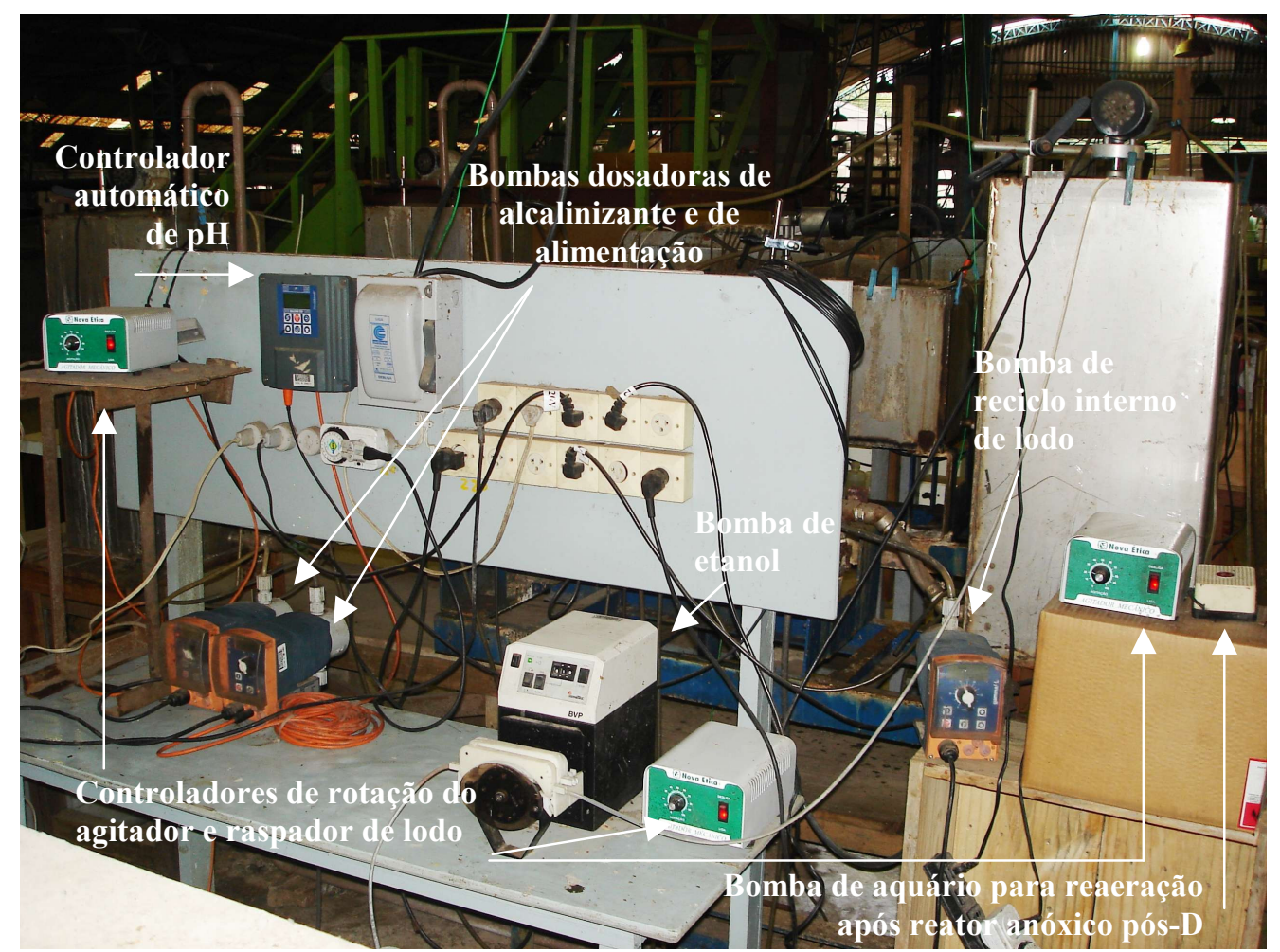

Figura 13 - Vista do painel de controle e bancada do sistema TOTAL (T)

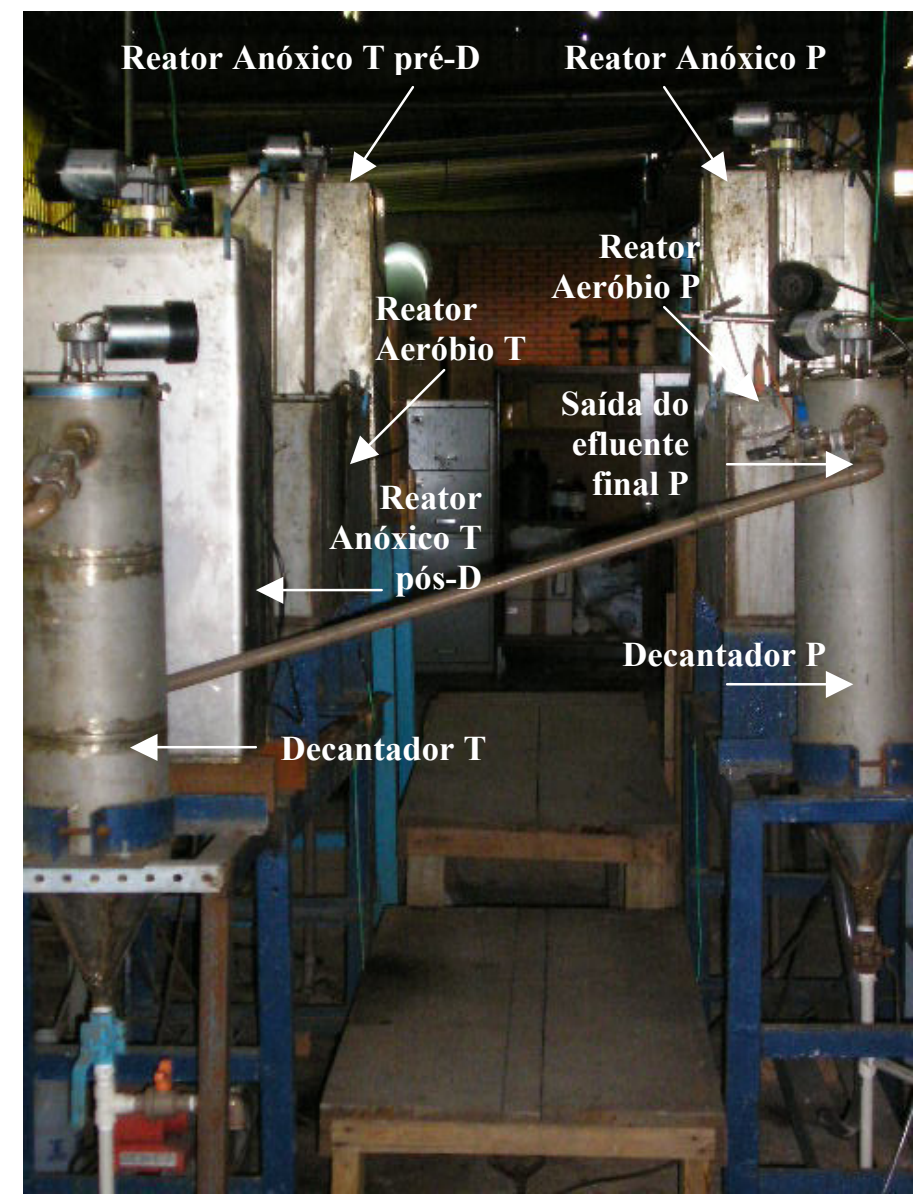

Figura 14 - Vista geral dos sistemas piloto em paralelo: à direita o sistema Parcial (P) e à esquerda, o Total $(T)$ 


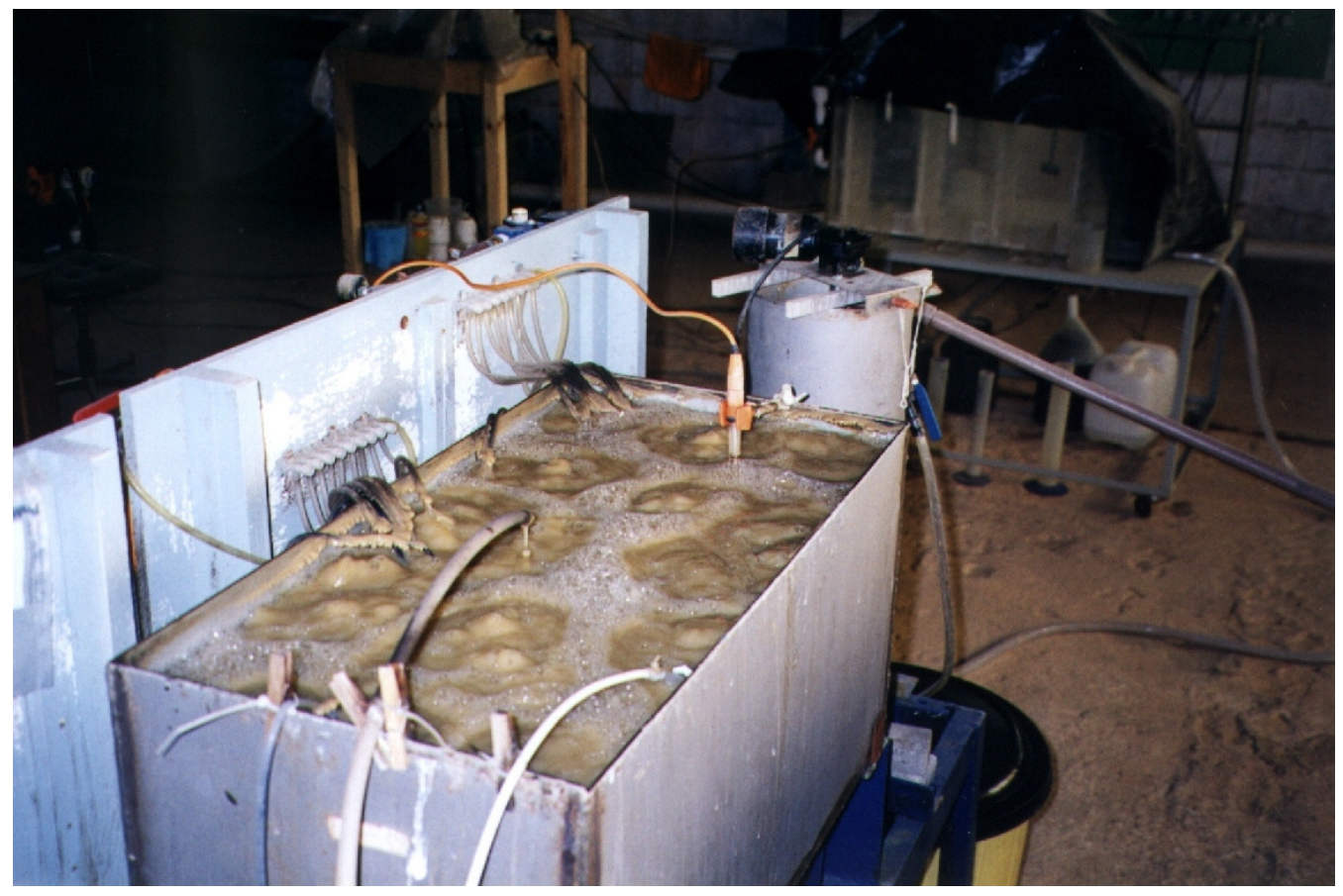

Figura 15 - Reator aeróbio do sistema PARCIAL ainda na fase de adaptação da biomassa, portanto sem controle e diminuição da aeração e sem agitador mecânico

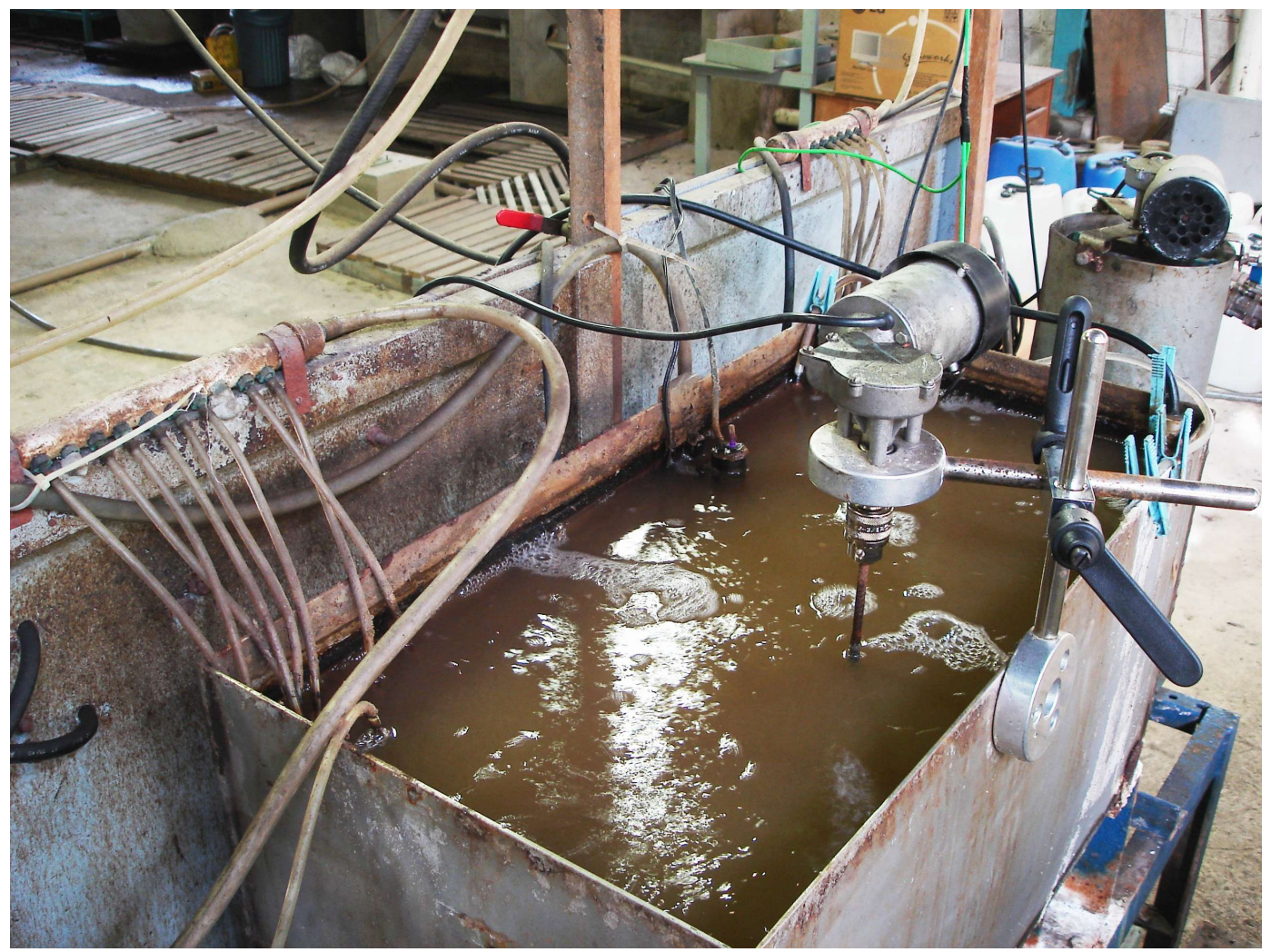

Figura 16 - Reator aeróbio do sistema PARCIAL, agora com controle de aeração e agitador mecânico instalado, evitando-se assim a decantação do lodo no fundo do reator. Mais ao fundo, o decantador secundário e seu motor do raspador de lodo. 


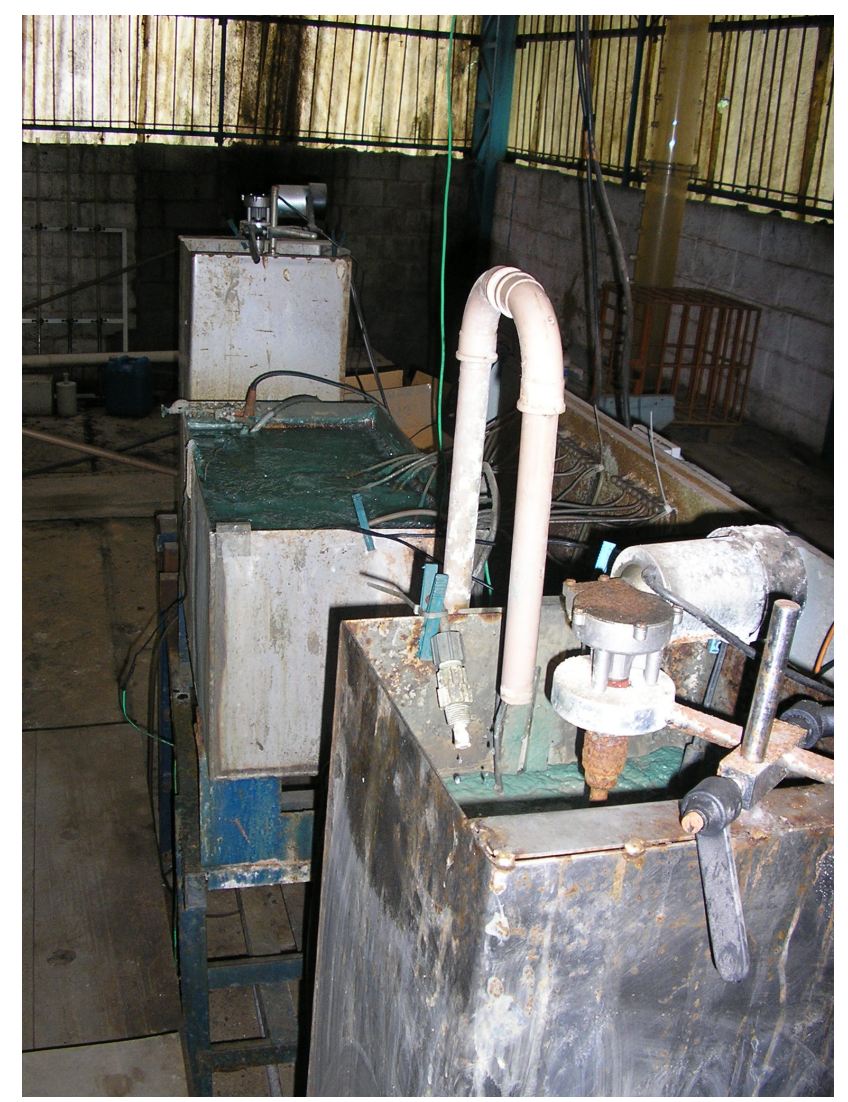

Figura 17 - Vista do sistema TOTAL: em primeiro plano o reator anóxico pré-D; no centro o reator aeróbio e ao fundo, 0 anóxico pós-D.

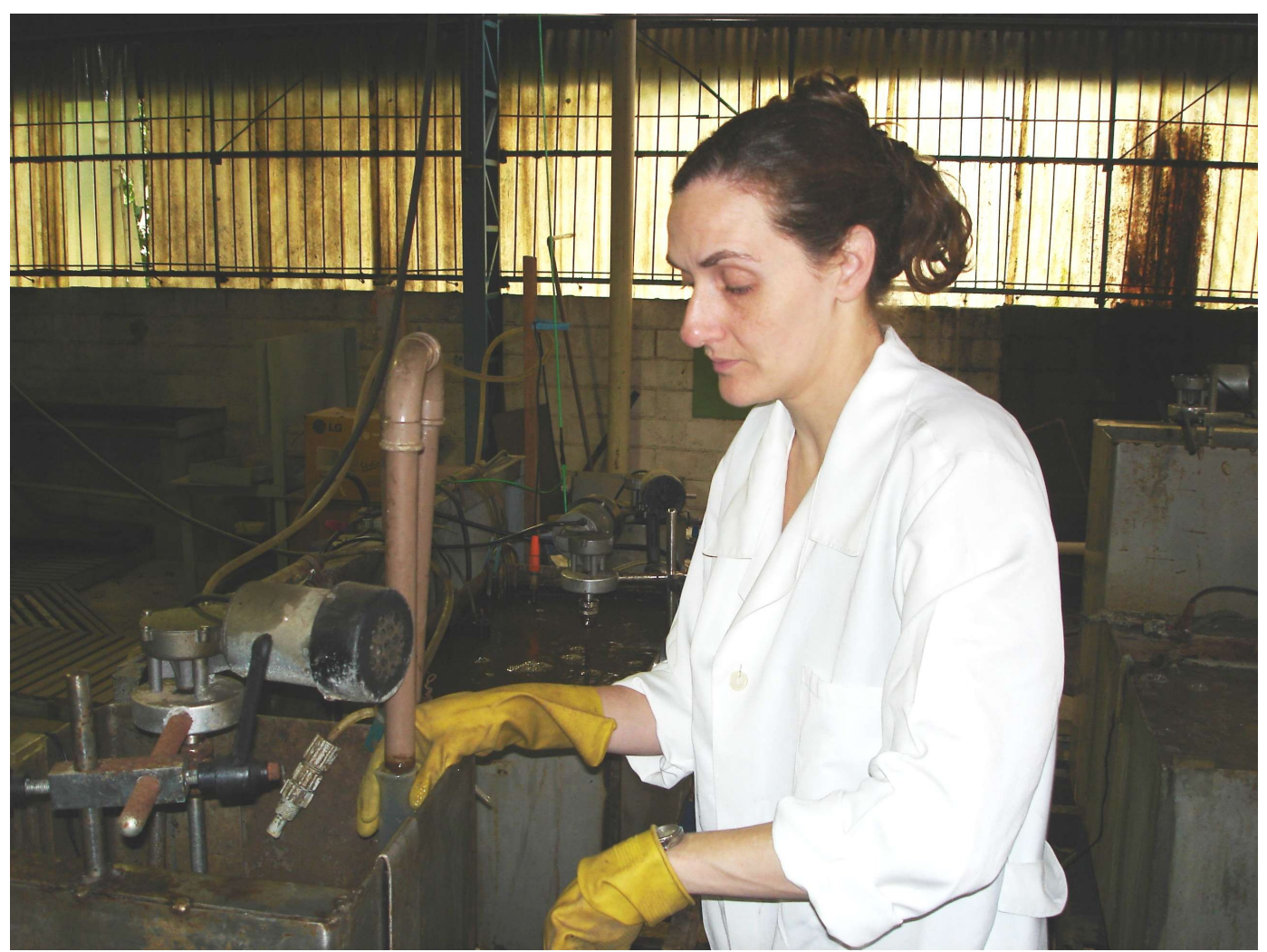

Figura 18 - Procedimento diário de leitura de vazões 


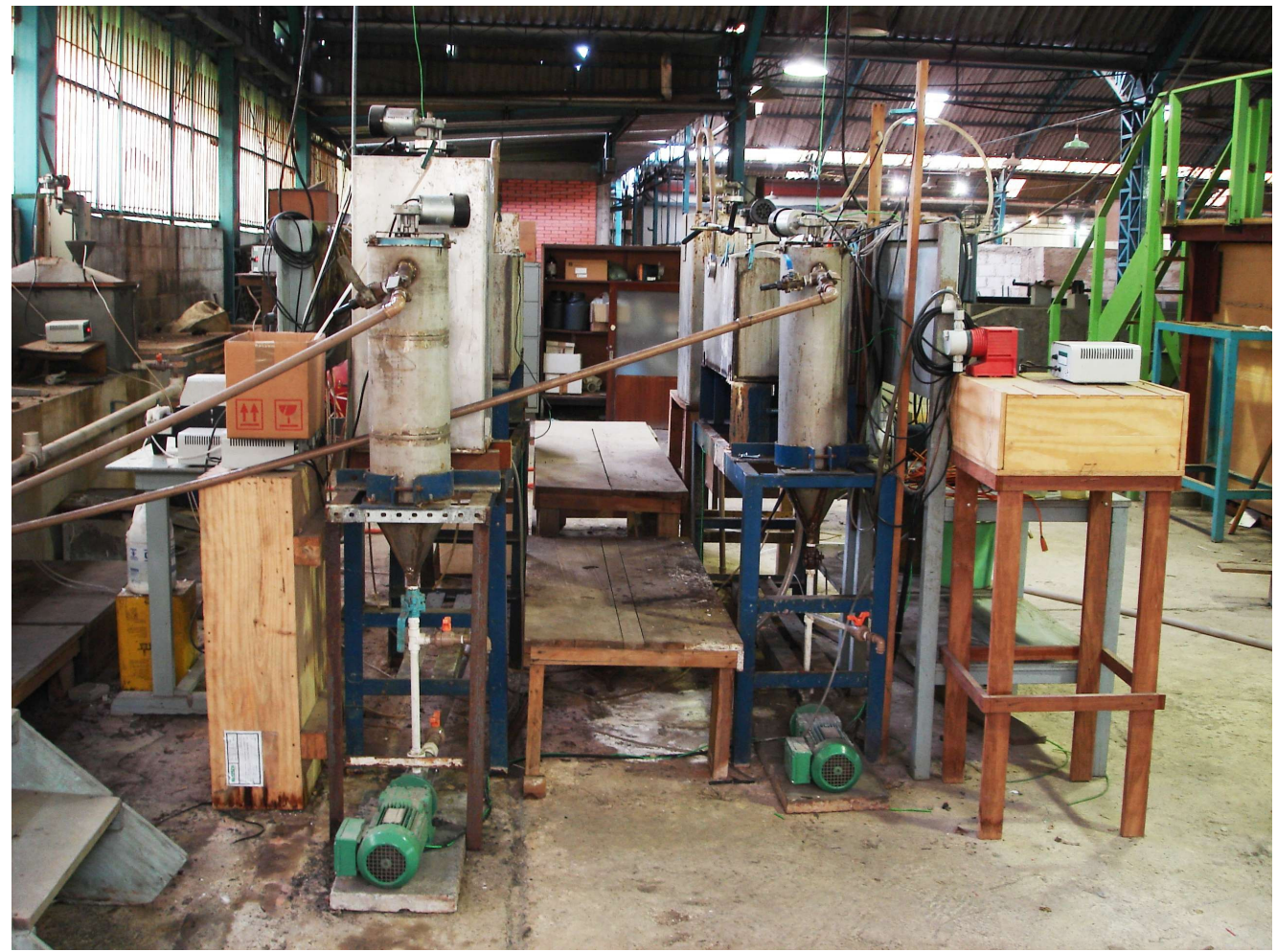

Figura 19 - Vista geral da ETE piloto; em primeiro plano, os decantadores e suas respectivas bombas de deslocamento positivo para retorno de lodo.

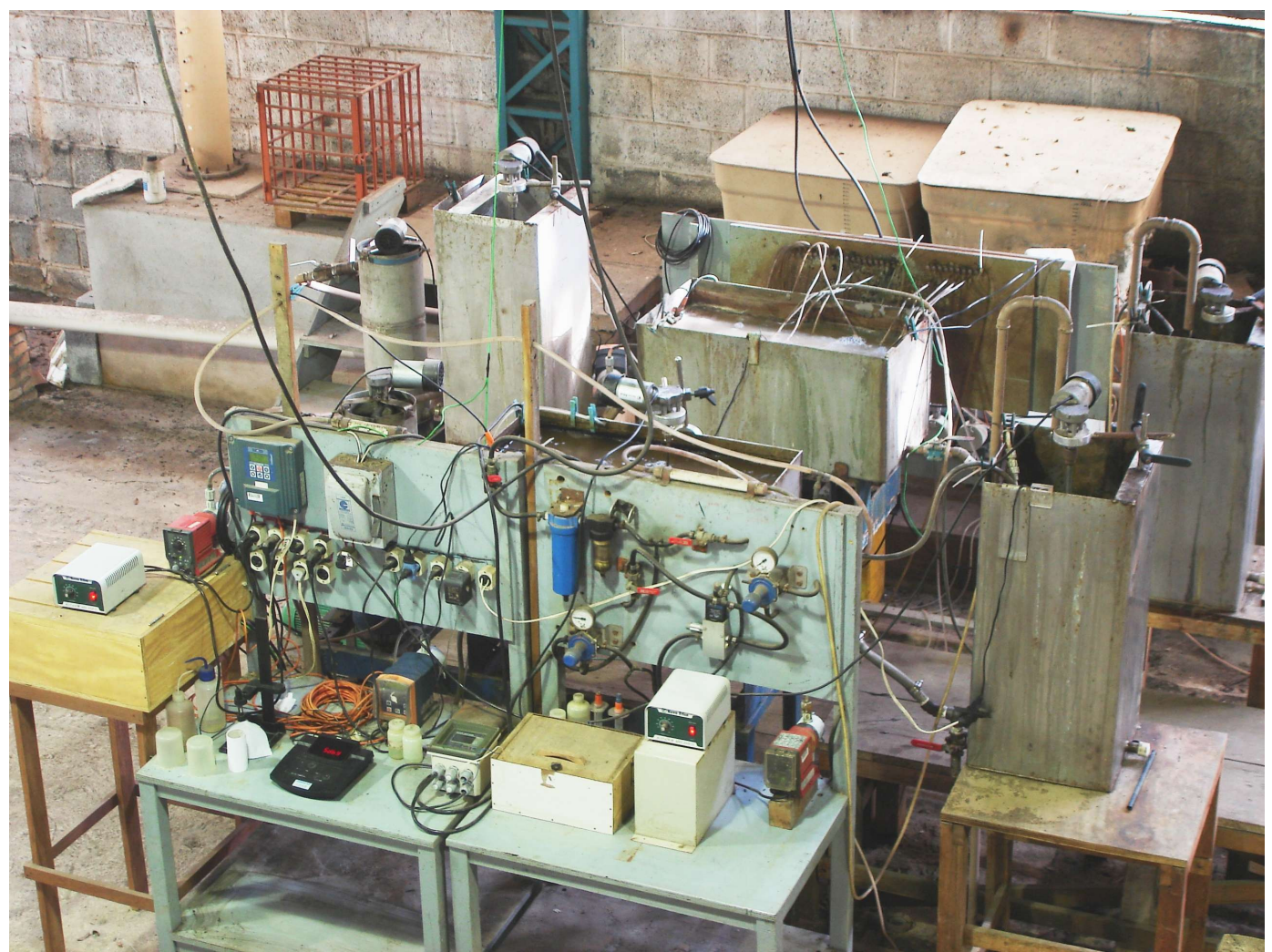

Figura 20 - Vista geral das instalações piloto em um plano superior: primeiramente, o sistema PARCIAL e, mais ao fundo, o TOTAL 


\subsection{Adaptação do Lodo Biológico}

A adaptação do lodo biológico foi feita de acordo com os procedimentos utilizados por Da Costa (1999) e Dombroski (2003), em virtude de se tratar do mesmo tipo de despejo:

a) preenchimento dos reatores com biomassa proveniente do sistema de tratamento da indústria petroquímica;

b) manutenção da concentração de oxigênio dissolvido em torno de $2 \mathrm{mgO}_{2} / \mathrm{L}$ e pH entre 6,8 e 7,2 na massa líquida dos reatores aeróbios dos dois sistemas (DA COSTA, 1999). Somente para o sistema PARCIAL, após adaptação da biomassa a esta concentração de OD, reduziu-se a entrada de ar até concentrações de OD inferiores a 1,0 mgO $2 / \mathrm{L}$. Posteriormente, instalou-se o medidor/controlador de OD e a válvula proporcional de vazão de ar para o controle da oxigenação do meio. Quanto ao $\mathrm{pH}$, passou-se a manipulá-lo ora para valores menores que 7,0, ora maiores, de modo a avaliar a faixa mais interessante para o acúmulo de nitrito;

c) aferição da razão de recirculação de lodo dos decantadores para os reatores anóxicos. Entretanto, durante a operação dos sistemas, observou-se a necessidade de aumento substancial dos retornos, inclusive com a introdução do reciclo interno de lodo (primeiramente para o TOTAL e, posteriormente, para o PARCIAL), tendo em vista que foi observado acúmulo de fenol nos anóxicos pré-D e uma das hipóteses prováveis para tal acúmulo era a baixa concentração das formas oxidadas de nitrogênio nesses reatores;

d) manutenção da temperatura nos reatores acima de $25^{\circ} \mathrm{C}$. Porém, no monitoramento diário dos sistemas, mesmo com o uso de aquecedores/termostatos, observou-se dificuldade em manter a temperatura nesse valor, sendo que essa acabou variando numa faixa bem mais ampla, entre cerca de 20 a $32^{\circ} \mathrm{C}$; 
e) manutenção da concentração de sólidos em suspensão voláteis nos reatores maior que $1500 \mathrm{mg} / \mathrm{L}$ (DA COSTA, 1999). Especificamente no caso do sistema PARCIAL, em determinada fase da pesquisa, o sistema apresentou uma brusca queda nas concentrações de SST e SSV, o que foi recuperado com o passar do tempo;

f) manutenção da dosagem de solução de bicarbonato de sódio para controle de $\mathrm{pH}$ nos reatores aeróbios. Apesar de Da Costa (1999) e Dombroski (2003) terem utilizado solução de bicarbonato de sódio juntamente com polímero catiônico para evitar lavagem de sólidos do sistema, como logo no início da operação os sistemas operaram sem problemas de perda de sólidos, decidiu-se pela não utilização de polímero, mas sim somente de alcalinizante, fato esse que se manteve até o final da pesquisa;

g) alimentação do sistema com água residuária sintética, com uma vazão inicial em torno de 0,4 L/h ( $10 \mathrm{~L} / \mathrm{dia})$ (DOMBROSKI, 2003). No caso específico do sistema PARCIAL, como não foi possível a obtenção de bons resultados no início da pesquisa com essa vazão de alimentação, procedeu-se a diminuição da mesma para aproximadamente metade da vazão inicial, ou seja, 0,2 L/h ( $5 \mathrm{~L} / \mathrm{dia})$;

h) monitoramento do sistema através de determinações analíticas, principalmente para os parâmetros fenol e nitrogênio amoniacal (DOMBROSKI, 2003);

i) quando eram observadas baixas concentrações de fenol e nitrogênio amoniacal nos anóxicos pré-D e nos decantadores (menores ou iguais a $1 \mathrm{mg}$ fenol/L e $20 \mathrm{mg} \mathrm{N} / \mathrm{L}$ ), procedia-se o aumento da vazão afluente e assim sucessivamente, até chegar à vazão de operação do sistema, que foi da ordem de $30 \mathrm{~L} /$ dia.

Além dos procedimentos similares aos de Da Costa (1999) e Dombroski (2003), na presente pesquisa, especificamente para o sistema PARCIAL, o aumento de vazão só iniciou quando foram observadas concentrações significativas de nitrito no tanque aeróbio, o que realmente levou bastante tempo. 
Além disso, no caso do sistema TOTAL, após a fase de adaptação da biomassa, iniciou-se a alimentação de etanol no reator anóxico pós-D, mas esse também não foi mantido continuamente até o final da pesquisa, já que foram observados diversos problemas de acúmulo de fenol e anaerobiose no sistema, que serão melhor detalhados no Capítulo de Apresentação dos Resultados.

\subsection{Operação e Monitoramento das Instalações Piloto}

O procedimento operacional básico consistiu em:

a) preparar 150 litros de água residuária sintética, para garantir a alimentação dos sistemas utilizando-a até que a mesma se esgotasse, para então proceder nova preparação;

b) preparar 50 litros de solução alcalinizante de bicarbonato de sódio a uma concentração em torno de $50 \mathrm{~g} / \mathrm{L}$, aproximadamente uma vez ao mês;

c) verificar diariamente o $\mathrm{pH}$ dos reatores aeróbios, anóxicos e do afluente, além da leitura de OD e temperaturas de todos os reatores;

d) aferir, diariamente, as vazões afluentes ao sistema, quais sejam: água residuária bruta, retornos de lodo e reciclos do conteúdo dos reatores aeróbios para os anóxicos, bem como as vazões efluentes e de etanol (para o sistema TOTAL);

e) verificar o controlador de OD e a válvula proporcional de vazão de ar (a partir da metade da pesquisa, quando foram instalados esses equipamentos) do sistema PARCIAL, lavando semanalmente o sensor de OD que ficava continuamente imerso no tanque aerado, evitando assim muita interferência nas leituras.

Para monitoramento dos sistemas, procedeu-se a determinação físico-química de amostras coletadas em diferentes pontos do mesmo. Os pontos de amostragem, 
especificações, freqüência e quantificação das determinações, assim como métodos analíticos empregados, são apresentados na Tabela 3. Um esquema dos pontos de amostragem é mostrado na Figura 21. A coleta e preservação de amostras, bem como os métodos empregados nas determinações, foram feitos de acordo com APHA; AWWA; WEF (1998).

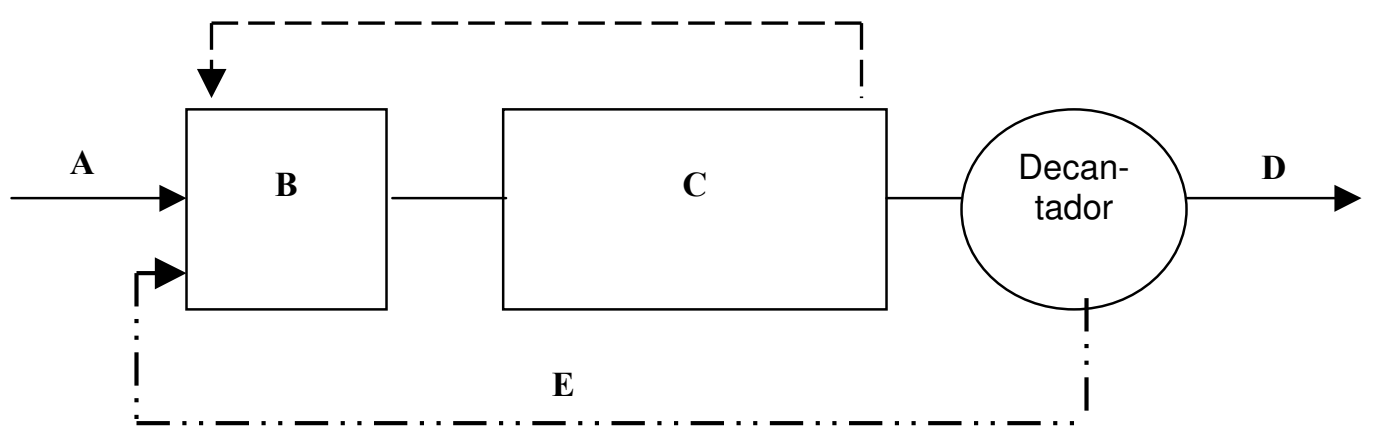

SISTEMA PARCIAL (P)

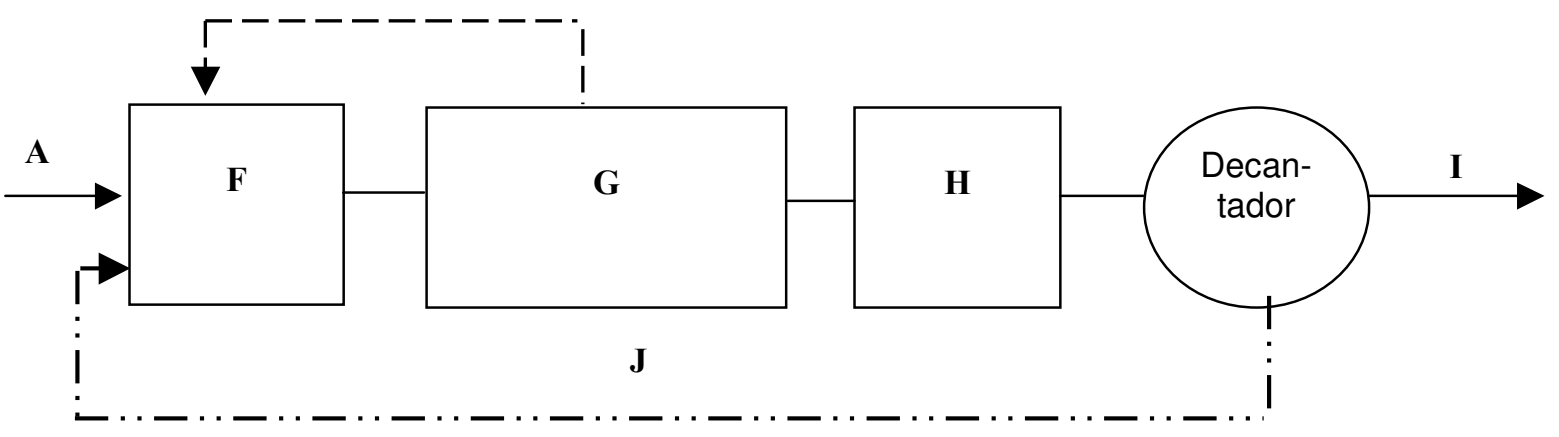

SISTEMA TOTAL (T)

Legenda:
A - afluente
$\mathrm{B}-$ reator anóxico $(\mathrm{P})$
$\mathrm{C}-$ reator aeróbio $(\mathrm{P})$
$\mathrm{D}$ - efluente $(\mathrm{P})$
$\mathrm{E}$ - retorno de lodo $(\mathrm{P})$
$\mathrm{F}$ - reator anóxico pré-D $(\mathrm{T})$
$\mathrm{G}$ - reator aeróbio (T)
$\mathrm{H}$ - reator anóxico pós-D $(\mathrm{T})$
I - efluente (T)
$\mathrm{J}$ - retorno de lodo (T)

Figura 21 - Esquema dos pontos de amostragens 
Tabela 3 - Plano de amostragem para monitoramento dos sistemas piloto

\begin{tabular}{|c|c|c|c|}
\hline \multicolumn{2}{|c|}{ Determinações } & \multirow{2}{*}{$\begin{array}{c}\text { Pontos de amostragem } \\
\text { (ver legenda da Figura 15) }\end{array}$} & \multirow{2}{*}{ Métodos analíticos } \\
\hline Especificação & Freqüência & & \\
\hline $\mathrm{DQO}^{(1,3)}$ & $1 \mathrm{vez} / \mathrm{semana}$ & $\mathrm{A}, \mathrm{B}, \mathrm{D}, \mathrm{F}, \mathrm{H}, \mathrm{I}$ & Refluxo aberto \\
\hline $\mathrm{DBO}_{5,20}$ & $1 \mathrm{vez} / \mathrm{semana}$ & $\mathrm{A}^{(2)}, \mathrm{D}, \mathrm{I}$ & DBO de 5 dias a $20^{\circ} \mathrm{C}$ \\
\hline Compostos fenólicos & 2 vezes/semana & $\mathrm{A}, \mathrm{B}, \mathrm{D}, \mathrm{F}, \mathrm{I}$ & Fotométrico direto com destilação preliminar \\
\hline Compostos fenólicos & $1 \mathrm{vez} / \mathrm{mês}$ & $\mathrm{D}, \mathrm{I}$ & Extração com clorofórmio com destilação preliminar \\
\hline Nitrogênio amoniacal & 2 vezes/semana & $\mathrm{A}, \mathrm{B}, \mathrm{C}, \mathrm{D}, \mathrm{F}, \mathrm{G}, \mathrm{I}$ & Titulométrico, com destilação preliminar \\
\hline Nitrato $^{(3)}$ & 2 vezes/semana & $\mathrm{B}, \mathrm{C}, \mathrm{D}, \mathrm{E}, \mathrm{F}, \mathrm{G}, \mathrm{H}, \mathrm{I}, \mathrm{J}$ & Eletrodo de nitrato \\
\hline Nitrito $^{(3)}$ & 2 vezes/semana & $\mathrm{B}, \mathrm{C}, \mathrm{D}, \mathrm{E}, \mathrm{F}, \mathrm{G}, \mathrm{H}, \mathrm{I}, \mathrm{J}$ & Colorimétrico \\
\hline Alcalinidade & $1 \mathrm{vez} / \mathrm{semana}$ & $\mathrm{B}, \mathrm{C}, \mathrm{D}, \mathrm{E}, \mathrm{F}, \mathrm{G}, \mathrm{H}, \mathrm{I}, \mathrm{J}$ & Titulação potenciométrica \\
\hline Temperatura & $1 \mathrm{vez} / \mathrm{dia}$ & $\mathrm{B}, \mathrm{C}, \mathrm{F}, \mathrm{G}, \mathrm{H}$ & Termômetro de mercúrio \\
\hline $\mathrm{pH}$ & $1 \mathrm{vez} /$ dia e/ou contínua ${ }^{(4)}$ & $\mathrm{A}, \mathrm{B}, \mathrm{C}, \mathrm{F}, \mathrm{G}, \mathrm{H}$ & Eletrométrico \\
\hline Oxigênio dissolvido (OD) & 1 vez/dia e/ou contínua ${ }^{(5)}$ & $\mathrm{B}, \mathrm{C}, \mathrm{F}, \mathrm{G}, \mathrm{H}$ & Eletrodo de membrana \\
\hline Sólidos em suspensão voláteis (SSV) & $1 \mathrm{vez} / \mathrm{semana}$ & $\mathrm{B}, \mathrm{C}, \mathrm{D}, \mathrm{E}, \mathrm{F}, \mathrm{G}, \mathrm{H}, \mathrm{I}, \mathrm{J}$ & Gravimétrico \\
\hline Sólidos em suspensão totais (SST) & $1 \mathrm{vez} / \mathrm{semana}$ & $\mathrm{B}, \mathrm{C}, \mathrm{D}, \mathrm{E}, \mathrm{F}, \mathrm{G}, \mathrm{H}, \mathrm{I}, \mathrm{J}$ & Gravimétrico \\
\hline
\end{tabular}

Obs:

(1) Tendo em vista o número de interferentes das amostras (principalmente de cloretos) para a análise de DQO, no decorrer do experimento, essa análise foi abandonada.

(2) Para o ponto A (afluente), foi necessária a utilização de semente do próprio tanque aeróbio dos sistemas para a análise de DBO.

${ }^{(3)}$ Para as determinações de nitrato, nitrito e DQO, as amostras foram filtradas (membrana de diâmetro de poro 0,45 $\mu \mathrm{m}$ ).

${ }^{(4)}$ A leitura e controle do $\mathrm{pH}$ são automáticos nos reatores aeróbios.

${ }^{(5)}$ No caso específico do reator aeróbio do sistema P, a leitura de OD é contínua, tendo em vista a necessidade do controle automático de oxigenação. 


\subsection{Operação do Sistema em Bateladas Seqüenciais}

Ainda como parte da presente pesquisa, além da operação dos sistemas piloto de lodo ativado, foi também operado um sistema em bateladas seqüenciais para promover a remoção biológica de nitrogênio via nitrito utilizando água residuária similar à utilizada para os sistemas de lodo ativado, que foi escopo do trabalho de mestrado desenvolvido por Queiroz (2006), como parte dessa linha de pesquisas do Departamento de Hidráulica e Sanitária da EPUSP.

A água residuária utilizada no sistema em bateladas seqüenciais diferiu do afluente aos sistemas piloto quanto às concentrações de cloreto de amônio utilizadas, tendo em vista que este experimento foi dividido em três etapas distintas: a primeira com o despejo contendo concentração de nitrogênio amoniacal de 200 mgN/L, a segunda com 300 mgN/L e a terceira com $500 \mathrm{mgN} / \mathrm{L}$. Os demais constituintes do despejo foram dosados nas mesmas concentrações utilizadas para os sistemas piloto.

Os experimentos foram realizados em reator em acrílico de dimensões 25 x 25 x $40 \mathrm{~cm}$ (volume útil 20 litros), dotado de agitador mecânico para homogeneização da massa líquida, além do uso de bomba peristáltica para o afluente, bomba com saída de ar acoplada a um rotâmetro para a regulagem da vazão de ar fornecida ao sistema para manutenção das concentrações de OD próximas a 1,0 $\mathrm{mgO}_{2} / \mathrm{L}$ na fase aerada do ciclo, timers para ajuste dos tempos de ciclo, aquecedor de imersão para manutenção da temperatura acima de $25^{\circ} \mathrm{C}$, controlador automático de $\mathrm{pH}$ associado a bomba dosadora de alcalinizante, medidor de oxigênio dissolvido e medidor de potencial redox (esse último utilizado a partir da segunda etapa do experimento). Entretanto, ao longo da pesquisa, observou-se muita imprecisão e problemas com o sensor de ORP, sendo que o mesmo se mostrou inadequado como parâmetro de controle operacional do sistema, em virtude de intensa atividade iônica do meio. 
As etapas do ciclo de tratamento do sistema foram: enchimento, anóxica, aerada, repouso e descarte. A duração das etapas do ciclo não foi pré-estabelecida, mas sim ajustada durante a pesquisa.

A etapa anóxica era realizada com alimentação e reação concomitante (adição gradual de afluente), visando evitar a ocorrência de cargas de choque de fenol. Vale observar que a etapa anóxica do ciclo iniciava com o nitrito presente no reator oriundo do ciclo anterior.

A seqüência cronológica das etapas subseqüentes manteve-se a mesma, independente da etapa da pesquisa: enchimento gradual com agitação e sem aeração - reator anóxico com agitação - aeração com agitação - sedimentação sem agitação e sem aeração descarte de 5 litros do sobrenadante através de sifonamento.

A ausência de sólidos em suspensão no afluente, em virtude da água residuária ser sintética, definiu os volumes utilizados: 5 litros de afluente e 15 litros de lodo biológico em todas etapas da pesquisa; pelo mesmo motivo, o único descarte de lodo realizado era aquele oriundo da realização das análises de laboratório. Esse procedimento também visou a manutenção de uma concentração de sólidos em suspensão voláteis no reator condizente com a necessidade de evitar cargas de choque de fenol.

A Figura 22 a seguir apresenta a seqüência das etapas do ciclo de tratamento.

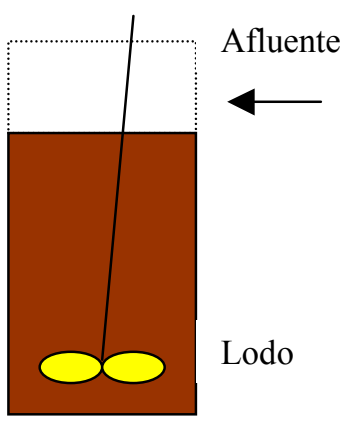

Enchimento com agitação

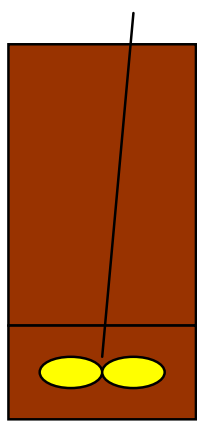

Anóxico

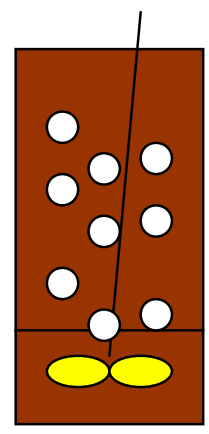

Aeração

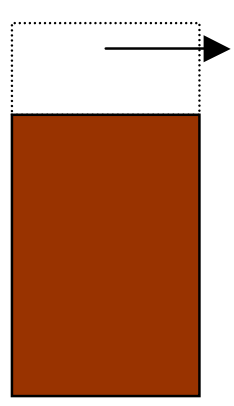

Sedimentação e descarte

Figura 22 - Seqüência cronológica das etapas do ciclo de tratamento do sistema em batelada 


\section{APRESENTAÇÃO E DISCUSSÃO DOS RESULTADOS}

A apresentação e discussão dos resultados serão feitas separadamente para os sistemas TOTAL e PARCIAL sendo que, para cada um dos dois sistemas, será feita divisão em duas fases distintas: a primeira fase com uma fração anóxica menor (39\% para o sistema TOTAL e 23\% para o PARCIAL) e a segunda, para uma fração anóxica maior (49\% para o sistema TOTAL e $41 \%$ para o PARCIAL). Por fim, serão apresentados os resultados obtidos com o sistema em batelada visando remoção de nitrogênio via nitrito.

Ressalta-se que, para o sistema TOTAL, ao invés da fração anóxica global que fora adotada, poderiam ser consideradas duas frações anóxicas, uma pré-anóxica e outra pós-anóxica, uma vez que estavam presentes duas diferentes fontes de carbono (interna e externa) para a desnitrificação. Entretanto, visando apresentar os resultados de forma mais didática, decidiu-se por utilizar a fração anóxica global do sistema, daí 39\% para a primeira fase e $49 \%$, para a segunda.

A primeira fase de operação dos sistemas contínuos foi mantida até o mês de abril de 2006 e, a segunda, de maio de 2006 até o término da operação dos sistemas, que ocorreu em janeiro de 2007.

A rigor, foi dada a partida nos sistemas piloto em outubro de 2004. Entretanto, como nesse período ocorreram diversos vazamentos com grandes perdas de biomassa e os resultados obtidos não terem sido satisfatórios, já que os sistemas ainda não contavam com a maioria dos equipamentos necessários, os resultados aqui apresentados referem-se somente à operação dos sistemas de setembro de 2005 a janeiro de 2007, sendo que os resultados anteriores a esse período foram desconsiderados.

Sendo assim, essa etapa preliminar, de outubro de 2004 a agosto de 2005, foi considerada como de adaptação da biomassa, que também durou muito mais tempo do que o previsto, muito provavelmente pela utilização de inóculo proveniente da indústria 
petroquímica que continha em sua composição ácido fólico para a redução na produção de lodo. Portanto, os resultados do monitoramento diário realizado nesse período preliminar serão apenas apresentados no Apêndice A.

Como mencionado anteriormente na metodologia, o monitoramento diário dos sistemas contou principalmente com a aferição de vazões, medição de $\mathrm{pH}$, temperatura e concentração de oxigênio dissolvido dos reatores.

Além dos parâmetros monitorados diariamente nos sistemas piloto, outros parâmetros como fenol, nitrogênio amoniacal, nitrito, nitrato, sólidos em suspensão totais e voláteis, $\mathrm{DQO}, \mathrm{DBO}$ e alcalinidade foram monitorados semanalmente.

Os parâmetros $\mathrm{DBO}$ e alcalinidade passaram a ser monitorados apenas no final do ano de 2005, quando os sistemas já se encontravam um pouco mais estabilizados, sendo que os demais foram monitorados desde o início dos experimentos.

No caso específico das análises de DQO realizadas pelo método do refluxo aberto (APHA; AWWA; WEF, 1998), apesar desse parâmetro ter sido monitorado desde o início dos trabalhos, seus resultados serão desprezados, tendo em vista a quantidade de interferentes analíticos que prejudicaram demasiadamente as análises e os resultados obtidos foram muito discrepantes da realidade.

A interferência de íons livres da família dos halogênios sofrendo oxidação e criando valores de DQO artificialmente superiores é reportada na literatura (APHA; AWWA; WEF, 1998). Normalmente, essa interferência é causada pela presença de íons cloreto e minimizada com sucesso pela adição de sulfato de mercúrio antes da etapa de digestão. Entretanto, a presença concomitante de amônia e íons cloreto torna ineficaz a adição de sulfato de mercúrio, resultando em valores de DQO superiores aos efetivamente presentes nas amostras (KIM, 1989). Outro fator de desvio nessas determinações é a excessiva concentração 
de nitrito no meio líquido, nem sempre minimizada pela adição de ácido sulfâmico, conforme sugerido pela literatura (APHA; AWWA; WEF, 1998; SU; LIU; CHANG, 2001).

Dessa forma, foram obtidas relações $\mathrm{DQO} /$ fenol muitas vezes superiores aos valores reportados na literatura, da ordem de 2,5 mg DQO/mg fenol (ALEM SOBRINHO; GARCIA, 1983; DOMBROSKI, 2003; SARFARAZ et al., 2004). Das fases da pesquisa efetivamente consideradas nos resultados, desprezando-se as etapas de aclimatação e perda de lodo por vazamentos, pode-se dizer que foram feitas 60 coletas por ponto de amostragem, sendo que os resultados obtidos para o afluente foram os que mais se aproximaram da relação $\mathrm{DQO} /$ fenol de 2,5 e que, para os demais pontos amostrados, essa relação foi extremamente superior a esse valor, podendo ser desprezados em termos de resultados, em virtude dos erros analíticos já mencionados. Assim, para o afluente, das 60 amostras analisadas, 36\% apresentaram a relação DQO/fenol menor do que 3,0;16\% foram superiores a 5,0 e o restante, ou seja, $48 \%$ apresentaram essa relação entre 3,0 e 5,0.

Sendo assim, apenas a título informativo, a Tabela B.1 apresentada no Apêndice B ilustra os resultados da DQO ao longo de todo o experimento para o sistema TOTAL e a Tabela B.2, para o PARCIAL.

Como já mencionado, os sistemas foram operados com idade do lodo elevada, bem superior a 100 dias, tendo em vista que não foi possível a realização de descarte programado de lodo. A taxa de reprodução dos microrganismos era muito lenta, o que inviabilizou retiradas de biomassa do sistema, além daquelas previstas nas coletas de amostras.

As condições operacionais utilizadas durante toda a operação dos sistemas de lodo ativado são apresentadas na Tabela 4.

Os resultados do monitoramento diário e semanal realizado nos sistemas piloto TOTAL e PARCIAL são apresentados nos Apêndices C, D, E e F. 
Tabela 4 - Condições operacionais utilizadas durante toda a operação das ETE piloto

\begin{tabular}{|c|c|c|c|c|c|c|c|c|c|c|c|c|c|c|c|c|c|}
\hline & \multicolumn{8}{|c|}{$1^{\mathrm{a}}$ Fase } & \multicolumn{9}{|c|}{$2^{\mathrm{a}}$ Fase } \\
\hline & set/05 & out/05 & nov/05 & dez/05 & jan/06 & fev/06 & mar/06 & abr/06 & mai/06 & jun/06 & jul/06 & ago/06 & set/06 & out/06 & nov/06 & $\mathrm{dez} / 06$ & $\mathrm{jan} / 07$ \\
\hline SISTEMA TOTAL & & & & & & & & & & & & & & & & & \\
\hline Fração anóxica & $39 \%$ & $39 \%$ & $39 \%$ & $39 \%$ & $39 \%$ & $39 \%$ & $39 \%$ & $39 \%$ & $49 \%$ & $49 \%$ & $49 \%$ & $49 \%$ & $49 \%$ & $49 \%$ & $49 \%$ & $49 \%$ & $49 \%$ \\
\hline Razão de retorno de lodo $\left(^{\star}\right)$ & 4,0 & 4,0 & 4,0 & 4,0 & 4,0 & 4,0 & 4,0 & 4,0 & 4,0 & 5,0 & 4,0 & 2,0 & 2,0 & 5,0 & 5,0 & 4,0 & 3,0 \\
\hline Razão de reciclo interno $\left({ }^{*}\right)$ & - & - & - & 2,0 & 4,0 & 4,0 & 4,0 & 8,0 & 4,0 & 3,0 & 3,0 & 4,0 & 4,0 & 4,0 & 7,0 & 6,0 & 7,0 \\
\hline $\mathrm{pH}$ do reator aeróbio & $\cong 7,0$ & $\cong 8,0$ & $\cong 7,0$ & $\cong 7,0$ & $\cong 7,0$ & $\cong 7,0$ & $\cong 8,3$ & $\cong 8,0$ & $\cong 6,5$ & $\cong 7,0$ & $\cong 7,0$ & $\cong 7,0$ & $\cong 7,0$ & $\cong 7,0$ & $\cong 6,5$ & $\cong 7,0$ & $\cong 7,0$ \\
\hline OD do reator aeróbio (mg/L) & $>3,0$ & $>3,0$ & $>3,0$ & $>2,0$ & $>2,0$ & $>2,0$ & $>3,0$ & $>3,0$ & $>2,0$ & $>3,0$ & $>3,0$ & $>3,0$ & $>1,0$ & $>1,0$ & $>1,0$ & $>0,5$ & $>0,5$ \\
\hline Dosagem de etanol $(\star \star)$ & & & & $X X X X X$ & & $x$ & $x$ & & & & $x$ & $x$ & $x x$ & $x x$ & & & \\
\hline SISTEMA PARCIAL & & & & & & & & & & & & & & & & & \\
\hline Fração anóxica & $23 \%$ & $23 \%$ & $23 \%$ & $23 \%$ & $23 \%$ & $23 \%$ & $23 \%$ & $23 \%$ & $41 \%$ & $41 \%$ & $41 \%$ & $41 \%$ & $41 \%$ & $41 \%$ & $41 \%$ & $41 \%$ & $41 \%$ \\
\hline Razão de retorno de lodo $\left(^{(\star \star}\right)$ & 4,0.Qa & 4,0.Qa & 3,5.Qa & 3,5.Qa & 6,5.Qa & 8,0 Qa & $5,0 \mathrm{Qa}$ & $5,0 . \mathrm{Qa}$ & 6,0.Qa & $8,0 . Q a$ & 8,0.Qa & $5,0 . Q a$ & $5,0 . \mathrm{Qa}$ & $5,0 . \mathrm{Qa}$ & $5,5 . \mathrm{Qa}$ & 4,0.Qa & 3,0.Qa \\
\hline Razão de reciclo interno $\left(^{(\star \star}\right)$ & - & - & - & - & - & - & - & - & - & - & - & - & - & - & - & $6,0 . \mathrm{Qa}$ & 8,0.Qa \\
\hline $\mathrm{pH}$ do reator aeróbio & $\cong 8,0$ & $\cong 8,0$ & $\cong 8,3$ & $\cong 8,3$ & $\cong 8,3$ & $\cong 8,3$ & $\cong 8,3$ & $\cong 8,3$ & $\cong 8,3$ & $\cong 8,0$ & $\cong 8,0$ & $\cong 8,0$ & $5,5-6,0$ & $5,5-6,0$ & $\cong 8,3$ & $\cong 8,3$ & $\cong 8,3$ \\
\hline OD do reator aeróbio (mg/L) & $0-5,0$ & $<1,5$ & $<0,5$ & $<0,5$ & $>2,0$ & $>3,0$ & $>3,0$ & $>3,0$ & $>1,5$ & $>2,0$ & $<2,0$ & $<2,0$ & $<2,0$ & $<1,5$ & $<1,0$ & $<0,5$ & $<0,5$ \\
\hline
\end{tabular}

Obs:

$\left.{ }^{\star}{ }^{\star}\right)$ A vazão de recirculação de lodo foi sendo alterada quando era observado considerável acúmulo de fenol no reator anóxico pré-D. Em virtude de limitação da bomba de retorno de lodo, logo nos primeiros meses de operação, instalou-se a bomba de reciclo do aeróbio para o anóxico pré-D. A diminuição de vazão de retorno em ago/set 2006 deveu-se a problemas na bomba de retorno de lodo do decantador.

$\left.{ }^{* \star}\right)$ Datas em que o etanol foi dosado no reator anóxico pós-D e indicação de proporção de sua dosagem.

$\left.{ }^{\star \star \star \star}\right)$ No início da operação do sistema Parcial, tentou-se utilizar razão de recirculação de lodo da ordem de 3 a 4 vezes a vazão afluente. Como em nov/dez 2005 observou-se grande acúmulo de fenol no reator anóxico,

procedeu-se substancial aumento no retorno de lodo e assim sucessivamente, até ser instalada bomba de reciclo interno no final de nov/2006 por limitação da bomba de retorno do decantador. 


\subsection{Sistema TOTAL}

\subsubsection{Primeira Fase - Fração Anóxica de 39\%}

Na primeira fase da pesquisa, o sistema TOTAL apresentava uma fração anóxica de $39 \%$, ou seja, o reator anóxico pré-D possuía volume útil de aproximadamente 30 litros, o aeróbio de 100 litros e o reator anóxico pós-D de 70 litros.

Nessa fase, o sistema TOTAL trabalhou com tempo de detenção hidráulico total que variou de 14 a 23 dias; o tempo de detenção do anóxico pré-D esteve entre 2 e 4 dias e o do aeróbio, entre 7 e 12 dias.

Como mencionado anteriormente, a primeira fase dos experimentos teve seu término no final de abril de 2006.

\subsubsection{Monitoramento Diário do Sistema TOTAL na Primeira Fase}

As Figuras 23, 24 e 25 apresentam o comportamento do $\mathrm{pH}$, da temperatura e da concentração de OD dos reatores do Sistema TOTAL ao longo da primeira fase da pesquisa.

As setas pretas na parte superior dos gráficos indicam a taxa de recirculação de lodo total (retorno de lodo do decantador mais reciclo do aeróbio para o anóxico pré-D) utilizada.

As setas vermelhas representam os períodos nos quais o etanol foi dosado no reator pós-D. A seta mais espessa indica a data em que o etanol foi dosado de maneira estequiométrica; entretanto, como ocorreu desequilíbrio do sistema com grande acúmulo de fenol no reator pré-D, na segunda tentativa, decidiu-se por dosar o etanol em quantidades 
inferiores a $5 \%$ do que havia sido aplicado na primeira vez, de modo a evitar cargas de choque no sistema.

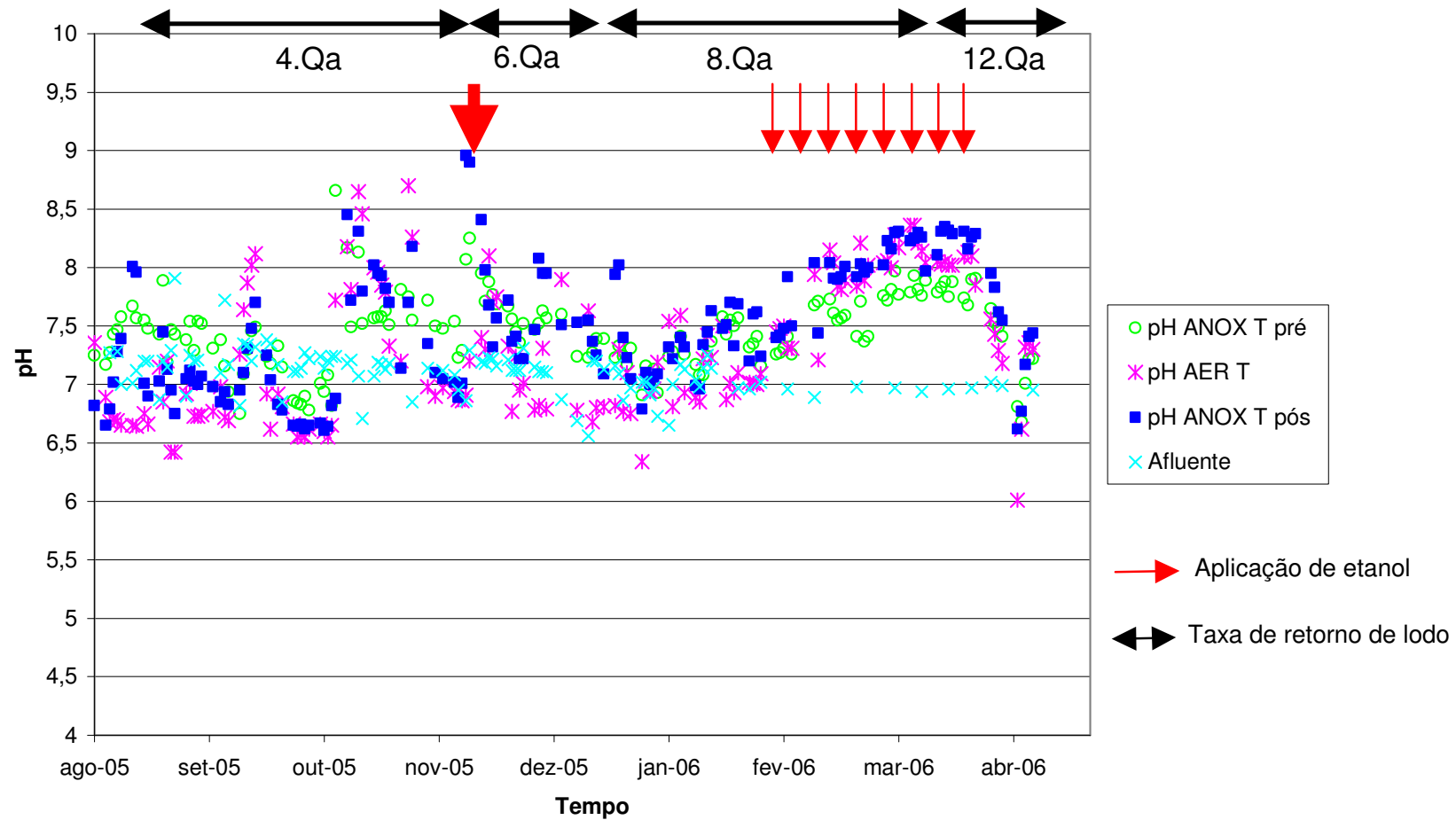

Figura 23 - Variação do pH do Sistema TOTAL (T) ao longo da primeira fase da pesquisa, com fração anóxica de $39 \%$.

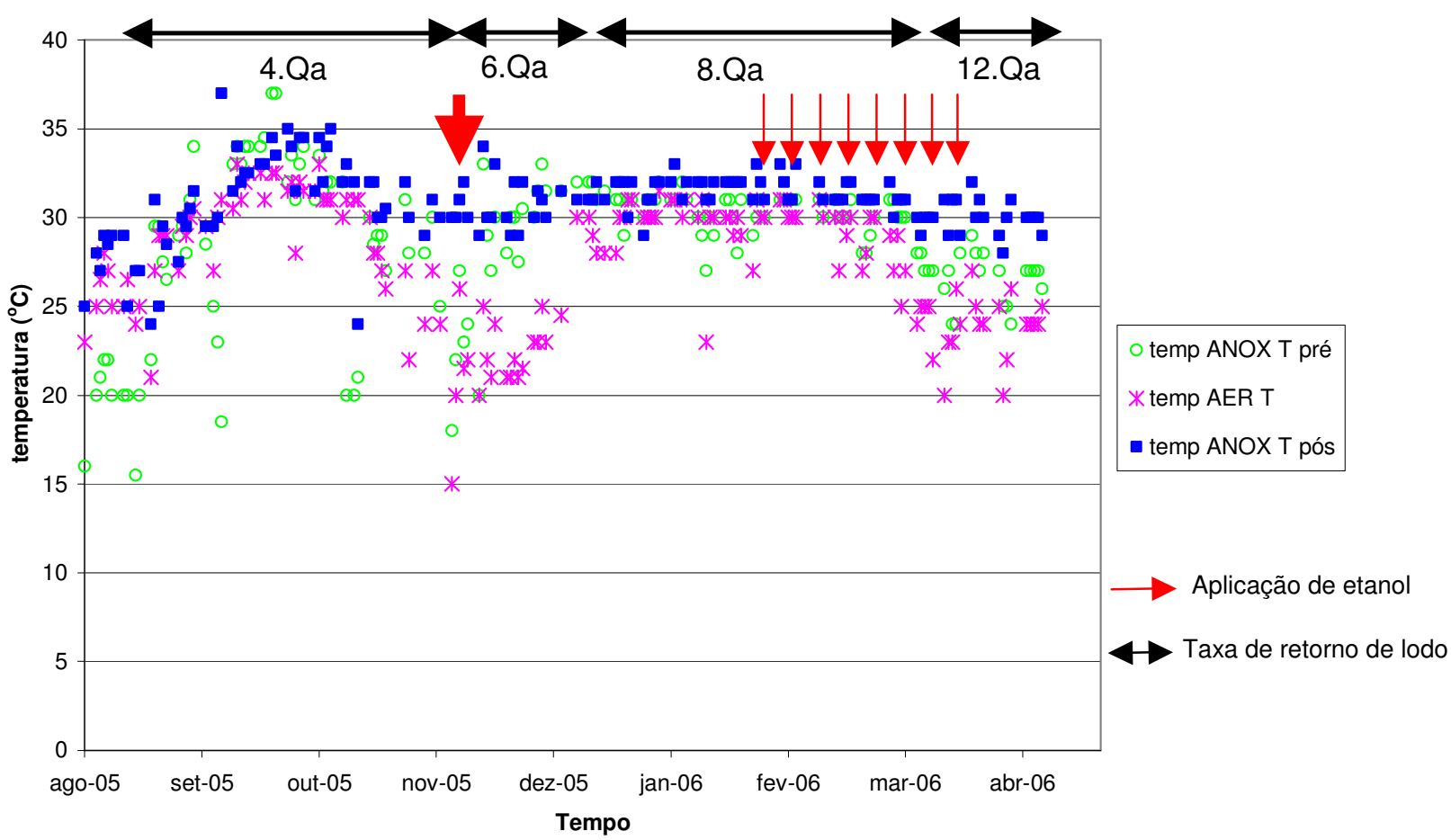

Figura 24 - Variação da temperatura do Sistema TOTAL (T) ao longo da primeira fase da pesquisa, com fração anóxica de $39 \%$. 


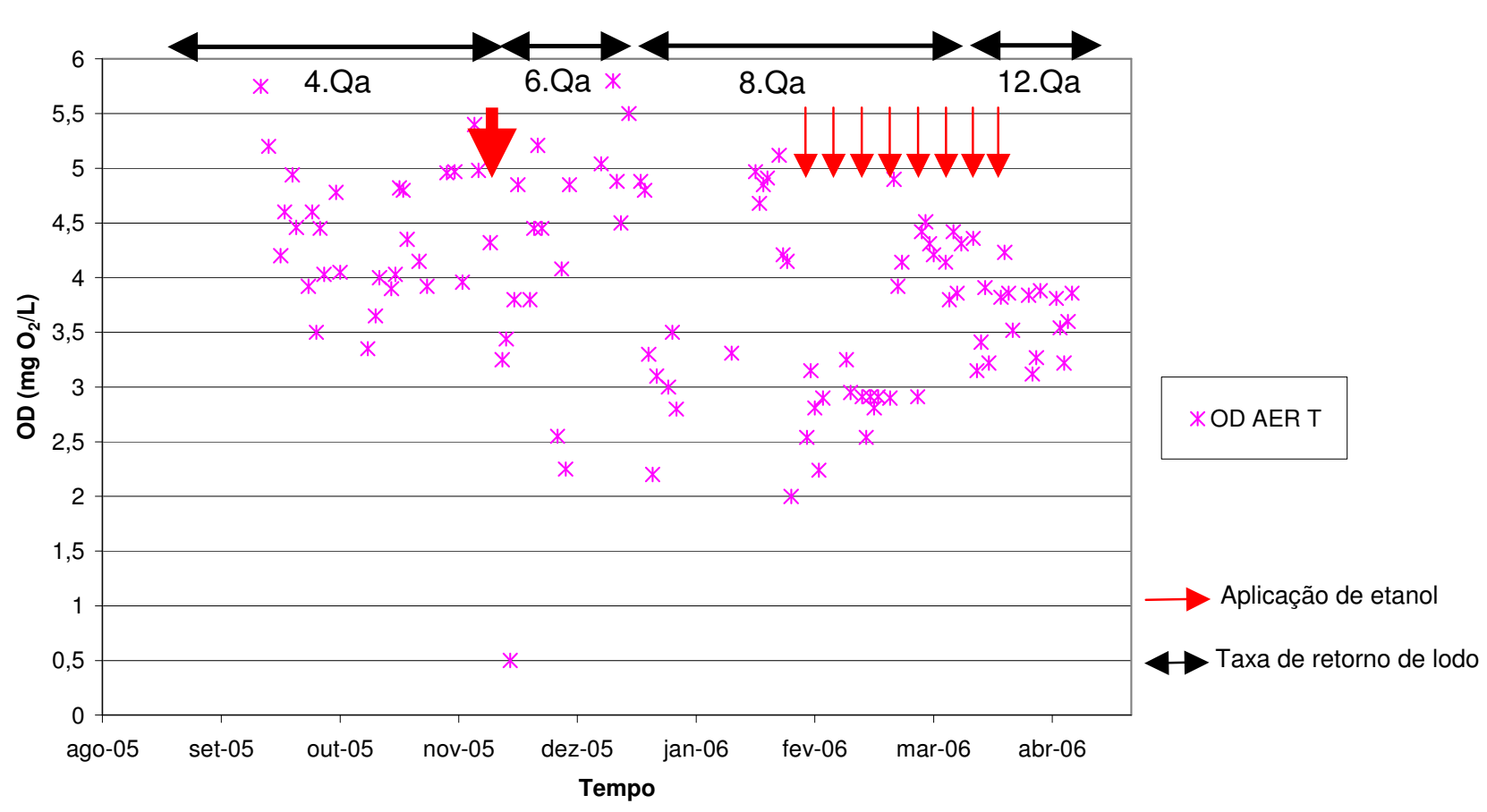

Figura 25 - Variação da concentração de OD do reator aeróbio do Sistema TOTAL (T) ao longo da primeira fase da pesquisa, com fração anóxica de $39 \%$.

Da Figura 23, pode-se observar que, nessa fase da pesquisa, o $\mathrm{pH}$ oscilou em todos os reatores principalmente entre 6,5 e 8,0 (inclusive no afluente), faixa essa já esperada, principalmente em virtude de haver controle automático de $\mathrm{pH}$ no reator aeróbio. Como já era previsto, o reator anóxico de pré-desnitrificação apresentou valores um pouco acima dos do aeróbio. Entretanto, no anóxico de pós-desnitrificação, os valores de $\mathrm{pH}$ foram maiores que os do aeróbio principalmente quando o etanol foi dosado nesse reator. Quando era cessada a alimentação de etanol em virtude de anomalias no processo, o $\mathrm{pH}$ ficava praticamente equivalente ao do aeróbio, sendo um indício de que a desnitrificação sem fonte externa de carbono só poderia mesmo ocorrer com taxas muito baixas.

Alguns valores de $\mathrm{pH}$ acima de 8,0 e abaixo de 6,5 ocorreram pontualmente em virtude de problemas operacionais como falta de ar ou falta de energia elétrica.

A Figura 24 apresentou o comportamento da temperatura dos reatores ao longo da primeira fase da pesquisa no Sistema TOTAL. Importante notar que ela oscilou entre 20 e 
$35^{\circ} \mathrm{C}$, faixa esta bastante ampla pois nem mesmo o uso de termostatos/aquecedores foi capaz de mantê-la em aproximadamente $25^{\circ} \mathrm{C}$. As temperaturas inferiores a $20^{\circ} \mathrm{C}$ ocorreram pontualmente quando os termostatos queimaram deixando o reator sem aquecimento, o que foi bastante prejudicial pois abaixo de $20^{\circ} \mathrm{C}$ a nitrificação fica inibida.

Em termos de oxigênio dissolvido, de um modo geral, o sistema esteve estável, com concentrações no reator aeróbio que variaram entre 2,0 e 5,0 $\mathrm{mgO}_{2} / \mathrm{L}$, faixa bastante favorável à nitrificação, ao passo que os anóxicos apresentaram concentrações praticamente desprezíveis, o que já era de se esperar, e portanto não foram representados na Figura 25.

\subsubsection{Monitoramento Semanal do Sistema TOTAL na Primeira Fase}

Uma das principais determinações analisadas semanalmente foram as concentrações de sólidos em suspensão totais e voláteis dos sistemas.

A Figura 26 ilustra as concentrações de SST e SSV do sistema TOTAL ao longo da primeira fase da pesquisa. De maneira geral, as concentrações observadas nos reatores anóxicos e no aeróbio oscilaram pouco, porém estiveram na maioria das vezes acima de $1.500 \mathrm{mg} / \mathrm{L}$, conforme indicado por Da Costa (1999) e Dombroski (2003). No caso do decantador, algumas semanas apresentaram concentrações um pouco elevadas de sólidos, porém não chegando a prejudicar tanto o sistema com perda de biomassa pelo efluente.

Já a Figura 27 apresenta o comportamento da alcalinidade do sistema TOTAL ao longo da primeira fase da pesquisa. 


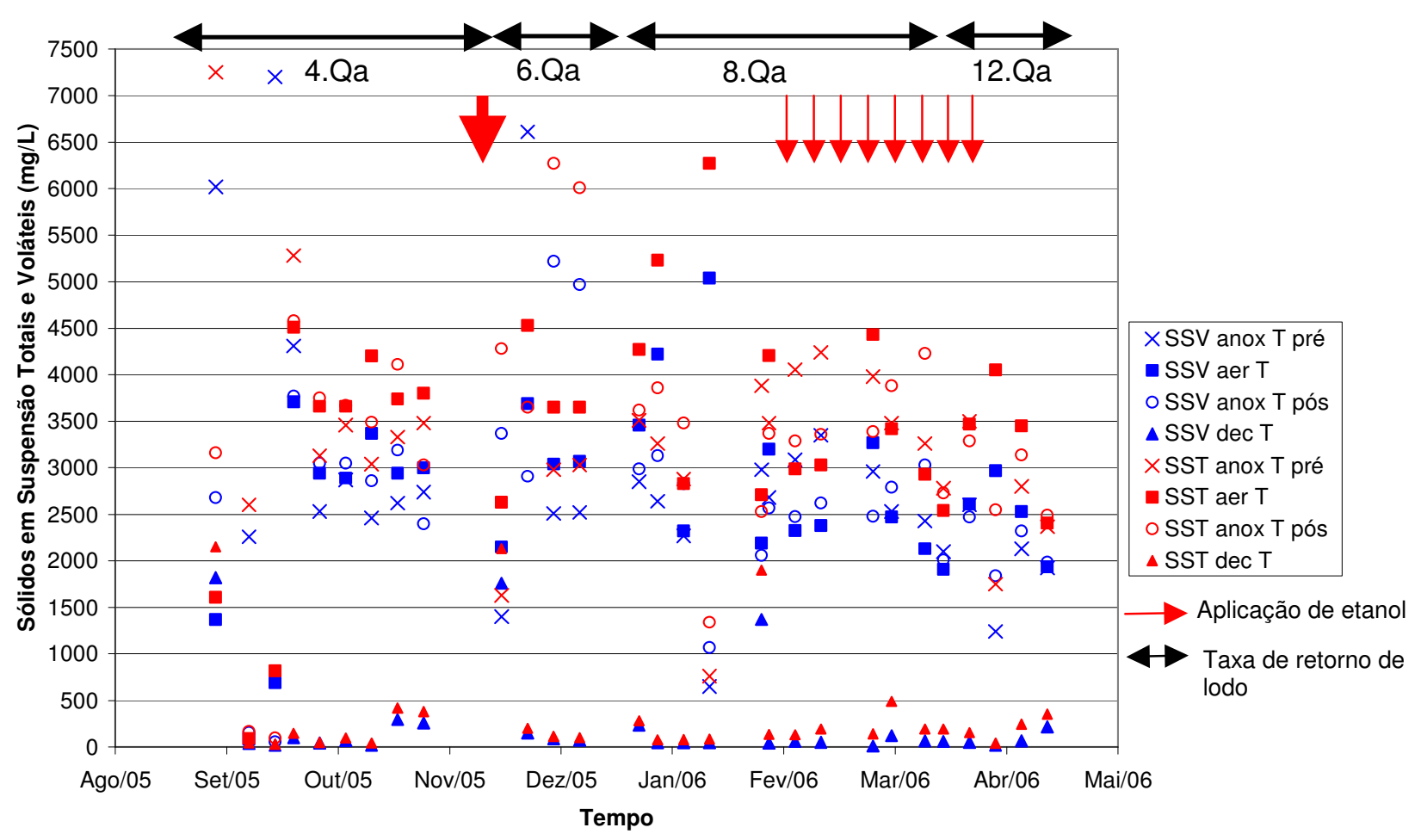

Figura 26 - Concentração de sólidos em suspensão totais e voláteis do Sistema TOTAL (T) ao longo da primeira fase da pesquisa, com fração anóxica de $39 \%$.

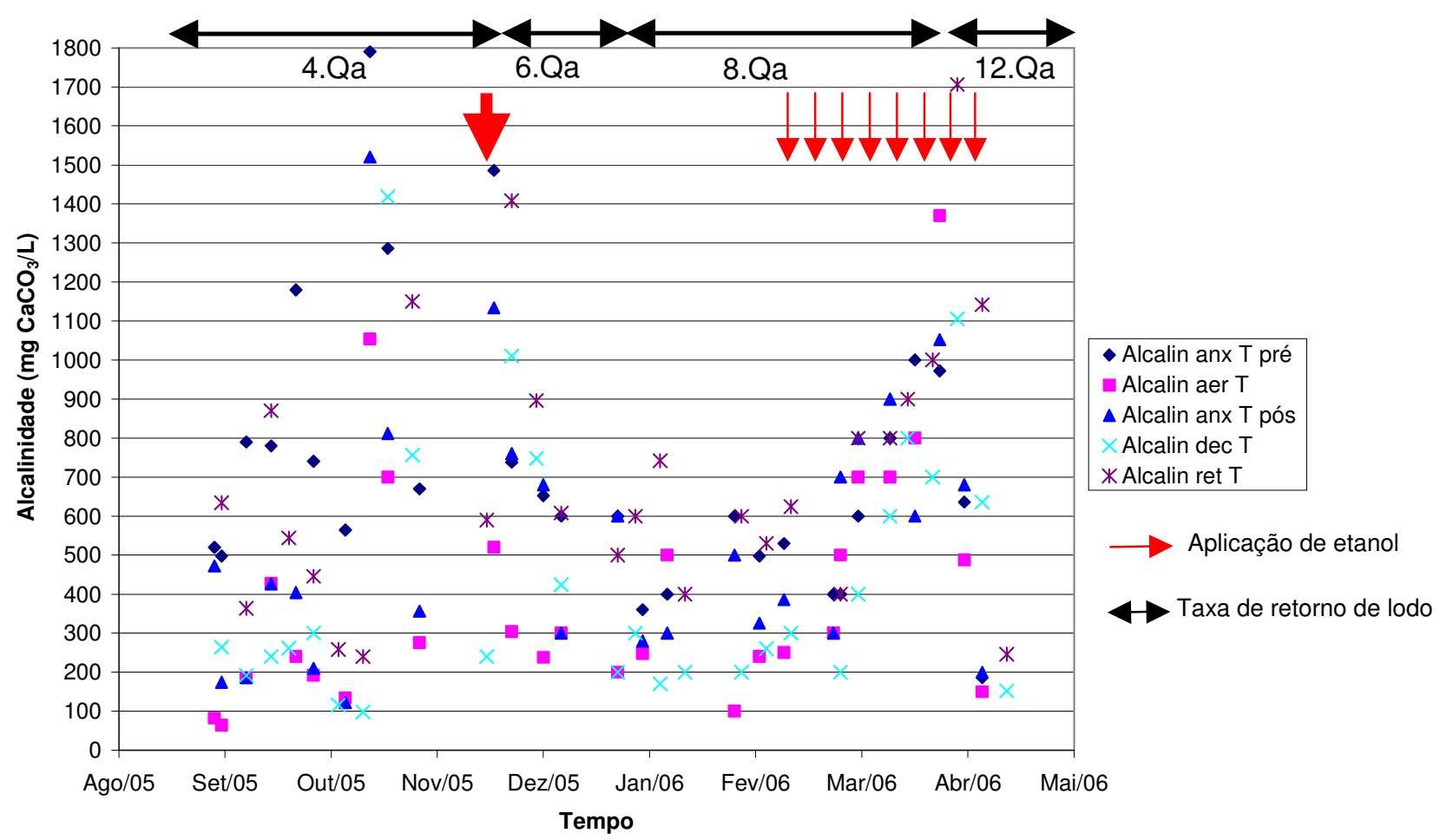

Figura 27 - Alcalinidade observada nas unidades do Sistema TOTAL (T) ao longo da primeira fase da pesquisa, com fração anóxica de $39 \%$. 
A Figura 27 mostra que a alcalinidade observada nas unidades do sistema TOTAL oscilou muito na primeira fase da pesquisa, ora com valores extremamente elevados $\left(>1500 \mathrm{mg} \mathrm{CaCO}_{3} / \mathrm{L}\right)$, ora com valores bem baixos $(<100 \mathrm{mg} \mathrm{CaCO} / \mathrm{L})$.

O monitoramento dos compostos nitrogenados do sistema TOTAL durante a primeira fase é apresentado nas Figuras 28 e 29. A Figura 30 ilustra as eficiências de remoção de nitrogênio amoniacal no reator aeróbio e no sistema como um todo.

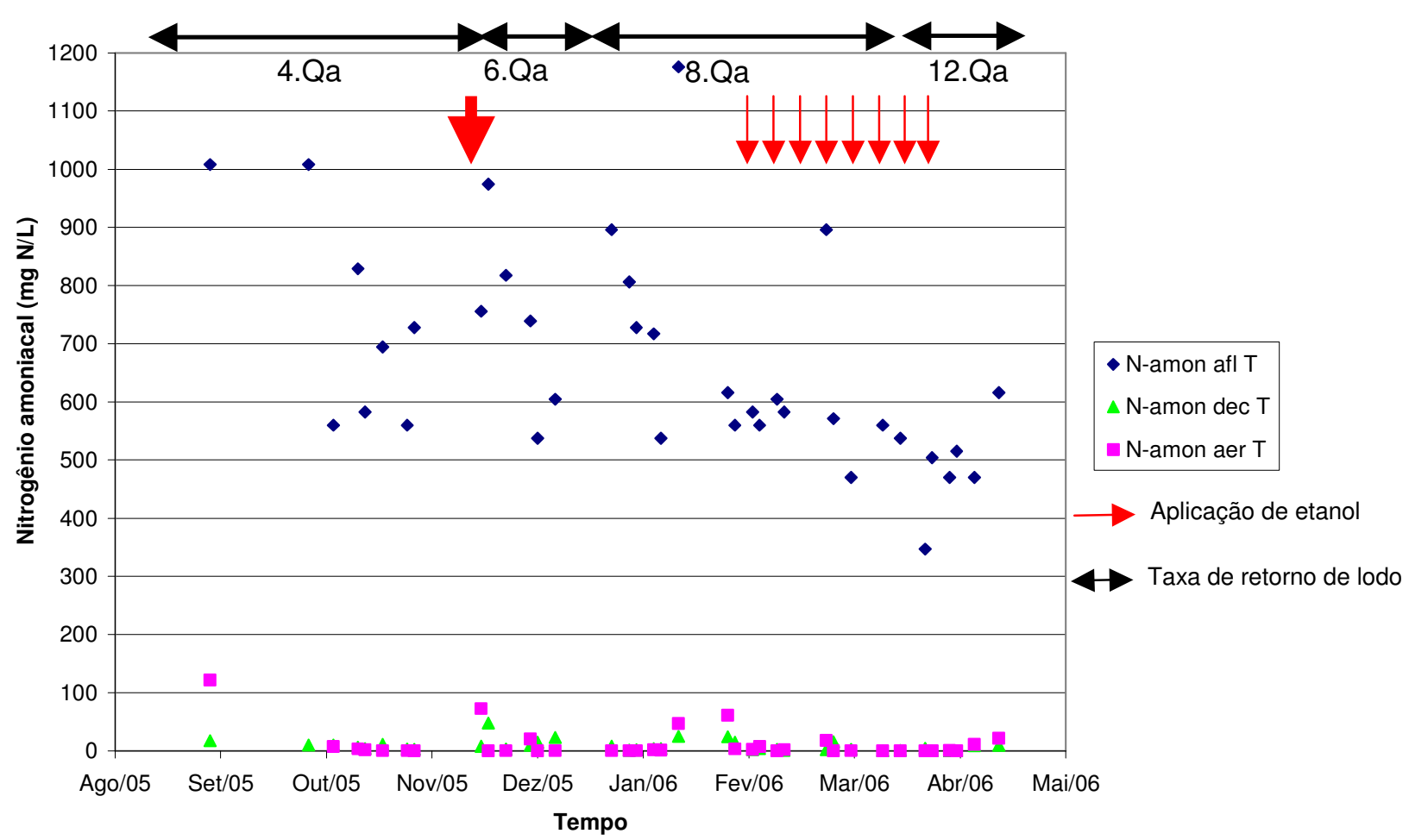

Figura 28 - Comportamento do nitrogênio amoniacal do Sistema TOTAL (T) ao longo da primeira fase da pesquisa, com fração anóxica de $39 \%$. 


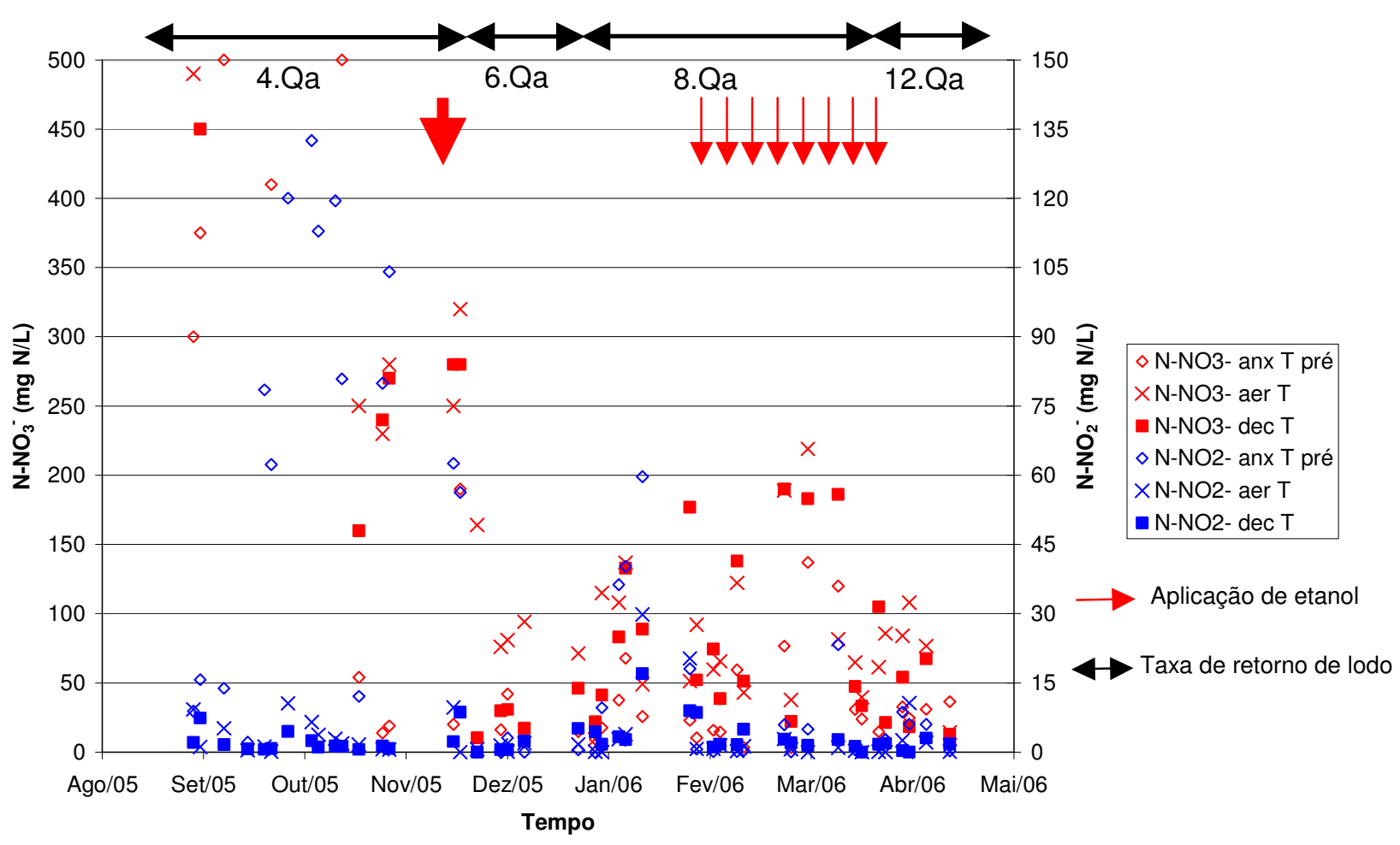

Figura 29 - Comportamento do nitrito e nitrato do Sistema TOTAL (T) ao longo da primeira fase da pesquisa, com fração anóxica de $39 \%$.

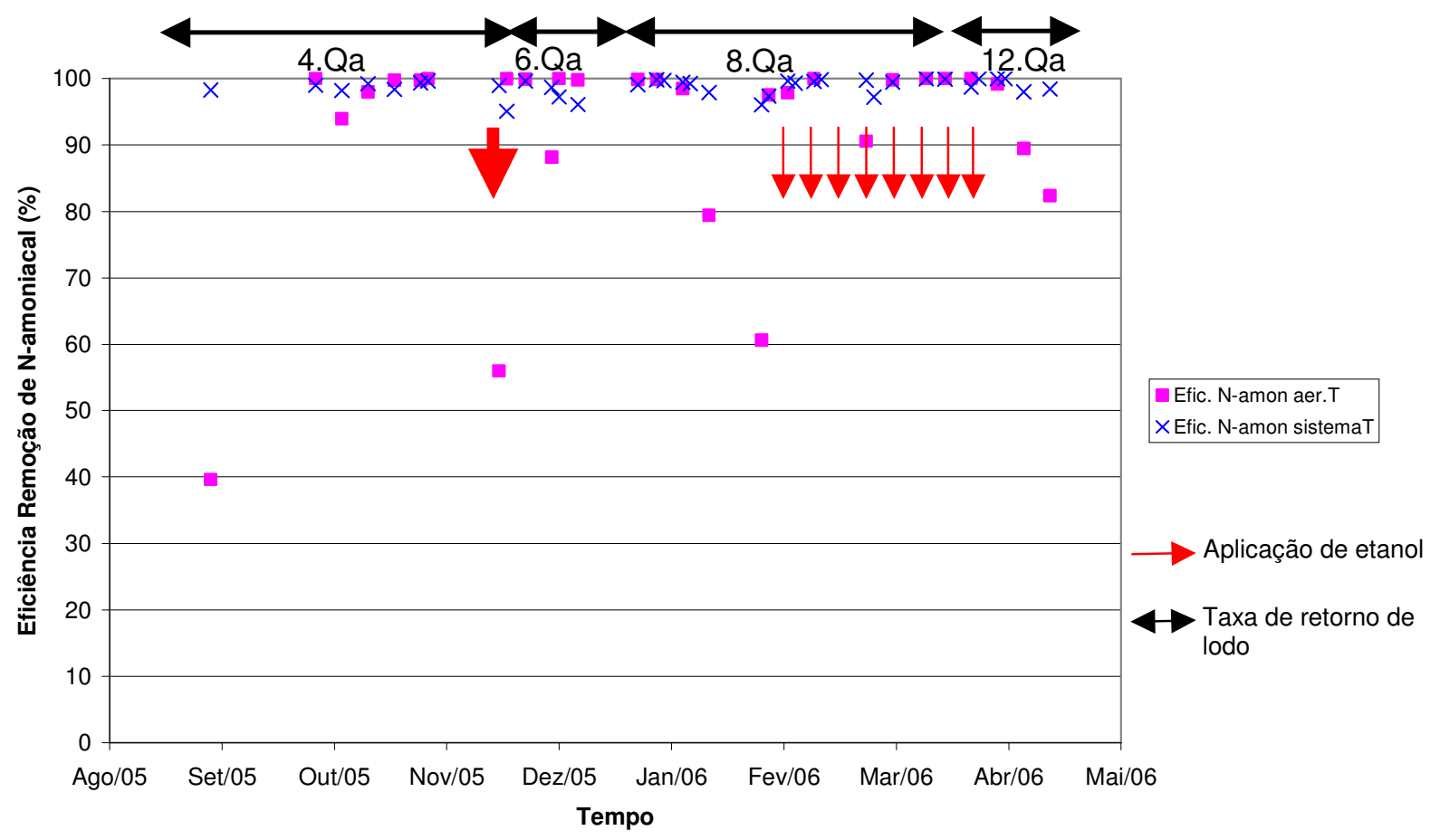

Figura 30 - Eficiência de remoção de nitrogênio amoniacal no reator aeróbio e no sistema ao longo da primeira fase da pesquisa para o Sistema TOTAL (T), com fração anóxica de $39 \%$. 
No início da pesquisa, utilizou-se concentração afluente de nitrogênio amoniacal de $750 \mathrm{mgN} / \mathrm{L}$, visando utilizar água residuária semelhante à do experimento de Da Costa (1999) e Dombroski (2003), o que foi alterado para $500 \mathrm{mgN} / \mathrm{L}$ no decorrer da pesquisa, tendo em vista que as coquerias de hoje não mais apresentam concentrações tão elevadas em seus despejos, já que as mesmas removem amônia com melhor eficiência em unidades anteriores ao tratamento biológico propriamente dito.

Note-se que, quanto às concentrações de nitrogênio amoniacal no efluente final, essas estiveram quase sempre abaixo dos $20 \mathrm{mgN} / \mathrm{L}$ estipulados pela Legislação CONAMA 357/05 (vide análise estatística na Figura 31 a seguir, essa apenas apresentada para os períodos com concentração afluente de nitrogênio amoniacal de aproximadamente $500 \mathrm{mgN} / \mathrm{L})$.

Mesmo se obtendo uma boa eficiência de remoção de nitrogênio amoniacal no sistema (Figura 30), observa-se que no reator aeróbio nem sempre foram observadas eficiências tão elevadas. Excetuando-se a baixa eficiência de remoção no reator aeróbio, ocorrida em novembro/dezembro de 2005, quando foi feita dosagem estequiométrica de etanol no reator anóxico pós-D desequilibrando o sistema, os demais valores baixos observados para o aeróbio devem-se ao fato de que boa parcela das amostras analisadas no período apresentou concentrações de nitrogênio amoniacal no aeróbio bem mais elevadas (principalmente da ordem de 2 a 3 vezes) do que o decantador do sistema TOTAL. Supõe-se que nesses casos possa ter ocorrido nitrificação de parte do nitrogênio não oxidado na reaeração do reator anóxico de pós-desnitrificação.

Quanto aos compostos oxidados de nitrogênio, a predominância do nitrato sobre o nitrito é visível e já esperada (vide análise estatística desses parâmetros na Figura 32, também apenas apresentada para os períodos com concentração de nitrogênio amoniacal afluente de $500 \mathrm{mgN} / \mathrm{L}$ ), sendo que se observa que, na segunda metade dessa fase, essas concentrações 
foram menores do que no início da operação em virtude da redução da concentração de nitrogênio amoniacal do afluente de $750 \mathrm{mgN} / \mathrm{L}$ para $500 \mathrm{mgN} / \mathrm{L}$, conforme já mencionado.

Também se observa que ocorreu considerável acúmulo de nitrito no reator anóxico pré-D quando as concentrações afluentes de nitrogênio amoniacal eram mais elevadas. Como esse acúmulo não foi observado nos demais reatores, pode-se concluir que nesse período ocorreu desnitrificação incompleta do nitrato a nitrito, e não a nitrogênio gasoso, como era desejado.

A taxa de desnitrificação obtida na primeira fase dos experimentos para o sistema TOTAL no reator anóxico pré-D esteve entre 0,01 a $0,03 \mathrm{~kg}$ N-NO $/ \mathrm{kg}$ SSV.dia, porém se observando alguns picos pontuais da ordem de $0,06 \mathrm{~kg} \mathrm{~N}-\mathrm{NO}_{\mathrm{x}} / \mathrm{kg} \mathrm{SSV}$.dia. No reator anóxico pós-D, as taxas observadas praticamente não excederam $0,02 \mathrm{~kg} \mathrm{~N}-\mathrm{NO}_{\mathrm{x}} / \mathrm{kg} \mathrm{SSV}$.dia, na maioria das vezes estando em $0,01 \mathrm{~kg} \mathrm{~N}-\mathrm{NO}_{\mathrm{x}} / \mathrm{kg} \mathrm{SSV}$.dia.

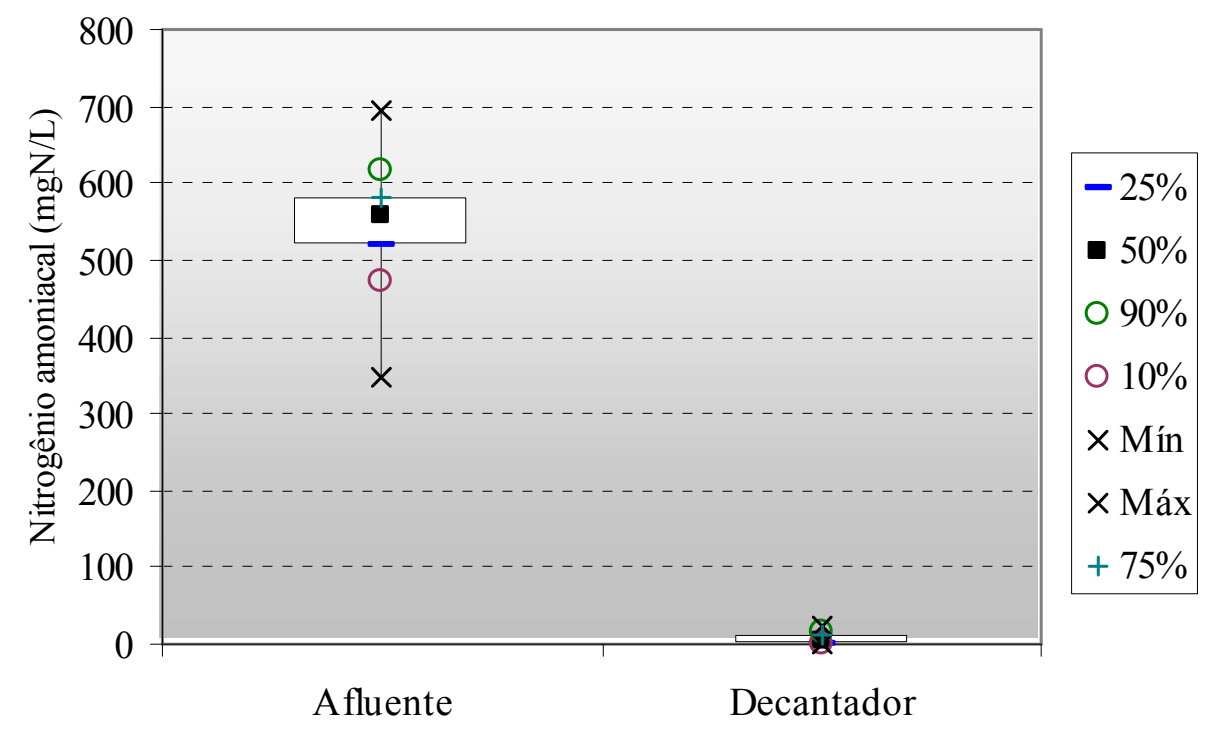

Figura 31 - Análise estatística de nitrogênio amoniacal do afluente e decantador do Sistema TOTAL (T), com concentração afluente da ordem de $500 \mathrm{mg} \mathrm{N} / \mathrm{L}$, durante a primeira fase da pesquisa, com fração anóxica de $39 \%$. 


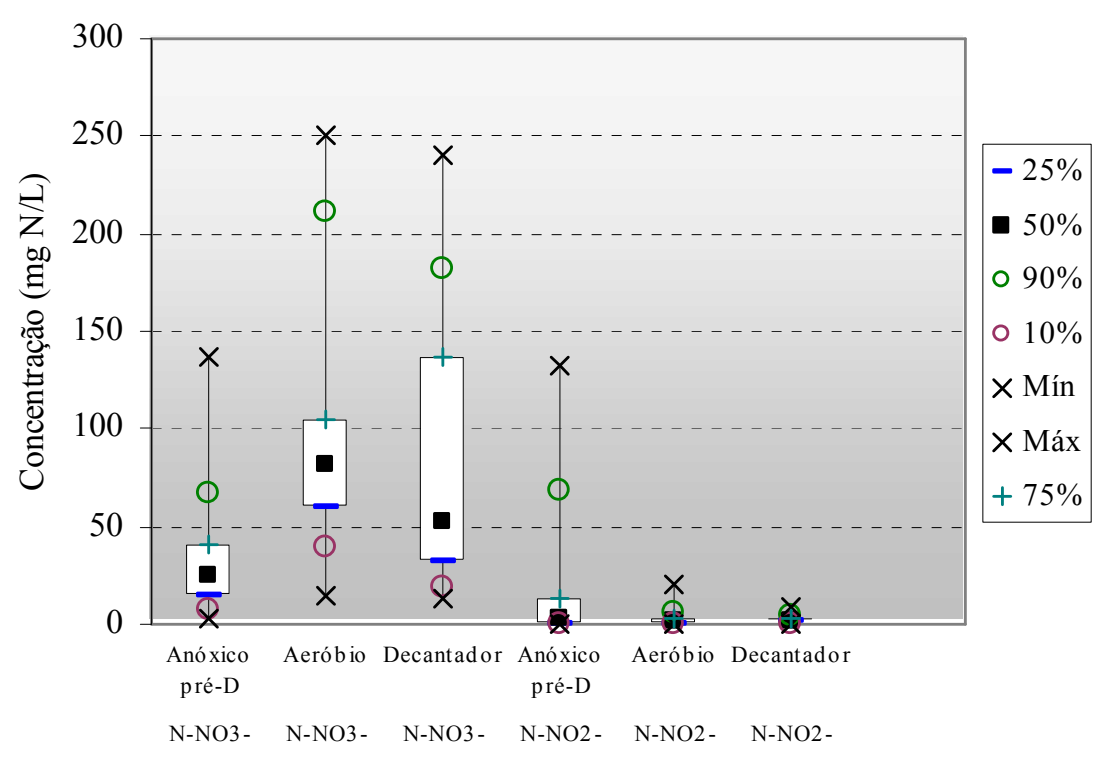

Figura 32 - Análise estatística dos compostos oxidados de nitrogênio do Sistema TOTAL (T), com concentração afluente de nitrogênio amoniacal da ordem de $500 \mathrm{mgN} / \mathrm{L}$, durante a primeira fase da pesquisa, com fração anóxica de $39 \%$.

O gráfico da Figura 33 apresenta o comportamento da DBO do sistema TOTAL ao longo da primeira fase dos trabalhos. Importante observar que são poucos os resultados disponíveis tendo em vista que essa análise foi feita apenas uma vez por semana e só passou a ser realizada a partir do mês de dezembro de 2005, como já mencionado na parte introdutória do presente capítulo.

Observa-se que, apesar da grande discrepância dos valores obtidos para a DBO do afluente, principalmente em virtude da imprecisão dessa análise, ainda assim os resultados foram bastante satisfatórios para esse parâmetro. Isso porque, mesmo quando os valores obtidos para as amostras do decantador/efluente final foram superiores a $60 \mathrm{mgO} / \mathrm{L}$, ainda assim a eficiência de remoção de DBO foi sempre maior do que os $80 \%$ exigidos pela Legislação (SÃO PAULO, 1976). 


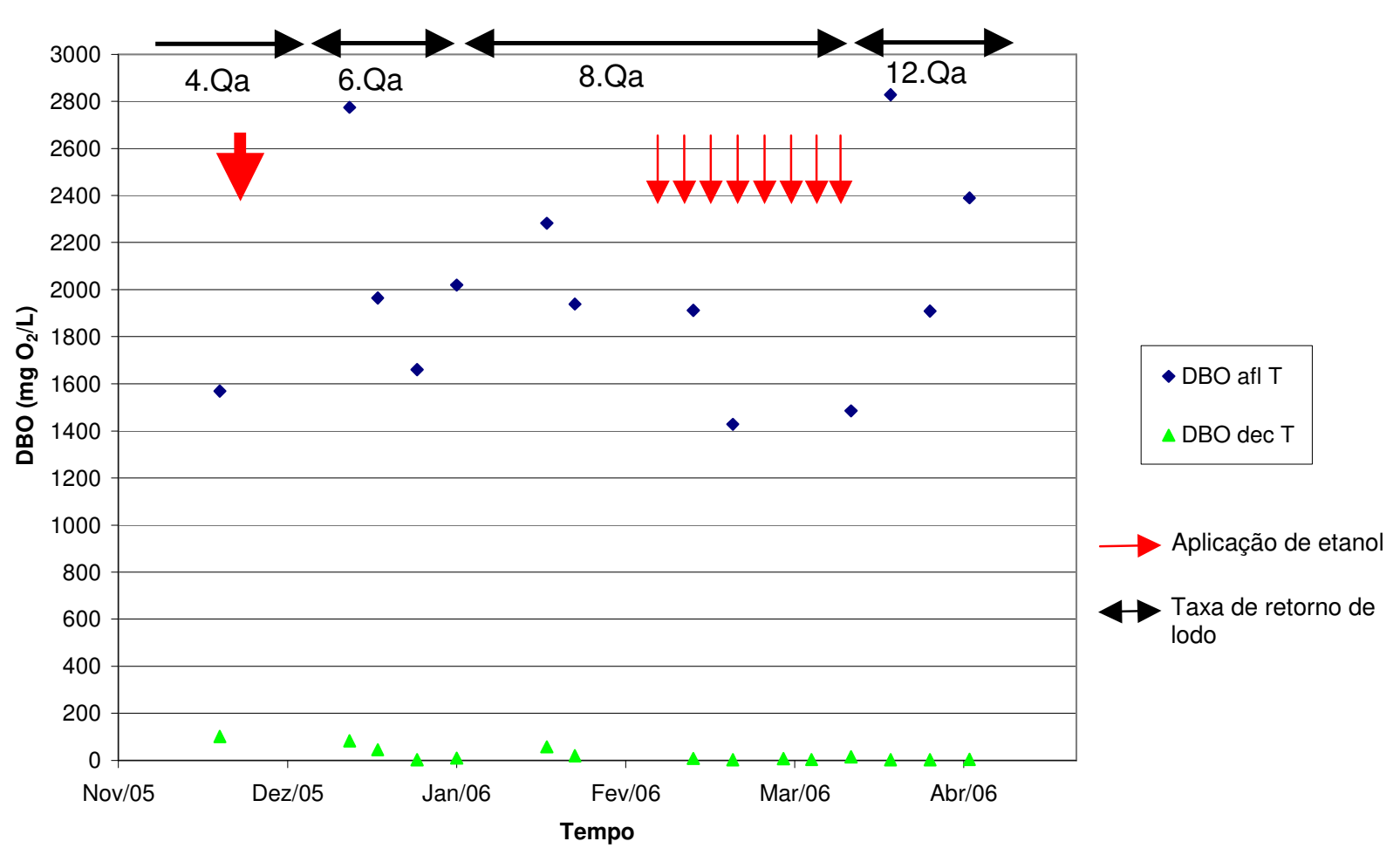

Figura 33 - Comportamento da DBO do Sistema TOTAL (T) ao longo da primeira fase da pesquisa, com fração anóxica de $39 \%$.

A Figura 34 ilustra o comportamento do fenol no sistema TOTAL e a Figura 35, a relação A/M (alimento/microrganismo) aplicada e a taxa de utilização de substrato no reator anóxico de pré-desnitrificação ao longo da primeira fase da pesquisa.

A Figura 36 apresenta o comportamento estatístico do fenol no sistema TOTAL nessa fase, entretanto somente considerando-se os resultados quando as concentrações de nitrogênio amoniacal afluentes eram da ordem de $500 \mathrm{mgN} / \mathrm{L}$. 


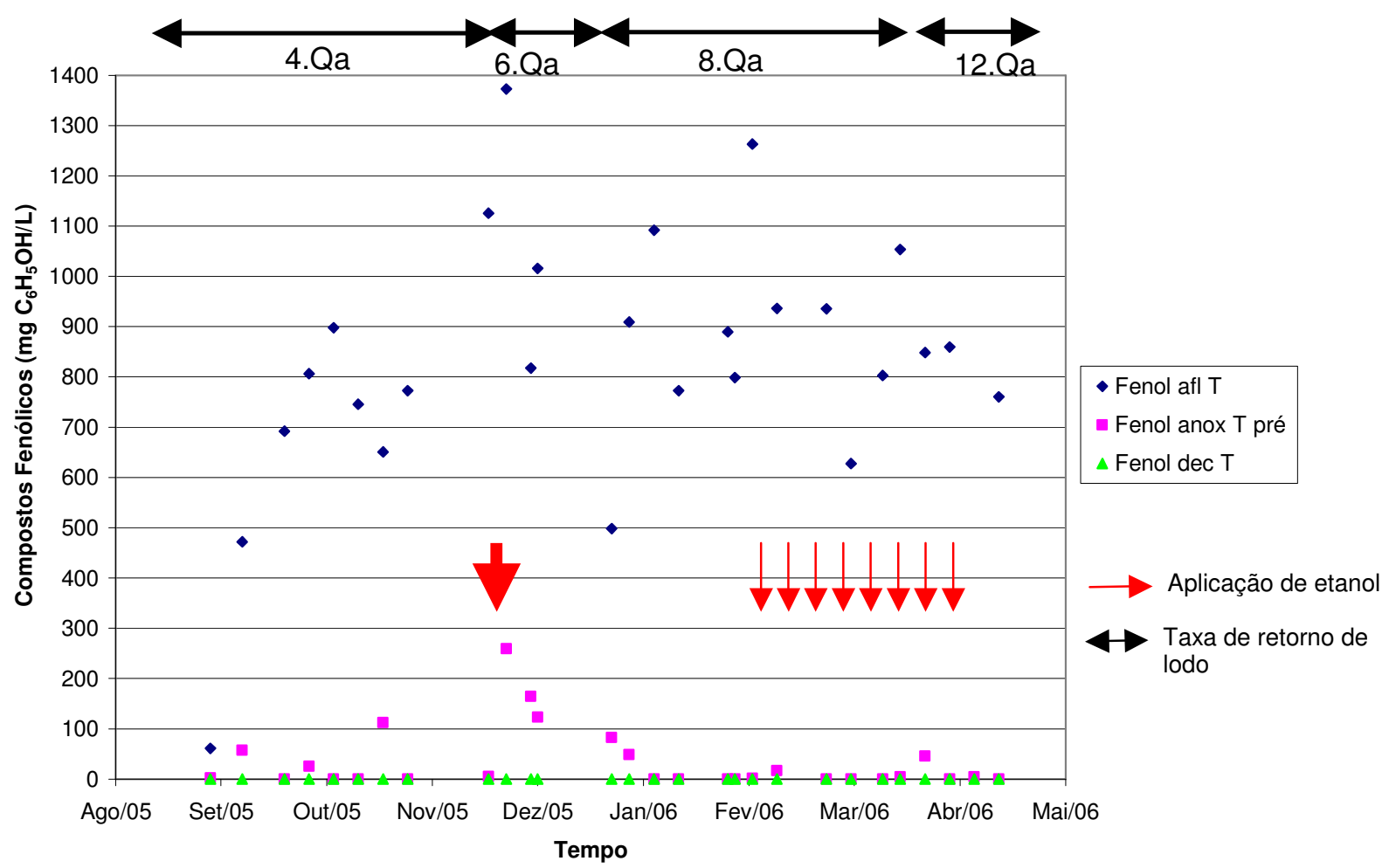

Figura 34 - Comportamento do fenol do Sistema TOTAL (T) ao longo da primeira fase da pesquisa, com fração anóxica de $39 \%$.

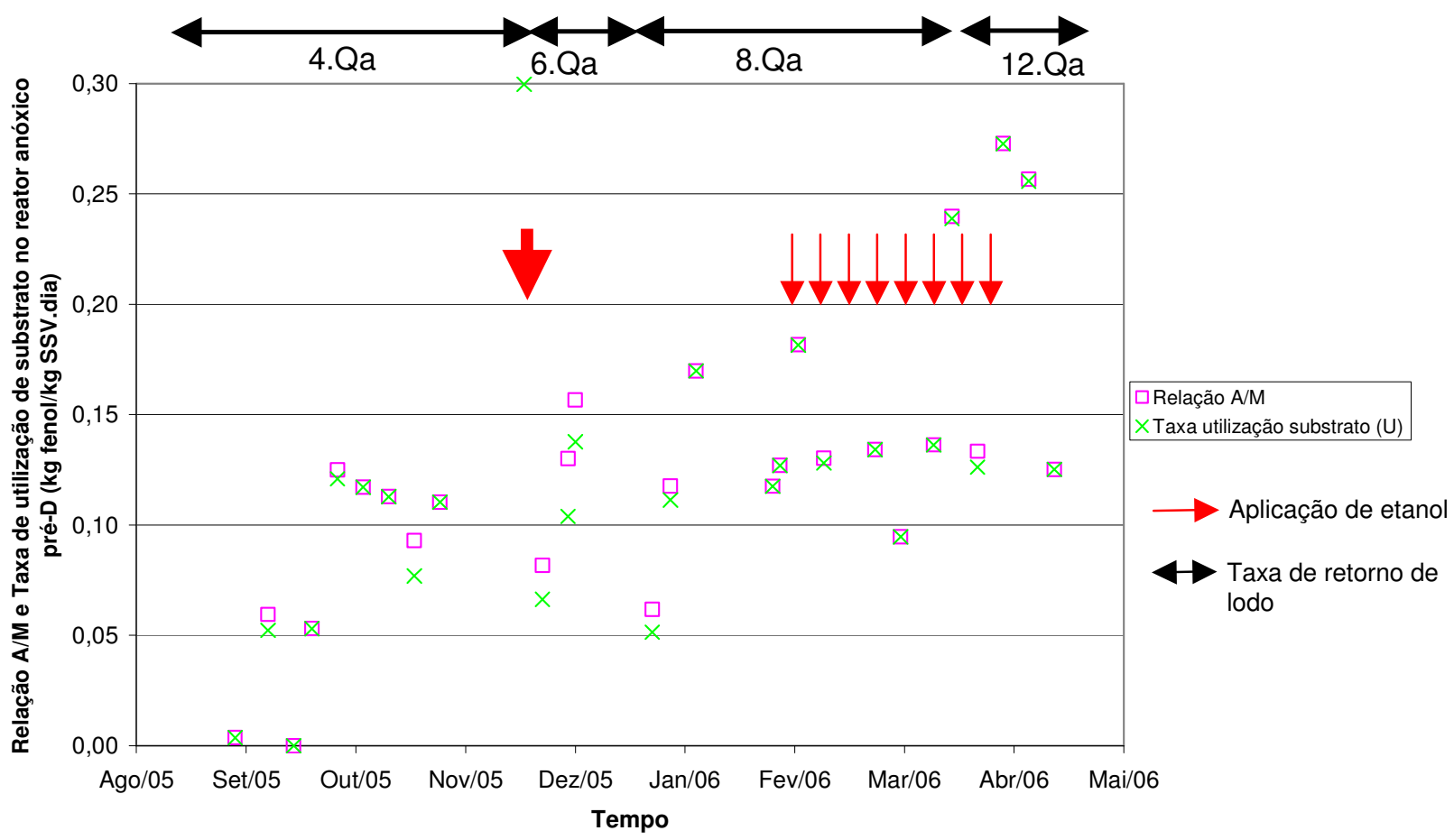

Figura 35 - Relação A/M e taxa de utilização de substrato para o reator anóxico pré-D do Sistema TOTAL (T) ao longo da primeira fase da pesquisa, com fração anóxica de $39 \%$. 


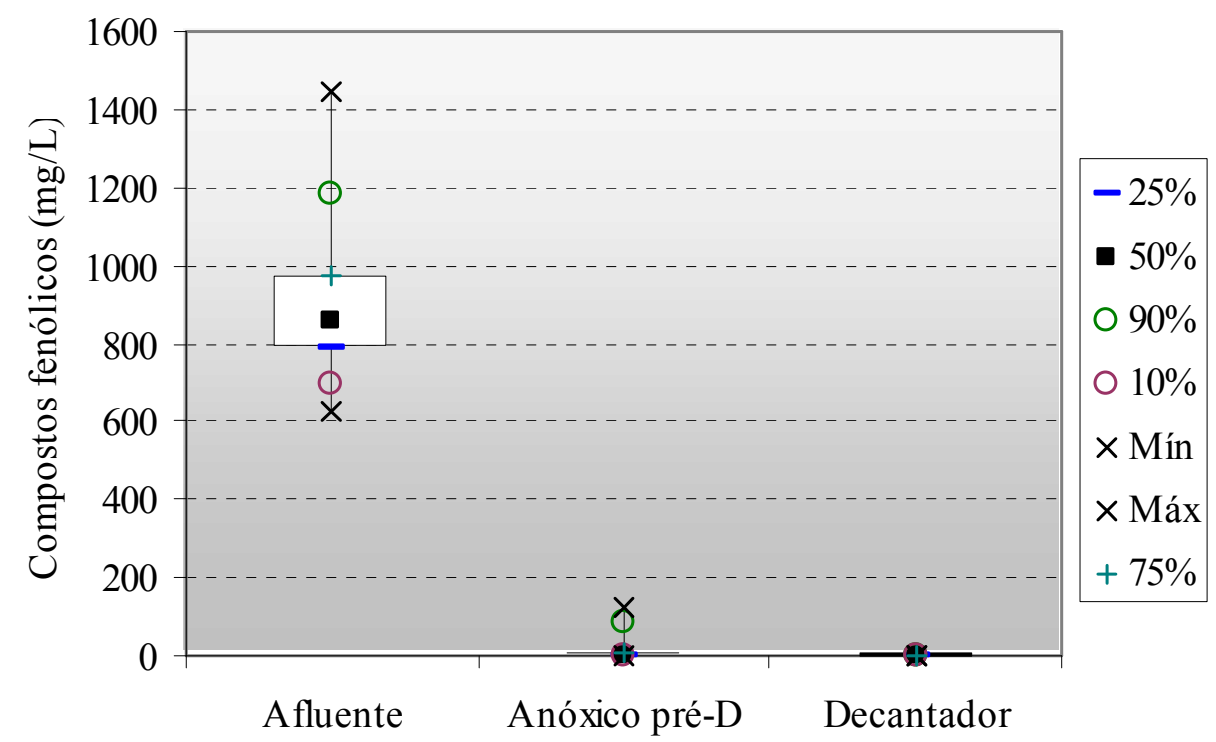

Figura 36 - Análise estatística dos compostos fenólicos nas unidades do Sistema TOTAL (T), quando as concentrações afluentes de nitrogênio amoniacal eram de $500 \mathrm{mg} \mathrm{N} / \mathrm{L}$, durante a primeira fase da pesquisa, com fração anóxica de 39\%.

A Figura 34 mostra grande variação da concentração de fenol no afluente, que pode ser justificada principalmente pois este era sintético e seu $\mathrm{pH}$ precisava ser mantido próximo da neutralidade pois, quando o mesmo decaía muito, quanto mais ácida a água, mais $\mathrm{H}^{+}$do anel benzênico era liberado no meio e assim a água ia se tornando cada vez mais ácida e o fenol desaparecendo da água residuária. No decorrer dos experimentos, quando se concluiu que esse era o fator que gerava redução na concentração de fenol do afluente, foi tomado devido cuidado de manter o $\mathrm{pH}$ sempre próximo a 7,0, o que solucionou definitivamente o problema.

Essa figura ainda mostra que a aplicação estequiométrica de etanol no reator anóxico pós-D foi suficiente para causar grande acúmulo de fenol no anóxico pré-D, desequilibrando completamente o sistema, gerando anaerobiose nos reatores anóxicos, odor desagradável, aspecto escuro e com escuma espessa do lodo. Foram necessárias semanas para se recuperar o sistema e quando o mesmo aparentou estar estabilizado, aplicou-se novamente 
etanol, dessa vez em quantidades mínimas (vazão de 5\% daquela dosada na primeira tentativa), o que ocorreu nos meses de fevereiro e março de 2006.

Analisando-se as Figuras 29 e 34, observa-se que a aplicação gradual de etanol de modo bastante conservador, apesar de não eliminar o nitrogênio oxidado do sistema, reduziu suas concentrações consideravelmente, comprovando essa ser uma fonte de carbono rapidamente biodegradável, bastante favorável aos microrganismos desnitrificantes. Entretanto, observar-se-á na segunda fase dos experimentos (com fração anóxica de 49\%) que dosagens um pouco maiores do que as aplicadas nessa fase já foram suficientes para desequilibrar novamente o sistema.

Muito embora tenham sido observados acúmulos indesejáveis de fenol no reator anóxico de pré-desnitrificação, ainda assim, o decantador secundário, e conseqüentemente, o efluente final apresentaram concentrações desprezíveis de fenol $\left(<0,5 \mathrm{mg} \mathrm{C}_{6} \mathrm{H}_{5} \mathrm{OH}\right)$ durante praticamente todo o decorrer do período (vide Figuras 34 e 36).

Da Figura 35, observa-se que as relações $\mathrm{A} / \mathrm{M}$ aplicadas no reator de pré-desnitrificação foram principalmente da ordem de 0,10 a $0,15 \mathrm{~kg}$ fenol $/ \mathrm{kg}$ SSV.dia, bastante compatíveis com as taxas utilizadas por Aun (2001) e Dombroski (2003), respectivamente, que citaram essas relações $\mathrm{A} / \mathrm{M}$ como as mais seguras para não ocorrer acúmulo de fenol no reator. Comparando-se as relações $\mathrm{A} / \mathrm{M}$ com as taxas de utilização de substrato no reator anóxico pré-D, nota-se que as mesmas apresentam-se bem compatíveis com as concentrações observadas de fenol, já que quanto mais afastados os pontos entre as duas taxas, menos fenol utilizado na desnitrificação e, portanto, maior acúmulo do mesmo, fato que ocorreu principalmente entre novembro de 2005 e janeiro de 2006. A Figura 37 ilustra as eficiências de remoção de fenol do sistema. 


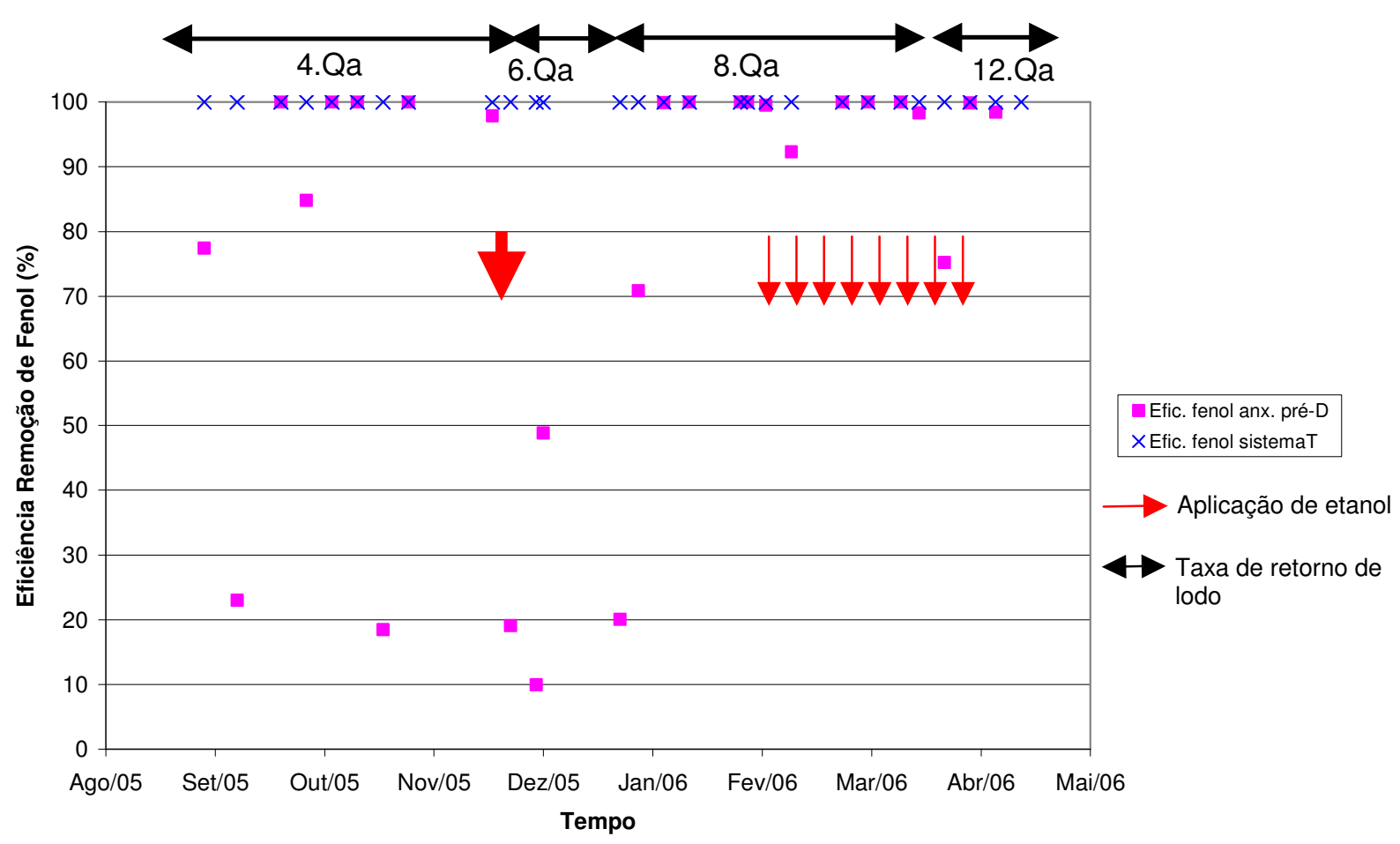

Figura 37 - Eficiência de remoção de fenol no reator anóxico pré-D e no sistema na primeira fase da pesquisa, com fração anóxica de 39\%, para o Sistema TOTAL (T).

Apesar das eficiências de remoção de fenol observadas no sistema como um todo na primeira fase terem sido satisfatórias, o gráfico mostra que de um modo geral o reator anóxico de pré-desnitrificação apresentou baixas eficiências de remoção, comprovando o que já foi anteriormente exposto. No reator aeróbio, o fenol era facilmente degradado; entretanto, o fato dele não ser completamente removido no anóxico pré-D e acabar passando para o aeróbio, de certo modo pode prejudicar a nitrificação pela competição entre as bactérias.

Nessa fase dos experimentos, a relação fenol removido $\mathrm{N}-\mathrm{NO} \mathrm{x}_{\text {removido }}$ no reator anóxico pré-D variou consideravelmente. Quando foi aplicado etanol no anóxico pós-D em novembro/dezembro de 2005, essa relação apresentou-se próxima de zero; entretanto, quando o mesmo foi aplicado de modo bem mais conservador, entre fevereiro e março de 2006, foram observados valores principalmente da ordem de 1,0 a 2,0 $\mathrm{kg}$ fenol $_{\text {removido }} / \mathrm{kg} \mathrm{N}-\mathrm{NOx}_{\text {removido. }}$. Nos demais períodos sem a utilização de etanol, a relação fenol $\mathrm{l}_{\text {removido }} / \mathrm{N}-\mathrm{NOx}_{\text {removido }}$ variou principalmente entre 2,0 a $3,5 \mathrm{~kg}$ fenol $1_{\text {removido }} / \mathrm{kg} \mathrm{N}-\mathrm{NOx}_{\text {removido. }}$. 


\subsubsection{Segunda Fase - Fração Anóxica de 49\%}

$\mathrm{Na}$ segunda fase, o sistema TOTAL apresentava uma fração anóxica de 49\%, ou seja, o anóxico pré-D passou a ter volume útil aproximado de 70 litros, ao passo que o aeróbio e o anóxico pós-D, os mesmos 100 e 70 litros da primeira fase, respectivamente. O objetivo de elevar a fração anóxica dos sistemas foi a tentativa de aumentar o tempo de permanência do lodo em ambiente anóxico, para possibilitar uma melhor eficiência na desnitrificação.

Nessa fase, o sistema TOTAL trabalhou com tempo de detenção hidráulico total que variou de 8 a 31 dias; o tempo de detenção do anóxico pré-D esteve entre 2 e 9 dias e o do aeróbio, entre 3 e 13 dias.

Como exposto anteriormente, essa fase iniciou-se em maio de 2006 e terminou no final da pesquisa, portanto, em janeiro de 2007.

\subsubsection{Monitoramento Diário do Sistema TOTAL na Segunda Fase}

As Figuras 38, 39 e 40 apresentam o comportamento do $\mathrm{pH}$, da temperatura e da concentração de OD dos reatores do Sistema TOTAL ao longo da segunda fase da pesquisa.

Da mesma forma como foi apresentado na primeira fase, as setas vermelhas indicam os períodos nos quais foi dosado etanol no reator anóxico de pós-desnitrificação e as pretas na parte superior dos gráficos mostram a taxa de recirculação de lodo total (retorno de lodo do decantador mais reciclo do aeróbio para o anóxico pré-D) utilizada no período. 


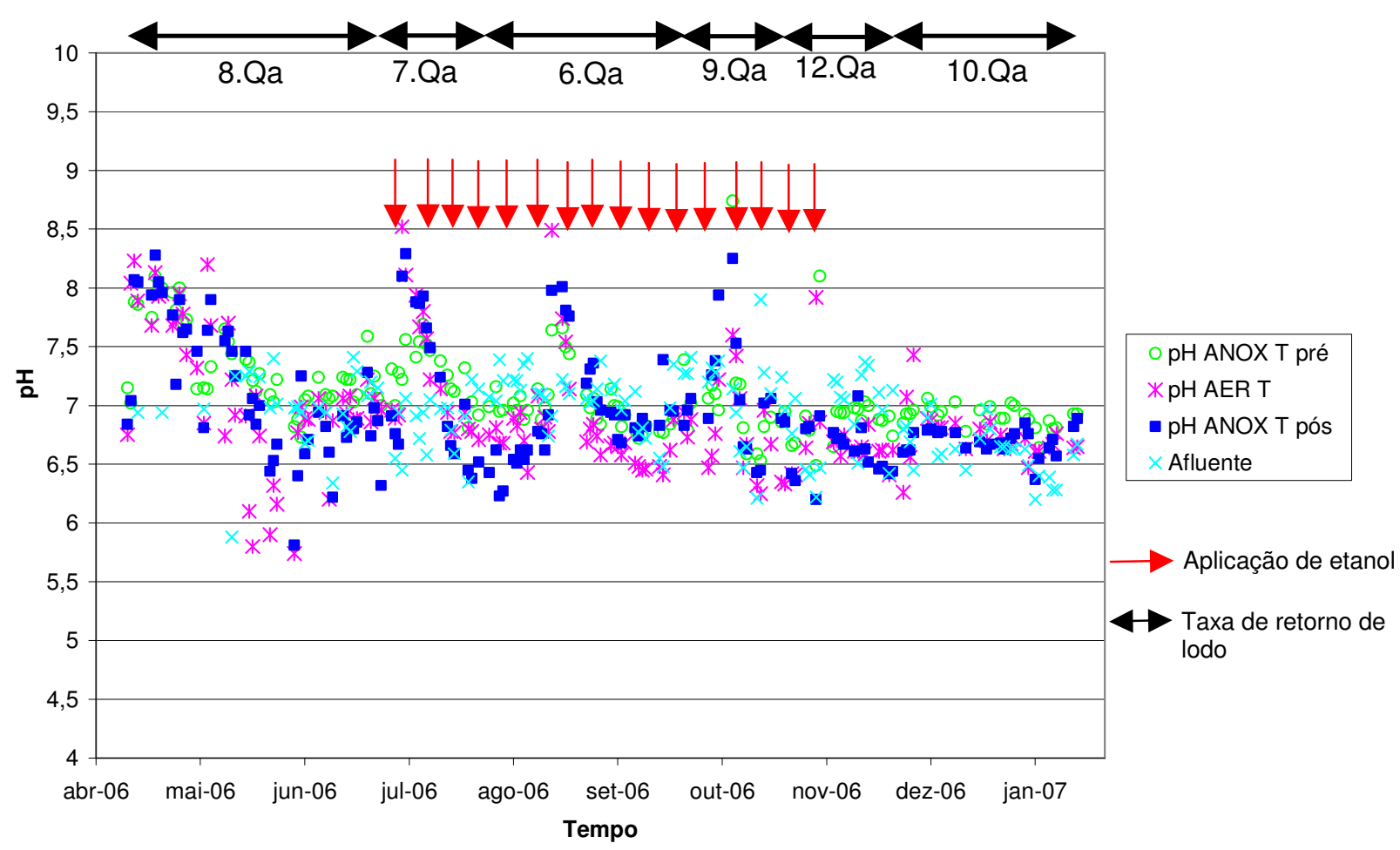

Figura 38 - Variação do pH do Sistema TOTAL (T) ao longo da segunda fase da pesquisa, com fração anóxica de $49 \%$.

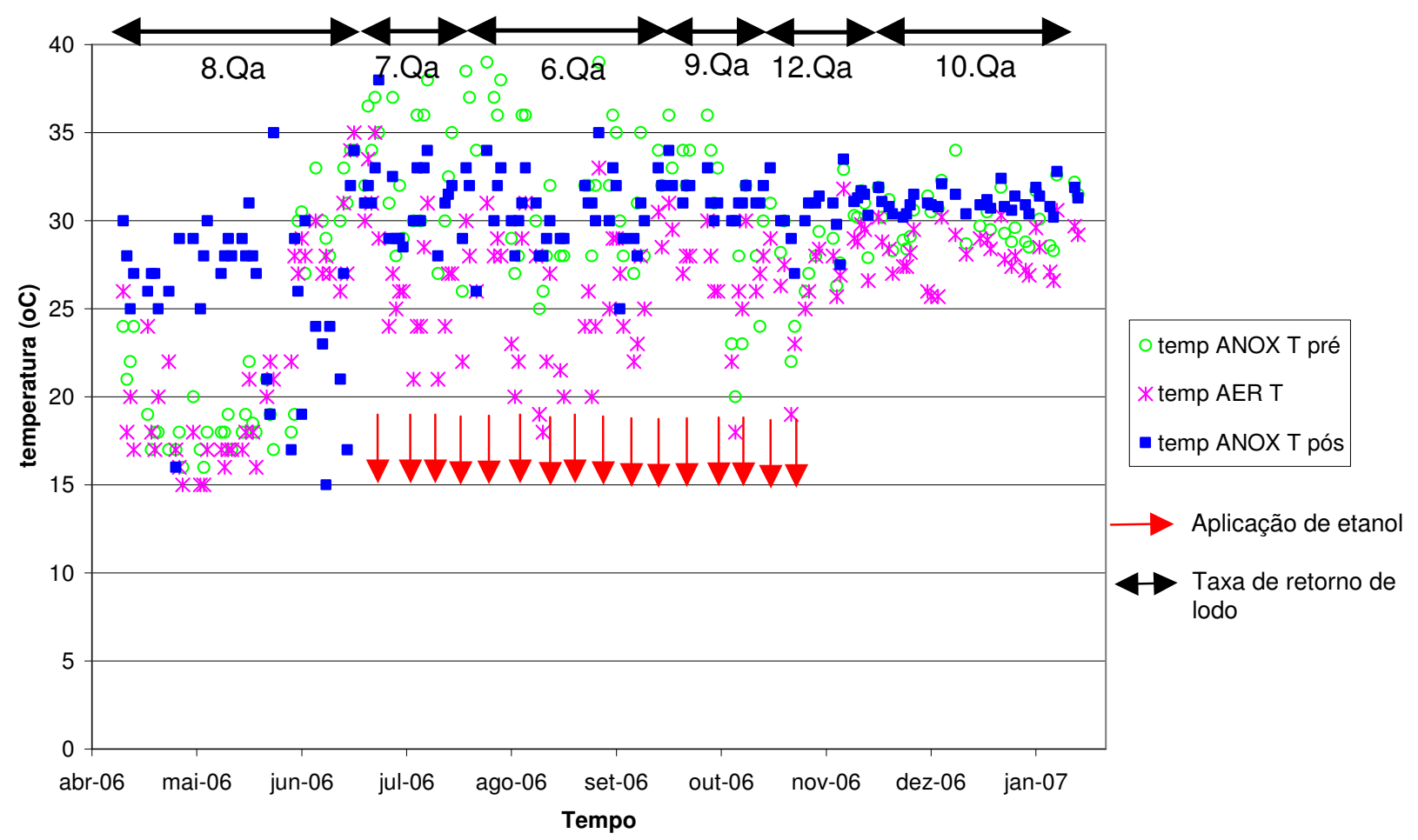

Figura 39 - Variação da temperatura do Sistema TOTAL (T) ao longo da segunda fase da pesquisa, com fração anóxica de $49 \%$. 


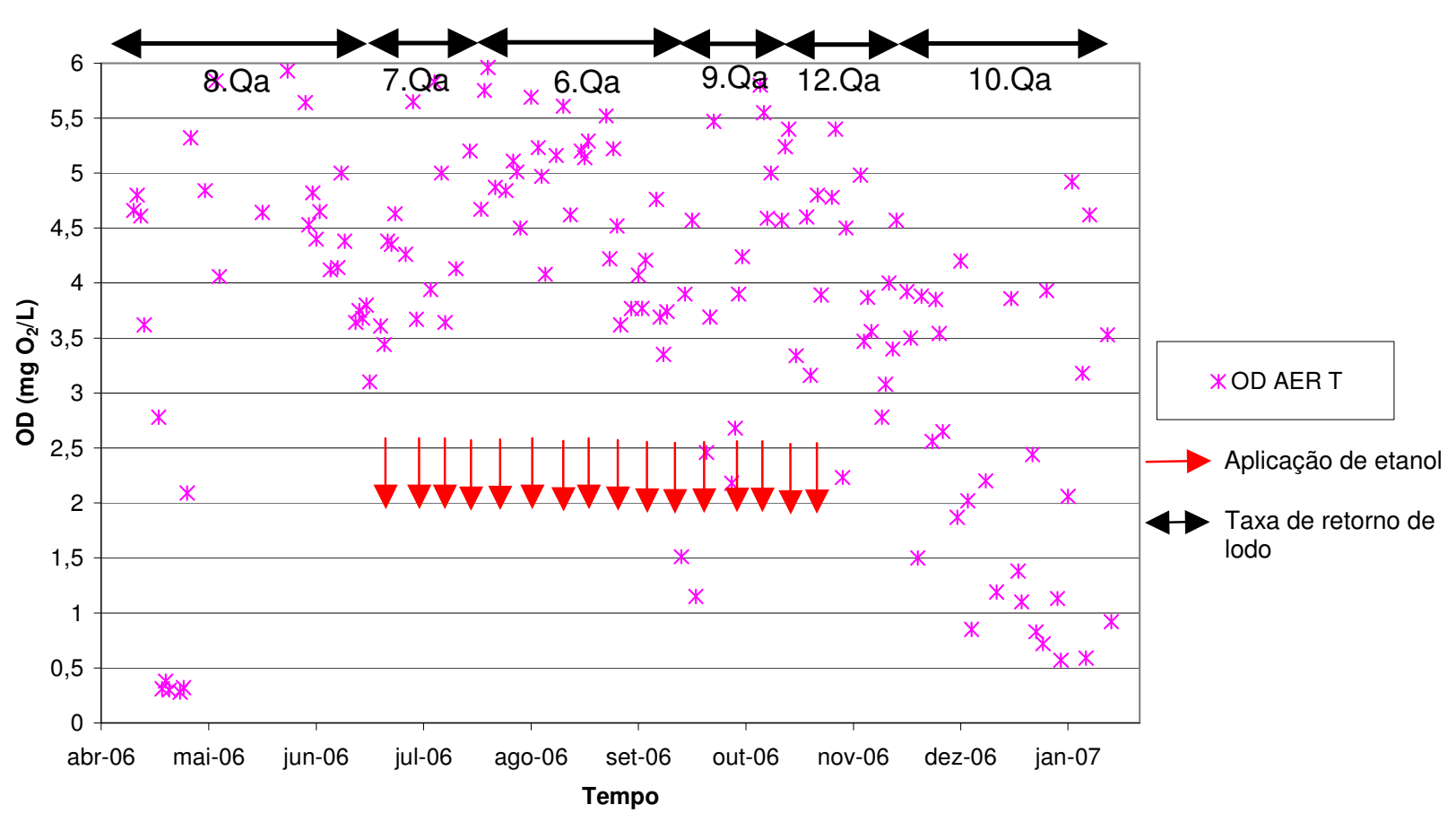

Figura 40 - Variação da concentração de OD do reator aeróbio do Sistema TOTAL (T) ao longo da segunda fase da pesquisa, com fração anóxica de $49 \%$.

Da Figura 38, pode-se observar que, da mesma forma que na primeira fase da pesquisa, nessa fase o $\mathrm{pH}$ também oscilou praticamente em todos os reatores entre 6,5 e 8,0. Como tendência geral e como já era previsto, o reator aeróbio apresentou valores de $\mathrm{pH}$ um pouco inferiores aos anóxicos, principalmente no caso do reator anóxico pré-D. Da mesma forma como ocorreu na primeira fase, os picos de $\mathrm{pH}$ observados no anóxico pós-D ocorreram em virtude da aplicação de etanol nesse reator e conseqüente desnitrificação a partir da fonte externa de carbono, gerando subida do $\mathrm{pH}$. Nos demais períodos sem a aplicação do etanol, o pH do aeróbio e do anóxico pós-D apresentaram-se equivalentes.

Da Figura 39, observa-se que nos meses mais frios, principalmente entre abril e julho de 2006, o uso de termostatos/aquecedores nos reatores não foi capaz de manter a temperatura dos reatores acima de $25^{\circ} \mathrm{C}$, o que foi prejudicial ao sistema.

No caso do OD, mesmo com a ampla faixa de variação das concentrações de oxigênio dissolvido no aeróbio, o sistema se mostrou estável em termos de nitrificação, 
podendo-se concluir que mesmo com valores mais baixos, que ocorreram principalmente de dezembro de 2006 a janeiro de 2007, a nitrificação não foi prejudicada, mostrando que esse não foi o parâmetro fundamental para a eficiência da nitrificação. Os anóxicos apresentaram concentrações de OD praticamente desprezíveis e, portanto, não foram representados no gráfico. Alguns picos de OD foram observados no anóxico pós-D que ocorreram em virtude da instalação de bomba e pedras porosas de aquário para reaeração, causando refluxo do ar por baixo do septo de separação do reator, o que foi posteriormente corrigido com a instalação de timer nessa bomba de aquário, fenômeno não mais observado até o final da pesquisa.

\subsubsection{Monitoramento Semanal do Sistema TOTAL na Segunda Fase}

O monitoramento semanal da concentração de sólidos em suspensão totais e voláteis dos reatores do sistema TOTAL durante a segunda fase é apresentado na Figura 41.

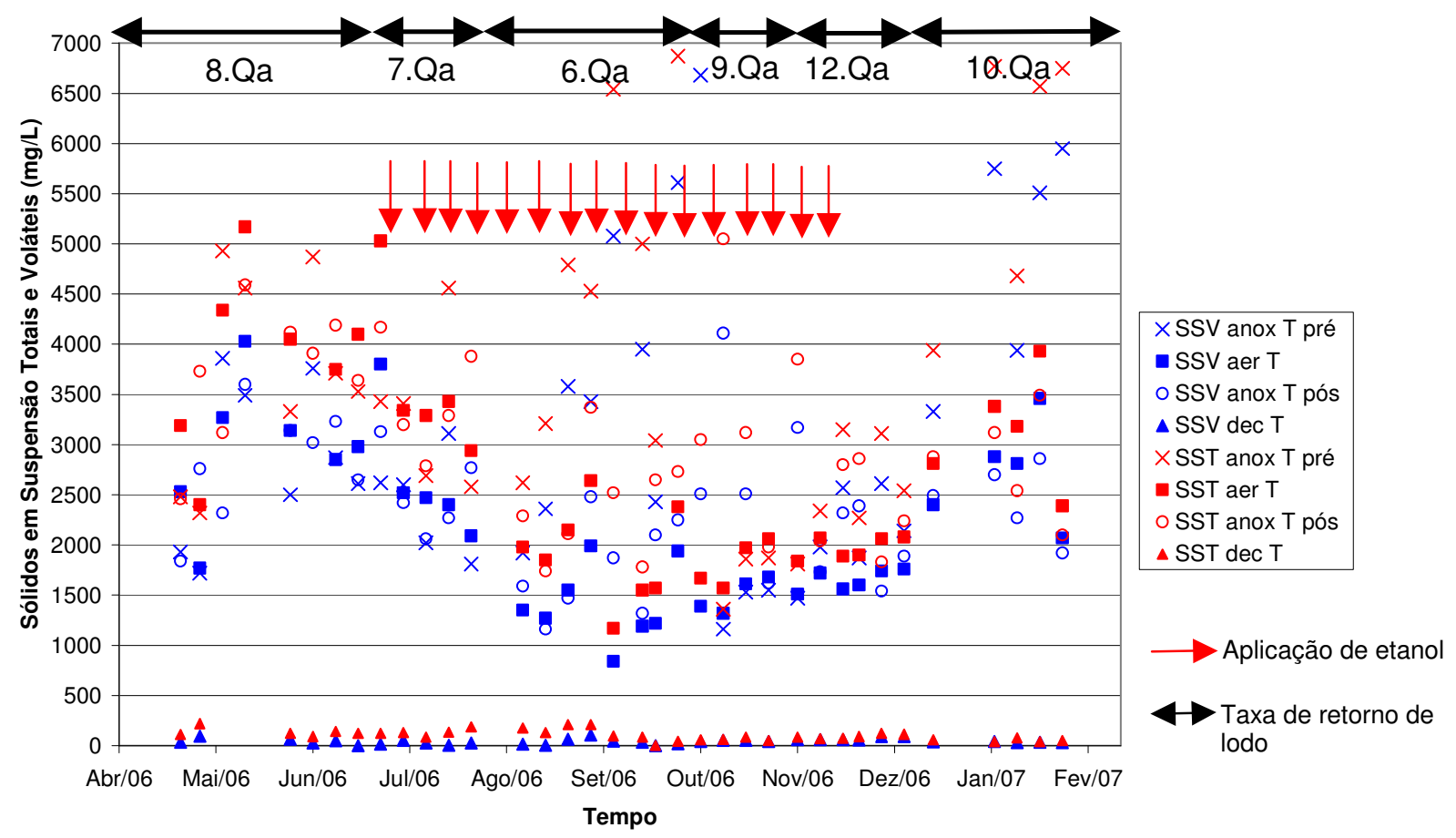

Figura 41 - Concentração de sólidos em suspensão totais e voláteis do Sistema TOTAL (T) ao longo da segunda fase da pesquisa, com fração anóxica de $49 \%$. 
Apesar da tendência de decaimento nas concentrações de SST e SSV observada no mês de setembro de 2006 no sistema TOTAL, essa não chegou a provocar lavagem da biomassa do sistema e, portanto maiores prejuízos ao mesmo, tendo em vista que em seguida o sistema já apresentou uma auto-recuperação e essas concentrações voltaram a subir normalmente. Queiroz (2006) também observou fenômeno semelhante em seus experimentos com lodo proveniente dos reatores dos sistemas de lodo ativado da presente pesquisa, podendo-se concluir ser essa uma característica desse tipo de lodo.

O efluente final do sistema TOTAL apresentou concentrações bem pequenas de sólidos, comprovando que o lodo apresentava boa sedimentação, mesmo sem o uso de polímero.

O que se observou ao longo de toda a pesquisa, não somente para o sistema TOTAL como também para o PARCIAL, foi a necessidade de seqüenciais aumentos na recirculação de lodo, inclusive com a introdução de reciclo interno durante a operação, visando manter uma concentração de nitrato no anóxico pré-D suficiente para não ocorrer acúmulo de fenol nesse reator. Mesmo assim, foi bastante difícil ajustar o retorno de lodo ideal, tendo em vista os constantes acúmulos de fenol observados. Isso porque as concentrações de compostos nitrogenados oxidados a partir do nitrogênio amoniacal afluente da ordem de $500 \mathrm{mgN} / \mathrm{L}$ não eram suficientes para promover a desnitrificação com o fenol como fonte de carbono, já que o mesmo apresentava concentração afluente muito elevada, da ordem de $1.000 \mathrm{mg} / \mathrm{L}$.

Portanto, ao final da pesquisa, o sistema TOTAL estava operando com retorno de lodo de aproximadamente 4 vezes ou $400 \%$ e o reciclo interno, com vazão de 6 vezes ou $600 \%$, totalizando assim, uma recirculação da ordem de 10 vezes a vazão afluente. Recirculações menores ao longo do experimento mostraram-se insuficientes para promover a desnitrificação sem acúmulo de fenol no reator anóxico de pré-desnitrificação. 
A Figura 42 ilustra o comportamento da alcalinidade nos reatores do sistema TOTAL ao longo da segunda fase da pesquisa.

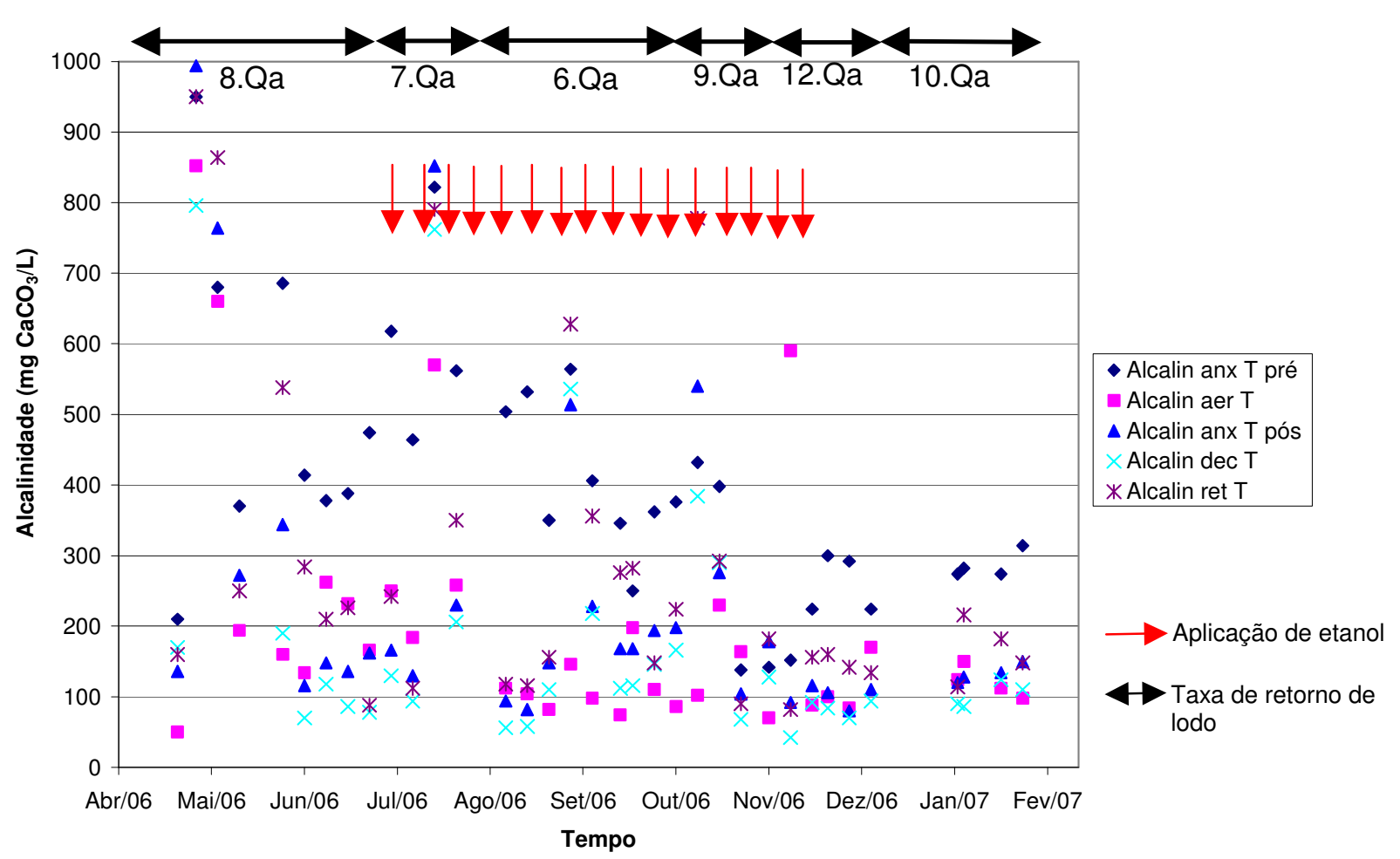

Figura 42 - Alcalinidade observada nas unidades do Sistema TOTAL (T) ao longo da segunda fase da pesquisa, com fração anóxica de $49 \%$.

Claramente nota-se que a alcalinidade do sistema como um todo teve uma tendência de decaimento ao longo do tempo, chegando a valores da ordem de 100 a $300 \mathrm{mgCaCO}_{3} / \mathrm{L}$ ao final da segunda fase. Entretanto, pode-se verificar que no reator aeróbio, no anóxico pós-D e no decantador, ela apresentou quase sempre a mesma ordem de grandeza, ao passo que no reator anóxico pré-D e no retorno de lodo, essa foi predominantemente maior, como já era previsto.

Sendo assim, verifica-se que realmente ocorreu ganho de alcalinidade no sistema com a desnitrificação no primeiro reator anóxico; porém, no segundo reator anóxico, nem sempre isso ocorreu, estando vinculado à dosagem ou não de etanol nesse reator. Nos últimos meses da pesquisa, quando foi cessada a dosagem de etanol, a alcalinidade do reator anóxico pós-D foi bastante similar à do aeróbio. Isso corrobora o fato de ocorrer desnitrificação em 
baixíssimas taxas em reator anóxico pós-D sem fonte externa de carbono. Portanto, para a boa eficiência desse tipo de configuração de sistema, a fonte externa de carbono torna-se fundamental.

O monitoramento dos compostos nitrogenados do sistema TOTAL durante a segunda fase é apresentado nas Figuras 43 e 44. A eficiência de remoção de nitrogênio amoniacal observada para o sistema TOTAL ao longo da segunda fase é apresentada na Figura 45.

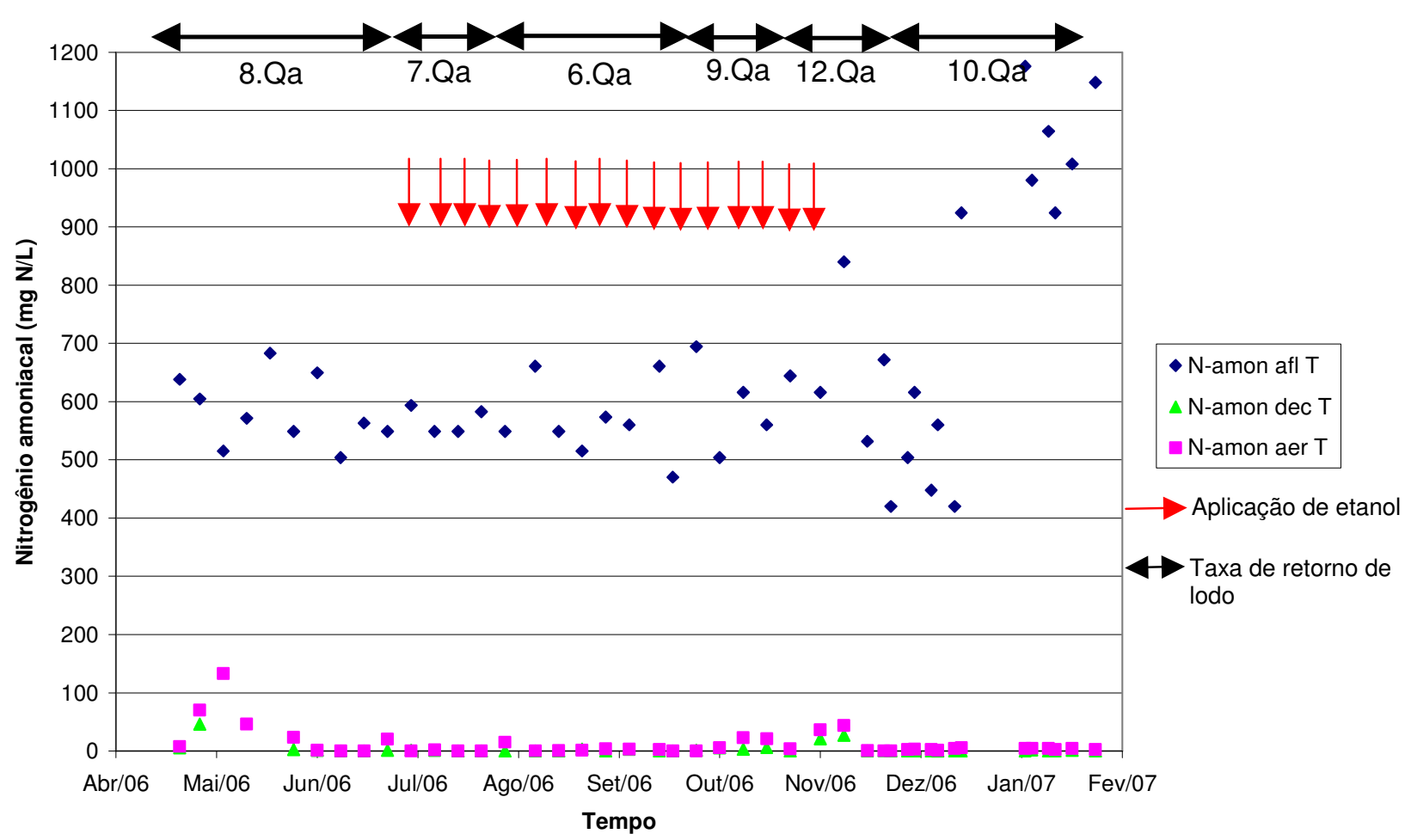

Figura 43 - Comportamento do nitrogênio amoniacal do Sistema TOTAL (T) ao longo da segunda fase da pesquisa, com fração anóxica de $49 \%$. 


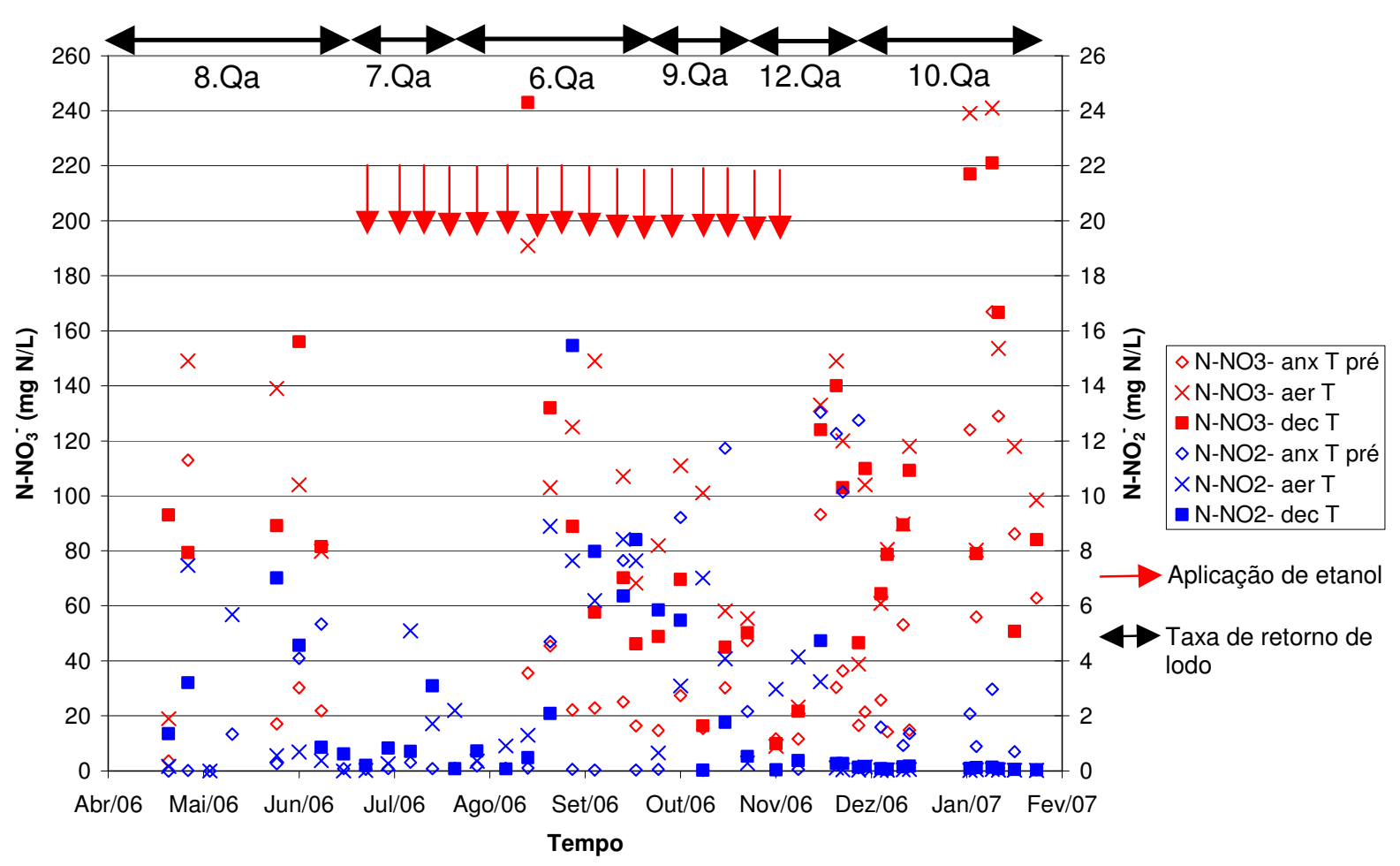

Figura 44 - Comportamento do nitrito e nitrato do Sistema TOTAL (T) ao longo da segunda fase da pesquisa, com fração anóxica de $49 \%$.

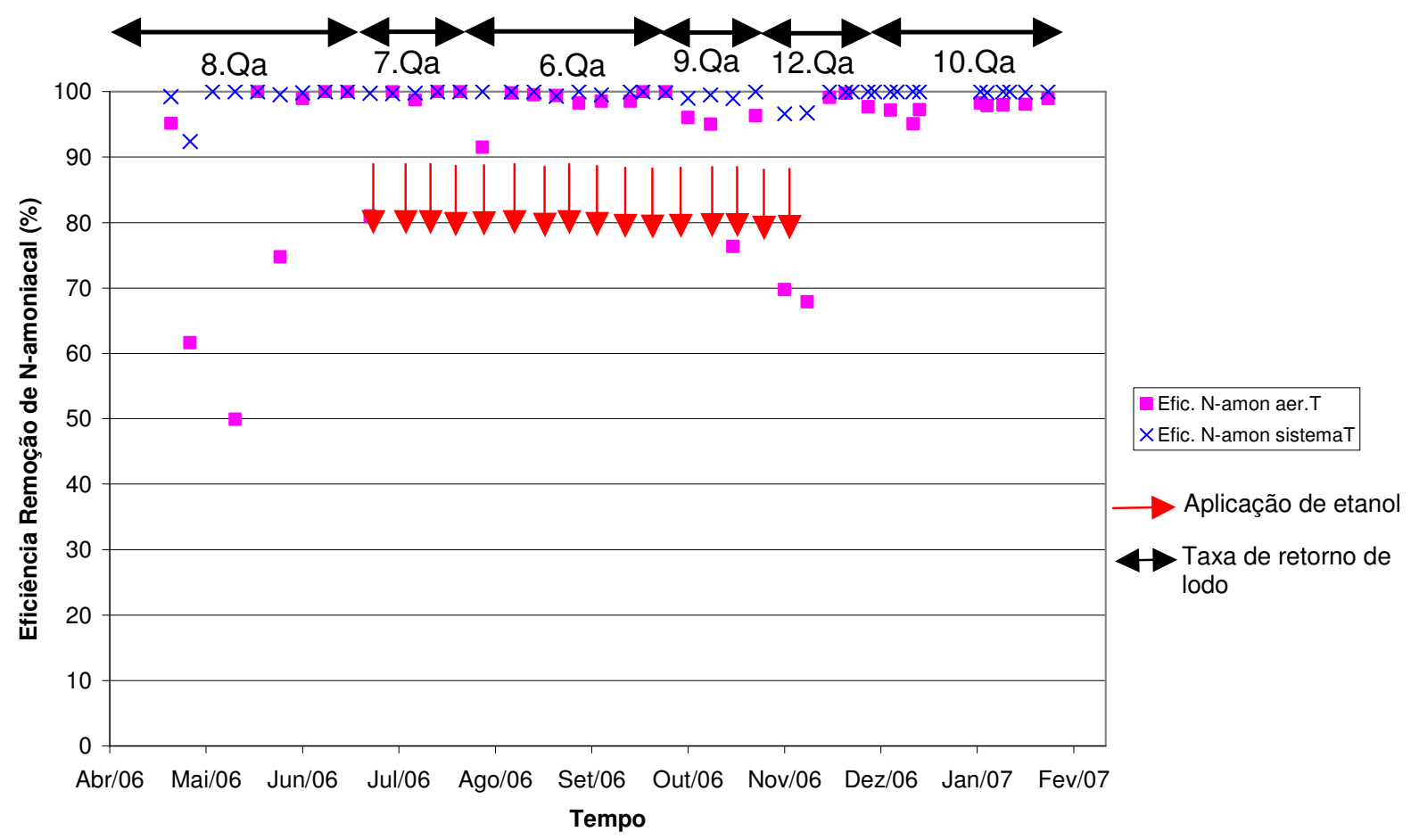

Figura 45 - Eficiência de remoção de nitrogênio amoniacal no reator aeróbio e no sistema ao longo da segunda fase da pesquisa, com fração anóxica de $49 \%$, para o Sistema TOTAL (T). 
Como já mencionado, no início da pesquisa, utilizou-se concentração afluente de nitrogênio amoniacal de $750 \mathrm{mgN} / \mathrm{L}$, o que foi alterado para $500 \mathrm{mgN} / \mathrm{L}$ no decorrer da pesquisa. Vale observar que as eficiências de remoção de nitrogênio amoniacal no sistema TOTAL na segunda fase foram muito boas, obtendo-se concentrações efluentes quase sempre desprezíveis (vide análise estatística na Figura 46, referente apenas aos resultados com concentração afluente de nitrogênio amoniacal da ordem de $500 \mathrm{mgN} / \mathrm{L}$ ).

Na segunda fase da pesquisa, a taxa de nitrificação observada para o sistema TOTAL no reator aeróbio foi principalmente de $0,01 \mathrm{~kg} \mathrm{~N}-\mathrm{NH}_{3} / \mathrm{kg} \mathrm{SSV}$.dia, valor este igual ao obtido por Dombroski (2003) na etapa de partida do sistema e adaptação da biomassa. Entretanto, esse valor esteve bem aquém daqueles observados por Dombroski (2003) durante a operação normal do sistema, que mencionou ter obtido taxas variando de 0,049 a $0,08 \mathrm{~kg} \mathrm{~N}-\mathrm{NH}_{3} / \mathrm{kg} \mathrm{SSV.dia.}$

Quanto aos compostos nitrito e nitrato, como já era de se esperar, ocorreu grande predominância do nitrato sobre o nitrito (vide análise estatística para esses compostos na Figura 47, para o período com concentração afluente de nitrogênio amoniacal de $500 \mathrm{mgN} / \mathrm{L}$ ), porém não foi possível fechar um balanço de nitrogênio do sistema, principalmente em virtude da grande oscilação de resultados de nitrato observada.

Os principais fatores que podem justificar os valores oscilantes de nitrato obtidos são a imprecisão do método analítico do eletrodo de íon específico de nitrato e muito provavelmente perdas de nitrogênio ocasionadas por formas alternativas de remoção de nitrogênio ainda não muito bem compreendidas, já citadas anteriormente na literatura, como a desnitrificação aeróbia, a nitrificação heterotrófica e a oxidação anaeróbia de amônio (VAN LOOSDRECHT; JETTEN, 1998; JETTEN et al., 1998).

No caso específico do nitrato, entre julho e agosto de 2006, ocorreu um hiato de resultados em virtude do eletrodo de íon específico ter apresentado problemas e ocorrer 
dificuldades para a reposição do mesmo junto ao fornecedor do equipamento, o que foi solucionado em meados do mês de agosto.

As taxas de desnitrificação observadas tanto no reator anóxico pré-D quanto no pós-D na segunda fase foram quase sempre inferiores a $0,02 \mathrm{~kg} \mathrm{N-NO} / \mathrm{kg}$ SSV.dia. Entretanto, em algumas datas pontuais, principalmente em agosto de 2006 , foram observadas taxas de desnitrificação um pouco maiores no reator anóxico pós-D, da ordem de 0,04 kg N-NO $/ \mathrm{kg}$ SSV.dia, essas evidentemente relacionadas à dosagem de etanol nesse tanque, que é uma fonte de carbono mais facilmente assimilável. Nesse mesmo período, as taxas de desnitrificação no anóxico pré-D apresentaram brusca queda, não chegando a alcançar $0,01 \mathrm{~kg} \mathrm{~N}-\mathrm{NO}_{x} / \mathrm{kg}$ SSV.dia, em virtude da dosagem de etanol e conseqüente diminuição da utilização de fenol pelos microrganismos desnitrificantes.

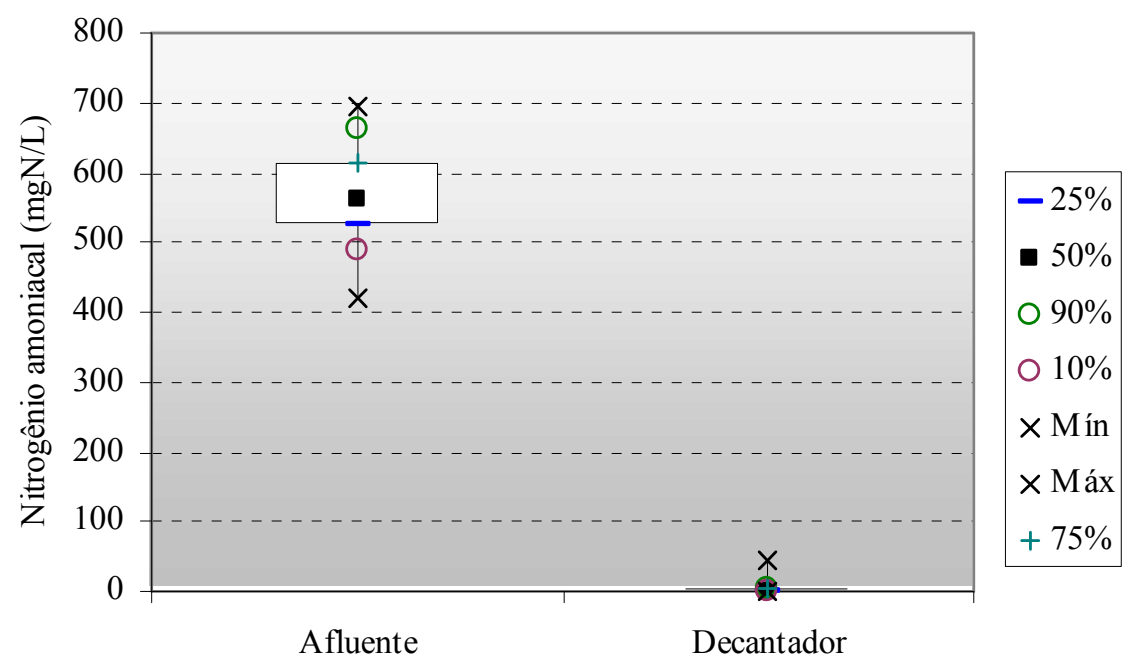

Figura 46 - Análise estatística de nitrogênio amoniacal para o Sistema TOTAL (T), com concentração afluente da ordem de $500 \mathrm{mgN} / \mathrm{L}$, durante a segunda fase da pesquisa, com fração anóxica de $49 \%$. 


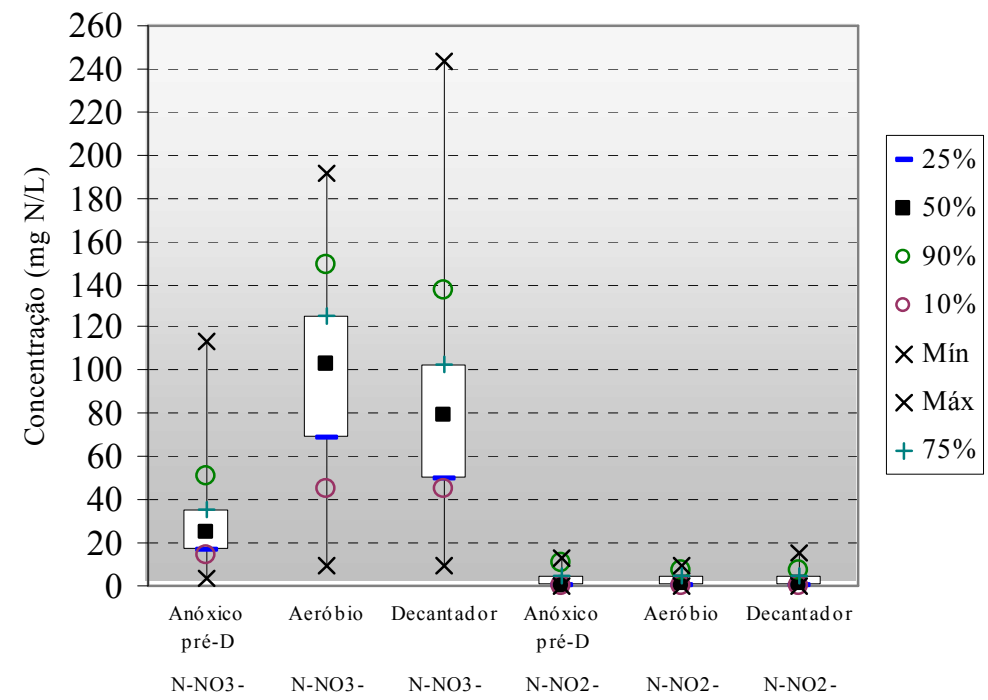

Figura 47 - Análise estatística dos compostos oxidados de nitrogênio para o Sistema TOTAL (T), quando as concentrações afluentes de nitrogênio amoniacal eram de $500 \mathrm{mgN} / \mathrm{L}$, durante a segunda fase da pesquisa, com fração anóxica de $49 \%$.

A Figura 48 a seguir apresenta o comportamento da DBO do sistema TOTAL ao longo da segunda fase dos trabalhos.

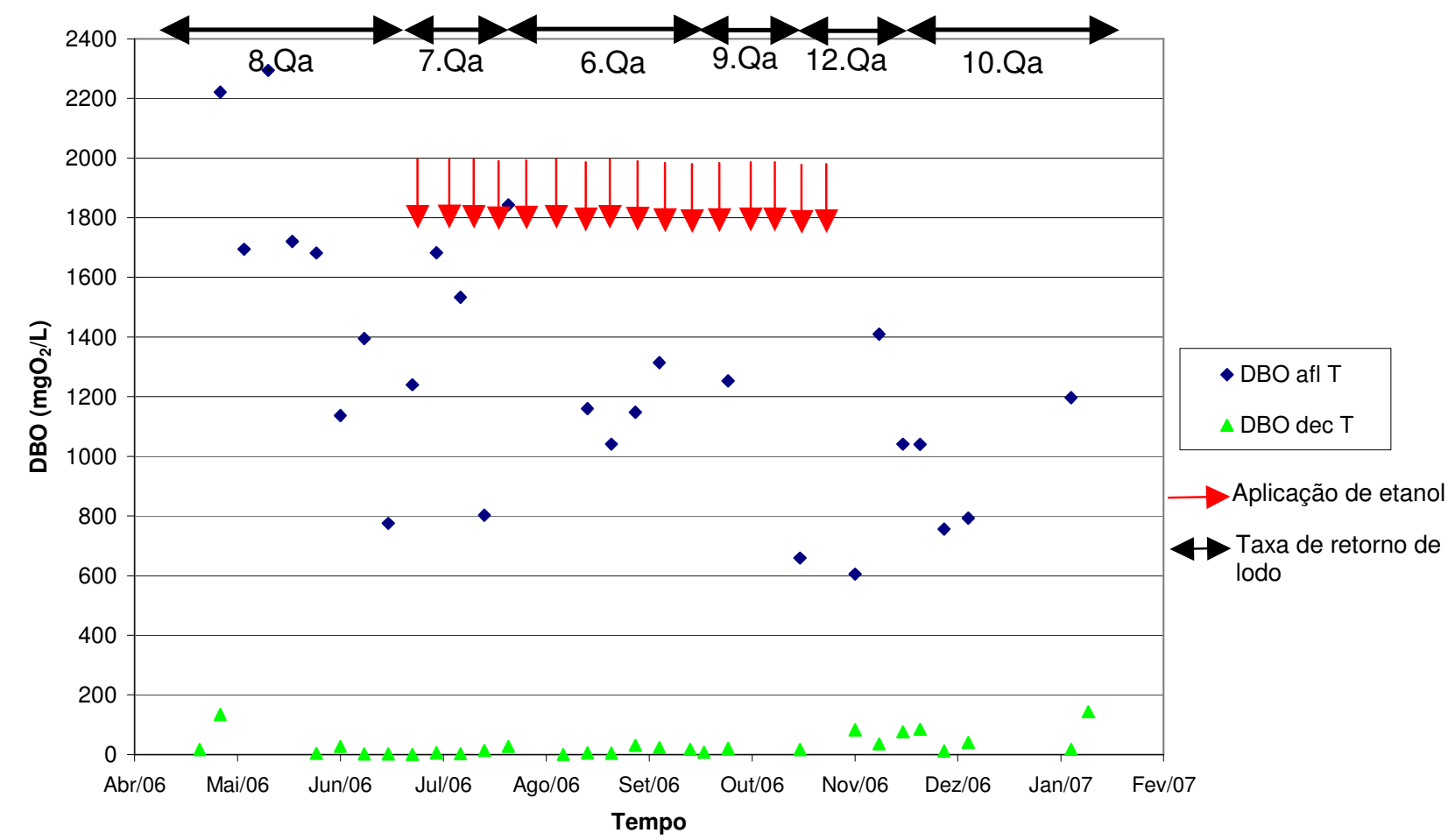

Figura 48 - Comportamento da DBO do Sistema TOTAL (T) ao longo da segunda fase da pesquisa, com fração anóxica de $49 \%$. 
Apesar de alguns valores obtidos para a DBO efluente terem excedido $60 \mathrm{mgO}_{2} / \mathrm{L}$, os resultados foram de certa forma satisfatórios, tendo em vista que a eficiência de remoção de DBO superior a $80 \%$ foi sempre atendida, conforme exigido pela Legislação (SÃO PAULO, 1976).

A Figura 49 ilustra o comportamento do fenol do sistema TOTAL e a Figura 50, a relação A/M (alimento/microrganismo) aplicada e a taxa de utilização de substrato no reator anóxico de pré-desnitrificação ao longo da segunda fase da pesquisa. As eficiências de remoção de fenol no reator anóxico pré-D e no sistema como um todo na segunda fase são apresentadas na Figura 51. A análise estatística dos compostos fenólicos nessa fase (para os resultados com concentração afluente de nitrogênio amoniacal de $500 \mathrm{mgN} / \mathrm{L}$ ) no sistema TOTAL é apresentada na Figura 52.

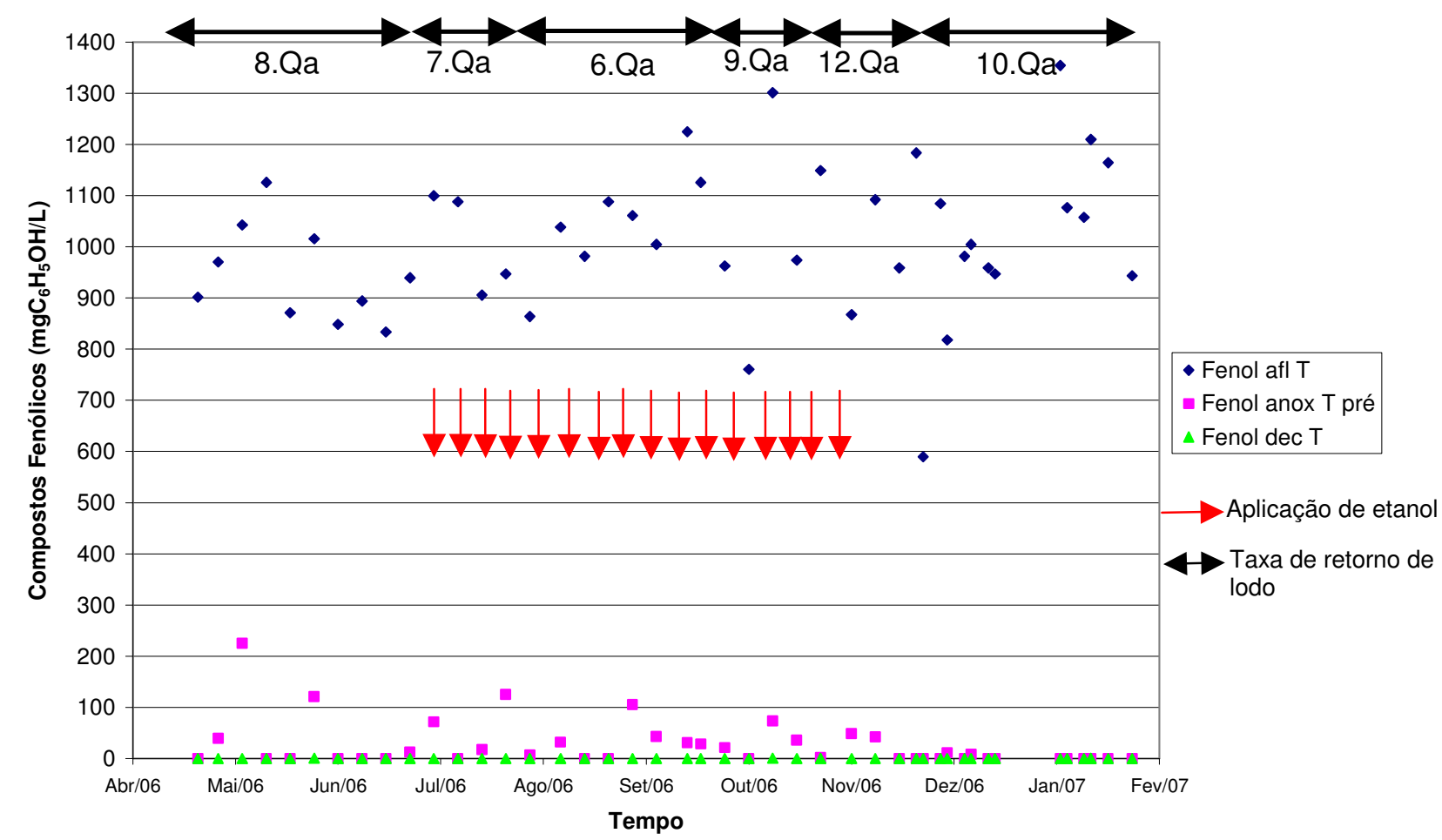

Figura 49 - Comportamento do fenol do Sistema TOTAL (T) ao longo da segunda fase da pesquisa, com fração anóxica de $49 \%$. 


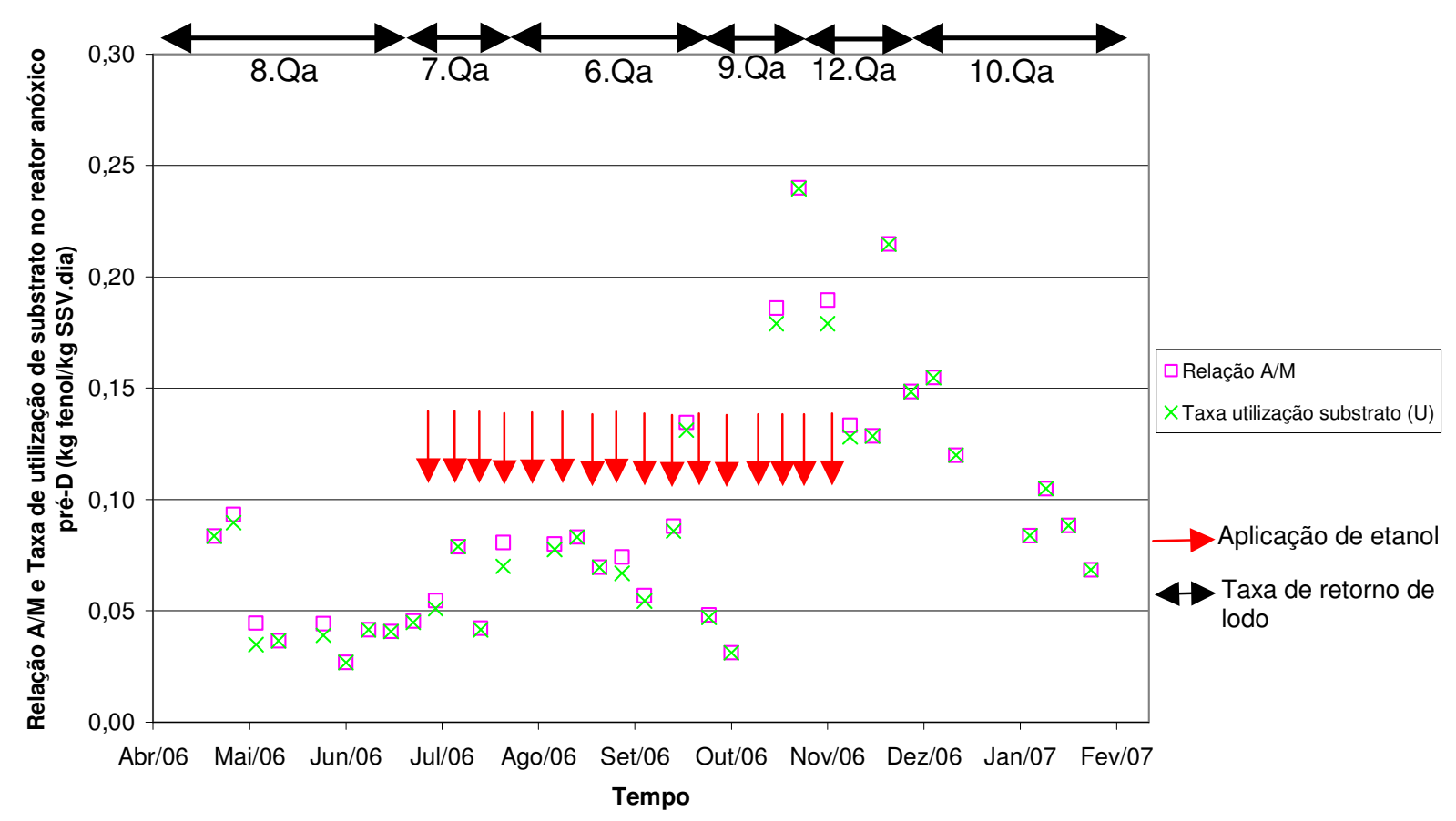

Figura 50 - Relação A/M e taxas de utilização de substrato para o reator anóxico pré-D do Sistema TOTAL (T) ao longo da segunda fase da pesquisa, com fração anóxica de $49 \%$.

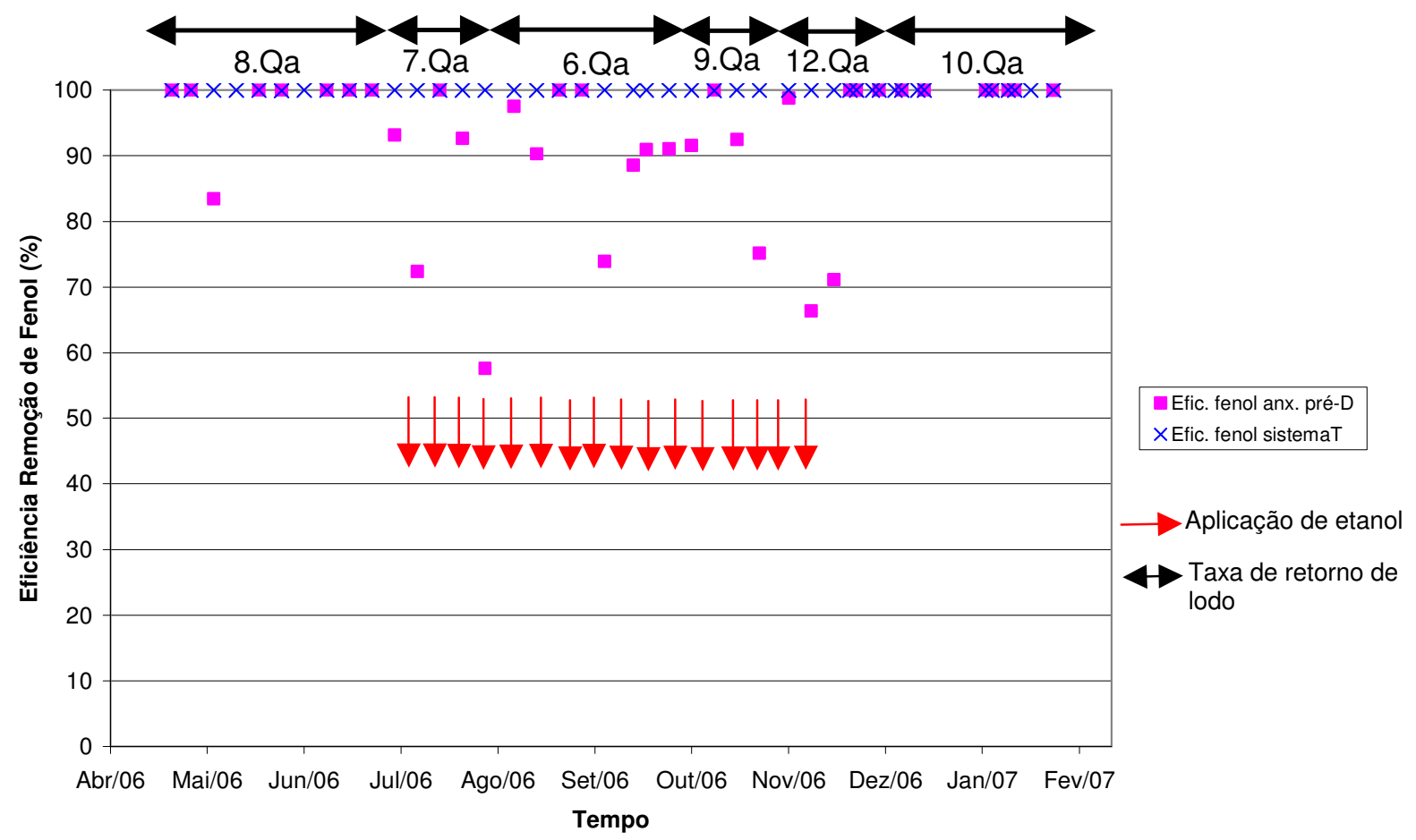

Figura 51 - Eficiência de remoção de fenol no reator anóxico pré-D e no sistema ao longo da segunda fase da pesquisa, com fração anóxica de $49 \%$, para o Sistema TOTAL (T). 


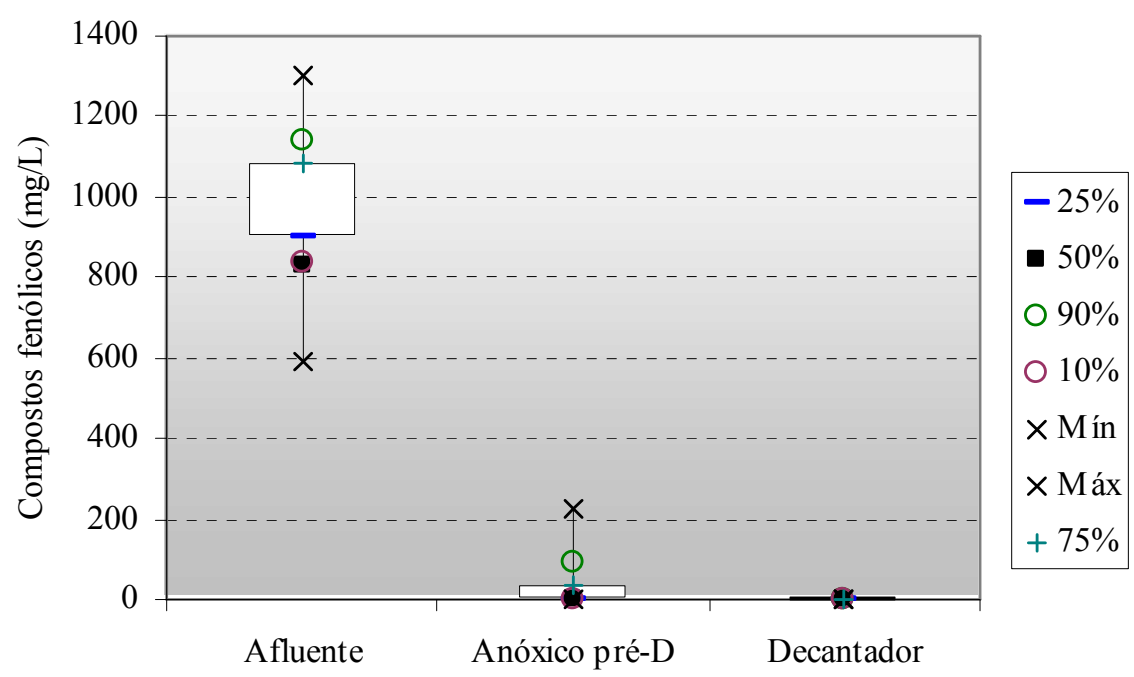

Figura 52 - Análise estatística dos compostos fenólicos para o Sistema TOTAL (T), quando a concentração afluente de nitrogênio amoniacal era de $500 \mathrm{mgN} / \mathrm{L}$, durante a segunda fase da pesquisa, com fração anóxica de $49 \%$.

Das Figuras 49 e 52, observa-se que apesar das concentrações de fenol do decantador final do sistema TOTAL também terem sido praticamente desprezíveis durante toda a operação da segunda fase, do mesmo modo como ocorreu na primeira fase, grande parte das amostras coletadas no anóxico pré-D mostrou que ocorreu acúmulo de fenol no reator, inibindo a desnitrificação. A Figura 51 corrobora essa afirmação, já que as eficiências de remoção de fenol nesse reator foram diversas vezes muito baixas.

As setas vermelhas indicam os períodos em que o etanol foi aplicado no reator de pós-desnitrificação como fonte externa de carbono. Exceto no mês de maio de 2006, quando ocorreram problemas na aeração do sistema e conseqüente diminuição das taxas de nitrificação, observando-se acúmulo de fenol no reator pré-D sem o uso de fonte externa de carbono, nos demais períodos parece claro que os acúmulos observados estão de alguma forma relacionados à dosagem de etanol no sistema. Entre julho e outubro de 2006, a aplicação de etanol foi feita variando-se de $7,5 \%$ até $37,5 \%$ da vazão dosada na primeira tentativa (que ocorreu na primeira fase, entre novembro e dezembro de 2005), sendo que 
praticamente em todo esse período observou-se acúmulo de fenol no reator de pré-desnitrificação. Mesmo com a utilização de etanol nesse período, ainda assim o nitrato não desapareceu do sistema, apesar de ter sido consideravelmente reduzido.

A Figura 50 mostra que as relações alimento/microrganismo aplicadas no reator anóxico de pré-desnitrificação foram na maioria das vezes inferiores à obtida por Aun (2001) (de $0,10 \mathrm{~kg}$ fenol/kg SSV.dia) e que as taxas de utilização de substrato estiveram muito próximas à relação $\mathrm{A} / \mathrm{M}$. Mesmo assim, em alguns momentos, observou-se elevadas concentrações de fenol no reator pré-D, comprovando não ser a relação $\mathrm{A} / \mathrm{M}$ utilizada a justificativa para o acúmulo de fenol.

A relação fenol removido $/ \mathrm{N}-\mathrm{NOx}_{\text {removido }}$ no reator anóxico de pré-desnitrificação na segunda fase dos experimentos do sistema TOTAL oscilou principalmente entre 1,0 e $2,0 \mathrm{~kg}$ fenol ${ }_{\text {removido }} / \mathrm{kg} \mathrm{N}-\mathrm{NOx}_{\text {removido }}$ no período em que foi aplicado etanol no reator anóxico de pós-desnitrificação. Nos demais períodos sem a utilização de etanol, essa relação foi bem superior a $2,0 \mathrm{~kg}$ fenol removido $_{\text {o }} / \mathrm{kg} \mathrm{N}-\mathrm{NOx}_{\text {removido. }}$

A conclusão que foi obtida desses resultados, principalmente comparando os períodos com e sem dosagem de etanol no reator anóxico pós-D, é que o etanol foi o responsável pelo desequilíbrio do sistema, pois toda vez que o mesmo foi adicionado, ocorreu anaerobiose nos reatores anóxicos, com cheiro característico, além do aspecto espesso e escuro do lodo no sistema. Em conseqüência, o fenol passava a não mais ser removido no anóxico pré-D, já que as bactérias não o consumiam dando preferência ao etanol que era adicionado mais adiante no reator pós-D, visto que o etanol possui fórmula estrutural totalmente diferente da do fenol, sendo um composto muito mais simples e de fácil degradação pelos microrganismos.

Assim, quando o sistema entrava em desequilíbrio e anaerobiose, cessava-se a dosagem de etanol e após aproximadamente uma ou duas semanas o sistema entrava em 
regime novamente, com eficiente consumo de fenol no reator de pré-desnitrificação. Isso pode ser facilmente verificado nos últimos meses da pesquisa, de meados de novembro de 2006 ao final de janeiro de 2007, quando o etanol não foi utilizado e praticamente não se observou fenol em nenhuma unidade do sistema.

A principal conclusão que se obteve desse resultado foi a impossibilidade de dosagem de fenol e etanol num sistema de lodo único pela preferência que os microrganismos dão ao etanol em detrimento do fenol e conseqüente acúmulo desse último no reator anóxico de pré-desnitrificação. O rompimento do anel benzênico torna-se mais difícil para os microrganismos desnitrificantes, tendo em vista a presença de uma fonte de carbono mais prontamente assimilável no sistema. Sendo assim, isso sugere que para a utilização desses dois compostos, seriam necessários dois sistemas em separado, ou seja, um sistema de dois lodos, com uma população microbiana independente para cada substrato em cada reator anóxico.

Em sua pesquisa sobre redução de sulfato de água residuária sintética, Silva (2005) mencionou que a adição de etanol ocasionava aumento na concentração de ácidos voláteis, provavelmente em virtude da oxidação incompleta do etanol a acetato pelas bactérias redutoras de sulfato. Como a água residuária da presente pesquisa apresentava concentrações relativamente consideráveis de sulfato, uma das hipóteses levantadas possíveis para o desequilíbrio e anaerobiose dos reatores anóxicos pode ter sido o mesmo fenômeno relatado por Silva (2005), muito embora a hipótese de incompatibilidade do uso dos substratos fenol e etanol simultaneamente seja a mais provável. 


\subsection{Sistema PARCIAL}

\subsubsection{Primeira Fase - Fração Anóxica de 23\%}

$\mathrm{Na}$ primeira fase da pesquisa, o sistema PARCIAL apresentava uma fração anóxica de $23 \%$, ou seja, o reator anóxico possuía volume útil aproximado de 30 litros e o aeróbio, de 100 litros.

Nessa fase, o sistema PARCIAL trabalhou com tempo de detenção hidráulico total que variou de 10 a 22 dias; o tempo de detenção do anóxico esteve entre 2 e 5 dias e o do aeróbio, entre 8 e 17 dias.

Como mencionado anteriormente, essa fase durou até o final de abril de 2006.

\subsubsection{Monitoramento Diário do Sistema PARCIAL na Primeira Fase}

As Figuras 53, 54 e 55 apresentam o comportamento do $\mathrm{pH}$, temperatura e concentração de oxigênio dissolvido dos reatores do Sistema PARCIAL ao longo da primeira fase de experimentos.

Assim como apresentado para o sistema TOTAL, no sistema PARCIAL também foram representadas as taxas de recirculação utilizadas em cada período na parte superior dos gráficos. Importante ressaltar que durante todos os meses da primeira fase de experimentos, só foi feito o retorno de lodo do fundo do decantador para o anóxico, sendo que o reciclo do aeróbio para o anóxico só foi instalado nos dois últimos meses da segunda fase, em virtude de limitação da bomba de retorno de lodo. 


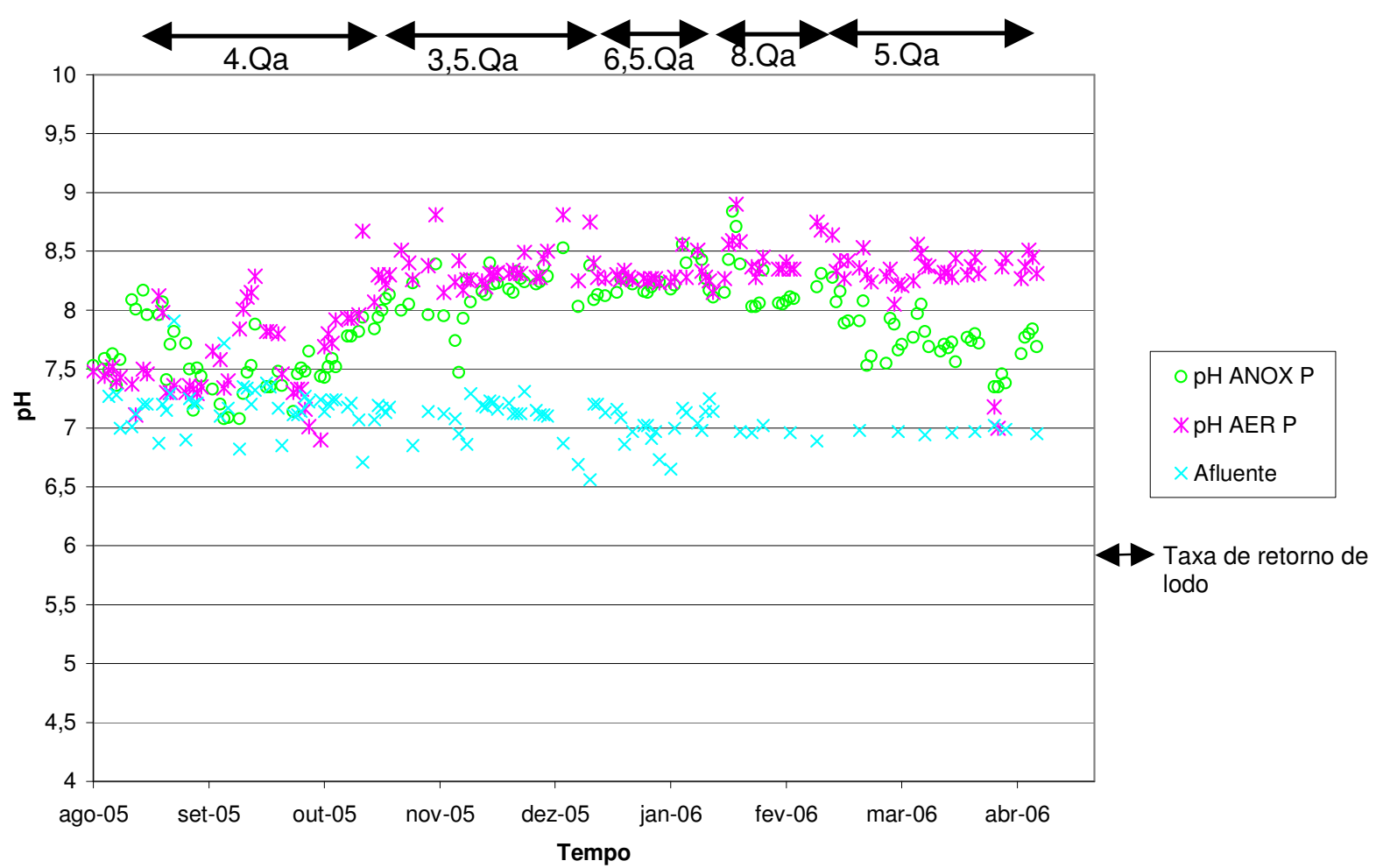

Figura 53 - Variação do pH do Sistema PARCIAL (P) ao longo da primeira fase da pesquisa, com fração anóxica de $23 \%$.

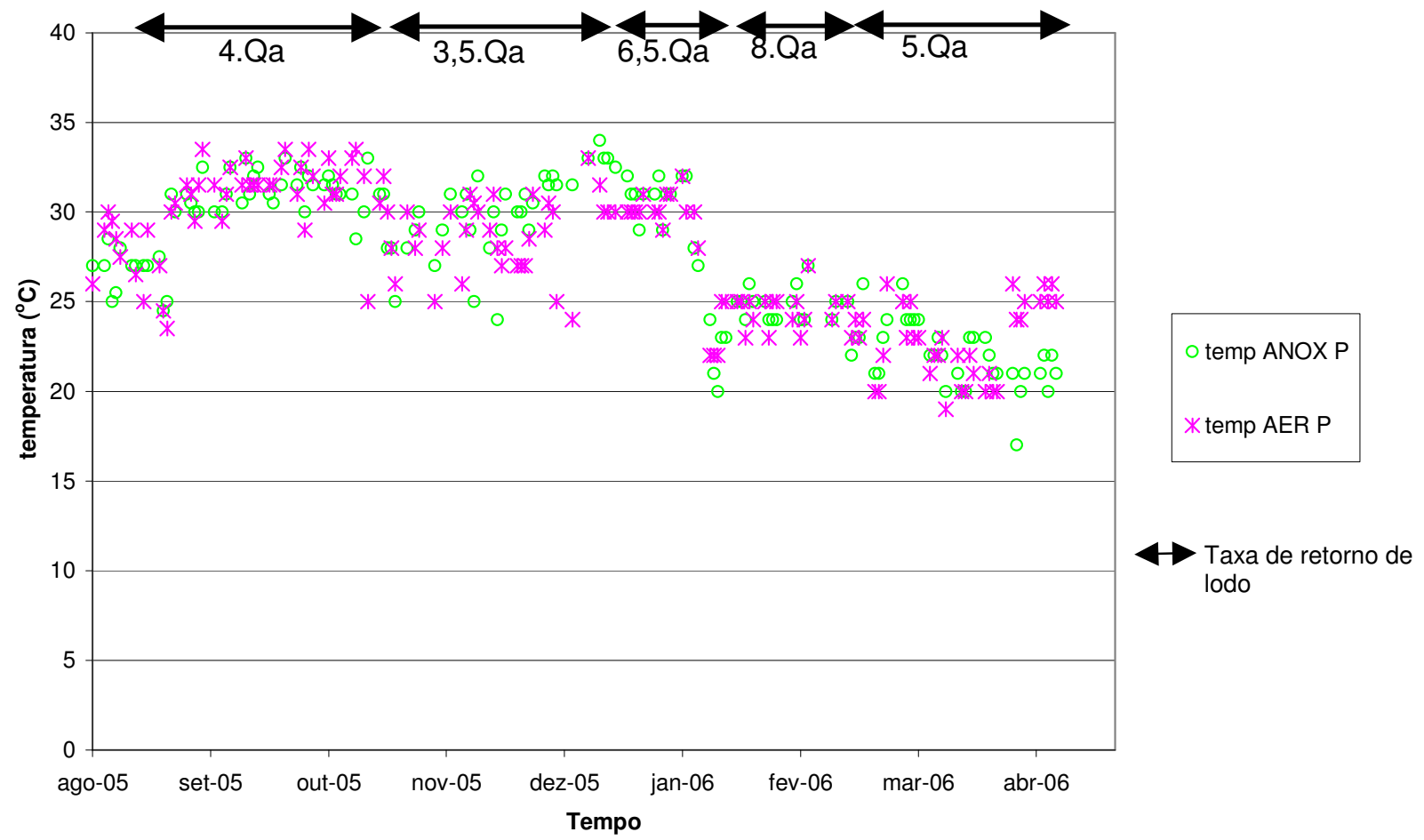

Figura 54 - Variação da temperatura do Sistema PARCIAL (P) ao longo da primeira fase da pesquisa, com fração anóxica de $23 \%$. 


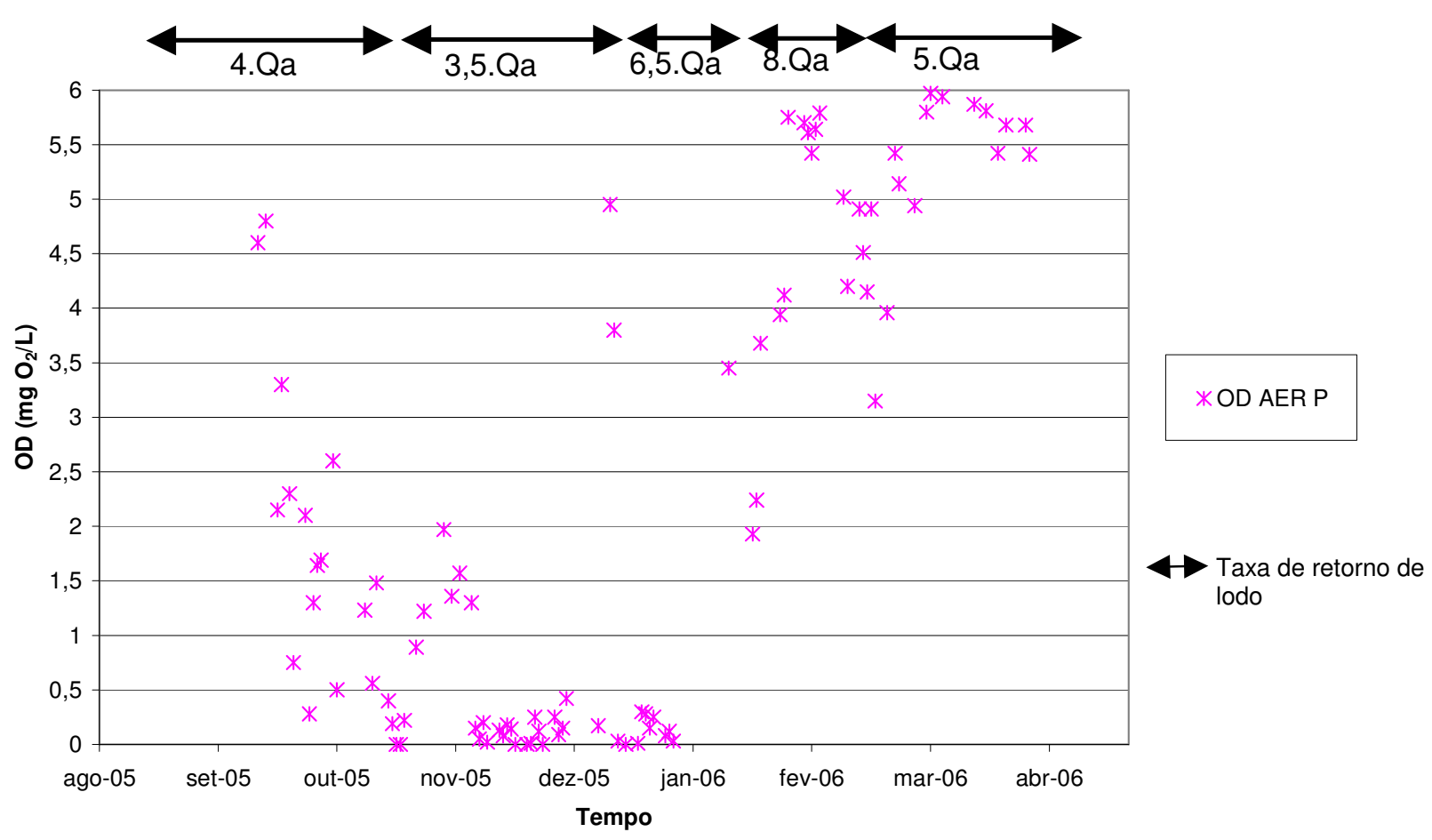

Figura 55 - Variação da concentração de OD do reator aeróbio do Sistema PARCIAL (P) ao longo da primeira fase da pesquisa, com fração anóxica de $23 \%$.

Da Figura 53 apresentada, pode-se observar que, nos primeiros meses dessa fase da pesquisa, o $\mathrm{pH}$ do reator aeróbio foi ajustado com controlador automático praticamente entre 6,5 e 7,5, em virtude de ainda não se saber ao certo qual a faixa ideal para favorecer a "nitritação". De outubro de 2005 a abril de 2006, como os resultados ainda estavam bastante insatisfatórios, decidiu-se por elevar o $\mathrm{pH}$ do aeróbio para a faixa entre 8,0 e 8,5, tendo em vista os bons resultados que eram obtidos com o sistema em batelada em $\mathrm{pH} \cong 8,3$ (QUEIROZ, 2006).

De modo bastante surpreendente, ao longo de todas as etapas da pesquisa nas quais se utilizou faixa de $\mathrm{pH}$ no aeróbio acima de 8,0 no Sistema PARCIAL, observou-se que o pH do anóxico não sofria incremento em relação ao do aeróbio, como geralmente ocorre em reatores desnitrificantes, mantendo-se praticamente equivalente ou até mesmo um pouco menor, muito embora não se possa desprezar que o $\mathrm{pH}$ do afluente era da ordem de 7,0, 
também contribuindo para a não elevação do pH no anóxico. Desse modo, observou-se não ocorrer incremento de alcalinidade no sistema com o reator anóxico (Figura 56).

Nos experimentos em batelada, também foi observado fenômeno similar, da mesma forma não sendo obtida recuperação de alcalinidade na fase anóxica, sendo que Queiroz (2006) associou esse fenômeno à utilização do fenol como fonte de carbono, já que nos testes em que o mesmo utilizou etanol para a desnitrificação, o pH do sistema elevou-se um pouco, nesse último caso sugerindo ter ocorrido recuperação de alcalinidade no reator.

A Figura 54 apresentou o comportamento da temperatura dos reatores ao longo da primeira fase da pesquisa no Sistema PARCIAL. Importante observar que entre março e abril de 2006, os aquecedores/termostatos também não foram capazes de manter a temperatura em $25^{\circ} \mathrm{C}$.

Tendo em vista que a válvula e o controlador de oxigênio dissolvido do reator aeróbio do sistema PARCIAL só foram instalados do meio para o final da pesquisa, no início foram feitos ajustes de oxigenação com o uso de válvula manual, porém não apresentava a precisão desejada. Sendo assim, como a piloto ainda estava em fase de ajuste experimental dos parâmetros operacionais, em determinadas fases, o oxigênio dissolvido foi ajustado para valores inferiores a $1,0 \mathrm{mgO}_{2} / \mathrm{L}$ e em outras, para valores bem superiores a 2,0 $\mathrm{mgO}_{2} / \mathrm{L}$. Como esse ainda era um parâmetro bastante incerto no que se refere ao acúmulo de nitrito no reator aeróbio, as concentrações de oxigênio oscilaram bastante nessa fase da pesquisa, principalmente pela falta do controle automático de OD. 


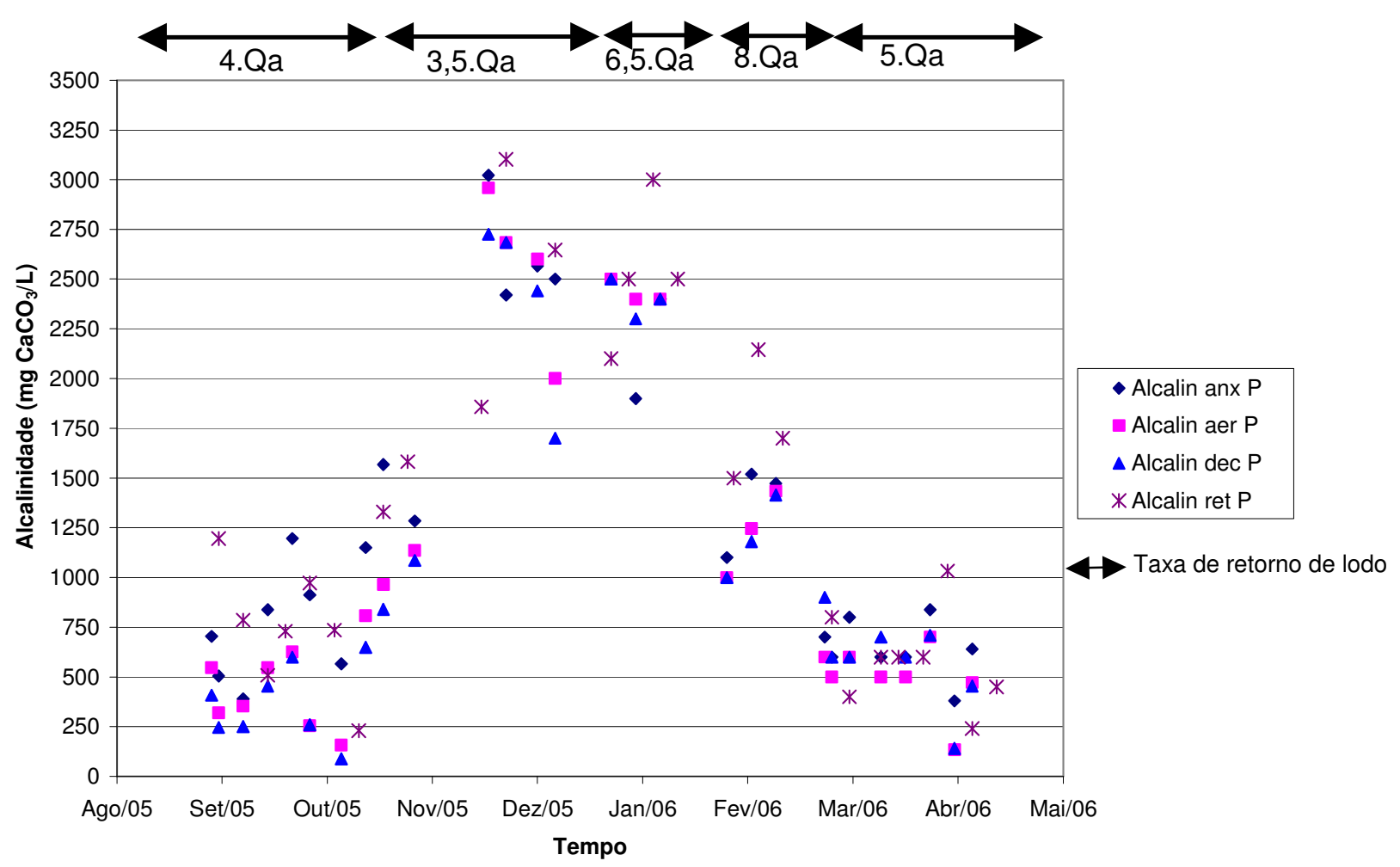

Figura 56 - Alcalinidade observada nas unidades do Sistema PARCIAL (P) ao longo da primeira fase da pesquisa, com fração anóxica de $23 \%$.

Da Figura 56, observa-se que, além de não ocorrer o ganho de alcalinidade desejado com o reator anóxico, conforme anteriormente mencionado, verifica-se também que a alcalinidade do sistema como um todo variou bastante, com valores bem mais elevados do que os demais entre novembro de 2005 e janeiro de 2006, que compreende o período em que se elevou o $\mathrm{pH}$ do sistema para valores acima de 8,0, na tentativa de acúmulo de nitrito. Porém, depois de algum tempo, a alcalinidade do sistema voltou a cair.

\subsubsection{Monitoramento Semanal do Sistema PARCIAL na Primeira Fase}

Da mesma forma como mencionado para o sistema TOTAL, também no caso do PARCIAL, uma das principais determinações semanais realizadas foi a das concentrações de sólidos de suspensão totais e voláteis. 
A Figura 57 ilustra o comportamento de SST e SSV do sistema PARCIAL ao longo da primeira fase dos experimentos.

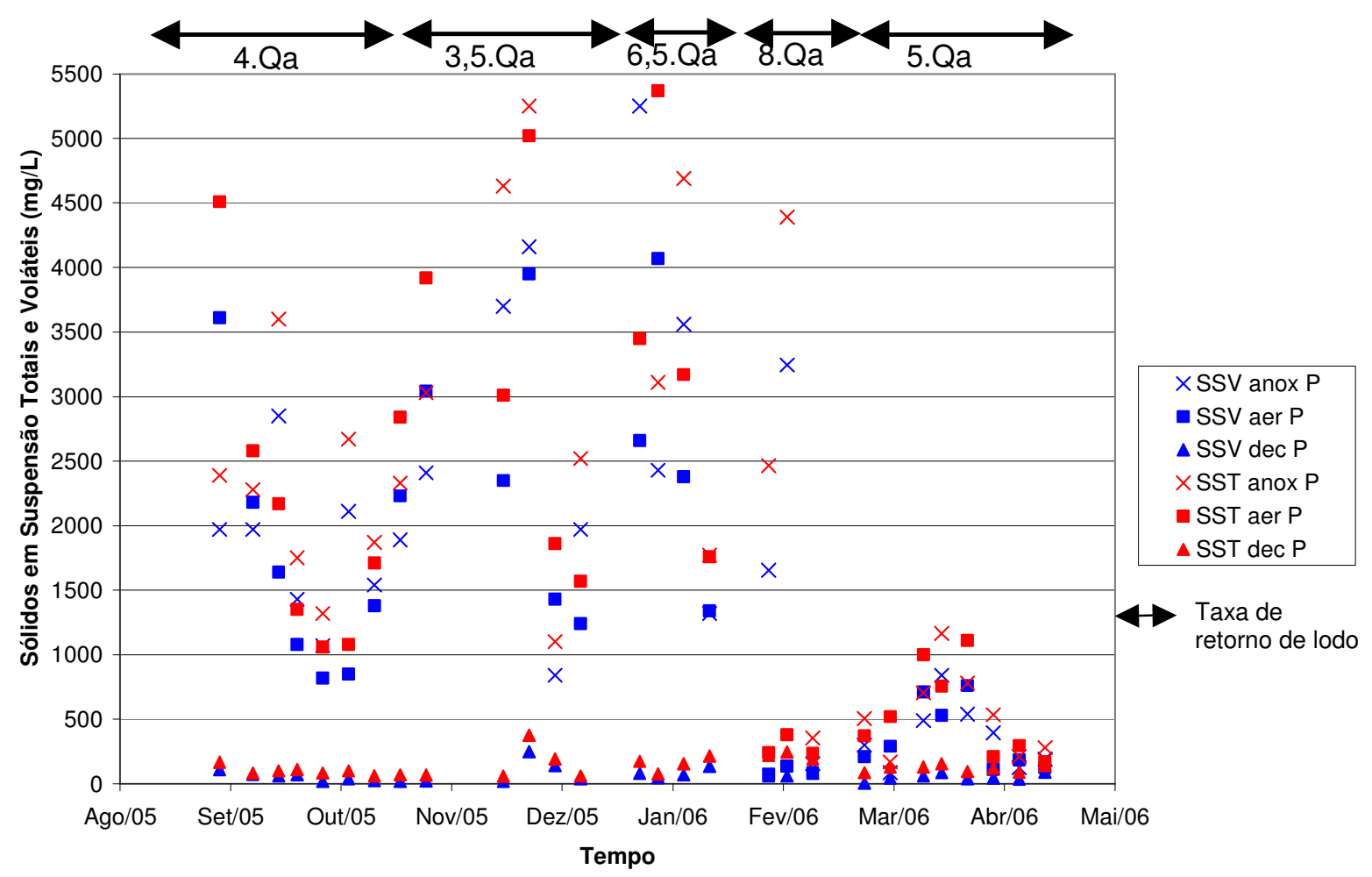

Figura 57 - Concentração de sólidos em suspensão totais e voláteis do Sistema PARCIAL (P) ao longo da primeira fase da pesquisa, com fração anóxica de $23 \%$.

Diferentemente do sistema TOTAL, o sistema PARCIAL apresentou problemas com a lavagem da biomassa do sistema entre fevereiro e junho de 2006, período esse que compreendeu o final da primeira fase da pesquisa e o início da segunda fase. Mesmo quando a concentração de sólidos não esteve tão baixa, ainda assim foi observada considerável oscilação nessas concentrações nos reatores, mostrando que este sistema mostrou-se bem mais sensível que o TOTAL.

Ainda assim, o sistema pôde ser recuperado pouco a pouco com a introdução de pequenas quantidades semanais de lodo proveniente do sistema TOTAL e de outros sistemas piloto de tratamento que também estavam em operação no Laboratório na mesma época desse trabalho. Essa fase de incremento da biomassa do sistema PARCIAL durou bastante tempo, 
porém evitou a perda total do lodo e a necessidade de re-inoculação com lodo da indústria petroquímica, o que provocaria um reinício da operação desse sistema.

Com relação ao monitoramento dos compostos nitrogenados do sistema PARCIAL durante a primeira fase de experimentos, esse é apresentado nas Figuras 58 e 59 . A relação entre o nitrito e a soma dos compostos oxidados de nitrogênio nos reatores anóxico e aeróbio é apresentada na Figura 60. A Figura 61 apresenta o comportamento dos compostos nitrogenados e do $\mathrm{pH}$ do reator aeróbio nessa fase dos experimentos e a Figura 62, a eficiência de remoção de nitrogênio amoniacal observada para o reator aeróbio e para o sistema como um todo.

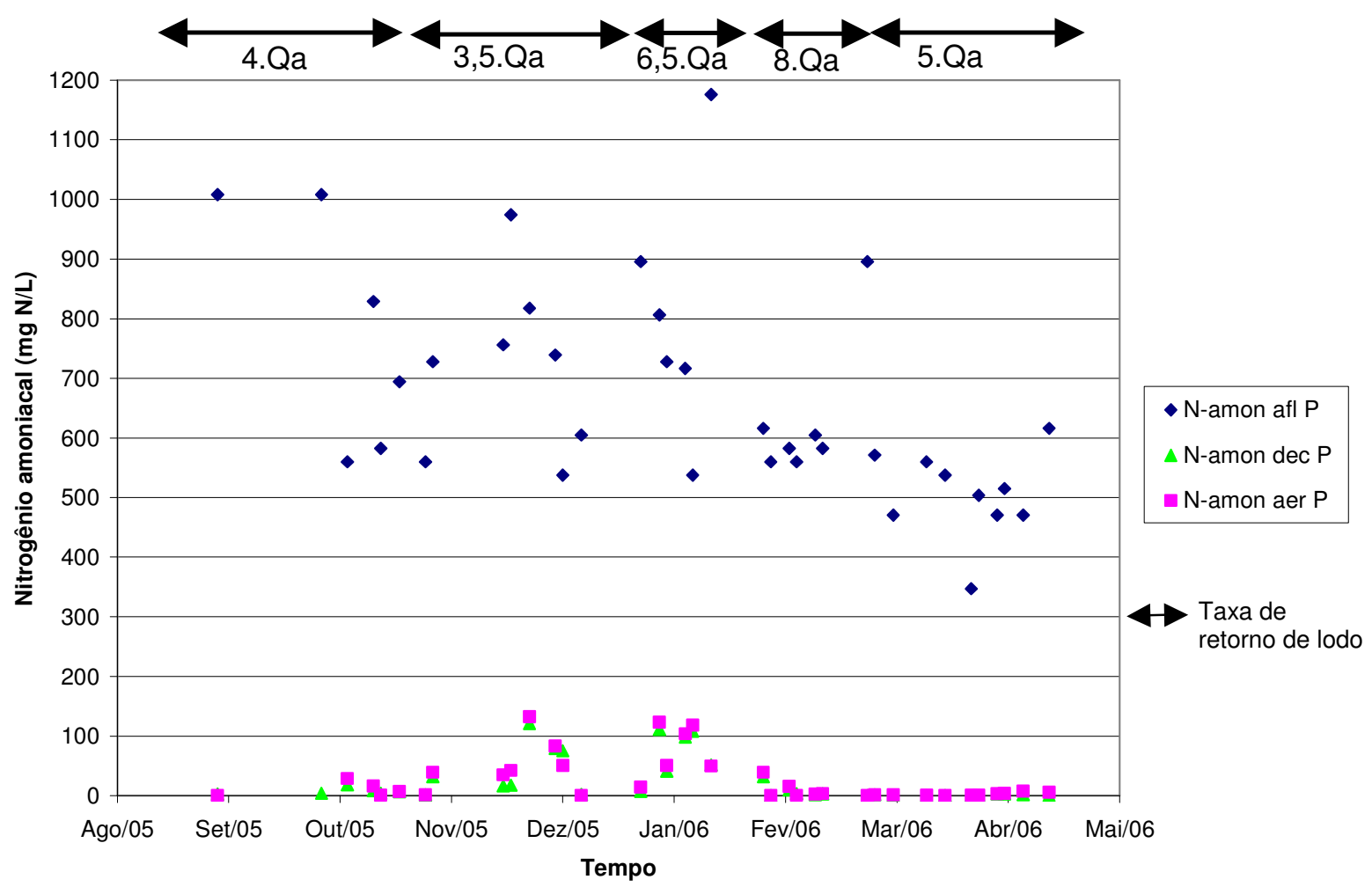

Figura 58 - Comportamento do nitrogênio amoniacal do Sistema PARCIAL (P) ao longo da primeira fase da pesquisa, com fração anóxica de $23 \%$. 


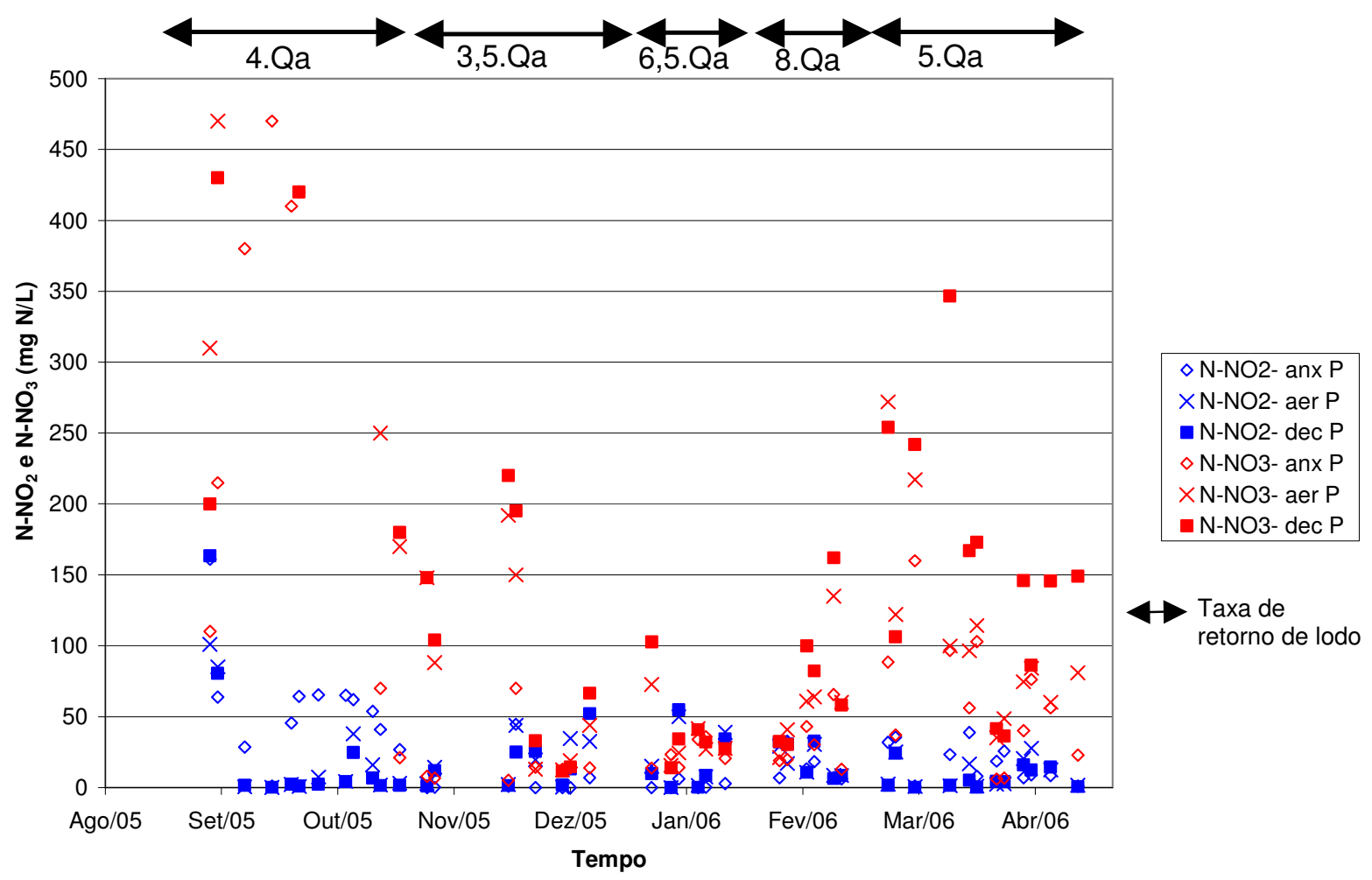

Figura 59 - Comportamento do nitrito e nitrato do Sistema PARCIAL (P) ao longo da primeira fase da pesquisa, com fração anóxica de $23 \%$.

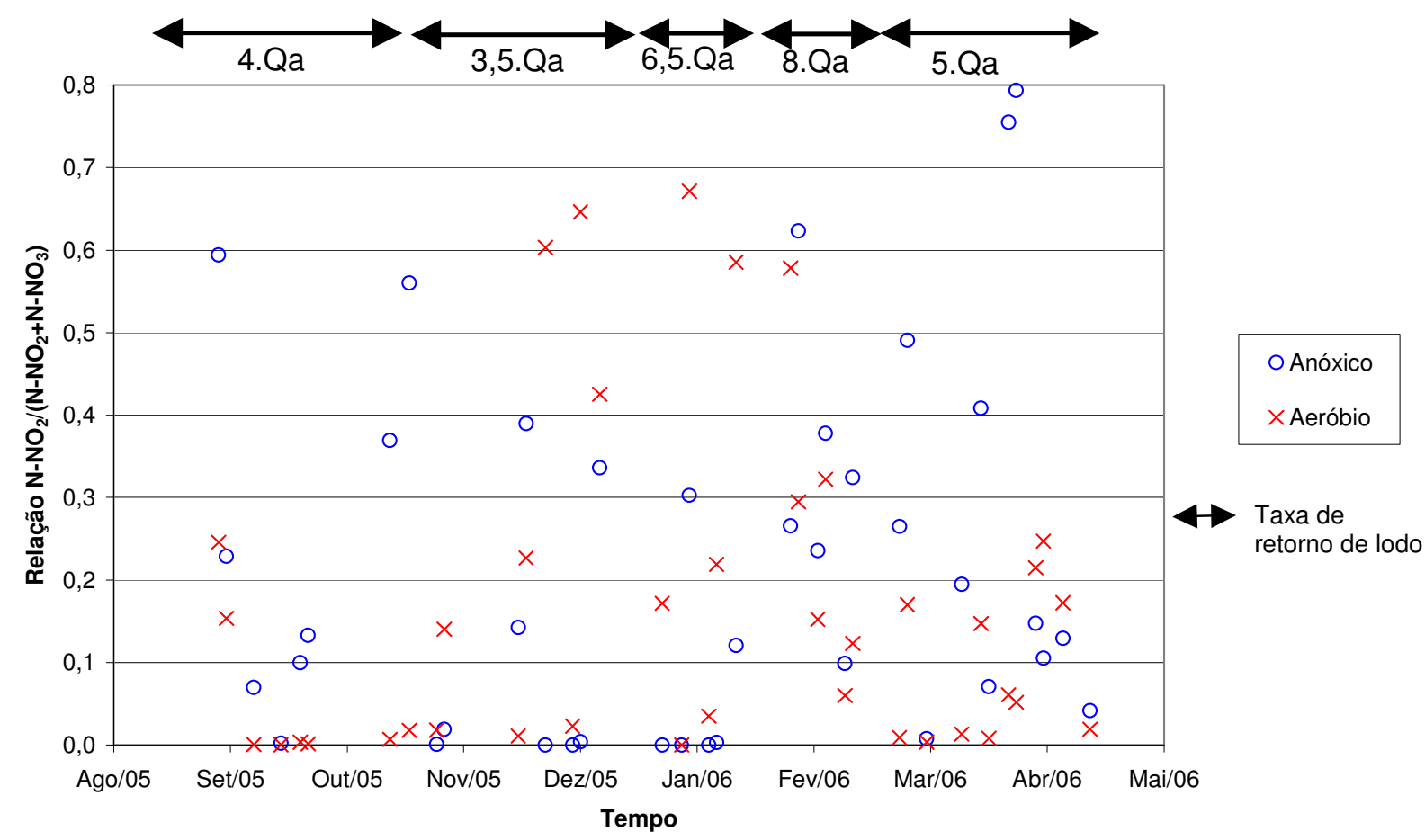

Figura 60 - Relação $\mathrm{N}-\mathrm{NO}_{2}{ }^{-} /\left(\mathrm{N}-\mathrm{NO}_{2}{ }^{-}+\mathrm{N}-\mathrm{NO}_{3}{ }^{-}\right)$nos reatores anóxico e aeróbio do Sistema PARCIAL (P) ao longo da primeira fase da pesquisa, com fração anóxica de $23 \%$. 


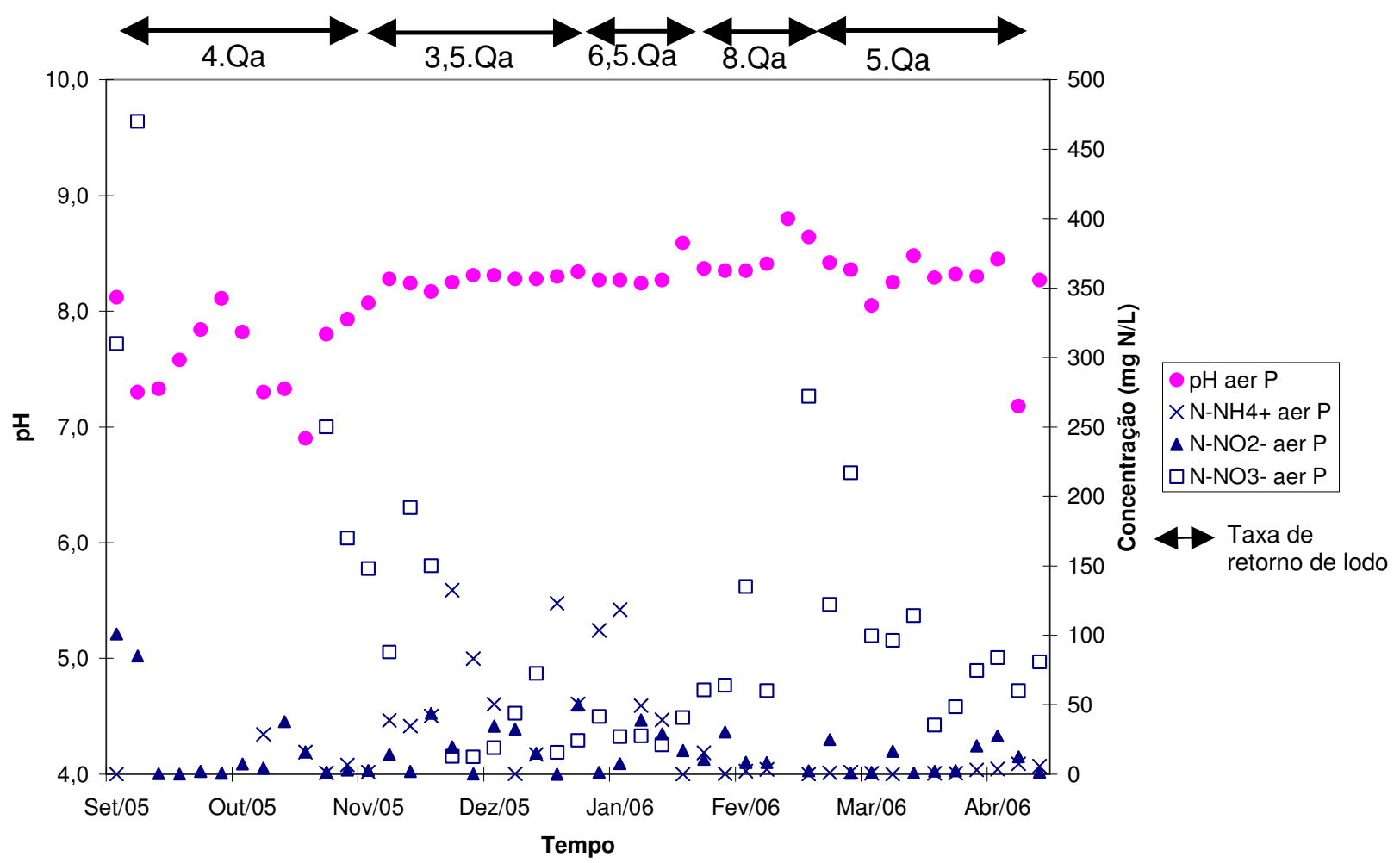

Figura 61 - Comportamento do pH e dos compostos nitrogenados no reator aeróbio do Sistema PARCIAL (P) ao longo da primeira fase da pesquisa, com fração anóxica de $23 \%$.

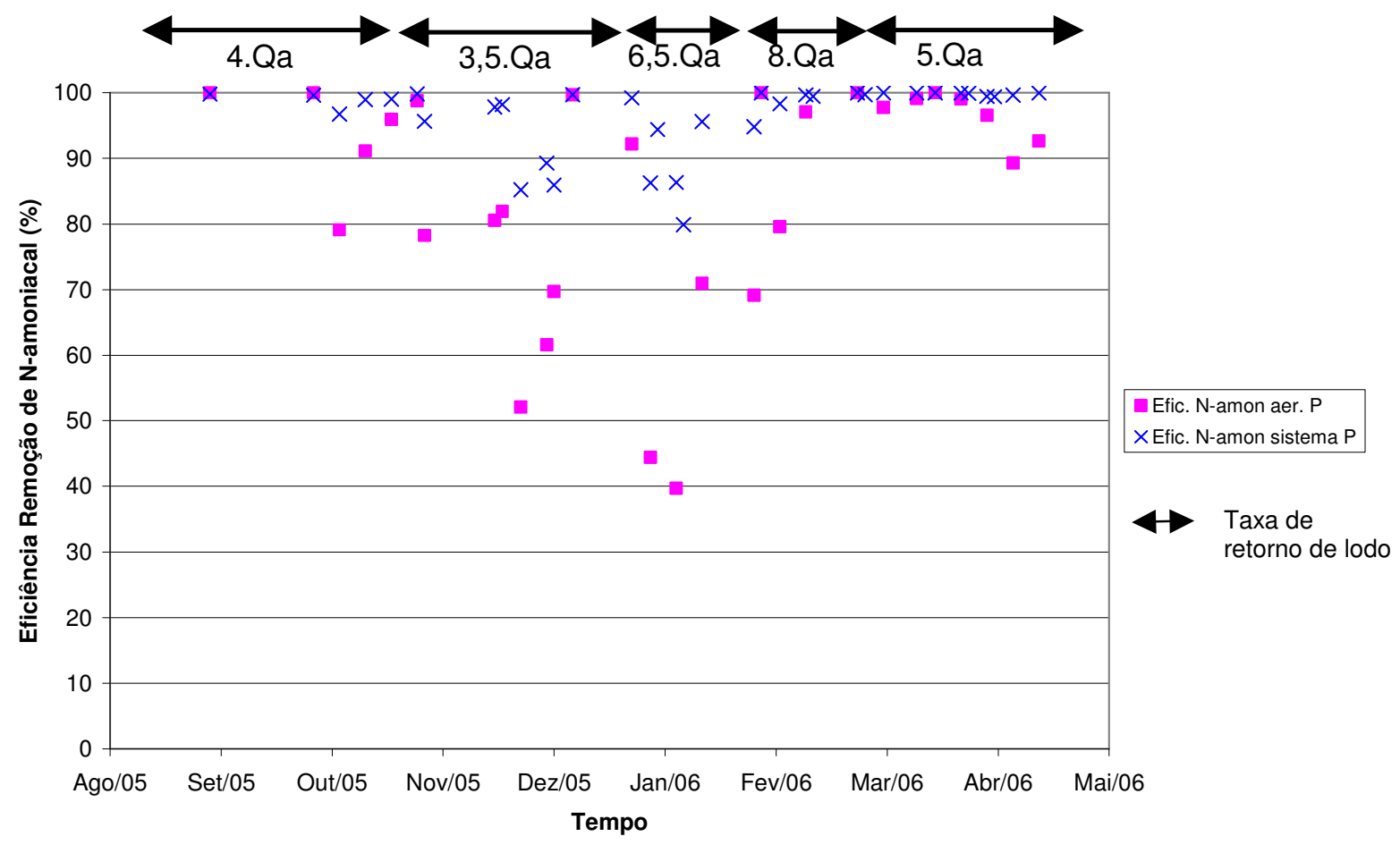

Figura 62 - Eficiência de remoção de nitrogênio amoniacal no reator aeróbio e no sistema ao longo da primeira fase da pesquisa, com fração anóxica de $23 \%$, para o Sistema PARCIAL (P). 
Como já mencionado anteriormente, no início dos experimentos, utilizou-se concentração afluente de nitrogênio amoniacal de $750 \mathrm{mgN} / \mathrm{L}$, o que foi alterado para $500 \mathrm{mgN} / \mathrm{L}$ no decorrer da pesquisa.

É possível notar que, na maior parte das vezes, as concentrações de nitrogênio amoniacal no efluente final apresentaram-se abaixo dos $20 \mathrm{mgN} / \mathrm{L}$ estipulados pela Legislação CONAMA 357/05 (vide análise estatística do nitrogênio amoniacal na Figura 63, para os resultados com concentração afluente $500 \mathrm{mgN} / \mathrm{L}$ ). No entanto, entre novembro de 2005 e fevereiro de 2006, esse valor foi ultrapassado diversas vezes. Da Figura 62, observa-se que de fato as eficiências de remoção de nitrogênio amoniacal estiveram bem aquém do desejado nesse período, chegando a apenas 40\% de remoção em janeiro de 2006 .

Analisando-se todo o período de operação do sistema PARCIAL, incluindo as etapas preliminares desprezadas em termos de resultados, a primeira e a segunda fase, a amônia livre no reator aeróbio só foi observada em níveis relativamente elevados (de 2,3 a $20,7 \mathrm{mg} \mathrm{NH}_{3} / \mathrm{L}$ ) durante esse mesmo período mencionado, de novembro de 2005 a fevereiro de 2006, no qual a nitrificação foi inibida por completo, não só pelas altas concentrações de amônia livre observadas como também pelas baixas concentrações de oxigênio dissolvido mantidas no reator aeróbio. Nos demais períodos, essa foi praticamente desprezível, quase sempre inferiores a $0,1 \mathrm{mg} \mathrm{NH} / \mathrm{L}$ e, de acordo com Anthonisen et al. (1976), para inibição das bactérias oxidadoras de nitrito, é necessária concentração de amônia livre no reator em concentrações de 0,1 a $1,0 \mathrm{mg} \mathrm{NH} / \mathrm{L}$.

De modo bastante coerente, observou-se que os compostos oxidados de nitrogênio também se apresentaram em concentrações relativamente baixas entre essas datas, mostrando que o sistema apresentava problemas na nitrificação, tanto completa quanto parcial.

Comparando-se a Figura 61 com o comportamento das concentrações de oxigênio dissolvido (Figura 55) do sistema PARCIAL, observa-se que mesmo com o pH da ordem de 
8,3, conforme observado nos experimentos em batelada (QUEIROZ, 2006), o acúmulo de amônia e conseqüente redução na "nitritação/nitratação" foi evidente e, portanto, as baixas concentrações de oxigênio dissolvido mantidas nessa fase $\left(<0,5 \mathrm{mgO}_{2} / \mathrm{L}\right)$ foram claramente prejudiciais ao sistema.

Quanto aos demais períodos, a predominância do nitrato sobre o nitrito é visível (vide análise estatística dos compostos oxidados de nitrogênio na Figura 64, para os resultados com concentração afluente de nitrogênio amoniacal de $500 \mathrm{mgN} / \mathrm{L}$ ), mesmo em alguns casos se observando concentrações consideráveis de nitrito no sistema. Entretanto, a Figura 60 mostra que a relação $\mathrm{N}-\mathrm{NO}_{2}{ }^{-} /\left(\mathrm{N}_{-} \mathrm{NO}_{2}{ }^{-}+\mathrm{N}^{-} \mathrm{NO}_{3}{ }^{-}\right)$variou bastante ao longo de toda essa fase, mas que a maioria dos resultados, tanto para o reator anóxico quanto para o aeróbio, esteve compreendida abaixo de 0,3 e que, portanto, na maioria das vezes o nitrito foi menor do que $30 \%$ da soma dos compostos oxidados. Além disso, observa-se que a relação superou 0,3 na maioria das vezes no reator anóxico, ou seja, nesses casos sugere-se que ocorreu desnitrificação incompleta a nitrito, e não a nitrogênio gasoso, como era desejável. A Figura 65 a seguir corrobora esse fato, apresentando a análise estatística da relação $\mathrm{N}-\mathrm{NO}_{2}{ }^{-} /\left(\mathrm{N}-\mathrm{NO}_{2}{ }^{-}+\mathrm{N}-\mathrm{NO}_{3}{ }^{-}\right)$nessa fase dos experimentos, para os resultados com concentração afluente de nitrogênio amoniacal de $500 \mathrm{mgN} / \mathrm{L}$.

As taxas de desnitrificação completa observadas no reator anóxico do sistema PARCIAL na primeira fase variaram de 0,01 a 0,07 $\mathrm{kg} \mathrm{N}-\mathrm{NO}_{\mathrm{x}} / \mathrm{kg}$ SSV.dia, ao passo que as taxas de "desnitritação" nesse mesmo período foram quase sempre de 0,01 kg N-NO $2 / \mathrm{kg} \mathrm{SSV.dia.}$ 


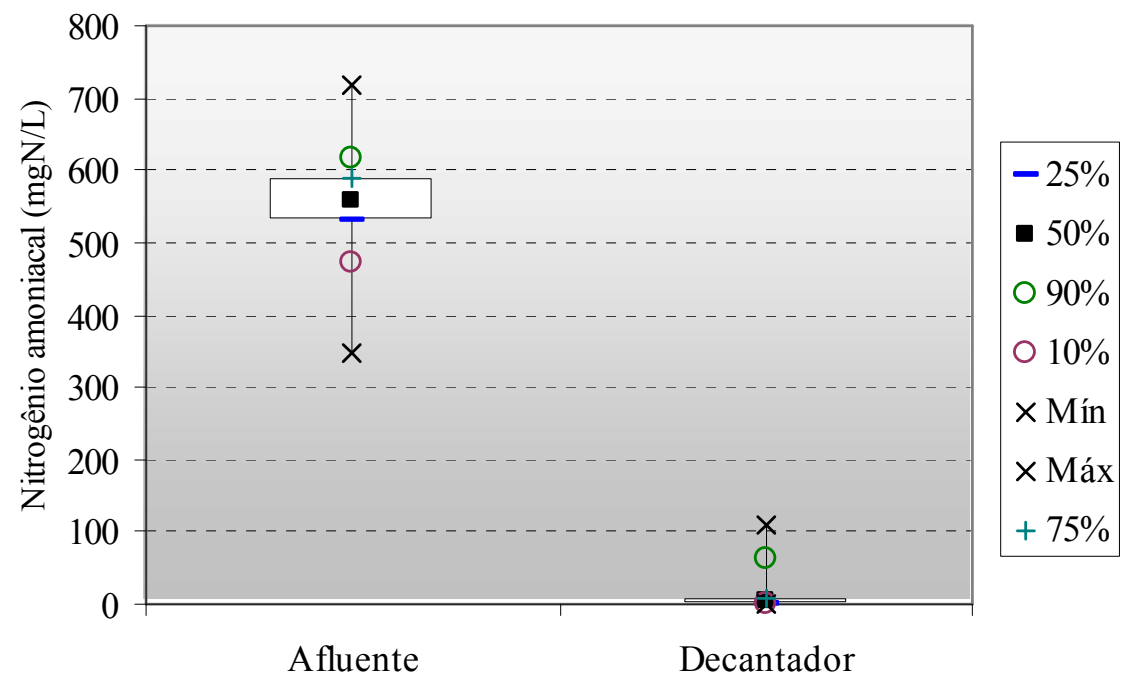

Figura 63 - Análise estatística do nitrogênio amoniacal no Sistema PARCIAL (P), para os resultados com concentração afluente de $500 \mathrm{mgN} / \mathrm{L}$, durante a primeira fase da pesquisa, com fração anóxica de $23 \%$.

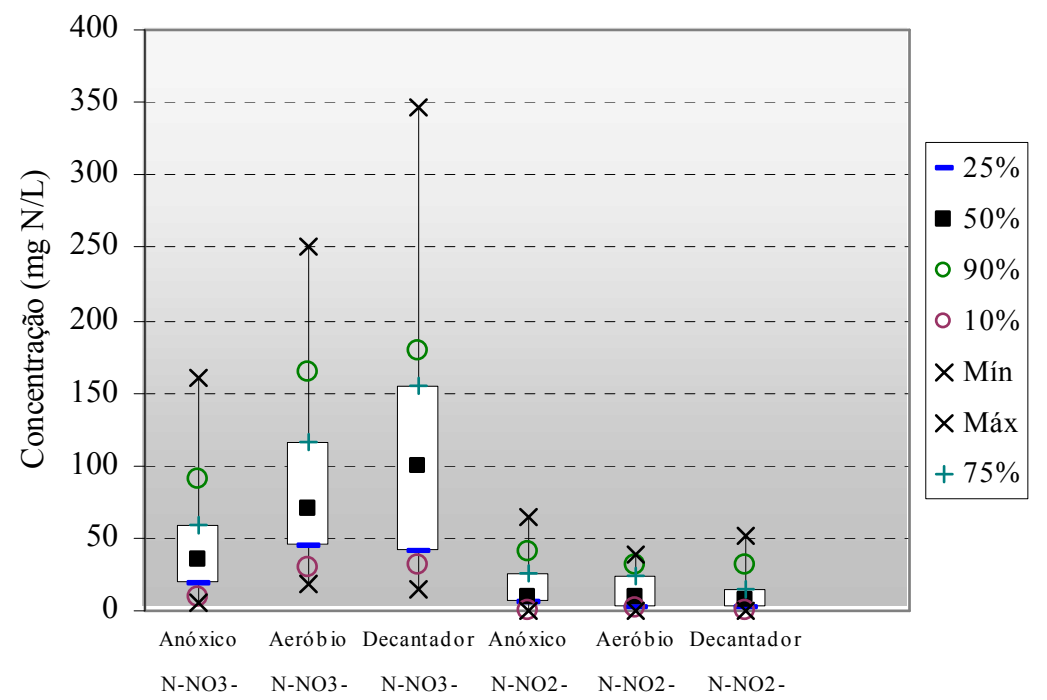

Figura 64 - Análise estatística dos compostos oxidados de nitrogênio no Sistema PARCIAL (P), para os resultados com concentração afluente de nitrogênio amoniacal de $500 \mathrm{mg} \mathrm{N} / \mathrm{L}$, durante a primeira fase da pesquisa, com fração anóxica de $23 \%$. 


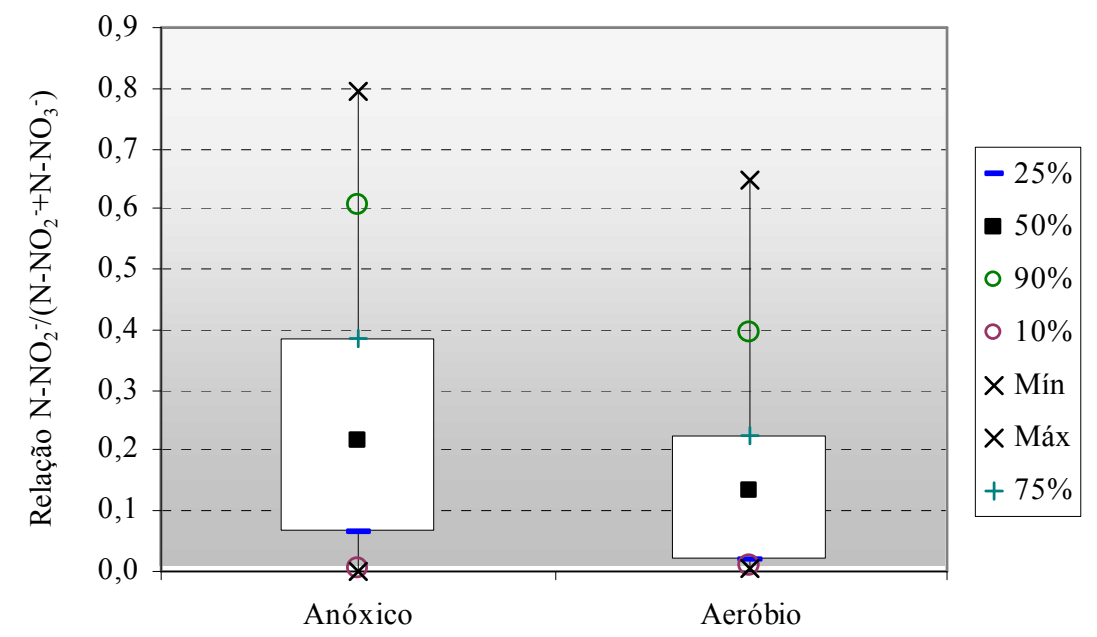

Figura 65 - Análise estatística da relação $\mathrm{N}-\mathrm{NO}_{2}{ }^{-} /\left(\mathrm{N}-\mathrm{NO}_{2}{ }^{-}+\mathrm{N}-\mathrm{NO}_{3}{ }^{-}\right)$nos reatores anóxico e aeróbio do Sistema PARCIAL (P), para os resultados com concentração afluente de nitrogênio amoniacal de $500 \mathrm{mgN} / \mathrm{L}$, durante a primeira fase da pesquisa, com fração anóxica de $23 \%$.

A Figura 66 apresenta o comportamento da DBO do sistema PARCIAL ao longo da primeira fase dos trabalhos.

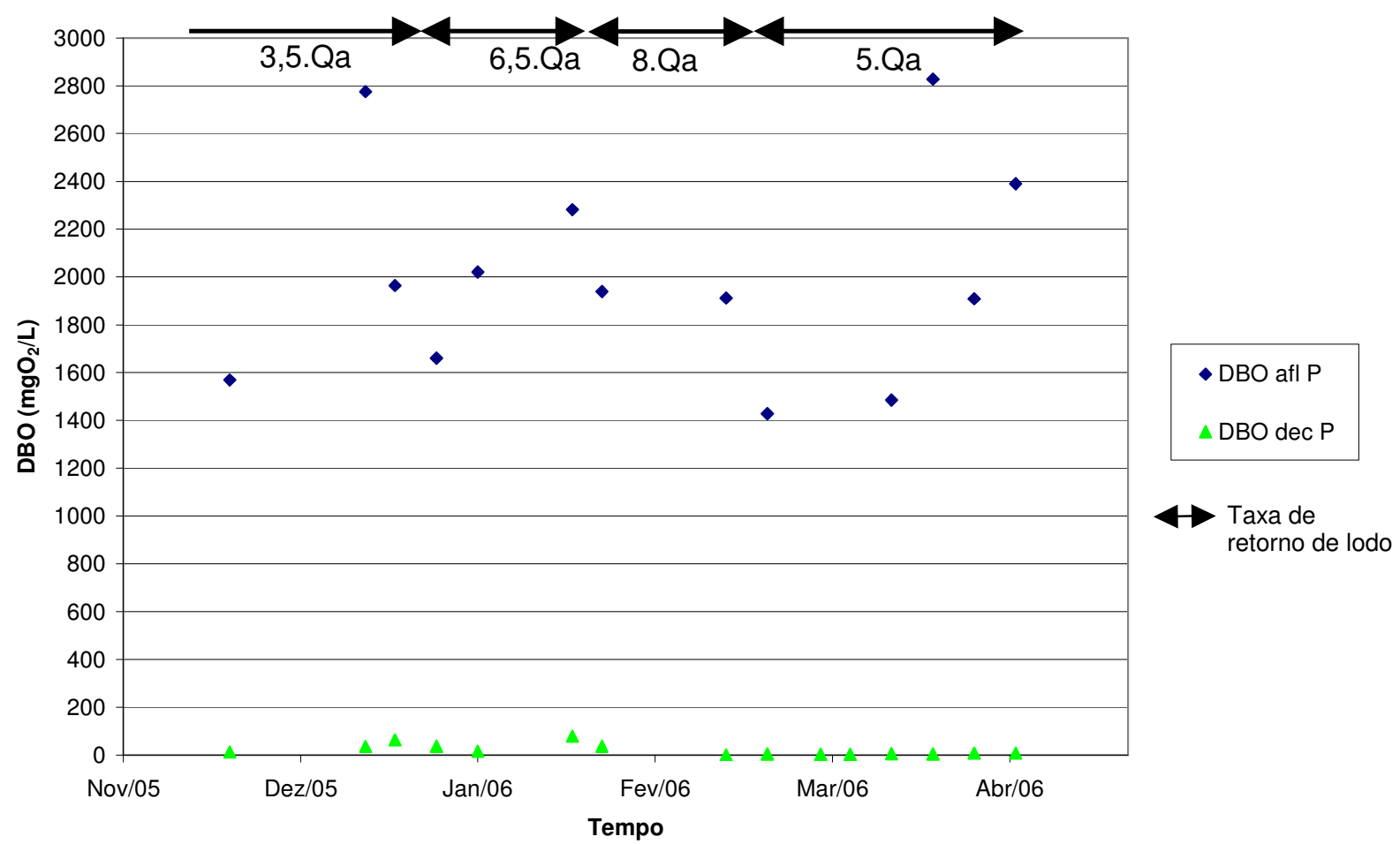

Figura 66 - Comportamento da DBO do Sistema PARCIAL (P) ao longo da primeira fase da pesquisa, com fração anóxica de $23 \%$. 
Observa-se que, apesar da grande discrepância dos valores obtidos para a DBO do afluente, ainda assim os resultados foram satisfatórios para esse parâmetro, já que os valores obtidos para as amostras do decantador/efluente final foram quase sempre inferiores a $60 \mathrm{mgO}_{2} / \mathrm{L}$, e quando não, a eficiência de remoção de DBO esteve maior do que os $80 \%$ exigidos pela Legislação (SÃO PAULO, 1976).

A Figura 67 ilustra o comportamento do fenol do sistema PARCIAL ao longo da primeira fase da pesquisa. A Figura 68 apresenta as relações $\mathrm{A} / \mathrm{M}$ e as taxas de utilização de substrato no reator anóxico e a Figura 69, a eficiência de remoção de fenol no reator anóxico e no sistema como um todo nessa mesma fase do experimento. A Figura 70 apresenta a análise estatística dos compostos fenólicos para o sistema PARCIAL na primeira fase, considerando-se os resultados quando as concentrações de nitrogênio amoniacal eram da ordem de $500 \mathrm{mgN} / \mathrm{L}$.

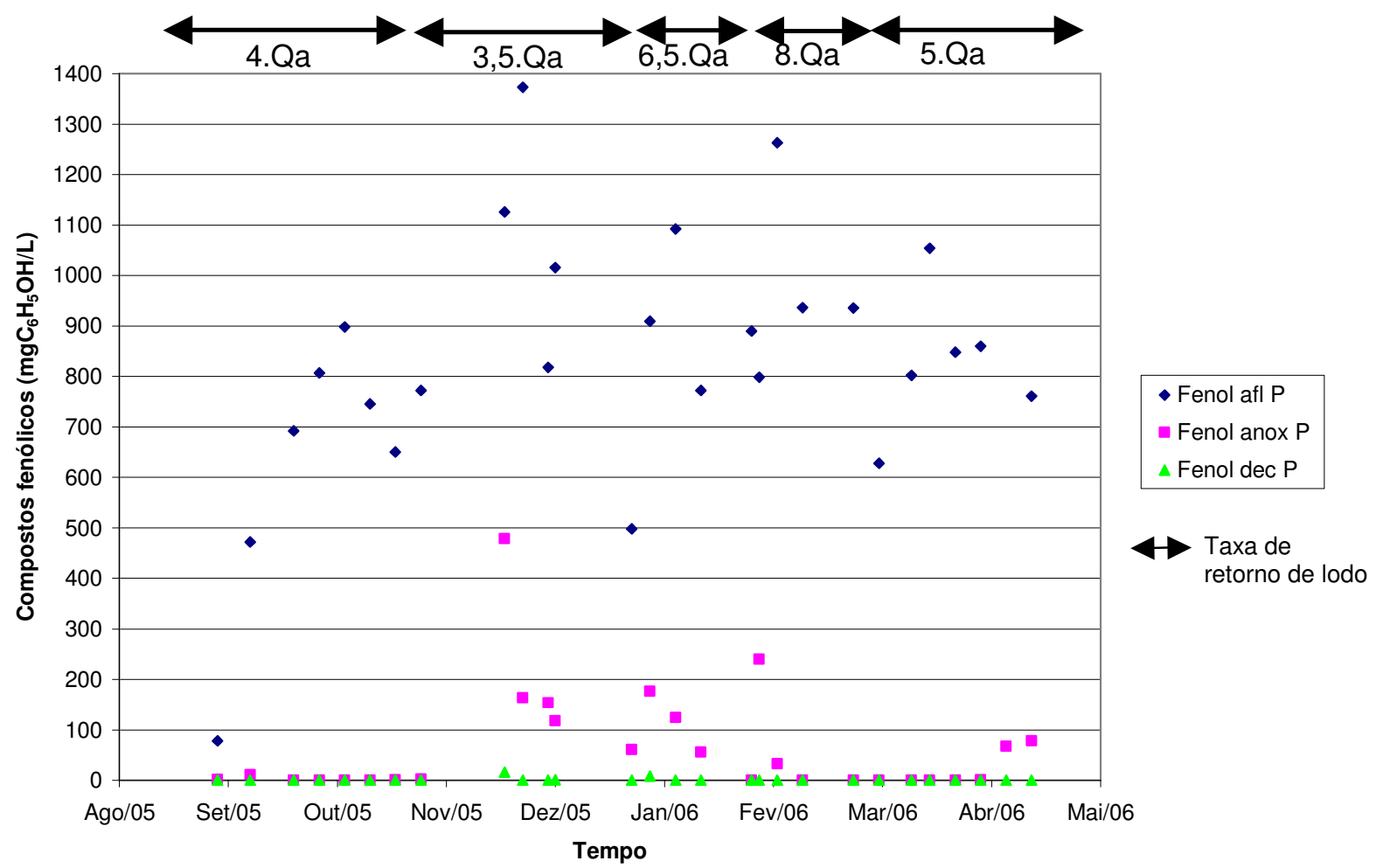

Figura 67 - Comportamento do fenol do Sistema PARCIAL (P) ao longo da primeira fase da pesquisa, com fração anóxica de $23 \%$. 


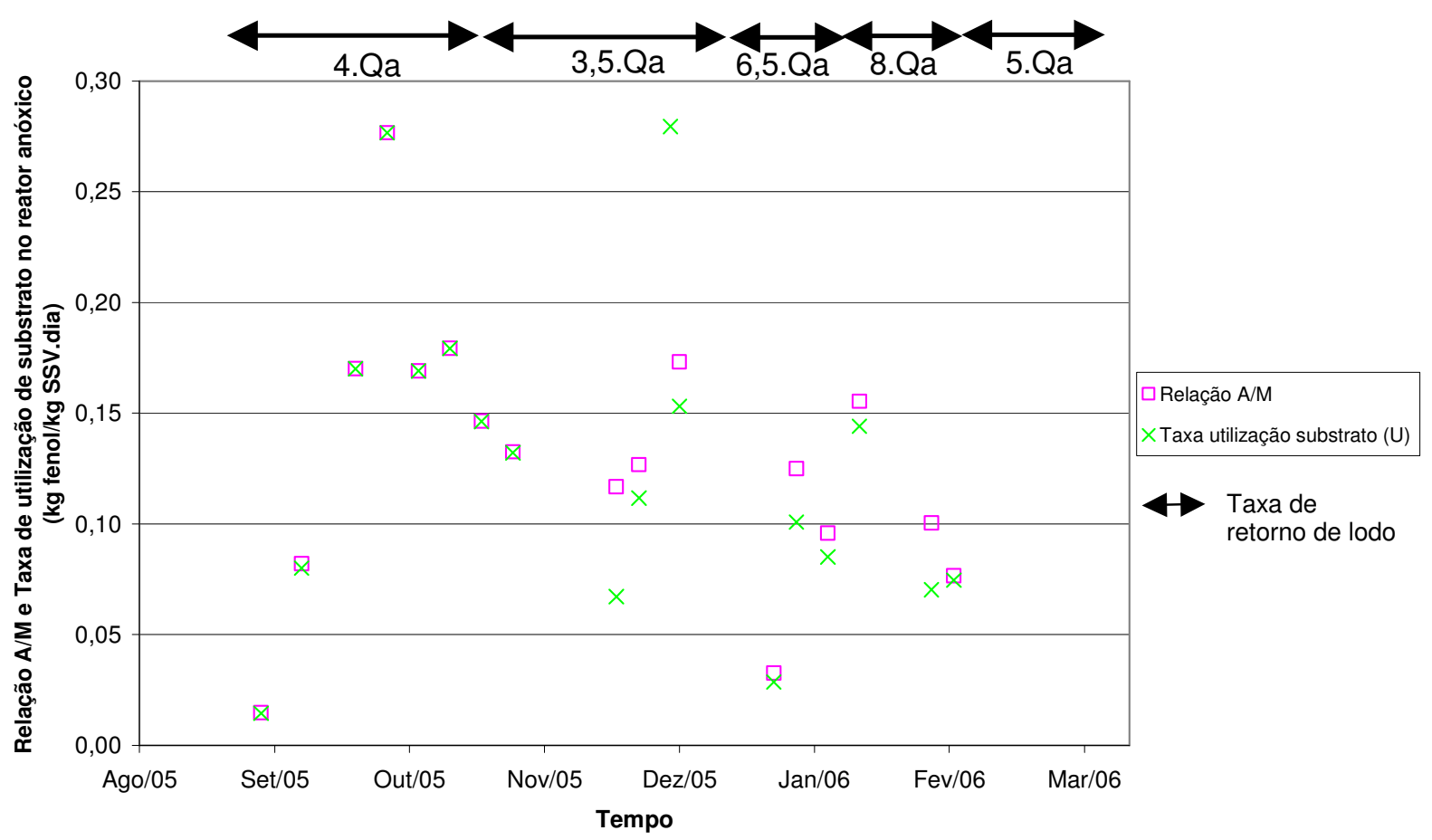

Figura 68 - Relação A/M e taxas de utilização de substrato no reator anóxico do Sistema PARCIAL (P) ao longo da primeira fase da pesquisa, com fração anóxica de $23 \%$.

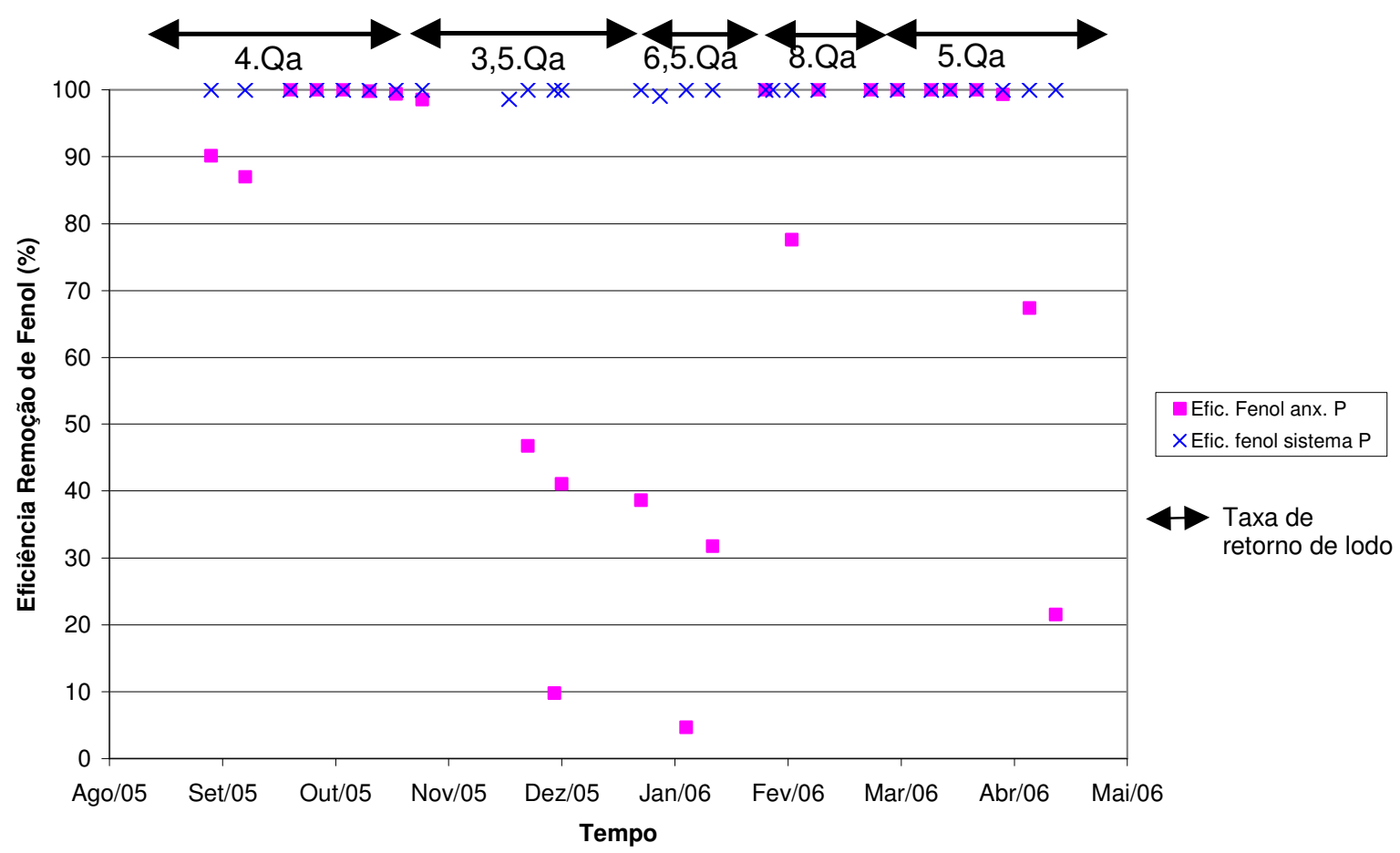

Figura 69 - Eficiência na remoção de fenol no reator anóxico e no sistema ao longo da primeira fase da pesquisa, com fração anóxica de $23 \%$, para o Sistema PARCIAL (P). 


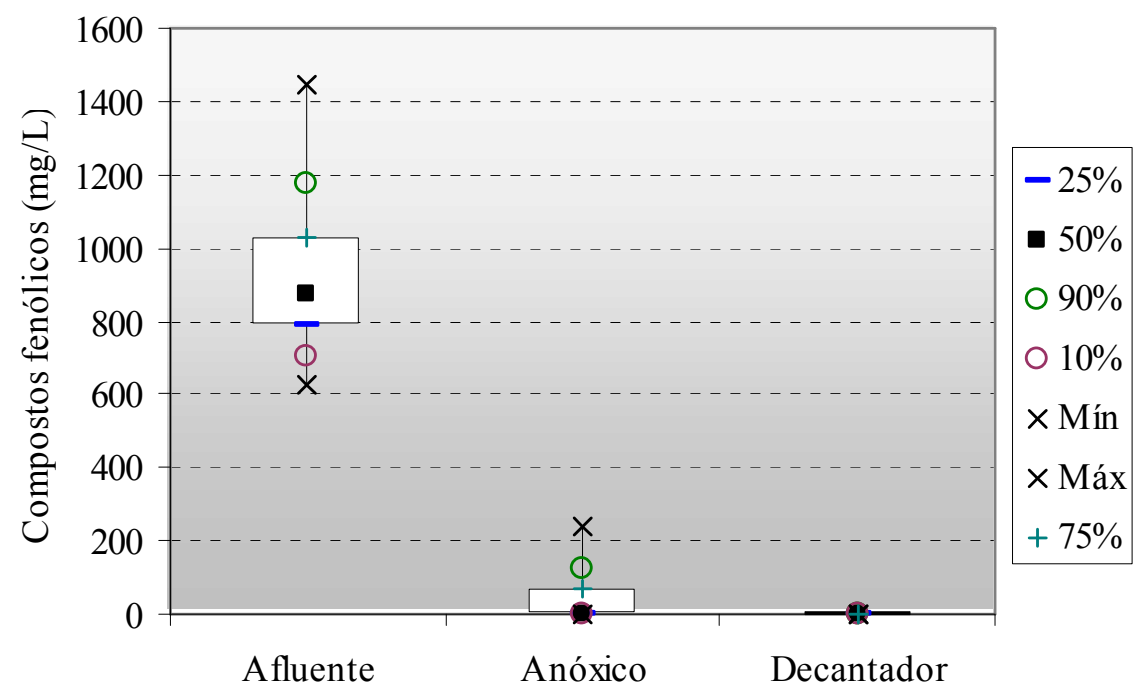

Figura 70 - Análise estatística dos compostos fenólicos para o Sistema PARCIAL (P), para os resultados com concentração afluente de nitrogênio amoniacal de $500 \mathrm{mgN} / \mathrm{L}$, na primeira fase da pesquisa, com fração anóxica de $23 \%$.

Assim como ocorreu com o sistema TOTAL, no sistema PARCIAL, apesar do decantador secundário apresentar concentrações desprezíveis de fenol $\left(<0,5 \mathrm{mg} \mathrm{C}_{6} \mathrm{H}_{5} \mathrm{OH} / \mathrm{L}\right)$, ainda assim muitas foram as vezes que o reator anóxico apresentou acúmulo de fenol (Figuras 67 e 70). Para esse sistema, o maior desequilíbrio observado ocorreu entre novembro de 2005 e janeiro de 2006, com acúmulos de fenol consideráveis no anóxico (Figuras 67 e 69) e taxas de utilização de substrato bem inferiores à relação $\mathrm{A} / \mathrm{M}$ aplicada (Figura 68). Em virtude desses acúmulos de fenol observados nesse período, procedeu-se consideráveis aumentos na razão de recirculação de lodo, na tentativa de se elevar as concentrações de nitrato e nitrito no reator anóxico.

Vale ressaltar que, como ocorreram problemas com a concentração de sólidos no final dessa fase, as relações $\mathrm{A} / \mathrm{M}$ e as taxas de utilização de substrato ficaram muito elevadas e seus resultados ficaram mascarados, sendo portanto desprezados.

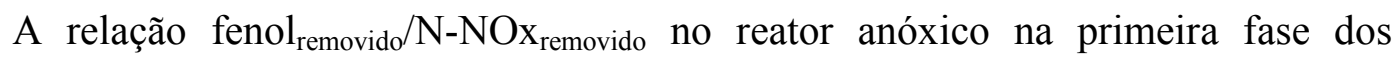
experimentos do sistema PARCIAL oscilou bastante, obtendo-se principalmente valores da 


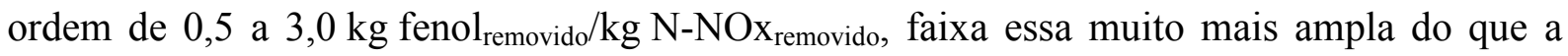
observada no sistema em bateladas seqüenciais, que variou entre 2,1 a 3,2 $\mathrm{kg}$ fenol $_{\text {removido }} / \mathrm{kg} \mathrm{N}-\mathrm{NOx}_{\text {removido }}$ (QUEIROZ, 2006), tendo em vista que no sistema contínuo, entre novembro de 2005 e janeiro de 2006, como já mencionado, a eficiência de remoção de fenol no anóxico foi muito baixa.

Sendo assim, em abril de 2006, decidiu-se por aumentar a fração anóxica do sistema, aumentando-se o volume útil do reator anóxico, marcando o início da segunda fase da pesquisa.

\subsubsection{Segunda Fase - Fração Anóxica de 41\%}

Na segunda fase, o sistema PARCIAL apresentava uma fração anóxica de 41\%, ou seja, o reator anóxico passou a ter volume útil de 70 litros, enquanto o aeróbio, os mesmos 100 litros da primeira fase.

Nessa fase, o sistema PARCIAL trabalhou com tempo de detenção hidráulico total que variou de 9 a 30 dias; o tempo de detenção do anóxico esteve entre 4 e 12 dias e o do aeróbio, entre 5 e 18 dias.

Conforme já exposto, essa fase iniciou-se em maio de 2006 e terminou em janeiro de 2007 . 
5.2.2.1 Monitoramento Diário do Sistema PARCIAL na Segunda Fase

As Figuras 71,72 e 73 a seguir apresentam o comportamento do $\mathrm{pH}$, da temperatura e da concentração de oxigênio dissolvido dos reatores do Sistema PARCIAL ao longo da segunda fase da pesquisa.

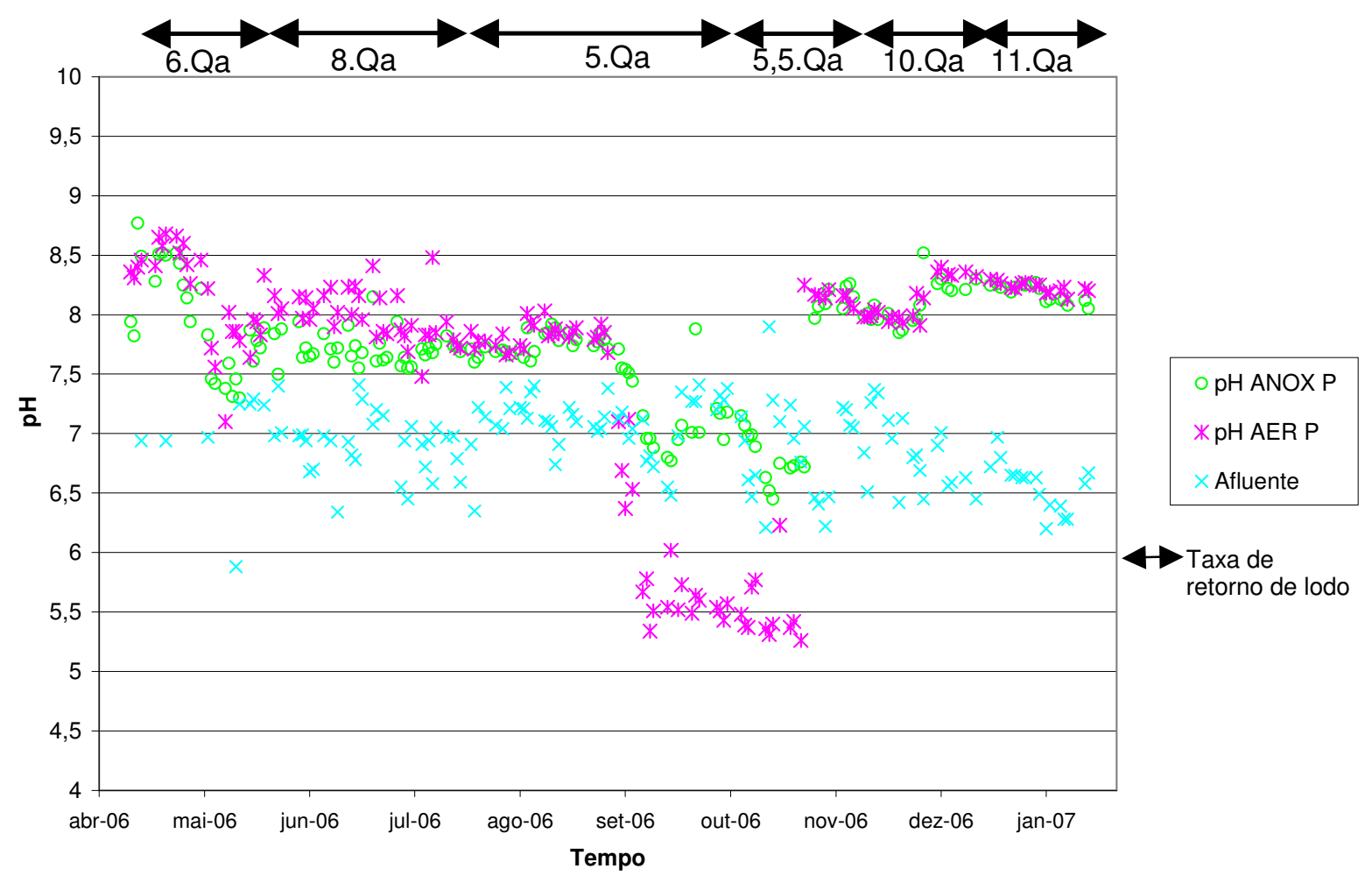

Figura 71 - Variação do pH do Sistema PARCIAL (P) ao longo da segunda fase da pesquisa, com fração anóxica de $41 \%$. 


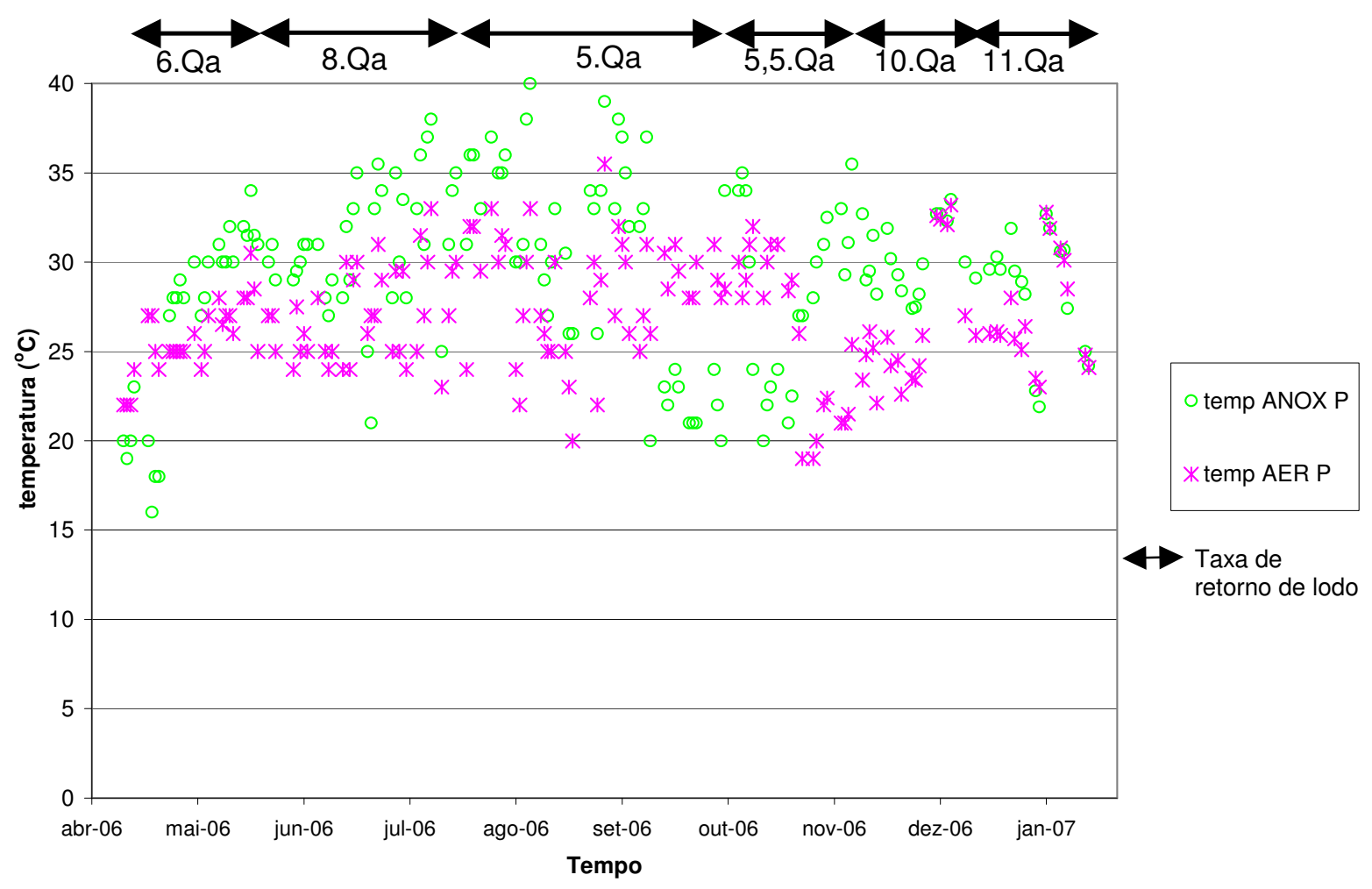

Figura 72 - Variação da temperatura do Sistema PARCIAL (P) ao longo da segunda fase da pesquisa, com fração anóxica de $41 \%$.

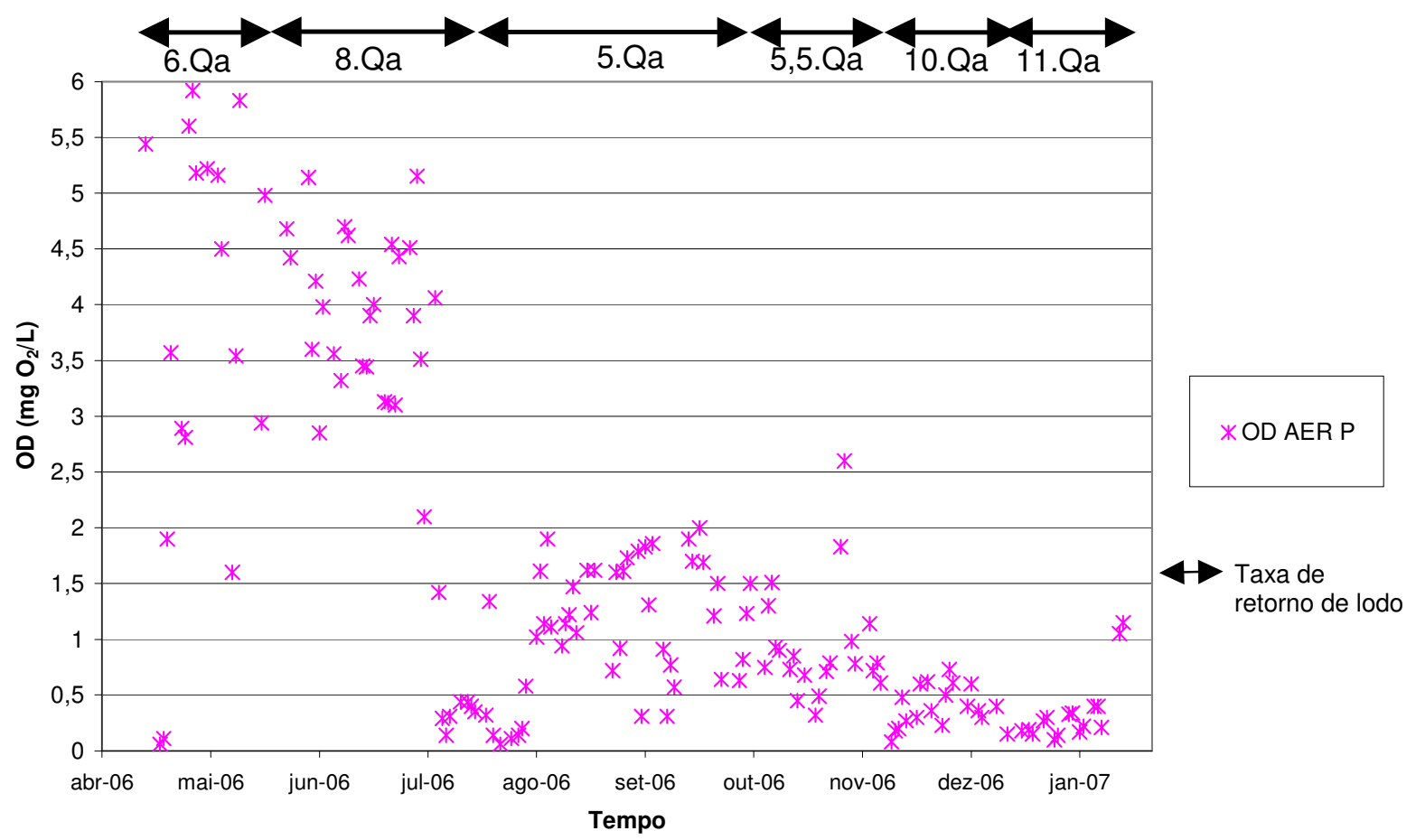

Figura 73 - Variação da concentração de OD do reator aeróbio do Sistema PARCIAL (P) ao longo da segunda fase da pesquisa, com fração anóxica de $41 \%$. 
Observe-se que os gráficos mostram as taxas de recirculação de lodo totais (retorno de lodo do fundo do decantador mais reciclo do aeróbio para o anóxico) utilizadas nessa fase da pesquisa. Vale ressaltar que de maio a novembro de 2006, o sistema operava apenas com o retorno de lodo do decantador secundário para o anóxico, sendo que nos dois últimos meses da pesquisa, entre dezembro de 2006 e janeiro de 2007, foi também instalada bomba de reciclo de lodo do aeróbio para o anóxico, em virtude de limitação da bomba de retorno do decantador. Os constantes acúmulos de fenol observados no anóxico justificam as várias taxas de recirculação de lodo adotadas, até se obter no final da pesquisa razões de reciclo da ordem de 10 a 11 vezes a vazão afluente, que foram as que forneceram melhores resultados.

$\mathrm{Na}$ tentativa de se obter a faixa ideal de $\mathrm{pH}$ que promovesse o acúmulo de nitrito no reator aeróbio, como o uso do $\mathrm{pH}$ acima de 8,0 não apresentava os resultados esperados, entre setembro e novembro de 2006, optou-se por tentar acumular nitrito com a inibição pelo ácido nitroso, não mais pela amônia livre como as tentativas anteriores e, portanto, reduziu-se o pH do aeróbio a valores menores do que 6,0 (ANTHONISEN et al., 1976). Mesmo assim, essa proposta também não apresentou resultado, pois o nitrito foi observado em níveis irrisórios, às vezes até desprezíveis, durante esses meses.

Após essa tentativa frustrada, retornou-se à opção do ajuste de $\mathrm{pH}$ a valores acima de 8,0 (ANTHONISEN et al, 1976), preferencialmente acima de 8,3, conforme observado no sistema em batelada (QUEIROZ, 2006), o que se manteve até o fim do trabalho. Alguns picos de nitrito foram observados nessa fase, mas nenhum deles com a estabilidade desejada, nem tampouco em níveis que se sobressaíssem ao nitrato.

Em relação à temperatura dos reatores, em alguns momentos, observou-se dificuldade em mantê-la em valores acima de $25^{\circ} \mathrm{C}$, pois diversas vezes os aquecedores/termostatos estavam queimados; outras vezes, os mesmos acumulavam um 
"filme biológico" envolto no equipamento, o que fazia o mesmo diminuir a transferência de calor e conseqüentemente sua eficiência, o que provocava brusca queda de temperatura, até ser providenciada a reposição por termostatos novos.

A Figura 73 apresentou o comportamento das concentrações de oxigênio dissolvido do reator aeróbio do sistema PARCIAL na segunda fase da pesquisa. No início dessa fase, as concentrações se apresentaram elevadas, acima de 2,0 $\mathrm{mgO}_{2} / \mathrm{L}$ e, do meio para o fim do trabalho, com a aquisição da válvula e do controlador de oxigênio dissolvido, foi possível manter o OD principalmente abaixo de $1,0 \mathrm{mgO}_{2} / \mathrm{L}$, na tentativa de se observar a "nitritação".

Entretanto, o que se observou com bastante clareza ao longo da operação do sistema entre julho de 2006 e janeiro de 2007, quando foi instalado o controle automático de oxigenação do meio no reator aeróbio, foi que apesar da válvula utilizada ter sido adequada para abertura e fechamento da vazão de ar, a mesma foi comandada pelo controlador de OD da YOKOGAWA que não se mostrou preciso o suficiente para a função a que foi destinado. A oscilação da concentração de OD mostrada no display do equipamento era muito grande, provocando aberturas e fechamentos da válvula seqüenciais, prejudicando a manutenção do reator com a concentração de OD desejada. Acredita-se que algum interferente com o sensor de OD estava presente na biomassa, enviando ao controlador sinais instáveis provocando leituras oscilatórias. Acrescente-se o fato de que, de um modo geral, sondas de OD acopladas a medidores são bastante imprecisos para leituras inferiores a $1,0 \mathrm{mgO}_{2} / \mathrm{L}$, o que também prejudica o ajuste das concentrações nessa faixa. Mesmo assim, segundo as leituras observadas, as concentrações de OD foram mantidas principalmente abaixo de $1,0 \mathrm{mgO}_{2} / \mathrm{L}$, conforme verificado nos experimentos em bateladas seqüenciais como faixa favorável à “nitritação” (QUEIROZ, 2006). 
5.2.2.2 Monitoramento Semanal do Sistema PARCIAL na Segunda Fase

O monitoramento da concentração de sólidos em suspensão totais e voláteis nos reatores do sistema PARCIAL na segunda fase de experimentos é apresentado na Figura 74.

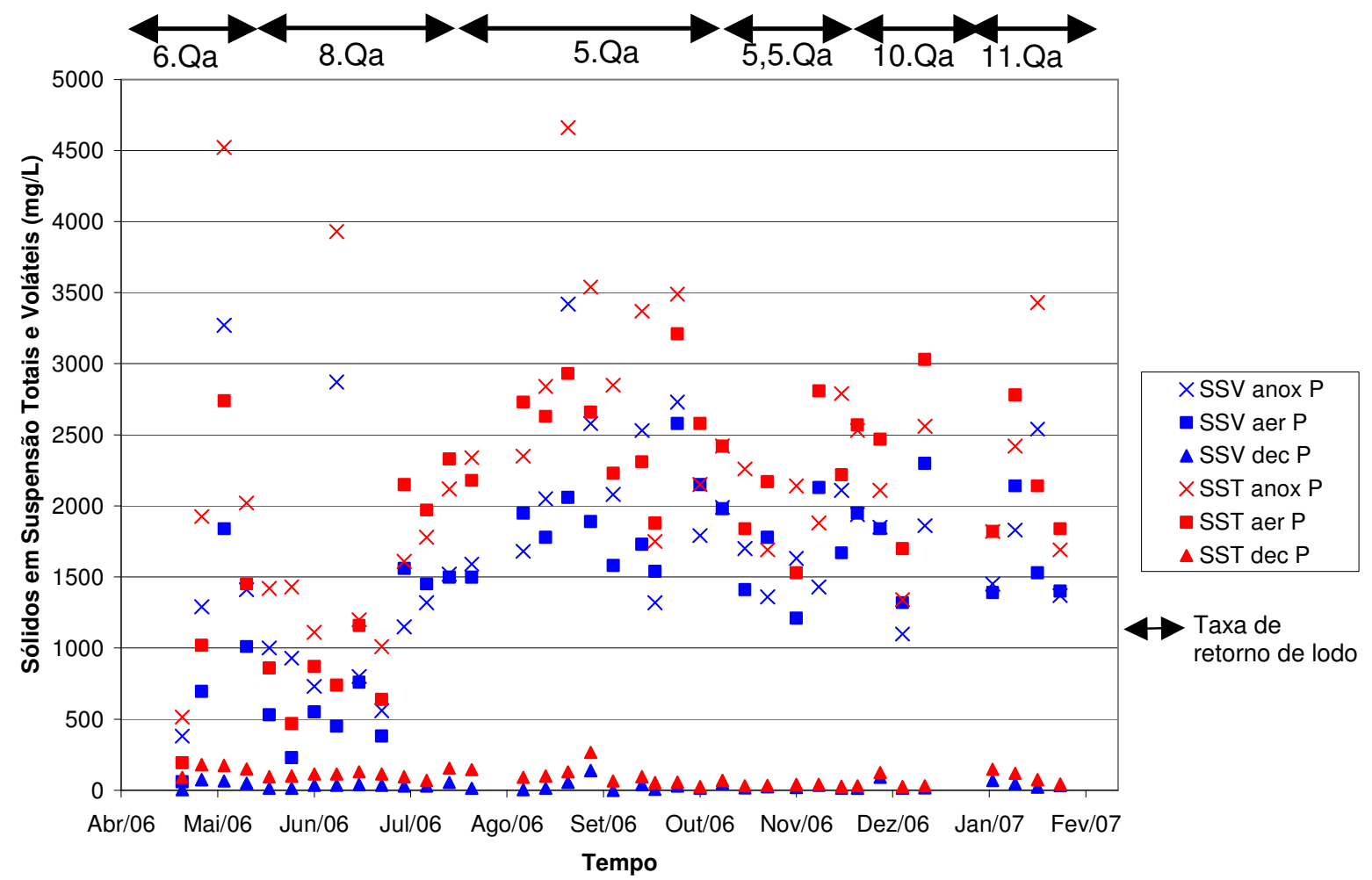

Figura 74 - Concentração de sólidos em suspensão totais e voláteis do Sistema PARCIAL (P) ao longo da segunda fase da pesquisa, com fração anóxica de $41 \%$.

A Figura 74 mostra que, apesar da perda de biomassa do sistema iniciada na primeira fase e que se estendeu até junho de 2006, o incremento de lodo feito com biomassa proveniente de outros sistemas piloto foi capaz de recuperar o sistema PARCIAL, sendo que a concentração de SST e SSV observada até o término na pesquisa se manteve principalmente entre 1.500 e $3.000 \mathrm{mg} / \mathrm{L}$.

Da mesma forma como ocorreu com o sistema TOTAL, a recirculação de lodo sofreu aumentos seqüenciais até o término do trabalho, como já mencionado anteriormente, visando manter concentrações ideais de nitrito e nitrato no reator anóxico para não ocorrer 
acúmulo de fenol. Ao final da pesquisa, o sistema PARCIAL estava trabalhando com retorno de lodo da ordem de 3 vezes ou $300 \%$ e recirculação interna de cerca de 8 vezes ou $800 \%$, totalizando um reciclo de aproximadamente 11 vezes a vazão afluente. Recirculações menores ao longo do experimento mostraram-se insuficientes para promover a desnitrificação sem acúmulo de fenol no reator anóxico.

O comportamento da alcalinidade do sistema PARCIAL na segunda fase da pesquisa é ilustrado na Figura 75.

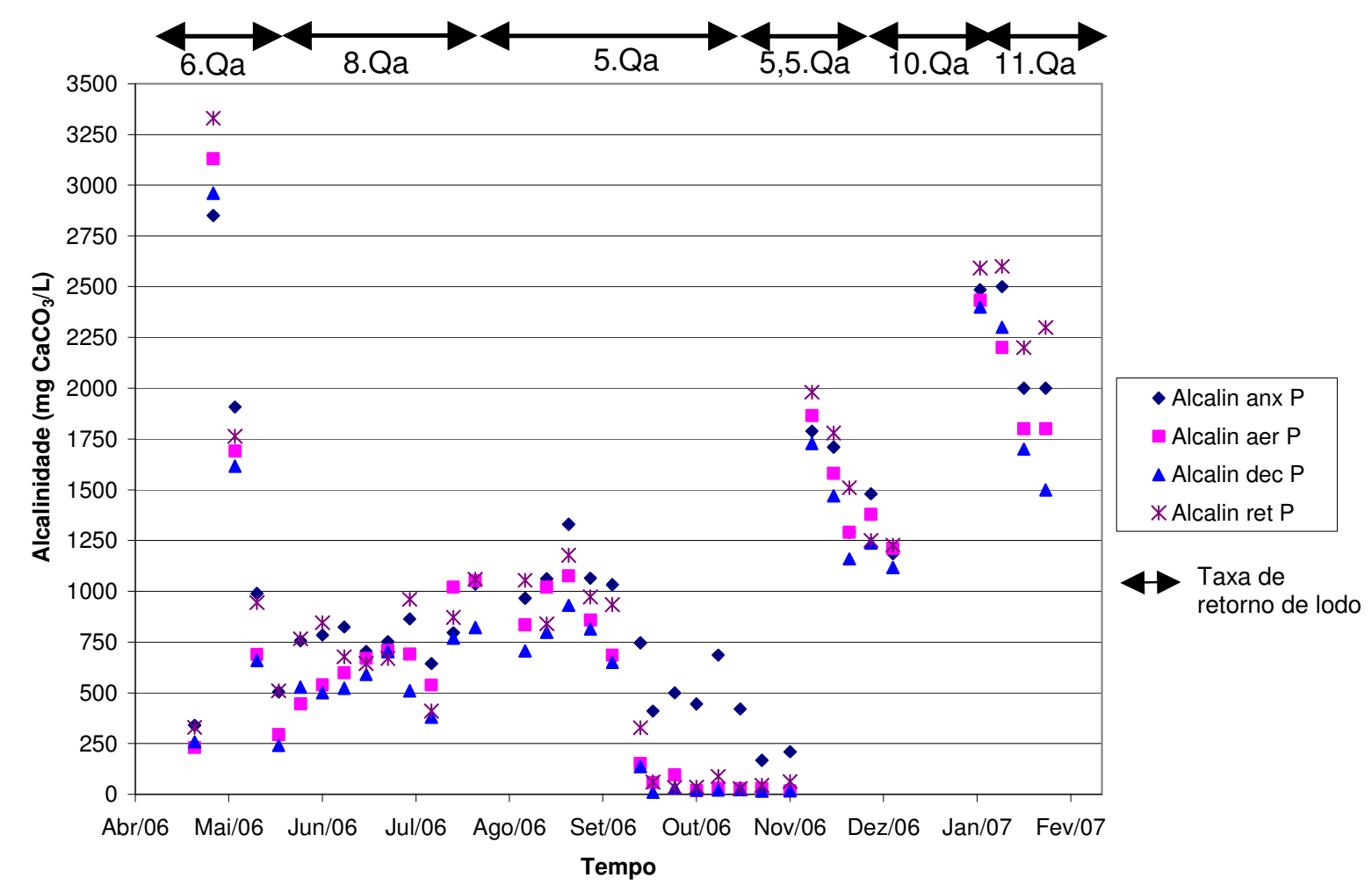

Figura 75 - Alcalinidade observada nas unidades do Sistema PARCIAL (P) ao longo da segunda fase da pesquisa, com fração anóxica de $41 \%$.

Comparando-se as Figuras 71 e 75 , nota-se que a alcalinidade do sistema durante essa fase dos trabalhos oscilou consideravelmente, porém os valores mais baixos foram observados entre setembro e novembro de 2006 , em virtude de se tentar reduzir o $\mathrm{pH}$ abaixo de 6,0 para acumular nitrito pela inibição via ácido nitroso.

Quanto ao monitoramento de nitrogênio amoniacal, nitrito e nitrato do sistema PARCIAL durante a segunda fase, esse é apresentado nas Figuras 76 e 77. A relação entre o 
nitrito e a soma dos compostos oxidados de nitrogênio nos reatores anóxico e aeróbio é apresentada na Figura 78. A Figura 79 apresenta o comportamento do $\mathrm{pH}$ e dos compostos nitrogenados no reator aeróbio e a Figura 80, a eficiência de remoção de nitrogênio amoniacal no reator aeróbio e na piloto como um todo, ao longo da segunda fase de experimentos.

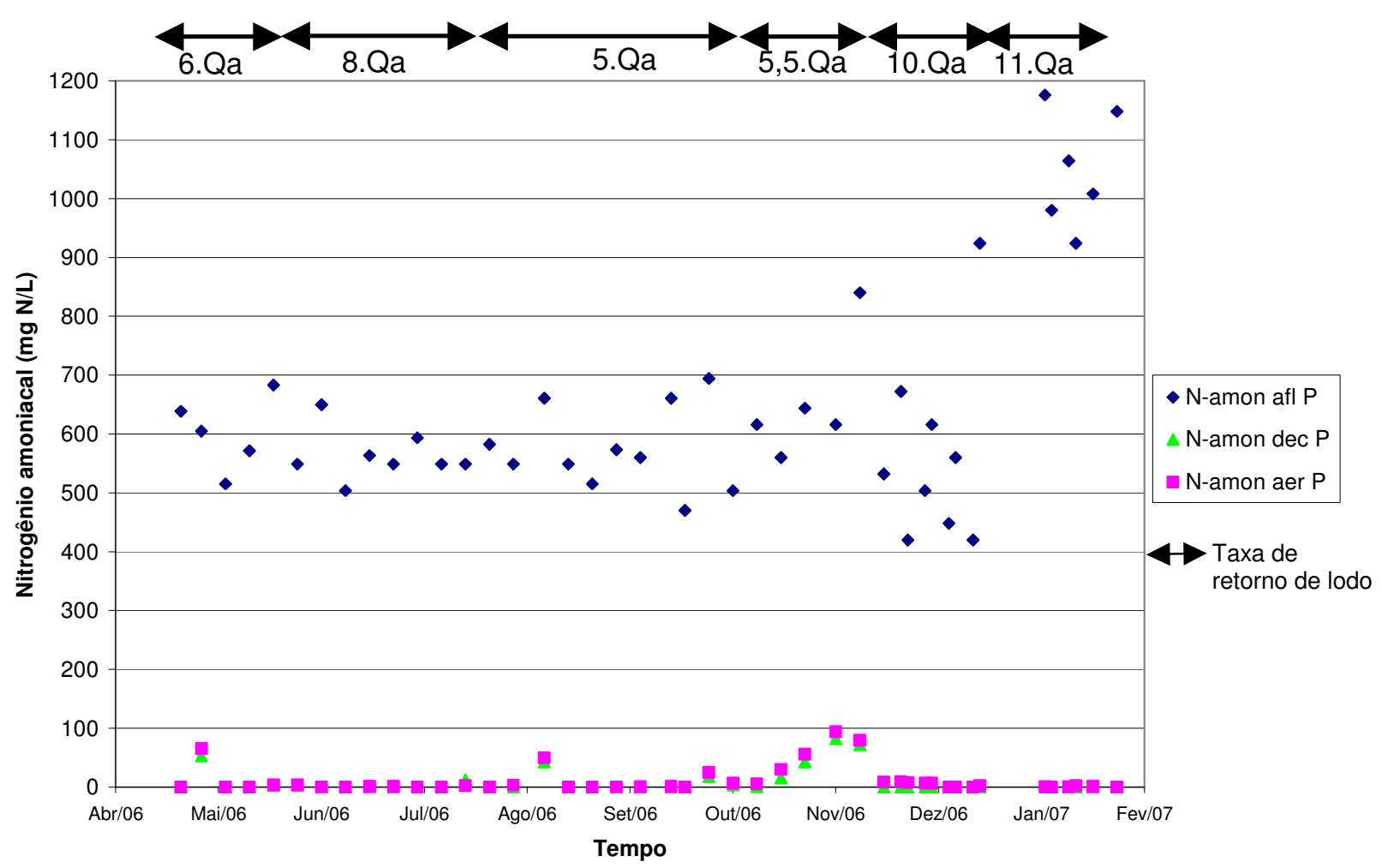

Figura 76 - Comportamento do nitrogênio amoniacal do Sistema PARCIAL (P) ao longo da segunda fase da pesquisa, com fração anóxica de $41 \%$. 


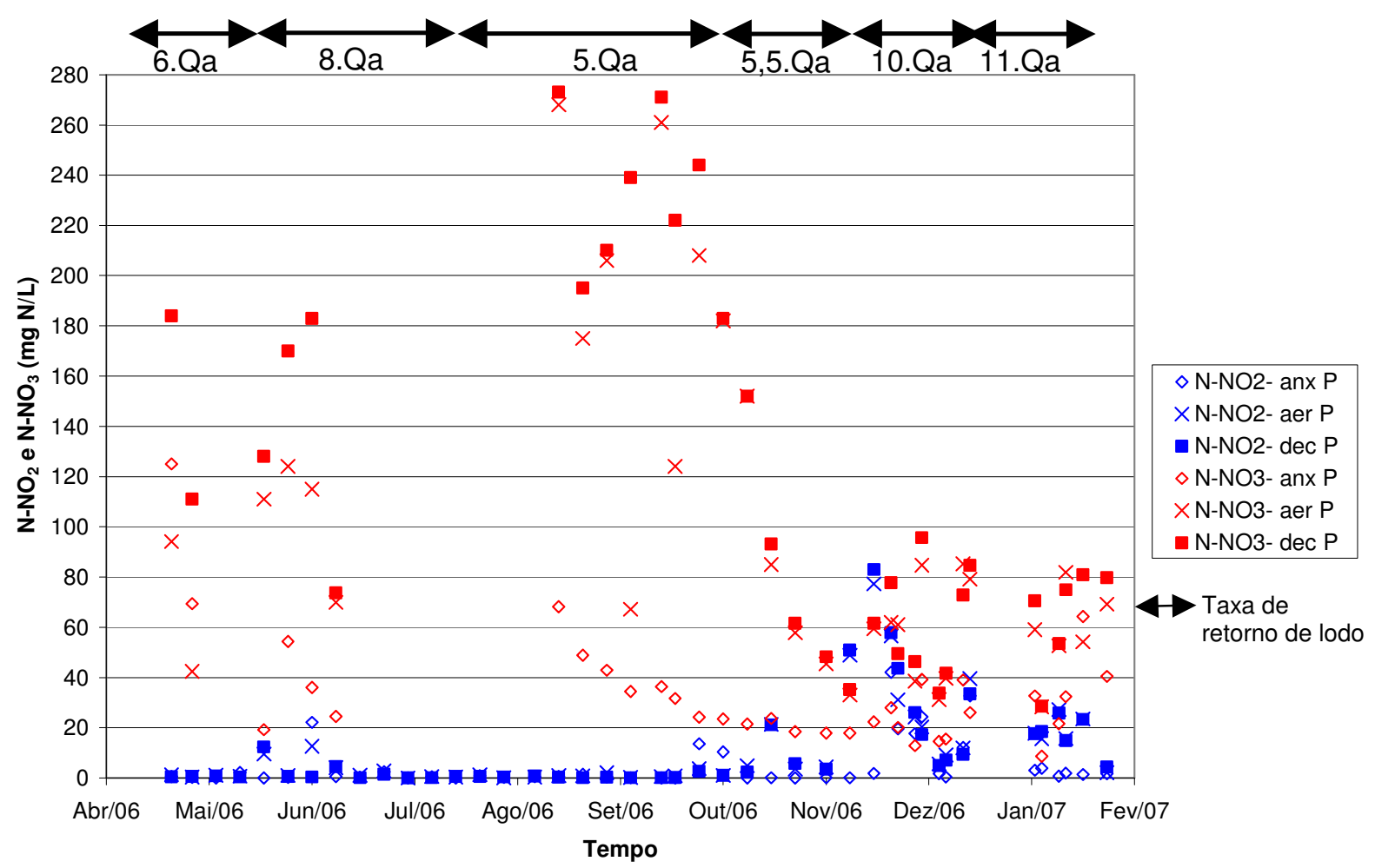

Figura 77 - Comportamento do nitrito e nitrato do Sistema PARCIAL (P) ao longo da segunda fase da pesquisa, com fração anóxica de $41 \%$.

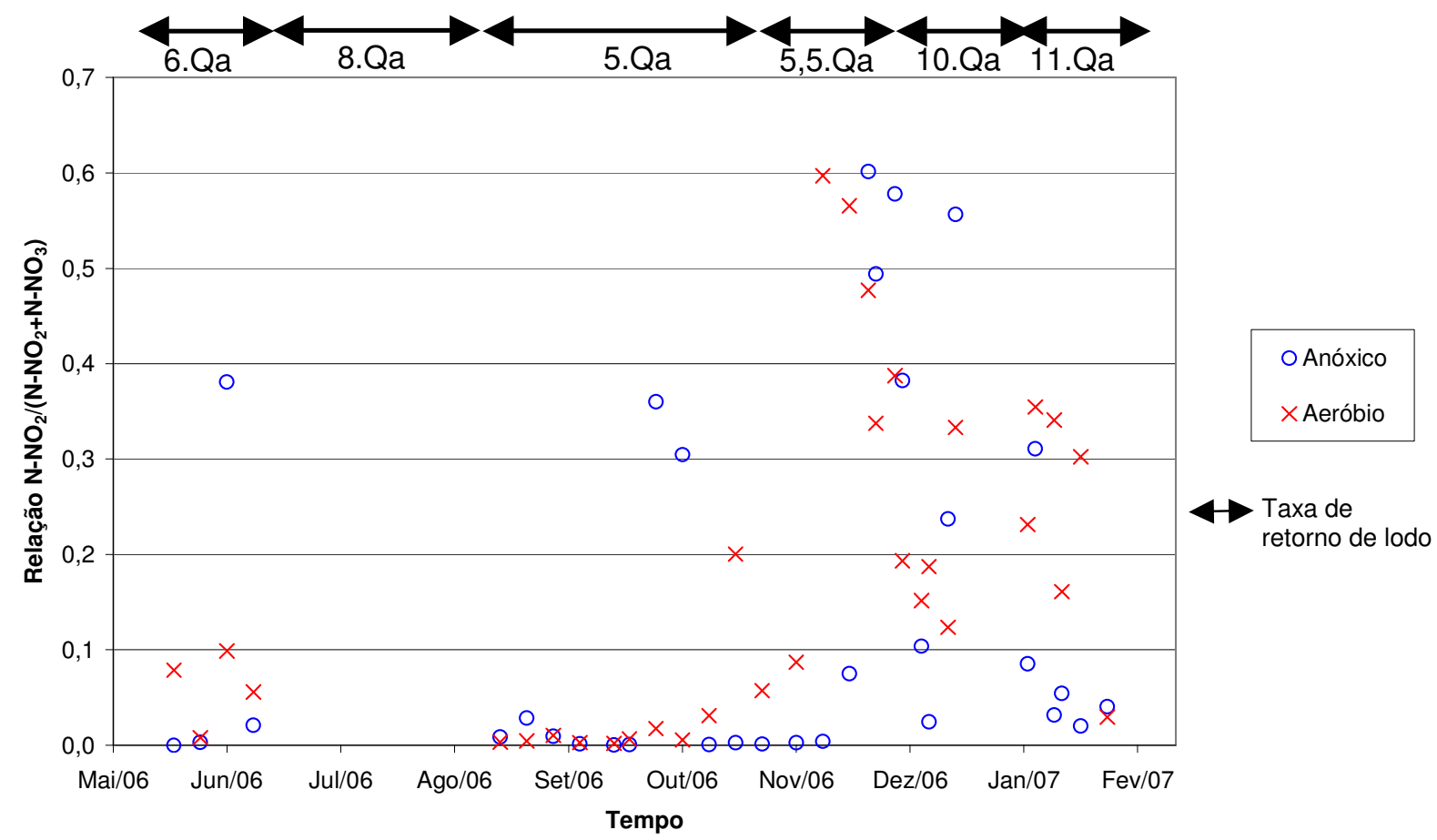

Figura 78 - Relação $\mathrm{N}-\mathrm{NO}_{2}{ }^{-} /\left(\mathrm{N}-\mathrm{NO}_{2}{ }^{-}+\mathrm{N}-\mathrm{NO}_{3}{ }^{-}\right)$nos reatores anóxico e aeróbio do Sistema PARCIAL (P) ao longo da segunda fase da pesquisa, com fração anóxica de $41 \%$. 


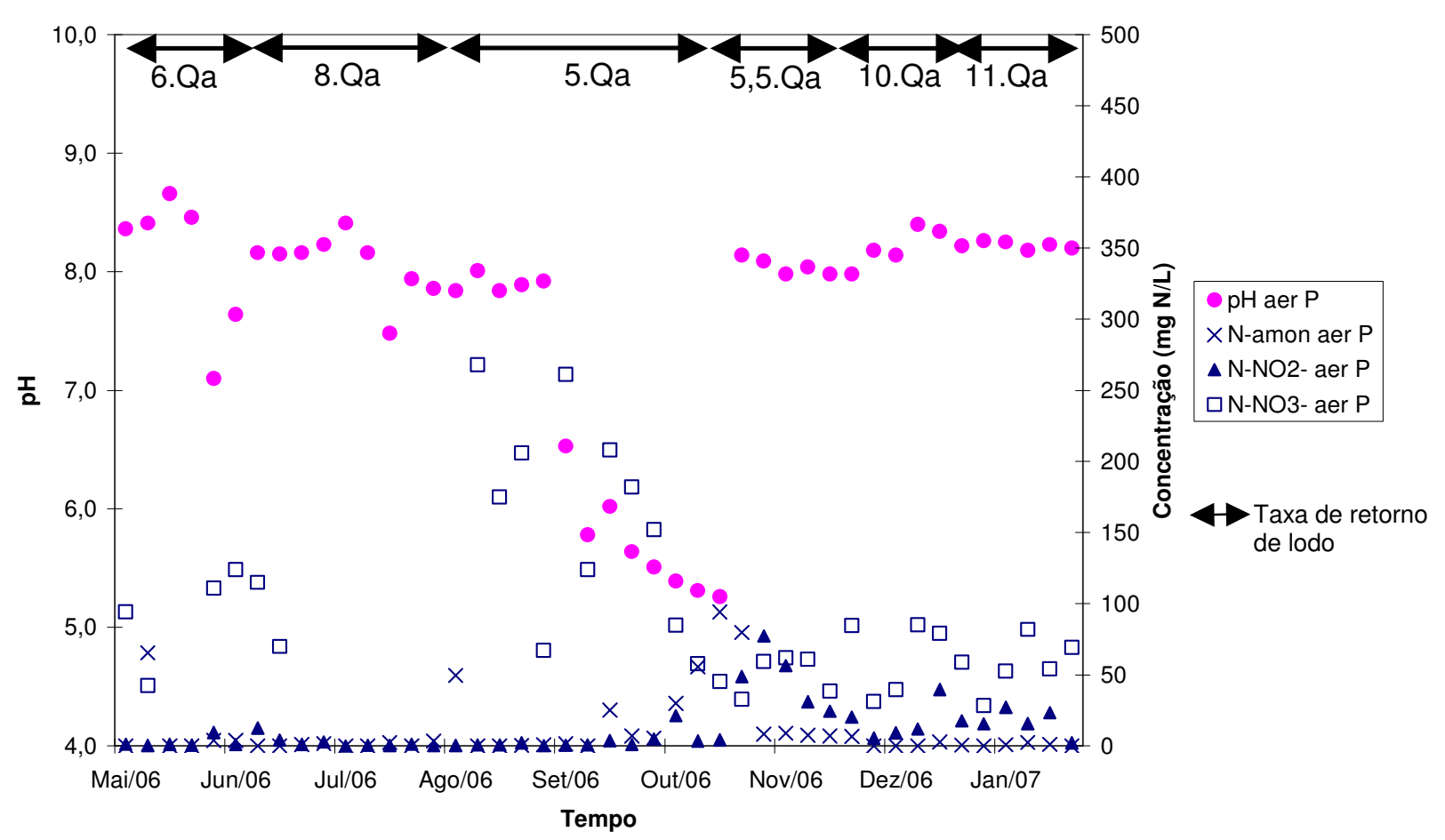

Figura 79 - Comportamento do pH e dos compostos nitrogenados no reator aeróbio do Sistema PARCIAL (P) ao longo da segunda fase da pesquisa, com fração anóxica de $41 \%$.

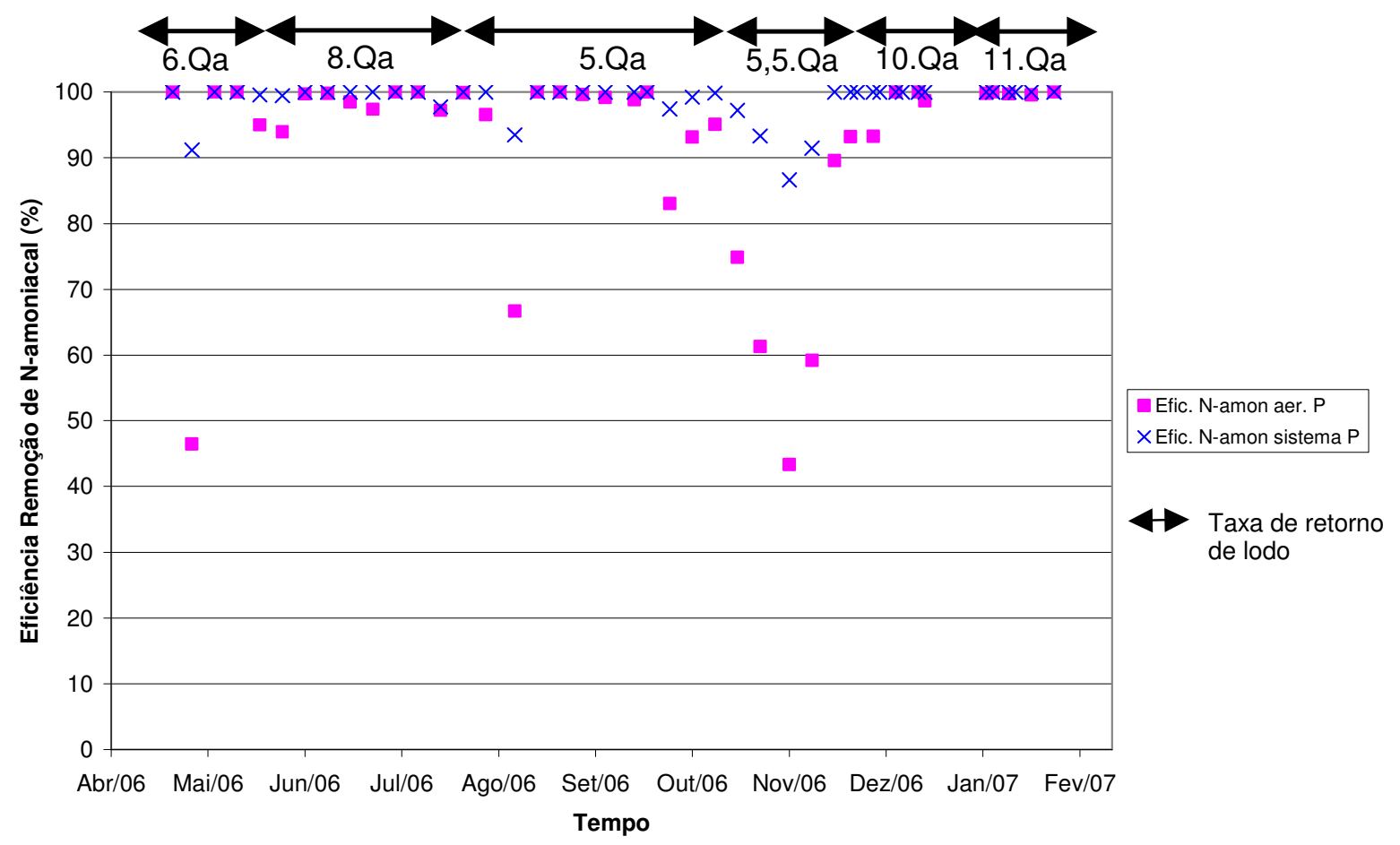

Figura 80 - Eficiência de remoção de nitrogênio amoniacal no reator aeróbio e no sistema ao longo da segunda fase da pesquisa, com fração anóxica de $41 \%$, para o Sistema PARCIAL (P). 
Analisando-se as Figuras 76, 77 e 79, observa-se que de setembro a novembro de 2006, que compreendeu o período de tempo em que se fez a tentativa do acúmulo de nitrito com a inibição pelo ácido nitroso não ionizado, e não mais pela amônia livre, reduzindo-se o $\mathrm{pH}$ a valores menores do que 6,0, a nitrificação completa a nitrato ficou clara, observando-se concentrações de nitrito desprezíveis. As concentrações de ácido nitroso observadas foram irrisórias (não somente nesses meses, como em todos os outros meses de operação do sistema), sendo que apenas em meados de outubro de 2006, foram detectadas concentrações da ordem de 0,1 a $0,2 \mathrm{mg} \mathrm{HNO}_{2} / \mathrm{L}$ no reator aeróbio, mas que não foram suficientes para promover o acúmulo estável de nitrito, apesar de Anthonisen et al. (1976) terem mencionado que concentrações de 0,2 a 2,8 mg $\mathrm{HNO}_{2} / \mathrm{L}$ de ácido nitroso já seriam capazes de inibir a nitrificação.

Nesse mesmo período (de setembro a novembro de 2006), foram observados inclusive os piores resultados referentes a nitrogênio amoniacal dessa fase, que ocorreram no final de outubro e início de novembro de 2006, com acúmulos consideráveis no reator aeróbio, mostrando que essa não seria uma condição operacional viável para o sistema.

Tendo em vista essa tentativa frustrada, em novembro de 2006, optou-se por retornar o $\mathrm{pH}$ a aproximadamente 8,3 , conforme verificado nos bons resultados obtidos com o sistema em batelada (QUEIROZ, 2006).

Em virtude da falta de êxito de todas as tentativas anteriores no que concerne ao acúmulo de nitrito, no final do experimento, mais precisamente entre dezembro de 2006 e janeiro de 2007, decidiu-se também por elevar as concentrações de nitrogênio amoniacal do afluente para valores da ordem de 900 a $1.000 \mathrm{mgN} / \mathrm{L}$, com o intuito de favorecer a manutenção de amônia livre na fase aeróbia, já que durante todo o experimento, foi muito difícil manter a mesma em concentrações inibitórias aos microrganismos oxidadores de nitrito. 
Quanto às eficiências de remoção de nitrogênio amoniacal no sistema PARCIAL na segunda fase (Figura 80), essas foram de certo modo aceitáveis, obtendo-se concentrações efluentes quase sempre desprezíveis (Figura 76). Apenas em aproximadamente $10 \%$ dos casos o efluente final apresentou valores superiores ao aceito pela Legislação (20 mg N/L), que ocorreram principalmente no final do período quando o reator aeróbio foi operado em $\mathrm{pH}$ baixo. Nesse período, as eficiências de remoção de nitrogênio amoniacal foram bastante insatisfatórias, chegando a valores de aproximadamente $40 \%$, que é uma eficiência bem aquém da desejada.

Durante toda a segunda fase da pesquisa, a taxa de nitrificação obtida para o sistema PARCIAL foi da ordem de $0,01 \mathrm{~kg} \mathrm{~N}-\mathrm{NH}_{3} / \mathrm{kg}$ SSV.dia no reator aeróbio.

Especificamente em relação ao nitrato, assim como já explicado para o sistema TOTAL, o hiato de resultados entre julho e agosto de 2006 ocorreu em virtude de defeito técnico no eletrodo de íon específico e dificuldade de reposição do equipamento junto ao fornecedor, sendo que o problema foi solucionado em meados de agosto de 2006.

Como anteriormente mencionado, os principais fatores que podem justificar os valores oscilantes de nitrato obtidos são a imprecisão do método analítico do eletrodo de íon específico de nitrato e muito provavelmente perdas de nitrogênio ocasionadas por formas alternativas de remoção de nitrogênio, já citadas anteriormente na literatura (VAN LOOSDRECHT; JETTEN, 1998).

Em relação ao nitrito, observa-se que na maioria das vezes ele foi superado pelo nitrato, exceto no final do experimento quando em algumas situações foram observados valores equiparados para os dois parâmetros (vide Figuras 77 e 78). Logo em seguida, o nitrato voltou a prevalecer mostrando muita instabilidade e dificuldade de inibição das bactérias oxidadoras de nitrito do sistema. Nem mesmo quando as concentrações afluentes de nitrogênio amoniacal apresentaram-se acima de $900 \mathrm{mgN} / \mathrm{L}$, ainda assim os valores de nitrito 
observados foram muito baixos. Isso sugere que, principalmente num sistema contínuo onde as condições operacionais persistem por um longo tempo, os microrganismos acabam se adaptando às condições mais adversas possíveis e passam a viver nessa condição de stress para não serem lavados do sistema.

A Figura 81 a seguir apresenta a análise estatística da relação $\mathrm{N}-\mathrm{NO}_{2}{ }^{-} /\left(\mathrm{N}_{-} \mathrm{NO}_{2}{ }^{-}+\mathrm{N}-\mathrm{NO}_{3}{ }^{-}\right)$nos reatores anóxico e aeróbio do Sistema PARCIAL (P) ao longo da segunda fase da pesquisa, quando as concentrações afluentes de nitrogênio amoniacal eram de $500 \mathrm{mgN} / \mathrm{L}$, corroborando-se a predominância de nitrato no sistema, já que a grande maioria dos resultados obtidos foi inferior a 30\%. As Figuras 82 e 83 analisam estatisticamente o nitrogênio amoniacal e os compostos oxidados de nitrogênio do sistema PARCIAL na segunda fase, respectivamente, também se considerando o período com concentrações afluentes de nitrogênio amoniacal de $500 \mathrm{mgN} / \mathrm{L}$ comprovando o que anteriormente já foi exposto.

As taxas de desnitrificação observadas no reator anóxico nessa fase do experimento variaram consideravelmente, porém observando-se valores bem baixos, de 0,002 a $0,008 \mathrm{~kg} \mathrm{~N}-\mathrm{NO}_{\mathrm{x}} / \mathrm{kg} \mathrm{SSV}$.dia, ao passo que as taxas de "desnitritação", essas foram ainda menores, não chegando a exceder $0,002 \mathrm{~kg} \mathrm{~N}-\mathrm{NO}_{2} / \mathrm{kg} \mathrm{SSV}$.dia.

É visível notar que no final do experimento ocorreram perdas de nitrogênio ainda não muito bem explicadas, como já mencionado, tendo em vista que a soma das duas formas oxidadas de nitrogênio totalizou pouco mais de $120 \mathrm{mgN} / \mathrm{L}$, bastante incompatível com as concentrações afluentes de nitrogênio amoniacal que, nesses meses finais, foram da ordem de $1.000 \mathrm{mgN} / \mathrm{L}$. 


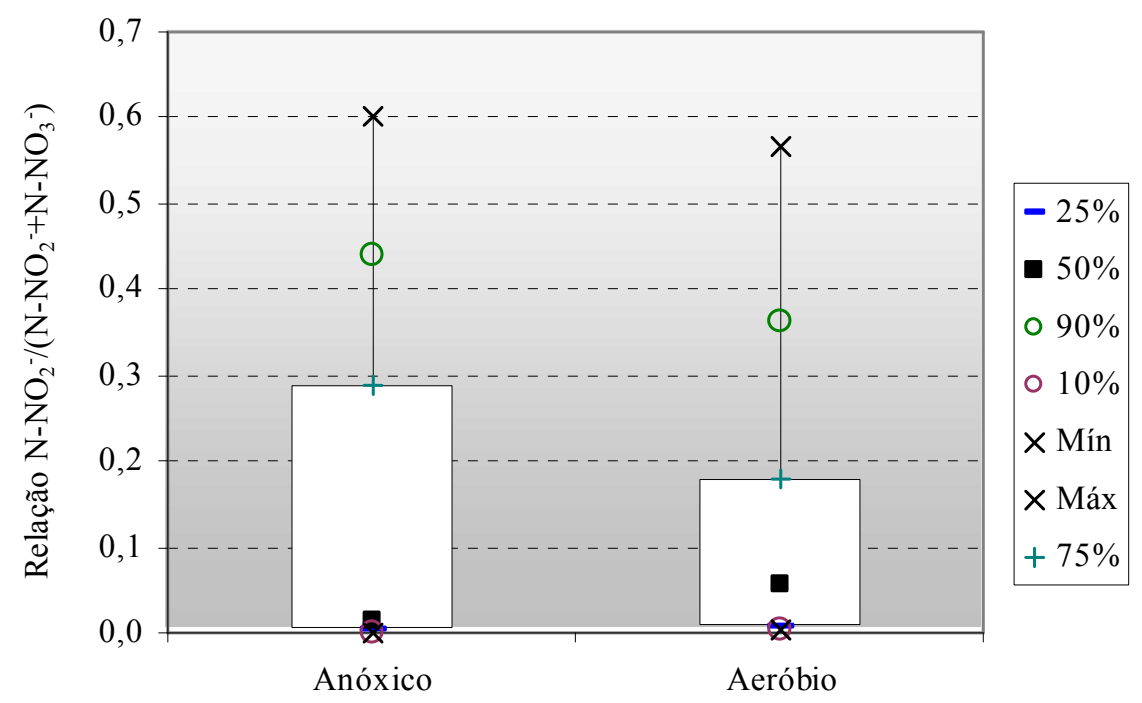

Figura 81 - Análise estatística da relação $\mathrm{N}-\mathrm{NO}_{2}{ }^{-} /\left(\mathrm{N}_{-} \mathrm{NO}_{2}{ }^{-}+\mathrm{N}-\mathrm{NO}_{3}{ }^{-}\right)$nos reatores do Sistema PARCIAL (P), quando as concentrações afluentes de nitrogênio amoniacal eram de $500 \mathrm{mgN} / \mathrm{L}$, durante a segunda fase da pesquisa, com fração anóxica de $41 \%$.

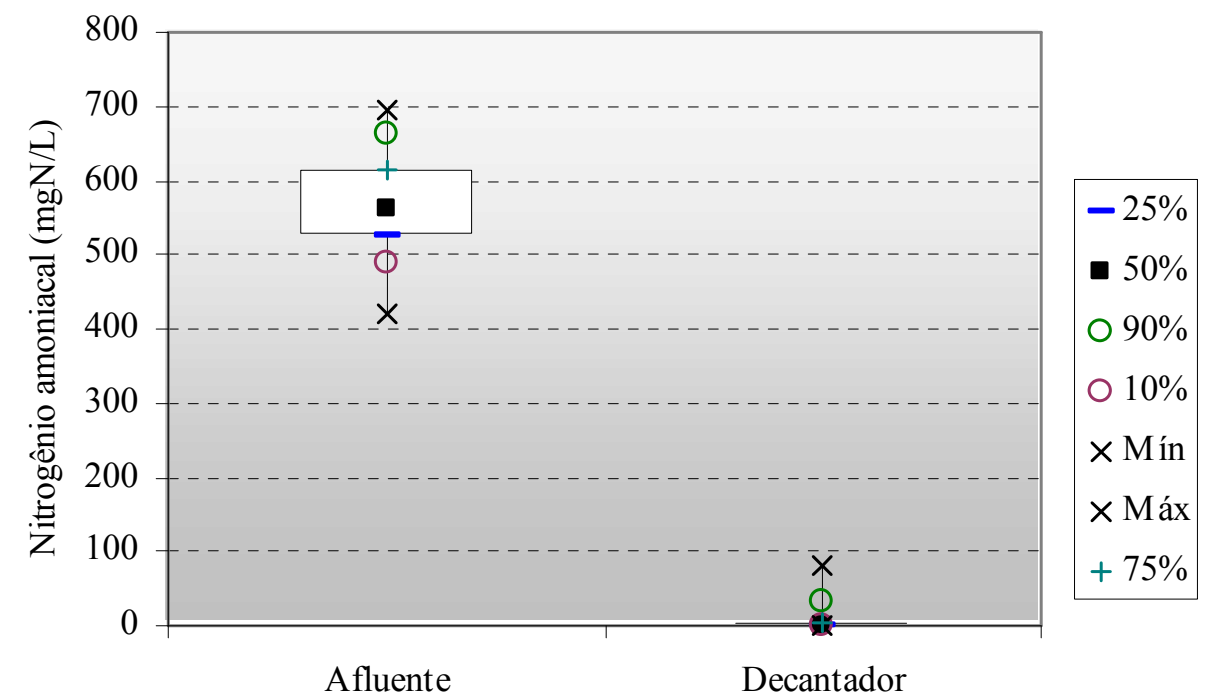

Figura 82 - Análise estatística do nitrogênio amoniacal no Sistema PARCIAL (P), quando as concentrações afluentes eram de $500 \mathrm{mgN} / \mathrm{L}$ ao longo da segunda fase da pesquisa, com fração anóxica de $41 \%$. 


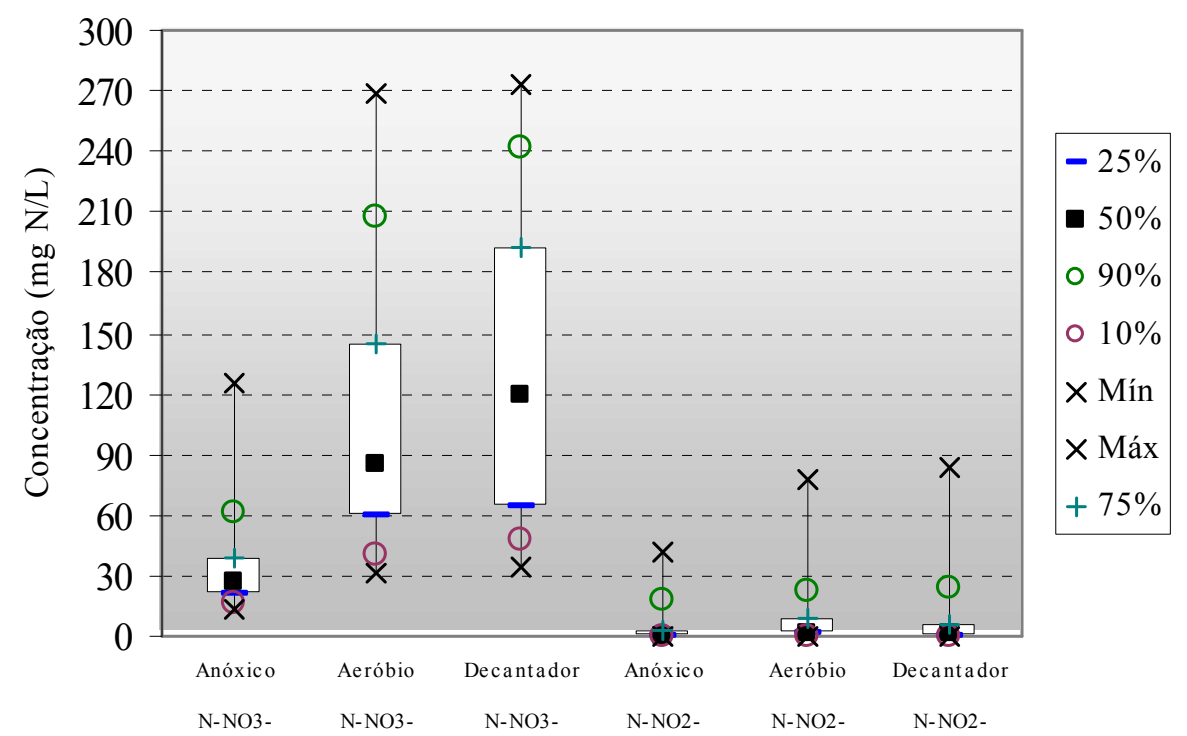

Figura 83 - Análise estatística dos compostos oxidados de nitrogênio no Sistema PARCIAL (P), quando as concentrações afluentes de nitrogênio amoniacal eram de $500 \mathrm{mgN} / \mathrm{L}$, durante a segunda fase da pesquisa, com fração anóxica de $41 \%$.

Da Figura 83, observa-se que as concentrações de nitrato do decantador apresentaram-se muito mais dispersas do que as do reator aeróbio, muito provavelmente pela imprecisão do método analítico, já que em teoria, os valores obtidos deveriam ser quase sempre bem próximos. Mesmo assim, os valores máximo, médio e mínimo para ambos são bem próximos.

A Figura 84 apresenta o comportamento da DBO do sistema PARCIAL ao longo da segunda fase dos trabalhos. 


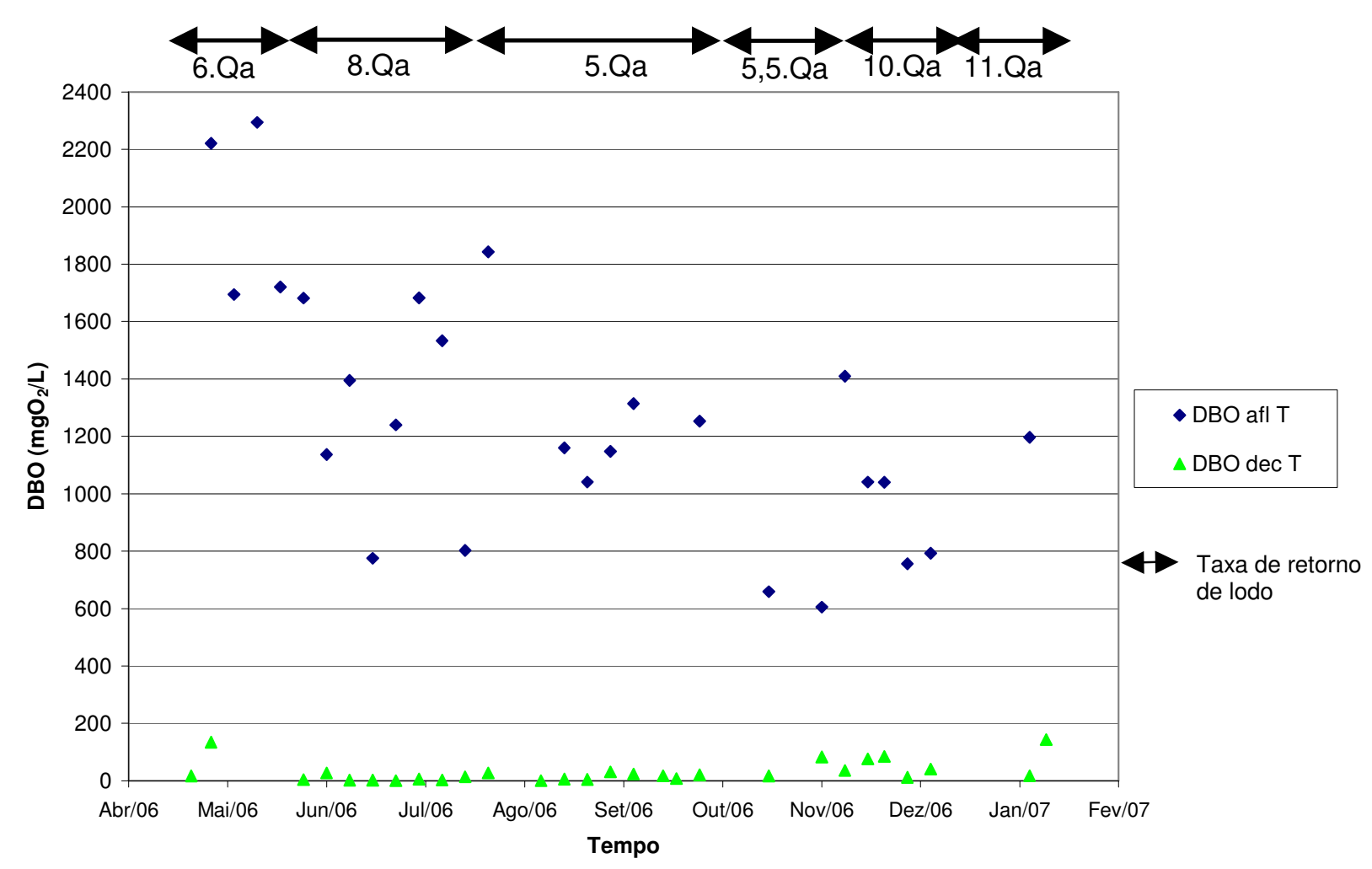

Figura 84 - Comportamento da DBO do Sistema PARCIAL (P) ao longo da segunda fase da pesquisa, com fração anóxica de $41 \%$.

Assim como para o sistema TOTAL e para a primeira fase do sistema PARCIAL, na segunda fase, observa-se que apesar da discrepância dos valores obtidos para a DBO do afluente, os resultados também foram de certo modo satisfatórios já que, mesmo quando os valores obtidos para o efluente final não foram menores do que $60 \mathrm{mgO}_{2} / \mathrm{L}$, ainda assim a eficiência de remoção sempre atendeu os $80 \%$ exigidos pela Legislação (SÃO PAULO, 1976).

A Figura 85 ilustra o comportamento do fenol do sistema PARCIAL ao longo da segunda fase da pesquisa e a Figura 86 , as relações $\mathrm{A} / \mathrm{M}$ e as taxas de utilização de substrato observadas no reator anóxico. A Figura 87 apresenta a eficiência de remoção de fenol para o reator anóxico e para o sistema como um todo, e a Figura 88, a análise estatística dos compostos fenólicos desse sistema nessa fase, quando as concentrações afluentes de nitrogênio amoniacal eram de $500 \mathrm{mgN} / \mathrm{L}$. 


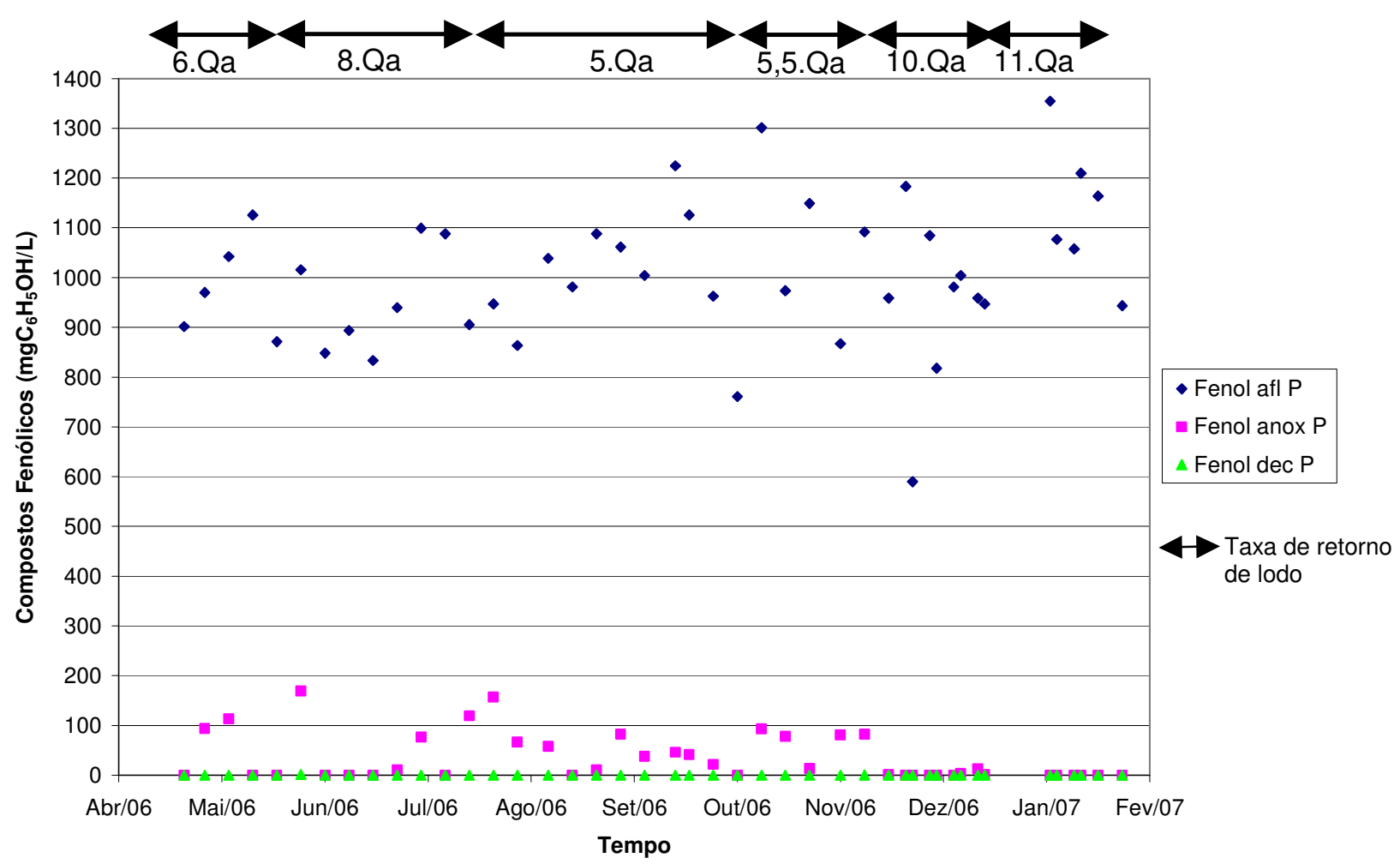

Figura 85 - Comportamento do fenol do Sistema PARCIAL (P) ao longo da segunda fase da pesquisa, com fração anóxica de $41 \%$.

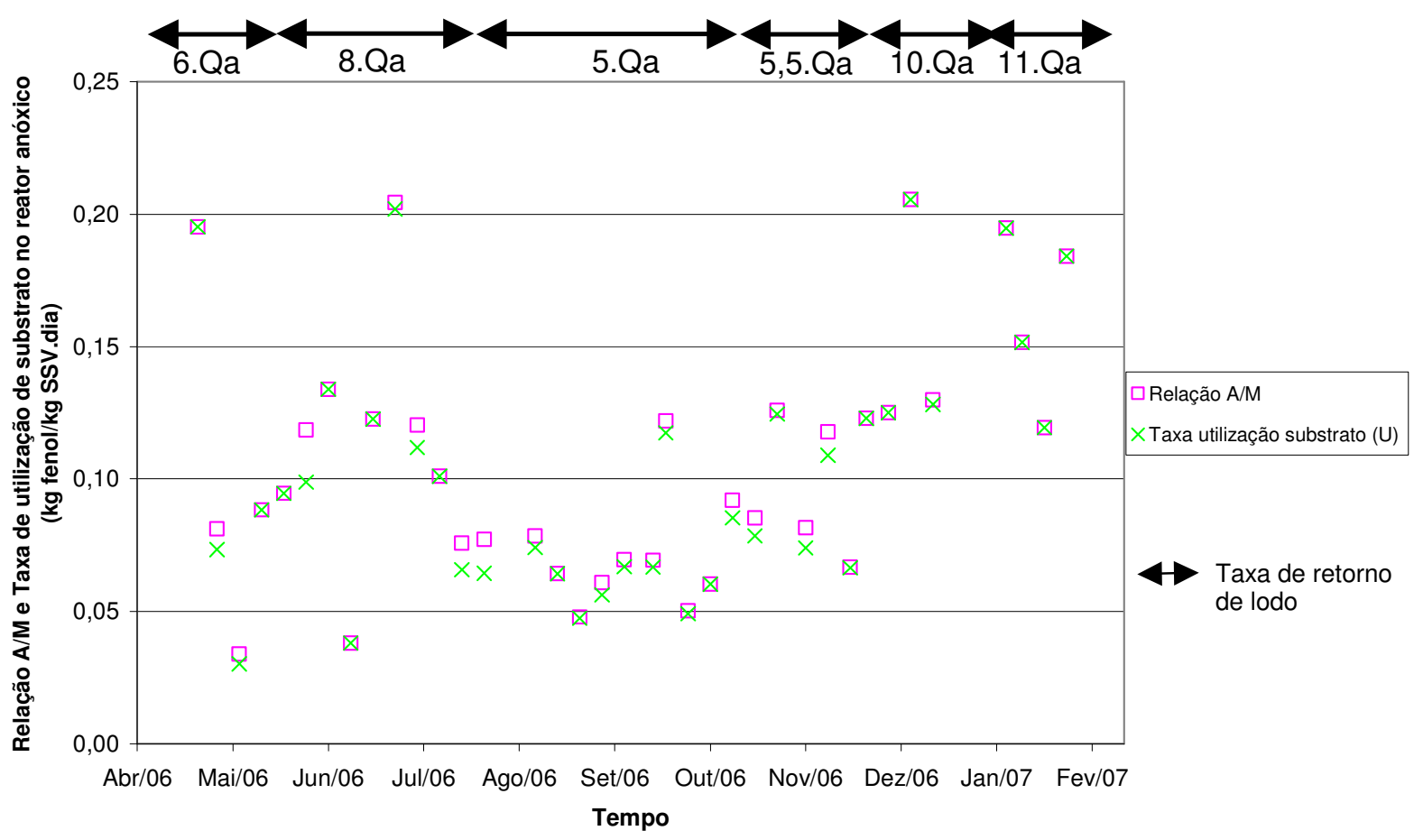

Figura 86 - Relações $\mathrm{A} / \mathrm{M}$ e taxas de utilização de substrato no reator anóxico do Sistema PARCIAL (P) ao longo da segunda fase da pesquisa, com fração anóxica de $41 \%$. 


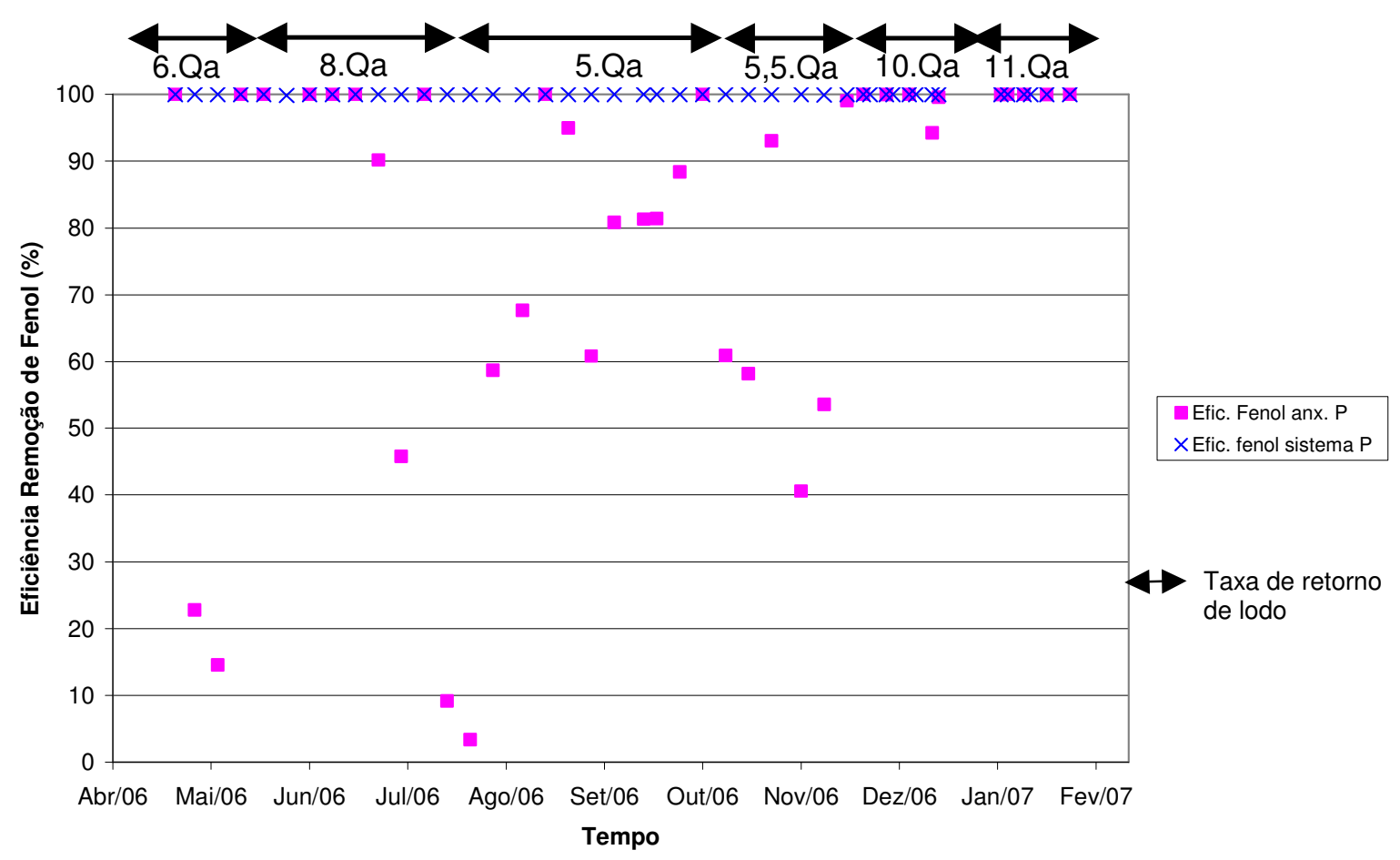

Figura 87 - Eficiência de remoção de fenol no reator anóxico e no sistema ao longo da segunda fase da pesquisa, com fração anóxica de $41 \%$, para o Sistema PARCIAL (P).

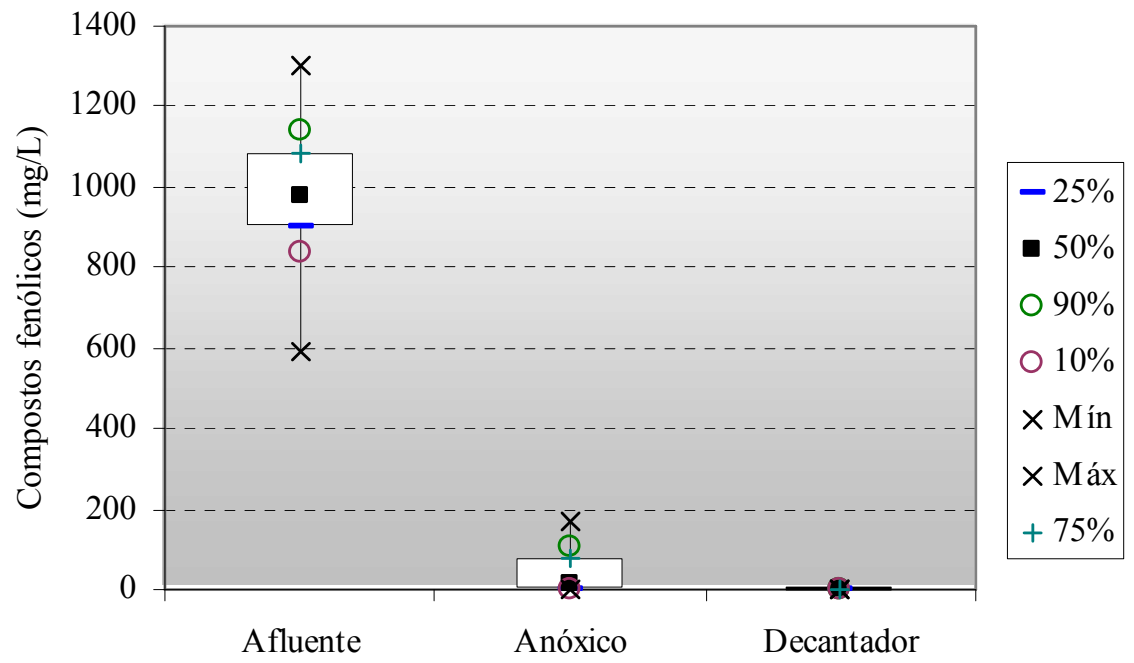

Figura 88 - Análise estatística dos compostos fenólicos no Sistema PARCIAL (P), quando as concentrações afluentes de nitrogênio amoniacal eram de $500 \mathrm{mgN} / \mathrm{L}$, durante a segunda fase da pesquisa, com fração anóxica de $41 \%$.

Conforme já exposto anteriormente, as taxas de recirculação de lodo foram ajustadas ao longo da pesquisa, principalmente em virtude dos acúmulos de fenol observados 
no reator anóxico. Sendo assim, nos dois últimos meses da pesquisa, em virtude de limitação da bomba de retorno de lodo do decantador secundário, instalou-se uma bomba de reciclo interno do aeróbio para o anóxico, sendo que ao final do trabalho, a razão de recirculação total de lodo do sistema (retorno do decantador mais reciclo interno) totalizava cerca de 10 a 11 vezes a vazão afluente.

Quanto à relação fenol $1_{\text {removido }} / \mathrm{N}-\mathrm{NOx}_{\text {removido }}$ no reator anóxico na segunda fase dos experimentos do sistema PARCIAL, pode-se dizer que a mesma oscilou principalmente entre 0,7 e 2,0 $\mathrm{kg}$ fenol ${ }_{\text {removido }} / \mathrm{kg} \mathrm{N}-\mathrm{NOx}_{\text {removido, }}$ valores bem inferiores aos obtidos nos experimentos em batelada, que variaram entre 2,1 a $3,2 \mathrm{~kg}$ fenol removido $/ \mathrm{kg} \mathrm{N}-\mathrm{NOx}_{\text {removido }}$ (QUEIROZ, 2006).

Observa-se da Figura 86 que, apesar da ampla faixa observada da relação A/M no reator anóxico nessa fase, que variou de cerca de 0,04 a $0,20 \mathrm{~kg}$ fenol $/ \mathrm{kg} \mathrm{SSV.dia,} \mathrm{mesmo}$ quando a mesma era inferior a $0,10 \mathrm{~kg}$ fenol $/ \mathrm{kg} \mathrm{SSV.dia,} \mathrm{valor} \mathrm{mencionado} \mathrm{por} \mathrm{Aun} \mathrm{(2001)}$ como máximo para não ocorrer acúmulo de fenol no reator, ainda assim grande parte das amostras do anóxico mostrou que ocorreu acúmulo de fenol no reator, inibindo a desnitrificação. Isso também pode ser verificado nos dados estatísticos ilustrados na Figura 88.

A Figura 87 também demonstra o exposto, já que grande parte das amostras coletadas no anóxico mostrou eficiências de remoção baixíssimas, chegando a valores da ordem de apenas 10 a 20\%, apesar do sistema como um todo apresentar eficiências elevadas, com concentrações praticamente não detectadas de fenol no efluente final, menores do que 0,5 $\mathrm{mg} \mathrm{C}_{6} \mathrm{H}_{5} \mathrm{OH} / \mathrm{L}$, conforme exigido pela Legislação (CONAMA 357/05; Decreto Estadual 8468/76). Isso porque no aeróbio o fenol era facilmente degradado, mesmo com as mais adversas condições operacionais $\left(\mathrm{pH}<6,0\right.$ e $\quad \mathrm{pH}>8,0 ; \quad$ temperaturas $<20^{\circ} \mathrm{C}$; $\left.\mathrm{OD}<0,5 \mathrm{mg} \mathrm{O}_{2} / \mathrm{L}\right)$ 
$\mathrm{Na}$ verdade, apenas nos últimos meses de operação do sistema, foram obtidos valores praticamente desprezíveis de fenol no anóxico. Sendo assim, conclui-se que o sistema apresentou muita instabilidade durante quase toda a operação e que, somente a partir de novembro de 2006, resultados mais satisfatórios foram observados, principalmente em termos de remoção de fenol e equiparação dos compostos oxidados de nitrogênio, sem grande prevalência de nitrato sobre o nitrito.

Do exposto, pode-se concluir que, como o nitrato prevaleceu sobre o nitrito durante praticamente toda a pesquisa, verifica-se que a manutenção de concentrações elevadas de oxigênio dissolvido no reator aeróbio $(>2,0 \mathrm{mg} \mathrm{O} / \mathrm{L})$ objetivando a nitrificação completa a nitrato nem sempre é necessária. Concentrações da ordem de 0,5 a $1,0 \mathrm{mg} \mathrm{O} \mathrm{O}_{2} / \mathrm{L}$ provavelmente já seriam suficientes para promover a nitrificação, podendo-se gerar uma boa economia de energia de aeração em estações de tratamento de efluentes visando remoção de nitrogênio.

\subsection{Resultados Obtidos com o Sistema em Bateladas Seqüenciais}

Além dos sistemas de lodo ativado piloto, ainda fez parte da presente pesquisa a operação de reator em bateladas seqüenciais objetivando a remoção de nitrogênio via nitrito, que foi instalado no Laboratório de Saneamento da Escola Politécnica da USP, e que também foi escopo da pesquisa de Queiroz (2006).

Alguns dos resultados obtidos por Queiroz (2006) com esse sistema serão aqui apresentados, de modo a exemplificar o bom desempenho do tratamento descontínuo do despejo estudado, visando remoção de nitrogênio pela via simplificada. Cabe ressaltar que, de um modo geral, esse sistema trabalhou com temperaturas um pouco superiores às dos sistemas contínuos $\left(>25^{\circ} \mathrm{C}\right)$. 
Para tanto, das três etapas realizadas, será apresentado resultado de um teste por etapa (concentração de nitrogênio amoniacal afluente de $200 \mathrm{mgN} / \mathrm{L}, 300 \mathrm{mgN} / \mathrm{L}$ e $500 \mathrm{mgN} / \mathrm{L}$ ). Os demais resultados que totalizaram a pesquisa de Queiroz (2006) podem ser obtidos em sua respectiva dissertação de mestrado.

\subsubsection{Primeira Etapa dos Experimentos em Bateladas Seqüenciais}

As Figuras 89 e 90 a seguir apresentam os resultados obtidos no sistema em bateladas seqüenciais para o ciclo 5 da $1^{\text {a }}$ etapa, cuja concentração afluente de nitrogênio amoniacal era de $200 \mathrm{mgN} / \mathrm{L}$.

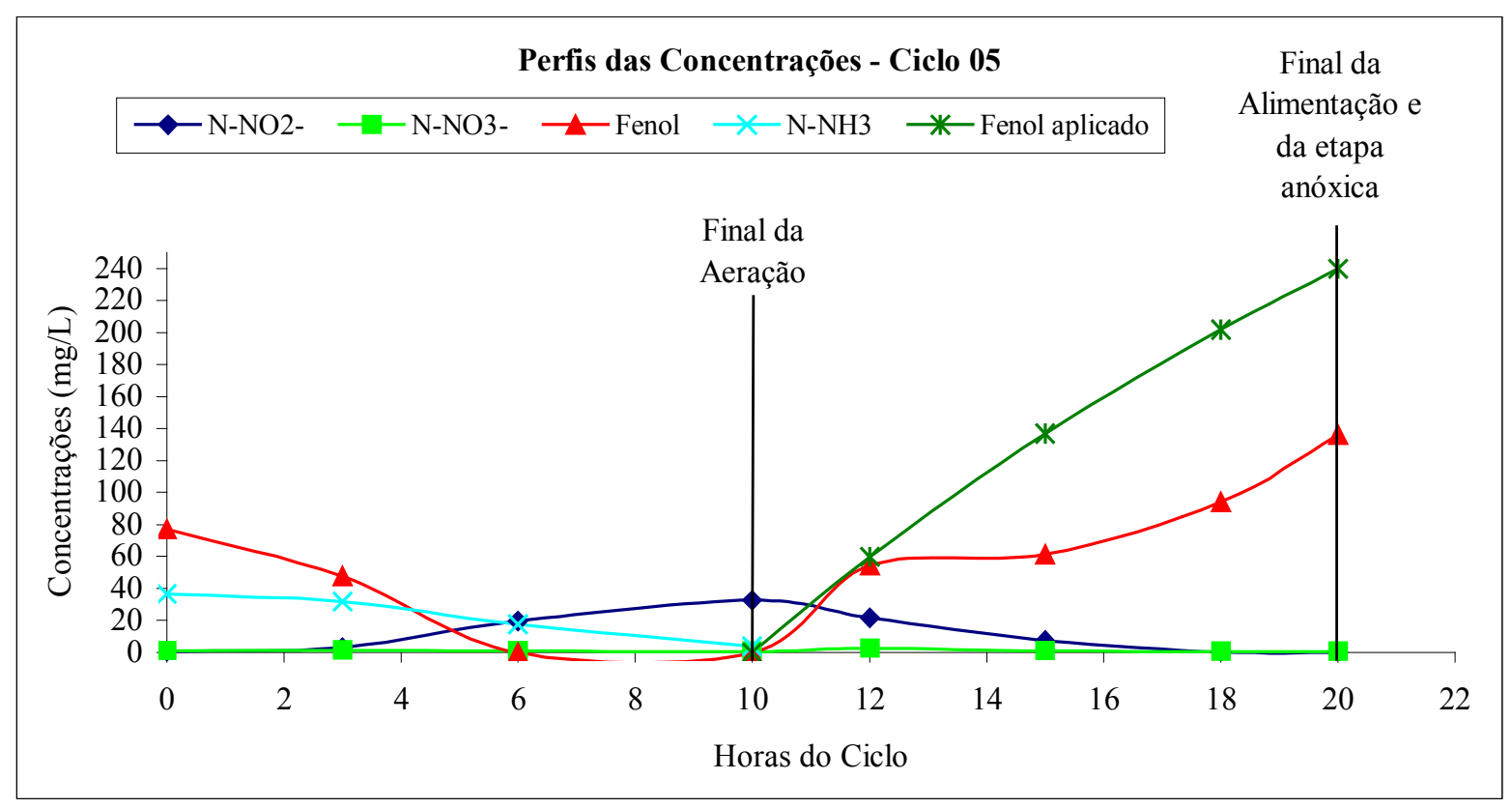

Figura 89 - Perfis temporais das concentrações de $\mathrm{N}_{-} \mathrm{NO}_{2}^{-}, \mathrm{N}-\mathrm{NO}_{3}{ }^{-}$, fenol, $\mathrm{N}_{-} \mathrm{NH}_{3}$ no conteúdo do reator - Ciclo 05 ( $\mathrm{pH}$ na etapa aeróbia $\cong 8,3 ; \mathrm{T} \cong 33^{\circ} \mathrm{C}$ ) - Etapa 01 do Sistema em Bateladas Seqüenciais

Fonte: QUEIROZ, 2006 


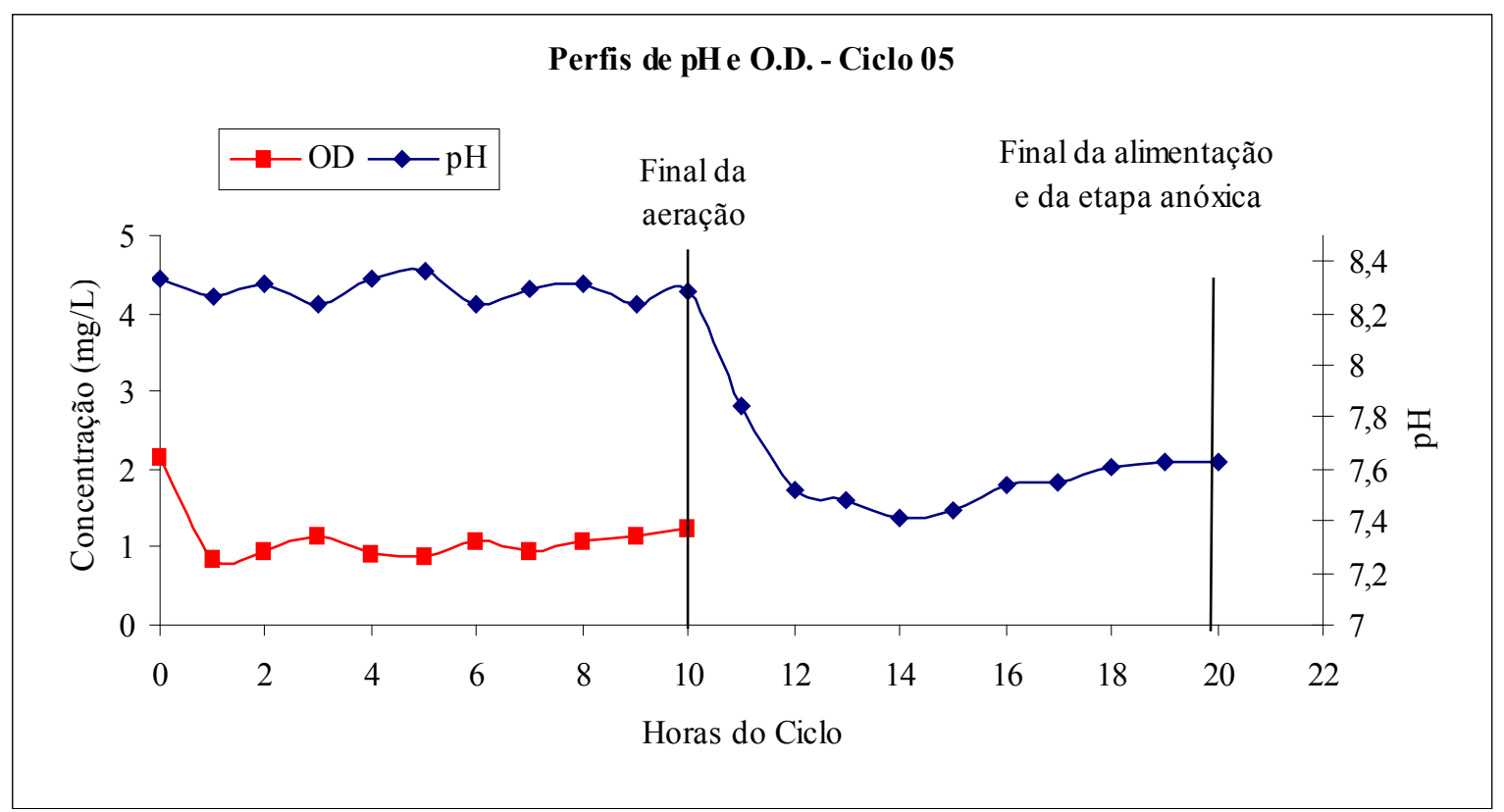

Figura 90 - Perfis temporais de pH e OD no conteúdo do reator - Ciclo 05 - Etapa 01 do Sistema em Bateladas Seqüenciais Fonte: QUEIROZ, 2006

Segundo Queiroz (2006), no ciclo 05 apresentado, para uma carga aplicada de

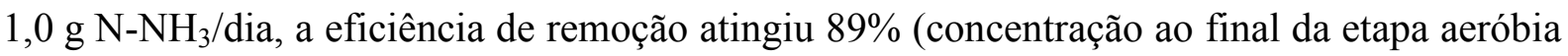
aproximadamente igual a $4 \mathrm{mg} \mathrm{N}-\mathrm{NH}_{3} / \mathrm{L}$ ) no ciclo apresentado. Foi obtido resultado expressivo para a relação $\mathrm{N}-\mathrm{NO}_{2}{ }^{-} /\left(\mathrm{N}_{-} \mathrm{NO}_{2}{ }^{-}+\mathrm{N}^{-\mathrm{NO}_{3}}{ }^{-}\right)$, que atingiu $97 \%$, maior valor desde o início da operação do sistema em batelada. A taxa de "nitritação" específica calculada foi igual a $0,03 \mathrm{~kg} \mathrm{~N}-\mathrm{NH}_{3} / \mathrm{kgSSV}$.dia para uma concentração de $\mathrm{SSV}$ de $2.808 \mathrm{mg} \mathrm{SSV} / \mathrm{L}$, no início do ciclo de tratamento.

Garrido et al. (1996) apud Queiroz (2006) observaram acúmulo estável de nitrito quando a relação entre as concentrações de oxigênio dissolvido e amônia livre na massa líquida era menor que $10 \mathrm{mgO}_{2} / \mathrm{mgNH}_{3}$; como durante a realização do quinto ciclo foi possível observar a leitura da concentração de OD (mantida próxima a $1,0 \mathrm{mgO}_{2} / \mathrm{L}$ ), calculou-se a relação $\mathrm{OD} / \mathrm{NH}_{3}$ constatando-se que a mesma variou entre 0,4 e 2,2 $\mathrm{mgO}_{2} / \mathrm{mgNH}_{3} / \mathrm{L}$. Além disso, a concentração de amônia livre também esteve naquela faixa considerada inibitória aos organismos que oxidam nitrito $\left(6,1\right.$ a $\left.0,5 \mathrm{mgNH}_{3} / \mathrm{L}\right)$. $\mathrm{O}$ 
excelente resultado, acima de $95 \%$, obtido para relação $\mathrm{N}-\mathrm{NO}_{2}{ }^{-} /\left(\mathrm{N}_{-} \mathrm{NO}_{2}{ }^{-}+\mathrm{N}^{-} \mathrm{NO}_{3}{ }^{-}\right)$apontou a necessidade de otimização do tempo de fornecimento de oxigênio à biomassa, de tal maneira que se disponibilizasse $\mathrm{O}_{2}$ apenas para oxidação do nitrogênio a nitrito; um tempo de aeração excessivo aparentemente favorecia a oxidação do nitrito acumulado no conteúdo do reator a nitrato (QUEIROZ, 2006).

A duração da etapa anóxica durante o ciclo 05 de tratamento foi de 10 horas; ao final dessas, as eficiências de remoção de fenol (carga afluente de 4,8 $\mathrm{g} \mathrm{C}_{6} \mathrm{H}_{5} \mathrm{OH} / \mathrm{dia}$ ) e nitrogênio amoniacal oxidado foram iguais a 49 e $97 \%$, respectivamente; a taxa de

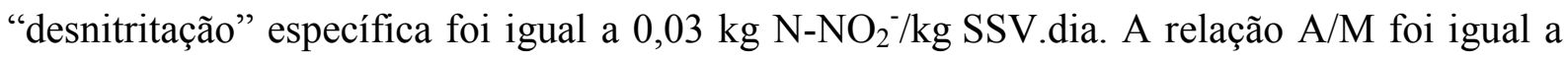
0,13 $\mathrm{kg}$ fenol/kg SSV.dia, obtendo-se uma relação de $3,4 \mathrm{~kg}$ fenol removido $/ \mathrm{kg} \mathrm{N}-\mathrm{NOx}_{\text {removido }}$ (QUEIROZ, 2006).

Os demais resultados obtidos com o sistema em batelada para concentração de nitrogênio amoniacal afluente de $200 \mathrm{mgN} / \mathrm{L}$ são apresentados de forma resumida na Tabela 5. 
Tabela 5 - Resumo dos resultados dos experimentos em batelada da Etapa 01 (nitrogênio amoniacal afluente $=200 \mathrm{mgN} / \mathrm{L}$ )

\begin{tabular}{|c|c|c|c|c|c|c|c|c|c|c|c|c|}
\hline \multirow{2}{*}{ PARÂMETROS } & \multicolumn{12}{|c|}{ CICLOS } \\
\hline & 01 & $\mathbf{0 2}$ & $\mathbf{0 3}$ & 04 & 05 & 06 & 07 & 08 & 09 & 10 & 11 & 12 \\
\hline $\begin{array}{l}\text { Carga de } \mathrm{N}-\mathrm{NH}_{3} \\
\left(\mathrm{~g} \mathrm{~N}-\mathrm{NH}_{3} / \text { dia }\right)\end{array}$ & 0,5 & 0,5 & 1,0 & 0,9 & 1,0 & 1,0 & 1,0 & 1,0 & 1,0 & 1,0 & 1,0 & 0,9 \\
\hline $\begin{array}{l}\text { Carga de FENOL } \\
\left(\mathrm{g} \mathrm{C}_{6} \mathrm{H}_{5} \mathrm{OH} / \text { dia }\right)\end{array}$ & 2,3 & 2,3 & 4,7 & 5,0 & 4,8 & 4,8 & 5,0 & 4,7 & 4,9 & 4,7 & 4,9 & 4,8 \\
\hline $\mathrm{Q}$ alimentação (mL/min) & 2,6 & 2,5 & 8,0 & 8,3 & 8,1 & 16 & 16 & 8,0 & 8,1 & 8,0 & 8,0 & 8,0 \\
\hline Temperatura Média $\left({ }^{\circ} \mathrm{C}\right)$ & 32 & 32,5 & 32 & 32 & 33 & 33 & 32 & 33 & 32 & 33 & 33 & 33 \\
\hline pH (etapa aeróbia) & 8,3 & 8,3 & 8,3 & 8,3 & 8,3 & 8,3 & 8,3 & 8,3 & 8,3 & 8,3 & 8,3 & 8,3 \\
\hline $\mathrm{SSV}(\mathrm{mg} \mathrm{SSV} / \mathrm{L})$ & 3.420 & 3.280 & 3.510 & 2.608 & 2.808 & 3.040 & 2.945 & 2.460 & 2.230 & 2.175 & 2.445 & 2.485 \\
\hline Etapa Aeróbia (Horas) & 15 & 15 & 15 & 15 & 10 & 10 & 10 & 10 & 10 & 10 & 10 & 10 \\
\hline Etapa Anóxica (Horas) & 18 & 18 & 10 & 10 & 10 & 10 & 10 & 10 & 10 & 10 & 10 & 10 \\
\hline $\begin{array}{l}\text { Taxa de nitritação específica } \\
\qquad\left(\mathrm{kg} \mathrm{N}-\mathrm{NH}_{3} / \mathrm{kg} \text { SSV.dia }\right)\end{array}$ & 0,01 & 0,01 & 0,02 & 0,03 & 0,03 & 0,03 & 0,03 & 0,03 & 0,04 & 0,05 & 0,04 & 0,04 \\
\hline$\left(\mathrm{N}-\mathrm{NO}_{2}^{-}+\mathrm{N}-\mathrm{NO}_{2}^{-}-\mathrm{NO}_{3}^{-}\right)$ & 90 & 64 & 83 & 84 & 97 & 91 & 97 & 94 & 99 & 98 & 95 & 97 \\
\hline $\begin{array}{c}\text { A/M } \\
\text { (kg Fenol/ kg SSV.dia) }\end{array}$ & 0,07 & 0,08 & 0,07 & 0,13 & 0,13 & 0,06 & 0,06 & 0,09 & 0,11 & 0,11 & 0,09 & 0,09 \\
\hline $\begin{array}{c}\text { Taxa de Desnitritação } \\
\text { (kg N-NO }{ }_{2}^{-} / \text {kg SSV.dia) }\end{array}$ & 0,01 & 0,01 & 0,03 & 0,04 & 0,03 & -- & 0,009 & 0,03 & 0,04 & 0,05 & 0,04 & 0,04 \\
\hline Remoção de $\mathrm{N}-\mathrm{NH}_{3}(\%)$ & 100 & 92 & 95 & 96 & 89 & 95 & 95 & 93 & 94 & 95 & 96 & 96 \\
\hline Remoção de FENOL na etapa anóxica (\%) & 28 & 40 & 42 & 46 & 45 & 33 & 26 & 39 & 42 & 41 & 37 & 38 \\
\hline Remoção de N oxidado (\%) & 99 & 64 & 83 & 99 & 97 & 53 & 28 & 97 & 100 & 97 & 99 & 100 \\
\hline$\frac{\mathrm{kg} \text { Fenol removido }}{\mathrm{kg} \mathrm{N} \text { oxidado removido }}$ & -- & 2,1 & 2,2 & 2,6 & 3,4 & -- & -- & 2,6 & 3,0 & 2,2 & 2,3 & 2,6 \\
\hline Amônia livre $(\mathrm{mg} / \mathrm{L})^{*}$ & 4,0 a 0,8 & 4,4 a 0,4 & 8,1 a 0,4 & 7,1 a 0,3 & 6,1 a 0,5 & 7,0 a 0,4 & 6,9 a 0,3 & 6,0 a 0,4 & 6,0 a 0,4 & 7,6 a 0,4 & 6,8 a 0,3 & 6,2 a 0,3 \\
\hline $\mathrm{HNO}_{2}(\mathrm{mg} / \mathrm{L}) *$ & $<0,002$ & $<0,007$ & $<0,001$ & $<0,001$ & $<0,001$ & $<0,001$ & $<0,001$ & $<0,001$ & $<0,001$ & $<0,001$ & $<0,001$ & $<0,001$ \\
\hline
\end{tabular}

Fonte: QUEIROZ, 2006 


\subsubsection{Segunda Etapa dos Experimentos em Bateladas Seqüenciais}

Diante da disponibilidade de fenol observada ao final da fase anóxica dos ciclos de tratamento da etapa anterior, que foi conduzida com concentração afluente de nitrogênio amoniacal igual a $200 \mathrm{mgN} / \mathrm{L}$, passou-se então a estudar o comportamento dos processos de “nitritação" e "desnitritação" utilizando fenol como fonte de carbono para concentrações afluentes de nitrogênio amoniacal e fenol próximas a $300 \mathrm{mgN} / \mathrm{L}$ e $1.000 \mathrm{mgC}_{6} \mathrm{H}_{5} \mathrm{OH} / \mathrm{L}$, respectivamente.

A partir desta nova etapa da pesquisa, passou-se também a monitorar o comportamento do potencial de óxido-redução no conteúdo do reator ao longo das diferentes etapas dos ciclos de tratamento. Além disso, reduziu-se a faixa de temperatura no conteúdo do reator para valores próximos a $25^{\circ} \mathrm{C}$, com a finalidade de observar o acúmulo sustentado de $\mathrm{N}-\mathrm{NO}_{2}{ }^{-}$nessa condição.O ensaio aqui ilustrado foi denominado de ciclo 2 da $2^{\mathrm{a}}$ etapa.

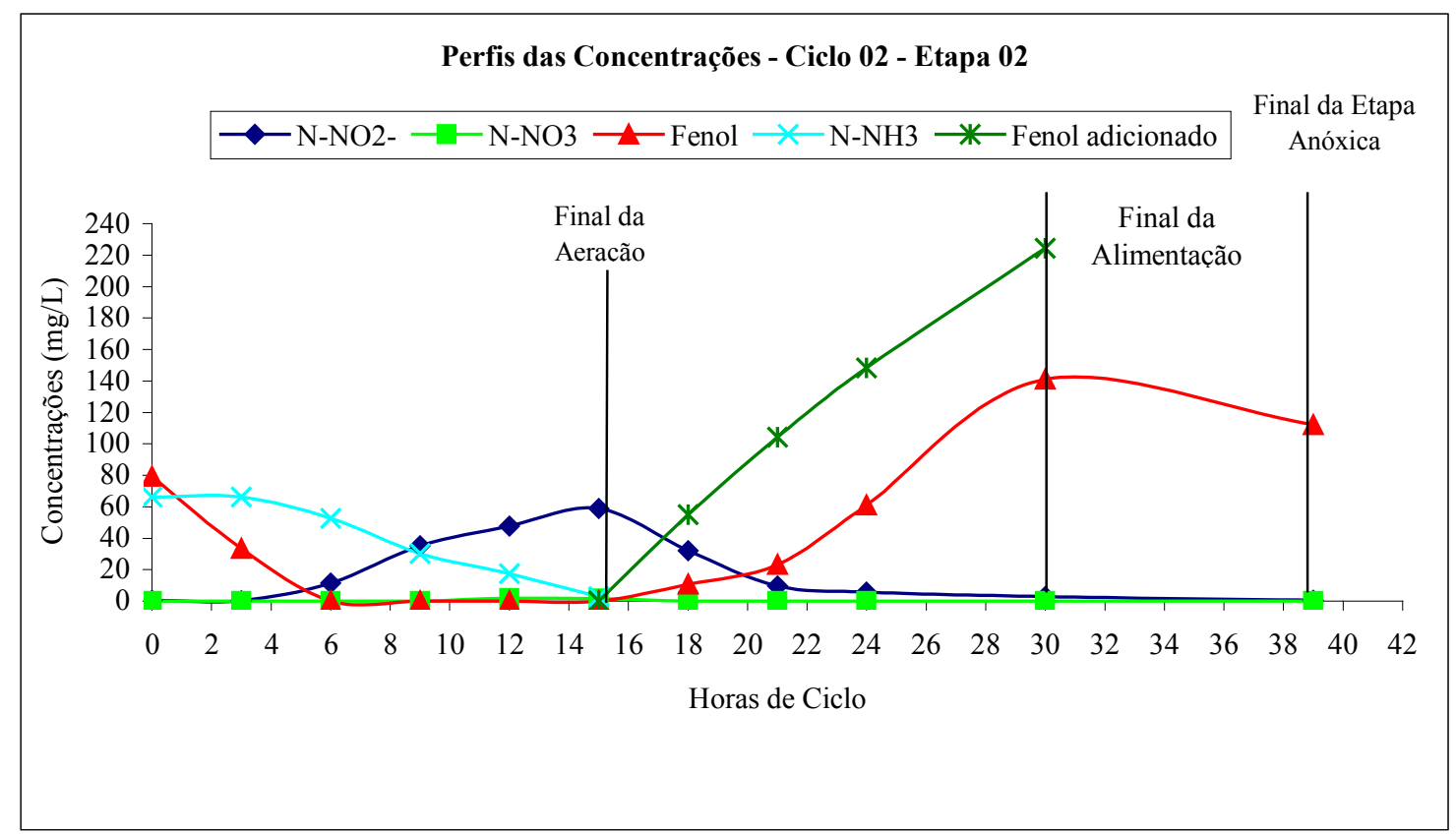

Figura 91 - Perfis temporais das concentrações de $\mathrm{N}_{-} \mathrm{NO}_{2}^{-}, \mathrm{N}_{-} \mathrm{NO}_{3}^{-}$, fenol, $\mathrm{N}_{-} \mathrm{NH}_{3}$ no conteúdo do reator - Ciclo $02-$ Etapa 02 (pH na etapa aeróbia $\cong 8,3 ; T \cong 25^{\circ} \mathrm{C}$ ) do Sistema em Bateladas Seqüenciais Fonte: QUEIROZ, 2006 


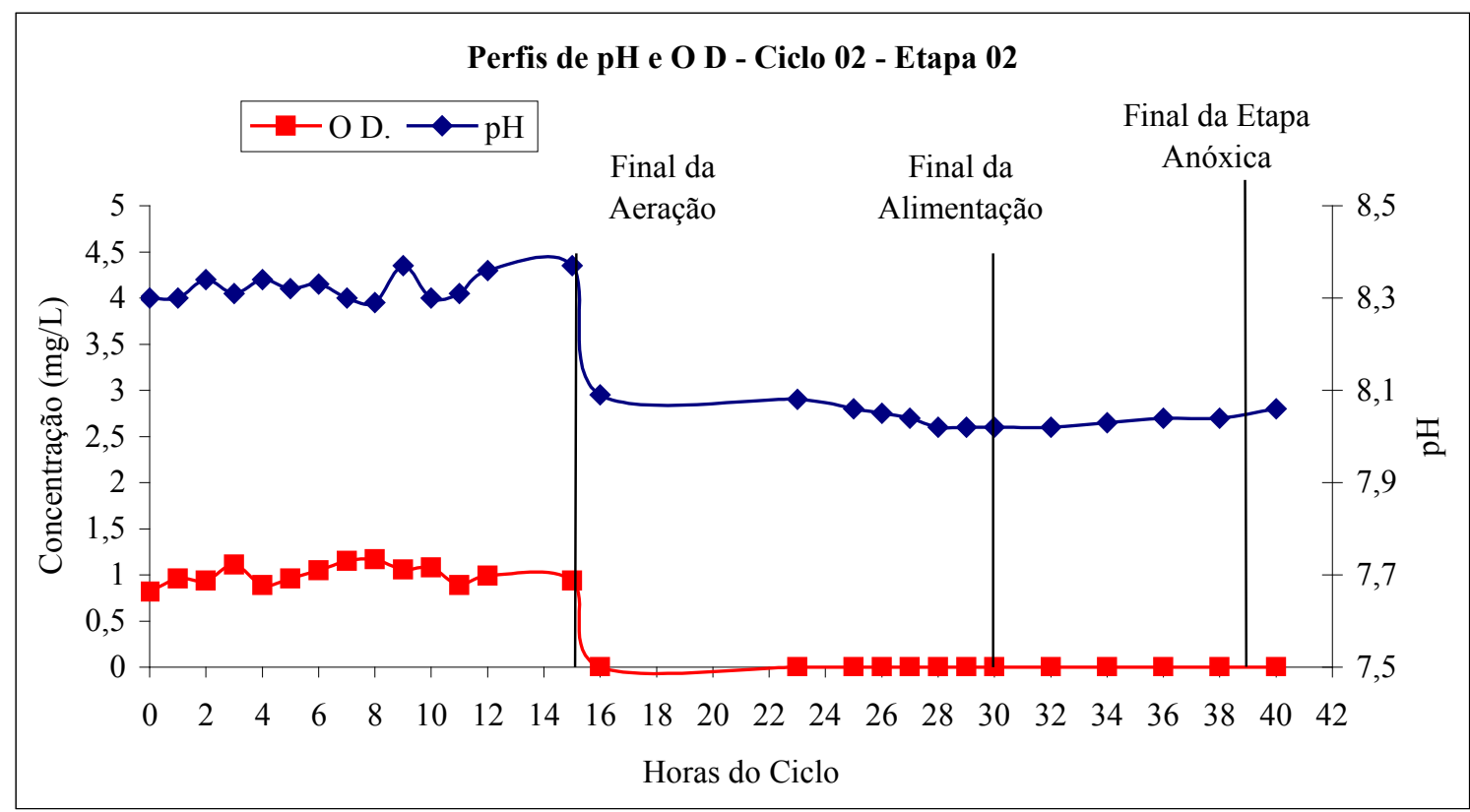

Figura 92 - Perfis temporais de pH e OD no conteúdo do reator - Ciclo 02 - Etapa 02 do Sistema em Bateladas Seqüenciais Fonte: QUEIROZ, 2006

Para a realização do ciclo 2 da $2^{\mathrm{a}}$ etapa, a etapa aeróbia foi programada com duração de 15 horas; entretanto, o tempo destinado à etapa anóxica foi avaliado até a redução significativa do nitrogênio amoniacal oxidado. O segundo ciclo de tratamento foi operado com uma temperatura próxima a $25^{\circ} \mathrm{C}$, valor de $\mathrm{pH}$ durante a etapa aeróbia próximo a 8,3 e concentração de oxigênio dissolvido próxima a $1,0 \mathrm{mgO}_{2} / \mathrm{L}$. A concentração de SSV no conteúdo do reator foi de $2.275 \mathrm{mgSSV} / \mathrm{L}$; a carga de nitrogênio amoniacal de 1,3 $\mathrm{g} \mathrm{N}_{-\mathrm{NH}_{3}} /$ dia e de fenol igual a $4,4 \mathrm{~g} \mathrm{C}_{6} \mathrm{H}_{5} \mathrm{OH} /$ dia. Para as condições aplicadas, a eficiência de remoção de $\mathrm{N}-\mathrm{NH}_{3}$ foi de $96 \%$ e a relação $\mathrm{N}-\mathrm{NO}_{2}{ }^{-} /\left(\mathrm{N}_{-} \mathrm{NO}_{2}{ }^{-}+\mathrm{N}_{-} \mathrm{NO}_{3}{ }^{-}\right)$atingiu 97\% sendo que a taxa de "nitritação" específica foi igual a $0,03 \mathrm{~kg} \mathrm{~N}-\mathrm{NH}_{3} / \mathrm{kg} \mathrm{SSV}$.dia (QUEIROZ, 2006).

A aplicação do afluente ocorreu ao longo de 15 horas da etapa anóxica do ciclo de remoção; entretanto, nota-se que foram necessárias 24 horas de duração dessa etapa para uma redução significativa do nitrogênio oxidado. Ao término desse intervalo de tempo, a concentração de $\mathrm{N}_{-} \mathrm{NO}_{2}^{-}$foi praticamente nula e não foi acusada a presença de $\mathrm{N}_{-} \mathrm{NO}_{3}^{-}$no 
reator. A eficiência de remoção de fenol foi de $63 \%$ e do nitrogênio oxidado alcançou $99 \%$. A taxa de "desnitritação" específica foi igual a $0,02 \mathrm{~kg} \mathrm{~N} \mathrm{NO}_{2}{ }^{-} / \mathrm{kg} \mathrm{SSV}^{-d i a}$; obteve-se uma relação $\mathrm{A} / \mathrm{M}$ de $0,10 \mathrm{~kg}$ fenol $/ \mathrm{kg} \mathrm{SSV}$.dia e fenol removido/N-NOx removido de 3,1 kg fenol removido $_{\text {/ }} \mathrm{kg} \mathrm{N-NOx_{ \text {removido } }}$ (QUEIROZ, 2006).

A Figura 93 mostra o perfil temporal do potencial de óxido-redução monitorado na massa líquida do reator ao longo desse ciclo de tratamento.

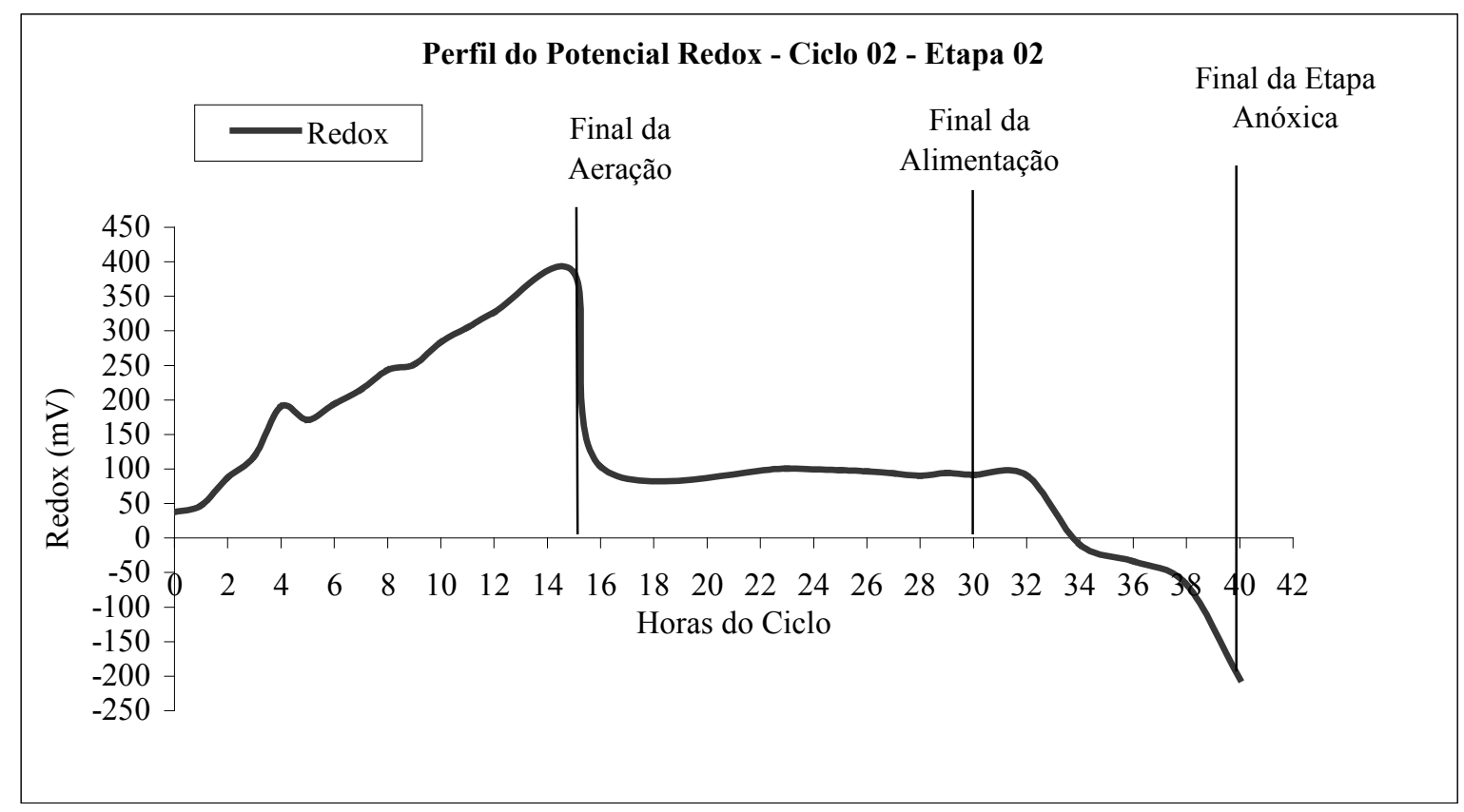

Figura 93 - Perfil temporal de ORP no conteúdo do reator - Ciclo 02 - Etapa 02 do Sistema em Bateladas Seqüenciais

Fonte: QUEIROZ, 2006

A Tabela 6 apresenta o restante dos resultados obtidos nos experimentos em batelada para a Etapa 02, cuja concentração de nitrogênio amoniacal afluente era de $300 \mathrm{mgN} / \mathrm{L}$. 
Tabela 6 - Resumo dos resultados dos experimentos em batelada da Etapa 02 (nitrogênio amoniacal afluente $=300 \mathrm{mgN} / \mathrm{L}$ )

\begin{tabular}{|c|c|c|c|c|c|}
\hline \multirow{2}{*}{ PARÂMETROS } & \multicolumn{5}{|c|}{ CICLOS } \\
\hline & 01 & 02 & 03 & 04 & 05 \\
\hline $\begin{array}{l}\text { Carga de N-NH } \\
(\text { g N-NH} / \text { dia })\end{array}$ & 1,4 & 1,3 & 1,4 & 1,4 & 1,3 \\
\hline $\begin{array}{l}\text { Carga de Fenol } \\
(\mathrm{g} \text { Fenol/dia })\end{array}$ & 4,7 & 4,4 & 4,9 & 4,5 & 4,5 \\
\hline $\mathrm{Q}$ alimentação (mL/min) & 5,4 & 5,0 & 5,0 & 5,0 & 5,0 \\
\hline Temperatura $\left({ }^{\circ} \mathrm{C}\right)$ & 25 & 25 & 24 & 24 & 23,5 \\
\hline pH médio (etapa aeróbia) & 8,3 & 8,3 & 8,3 & 8,3 & 8,2 \\
\hline $\operatorname{SSV}(\mathrm{mg} / \mathrm{L})$ & 2.210 & 2.275 & 2.460 & 2.544 & 2.604 \\
\hline Etapa Aeróbia (Horas) & 15 & 15 & 17 & 15 & 15 \\
\hline Etapa Anóxica (Horas) & 15 & 24 & 22 & 24 & 24 \\
\hline $\begin{array}{c}\text { Taxa de nitritação } \\
\left(\mathrm{kg} \mathrm{N}-\mathrm{NH}_{3} / \mathrm{kg} \text { SSV.dia) }\right.\end{array}$ & 0,04 & 0,03 & 0,04 & 0,04 & 0,03 \\
\hline$\frac{\mathrm{N}-\mathrm{NO}_{2}{ }^{-}}{\left(\mathrm{N}-\mathrm{NO}_{2}{ }^{-}+\mathrm{N}^{-\mathrm{NO}_{3}}{ }^{-}\right)}$ & 89 & 97 & 98 & 96 & 97 \\
\hline $\begin{array}{c}\mathrm{A} / \mathrm{M} \\
\text { (kg fenol/kg SSV.dia) }\end{array}$ & 0,11 & 0,10 & 0,10 & 0,09 & 0,09 \\
\hline $\begin{array}{c}\text { Taxa de desnitritação } \\
\text { (kg N-NO }{ }_{2}^{-} / \text {kg SSV.dia) }\end{array}$ & 0,005 & 0,02 & 0,02 & 0,02 & 0,02 \\
\hline Remoção de N-NH ${ }_{3}(\%)$ & 95 & 96 & 97 & 98 & 97 \\
\hline $\begin{array}{c}\text { Remoção de fenol na etapa } \\
\text { anóxica }(\%)\end{array}$ & 39 & 63 & 60 & 65 & 64 \\
\hline $\begin{array}{l}\text { Remoção de Nitrogênio } \\
\text { amoniacal oxidado (\%) } \\
\text { FENOL removido }\end{array}$ & 22 & 99 & 99 & 100 & 98 \\
\hline $\begin{array}{c}\overline{\mathrm{N}^{-N O} \mathrm{x}_{\mathrm{x}} \text { removido }} \\
(\mathrm{mg} \text { Fenol / mg N-NOx) }\end{array}$ & -- & 3,1 & 3,2 & 2,5 & 3,0 \\
\hline $\mathrm{NH}_{3}(\mathrm{mg} / \mathrm{L})^{*}$ & 9,9 a 0,6 & 8,2 a 0,4 & 9,3 a 0,3 & 7,0 a 0,2 & 7,4 a 0,3 \\
\hline $\mathrm{HNO}_{2}(\mathrm{mg} / \mathrm{L}) *$ & $<0,002$ & $<0,002$ & $<0,003$ & $<0,003$ & $<0,002$ \\
\hline
\end{tabular}

Fonte: QUEIROZ, 2006

\subsubsection{Terceira Etapa dos Experimentos em Bateladas Seqüenciais}

$\mathrm{Na}$ terceira etapa dos experimentos em bateladas seqüenciais, com concentração afluente de nitrogênio amoniacal de $500 \mathrm{mgN} / \mathrm{L}$, reduziu-se a vazão de alimentação e a aplicação do afluente foi estendida até o final das 24 horas destinadas à fase anóxica. Além disso, controlou-se o valor do $\mathrm{pH}$ durante a etapa aeróbia em valor aproximadamente igual a 8,3 ; a temperatura foi mantida em torno de $25^{\circ} \mathrm{C}$ ao longo dos ciclos de tratamento e a 
concentração de oxigênio dissolvido na massa líquida, durante a etapa aeróbia, foi próxima a $1,0 \mathrm{mgO}_{2} / \mathrm{L}$. A seguir são apresentados os resultados obtidos para o ciclo 2 da $3^{\mathrm{a}}$ etapa.

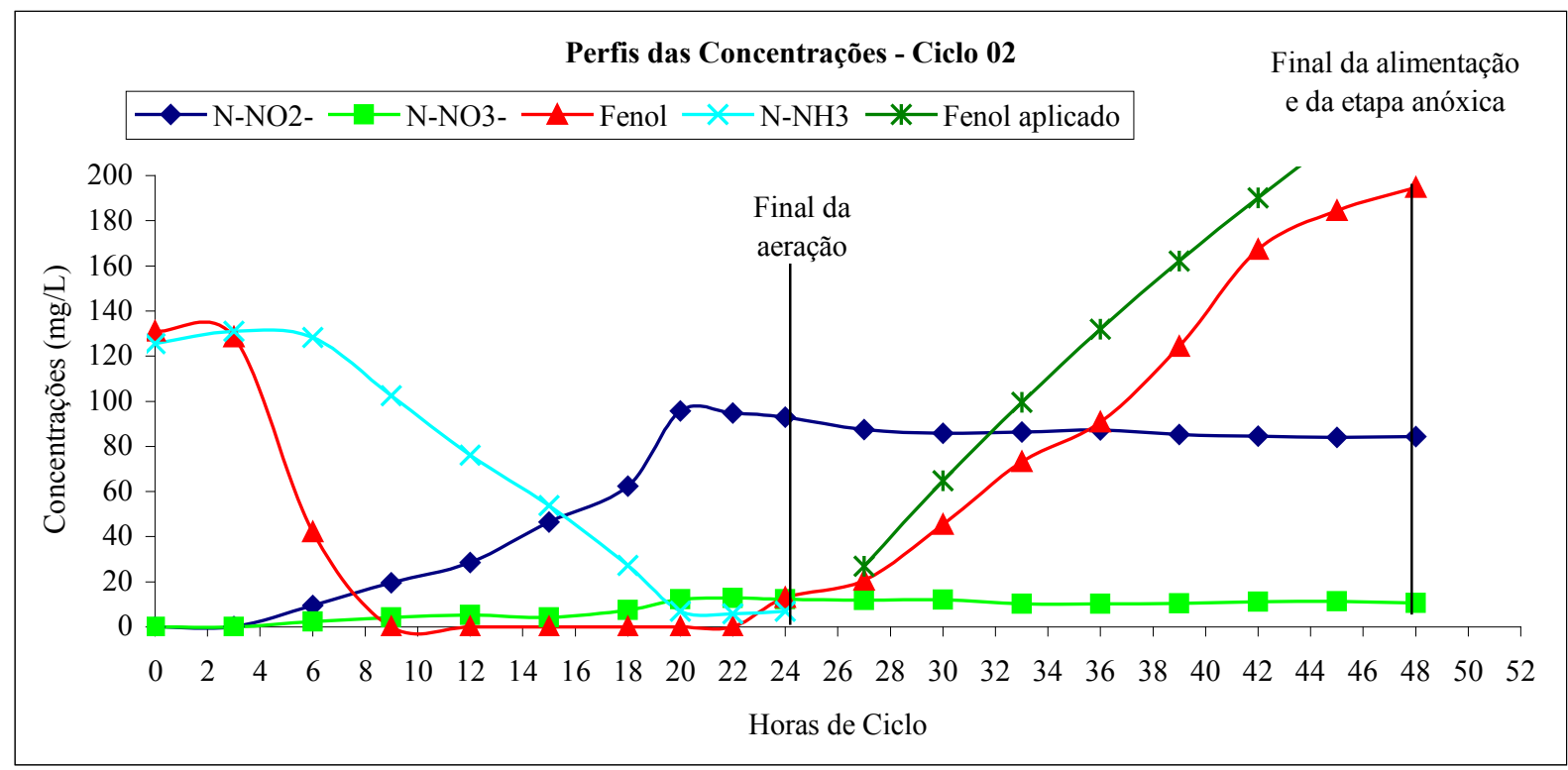

Figura 94 - Perfis temporais das concentrações de $\mathrm{N}_{-} \mathrm{NO}_{2}^{-}, \mathrm{N}_{-} \mathrm{NO}_{3}^{-}$, fenol, $\mathrm{N}-\mathrm{NH}_{3}$ no conteúdo do reator - Ciclo 02 - Etapa $03\left(\mathrm{~T} \cong 25^{\circ} \mathrm{C}\right.$; pH na etapa aeróbia $\left.\cong 8,3\right)$ do Sistema em Bateladas Seqüenciais

Fonte: QUEIROZ, 2006

Nesse ciclo da Etapa 03, a eficiência de remoção de $\mathrm{N}^{-\mathrm{NH}_{3}}$ esteve acima de 95\%, com taxa específica de "nitritação" igual a 0,05 kg N-NH$/ 2 / \mathrm{kgSV}$.dia; a relação $\mathrm{N}-\mathrm{NO}_{2}{ }^{-} /\left(\mathrm{N}-\mathrm{NO}_{2}{ }^{-}+\mathrm{N}-\mathrm{NO}_{3}{ }^{-}\right)$ao final da fase aeróbia do ciclo 02 foi igual a $88 \%$. A predominância do nitrito ao final da fase aeróbia $\left(95{\mathrm{mg} \mathrm{N}-\mathrm{NO}_{2}}^{-} / \mathrm{L}\right)$ possivelmente deveu-se ao valor do $\mathrm{pH}$ mantido próximo a 8,3. Esse valor permitiu a manutenção de uma concentração de amônia livre na massa líquida entre 16 e $0,3 \mathrm{mgNH}_{3} / \mathrm{L}$. Portanto, nota-se que no início da etapa aeróbia do ciclo de remoção a concentração de amônia livre no conteúdo do reator esteve acima de $10 \mathrm{mgNH}_{3} / \mathrm{L}$ (16 mg NH$\left./ \mathrm{L}\right)$ (QUEIROZ, 2006). Esse valor é considerado inibitório por alguns pesquisadores à oxidação do nitrogênio amoniacal (ANTHONISEN et al., 1976; AKERMAN, 2005); entretanto, outras pesquisas conseguiram sucesso na remoção de nitrogênio amoniacal via nitrito mesmo com concentrações de amônia 
livre na massa líquida dos reatores variando entre 14 a $32 \mathrm{mgNH}_{3} / \mathrm{L}$ (TURK; MAVINIC, 1989a; DANIEL, 2005).

A remoção do nitrogênio oxidado ao longo da fase anóxica apresentou baixa eficiência (13\%), assim como a remoção de fenol (24\%). Esse resultado sugeriu, portanto, que estaria ocorrendo inibição do processo de "desnitritação".

A inibição da redução do nitrogênio oxidado pode ser oriunda da toxicidade conferida aos microrganismos heterotróficos degradadores de fenol por elevadas concentrações de nitrito e, conseqüentemente, de ácido nitroso não ionizado $\left(\mathrm{HNO}_{2}\right)$ no conteúdo do reator. Em seu trabalho, Queiroz (2006) citou diversas pesquisas que constataram a inibição do processo de desnitrificação com elevadas concentrações de nitrito no reator e, como as concentrações desse composto foram superiores a $80 \mathrm{mgN}^{-\mathrm{NO}_{2}}{ }^{-}$, o autor mencionou ser esse o fator mais provável para a inibição dos microrganismos.

A Figura 95 apresenta os perfis de $\mathrm{pH}$ e OD ao longo do ciclo 02 da terceira etapa.

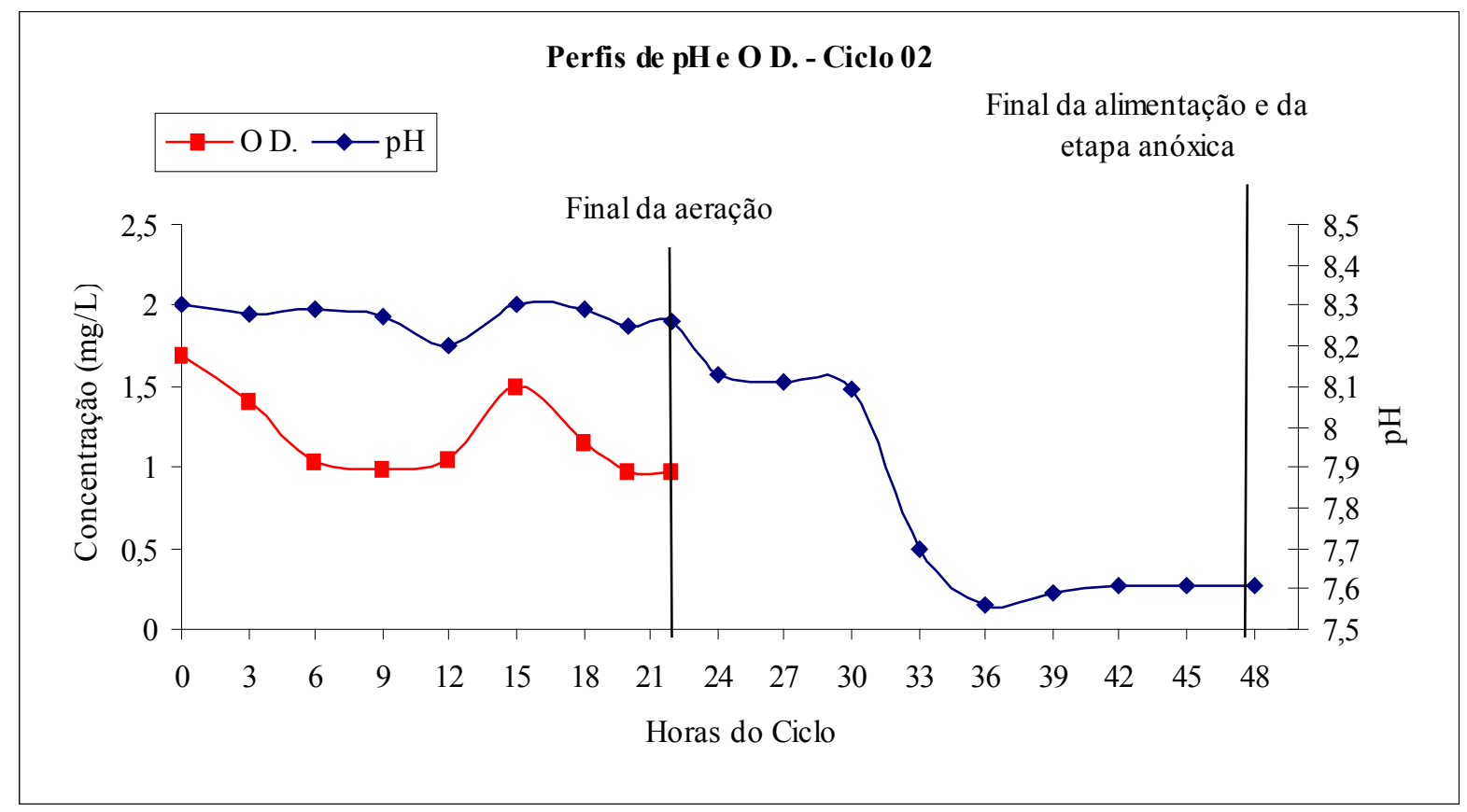

Figura 95 - Perfis temporais de pH e OD no conteúdo do reator - Ciclo 02 - Etapa 03 do Sistema em Bateladas Seqüenciais

Fonte: QUEIROZ, 2006 
Não somente nesse ciclo como também nos demais, observa-se que, diferentemente do que se espera em reatores anóxicos, o pH observado foi inferior ao da etapa aerada. Isso porque pHs muito elevados mostraram-se prejudiciais à desnitritação e observou-se a necessidade de baixar o pH nessa etapa por meio de adição de um ácido, no caso o ácido sulfúrico, para aumentar a eficiência da redução de nitrito.

\subsection{Comparação entre os Resultados Obtidos com o Sistema PARCIAL e o Reator em Bateladas Sequienciais}

Das Figuras 89, 91 e 94, observa-se que nos experimentos em bateladas seqüenciais foi possível manter um acúmulo de nitrito estável no reator durante a etapa aeróbia, com a manutenção da concentração de amônia livre no reator capaz de inibir a atividade dos microrganismos oxidadores de nitrito a nitrato. Apesar de Anthonisen et al. (1976) mencionarem que concentrações entre 0,1 a $1,0 \mathrm{mgNH}_{3} / \mathrm{L}$ são suficientes para a inibição das bactérias oxidadoras de nitrito, nos experimentos em batelada, foi necessária a manutenção de uma concentração mínima de $0,3 \mathrm{mgNH}_{3} / \mathrm{L}$ no reator para que esses microrganismos fossem inibidos (QUEIROZ, 2006), provocando assim seu acúmulo no sistema.

Entretanto, no sistema piloto de lodo ativado PARCIAL, em nenhuma fase da pesquisa foi observado acúmulo estável de nitrito, apenas ocorrendo alguns picos suaves, porém sempre se observando concentrações consideráveis de nitrato e/ou nitrogênio amoniacal concomitantemente.

Na primeira fase da pesquisa, com fração anóxica de 23\%, o pH foi mantido grande parte do tempo em 8,3 no reator aeróbio (Figura 53), conforme os bons resultados que tinham sido obtidos dos experimentos em batelada, objetivando a manutenção de amônia livre 
em concentrações inibitórias aos oxidadores de nitrito e ainda assim não se observou acúmulo de nitrito. Amônia livre no reator aeróbio só foi observada em níveis relativamente elevados (de 2,3 a 20,7 $\mathrm{mgNH}_{3} / \mathrm{L}$ ) de novembro de 2005 a fevereiro de 2006, no qual a nitrificação foi inibida por completo, não só pelas altas concentrações de amônia livre observadas como também pelas baixas concentrações de oxigênio dissolvido $\left(<0,5 \mathrm{mgO}_{2} / \mathrm{L}\right)$ mantidas no reator aeróbio (Figura 55), que foram claramente prejudiciais ao sistema. Nos demais períodos, essa foi praticamente desprezível, quase sempre inferior a $0,1 \mathrm{mgNH}_{3} / \mathrm{L}$, condição não favorável à inibição desses microrganismos (ANTHONISEN et al., 1976). Conseqüentemente, nesse período, foi observado também acúmulo de nitrogênio amoniacal no efluente final, inviabilizando a manutenção dessas condições operacionais para o sistema PARCIAL.

No caso da segunda fase, com fração anóxica de 41\%, observando-se a Figura 73, nota-se que foram instalados a válvula e o controlador automático de OD que até então não existiam e, a partir desse momento, este parâmetro foi mantido principalmente abaixo de $1,0 \mathrm{mgO}_{2} / \mathrm{L}$, assim como no sistema em batelada. Da Figura 71, observa-se que o $\mathrm{pH}$ foi controlado a valores menores que 6,0 entre setembro e novembro de 2006, e em 8,3, de novembro de 2006 a janeiro de 2007. Das Figuras 77, 78 e 79, é possível notar que nenhuma dessas condições foi suficiente para a obtenção de acúmulo estável de nitrito no reator aeróbio, observando-se apenas alguns resultados próximos de nitrito e nitrato entre novembro e dezembro de 2006, que não se mantiveram até o fim da pesquisa e, portanto, confirmou-se a instabilidade de nitrito em sistema contínuo, diferentemente do que foi observado para o sistema em batelada.

A principal conclusão obtida desses resultados é que o regime operacional foi fundamental para o sucesso da remoção de nitrogênio via nitrito e que o sistema contínuo não foi favorável, já que foi muito difícil a manutenção de amônia livre (bem como de ácido nitroso não ionizado) na fase aeróbia de forma contínua em concentrações inibitórias aos 
microrganismos oxidadores de nitrito. Isso porque ou essa acabava se mantendo em concentrações muito elevadas provocando inibição total da nitrificação em virtude de uma ou mais condições operacionais desfavoráveis desbalanceando completamente o sistema, ou acabava aparecendo em concentrações desprezíveis, insuficientes para provocar tal inibição. Acredita-se que essa segunda condição ocorreu porque a entrada de afluente no sistema é feita de forma parcelada (diferentemente do que ocorre num sistema descontínuo) promovendo a diluição do afluente, não restando/mantendo amônia livre no reator, já que segundo os resultados satisfatórios do sistema em bateladas seqüenciais, a existência de amônia livre e o pH aparentam ser os principais parâmetros que regem o acúmulo de nitrito no sistema. 


\section{CONCLUSÕES E RECOMENDAÇÕES}

A pesquisa utilizando sistemas de lodo ativado com nitrificação/desnitrificação completa a nitrato com o uso de etanol como fonte externa de carbono para a desnitrificação (Sistema TOTAL) e nitrificação/desnitrificação parcial a nitrito (Sistema PARCIAL), bem como o sistema em bateladas seqüenciais para remoção de nitrogênio via nitrito, permitiu obter as seguintes conclusões:

- o fenol presente no afluente mostrou-se uma fonte de carbono adequada para promover a desnitrificação do despejo sintético objeto da presente pesquisa;

- em termos de fenol e nitrogênio amoniacal, os resultados foram bastante satisfatórios, já que os sistemas apresentaram na maioria das vezes concentrações muito baixas dos mesmos no efluente final $\left(<0,5 \mathrm{mgC}_{6} \mathrm{H}_{5} \mathrm{OH} / \mathrm{L} \mathrm{e}<20 \mathrm{mgN} / \mathrm{L}\right)$;

- os sistemas mostraram-se de difícil adaptação/aclimatação da biomassa;

- os melhores resultados foram obtidos quando os sistemas de lodo ativado foram operados com frações anóxicas maiores, ou seja, 41\% no caso do sistema PARCIAL e, 49\%, no TOTAL, quando ambos os sistemas operaram com taxas de recirculação de lodo da ordem de 10 vezes a vazão afluente (considerando-se a soma do retorno de lodo do decantador e do reciclo interno);

- o etanol, como fonte adicional de carbono para a desnitrificação, inibiu a desnitrificação com fenol, sendo que eles não se mostraram adequados para serem utilizados concomitantemente em sistema de lodo único, em virtude dos microrganismos darem preferência ao etanol que é uma fonte de carbono mais prontamente assimilável e não consumirem o fenol, provocando acúmulo desse último no sistema. Sendo assim, para a utilização desses dois compostos, seriam necessários dois sistemas em separado, ou seja, um 
sistema de dois lodos, com uma população microbiana independente para cada substrato em cada reator anóxico;

- as taxas de desnitrificação obtidas nos reatores anóxicos do sistema TOTAL foram de:

- $\quad$ 0,01 a 0,03 kg N-NOx/kg SSV.dia - anóxico pré-D sem o uso de etanol

- $\quad<0,01 \mathrm{~kg} \mathrm{~N}-\mathrm{NOx} / \mathrm{kg}$ SSV.dia - anóxico pré-D com o uso de etanol

- $\quad<0,02 \mathrm{~kg} \mathrm{~N}-\mathrm{NOx} / \mathrm{kg}$ SSV.dia - anóxico pós-D sem o uso de etanol

- $\quad 0,01$ a 0,04 kg N-NOx/kg SSV.dia - anóxico pós-D com o uso de etanol

- as taxas de desnitrificação e "desnitritação" obtidas no reator anóxico do sistema PARCIAL foram de:

- 0,01 a 0,07 kg N-NOx/kg SSV.dia - desnitrificação

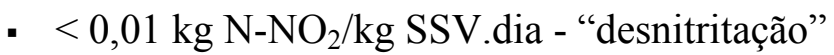

- as relações fenol $1_{\text {removido }} / \mathrm{N}-\mathrm{NO} \mathrm{x}_{\text {removido }}$ obtidas para o reator anóxico pré-D do sistema TOTAL quando não foi adicionado etanol no pós-D estiveram entre 2,0 e 3,5 $\mathrm{kg}$ fenol $_{\text {removido }} / \mathrm{kg} \mathrm{N}-\mathrm{NOx}_{\text {removido; }}$; porém com o uso de etanol, as mesmas variaram entre 1,0 e 2,0 kg fenol ${ }_{\text {removido }} / \mathrm{kg} \mathrm{N}-\mathrm{NOx}_{\text {removido. }}$ Para o sistema PARCIAL, essa relação esteve principalmente entre 0,7 a $2,0 \mathrm{~kg}$ fenol removido $/ \mathrm{kg} \mathrm{N}-\mathrm{NOx}_{\text {removido, }}$ valores um pouco inferiores aos obtidos no sistema em batelada, que foram de 2,1 a 3,2 $\mathrm{kg}$ fenol removido $_{\text {o }} / \mathrm{kg} \mathrm{N}-\mathrm{NOx}_{\text {removido; }}$;

- o regime operacional mostrou-se fundamental para a remoção de nitrogênio pela via simplificada (via nitrito), sendo que o sistema contínuo não se mostrou favorável para o acúmulo de nitrito, por ser difícil a manutenção da amônia livre (e ácido nitroso não ionizado) em concentrações inibitórias aos microrganismos oxidadores de nitrito, dificultando o seu acúmulo no reator aeróbio; mesmo com a manutenção das condições operacionais utilizadas com êxito no sistema em bateladas seqüenciais, de $\mathrm{pH}$ em 8,3 e concentrações de OD inferiores a $0,1 \mathrm{mgO}_{2} / \mathrm{L}$, ainda assim o acúmulo de nitrito mostrou-se instável, com apenas 
alguns valores apresentando-se levemente mais elevados, porém logo em seguida o nitrato voltava a se apresentar como forma oxidada predominante. $\mathrm{O}$ regime em bateladas seqüenciais mostrou-se muito mais favorável à remoção de nitrogênio via nitrito, principalmente quando as concentrações afluentes de nitrogênio amoniacal foram inferiores a $300 \mathrm{mgN} / \mathrm{L}$;

- como o nitrato prevaleceu sobre o nitrito no sistema PARCIAL durante praticamente toda a pesquisa, verifica-se que a manutenção de concentrações elevadas de oxigênio dissolvido em reatores aeróbios $\left(>2,0 \mathrm{mgO}_{2} / \mathrm{L}\right)$ objetivando a nitrificação completa a nitrato nem sempre é necessária. Concentrações da ordem de 0,5 a $1,0 \mathrm{mgO}_{2} / \mathrm{L}$ provavelmente já seriam suficientes para se obter a nitrificação com idades do lodo altas, podendo-se gerar uma boa economia de energia de aeração em estações de tratamento de efluentes visando remoção de nitrogênio.

Como recomendações para futuras pesquisas, sugere-se:

- a utilização de sistema de dois lodos, com biomassas independentes para promover a desnitrificação com fenol como fonte de carbono no primeiro sistema e etanol no segundo sistema, portanto cada substrato atuando num estágio;

- a investigação da formação de nitrofenóis em sistemas de lodo ativado tratando água residuária de coqueria, com a realização de bioensaios para verificação da toxicidade desses compostos aos microrganismos aquáticos. 


\section{REFERÊNCIAS BIBLIOGRÁFICAS}

AHAMAD, P.Y.A.; KUNHI, A.A.M. Degradation of phenol through ortho-cleavage pathway by Pseudomonas stutzeri strain SPC2. Letters in Applied Microbiology, v. 22, n.1, p.26-29, 1996.

AKERMAN, A. Feasibility of nitrate-shunt (nitritation) on landfill leachate. Suécia, 2005. 52p. Tese (Mestrado) - Instituto de Tecnologia, Universidade de Lund, Sweden, 2005.

ALEM SOBRINHO, P.; GARCIA JR., A.D. Tratamento de águas residuárias com elevadas concentrações de fenóis pelo processo de lodos ativados. In: CONGRESSO BRASILEIRO DE ENGENHARIA SANITÁRIA E AMBIENTAL, 12., Balneário Camboriú, 1983. Anais. São Paulo, CETESB, 1983. v.7, p.1-13.

AMERICAN PUBLIC HEALTH ASSOCIATION (APHA); AMERICAN WATER WORKS ASSOCIATION (AWWA); WATER ENVIRONMENTAL FEDERATION (WEF). Standard methods for the examination of water and wastewater. 20.ed., Washington, APHA/AWWA/WEF, 1998.

ANTHONISEN, A.C.; LOEHR, R.C.; PRAKASAM, T.B.S.; SRINATH, E.G. Inibition of nitrification by ammonia and nitrous acid. Journal of Water Pollution Control Federation, v.48, n.5, p.835-852, May 1976.

ARAÚJO, L.A. de. Manual de siderurgia: produção. São Paulo, Arte \& Ciência, 1997. v.1.

ARGAMAN, Y. Nitrogen removal in a semi-continuous process. Water Research, v.20, n.2, p.173-183, 1986.

AUN, M.V. Contribuição ao estudo da desnitrificação utilizando fenol como fonte de carbono. São Paulo, 2001. 171p. Dissertação (Mestrado) - Escola Politécnica, Universidade de São Paulo, São Paulo, 2001.

BAE, W.; BAEK, S.; CHUNG, J.; LEE, Y. Optimal operacional factors for nitrite accumulation in batch reactors. Biodegradation, v.12, p.359-366, 2002.

BAlMELlE, B.; NGUYEN, K.M.; CAPDEVILlE, B.; CORNIER, J.C.; DEGUIN, A. Study of factors controlling nitrite build-up in biological processes for water nitrification. Water Science and Technology, v.26, p.1017-1025, 1992.

BARTON, P.J.; HAMMER, C.A.; KENNEDY, D.C. Analysis of cyanides in coke plant wastewater effluents. Journal of the Water Pollution Control Federation, v.50, n.2, p.234-239, 1978.

BECCARI, M.; DI PINTO, A.C., RAMADORI, R.; TOMEI, M.C. Effects of dissolved oxygen and diffusion resistances on nitrification kinetics. Water Research, v.26, n.8, p.1099-1104, 1992.

BITTON, G. Wastewater microbiology. New York, Wiley-Liss, 1994. 
BLAGODATSKY, S.; KESIK, M.; PAPEN, H.; BUTTERBACH-BAHL, K. Production of $\mathrm{NO}$ and $\mathrm{N}_{2} \mathrm{O}$ by the heterotrophic nitrifier Alcaligenes faecalis parafaecalis under varying conditions of oxygen saturation. Geomicrobiology Journal, v.23, n.3, p.165-176, Apr 2006.

BLUM, D.J.W.; SPEECE, R.E. A database of chemical toxicity to environmental bacteria and its use in interspecies comparisons and correlations. Research Journal of the Water Pollution Control Federation, v.63, n.3, p.198-207, 1991.

BODE, H.; SEYFRIED, C.F.; KRAFT, A. High-rate denitrification of concentrated nitrate wastewater. Water Science and Technology, v.19, p.163-174, 1987.

BRAILE, P.M.; CAVALCANTI, J.E.W.A. Manual de tratamento de águas residuárias industriais. São Paulo, CETESB, 1993.

BRASIL. Ministério da Saúde. Portaria n. 518. Estabelece os procedimentos e responsabilidades relativos ao controle e vigilância da qualidade da água para consumo humano e seu padrão de potabilidade, e dá outras providências. 25 mar. 2004.

. Ministério de Desenvolvimento Urbano e Meio Ambiente. Conselho Nacional do Meio Ambiente. Resolução $n^{\circ} 357$ de 17 de março de 2005. Dispõe sobre a classificação e diretrizes ambientais para o seu enquadramento, bem como estabelece as condições e padrões de lançamento de efluentes, e dá outras providências. Diário Oficial da União, 18 mar. 2005.

BROND, S.; SUND, C. Biological removal of nitrogen in toxic industrial effluents, high in ammonia. Water Science and Technology, v.29, n.9, p.231-240, 1994.

BURRELL, P.C.; KELLER, J.; BLACKALL, L.L. Microbiology of a nitrite-oxidizing bioreactor. Applied and Environmental Microbiology, v.64, n.5, p.1878-1883, May 1998.

CARLSON, C.A.; INGRAHAM, J.L. Comparison of denitrification by Pseudomonas stutzeri, Pseudomonas aeruginosa, and Paracoccus denitrificans. Applied and Environmental Microbiology, v.45, n.4, p.1247-1253, Apr 1983.

CERNIGLIA, C.E. Biodegradation of polycyclic aromatic hydrocarbons. Biodegradation, v.3, n.2-3, p.351-368, 1992.

COMPANHIA DE TECNOLOGIA DE SANEAMENTO AMBIENTAL (CETESB). Relatório de qualidade de águas interiores no estado de São Paulo 2005. São Paulo, CETESB, 2006. v.1.

CONSTANTIN, H.; FICK, M. Influence of C-sources on the denitrification rate of a high-nitrate concentrated industrial wastewater. Water Research, v.31, n.3, p.583-589, 1997.

COPP, J.B.; DOLD, P.L. Confirming the nitrate-to-oxygen conversion factor for denitrification. Water Research, v.32, n.4, p.1296-1304, 1998.

DA COSTA, A.J.M. Estudo da tratabilidade de água residuária sintética simulando despejo líquido de coquerias. São Paulo, 1999. 207p. Tese (Doutorado) - Escola Politécnica, Universidade de São Paulo, São Paulo, 1999. 
DANIEL, L.M.C. Remoção de nitrogênio via nitrito em reator operado em bateladas seqüenciais contendo biomassa imobilizada e aeração intermitente. São Carlos, 2005. 102p. Tese (Doutorado) - Escola de Engenharia de São Carlos, Universidade de São Paulo, São Carlos, 2005.

DOMBROSKI, S.A.G. Nitrificação e desnitrificação de água residuária de coqueria utilizando fonte interna de carbono. São Paulo, 2003. 409p. Tese (Doutorado) - Escola Politécnica, Universidade de São Paulo, São Paulo, 2003.

EIROA, M.; VILAR, A.; AMOR, L.; KENNES, C.; VEIGA, M.C. Biodegradation and effect of formaldehyde and phenol on the denitrification process. Water Research, v.39, p.449-455, 2005 .

EKAMA, G.A.; MARAIS, G.v.R. Biological nitrogen removal. In: MARAIS, G.v.R. Seminario Internacional sobre Tratamiento de Desagües Cloacales - Lodos Activados, Buenos Aires, 1997. Cap. 6, p.1-26.

ENVIRONMENTAL PROTECTION AGENCY. Manual: nitrogen control. Washington, DC, Office of Research and Development/Office of Water, 1993.

Profile of the iron and steel industry. Washington, DC, Office of Compliance/Office of Enforcement and Compliance Assurance, 1995.

Water Quality Standards Database. EPA Numeric Criteria. Disponível em: $<$ http://oaspub.epa.gov/wqsdatabase/wqsi epa criteria.rep parameter $>$ Acesso em: 12 fevereiro 2007.

FANG, H.H.P.; YEONG, C.L.Y. Biological wastewater treatment in reactors with fibrous packing. Journal of Environmental Engineering, v.119, n.5, p.946-957, Sep./Oct. 1993.

FDZ-POLANCO, F.; VILLAVERDE, S.; GARCIA, P.A. Nitrite accumulation in submerged biofilters - combined effects. Water Science and Technology, v.34, n.3-4, p.371-378, 1996.

FELLENBERG, G. Introdução aos problemas da poluição ambiental. Trad. de Juergen Heinrich Maar e Cláudio Gilberto Froehlich. São Paulo, EPU/Springer/EDUSP, 1980.

FITTIPALDO, J.J.; MILLS, W.M.; WONG-CHONG, G.M. Mercury compliance at the LTV Warren coke plant. Iron and Steel Engineer, Oct 1997.

FUX, C.; SIEGRIST, H. Nitrogen removal from sludge digester liquids by nitrification/denitrification or partial nitritation/anammox: environmental and economical considerations. Water Science and Technology, v.50, n.10, p.19-26, 2004.

GANCZARCZYK, J.J. Second-stage activated sludge treatment of coke-plant effluents. Water Research, v.13, p.337-42, Jan./Jun.1979.

GHOSE, M.K. Physico-chemical treatment as a suitable option for treatment of coke-plant effluent. IE (I) Journal-CH, v. 84, p.50-54, Mar.2004. 
GIBBS, B.M.; SHEPHARD, L.R.; THIRD, K.A.; CORD-RUWISCH, R. The presence of ammonium facilitates nitrite reduction under PHB driven simultaneous nitrification and denitrification. Water Science and Technology, v.50, n.10, p.181-188, 2004.

GLANCER, M.; BAN, S.N.; SOLJAN, V.; PASCIK, I. Upgrading of waste-water treatment plants for the biological nitrogen elimination by the injection of on-line prepared mixed cultures. Water Science and Technology, v.29, n.12, p.129-138, 1994.

GORONSZY, M.C.; DEMOULIN, G.; NEWLAND, M. Aerated denitrification in full-scale activated sludge facilities. Water Science and Technology, v.35, n.10, p.103-110, 1997.

GUPTA, S.K.; SHARMA, R. Biological oxidation of high strength nitrogenous wastewater. Water Research, v.30, n.3, p.593-600, 1996.

HA, J.H.; ONG, S.K. Nitrification and denitrification in partially aerated biological aerated filter (BAF) with dual size sand media. Water Science and Technology, v.55, n.1-2, p.9-17, 2007.

HARTMANN, C.C. Avaliação de um efluente industrial através de ensaios ecotoxicológicos e análises físicas e químicas. Porto Alegre, 2004. 85p. Dissertação (Mestrado) - Instituto de Biociências, Universidade Federal do Rio Grande do Sul, Porto Alegre, 2004.

HELLINGA, C.; SCHELLEN, A.A.J.C.; MULDER, J.W.; VAN LOOSDRECHT, M.C.M.; HEIJNEN, J.J. The SHARON process: an innovative method for nitrogen removal from ammonium-rich waste water. Water Science and Technology, v.37, n.9, p.135-142, 1998.

HENZE, M. Capabilities of biological nitrogen removal processes from wastewater. Water Science and Technology, v.23, n.44, p.669-679, 1991.

HUTCHINS, S.R.; SEWELL, G.W.; KOVACS, D.A.; SMITH, G.A. Biodegradation of aromatic hydrocarbons by aquifer microorganisms under denitrifying conditions. Environmental Science Technology, v.25, n.1, p.68-76, 1991.

IAMAMOTO, C.Y. Remoção de nitrogênio em reator em batelada seqüencial com biomassa suspensa tratando águas residuárias com elevada concentração de nitrogênio amoniacal. São Carlos, 2006. 119p. Tese (Doutorado) - Escola de Engenharia de São Carlos, Universidade de São Paulo, São Carlos, 2006.

ISAACS, S.H.; HENZE, M.; SOEBERG, H.; KUEMMEL, M. External carbon source addition as a mean to control an activated sludge nutrient removal process. Water Research, v.28, n.3, p.511-520, 1994.

JETTEN, M.S.M.; STROUS, M.; VAN DE PAS-SCHOONEN, K.T.; SCHALK, J.; VAN DONGEN, U.G.J.M.; VAN DE GRAAF, A.A.; LOGEMANN, S.; MUYZER. G.; VAN LOOSDRECHT, M.C.M.; KUENEN, J.G. The anaerobic oxidation of ammonium. FEMS Microbiology Reviews, v.22, n.5, p.421-437, 1998.

JOO, H.S.; HIRAI, M.; SHODA, M. Nitrification and denitrification in high-strength ammonium by Alcaligenes faecalis. Biotechnology Letters, v.27, n.11, p.773-778, Jun 2005. 
KANG, M.H.; PARK, J.M. Sequential degradation of phenol and cyanide by a commensal interaction between two microorganisms. Journal of Chemical Technology \& Biotechnology, v.69, n.2, p.226-230, 1997.

KINDZIERSKI, W.B.; FEDORAK, P.M.; HRUDEY, S.E. Anaerobic treatability of a phenolic coal conversion wastewater after diisopropyl ether extraction. Water Research, v.25, n.4, p.479-484, Apr. 1991.

KIM, R.B. Effect of ammonia on COD analysis. Journal of Water Pollution Control Federation, v.61, n.5, p.614-617, 1989.

KIM, Y.M.; PARK, D.; LEE, D.S.; PARK, J.M. Instability of biological nitrogen removal in a cokes wastewater treatment facility during summer. Journal of Hazardous Materials, v.141, p.27-32, 2007.

KOSTENBADER, P.D.; FLECKSTEINER, J.W. Biological oxidation of coke plant weak ammonia liquor. Journal of Water Pollution Control Federation, v.41, n.2, part 1, p.199-207, Feb. 1969.

KUAI, L.; VERSTRAETE, W. Autotrophic denitrification with elemental sulphur in smallscale wastewater treatment facilities. Environmental Technology, v.20, n.2, p.201-209, Feb. 1999.

LAI, E.; SENKPIEL, S.; SOLLEY, D.; KELLER, J. Nitrogen removal of high strength wastewater via nitritation/denitritation using a sequencing batch reactor. Water Science and Technology, v.50, n.10, p.27-33, 2004.

LALLAI, A.; MURA, G. $\mathrm{pH}$ variation during phenol biodegradation in mixed cultures of microorganisms. Water Research, v.23, n.11, p.1335-1338, 1989.

LEE, M.W.; PARK, J.M. Biological nitrogen removal from coke plant wastewater with external carbon addition. Water Environment Research, v.70, n.5, p.1090-1095, July/Aug. 1998.

LEITE, J.V. Avaliação da toxicidade do fenol em sistemas de lodos ativados - utilização do método fed-batch reactor (FBR) modificado. São Paulo, 1997. Dissertação (Mestrado) Escola Politécnica, Universidade de São Paulo, São Paulo, 1997.

LI, B.; SUN, Y.; LI, Y. Pretreatment of coking wastewater using anaerobic sequencing batch reactor (ASBR). Journal of Zhejiang University Science, v.6, n.11, p.1115-1123, Nov. 2005.

LI, P.; LIU, D.; NAHIMANA, L.; CHEN, S.; YANG, X.; ZHAO, L. High nitrogen removal from wastewater with several new aerobic bacteria isolated from diverse ecosystems. Journal of Environmental Sciences, v.18, n.3, p.525-529, 2006.

MELCER, H.; NUTT, S.G. The application of predenitrification nitrification technology for trace contaminant control. Water Science and Technology, v.17, n.2-3, p.399-408, 1985. 
METCALF \& EDDY. Wastewater engineering: treatment, disposal and reuse. 3.ed. Singapore, McGraw-Hill, 1991.

MORITA, D.M. Tratabilidade de águas residuárias contendo poluentes perigosos: estudo de caso. São Paulo, 1993. 4v. Tese (Doutorado) - Escola Politécnica, Universidade de São Paulo.

MOSER, G.I.F. Estudo da nitrificação de líquido percolado de aterro sanitário utilizando-se sistemas de lagoa aerada e lodos ativados. São Paulo, 2003. 120p. Dissertação (Mestrado) - Escola Politécnica, Universidade de São Paulo, São Paulo, 2003.

MOSQUERA-CORRAL, A.; GONZÁLEZ, F.; CAMPOS, J.L.; MÉNDEZ, R. Partial nitrification in a SHARON reactor in the presence of salts and organic carbon compounds. Process Biochemistry, v.40, p.3109-3118, 2005.

MOTA, C.; HEAD, M.A.; RIDENOURE, J.A.; CHENG, J.J.; DE LOS REYES, F.L. Effects of aeration cycles on nitrifying bacterial populations and nitrogen removal in intermittently aerated reactors. Applied and Environmental Microbiology, v.71, n.12, p.8565-8572, Dec. 2005 .

MULDER, A.; VAN DE GRAAF, A.A.; ROBERTSON, L.A.; KUENEN, J.G. Anaerobic ammonium oxidation discovered in a denitrifying fluidized bed reactor. FEMS Microbiology Ecology, v.16, p.177-184, 1995.

MUTZEL, A.; REINSCHEID, U.M.; ANTRANIKIAN, G.; MÜLLER, R. Isolation and characterization of a thermophilic bacillus strain, that degrades phenol and cresols as sole carbon source at $70{ }^{\circ} \mathrm{C}$. Applied Microbiology and Biotechnology, v.46, n.5-6, p.593-596, 1995.

NOGUEIRA, R.; MELO, L.F. Competition between Nitrospira spp. and Nitrobacter spp. in nitrite-oxidizing bioreactors. Biotechnology and Bioengineering, v.95, n.1, p.169-175, 2006.

NOOPHAN, P.; FIGUEROA, L.A.; MUNAKATA-MARR, J. Nitrite oxidation inhibition by hidroxylamine: experimental and model evaluation. Water Science and Technology, v.50, n.6, p.295-304, 2004.

NOWAK, O.; KÜHN, V.; MÜLLER, V. A comparison of different concepts of the runningin of nitrification and denitrification in activated sludge plants. Water Science and Technology, v.39, n.6, p.53-60, 1999.

PAI, S.-L.; CHONG, N.-M.; CHEN, C.-H. Potencial applications of aerobic denitrifying bacteria as bioagentes in wastewater treatment. Bioresource Technology, v.68, p.179-185, 1999.

PATUREAU, D.; HELlOIN, E.; RUSTRIAN, E.; BOUCHEZ, T.; DELGENES, J.P.; MOLETTA, R. Combined phosphate and nitrogen removal in a sequencing batch reactor using the aerobic denitrifier, Microvirgula aerodenitrificans. Water Research, v.35, n.1, p.189-197, 2001. 
POCHANA, K.; KELLER, J. Study of factors affecting simultaneous nitrification and denitrification (SND). Water Science and Technology, v.39, n.6, p.61-68, 1999.

POLLICE, A.; TANDOI, V.; LESTINGI, C. Influence of aeration and sludge retention time on ammonium oxidation to nitrite and nitrate. Water Research, v.36, p.2541-2546, 2002.

PRAKASAM, T.B.S.; LOEHR, R.C. Microbial nitrification and denitrification in concentrated wastes. Water Research, v.6, p.859-869, 1972.

PYNAERT, K.; SMETS, B.F.; WYFFELS, S.; BEHEYDT, D.; SICILIANO, S.D.; VERSTRAETE, W. Characterization of an autotrophic nitrogen-removing biofilm from a highly loaded lab-scale rotating biological contactor. Applied and Environmental Microbiology, v.69, n.6, p.3626-3635, Jun 2003.

QUEIROZ, L.M. Estudo da remoção biológica de nitrogênio via nitrito utilizando fenol como fonte de carbono operando um reator em bateladas seqüenciais (SBR) em escala piloto. São Paulo, 2006. 179p. Dissertação (Mestrado) - Escola Politécnica, Universidade de São Paulo, São Paulo, 2006.

RANDALL, C.W.; BUTH, D. Nitrite build-up in activated sludge resulting from combined temperature and toxicity effects. Journal of Water Pollution Control Federation, v.56, n.9, p.1045-1049, Sep. 1984.

RANDALL, C.W.; BARNARD, J.L.; STENSEL, H.D. Design and retrofit of wastewater treatment plants for biological nutrient removal. Lancaster, Technomic Publishing Company, 1992. v.5

ROBERTSON, L.A.; KUENEN, J.G. Aerobic denitrification: a controversy revived. Archives of Microbiology, v.139, p.351-354, 1984.

ROBERTSON, L.A.; KUENEN, J.G. Combined heterotrophic nitrification and aerobic denitrification in Thiosphaera pantotropha and other bacteria. Antonie van Leeuwenhoek, v.57, n.3, p.139-152, Apr 1990.

SANTOS, S.G. Utilização de metanol, etanol e metano como doadores de elétrons para a desnitrificação. São Carlos, 2003. 130p. Tese (Doutorado) - Escola de Engenharia de São Carlos, Universidade de São Paulo, São Carlos, 2003.

SÃO PAULO (Estado). Decreto ${ }^{\circ} 8468$ de 08 de setembro de 1976. Aprova o regulamento da Lei $n^{0} 997$ de 31 de maio de 1976, que dispõe sobre a prevenção e o controle da poluição do meio ambiente. Legislação estadual: controle de poluição ambiental, São Paulo, CETESB, 1991.

Secretaria de Estado do Meio Ambiente. Resolução SMA-3 de 22 de fevereiro de 2000. Implementa o controle ecotoxicológico de efluentes líquidos do Estado de São Paulo. Gabinete do Secretário, São Paulo, 22 fev. 2000.

SARFARAZ, S.; THOMAS, S.; TEWARI, U.K.; IYENGAR, L. Anoxic treatment of phenolic wastewater in sequencing batch reactor. Water Research, v.38, n.4, p.965-971, 2004. 
SCHRAMM, A.; BEER, D.; WAGNER, M.; AMANN, R. Identification and activities in situ of Nitrosospira and Nitrospira spp. as dominant populations in a nitrifying fluidized bed reactor. Applied and Environmental Microbiology, v.64, n.9, p.3480-3485, Sep. 1998.

SILVA, A.J. Biodessulfatação com posterior oxidação parcial do sulfeto em reatores operados em bateladas seqüenciais. São Carlos, 2005. 159p. Tese (Doutorado) - Escola de Engenharia de São Carlos, Universidade de São Paulo, São Carlos, 2005.

SLIEKERS, A.O.; DERWORT, N.; GOMEZ, J.L.C.; STROUS, M.; KUENEN, J.G.; JETTEN, M.S.M. Completely autotrophic nitrogen removal over nitrite in one single reactor. Water Research, v.36, p.2475-2482, 2002.

STROUS, M.; VAN GERVEN, E.; ZHENG, P.; KUENEN, J.G.; JETTEN, M.S.M. Ammonium removal from concentrated waste streams with the anaerobic ammonium oxidation (ANNAMOX) process in different reactor configurations. Water Research, v.31, n.8, p.1955-1962, 1997.

STROUS, M.; HEIJNEN, J.J.; KUENEN, J.G.; JETTEN, M.S.M. The sequencing batch reactor as a powerful tool for the study of slowly growing anaerobic ammonium-oxidizing microorganisms. Applied Microbiology and Biotechnology, v.50, n.5, p.589-596, Nov 1998.

STROUS, M.; FUERST, J.A.; KRAMER, E.H.M.; LOGEMANN, S; MUYZER, G.; VAN DE PAS-SCHOONEN K.T.; WEBB, R.; KUENEN, J.G.; JETTEN, M.S.M. Missing lithotroph identified as a new planctomycete. Nature, v.400, 446-449, 1999.

STÜVEN, R.; BOCK, E. Nitrification and denitrification as a source for $\mathrm{NO}$ and $\mathrm{NO}_{2}$ production in high-strength wastewater. Water Research, v.35, n.8, p.1905-1914, 2001.

SU, J.J.; LIU, B.Y.; CHANG, Y.C. Identifying an interfering factor on chemical oxygen demand (COD) determination in piggery wastewater and eliminating the factor by an indigenous Pseudomonas stutzeri strain. Letters in Applied Microbiology, n.33, p.440-444, 2001 .

SURMACZ-GÓRSKA, J.; CICHON, A.; MIKSCH, K. Nitrogen removal from wastewater with high ammonia nitrogen concentration via shorter nitrification and denitrification. Water Science and Technology, v.36, n.10, p.73-78, 1997.

SUTTON, P.M.; HURVID, J.; HOEKSEMA, M. Biological fluidized-bed treatment of wastewater from byproduct coking operations: full-scale case history. Water Environment Research, v.71, n.1, p.5-9, 1999.

TAM, N.F.Y.; WONG, Y.S.; LEUNG, G. Effect of exogenous carbon sources on removal of inorganic nutrient by the nitrification-denitrification process. Water Research, v.26, n.9, p.1229-1236, 1992.

THIRD, K.A.; NEWLAND, M.; CORD-RUWISCH, R. The effect of dissolved oxygen on PHB accumulation in activated sludge cultures. Biotechnology and Bioengineering, v.82, n.2, p.238-250, Feb 2003. 
TOH, S.; ASHBOLT, N. Adaptation of anaerobic ammonium-oxidising consortium to synthetic coke-ovens wastewater. Applied Microbiology and Biotechnology, v.59, n.2-3, p.344-352, Jul 2002.

TURK, O.; MAVINIC, D.S. Benefits of using selective inhibition to remove nitrogen from highly nitrogenous wastes. Environmental Technology Letters, v.8, n.9, p.419-426, 1987.

TURK, O.; MAVINIC, D.S. Maintaining nitrite build-up in a system acclimated to free ammonia. Water Research, v.23, n.11, p.1383-1388, 1989a.

TURK, O.; MAVINIC, D.S. Stability of nitrite build-up in an activated sludge system. Journal of Water Pollution Control Federation, v.61, n.8, p.1440-1448, 1989b.

UPTON, J.; FERGUSSON, A.; SAVAGE, S. Denitrification of wastewater: operating experiences in the US and pilot-plant studies in the UK. J. IWEM, v.7, p.1-11, 1993.

VAN DONGEN, U.; JETTEN, M.S.M.; VAN LOOSDRECHT, M.C.M. The SHARON $^{\circledR}$-Anammox ${ }^{\circledR}$ process for treatment of ammonium rich wastewater. Water Science and Technology, v.44, n.1, p.153-160, 2001.

VAN HAANDEL, A.C.; EKAMA, G.A.; MARAIS, G.v.R. The activated sludge process-3: single sludge denitrification. Water Research, v.15, p.1135-1152, 1981.

VAN HAANDEL, A.; MARAIS, G.v.R. O comportamento do sistema de lodo ativado: teoria e aplicações para projetos e operação. Campina Grande, epgraf, 1999.

VAN LOOSDRECHT, M.C.M.; JETTEN, M.S.M. Microbiological conversions in nitrogen removal. Water Science and Technology, v.38, n.1, p.1-7, 1998.

VERSTRAETE, W.; PHILIPS, S. Nitrification-denitrification processes and technologies in new contexts. Environmental Pollution, v.102, n.1, p.717-726, 1998.

VILLAS BÔAS, D.M.F. Estudo microbiológico de sistemas de lodos ativados com ênfase nas bactérias degradadoras de fenol. São Paulo, 1999. 161p. Tese (Doutorado) - Escola Politécnica, Universidade de São Paulo, São Paulo, 1999.

VON SPERLING, M. Princípios do tratamento biológico de águas residuárias: lodos ativados. Belo Horizonte, Departamento de Engenharia Sanitária e Ambiental - UFMG, 1997. v.4.

WU, X.; CHEN, L.; PENG, Y.; WANG, Y.; WANG, P. Experimental study of nitrite accumulation in pre-denitrification biological nitrogen removal process. Huan Jing Ke Xue, v.27, n.12, p.2472-2476, Dec.2006.

YANG, L.; ALLEMAN, J.E. Investigation of batchwise nitrite build-up by an enriched nitrification culture. Water Science and Technology, v.26, n. 5-6, p.997-1005, 1992. 
YI, Q.; YIBO, W.; HUIMING, Z. Efficacy of pre-treatment methods in the activated sludge removal of refractory compounds in coke-plant wastewater. Water Research, v.28, n.3, p.701-707, 1994.

YIBO, W.; MIN, Z.; YI, Q. Biological treatment of coke-plant wastewater for COD and $\mathrm{NH}_{3}-\mathrm{N}$ removal. Water Science and Technology, v.23, n.10-12, p.1883-1892, 1991.

YOO, H.; AHN, K.; LEE, H.; LEE, K.; KWAK, Y.; SONG, K. Nitrogen removal from synthetic wastewater by simultaneous nitrification and denitrification (SND) via nitrite in an intermittently-aerated reactor. Water Research, v.33, n.1, p.145-154, 1999.

ZDRADEK, C.P. Seleção de linhagens oxidadoras de amônio e remoção de nitrogênio via nitrito em reator descontínuo alimentado (SBR), sob condições de limitação de oxigênio. Florianópolis, 2005. 195p. Tese (Doutorado) - Departamento de Engenharia Química e Engenharia de Alimentos, Universidade Federal de Santa Catarina, Florianópolis, 2005.

ZHANG, M.; TAY, J.H.; QIAN, Y.; GU, X.S. Coke plant wastewater treatment by fixed biofilm system for $\mathrm{COD}$ and $\mathrm{NH}_{3}-\mathrm{N}$ removal. Water Research, v.32, n.2, p.519-527, Feb. 1998. 
APÊNDICE A - RESULTADOS DO MONITORAMENTO NA FASE DE ACLIMATAÇÃO DA BIOMASSA 
Tabela A.1 - Resultados do Monitoramento do Sistema TOTAL ("T") na Fase de Aclimatação (Continua)

\begin{tabular}{|c|c|c|c|c|c|c|c|c|c|c|c|c|c|c|c|}
\hline Data & $\begin{array}{c}\mathrm{pH} \text { ANOX T } \\
\text { pré }\end{array}$ & $\begin{array}{c}\mathrm{pH} \\
\text { AER T }\end{array}$ & $\begin{array}{l}\text { pH ANOX T } \\
\text { pós }\end{array}$ & $\begin{array}{c}\text { OD ANX T } \\
\text { pré } \\
(\mathrm{mg} / \mathrm{L})\end{array}$ & $\begin{array}{c}\text { OD AER } \\
T \\
(\mathrm{mg} / \mathrm{L})\end{array}$ & $\begin{array}{c}\text { OD ANX T } \\
\text { pós } \\
\text { (mg/L) }\end{array}$ & $\begin{array}{c}\text { temp ANOX T } \\
\text { pré } \\
(\mathrm{oC})\end{array}$ & $\begin{array}{c}\text { temp AER } \\
\mathrm{T} \\
(\mathrm{oC})\end{array}$ & $\begin{array}{c}\text { temp ANOX T } \\
\text { pós } \\
\text { (oC) }\end{array}$ & $\begin{array}{c}\text { Qafl T } \\
\text { (mL/min) }\end{array}$ & $\begin{array}{c}\text { Qret T } \\
\text { (mL/min) }\end{array}$ & $\begin{array}{c}\text { Qefl T } \\
\text { (mL/min) }\end{array}$ & $\begin{array}{l}\text { Qetanol } \\
\text { (mL/min) }\end{array}$ & $\begin{array}{l}\text { QrecicloT } \\
\text { (mL/min) }\end{array}$ & $\begin{array}{c}\text { Afluente } \\
\mathrm{pH}\end{array}$ \\
\hline $04 / 10 / 2004$ & 7,2 & 6,4 & 7,0 & & & & & & & 8,0 & 16,0 & & & & \\
\hline 05/10/2004 & 7,8 & 6,6 & 6,5 & & & & 21,0 & 24,0 & 21,0 & & & & & & \\
\hline $08 / 10 / 2004$ & 7,3 & 6,4 & & 0,3 & 7,2 & 0,4 & 15,0 & 21,0 & 15,0 & & & & & & \\
\hline $13 / 10 / 2004$ & 7,5 & 7,2 & 6,9 & & & & & & & & & & & & \\
\hline $14 / 10 / 2004$ & 7,4 & 8,1 & 7,2 & & & & 26,0 & 26,0 & 26,0 & & & & & & 6,6 \\
\hline $15 / 10 / 2004$ & 7,4 & 7,2 & 7,6 & 0,4 & 1,0 & 0,4 & & & & & & & & & \\
\hline $18 / 10 / 2004$ & 7,4 & 6,9 & 6,4 & 0,5 & 4,3 & 0,4 & 26,0 & 26,0 & 26,0 & & & & & & \\
\hline $19 / 10 / 2004$ & 7,5 & 6,6 & 7,2 & & & & & & & 8,0 & 18,0 & & & & 6,6 \\
\hline $21 / 10 / 2004$ & 8,8 & 7,7 & 7,0 & & & & & & & & & & & & \\
\hline $22 / 10 / 2004$ & 7,5 & 6,8 & 7,0 & 0,2 & 3,4 & 0,0 & 26,0 & 23,0 & 28,0 & & & & & & \\
\hline $25 / 10 / 2004$ & 7,5 & 6,7 & 6,9 & & & & & & & & & & & & \\
\hline $26 / 10 / 2004$ & 7,5 & 7,0 & 6,9 & & & & 27,0 & 25,0 & 28,0 & & & & & & \\
\hline $27 / 10 / 2004$ & 7,6 & 6,7 & 7,0 & 0,7 & 4,8 & 0,6 & & & & 8,0 & 16,0 & & & & \\
\hline 29/10/2004 & 7,3 & 6,7 & 8,5 & & & & & & & & & & & & \\
\hline $03 / 11 / 2004$ & 8,0 & 7,8 & 6,2 & 0,5 & 7,2 & 0,7 & 28,0 & 26,0 & 24,0 & & & & & & \\
\hline $04 / 11 / 2004$ & 7,5 & 7,4 & 7,0 & & & & & & & & 22,0 & & & & \\
\hline $05 / 11 / 2004$ & & 6,8 & & & & & & 30,2 & & & & & & & \\
\hline 08/11/2004 & 7,8 & 6,8 & 6,7 & & & & & & & & & & & & \\
\hline $10 / 11 / 2004$ & 8,2 & 6,8 & 8,2 & 0,2 & & & & 28,0 & & & 12,0 & & & & \\
\hline $12 / 11 / 2004$ & 8,2 & 6,8 & 8,2 & & & & 25,0 & 25,0 & 24,0 & & 18,0 & & & & \\
\hline $16 / 11 / 2004$ & & 7,5 & & & & & & 26,0 & & 6,0 & 30,0 & & & & \\
\hline $17 / 11 / 2004$ & & 7,3 & & 0,1 & 5,6 & 0,3 & & & & & & & & & \\
\hline $18 / 11 / 2004$ & 7,2 & 6,8 & 7,1 & & & & 30,6 & 28,9 & 28,2 & & & & & & \\
\hline $19 / 11 / 2004$ & & 6,8 & & 0,4 & 5,5 & 0,1 & & 29,2 & & 6,0 & 18,0 & & & & \\
\hline $22 / 11 / 2004$ & & 6,8 & & & & & & 23,7 & & & & & & & \\
\hline $23 / 11 / 2004$ & & 6,8 & & & & & & & & & & & & & \\
\hline $24 / 11 / 2004$ & 7,5 & 8,8 & & & & & 27,5 & 25,9 & & & 24,0 & & & & \\
\hline $25 / 11 / 2004$ & & 8,6 & & 0,8 & 8,1 & 1,5 & & 25,6 & & 8,0 & 21,0 & & & & \\
\hline $26 / 11 / 2004$ & 7,6 & 6,8 & 8,3 & & & & 30,1 & 29,8 & 26,5 & & & & & & \\
\hline $29 / 11 / 2004$ & 7,7 & 6,8 & 8,1 & & & & 29,8 & 29,5 & 27,2 & 8,5 & 19,0 & & & & \\
\hline $30 / 11 / 2004$ & & 7,4 & & & & & & 27,0 & & & & & & & \\
\hline $01 / 12 / 2004$ & 7,5 & 6,8 & 7,1 & & & & 28,5 & 28,1 & 27,3 & 7,5 & 34,0 & & & & \\
\hline $02 / 12 / 2004$ & & 6,8 & & & & & & 28,5 & & & & & & & \\
\hline $03 / 12 / 2004$ & 7,7 & 7,4 & 7,9 & & & & 28,6 & 27,5 & 31,4 & 8,0 & 13,0 & & & & \\
\hline $06 / 12 / 2004$ & 7,5 & 6,8 & 7,8 & 0,2 & 5,6 & 0,9 & 30,0 & 29,4 & 31,1 & 7,0 & 16,0 & & & & \\
\hline $07 / 12 / 2004$ & & 6,8 & & & & & & 29,5 & & & & & & & \\
\hline $08 / 12 / 2004$ & & 6,8 & & 0,2 & 5,0 & 0,3 & & 30,2 & & 6,0 & 24,0 & & & & \\
\hline $09 / 12 / 2004$ & 7,4 & 6,75 & 6,86 & & & & 30,2 & 30,3 & 30,6 & & & & & & \\
\hline $10 / 12 / 2004$ & & 6,8 & & 0,3 & 6,6 & 0,4 & & 28,6 & & 8,0 & 22,0 & & & & \\
\hline
\end{tabular}


Tabela A.1 - Resultados do Monitoramento do Sistema TOTAL ("T") na Fase de Aclimatação (Continuação)

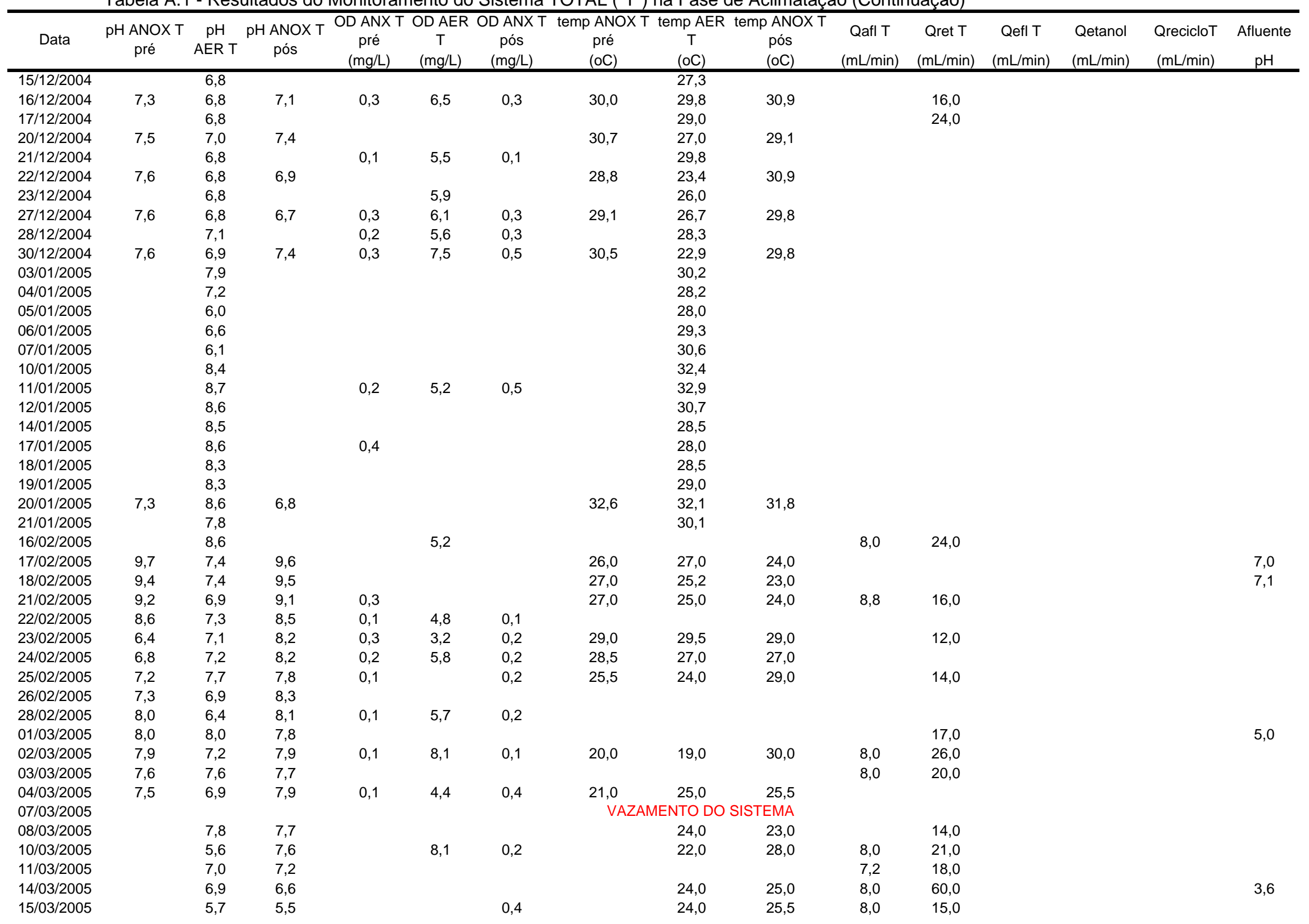


Tabela A.1 - Resultados do Monitoramento do Sistema TOTAL ("T") na Fase de Aclimatação (Continuação)

\begin{tabular}{|c|c|c|c|c|c|c|c|c|c|c|c|c|c|c|c|}
\hline Data & $\begin{array}{c}\text { pH ANOX T } \\
\text { pré }\end{array}$ & $\begin{array}{c}\mathrm{pH} \\
\text { AER T }\end{array}$ & $\begin{array}{l}\text { pH ANOX T } \\
\text { pós }\end{array}$ & $\begin{array}{c}\text { OD ANX T } \\
\text { pré } \\
(\mathrm{mg} / \mathrm{L})\end{array}$ & $\begin{array}{c}\text { OD AER } \\
T \\
(\mathrm{mg} / \mathrm{L})\end{array}$ & $\begin{array}{l}\text { OD ANX T } \\
\text { pós } \\
\text { (mg/L) }\end{array}$ & $\begin{array}{c}\text { temp ANOX T } \\
\text { pré } \\
\text { (oC) }\end{array}$ & $\begin{array}{c}\text { temp AER } \\
\mathrm{T} \\
(\mathrm{oC})\end{array}$ & $\begin{array}{l}\text { temp ANOX T } \\
\text { pós } \\
\text { (oC) }\end{array}$ & $\begin{array}{c}\text { Qafl T } \\
\text { (mL/min) }\end{array}$ & $\begin{array}{c}\text { Qret T } \\
\text { (mL/min) }\end{array}$ & $\begin{array}{c}\text { Qefl T } \\
\text { (mL/min) }\end{array}$ & $\begin{array}{l}\text { Qetanol } \\
\text { (mL/min) }\end{array}$ & $\begin{array}{l}\text { QrecicloT } \\
\text { (mL/min) }\end{array}$ & $\begin{array}{c}\text { Afluente } \\
\mathrm{pH}\end{array}$ \\
\hline $16 / 03 / 2005$ & & 6,8 & 7,0 & & & & & & & 7,8 & 18,0 & & & & \\
\hline $17 / 03 / 2005$ & & 7,2 & 7,2 & & & 0,3 & & 24,5 & 26,0 & 3,5 & 26,0 & & & & 7,1 \\
\hline 21/03/2005 & & 7,5 & 8,7 & & & 0,4 & & 31,0 & 30,0 & 8,0 & 30,0 & & & & \\
\hline 22/03/2005 & & 6,9 & 8,5 & & & & & 33,5 & 30,0 & 8,2 & 28,0 & & & & \\
\hline $23 / 03 / 2005$ & & 6,8 & 8,2 & & & 0,1 & & 32,6 & 30,0 & 8,0 & 27,6 & & & & \\
\hline $24 / 03 / 2005$ & & 6,8 & 8,0 & & 4,0 & 0,3 & & 32,8 & 30,0 & 8,0 & 46,0 & & & & \\
\hline $27 / 03 / 2005$ & & 6,2 & & & & & & 31,7 & & & & & & & \\
\hline 28/03/2005 & & 9,3 & 9,3 & & & & & & & & & & & & \\
\hline 29/03/2005 & 9,5 & 7,8 & & & & & & & & & & & & & \\
\hline $30 / 03 / 2005$ & 8,9 & 6,6 & 9,0 & & & & & & & 6,0 & 22,4 & & & & \\
\hline $31 / 03 / 2005$ & 6,6 & 9,2 & 9,1 & 0,1 & 3,3 & 0,2 & & & & & & & & & \\
\hline $01 / 04 / 2005$ & 8,9 & 7,9 & 9,1 & & & & & & & & & & & & 6,0 \\
\hline $02 / 04 / 2005$ & 8,2 & 7,9 & 8,5 & & & & 30,0 & 29,5 & 27,0 & & & & & & 5,8 \\
\hline 04/04/2005 & 8,0 & 8,1 & 7,9 & & & & 29,0 & 29,5 & 29,5 & & & & & & 5,9 \\
\hline 05/04/2005 & 7,5 & 7,4 & 7,7 & 0,4 & 3,0 & & 27,5 & 30,0 & 25,5 & & 33,6 & & & & 6,2 \\
\hline 06/04/2005 & 8,3 & 8,6 & 8,6 & & & & & & & 6,0 & 48,0 & & & & \\
\hline $07 / 04 / 2005$ & 7,3 & 7,3 & 7,7 & 0,9 & 3,9 & 0,3 & 25,0 & 29,5 & 30,0 & 8,0 & 28,8 & & & & \\
\hline 08/04/2005 & 7,2 & 7,0 & 7,1 & & & & & & & 7,0 & 28,0 & & & & 7,2 \\
\hline $11 / 04 / 2005$ & 7,6 & 6,8 & 7,1 & & & & 26,0 & 29,5 & 29,0 & 7,0 & 28,0 & & & & 7,0 \\
\hline $12 / 04 / 2005$ & 7,5 & 6,7 & 7,0 & & & & & & & 6,5 & 31,0 & & & & \\
\hline $13 / 04 / 2005$ & 7,3 & 7,1 & 7,0 & & & & & & & & 25,6 & & & & \\
\hline $14 / 04 / 2005$ & 7,2 & 7,0 & 7,0 & & & & 28,0 & 30,0 & 30,0 & & 36,0 & & & & \\
\hline $15 / 04 / 2005$ & 7,1 & 7,1 & 7,0 & 0,2 & 4,5 & 0,1 & 28,5 & 30,0 & 30,0 & 7,0 & 30,0 & & & & 7,4 \\
\hline $18 / 04 / 2005$ & 7,1 & 6,7 & 6,7 & 0,2 & 4,2 & 0,2 & 27,0 & 30,0 & 29,5 & 8,6 & 32,0 & & & & \\
\hline $19 / 04 / 2005$ & 7,3 & 6,6 & 6,7 & 0,1 & 4,3 & 0,2 & 29,5 & 30,0 & 29,0 & 9,6 & 24,0 & & & & 7,2 \\
\hline 20/04/2005 & 6,5 & 6,6 & 6,5 & 0,2 & 3,1 & 0,3 & 25,5 & 29,5 & 27,0 & & 28,0 & & & & 7,1 \\
\hline $22 / 04 / 2005$ & & 7,0 & & & & & & & & & & & & & \\
\hline $25 / 04 / 2005$ & 6,8 & 7,0 & 6,7 & 0,2 & 3,8 & 0,2 & 28,5 & 29,5 & 30,0 & 5,0 & 26,0 & & & & 7,1 \\
\hline $26 / 04 / 2005$ & 7,0 & 6,7 & 6,5 & 0,1 & 4,0 & 0,1 & 27,0 & 26,0 & 29,0 & 4,0 & 34,8 & & & & 7,3 \\
\hline $27 / 04 / 2005$ & 6,9 & 6,6 & 6,5 & & & & 25,5 & 27,5 & 28,5 & 4,0 & 36,0 & & & & \\
\hline $28 / 04 / 2005$ & 6,8 & 6,5 & 6,5 & 0,2 & 4,1 & 0,2 & 27,0 & 25,0 & 29,0 & & 43,6 & & & & 7,0 \\
\hline $29 / 04 / 2005$ & 6,6 & 7,0 & 7,1 & 0,0 & 6,5 & 0,0 & 26,5 & 28,0 & 28,5 & 5,6 & 44,0 & & & & 6,9 \\
\hline $02 / 05 / 2005$ & 6,7 & 6,7 & 6,8 & 0,1 & 2,8 & 0,1 & 24,5 & 27,0 & 28,5 & 6,8 & 46,4 & & & & 7,1 \\
\hline 03/05/2005 & 7,0 & 6,8 & 6,8 & 0,0 & 3,7 & 0,0 & 27,0 & 27,5 & 27,5 & 8,0 & 36,4 & & 1,4 & & \\
\hline 04/05/2005 & 7,3 & 6,7 & 7,2 & & & & & & & 7,0 & 32,0 & & & & 7,3 \\
\hline 05/05/2005 & 8,4 & 7,0 & 8,4 & 0,0 & 5,9 & 0,1 & 31,0 & 27,0 & 29,0 & 7,0 & 17,0 & & & & \\
\hline 06/05/2005 & 8,9 & 6,7 & 8,5 & 0,0 & 6,4 & 0,0 & 31,0 & 28,0 & 30,0 & & 30,0 & & & & 7,1 \\
\hline 09/05/2005 & 8,0 & 7,5 & 8,1 & 0,0 & 5,3 & 0,0 & 31,0 & 28,0 & 32,0 & 6,0 & 17,0 & & & & 6,9 \\
\hline $10 / 05 / 2005$ & 7,3 & 8,0 & 8,3 & 0,0 & 2,9 & 0,0 & 30,0 & 29,5 & 33,0 & 4,6 & 22,0 & & & & \\
\hline $13 / 05 / 2005$ & 8,2 & 8,5 & 8,4 & 0,0 & 4,5 & 0,3 & 29,5 & 28,5 & 24,0 & 4,8 & 12,4 & & & 19,8 & 7,3 \\
\hline
\end{tabular}


Tabela A.1 - Resultados do Monitoramento do Sistema TOTAL ("T") na Fase de Aclimatação (Continuação)

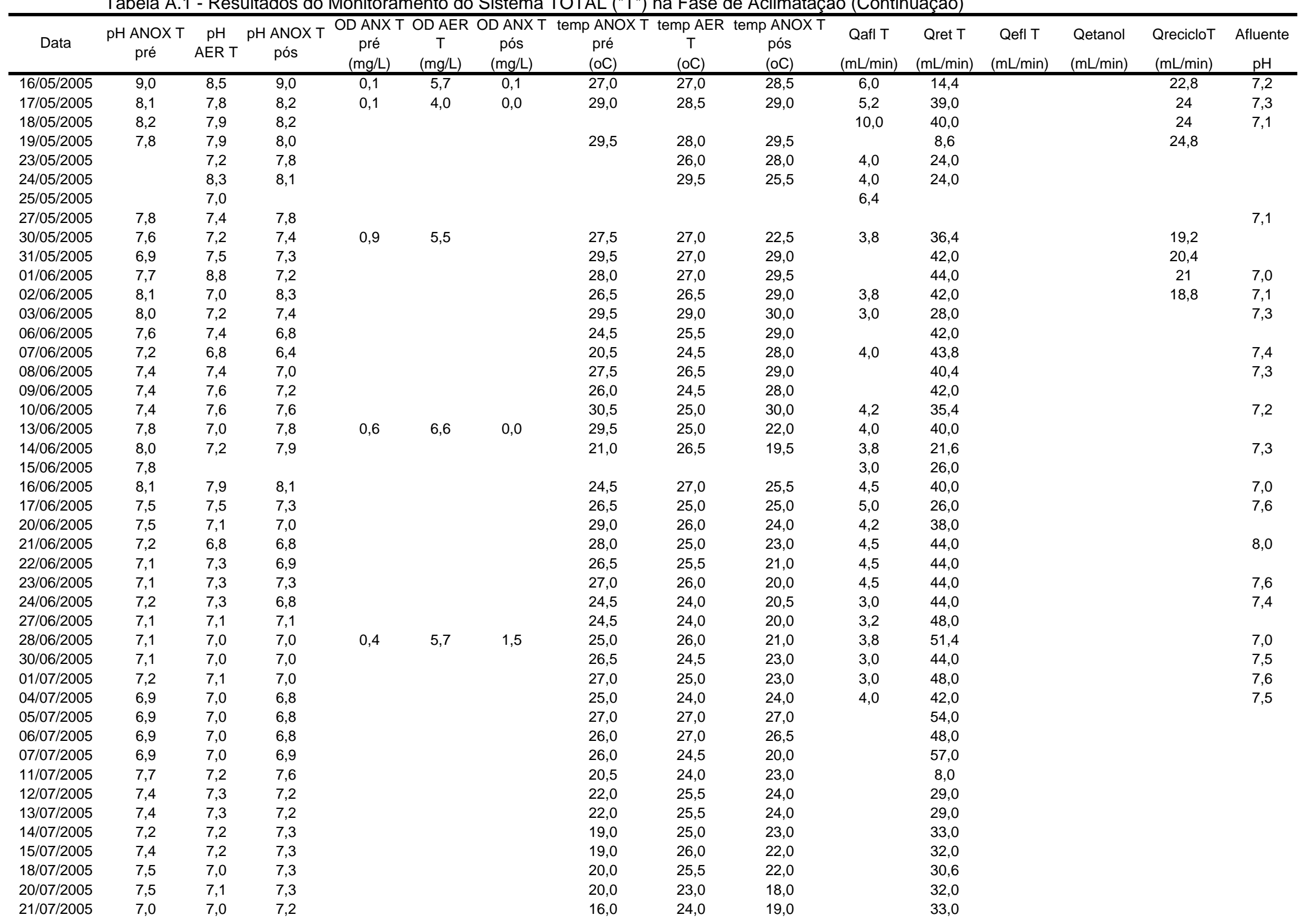


Tabela A.1 - Resultados do Monitoramento do Sistema TOTAL ("T") na Fase de Aclimatação (Conclusão)

\begin{tabular}{|c|c|c|c|c|c|c|c|c|c|c|c|c|c|c|c|}
\hline Data & $\begin{array}{l}\text { pH ANOX T } \\
\text { pré }\end{array}$ & $\begin{array}{c}\mathrm{pH} \\
\text { AER T }\end{array}$ & $\begin{array}{l}\text { pH ANOX T } \\
\text { pós }\end{array}$ & $\begin{array}{c}\text { OD ANX T } \\
\text { pré } \\
\text { (mg/L) }\end{array}$ & $\begin{array}{c}\text { OD AER } \\
T \\
(\mathrm{mg} / \mathrm{L}) \\
\end{array}$ & $\begin{array}{c}\text { OD ANX T } \\
\text { pós } \\
\text { (mg/L) } \\
\end{array}$ & $\begin{array}{l}\text { temp ANOX T } \\
\text { pré } \\
\text { (oC) } \\
\end{array}$ & $\begin{array}{c}\text { temp AER } \\
\mathrm{T} \\
(\mathrm{oC}) \\
\end{array}$ & $\begin{array}{c}\text { temp ANOX T } \\
\text { pós } \\
\text { (oC) } \\
\end{array}$ & $\begin{array}{c}\text { Qafl T } \\
\text { (mL/min) }\end{array}$ & $\begin{array}{c}\text { Qret T } \\
\text { (mL/min) }\end{array}$ & $\begin{array}{c}\text { Qefl T } \\
\text { (mL/min) }\end{array}$ & $\begin{array}{l}\text { Qetanol } \\
\text { (mL/min) }\end{array}$ & $\begin{array}{l}\text { QrecicloT } \\
\text { (mL/min) }\end{array}$ & $\begin{array}{c}\text { Afluente } \\
\mathrm{pH}\end{array}$ \\
\hline $22 / 07 / 2005$ & 6,9 & 6,9 & 7,1 & & & & 17,0 & 25,0 & 21,0 & & 36,0 & & & & \\
\hline $25 / 07 / 2005$ & 8,1 & 7,9 & 8,6 & & & & 20,0 & 25,0 & 21,0 & & 23,6 & & & & \\
\hline $27 / 07 / 2005$ & 7,5 & 8,2 & 7,5 & & & & 16,0 & 24,0 & 20,0 & & 28,0 & & & & \\
\hline
\end{tabular}


Tabela A.2 - Resultados do Monitoramento do Sistema PARCIAL ("P") na Fase de Aclimatação (Continua)

\begin{tabular}{|c|c|c|c|c|c|c|c|c|c|c|c|}
\hline Data & $\mathrm{pH}$ ANOX $\mathrm{P}$ & $\mathrm{pH}$ AER $\mathrm{P}$ & $\begin{array}{c}\text { OD ANX P } \\
(\mathrm{mg} / \mathrm{L})\end{array}$ & $\begin{array}{l}\text { OD AER P } \\
(\mathrm{mg} / \mathrm{L})\end{array}$ & $\begin{array}{c}\text { temp } \\
\text { ANOX P } \\
(\mathrm{oC})\end{array}$ & $\begin{array}{c}\text { temp AER P } \\
\text { (oC) }\end{array}$ & $\begin{array}{c}\text { Qafl P } \\
(\mathrm{mL} / \mathrm{min})\end{array}$ & $\begin{array}{c}\text { Qret P } \\
(\mathrm{mL} / \mathrm{min})\end{array}$ & $\begin{array}{c}\text { Qefl P } \\
(\mathrm{mL} / \mathrm{min})\end{array}$ & $\begin{array}{l}\text { QrecicloP } \\
\text { (mL/min) }\end{array}$ & $\begin{array}{c}\text { Afluente } \\
\mathrm{pH}\end{array}$ \\
\hline $04 / 10 / 2004$ & 8,0 & 6,8 & & & & 20,0 & 8,0 & 16,0 & & & \\
\hline 05/10/2004 & 7,6 & 6,7 & & & 27,0 & 24,0 & & & & & \\
\hline 06/10/2004 & 7,5 & 7,1 & & & 27,0 & 24,5 & & & & & 7,1 \\
\hline 08/10/2004 & 7,7 & 7,4 & 0,4 & 0,5 & 22,5 & 24,0 & & & & & \\
\hline $13 / 10 / 2004$ & 7,9 & 7,8 & & & & & & & & & \\
\hline $14 / 10 / 2004$ & 7,8 & 8,0 & & & 30,0 & 29,0 & & & & & 6,6 \\
\hline $15 / 10 / 2004$ & 7,8 & 8,0 & 0,8 & 0,3 & & & & & & & \\
\hline $18 / 10 / 2004$ & 7,6 & 8,0 & 0,5 & 0,4 & 30,0 & 27,0 & & & & & \\
\hline 19/10/2004 & 7,8 & 7,9 & & & & & 8,0 & 48,0 & & & 6,6 \\
\hline 21/10/2004 & 7,7 & 7,8 & & & & & & & & & \\
\hline 22/10/2004 & 7,7 & 7,7 & 0,2 & 0,1 & 28,0 & 28,0 & & & & & \\
\hline $25 / 10 / 2004$ & 7,8 & 8,0 & & & & & & & & & \\
\hline 26/10/2004 & 7,9 & 8,1 & & & 29,0 & 30,0 & & & & & \\
\hline 27/10/2004 & 7,9 & 8,1 & 0,4 & 0,5 & & & 7,5 & 40,0 & & & \\
\hline 29/10/2004 & 7,7 & 8,0 & & & & & & & & & \\
\hline 03/11/2004 & 7,8 & 7,9 & 0,4 & 1,2 & 29,0 & 30,0 & & & & & \\
\hline $04 / 11 / 2004$ & 7,8 & 7,6 & & & & & & 36,0 & & & \\
\hline 05/11/2004 & & 7,9 & & & & 32,5 & & & & & \\
\hline $08 / 11 / 2004$ & 7,7 & 7,8 & & & & & & & & & \\
\hline 09/11/2004 & & 6,9 & & & & & & & & & \\
\hline $10 / 11 / 2004$ & 7,4 & 6,6 & 0,6 & & & 31,3 & & 26,0 & & & \\
\hline $12 / 11 / 2004$ & 7,3 & 6,7 & & & 29,0 & 29,0 & & 16,0 & & & \\
\hline $16 / 11 / 2004$ & & 7,0 & & & & 26,2 & 6,0 & 30,0 & & & \\
\hline $17 / 11 / 2004$ & & 6,7 & 0,9 & 0,9 & & & & & & & \\
\hline $18 / 11 / 2004$ & 7,1 & 7,1 & & & 28,1 & 23,9 & & & & & \\
\hline 19/11/2004 & & 6,8 & 0,1 & 0,4 & & 27,7 & 7,0 & 40,0 & & & \\
\hline 22/11/2004 & & 6,8 & & & & 28,0 & & & & & \\
\hline 23/11/2004 & & 9,0 & & & & & & & & & \\
\hline $24 / 11 / 2004$ & 7,5 & 7,9 & & & 29,3 & 28,6 & 5,0 & 24,0 & & & \\
\hline 25/11/2004 & & 8,2 & 0,9 & 0,5 & & 30,6 & 7,0 & 22,0 & & & \\
\hline $26 / 11 / 2004$ & 7,8 & 8,4 & & & 28,6 & 26,5 & & & & & \\
\hline 29/11/2004 & 7,9 & 6,8 & & & 30,3 & 29,3 & 8,0 & 18,0 & & & \\
\hline $30 / 11 / 2004$ & & 7,0 & & & & 28,0 & & & & & \\
\hline 01/12/2004 & 7,7 & 6,8 & & & 28,1 & 28,9 & 6,0 & 24,0 & & & \\
\hline $02 / 12 / 2004$ & & 7,0 & & & & 28,9 & & & & & \\
\hline 03/12/2004 & 7,6 & 6,8 & & & 28,7 & 28,5 & 6,0 & 16,0 & & & \\
\hline 06/12/2004 & 6,9 & 7,6 & 0,5 & 1,0 & 29,6 & 29,8 & 4,5 & 16,0 & & & \\
\hline $07 / 12 / 2004$ & & 7,0 & & & & 29,5 & & & & & \\
\hline 08/12/2004 & & 7,1 & 0,2 & 3,6 & & 29,5 & 5,0 & 14,0 & & & \\
\hline 09/12/2004 & 6,6 & 6,8 & & & 29,0 & 28,0 & & & & & \\
\hline $10 / 12 / 2004$ & & 6,8 & 0,4 & 2,6 & & 29,7 & 8,0 & 22,0 & & & \\
\hline $13 / 12 / 2004$ & 7,2 & 6,8 & 0,1 & 5,0 & 25,7 & 28,0 & 8,0 & 28,0 & & & \\
\hline $14 / 12 / 2004$ & & 6,8 & & & & 28,2 & & & & & \\
\hline $15 / 12 / 2004$ & & 6,7 & & & & 28,0 & & & & & \\
\hline
\end{tabular}


Tabela A.2 - Resultados do Monitoramento do Sistema PARCIAL ("P") na Fase de Aclimatação (Continuação)

\begin{tabular}{|c|c|c|c|c|c|c|c|c|c|c|c|}
\hline Data & $\mathrm{pH}$ ANOX $\mathrm{P}$ & $\mathrm{pH}$ AER $\mathrm{P}$ & $\begin{array}{c}\text { OD ANX P } \\
(\mathrm{mg} / \mathrm{L})\end{array}$ & $\begin{array}{c}\text { OD AER P } \\
(\mathrm{mg} / \mathrm{L})\end{array}$ & $\begin{array}{c}\text { temp } \\
\text { ANOX P } \\
(\mathrm{oC})\end{array}$ & $\begin{array}{c}\text { temp AER P } \\
\text { (oC) }\end{array}$ & $\begin{array}{c}\text { Qafl P } \\
(\mathrm{mL} / \mathrm{min})\end{array}$ & $\begin{array}{l}\text { Qret P } \\
(\mathrm{mL} / \mathrm{min})\end{array}$ & $\begin{array}{c}\text { Qefl P } \\
(\mathrm{mL} / \mathrm{min})\end{array}$ & $\begin{array}{l}\text { QrecicloP } \\
\text { (mL/min) }\end{array}$ & $\begin{array}{c}\text { Afluente } \\
\mathrm{pH}\end{array}$ \\
\hline $16 / 12 / 2004$ & 7,4 & 6,7 & $\overline{0,4}$ & 2,7 & 29,2 & 28,6 & & 9,0 & & & \\
\hline $17 / 12 / 2004$ & & 6,7 & & & & 28,3 & & 60,0 & & & \\
\hline 20/12/2004 & 7,0 & 6,8 & & & 27,1 & 28,3 & & & & & \\
\hline 21/12/2004 & & 6,8 & 0,3 & 1,3 & & 27,5 & & & & & \\
\hline $22 / 12 / 2004$ & 6,9 & 6,7 & & & 25,5 & 26,3 & & & & & \\
\hline $23 / 12 / 2004$ & & 6,8 & & 1,3 & & 24,2 & & & & & \\
\hline $27 / 12 / 2004$ & 7,0 & 6,8 & 0,5 & 1,8 & 25,4 & 25,5 & & & & & \\
\hline $28 / 12 / 2004$ & & 7,0 & 0,7 & 1,3 & & 25,9 & & & & & \\
\hline $30 / 12 / 2004$ & 7,1 & 6,7 & 0,5 & 1,2 & 29,5 & 25,6 & & & & & \\
\hline 03/01/2005 & & 7,2 & & & & 27,1 & & & & & \\
\hline 04/01/2005 & & 9,0 & & & & 27,5 & & & & & \\
\hline 05/01/2005 & & 9,5 & & & & 27,7 & & & & & \\
\hline 06/01/2005 & & 9,3 & & & & 28,4 & & & & & \\
\hline 07/01/2005 & 10,0 & 7,8 & & & 28,1 & 30,8 & & & & & \\
\hline $10 / 01 / 2005$ & & 9,7 & & & & 28,8 & & & & & \\
\hline $11 / 01 / 2005$ & & 9,2 & 0,3 & 1,8 & & 31,1 & & & & & \\
\hline $12 / 01 / 2005$ & & 9,3 & & & & 28,1 & & & & & \\
\hline $14 / 01 / 2005$ & & 7,2 & & & & 25,4 & & & & & \\
\hline $17 / 01 / 2005$ & & 8,6 & 0,3 & 4,2 & & 25,0 & & & & & \\
\hline $18 / 01 / 2005$ & & 7,6 & & & & 27,1 & & & & & \\
\hline $19 / 01 / 2005$ & & 8,8 & & & & 28,1 & & & & & \\
\hline $20 / 01 / 2005$ & 8,3 & 7,7 & & & 29,2 & 28,1 & & & & & \\
\hline $21 / 01 / 2005$ & & 8,0 & & & & 28,1 & & & & & \\
\hline $16 / 02 / 2005$ & & 8,1 & & 3,8 & & & 8,0 & 24,0 & & & \\
\hline $17 / 02 / 2005$ & 7,6 & 7,6 & & & 30,0 & 24,3 & & & & & 7,0 \\
\hline $18 / 02 / 2005$ & 7,3 & 7,2 & & & 31,5 & 23,9 & & & & & 7,1 \\
\hline 21/02/2005 & 7,8 & 6,9 & 0,3 & & 26,5 & 23,0 & 8,0 & 18,0 & & & \\
\hline $22 / 02 / 2005$ & 7,6 & 6,8 & 0,1 & 4,0 & & 21,5 & & & & & \\
\hline 23/02/2005 & 7,3 & 6,8 & 0,1 & 2,9 & 29,0 & 29,0 & & 12,0 & & & \\
\hline 24/02/2005 & 7,4 & 6,8 & 0,1 & 6,5 & 29,0 & 27,3 & & & & & \\
\hline 25/02/2005 & 7,4 & 7,4 & 0,4 & 7,4 & 29,5 & 30,0 & & 22,0 & & & \\
\hline $26 / 02 / 2005$ & 7,4 & 6,8 & & & 29,5 & 29,0 & & & & & \\
\hline 28/02/2005 & 7,6 & 6,6 & 0,3 & 3,4 & & & & & & & \\
\hline 01/03/2005 & 7,5 & 6,8 & & & & & & 22,0 & & & 5,0 \\
\hline 02/03/2005 & 7,2 & 6,6 & 0,2 & 6,6 & 25,0 & 22,0 & 8,0 & 16,0 & & & \\
\hline 03/03/2005 & 7,0 & 6,5 & & & & & 8,0 & 12,0 & & & \\
\hline 04/03/2005 & 7,2 & 6,7 & 0,2 & 3,4 & 29,0 & 23,6 & 8,0 & 24,0 & & & \\
\hline 07/03/2005 & 6,9 & 6,7 & 0,2 & 6,3 & 24,5 & 27,0 & 6,4 & 28,0 & & & \\
\hline 08/03/2005 & 7,0 & 7,4 & & & 30,0 & 27,0 & 7,0 & 26,0 & & & \\
\hline $10 / 03 / 2005$ & 7,2 & 6,7 & 0,3 & & 24,5 & 29,0 & 7,2 & 22,0 & & & \\
\hline $11 / 03 / 2005$ & 7,1 & 6,6 & & & & & 8,4 & 28,0 & & & \\
\hline $14 / 03 / 2005$ & 7,1 & 7,7 & & & 29,0 & 27,5 & & 22,0 & & & 3,6 \\
\hline $15 / 03 / 2005$ & 7,4 & 6,7 & 0,4 & & 29,5 & 28,0 & 8,0 & 26,0 & & & \\
\hline $16 / 03 / 2005$ & 7,1 & 6,5 & & & & & 7,2 & 24,0 & & & \\
\hline $17 / 03 / 2005$ & 6,9 & 6,7 & 0,4 & & 30,0 & 25,0 & 4,0 & 38,0 & & & 7,1 \\
\hline
\end{tabular}


Tabela A.2 - Resultados do Monitoramento do Sistema PARCIAL ("P") na Fase de Aclimatação (Continuação)

\begin{tabular}{|c|c|c|c|c|c|c|c|c|c|c|c|}
\hline Data & $\mathrm{pH}$ ANOX $\mathrm{P}$ & pH AER P & $\begin{array}{c}\text { OD ANX P } \\
(\mathrm{mg} / \mathrm{L})\end{array}$ & $\begin{array}{c}\text { OD AER P } \\
(\mathrm{mg} / \mathrm{L})\end{array}$ & $\begin{array}{c}\text { temp } \\
\text { ANOX P } \\
(\mathrm{oC})\end{array}$ & $\begin{array}{c}\text { temp AER P } \\
(\mathrm{oC})\end{array}$ & $\begin{array}{c}\text { Qafl P } \\
\text { (mL/min) }\end{array}$ & $\begin{array}{c}\text { Qret P } \\
\text { (mL/min) }\end{array}$ & $\begin{array}{c}\text { Qefl P } \\
\text { (mL/min) }\end{array}$ & $\begin{array}{l}\text { QrecicloP } \\
\text { (mL/min) }\end{array}$ & $\begin{array}{c}\text { Afluente } \\
\mathrm{pH}\end{array}$ \\
\hline $18 / 03 / 2005$ & 6,7 & 6,7 & & & 30,0 & 28,0 & & & & & \\
\hline $21 / 03 / 2005$ & 6,2 & 6,7 & 0,4 & & 30,5 & 27,5 & 8,8 & 26,0 & & & \\
\hline $22 / 03 / 2005$ & 6,8 & 6,7 & & & 29,0 & 28,0 & 8,0 & 26,0 & & & \\
\hline 23/03/2005 & 6,8 & 7,2 & 0,3 & & 29,0 & 27,0 & 7,8 & 26,4 & & & \\
\hline $24 / 03 / 2005$ & 7,3 & 7,0 & 0,1 & 5,0 & 29,0 & 28,0 & 8,2 & 24,0 & & & \\
\hline $27 / 03 / 2005$ & & 7,7 & & & & 26,1 & & & & & \\
\hline $28 / 03 / 2005$ & 7,0 & 6,9 & & & & & 8,0 & 25,0 & & & \\
\hline 29/03/2005 & 7,1 & 7,0 & & & 29,0 & 28,9 & 4,8 & 15,6 & & & \\
\hline 30/03/2005 & 7,6 & 6,6 & & & 30,0 & 29,5 & 8,0 & 26,0 & & & \\
\hline $31 / 03 / 2005$ & 7,2 & 7,1 & 0,1 & 4,2 & 30,0 & 27,9 & 7,8 & 28,0 & & & \\
\hline 01/04/2005 & 7,1 & 6,8 & 0,2 & 5,0 & 30,0 & 29,6 & 8,6 & 20,0 & & & 6,0 \\
\hline 02/04/2005 & 7,1 & 7,4 & & & 30,5 & 29,6 & 8,4 & 28,8 & & & 5,8 \\
\hline 04/04/2005 & 7,5 & 6,9 & 0,2 & 4,2 & 30,0 & 29,5 & 9,4 & 32,6 & & & 5,9 \\
\hline 05/04/2005 & 7,0 & 6,6 & 0,1 & 2,0 & 28,5 & 30,0 & 10,4 & 42,0 & & & 6,2 \\
\hline 06/04/2005 & 6,8 & 6,3 & & & 29,0 & 30,0 & 10,0 & 28,0 & & & \\
\hline $07 / 04 / 2005$ & 6,6 & 6,6 & 0,4 & 4,2 & 30,0 & 27,5 & 8,8 & 32,8 & & & \\
\hline 08/04/2005 & 6,4 & 6,3 & & & & & & & & & 7,2 \\
\hline 09/04/2005 & 6,8 & 6,4 & 0,5 & 6,5 & 29,5 & 29,0 & 8,0 & 26,0 & & & 7,2 \\
\hline $11 / 04 / 2005$ & 6,9 & 6,3 & 0,4 & 7,5 & 26,0 & 27,5 & 8,0 & 32,0 & & & 7,0 \\
\hline $12 / 04 / 2005$ & 6,9 & 6,4 & & & & & 8,0 & 28,0 & & & \\
\hline $13 / 04 / 2005$ & 7,8 & 5,7 & & & & & & 28,0 & & & \\
\hline $14 / 04 / 2005$ & 6,6 & 6,6 & & & 28,0 & 28,5 & & 42,0 & & & \\
\hline $15 / 04 / 2005$ & 6,4 & 6,6 & 0,2 & 3,7 & 30,0 & 28,0 & 8,0 & 32,0 & & & 7,4 \\
\hline $18 / 04 / 2005$ & 7,1 & 7,4 & 0,2 & 1,8 & 27,5 & 29,0 & 9,2 & 28,0 & & & \\
\hline $19 / 04 / 2005$ & 7,0 & 6,5 & 0,2 & 1,3 & 28,5 & 28,5 & 9,6 & 32,0 & & & 7,2 \\
\hline $20 / 04 / 2005$ & 7,0 & 6,5 & 0,2 & 0,5 & 26,5 & 26,0 & & 30,0 & & & 7,1 \\
\hline $22 / 04 / 2005$ & & 6,8 & & & & & & & & & \\
\hline $25 / 04 / 2005$ & 7,8 & 7,4 & 0,3 & 0,9 & 29,0 & 28,5 & 6,0 & 30,0 & & & 7,1 \\
\hline $26 / 04 / 2005$ & 7,2 & 7,3 & 0,2 & 1,8 & 25,0 & 26,5 & 5,4 & 60,0 & & & 7,3 \\
\hline $27 / 04 / 2005$ & 7,1 & 6,9 & & & 25,0 & 26,5 & 5,4 & 18,0 & & & \\
\hline $28 / 04 / 2005$ & 7,2 & 7,0 & 0,4 & 3,8 & 26,5 & 26,5 & & 28,4 & & & 7,0 \\
\hline $29 / 04 / 2005$ & 8,0 & 8,6 & 0,0 & 0,7 & 25,5 & 26,0 & 6,0 & 32,0 & & & 6,9 \\
\hline $02 / 05 / 2005$ & 7,9 & 7,1 & 0,1 & 2,1 & 24,0 & 27,5 & 6,0 & 37,6 & & & 7,1 \\
\hline 03/05/2005 & 7,5 & 7,6 & 0,0 & 3,1 & 25,0 & 26,5 & 7,8 & 41,0 & & & \\
\hline 04/05/2005 & 7,5 & 7,5 & & & & & 8,0 & 39,0 & & & 7,3 \\
\hline 05/05/2005 & 7,3 & 6,7 & 0,0 & 1,7 & 22,5 & 27,5 & 8,0 & 25,0 & & & \\
\hline 06/05/2005 & 7,8 & 6,6 & 0,0 & 1,1 & 27,5 & 28,0 & & 52,2 & & & 7,1 \\
\hline 09/05/2005 & 7,9 & 7,5 & 0,0 & 4,6 & 26,0 & 28,5 & 6,0 & 37,0 & & & 6,9 \\
\hline $10 / 05 / 2005$ & 7,6 & 7,3 & 0,1 & 0,4 & 22,0 & 28,5 & 5,6 & 35,2 & & & \\
\hline $11 / 05 / 2005$ & & 7,2 & 0,0 & 2,1 & & & 4,6 & 46,5 & & & \\
\hline $12 / 05 / 2005$ & 8,0 & 7,6 & & & 24,5 & 25,0 & 5,6 & 36,0 & & & \\
\hline $13 / 05 / 2005$ & 7,3 & 7,0 & 0,0 & 0,5 & 25,5 & 25,5 & 5,4 & 35,4 & & & 7,3 \\
\hline $16 / 05 / 2005$ & 8,6 & 8,7 & 0,5 & 0,8 & 25,0 & 27,0 & 5,4 & 34,0 & & & 7,2 \\
\hline $17 / 05 / 2005$ & 7,9 & 7,5 & 0,4 & 1,9 & 26,0 & 28,0 & 4,6 & 36,4 & & & 7,3 \\
\hline $18 / 05 / 2005$ & 7,4 & 6,7 & & & & & 5,5 & 40,0 & & & 7,1 \\
\hline
\end{tabular}


Tabela A.2 - Resultados do Monitoramento do Sistema PARCIAL ("P") na Fase de Aclimatação (Conclusão)

\begin{tabular}{|c|c|c|c|c|c|c|c|c|c|c|c|}
\hline Data & pH ANOX P & $\mathrm{pH} A E R \mathrm{P}$ & $\begin{array}{c}\text { OD ANX P } \\
(\mathrm{mg} / \mathrm{L})\end{array}$ & $\begin{array}{c}\text { OD AER P } \\
(\mathrm{mg} / \mathrm{L})\end{array}$ & $\begin{array}{c}\text { temp } \\
\text { ANOX P } \\
(\mathrm{oC})\end{array}$ & $\begin{array}{c}\text { temp AER P } \\
(\mathrm{oC})\end{array}$ & $\begin{array}{c}\text { Qafl P } \\
(\mathrm{mL} / \mathrm{min})\end{array}$ & $\begin{array}{l}\text { Qret P } \\
(\mathrm{mL} / \mathrm{min})\end{array}$ & $\begin{array}{c}\text { Qefl P } \\
(\mathrm{mL} / \mathrm{min})\end{array}$ & $\begin{array}{l}\text { QrecicloP } \\
\text { (mL/min) }\end{array}$ & $\begin{array}{c}\text { Afluente } \\
\mathrm{pH}\end{array}$ \\
\hline $19 / 05 / 2005$ & 7,9 & 7,2 & 0,7 & 4,0 & 28,0 & 29,5 & $\overline{5,4}$ & 21,4 & & & \\
\hline $23 / 05 / 2005$ & 7,4 & 7,6 & & & 24,0 & 27,0 & & 21,0 & & & \\
\hline $24 / 05 / 2005$ & 7,7 & 6,4 & & & 25,0 & 27,0 & 5,8 & 18,6 & & & \\
\hline $25 / 05 / 2005$ & 6,0 & & & & & & 5,4 & & & & \\
\hline $27 / 05 / 2005$ & 7,3 & 6,7 & & & & & & & & & 7,1 \\
\hline $30 / 05 / 2005$ & 7,3 & 7,6 & 0,3 & 2,7 & 28,0 & 26,0 & 4,8 & 16,0 & & & \\
\hline $31 / 05 / 2005$ & 6,9 & 6,1 & & & 29,0 & 28,0 & & 28,0 & & & \\
\hline $01 / 06 / 2005$ & 7,0 & 6,8 & & & 26,5 & 30,0 & & 34,0 & & & 7,0 \\
\hline 02/06/2005 & 8,7 & 6,8 & & & 28,0 & 30,0 & 4,6 & 43,2 & & & 7,1 \\
\hline 03/06/2005 & 7,5 & 7,6 & & & 28,5 & 30,0 & 4,5 & 16,8 & & & 7,3 \\
\hline 06/06/2005 & 7,2 & 6,8 & & & 30,5 & 29,5 & & 35,4 & & & \\
\hline $07 / 06 / 2005$ & 6,8 & 6,7 & & & 30,5 & 28,0 & 4,4 & 34,8 & & & 7,4 \\
\hline 08/06/2005 & 6,8 & 6,8 & & & 31,0 & 29,5 & & 42,6 & & & 7,3 \\
\hline 09/06/2005 & 7,1 & 6,8 & & & 30,0 & 27,0 & & 36,0 & & & \\
\hline $10 / 06 / 2005$ & 6,7 & 6,8 & & & 31,0 & 25,0 & 4,8 & 39,0 & & & 7,2 \\
\hline $13 / 06 / 2005$ & 6,8 & 6,7 & 0,6 & 2,6 & 30,5 & 26,5 & 4,5 & 42,0 & & & \\
\hline $14 / 06 / 2005$ & 6,8 & 6,7 & & & 29,5 & 27,5 & 4,4 & 39,0 & & & 7,3 \\
\hline $15 / 06 / 2005$ & 6,9 & 6,7 & & & 29,5 & 27,5 & 4,4 & 33,6 & & & \\
\hline $16 / 06 / 2005$ & 7,0 & 6,7 & & & 30,0 & 26,5 & 4,5 & 35,0 & & & 7,0 \\
\hline $17 / 06 / 2005$ & 7,0 & 6,7 & & & 30,0 & 26,5 & 5,0 & 36,0 & & & 7,6 \\
\hline 20/06/2005 & 7,5 & 6,7 & & & 29,5 & 27,5 & 5,2 & 22,4 & & & \\
\hline $21 / 06 / 2005$ & 7,1 & 6,6 & & & 29,5 & 29,0 & 5,0 & 33,0 & & & 8,0 \\
\hline $22 / 06 / 2005$ & 7,0 & 6,8 & & & 29,5 & 27,0 & 5,0 & 32,0 & & & \\
\hline $23 / 06 / 2005$ & 6,8 & 6,7 & & & 27,0 & 26,5 & 5,0 & 44,0 & & & 7,6 \\
\hline $24 / 06 / 2005$ & 6,9 & 6,9 & & & 27,5 & 25,0 & 5,2 & 40,0 & & & 7,4 \\
\hline $27 / 06 / 2005$ & 7,3 & 7,9 & & & 27,5 & 25,0 & 5,0 & 44,0 & & & \\
\hline $28 / 06 / 2005$ & 7,9 & 7,9 & 0,2 & 4,5 & 29,0 & 24,5 & 5,6 & 40,2 & & & 7,0 \\
\hline $30 / 06 / 2005$ & 7,4 & 7,8 & & & 29,5 & 28,0 & 5,0 & 40,0 & & & 7,5 \\
\hline $01 / 07 / 2005$ & 7,5 & 7,3 & & & 31,0 & 29,5 & 5,2 & 56,0 & & & 7,6 \\
\hline 04/07/2005 & 7,7 & 7,1 & & & 29,5 & 28,0 & 5,0 & 60,0 & & & 7,5 \\
\hline 05/07/2005 & 7,6 & 6,9 & & & 29,0 & 29,0 & & 52,0 & & & \\
\hline 06/07/2005 & 7,2 & 7,0 & & & 29,0 & 28,5 & & 56,0 & & & \\
\hline 07/07/2005 & 7,2 & 7,3 & & & 25,0 & 24,5 & & 48,0 & & & \\
\hline $11 / 07 / 2005$ & 7,3 & 7,5 & & & 27,0 & 25,0 & & 28,0 & & & \\
\hline $12 / 07 / 2005$ & 7,1 & 7,2 & & & 24,0 & 26,0 & & 37,4 & & & \\
\hline $13 / 07 / 2005$ & 7,0 & 7,2 & & & 30,0 & 27,0 & & 23,6 & & & \\
\hline $14 / 07 / 2005$ & 6,9 & 7,1 & & & 29,0 & 26,0 & & 37,6 & & & \\
\hline $15 / 07 / 2005$ & 6,9 & 7,1 & & & 29,0 & 26,5 & & 36,0 & & & \\
\hline $18 / 07 / 2005$ & 7,1 & 7,3 & & & 31,0 & 27,0 & & 30,0 & & & \\
\hline 20/07/2005 & 7,1 & 7,5 & & & 28,0 & 25,0 & & 26,0 & & & \\
\hline $21 / 07 / 2005$ & 7,0 & 6,8 & & & 33,5 & 24,5 & & 35,2 & & & \\
\hline $22 / 07 / 2005$ & 6,6 & 6,4 & & & 31,0 & 24,5 & & 32,6 & & & \\
\hline $25 / 07 / 2005$ & 6,8 & 7,1 & & & 29,0 & 24,5 & & 36,0 & & & \\
\hline $27 / 07 / 2005$ & 6,6 & 7,1 & & & 34,0 & 26,0 & & 36,0 & & & \\
\hline
\end{tabular}


APÊNDICE B - RESULTADOS DAS ANÁLISES DE DQO OBTIDOS EM TODAS AS FASES DA PESQUISA 
Tabela B.1 - Resultados do Monitoramento do Sistema TOTAL ("T") das Análises de DQO

\begin{tabular}{|c|c|c|c|c|c|}
\hline Mês/Ano & Fase & $\begin{array}{l}\text { DQO afl T } \\
(\mathrm{mg} / \mathrm{L})\end{array}$ & $\begin{array}{c}\text { DQO anx T pré } \\
(\mathrm{mg} / \mathrm{L})\end{array}$ & $\begin{array}{c}\text { DQO anx T pós } \\
(\mathrm{mg} / \mathrm{L})\end{array}$ & $\begin{array}{c}\text { DQO dec T } \\
(\mathrm{mg} / \mathrm{L})\end{array}$ \\
\hline \multirow[t]{3}{*}{ set/05 } & & 2059 & 772 & 554 & 495 \\
\hline & & 2857 & 714 & 939 & 1347 \\
\hline & & 2951 & 524 & 680 & 641 \\
\hline \multirow[t]{5}{*}{ out/05 } & & 3340 & 854 & 621 & 680 \\
\hline & & 3573 & 1379 & 388 & 388 \\
\hline & & 3321 & 774 & 302 & 623 \\
\hline & & 2218 & 495 & 653 & 535 \\
\hline & & 3608 & 1510 & 373 & 549 \\
\hline \multirow[t]{2}{*}{ nov/05 } & & 3200 & 2460 & 960 & 840 \\
\hline & & 2874 & 1087 & 583 & 544 \\
\hline \multirow[t]{3}{*}{ dez/05 } & & 7612 & 1107 & 602 & 757 \\
\hline & & 3048 & 438 & 57 & 38 \\
\hline & & 2951 & 524 & 598 & 520 \\
\hline \multirow[t]{4}{*}{ jan/06 } & & 4077 & 77 & 135 & 404 \\
\hline & $1^{a}$ fase & 4444 & 667 & 241 & 648 \\
\hline & & 3881 & 178 & 139 & 139 \\
\hline & & 10931 & 198 & 178 & 475 \\
\hline \multirow[t]{4}{*}{ fev/06 } & & 5333 & 157 & 110 & 118 \\
\hline & & 3686 & 47 & 63 & 118 \\
\hline & & 3000 & 54 & 146 & 100 \\
\hline & & 2741 & 52 & 52 & 59 \\
\hline \multirow[t]{4}{*}{ mar/06 } & & 2943 & 98 & 106 & 68 \\
\hline & & 3440 & 64 & 104 & 112 \\
\hline & & 3286 & 150 & 143 & 143 \\
\hline & & 3200 & 96 & 32 & 32 \\
\hline \multirow[t]{4}{*}{$\mathrm{abr} / 06$} & & 3441 & 413 & 361 & 344 \\
\hline & & 3167 & 150 & 167 & 92 \\
\hline & & 3417 & 179 & 171 & 148 \\
\hline & & 2641 & 101 & 443 & 132 \\
\hline \multirow[t]{4}{*}{ mai/06 } & & 3048 & 107 & 76 & 46 \\
\hline & & 5053 & 362 & 168 & 152 \\
\hline & & 2133 & 324 & 152 & \\
\hline & & 2943 & 181 & 204 & \\
\hline \multirow[t]{4}{*}{ jun/06 } & & 3010 & 372 & 158 & 135 \\
\hline & & 2718 & 109 & 85 & 70 \\
\hline & & 1724 & 76 & 83 & 62 \\
\hline & & 2692 & 77 & 62 & 69 \\
\hline \multirow[t]{5}{*}{ jul/06 } & & 2902 & 110 & 102 & 31 \\
\hline & & 2538 & 192 & 69 & 77 \\
\hline & & 2766 & 52 & 30 & 45 \\
\hline & & 2593 & 296 & 393 & 422 \\
\hline & & 2667 & 137 & 114 & 91 \\
\hline \multirow[t]{3}{*}{ ago/06 } & & 3170 & 189 & 113 & 98 \\
\hline & & 3168 & 48 & 135 & 297 \\
\hline & $2^{a}$ fase & 3686 & 98 & 133 & 102 \\
\hline \multirow[t]{4}{*}{ set/06 } & & 3615 & 327 & 154 & 77 \\
\hline & & 2951 & 184 & 117 & 78 \\
\hline & & 2308 & 115 & 62 & 23 \\
\hline & & 4038 & 124 & 46 & 122 \\
\hline \multirow[t]{5}{*}{ out/06 } & & 3089 & 129 & 127 & 143 \\
\hline & & 1613 & 169 & 105 & 81 \\
\hline & & 3010 & 307 & 475 & 475 \\
\hline & & 2097 & 311 & 311 & 97 \\
\hline & & 3728 & 233 & 214 & 179 \\
\hline \multirow[t]{4}{*}{ nov/06 } & & 2308 & 337 & 346 & 58 \\
\hline & & 2535 & 139 & 89 & 59 \\
\hline & & 2535 & 158 & 149 & 129 \\
\hline & & 3960 & 158 & 99 & 139 \\
\hline \multirow[t]{2}{*}{ dez/06 } & & 3029 & 357 & 311 & 287 \\
\hline & & 2415 & 128 & 226 & 128 \\
\hline
\end{tabular}


Tabela B.2 - Resultados do Monitoramento do Sistema PARCIAL ("P") das Análises de DQO

\begin{tabular}{|c|c|c|c|c|}
\hline Mês/Ano & Fase & $\begin{array}{c}\text { DQO afl P } \\
(\mathrm{mg} / \mathrm{L})\end{array}$ & $\begin{array}{c}\text { DQO anx P } \\
(\mathrm{mg} / \mathrm{L})\end{array}$ & $\begin{array}{c}\text { DQO dec } P \\
(\mathrm{mg} / \mathrm{L})\end{array}$ \\
\hline \multirow[t]{3}{*}{ set/05 } & & 2059 & 931 & 1109 \\
\hline & & 2857 & 2163 & 3082 \\
\hline & & 2951 & 796 & 583 \\
\hline \multirow[t]{5}{*}{ out/05 } & & 3340 & 2602 & 1165 \\
\hline & & 3573 & 1786 & 136 \\
\hline & & 3321 & 453 & 321 \\
\hline & & 2218 & 356 & 386 \\
\hline & & 3608 & 314 & 78 \\
\hline \multirow[t]{2}{*}{ nov/05 } & & 3200 & 480 & 440 \\
\hline & & 2874 & 1282 & 466 \\
\hline \multirow[t]{3}{*}{ dez/05 } & & 7612 & 544 & 369 \\
\hline & & 3048 & 400 & 114 \\
\hline & & 2951 & 447 & 660 \\
\hline \multirow[t]{4}{*}{ jan/06 } & $1^{a} f a c e$ & 4077 & 115 & 288 \\
\hline & 1 tase & 4444 & 685 & 352 \\
\hline & & 3881 & 297 & 139 \\
\hline & & 10931 & 238 & 386 \\
\hline \multirow[t]{3}{*}{ fev/06 } & & 3686 & 118 & 94 \\
\hline & & 3000 & 231 & 54 \\
\hline & & 2741 & 111 & 81 \\
\hline \multirow{4}{*}{ mar/06 } & & 2943 & 106 & 83 \\
\hline & & 3440 & 48 & 48 \\
\hline & & 3286 & 121 & 79 \\
\hline & & 3200 & 141 & 32 \\
\hline \multirow{4}{*}{ abr/06 } & & 3441 & 387 & 344 \\
\hline & & 3167 & 142 & 108 \\
\hline & & 3417 & 249 & 171 \\
\hline & & 2641 & 93 & 78 \\
\hline \multirow{5}{*}{ mai/06 } & & 3048 & 190 & 145 \\
\hline & & 5053 & 371 & 152 \\
\hline & & 2133 & 366 & 168 \\
\hline & & 2943 & 196 & 219 \\
\hline & & 4400 & 140 & 147 \\
\hline \multirow[t]{4}{*}{ jun/06 } & & 3010 & 491 & 253 \\
\hline & & 2718 & 155 & 163 \\
\hline & & 1724 & 90 & 103 \\
\hline & & 2692 & 54 & 85 \\
\hline \multirow{5}{*}{ jul/06 } & & 2902 & 141 & 63 \\
\hline & & 2538 & 115 & 100 \\
\hline & & 2766 & 67 & 60 \\
\hline & & 2593 & 800 & 393 \\
\hline & & 2667 & 244 & 99 \\
\hline \multirow[t]{3}{*}{ ago/06 } & & 3170 & 255 & 121 \\
\hline & & 3168 & 119 & 131 \\
\hline & $2^{a}$ fase & 3686 & 167 & 94 \\
\hline \multirow[t]{4}{*}{ set/06 } & & 3615 & 269 & 292 \\
\hline & & 2951 & 194 & 101 \\
\hline & & 2308 & 154 & 100 \\
\hline & & 4038 & 86 & 30 \\
\hline \multirow[t]{5}{*}{ out/06 } & & 3089 & 307 & 95 \\
\hline & & 1613 & 137 & 137 \\
\hline & & 3010 & 337 & 178 \\
\hline & & 2097 & 252 & 350 \\
\hline & & 3728 & 282 & 186 \\
\hline \multirow[t]{4}{*}{ nov/06 } & & 2308 & 385 & 260 \\
\hline & & 2535 & 307 & 158 \\
\hline & & 2535 & 198 & 228 \\
\hline & & 3960 & 248 & 178 \\
\hline \multirow[t]{2}{*}{ dez/06 } & & 3029 & 466 & 233 \\
\hline & & 2415 & 170 & 158 \\
\hline
\end{tabular}


APÊNDICE C - RESULTADOS DO MONITORAMENTO DIÁRIO DO SISTEMA TOTAL 
Tabela C.1 - Resultados do Monitoramento Diário do Sistema TOTAL ("T") na $1^{\text {a }}$ Fase na Pesquisa (Continua)

\begin{tabular}{|c|c|c|c|c|c|c|c|c|c|c|c|c|c|c|c|}
\hline Data & $\begin{array}{l}\mathrm{pH} \text { ANOX T } \\
\text { pré }\end{array}$ & $\begin{array}{c}\mathrm{pH} \\
\text { AER T }\end{array}$ & $\begin{array}{l}\mathrm{pH} \text { ANOX T } \\
\text { pós }\end{array}$ & $\begin{array}{c}\text { OD ANX T } \\
\text { pré } \\
\text { (mg/L) }\end{array}$ & $\begin{array}{c}\text { OD AER } \\
T \\
(\mathrm{mg} / \mathrm{L})\end{array}$ & $\begin{array}{c}\text { OD ANX T } \\
\text { pós } \\
\text { (mg/L) }\end{array}$ & $\begin{array}{c}\text { temp ANOX T } \\
\text { pré } \\
\text { (oC) }\end{array}$ & $\begin{array}{c}\text { temp AER } \\
T \\
(\mathrm{oC})\end{array}$ & $\begin{array}{c}\text { temp ANOX T } \\
\text { pós } \\
\text { (oC) }\end{array}$ & $\begin{array}{l}\text { Qafl T } \\
\text { (mL/min) }\end{array}$ & $\begin{array}{l}\text { Qret T } \\
\text { (mL/min) }\end{array}$ & $\begin{array}{c}\text { Qefl T } \\
\text { (mL/min) }\end{array}$ & $\begin{array}{l}\text { Qetanol } \\
\text { (mL/min) }\end{array}$ & $\begin{array}{l}\text { QrecicloT } \\
\text { (mL/min) }\end{array}$ & $\begin{array}{c}\text { Afuente } \\
\mathrm{pH}\end{array}$ \\
\hline $01 / 09 / 2005$ & 7,5 & 6,7 & 7,3 & & & & 22,0 & 27,0 & 28,5 & 7,4 & 13,2 & & & & 7,3 \\
\hline $02 / 09 / 2005$ & 7,6 & 6,7 & 7,4 & & & & 20,0 & 25,0 & 29,0 & 6,8 & 10,0 & & & & 7,0 \\
\hline 06/09/2005 & 7,6 & 6,6 & 8,0 & & & & 20,0 & 26,5 & 25,0 & 10,0 & 11,0 & & & & 7,1 \\
\hline 08/09/2005 & 7,6 & 6,8 & 7,0 & & & & 15,5 & 24,0 & 27,0 & 8,8 & 34,8 & & & & 7,2 \\
\hline 09/09/2005 & 7,5 & 6,7 & 6,9 & & & & 20,0 & 25,0 & 27,0 & 8,0 & 34,0 & & & & 7,2 \\
\hline $12 / 09 / 2005$ & 7,4 & 7,2 & 7,0 & & & & 22,0 & 21,0 & 24,0 & 8,0 & 36,0 & & & & 6,9 \\
\hline $13 / 09 / 2005$ & 7,9 & 6,9 & 7,5 & & & & 29,5 & 27,0 & 31,0 & 8,0 & 34,0 & & & & 7,2 \\
\hline $15 / 09 / 2005$ & 7,5 & 6,4 & 7,0 & & & & 27,5 & 29,0 & 29,5 & 7,6 & 34,0 & & & & 7,3 \\
\hline $16 / 09 / 2005$ & 7,4 & 6,4 & 6,8 & & & & 26,5 & 29,0 & 28,5 & 7,8 & 34,0 & & & & 7,9 \\
\hline $19 / 09 / 2005$ & 7,4 & 6,9 & 7,1 & & & & 29,0 & 27,0 & 27,5 & 5,0 & 28,0 & & & & 6,9 \\
\hline $20 / 09 / 2005$ & 7,5 & 7,0 & 7,1 & & & & 29,5 & 29,5 & 30,0 & 4,8 & 32,0 & & & & 7,3 \\
\hline $21 / 09 / 2005$ & 7,3 & 6,7 & 7,0 & & & & 28,0 & 29,0 & 29,5 & 8,0 & 34,0 & & & & 7,2 \\
\hline $22 / 09 / 2005$ & 7,5 & 6,7 & 7,0 & & & & 31,0 & 30,0 & 30,5 & & 34,0 & & & & 7,2 \\
\hline $23 / 09 / 2005$ & 7,5 & 6,7 & 7,1 & & & & 34,0 & 30,5 & 31,5 & & 32,0 & & & & \\
\hline $26 / 09 / 2005$ & 7,3 & 6,8 & 7,0 & & & & 28,5 & 29,5 & 29,5 & & 30,0 & & & & \\
\hline $28 / 09 / 2005$ & 7.4 & 7,0 & 6,9 & & & & 25,0 & 27,0 & 29,5 & 7,8 & 30,4 & & & & 7.1 \\
\hline $29 / 09 / 2005$ & 7,2 & 6,7 & 6,9 & & & & 23,0 & 30,0 & 30,0 & 8,0 & 32,0 & & & & 7,7 \\
\hline 03/10/2005 & 6,8 & 7,3 & 7,0 & & & & 33,0 & 30,5 & 31,5 & 7,8 & 32,0 & & & & 6,8 \\
\hline $04 / 10 / 2005$ & 7,1 & 7,6 & 7,1 & & & & 34,0 & 33,0 & 34,0 & 7,4 & 30,0 & & & & 7,4 \\
\hline 05/10/2005 & 7,3 & 7,9 & 7,3 & 0,1 & 5,8 & 0,0 & 33,0 & 31,0 & 32,0 & 7,2 & 28,0 & & & & 7,3 \\
\hline $06 / 10 / 2005$ & 7,5 & 8,0 & 7,5 & & & & 34,0 & 32,0 & 32,5 & 4,0 & 30,0 & & & & 7,2 \\
\hline $07 / 10 / 2005$ & 7,5 & 8,1 & 7,7 & 0,0 & 5,2 & 0,1 & 34,0 & 32,5 & 32,5 & 8,0 & 32,0 & & & & 7,3 \\
\hline $10 / 10 / 2005$ & 7,2 & 6,9 & 7,3 & 0,0 & 4,2 & 0,0 & 34,0 & 32,5 & 33,0 & 9,0 & 32,0 & & & & 7,4 \\
\hline $11 / 10 / 2005$ & 7,2 & 6,6 & 7,0 & 0,0 & 4,6 & 0,0 & 34,5 & 31,0 & 33,0 & & 32,0 & & & & 7,4 \\
\hline $13 / 10 / 2005$ & 7,3 & 6,9 & 6,8 & 0,0 & 4,9 & 0,0 & 37,0 & 32,5 & 34,5 & 8,0 & 30,0 & & & & 7,2 \\
\hline $14 / 10 / 2005$ & 7,2 & 6,8 & 6,8 & 0,0 & 4,5 & 0,0 & 37,0 & 32,5 & 33,5 & 7,5 & 29,5 & & & & 6,9 \\
\hline $17 / 10 / 2005$ & 6,9 & 6,7 & 6,7 & 0,0 & 3,9 & 0,0 & 32,0 & 31,5 & 35,0 & 8,6 & 32,0 & & & & 7,1 \\
\hline $18 / 10 / 2005$ & 6,8 & 6,6 & 6,6 & 0,0 & 4,6 & 0,1 & 33,5 & 32,0 & 34,0 & 7,8 & 30,0 & & & & 7,1 \\
\hline $19 / 10 / 2005$ & 6,8 & 6,6 & 6,7 & 0,0 & 3,5 & 0,0 & 31,0 & 28,0 & 31,5 & 8,0 & 32,2 & & & & 7,1 \\
\hline $20 / 10 / 2005$ & 6,9 & 6,6 & 6,6 & 0,2 & 4,5 & 0,0 & 33,0 & 32,0 & 34,5 & 7,0 & 28,0 & & & & 7,3 \\
\hline $21 / 10 / 2005$ & 6,8 & 6,6 & 6,7 & 0,1 & 4,0 & 0,1 & 34,0 & 31,5 & 34,5 & 7,6 & 29,2 & & & & 7,2 \\
\hline $24 / 10 / 2005$ & 7,0 & 6,7 & 6,7 & 0,1 & 4,8 & 0,0 & 31,0 & 31,5 & 31,5 & 8,2 & 29,6 & & & & 7,2 \\
\hline $25 / 10 / 2005$ & 6,9 & 6,6 & 6,6 & 0,0 & 4,1 & 0,0 & 33,5 & 33,0 & 34,5 & 7,0 & 28,5 & & & & 7,1 \\
\hline $26 / 10 / 2005$ & 7,1 & 6,6 & 6,6 & & & & 31,5 & 31,0 & 32,0 & 8,0 & 29,8 & & & & 7,2 \\
\hline $27 / 10 / 2005$ & 6,8 & 6,7 & 6,8 & & & & 32,0 & 31,0 & 34,0 & 7,6 & 30,0 & & & & 7,2 \\
\hline 28/10/2005 & 8,7 & 7,7 & 6,9 & & & & 32,0 & 31,0 & 35,0 & 8,0 & 30,0 & & & & 7,2 \\
\hline $31 / 10 / 2005$ & 8,2 & 8,2 & 8,5 & & & & 32,0 & 30,0 & 32,0 & 8,0 & 28,8 & & & & 7,2 \\
\hline $01 / 11 / 2005$ & 7,5 & 7,8 & 7,7 & 0,0 & 3,4 & 0,0 & 20,0 & 31,0 & 33,0 & & 32,0 & & & & 7,2 \\
\hline
\end{tabular}


Tabela C.1 - Resultados do Monitoramento Diário do Sistema TOTAL ("T") na $1^{\text {a }}$ Fase na Pesquisa (Continuação)

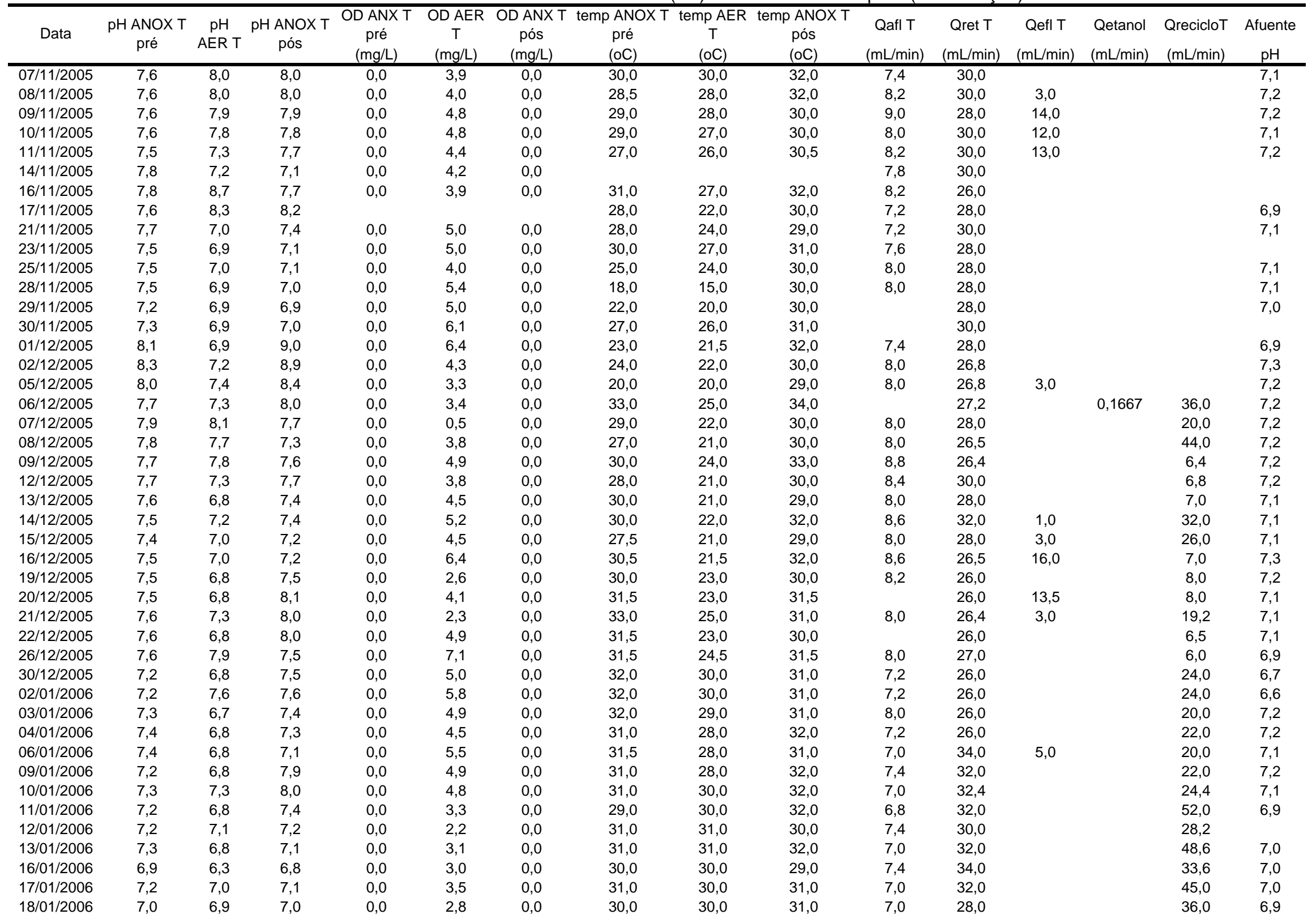


Tabela C.1 - Resultados do Monitoramento Diário do Sistema TOTAL ("T") na $1^{\text {a }}$ Fase na Pesquisa (Continuacão)

\begin{tabular}{|c|c|c|c|c|c|c|c|c|c|c|c|c|c|c|c|}
\hline Data & $\begin{array}{c}\text { pH ANOX T } \\
\text { pré }\end{array}$ & $\begin{array}{c}\text { pH } \\
\text { AER T }\end{array}$ & $\begin{array}{l}\mathrm{pH} \text { ANOX T } \\
\text { pós }\end{array}$ & $\begin{array}{c}\text { OD ANX T } \\
\text { pré } \\
\text { (mg/L) }\end{array}$ & $\begin{array}{c}\text { OD AER } \\
T \\
(\mathrm{mg} / \mathrm{L})\end{array}$ & $\begin{array}{c}\text { OD ANX T } \\
\text { pós } \\
\text { (mg/L) }\end{array}$ & $\begin{array}{c}\text { temp ANOX T } \\
\text { pré } \\
\text { (oC) }\end{array}$ & $\begin{array}{c}\text { temp AER } \\
T \\
(\mathrm{oC})\end{array}$ & $\begin{array}{l}\text { temp ANOX T } \\
\text { pós } \\
\text { (oC) }\end{array}$ & $\begin{array}{c}\text { Qafl T } \\
\text { (mL/min) }\end{array}$ & $\begin{array}{c}\text { Qret T } \\
\text { (mL/min) }\end{array}$ & $\begin{array}{c}\text { Qefl T } \\
\text { (mL/min) }\end{array}$ & $\begin{array}{l}\text { Qetanol } \\
\text { (mL/min) }\end{array}$ & $\begin{array}{l}\text { QrecicloT } \\
\text { (mL/min) }\end{array}$ & $\begin{array}{c}\text { Afuente } \\
\mathrm{pH}\end{array}$ \\
\hline $19 / 01 / 2006$ & 7,1 & 7,0 & 7,1 & & & & 31,0 & 30,0 & 32,0 & 7,4 & 32,0 & & & 51,0 & 7,0 \\
\hline $20 / 01 / 2006$ & 6,9 & 7,2 & 7,1 & & & & 32,0 & 31,5 & 32,0 & 8,0 & 32,0 & & & 44,0 & 6,7 \\
\hline $23 / 01 / 2006$ & 7,2 & 7,5 & 7,3 & & & & 31,0 & 31,0 & 32,0 & 6,8 & 36,0 & & & 45,0 & 6,7 \\
\hline $24 / 01 / 2006$ & 7,3 & 6,8 & 7,2 & & & & 31,0 & 31,0 & 33,0 & 7,0 & 32,0 & & & 52,0 & 7,0 \\
\hline $26 / 01 / 2006$ & 7,4 & 7,6 & 7,4 & & & & 32,0 & 30,0 & 31,0 & 7,0 & 34,0 & & & 45,0 & 7,2 \\
\hline $27 / 01 / 2006$ & 7,3 & 6,9 & 7,3 & & & & 31,0 & 31,0 & 32,0 & 8,0 & 32,0 & & & 42,0 & 7,1 \\
\hline $30 / 01 / 2006$ & 7,2 & 6,9 & 7,0 & & & & 30,0 & 30,0 & 32,0 & 8,0 & 30,0 & & & 32,0 & 7,0 \\
\hline $31 / 01 / 2006$ & 7,1 & 6,9 & 7,0 & & & & 29,0 & 31,0 & 32,0 & 8,0 & 32,0 & & & 42,0 & 7,0 \\
\hline $02 / 02 / 2006$ & 7,2 & 7,4 & 7,5 & & & & 30,0 & 30,0 & 31,0 & 8,2 & 30,0 & & 0,0069 & 42,0 & 7,3 \\
\hline 03/02/2006 & 7,4 & 7,2 & 7,6 & & & & 29,0 & 30,0 & 32,0 & 8,2 & 22,0 & & & 22,0 & 7,1 \\
\hline $06 / 02 / 2006$ & 7,6 & 7,5 & 7,5 & & & & 31,0 & 30,0 & 32,0 & 8,2 & 30,0 & & & 27,0 & \\
\hline $07 / 02 / 2006$ & 7,4 & 6,9 & 7,5 & 0,0 & 5,0 & 0,0 & 31,0 & 30,0 & 32,0 & 9,0 & 30,6 & & 0,0069 & 27,0 & \\
\hline 08/02/2006 & 7,6 & 7,0 & 7,7 & 0,0 & 4,7 & 0,0 & 30,0 & 29,0 & 32,0 & 9,8 & 30,0 & & & 27,0 & \\
\hline 09/02/2006 & 7,5 & 6,9 & 7,3 & 0,0 & 4,9 & 0,0 & 28,0 & 30,0 & 32,0 & 9,0 & 28,0 & & & 27,0 & \\
\hline $10 / 02 / 2006$ & 7,6 & 7,1 & 7,7 & 0,0 & 4,9 & 0,0 & 31,0 & 29,0 & 32,0 & 8,4 & 32,4 & & 0,0069 & 24,0 & 7,0 \\
\hline $13 / 02 / 2006$ & 7,3 & 7,0 & 7,2 & 0,0 & 5,1 & 0,0 & 29,0 & 27,0 & 31,0 & 9,2 & 32,0 & & 0,0069 & 56,0 & 7,0 \\
\hline $14 / 02 / 2006$ & 7,4 & 7,0 & 7,6 & 0,0 & 4,2 & 0,0 & 30,0 & 31,0 & 33,0 & 9,2 & 33,0 & & & 30,0 & \\
\hline $15 / 02 / 2006$ & 7,4 & 7,0 & 7,6 & 0,0 & 4,2 & 0,0 & 31,0 & 30,0 & 32,0 & 9,0 & 34,0 & & & & \\
\hline $21 / 02 / 2006$ & 7,3 & 7,5 & 7,4 & 0,0 & 3,2 & 0,0 & 31,0 & 31,0 & 32,0 & 10,0 & 32,0 & & 0,0069 & 38,4 & \\
\hline $22 / 02 / 2006$ & 7,3 & 7,5 & 7,5 & 0,0 & 2,8 & 0,0 & 31,0 & 30,0 & 31,0 & 9,6 & 32,0 & & 0,0069 & 40,0 & \\
\hline $23 / 02 / 2006$ & 7,4 & 7,3 & 7,9 & 0,0 & 2,2 & 0,0 & 31,0 & 30,0 & 31,0 & 9,2 & 32,0 & & 0,0069 & 41,2 & 7,0 \\
\hline $24 / 02 / 2006$ & 7,3 & 7,3 & 7,5 & 0,0 & 2,9 & 0,0 & 31,0 & 30,0 & 33,0 & 9,0 & 32,0 & & 0,0069 & 38,0 & \\
\hline $02 / 03 / 2006$ & 7,7 & 7,9 & 8,0 & 0,0 & 3,3 & 0,0 & 31,0 & 31,0 & 32,0 & 9,2 & 36,0 & & & 36,0 & 6,9 \\
\hline 03/03/2006 & 7,7 & 7,2 & 7,4 & 0,0 & 3,0 & 0,0 & 30,0 & 30,0 & 31,0 & 9,2 & 32,6 & & 0,0035 & 30,0 & \\
\hline $06 / 03 / 2006$ & 7,7 & 8,2 & 8,0 & 0,0 & 2,9 & 0,0 & 31,0 & 30,0 & 31,0 & 9,6 & 36,0 & & 0,0035 & 30,0 & \\
\hline $07 / 03 / 2006$ & 7,6 & 8,0 & 7,9 & 0,0 & 2,5 & 0,0 & 30,0 & 27,0 & 31,0 & 8,0 & 32,6 & & & 36,0 & \\
\hline 08/03/2006 & 7,6 & 7,8 & 7,9 & 0,0 & 2,9 & 0,0 & 30,0 & 30,0 & 31,0 & 9,0 & 32,0 & & 0,0035 & 36,0 & \\
\hline 09/03/2006 & 7,6 & 7,8 & 7,9 & 0,0 & 2,8 & 0,0 & 30,0 & 29,0 & 32,0 & 9,2 & 31,2 & & 0,0035 & 32,4 & \\
\hline $10 / 03 / 2006$ & 7,6 & 7,9 & 8,0 & 0,0 & 2,9 & 0,0 & 31,0 & 30,0 & 32,0 & 8,4 & 32,4 & & 0,0035 & 50,4 & \\
\hline $13 / 03 / 2006$ & 7,4 & 7,8 & 7,9 & 0,0 & 2,9 & 0,0 & 28,0 & 27,0 & 31,0 & 8,8 & 34,4 & & 0,0035 & 38,0 & 7,0 \\
\hline $14 / 03 / 2006$ & 7,7 & 8,2 & 8,0 & 0,0 & 4,9 & 0,0 & 28,0 & 28,0 & 31,0 & 8,8 & 33,6 & & 0,0035 & 24,0 & \\
\hline $15 / 03 / 2006$ & 7,4 & 7,9 & 8,0 & 0,0 & 3,9 & 0,0 & 29,0 & 30,0 & 31,0 & 7,2 & 30,0 & & 0,0035 & 60,0 & \\
\hline $16 / 03 / 2006$ & 7,4 & 8,0 & 8,0 & 0,0 & 4,1 & 0,0 & 30,0 & 30,0 & 31,0 & 7,0 & 28,0 & & 0,0035 & 52,0 & \\
\hline $20 / 03 / 2006$ & 7,8 & 8,0 & 8,0 & 0,0 & 2,9 & 0,0 & 31,0 & 29,0 & 32,0 & 8,0 & 30,0 & & 0,0035 & 27,0 & \\
\hline $21 / 03 / 2006$ & 7,7 & 8,1 & 8,2 & 0,0 & 4,4 & 0,0 & 31,0 & 27,0 & 30,0 & 8,0 & 35,2 & & 0,0035 & 30,0 & \\
\hline $22 / 03 / 2006$ & 7,8 & 8,0 & 8,2 & 0,0 & 4,5 & 0,0 & 30,0 & 29,0 & 31,0 & 7,8 & 36,0 & & 0,0035 & 30,0 & \\
\hline $23 / 03 / 2006$ & 8,0 & 8,3 & 8,3 & 0,0 & 4,3 & 0,0 & 30,0 & 25,0 & 31,0 & 10,4 & 36,0 & & 0,0035 & 54,0 & 7,0 \\
\hline $24 / 03 / 2006$ & 7,8 & 8,2 & 8,3 & 0,0 & 4,2 & 0,0 & 30,0 & 27,0 & 31,0 & 8,8 & 30,0 & & 0,0035 & 54,4 & \\
\hline
\end{tabular}




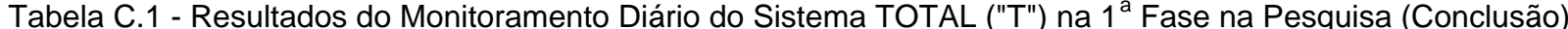

\begin{tabular}{|c|c|c|c|c|c|c|c|c|c|c|c|c|c|c|c|}
\hline Data & $\begin{array}{l}\text { pH ANOX T } \\
\text { pré }\end{array}$ & $\begin{array}{c}\mathrm{pH} \\
\text { AER T }\end{array}$ & $\begin{array}{l}\text { pH ANOX T } \\
\text { pós }\end{array}$ & $\begin{array}{c}\text { OD ANX T } \\
\text { pré } \\
(\mathrm{mg} / \mathrm{L}) \\
\end{array}$ & $\begin{array}{c}\text { OD AER } \\
\mathrm{T} \\
(\mathrm{mg} / \mathrm{L}) \\
\end{array}$ & $\begin{array}{c}\text { OD ANX T } \\
\text { pós } \\
\text { (mg/L) } \\
\end{array}$ & $\begin{array}{c}\text { temp ANOX T } \\
\text { pré } \\
\text { (oC) } \\
\end{array}$ & $\begin{array}{c}\text { temp AER } \\
\mathrm{T} \\
(\mathrm{oC}) \\
\end{array}$ & $\begin{array}{c}\text { temp ANOX T } \\
\text { pós } \\
\text { (oC) } \\
\end{array}$ & $\begin{array}{c}\text { Qafl T } \\
\text { (mL/min) }\end{array}$ & $\begin{array}{c}\text { Qret T } \\
\text { (mL/min) }\end{array}$ & $\begin{array}{c}\text { Qefl T } \\
\text { (mL/min) }\end{array}$ & $\begin{array}{l}\text { Qetanol } \\
\text { (mL/min) }\end{array}$ & $\begin{array}{l}\text { QrecicloT } \\
\text { (mL/min) }\end{array}$ & $\begin{array}{c}\text { Afuente } \\
\mathrm{pH} \\
\end{array}$ \\
\hline $30 / 03 / 2006$ & 7,8 & 8,1 & 8,3 & 0,0 & 3,9 & 0,0 & 27,0 & 25,0 & 30,0 & 8,0 & 33,0 & & 0,0069 & 60,0 & 6,9 \\
\hline $31 / 03 / 2006$ & 7,9 & 8,0 & 8,0 & 0,0 & 4,3 & 0,0 & 27,0 & 22,0 & 30,0 & 12,0 & 32,0 & & 0,0035 & 78,0 & \\
\hline $03 / 04 / 2006$ & 7,8 & 8,1 & 8,1 & 0,0 & 4,4 & 0,0 & 26,0 & 20,0 & 31,0 & 9,0 & 30,0 & & 0,0035 & 64,0 & \\
\hline $04 / 04 / 2006$ & 7,8 & 8,0 & 8,3 & 0,0 & 3,2 & 0,0 & 27,0 & 23,0 & 29,0 & 9,0 & 30,0 & & 0,0035 & 36,0 & \\
\hline $05 / 04 / 2006$ & 7,9 & 8,1 & 8,4 & 0,0 & 3,4 & 0,0 & 24,0 & 23,0 & 31,0 & 8,0 & 32,0 & & 0,0035 & 21,0 & \\
\hline $06 / 04 / 2006$ & 7,8 & 8,0 & 8,3 & 0,0 & 3,9 & 0,0 & 24,0 & 26,0 & 31,0 & 8,2 & 30,0 & & 0,0035 & 46,0 & 7,0 \\
\hline $07 / 04 / 2006$ & 7,9 & 8,0 & 8,3 & 0,0 & 3,2 & 0,0 & 28,0 & 24,0 & 29,0 & 8,4 & 32,0 & & 0,0035 & 34,0 & \\
\hline $10 / 04 / 2006$ & 7,7 & 8,1 & 8,3 & 0,0 & 3,8 & 0,0 & 29,0 & 27,0 & 32,0 & 8,0 & 30,0 & & 0,0069 & 54,0 & \\
\hline $12 / 04 / 2006$ & 7,9 & 8,1 & 8,3 & 0,0 & 3,9 & 0,0 & 27,0 & 24,0 & 31,0 & 8,4 & 60,0 & & 0,0069 & 30,0 & 7,0 \\
\hline $13 / 04 / 2006$ & 7,9 & 7,9 & 8,3 & 0,0 & 3,5 & 0,0 & 28,0 & 24,0 & 30,0 & 8,0 & 28,0 & & 0,0069 & 70,0 & \\
\hline $17 / 04 / 2006$ & 7,7 & 7,6 & 8,0 & 0,0 & 3,8 & 0,0 & 27,0 & 25,0 & 29,0 & 8,0 & 30,0 & & 0,0069 & 54,0 & 7,0 \\
\hline $18 / 04 / 2006$ & 7,5 & 7,4 & 7,8 & 0,0 & 3,1 & 0,0 & 25,0 & 20,0 & 28,0 & 8,0 & 30,0 & & & 64,0 & \\
\hline $19 / 04 / 2006$ & 7,5 & 7,3 & 7,6 & 0,0 & 3,3 & 0,0 & 25,0 & 22,0 & 30,0 & 7,6 & 28,8 & & & 72,0 & \\
\hline $20 / 04 / 2006$ & 7,4 & 7,2 & 7,6 & 0,0 & 3,9 & 0,0 & 24,0 & 26,0 & 31,0 & 8,0 & 30,0 & & & 64,0 & 7,0 \\
\hline $24 / 04 / 2006$ & 6,8 & 6,0 & 6,6 & 0,0 & 3,8 & 0,0 & 27,0 & 24,0 & 30,0 & 7,6 & 30,0 & & & 64,0 & \\
\hline $25 / 04 / 2006$ & 6,7 & 6,6 & 6,8 & 0,0 & 3,5 & 0,0 & 27,0 & 24,0 & 30,0 & 7,0 & 28,0 & & 0,0069 & 52,8 & \\
\hline $26 / 04 / 2006$ & 7,0 & 7,3 & 7,2 & 0,0 & 3,2 & 0,0 & 27,0 & 24,0 & 30,0 & 7,0 & 28,0 & & 0,0069 & 54,0 & \\
\hline $27 / 04 / 2006$ & 7,2 & 7,4 & 7,4 & 0,0 & 3,6 & 0,0 & 27,0 & 24,0 & 30,0 & 3,4 & 28,0 & & 0,0069 & 63,0 & \\
\hline
\end{tabular}


Tabela C.2 - Resultados do Monitoramento Diário do Sistema TOTAL ("T") na $2^{\text {a }}$ Fase na Pesquisa (Continua)

\begin{tabular}{|c|c|c|c|c|c|c|c|c|c|c|c|c|c|c|c|}
\hline Data & $\begin{array}{l}\mathrm{pH} \text { ANOX T } \\
\text { pré }\end{array}$ & $\begin{array}{c}\mathrm{pH} \\
\text { AER T }\end{array}$ & $\begin{array}{l}\text { pH ANOX T } \\
\text { pós }\end{array}$ & $\begin{array}{c}\text { OD ANX T } \\
\text { pré } \\
(\mathrm{mg} / \mathrm{L})\end{array}$ & $\begin{array}{c}\text { OD AER } \\
T \\
(\mathrm{mg} / \mathrm{L})\end{array}$ & $\begin{array}{c}\text { OD ANX T } \\
\text { pós } \\
\text { (mg/L) }\end{array}$ & $\begin{array}{c}\text { temp ANOX T } \\
\text { pré } \\
\text { (oC) }\end{array}$ & $\begin{array}{c}\text { temp AER } \\
T \\
\text { (oC) }\end{array}$ & $\begin{array}{c}\text { temp ANOX T } \\
\text { pós } \\
\text { (oC) }\end{array}$ & $\begin{array}{c}\text { Qafl T } \\
\text { (mL/min) }\end{array}$ & $\begin{array}{c}\text { Qret T } \\
\text { (mL/min) }\end{array}$ & $\begin{array}{c}\text { Qefl T } \\
\text { (mL/min) }\end{array}$ & $\begin{array}{l}\text { Qetanol } \\
\text { (mL/min) }\end{array}$ & $\begin{array}{l}\text { QrecicloT } \\
\text { (mL/min) }\end{array}$ & $\begin{array}{c}\text { Afluente } \\
\mathrm{pH}\end{array}$ \\
\hline $02 / 05 / 2006$ & 7,2 & 6,8 & 6,8 & $\overline{0,0}$ & 4,7 & 0,0 & 24,0 & 26,0 & 30,0 & 8,4 & 29,0 & & & 24,0 & \\
\hline $03 / 05 / 2006$ & 7,0 & 8,0 & 7,0 & 0,0 & 4,8 & 0,0 & 21,0 & 18,0 & 28,0 & 8,2 & 30,0 & & & 54,0 & \\
\hline 04/05/2006 & 7,9 & 8,2 & 8,1 & 0,0 & 4,6 & 0,0 & 22,0 & 20,0 & 25,0 & 8,2 & 20,0 & & & 69,0 & \\
\hline 05/05/2006 & 7,9 & 7,9 & 8,1 & 0,0 & 3,6 & 0,0 & 24,0 & 17,0 & 27,0 & 10,0 & 27,0 & & & 54,0 & 6,9 \\
\hline 09/05/2006 & 7,8 & 7,7 & 7,9 & 0,0 & 2,8 & 0,0 & 19,0 & 24,0 & 26,0 & 8,0 & 25,0 & & & 28,0 & \\
\hline $10 / 05 / 2006$ & 8,1 & 8,1 & 8,3 & 0,0 & 0,3 & 0,0 & 17,0 & 18,0 & 27,0 & 9,0 & 25,0 & & & 36,0 & \\
\hline $11 / 05 / 2006$ & 8,0 & 7,9 & 8,1 & 0,0 & 0,4 & 0,0 & 18,0 & 17,0 & 27,0 & 8,2 & 22,0 & & & 38,0 & \\
\hline $12 / 05 / 2006$ & 8,0 & 8,0 & 8,0 & 0,0 & 0,3 & 0,0 & 18,0 & 20,0 & 25,0 & 7,0 & 27,0 & & & 8,0 & 6,9 \\
\hline $15 / 05 / 2006$ & 8,0 & 7,7 & 7,8 & 0,0 & 0,3 & 0,0 & 17,0 & 22,0 & 26,0 & 8,0 & 26,0 & & & 7,5 & \\
\hline $16 / 05 / 2006$ & 7,8 & 7,7 & 7,2 & 0,0 & 0,3 & 0,0 & & & & & 29,0 & & & & \\
\hline $17 / 05 / 2006$ & 8,0 & 8,0 & 7,9 & 0,0 & 2,1 & 0,0 & 17,0 & 17,0 & 16,0 & & 25,0 & & & 13,8 & \\
\hline $18 / 05 / 2006$ & 7,7 & 7,8 & 7,6 & 0,0 & 5,3 & 0,0 & 18,0 & 16,0 & 29,0 & & 30,0 & & & 12,5 & \\
\hline $19 / 05 / 2006$ & 7,7 & 7,4 & 7,7 & 0,0 & 6,6 & 0,0 & 16,0 & 15,0 & & & 30,0 & & & 17,5 & \\
\hline $22 / 05 / 2006$ & 7,1 & 7,3 & 7,5 & 0,0 & 4,8 & 0,0 & 20,0 & 18,0 & 29,0 & 7,0 & 30,0 & & & 13,0 & \\
\hline $24 / 05 / 2006$ & 7,2 & 6,9 & 6,8 & 0,0 & 8,4 & 0,0 & 17,0 & 15,0 & 25,0 & 4,0 & 30,0 & & & 9,5 & 7,0 \\
\hline $25 / 05 / 2006$ & 7,1 & 8,2 & 7,6 & 0,0 & 5,8 & 0,0 & 16,0 & 15,0 & 28,0 & 5,0 & 30,0 & & & & \\
\hline $26 / 05 / 2006$ & 7,3 & 7,7 & 7,9 & 0,0 & 4,1 & 0,0 & 18,0 & 17,0 & 30,0 & 6,0 & 25,0 & & & & \\
\hline $29 / 05 / 2006$ & & & & & & & & & & & & & & & \\
\hline $30 / 05 / 2006$ & 7,7 & 6,7 & 7,6 & 0,0 & 6,7 & 0,0 & 18,0 & 17,0 & 27,0 & 5,0 & 30,0 & & & 9,8 & \\
\hline $31 / 05 / 2006$ & 7,5 & 7,7 & 7,6 & 0,0 & 7,3 & 0,0 & 18,0 & 16,0 & 28,0 & 5,1 & 25,0 & & & & \\
\hline $01 / 06 / 2006$ & 7,4 & 7,2 & 7,5 & & & & 19,0 & 17,0 & 29,0 & 5,2 & 30,0 & & & & 5,9 \\
\hline 02/06/2006 & 7,3 & 6,9 & 7,3 & & & & 17,0 & 17,0 & 28,0 & 6,0 & 26,0 & & & 10,0 & 7,3 \\
\hline 05/06/2006 & 7,4 & 6,9 & 7,5 & & & & 18,0 & 17,0 & 29,0 & 5,0 & 27,0 & & & 13,0 & 7,3 \\
\hline 06/06/2006 & 7,4 & 6,1 & 6,9 & 0,1 & 6,4 & 0,0 & 19,0 & 18,0 & 28,0 & 5,5 & 32,0 & & & 10,0 & 7,3 \\
\hline 07/06/2006 & 7,2 & 5,8 & 7,1 & 0,0 & 4,6 & 0,0 & 22,0 & 21,0 & 31,0 & 5,2 & 28,0 & & & 11,8 & \\
\hline 08/06/2006 & 7,1 & 7,1 & 6,8 & & & & 18,5 & 18,0 & 28,0 & & 26,5 & & & 20,0 & \\
\hline 09/06/2006 & 7,3 & 6,7 & 7,0 & & & & 18,0 & 16,0 & 27,0 & 5,5 & 20,0 & & & 18,0 & 7,2 \\
\hline $12 / 06 / 2006$ & 7,1 & 5,9 & 6,4 & & & & 21,0 & 20,0 & 21,0 & 5,2 & 27,0 & & & 15,3 & 7,0 \\
\hline $13 / 06 / 2006$ & 7,0 & 6,3 & 6,5 & & & & 19,0 & 22,0 & 19,0 & 6,5 & 31,0 & & & 16,0 & 7,4 \\
\hline $14 / 06 / 2006$ & 7,2 & 6,2 & 6,7 & 0,0 & 5,9 & 0,0 & 17,0 & 21,0 & 35,0 & 5,6 & 30,0 & & & 13,5 & 7,0 \\
\hline $19 / 06 / 2006$ & 6,8 & 5,7 & 5,8 & 0,0 & 5,6 & 0,0 & 18,0 & 22,0 & 17,0 & 6,0 & 32,0 & 48,0 & & 15,5 & 7,0 \\
\hline 20/06/2006 & 6,9 & 6,8 & 6,4 & 0,1 & 4,5 & 0,1 & 19,0 & 28,0 & 29,0 & 6,2 & 31,0 & 2,0 & & 18,0 & 7,0 \\
\hline $21 / 06 / 2006$ & 6,7 & 7,0 & 7,3 & 0,0 & 4,8 & 0,0 & 30,0 & 27,0 & 26,0 & 7,0 & 30,0 & 4,0 & & 16,0 & 6,9 \\
\hline $22 / 06 / 2006$ & 7,1 & 6,9 & 6,6 & 0,1 & 4,4 & 0,1 & 30,5 & 29,0 & 19,0 & 6,8 & 30,0 & 2,0 & & 14,0 & 6,7 \\
\hline $23 / 06 / 2006$ & 7,1 & 6,9 & 6,7 & 0,0 & 4,7 & 0,0 & 27,0 & 28,0 & 30,0 & 6,4 & 30,0 & 3,0 & & 15,0 & 6,7 \\
\hline $26 / 06 / 2006$ & 7,2 & 7,1 & 6,9 & 0,0 & 4,1 & 0,0 & 33,0 & 30,0 & 24,0 & 5,6 & 32,0 & 2,5 & & 17,0 & 7,0 \\
\hline $28 / 06 / 2006$ & 7,1 & 6,9 & 6,8 & 0,0 & 4,1 & 0,0 & 30,0 & 27,0 & 23,0 & 6,0 & 28,0 & 10,0 & & 10,5 & 6,9 \\
\hline 29/06/2006 & 7,1 & 6,2 & 6,6 & 0,0 & 5,0 & 0,0 & 29,0 & 28,0 & 15,0 & 7,0 & 29,0 & & & & \\
\hline $30 / 06 / 2006$ & 7,1 & 6,9 & 6,2 & 0,0 & 4,4 & 0,0 & 28,0 & 27,0 & 24,0 & 6,2 & 26,0 & 5,0 & & 13,0 & 6,3 \\
\hline 03/07/2006 & 7,2 & 7,1 & 6,9 & 0,0 & 3,6 & 0,0 & 30,0 & 26,0 & 21,0 & 5,8 & 30,0 & 4,6 & & 12,0 & 6,9 \\
\hline $04 / 07 / 2006$ & 7,2 & 6,9 & 6,7 & 0,0 & 3,8 & 0,0 & 33,0 & 31,0 & 27,0 & 5,4 & 25,0 & 4,5 & & 11,3 & 6,8 \\
\hline 05/07/2006 & 7,2 & 7,1 & 6,8 & 0,0 & 3,7 & 0,0 & 31,0 & 27,0 & 17,0 & 6,2 & 25,0 & 4,0 & & 15,3 & 6,8 \\
\hline $06 / 07 / 2006$ & 7,0 & 6,9 & 6,8 & 0,1 & 3,8 & 0,1 & 34,0 & 34,0 & 32,0 & 6,8 & 26,0 & 2,0 & & 11,3 & 7,4 \\
\hline
\end{tabular}


Tabela C.2 - Resultados do Monitoramento Diário do Sistema TOTAL ("T") na $2^{\mathrm{a}}$ Fase na Pesquisa (Continuação)

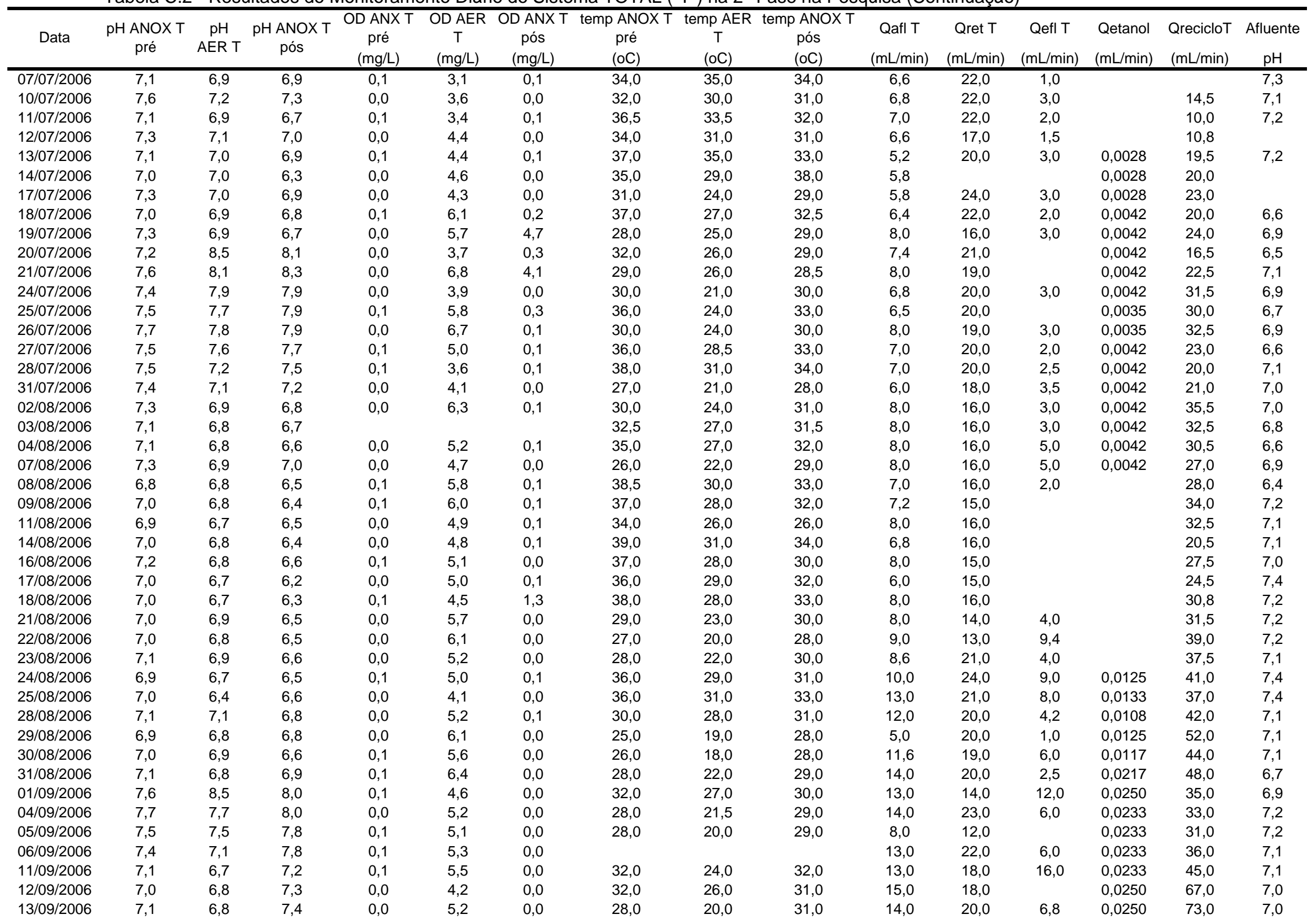


Tabela C.2 - Resultados do Monitoramento Diário do Sistema TOTAL ("T") na $2^{\mathrm{a}}$ Fase na Pesquisa (Continuação)

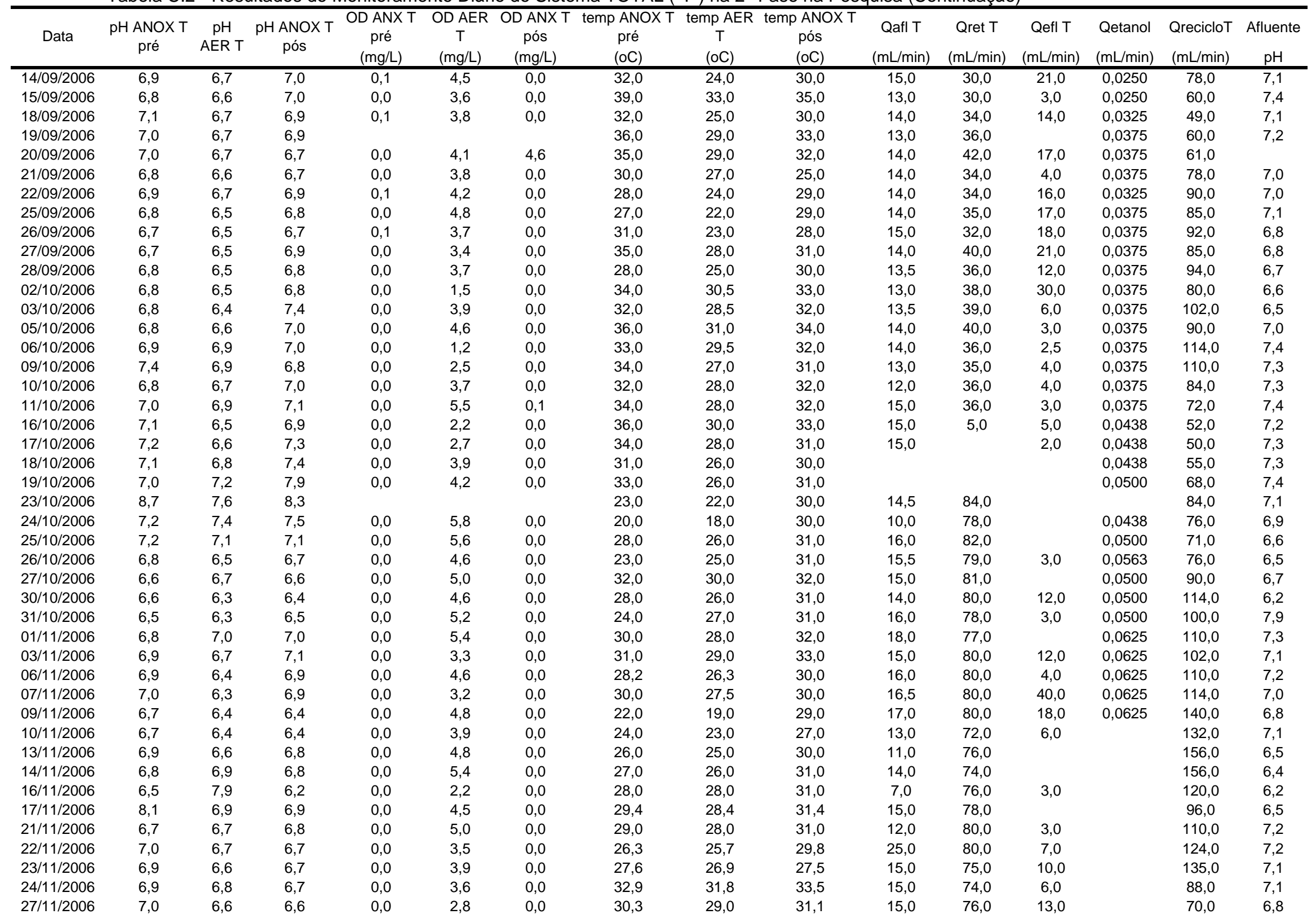


Tabela C.2 - Resultados do Monitoramento Diário do Sistema TOTAL ("T") na $2^{\text {a }}$ Fase na Pesquisa (Conclusão)

\begin{tabular}{|c|c|c|c|c|c|c|c|c|c|c|c|c|c|c|c|}
\hline Data & $\begin{array}{l}\text { pH ANOX T } \\
\text { pré }\end{array}$ & $\begin{array}{c}\mathrm{pH} \\
\text { AER T }\end{array}$ & $\begin{array}{l}\text { pH ANOX T } \\
\text { pós }\end{array}$ & $\begin{array}{l}\text { OD ANX T } \\
\text { pré } \\
\text { (mg/L) }\end{array}$ & $\begin{array}{c}\text { OD AER } \\
T \\
(\mathrm{mg} / \mathrm{L})\end{array}$ & $\begin{array}{l}\text { OD ANX T } \\
\text { pós } \\
\text { (mg/L) }\end{array}$ & $\begin{array}{l}\text { temp ANOX T } \\
\text { pré } \\
(\mathrm{oC})\end{array}$ & $\begin{array}{c}\text { temp AER } \\
\mathrm{T} \\
(\mathrm{oC})\end{array}$ & $\begin{array}{l}\text { temp ANOX T } \\
\text { pós } \\
\text { (oC) }\end{array}$ & $\begin{array}{c}\text { Qafl T } \\
\text { (mL/min) }\end{array}$ & $\begin{array}{c}\text { Qret T } \\
\text { (mL/min) }\end{array}$ & $\begin{array}{c}\text { Qefl T } \\
\text { (mL/min) }\end{array}$ & $\begin{array}{l}\text { Qetanol } \\
\text { (mL/min) }\end{array}$ & $\begin{array}{l}\text { QrecicloT } \\
\text { (mL/min) }\end{array}$ & $\begin{array}{c}\text { Afluente } \\
\mathrm{pH}\end{array}$ \\
\hline $28 / 11 / 2006$ & 7,0 & 6,6 & 7,1 & 0,0 & 3,1 & 0,0 & 30,2 & 28,8 & 31,3 & 15,0 & 76,0 & 5,0 & & 70,0 & 6,5 \\
\hline 29/11/2006 & 6,9 & 6,7 & 6,8 & 0,0 & 4,0 & 0,0 & 31,7 & 29,8 & 31,7 & 18,0 & 74,0 & 4,0 & & 64,0 & 7,3 \\
\hline $30 / 11 / 2006$ & 7,0 & 6,6 & 6,6 & 0,0 & 3,4 & 0,0 & 31,0 & 29,5 & 31,5 & 17,5 & 76,0 & 7,0 & & 56,0 & 7,4 \\
\hline $01 / 12 / 2006$ & 7,0 & 6,8 & 6,5 & 0,0 & 4,6 & 0,0 & 27,9 & 26,6 & 30,3 & 17,0 & 74,0 & 3,0 & & 60,0 & 7,3 \\
\hline $04 / 12 / 2006$ & 6,9 & 6,6 & 6,5 & 0,0 & 3,9 & 0,0 & 31,9 & 30,2 & 31,9 & 17,0 & 70,0 & 6,0 & & 68,0 & 7,1 \\
\hline $05 / 12 / 2006$ & 6,9 & 6,6 & 6,5 & 0,0 & 3,5 & 0,0 & 30,2 & 28,8 & 31,1 & 17,0 & 70,0 & 3,0 & & 55,0 & 7,0 \\
\hline $07 / 12 / 2006$ & 6,9 & 6,4 & 6,4 & 0,0 & 1,5 & 0,0 & 31,2 & 28,4 & 30,8 & 17,0 & 76,0 & 4,0 & & 60,0 & 6,4 \\
\hline 08/12/2006 & 6,7 & 6,6 & 6,4 & 0,0 & 3,9 & 0,0 & 28,3 & 27,0 & 30,4 & 18,5 & 76,0 & 3,0 & & 70,0 & 7,1 \\
\hline $12 / 12 / 2006$ & 6,9 & 7,1 & 6,6 & 0,0 & 3,9 & 0,0 & 28,4 & 27,4 & 30,4 & 10,0 & 82,0 & 8,0 & & 92,0 & 6,8 \\
\hline $13 / 12 / 2006$ & 6,9 & 6,6 & 6,6 & 0,0 & 3,5 & 0,0 & 29,1 & 28,2 & 30,9 & 20,0 & 82,0 & & & 76,0 & 6,7 \\
\hline $14 / 12 / 2006$ & 7,0 & 7,4 & 6,8 & 0,0 & 2,7 & 0,0 & 30,6 & 29,5 & 31,5 & 20,0 & 76,0 & 3,0 & & 70,0 & 6,5 \\
\hline $15 / 12 / 2006$ & & & & & & & & & & 15,0 & 76,0 & & & 80,0 & \\
\hline $18 / 12 / 2006$ & 7,1 & 6,9 & 6,8 & 0,0 & 1,9 & 0,0 & 31,4 & 26,0 & 31,0 & 20,0 & 80,0 & 6,0 & & 115,0 & 6,9 \\
\hline $19 / 12 / 2006$ & 7,0 & 6,9 & 6,8 & 0,0 & 4,2 & 0,0 & 30,5 & 25,7 & 30,9 & 20,0 & 78,0 & 2,0 & & 126,0 & 7,0 \\
\hline $21 / 12 / 2006$ & 6,9 & 6,8 & 6,8 & 0,0 & 2,0 & 0,0 & 30,7 & 25,7 & 30,8 & 20,0 & 80,0 & 16,0 & & 90,0 & 6,6 \\
\hline 22/12/2006 & 7,0 & 6,8 & 6,8 & 0,0 & 0,9 & 0,0 & 32,3 & 30,2 & 32,1 & 21,0 & 80,0 & 5,0 & & 150,0 & 6,6 \\
\hline $26 / 12 / 2006$ & 7,0 & 6,9 & 6,8 & 0,0 & 2,2 & 0,0 & 34,0 & 29,2 & 31,5 & 21,0 & 80,0 & 3,0 & & & 6,6 \\
\hline 29/12/2006 & 6,8 & 6,6 & 6,6 & 0,0 & 1,2 & 0,0 & 28,7 & 28,1 & 30,4 & 21,0 & 80,0 & 14,0 & & 110,0 & 6,5 \\
\hline 04/01/2007 & 6,8 & 6,7 & 6,6 & 0,0 & 1,4 & 0,0 & 30,5 & 28,9 & 31,2 & 20,0 & 75,0 & 8,0 & & 152,0 & 7,0 \\
\hline 05/01/2007 & 7,0 & 6,9 & 6,7 & 0,0 & 1,1 & 0,0 & 29,5 & 28,4 & 30,7 & 22,0 & 77,0 & 5,0 & & 156,0 & 6,8 \\
\hline 08/01/2007 & 6,9 & 6,8 & 6,7 & 0,0 & 2,4 & 0,0 & 31,9 & 30,3 & 32,4 & 21,0 & 80,0 & 14,0 & & 190,0 & 6,7 \\
\hline 09/01/2007 & 6,9 & 6,6 & 6,6 & 0,0 & 0,8 & 0,0 & 29,3 & 27,8 & 30,8 & 22,0 & 80,0 & 2,0 & & 200,0 & 6,7 \\
\hline 11/01/2007 & 7,0 & 6,7 & 6,7 & 0,0 & 0,7 & 0,0 & 28,8 & 27,4 & 30,6 & 22,0 & 80,0 & 2,0 & & 200,0 & 6,6 \\
\hline $12 / 01 / 2007$ & 7,0 & 6,7 & 6,8 & 0,0 & 3,9 & 0,0 & 29,6 & 28,0 & 31,4 & 22,0 & 76,0 & 3,0 & & 180,0 & 6,6 \\
\hline $15 / 01 / 2007$ & 6,9 & 6,7 & 6,9 & 0,0 & 1,1 & 0,0 & 28,8 & 27,2 & 30,9 & 22,0 & 80,0 & 5,0 & & 182,0 & 6,6 \\
\hline $16 / 01 / 2007$ & 6,9 & 6,5 & 6,8 & 0,0 & 0,6 & 0,0 & 28,5 & 26,9 & 30,4 & 23,0 & 80,0 & 10,0 & & 190,0 & 6,5 \\
\hline $18 / 01 / 2007$ & 6,8 & 6,6 & 6,4 & 0,0 & 2,1 & 0,0 & 31,7 & 29,6 & 31,9 & 8,0 & 80,0 & 4,0 & & 170,0 & 6,2 \\
\hline $19 / 01 / 2007$ & 6,6 & 6,6 & 6,6 & 0,0 & 4,9 & 0,0 & 30,1 & 28,5 & 31,4 & 23,0 & 78,0 & 3,0 & & 170,0 & 6,4 \\
\hline 22/01/2007 & 6,9 & 6,6 & 6,6 & 0,0 & 3,2 & 0,0 & 28,6 & 27,1 & 30,8 & 22,0 & 75,0 & 15,0 & & 190,0 & 6,4 \\
\hline $23 / 01 / 2007$ & 6,8 & 6,7 & 6,7 & 0,0 & 0,6 & 0,0 & 28,3 & 26,6 & 30,2 & 22,0 & 76,0 & 9,0 & & 190,0 & 6,3 \\
\hline $24 / 01 / 2007$ & 6,8 & 6,8 & 6,6 & 0,0 & 4,6 & 0,0 & 32,6 & 30,6 & 32,8 & 17,0 & 70,0 & 3,0 & & 102,0 & 6,3 \\
\hline 29/01/2007 & 6,9 & 6,6 & 6,8 & 0,0 & 3,5 & 0,0 & 32,2 & 29,7 & 31,9 & 22,0 & 80,0 & 4,0 & & 120,0 & 6,6 \\
\hline $30 / 01 / 2007$ & 6,9 & 6,7 & 6,9 & 0,0 & 0,9 & 0,0 & 31,5 & 29,2 & 31,3 & 20,0 & 76,0 & 3,0 & & 124,0 & 6,7 \\
\hline
\end{tabular}


APÊNDICE D - RESULTADOS DO MONITORAMENTO DIÁRIO DO SISTEMA PARCIAL 
Tabela D.1 - Resultados do Monitoramento Diário do Sistema PARCIAL ("P") na $1^{\mathrm{a}}$ Fase na Pesquisa (Continua)

\begin{tabular}{|c|c|c|c|c|c|c|c|c|c|c|c|}
\hline Data & $\begin{array}{c}\mathrm{pH} \text { ANOX } \\
\mathrm{P}\end{array}$ & $\begin{array}{c}\mathrm{pH} \text { AER } \\
\mathrm{P}\end{array}$ & $\begin{array}{c}\text { OD ANX } \\
\mathrm{P} \\
(\mathrm{mg} / \mathrm{L})\end{array}$ & $\begin{array}{c}\text { OD AER } \\
P \\
(\mathrm{mg} / \mathrm{L})\end{array}$ & $\begin{array}{c}\text { temp } \\
\text { ANOX P } \\
(\mathrm{oC})\end{array}$ & $\begin{array}{c}\text { temp } \\
\text { AER P } \\
(\mathrm{oC}) \\
\end{array}$ & $\begin{array}{c}\text { Qafl P } \\
\text { (mL/min) }\end{array}$ & $\begin{array}{c}\text { Qret } \mathrm{P} \\
(\mathrm{mL} / \mathrm{min})\end{array}$ & $\begin{array}{c}\text { Qefl P } \\
\text { (mL/min) }\end{array}$ & $\begin{array}{l}\text { QrecicloP } \\
\text { (mL/min) }\end{array}$ & $\begin{array}{c}\text { Afluente } \\
\mathrm{pH}\end{array}$ \\
\hline 01/09/2005 & 7,4 & 7,4 & & & 25,5 & 28,5 & 7,0 & 28,0 & & & 7,3 \\
\hline 02/09/2005 & 7,6 & 7,4 & & & 28,0 & 27,5 & 7,0 & 30,0 & & & 7,0 \\
\hline 05/09/2005 & 8,1 & 7,4 & & & 27,0 & 29,0 & 7,0 & 29,0 & & & 7,0 \\
\hline 06/09/2005 & 8,0 & 7,1 & & & 27,0 & 26,5 & 10,0 & 30,0 & & & 7,1 \\
\hline 08/09/2005 & 8,2 & 7,5 & & & 27,0 & 25,0 & 9,2 & 34,4 & & & 7,2 \\
\hline 09/09/2005 & 8,0 & 7,5 & & & 27,0 & 29,0 & 5,6 & 34,0 & & & 7,2 \\
\hline $12 / 09 / 2005$ & 8,0 & 8,1 & & & 27,5 & 27,0 & 7,8 & 34,0 & & & 6,9 \\
\hline $13 / 09 / 2005$ & 8,1 & 8,0 & & & 24,5 & 24,5 & 7,0 & 24,0 & & & 7,2 \\
\hline $14 / 09 / 2005$ & 7,4 & 7,3 & & & 25,0 & 23,5 & 8,0 & 34,0 & & & 7,2 \\
\hline $15 / 09 / 2005$ & 7,7 & 7,3 & & & 31,0 & 30,0 & 8,0 & 34,0 & & & 7,3 \\
\hline $16 / 09 / 2005$ & 7,8 & 7,4 & & & 30,0 & 30,5 & 8,0 & 34,0 & & & 7,9 \\
\hline 19/09/2005 & 7,7 & 7,3 & & & 31,0 & 31,5 & 6,8 & 28,0 & & & 6,9 \\
\hline 20/09/2005 & 7,5 & 7,4 & & & 30,5 & 31,0 & 7,0 & 34,0 & & & 7,3 \\
\hline 21/09/2005 & 7,2 & 7,3 & & & 30,0 & 29,5 & 7,6 & 34,0 & & & 7,2 \\
\hline 22/09/2005 & 7,5 & 7,3 & & & 30,0 & 31,5 & & 34,0 & & & 7,2 \\
\hline 23/09/2005 & 7,4 & 7,4 & & & 32,5 & 33,5 & & 30,0 & & & \\
\hline 26/09/2005 & 7,3 & 7,7 & & & 30,0 & 31,5 & & 30,0 & & & \\
\hline 28/09/2005 & 7,2 & 7,6 & & & 30,0 & 29,5 & 8,2 & 34,0 & & & 7,1 \\
\hline 29/09/2005 & 7,1 & 7,3 & & & 31,0 & 31,0 & 8,0 & 32,0 & & & 7,7 \\
\hline 30/09/2005 & 7,1 & 7,4 & & & 32,5 & 32,5 & 7,5 & 30,0 & & & 7,2 \\
\hline 03/10/2005 & 7,1 & 7,8 & & & 30,5 & 31,5 & 8,0 & 32,0 & & & 6,8 \\
\hline 04/10/2005 & 7,3 & 8,0 & & & 33,0 & 33,0 & 7,0 & 34,0 & & & 7,4 \\
\hline 05/10/2005 & 7,5 & 8,1 & 0,1 & 4,6 & 31,0 & 31,5 & 6,8 & 30,0 & & & 7,3 \\
\hline 06/10/2005 & 7,5 & 8,2 & & & 32,0 & 31,5 & 7,0 & 32,0 & & & 7,2 \\
\hline 07/10/2005 & 7,9 & 8,3 & 0,0 & 4,8 & 32,5 & 31,5 & 7,8 & 30,0 & & & 7,3 \\
\hline 10/10/2005 & 7,4 & 7,8 & 0,1 & 2,2 & 31,0 & 31,5 & 7,4 & 32,0 & & & 7,4 \\
\hline $11 / 10 / 2005$ & 7,4 & 7,8 & 0,1 & 3,3 & 30,5 & 31,5 & 8,2 & 30,0 & & & 7,4 \\
\hline 13/10/2005 & 7,5 & 7,8 & 0,0 & 2,3 & 31,5 & 32,5 & 7,0 & 30,0 & & & 7,2 \\
\hline $14 / 10 / 2005$ & 7,4 & 7,5 & 0,0 & 0,8 & 33,0 & 33,5 & 8,0 & 30,0 & & & 6,9 \\
\hline 17/10/2005 & 7,1 & 7,3 & 0,1 & 2,1 & 31,5 & 31,0 & 8,2 & 32,0 & & & 7,1 \\
\hline 18/10/2005 & 7,5 & 7,3 & 0,0 & 0,3 & 32,5 & 32,5 & 8,0 & 28,0 & & & 7,1 \\
\hline 19/10/2005 & 7,5 & 7,3 & 0,0 & 1,3 & 30,0 & 29,0 & 8,8 & 30,0 & & & 7,1 \\
\hline 20/10/2005 & 7,5 & 7,2 & 0,0 & 1,6 & 32,0 & 33,5 & 8,6 & 28,0 & & & 7,3 \\
\hline 21/10/2005 & 7,7 & 7,0 & 0,0 & 1,7 & 31,5 & 32,0 & 7,8 & 28,4 & & & 7,2 \\
\hline 24/10/2005 & 7,4 & 6,9 & 0,0 & 2,6 & 31,5 & 30,5 & 7,8 & 28,4 & & & 7,2 \\
\hline 25/10/2005 & 7,4 & 7,7 & 0,0 & 0,5 & 32,0 & 33,0 & 7,0 & 28,0 & & & 7,1 \\
\hline 26/10/2005 & 7,5 & 7,8 & & & 31,5 & 31,0 & 7,2 & 28,4 & & & 7,2 \\
\hline 27/10/2005 & 7,6 & 7,7 & & & 31,0 & 31,0 & 8,4 & 30,4 & & & 7,2 \\
\hline 28/10/2005 & 7,5 & 7,9 & & & 31,0 & 32,0 & 8,2 & 30,4 & & & 7,2 \\
\hline 31/10/2005 & 7,8 & 7,9 & & & 31,0 & 33,0 & 8,4 & 30,0 & & & 7,2 \\
\hline 01/11/2005 & 7,8 & 7,9 & 0,0 & 1,2 & 28,5 & 33,5 & 9,0 & 28,0 & & & 7,2 \\
\hline 03/11/2005 & 7,8 & 8,0 & 0,0 & 0,6 & 30,0 & 32,0 & 9,2 & 30,0 & & & 7,1 \\
\hline 04/11/2005 & 7,9 & 8,7 & 0,0 & 1,5 & 33,0 & 25,0 & & & & & 6,7 \\
\hline 07/11/2005 & 7,8 & 8,1 & 0,0 & 0,4 & 31,0 & 30,5 & 8,5 & 28,0 & & & 7,1 \\
\hline 08/11/2005 & 7,9 & 8,3 & 0,0 & 0,2 & 31,0 & 32,0 & 9,0 & 30,0 & 10,0 & & 7,2 \\
\hline 09/11/2005 & 8,0 & 8,3 & 0,0 & 0,0 & 28,0 & 30,0 & 7,8 & 28,0 & 7,0 & & 7,2 \\
\hline 10/11/2005 & 8,1 & 8,2 & 0,0 & 0,0 & 28,0 & 28,0 & 9,2 & 28,0 & 1,5 & & 7,1 \\
\hline 11/11/2005 & 8,1 & 8,3 & 0,0 & 0,2 & 25,0 & 26,0 & 8,6 & 28,0 & & & 7,2 \\
\hline $14 / 11 / 2005$ & 8,0 & 8,5 & 0,0 & 0,9 & 28,0 & 30,0 & 8,2 & 28,0 & & & \\
\hline 16/11/2005 & 8,1 & 8,4 & 0,0 & 1,2 & 29,0 & 28,0 & 7,8 & 28,0 & & & \\
\hline 17/11/2005 & 8,2 & 8,3 & & & 30,0 & 29,0 & 7,0 & 29,8 & & & 6,9 \\
\hline 21/11/2005 & 8,0 & 8,4 & 0,0 & 2,0 & 27,0 & 25,0 & 8,0 & 28,0 & & & 7,1 \\
\hline 23/11/2005 & 8,4 & 8,8 & 0,0 & 1,4 & 29,0 & 28,0 & 8,0 & 30,0 & & & \\
\hline 25/11/2005 & 8,0 & 8,2 & 0,0 & 1,6 & 31,0 & 30,0 & 7,6 & 26,0 & & & 7,1 \\
\hline 28/11/2005 & 7,7 & 8,2 & 0,0 & 1,3 & 30,0 & 26,0 & 8,0 & 30,0 & & & 7,1 \\
\hline 29/11/2005 & 7,5 & 8,4 & 0,0 & 0,2 & 31,0 & 29,0 & & 24,0 & & & 7,0 \\
\hline 30/11/2005 & 7,9 & 8,2 & 0,0 & 0,1 & 29,0 & 31,0 & & 26,0 & & & \\
\hline 01/12/2005 & 8,3 & 8,3 & 0,0 & 0,2 & 25,0 & 30,5 & 8,0 & 30,0 & & & 6,9 \\
\hline 02/12/2005 & 8,1 & 8,3 & 0,0 & 0,0 & 32,0 & 30,0 & 8,0 & 28,0 & & & 7,3 \\
\hline 05/12/2005 & 8,2 & 8,3 & 0,0 & 0,1 & 28,0 & 29,0 & 8,0 & 26,8 & 0,0 & & 7,2 \\
\hline 06/12/2005 & 8,1 & 8,2 & 0,0 & 0,1 & 30,0 & 31,0 & & 27,8 & & & 7,2 \\
\hline
\end{tabular}


Tabela D.1 - Resultados do Monitoramento Diário do Sistema PARCIAL ("P") na $1^{a}$ Fase na Pesquisa (Continuação)

\begin{tabular}{|c|c|c|c|c|c|c|c|c|c|c|c|}
\hline Data & $\begin{array}{c}\mathrm{pH} \text { ANOX } \\
\mathrm{P}\end{array}$ & $\begin{array}{c}\mathrm{pH} \text { AER } \\
\mathrm{P}\end{array}$ & $\begin{array}{c}\text { OD ANX } \\
\text { P } \\
(\mathrm{mg} / \mathrm{L})\end{array}$ & $\begin{array}{c}\text { OD AER } \\
P \\
(\mathrm{mg} / \mathrm{L})\end{array}$ & $\begin{array}{c}\text { temp } \\
\text { ANOX P } \\
(\mathrm{oC})\end{array}$ & $\begin{array}{l}\text { temp } \\
\text { AER P } \\
(\mathrm{oC})\end{array}$ & $\begin{array}{c}\text { Qafl P } \\
\text { (mL/min) }\end{array}$ & $\begin{array}{c}\text { Qret P } \\
\text { (mL/min) }\end{array}$ & $\begin{array}{c}\text { Qefl P } \\
\text { (mL/min) }\end{array}$ & $\begin{array}{l}\text { QrecicloP } \\
\text { (mL/min) }\end{array}$ & $\begin{array}{c}\text { Afluente } \\
\mathrm{pH}\end{array}$ \\
\hline 07/12/2005 & 8,4 & 8,3 & 0,0 & $\overline{0,2}$ & 24,0 & 28,0 & $\overline{8,0}$ & 30,0 & & & 7,2 \\
\hline 08/12/2005 & 8,2 & 8,3 & 0,0 & 0,1 & 29,0 & 27,0 & 8,0 & 28,0 & & & 7,2 \\
\hline 09/12/2005 & 8,2 & 8,3 & 0,0 & 0,0 & 31,0 & 28,0 & 8,0 & 26,8 & & & 7,2 \\
\hline $12 / 12 / 2005$ & 8,2 & 8,3 & 0,0 & 0,0 & 30,0 & 27,0 & 7,6 & 26,4 & & & 7,2 \\
\hline $13 / 12 / 2005$ & 8,2 & 8,3 & 0,0 & 0,0 & 30,0 & 27,0 & 7,4 & 28,0 & 28,0 & & 7,1 \\
\hline $14 / 12 / 2005$ & 8,3 & 8,3 & 0,0 & 0,3 & 31,0 & 27,0 & 7,8 & 26,0 & & & 7,1 \\
\hline $15 / 12 / 2005$ & 8,3 & 8,3 & 0,0 & 0,1 & 29,0 & 28,5 & 7,0 & 30,0 & 4,0 & & 7,1 \\
\hline $16 / 12 / 2005$ & 8,2 & 8,5 & 0,0 & 0,0 & 30,5 & 31,0 & 7,0 & 30,0 & 12,0 & & 7,3 \\
\hline 19/12/2005 & 8,2 & 8,3 & 0,0 & 0,3 & 32,0 & 29,0 & 7,0 & 32,0 & & & 7,2 \\
\hline 20/12/2005 & 8,2 & 8,3 & 0,0 & 0,1 & 31,5 & 30,5 & & 28,0 & 4,0 & & 7,1 \\
\hline 21/12/2005 & 8,4 & 8,4 & 0,0 & 0,2 & 32,0 & 30,0 & 7,0 & 28,4 & & & 7,1 \\
\hline $22 / 12 / 2005$ & 8,3 & 8,5 & 0,0 & 0,4 & 31,5 & 25,0 & & 26,0 & & & 7,1 \\
\hline $26 / 12 / 2005$ & 8,5 & 8,8 & 0,0 & 6,8 & 31,5 & 24,0 & 7,0 & 28,0 & & & 6,9 \\
\hline $30 / 12 / 2005$ & 8,0 & 8,3 & 0,0 & 0,2 & 33,0 & 33,0 & 7,0 & 28,0 & & & 6,7 \\
\hline 02/01/2006 & 8,4 & 8,8 & 0,0 & 5,0 & 34,0 & 31,5 & 7,0 & 28,0 & & & 6,6 \\
\hline 03/01/2006 & 8,1 & 8,4 & 0,0 & 3,8 & 33,0 & 30,0 & 7,0 & 28,0 & & & 7,2 \\
\hline 04/01/2006 & 8,1 & 8,3 & 0,0 & 0,0 & 33,0 & 30,0 & 7,4 & 26,0 & & & 7,2 \\
\hline 06/01/2006 & 8,1 & 8,3 & 0,0 & 0,0 & 32,5 & 30,0 & 7,2 & 33,5 & 5,0 & & 7,1 \\
\hline 09/01/2006 & 8,2 & 8,3 & 0,0 & 0,0 & 32,0 & 30,0 & 7,2 & 34,0 & & & 7,2 \\
\hline $10 / 01 / 2006$ & 8,3 & 8,3 & 0,0 & 0,3 & 31,0 & 30,0 & 6,8 & 35,8 & & & 7,1 \\
\hline $11 / 01 / 2006$ & 8,3 & 8,3 & 0,0 & 0,3 & 31,0 & 30,0 & 7,0 & 32,8 & & & 6,9 \\
\hline $12 / 01 / 2006$ & 8,3 & 8,3 & 0,0 & 0,2 & 29,0 & 30,0 & 7,0 & 36,0 & & & \\
\hline 13/01/2006 & 8,2 & 8,3 & 0,0 & 0,3 & 31,0 & 31,0 & 6,8 & 46,0 & & & 7,0 \\
\hline $16 / 01 / 2006$ & 8,2 & 8,3 & 0,0 & 0,1 & 31,0 & 30,0 & 7,0 & 48,0 & & & 7,0 \\
\hline $17 / 01 / 2006$ & 8,2 & 8,3 & 0,0 & 0,1 & 32,0 & 30,0 & 7,0 & 48,0 & & & 7,0 \\
\hline 18/01/2006 & 8,2 & 8,3 & 0,0 & 0,0 & 29,0 & 29,0 & 6,8 & 46,0 & & & 6,9 \\
\hline 19/01/2006 & 8,2 & 8,3 & & & 31,0 & 31,0 & 6,0 & 52,0 & & & 7,0 \\
\hline 20/01/2006 & 8,2 & 8,2 & & & 31,0 & 31,0 & 5,8 & 47,0 & & & 6,7 \\
\hline 23/01/2006 & 8,2 & 8,2 & & & 32,0 & 32,0 & 6,2 & 44,0 & & & 6,7 \\
\hline 24/01/2006 & 8,2 & 8,3 & & & 32,0 & 30,0 & & 52,0 & & & 7,0 \\
\hline $26 / 01 / 2006$ & 8,6 & 8,6 & & & 28,0 & 30,0 & 5,0 & 44,0 & & & 7,2 \\
\hline $27 / 01 / 2006$ & 8,4 & 8,3 & & & 27,0 & 28,0 & 5,4 & 48,0 & & & 7,1 \\
\hline $30 / 01 / 2006$ & 8,5 & 8,5 & & & 24,0 & 22,0 & 5,8 & 14,0 & & & 7,0 \\
\hline $31 / 01 / 2006$ & 8,4 & 8,3 & & & 21,0 & 22,0 & 5,0 & 42,0 & & & 7,0 \\
\hline 01/02/2006 & 8,3 & 8,3 & 0,0 & 3,5 & 20,0 & 22,0 & 6,0 & 33,0 & & & 7,1 \\
\hline $02 / 02 / 2006$ & 8,2 & 8,3 & & & 23,0 & 25,0 & 5,0 & 26,0 & & & 7,3 \\
\hline $03 / 02 / 2006$ & 8,1 & 8,2 & & & 23,0 & 25,0 & 6,0 & 28,0 & & & 7,1 \\
\hline $06 / 02 / 2006$ & 8,2 & 8,3 & & & 25,0 & 25,0 & 5,0 & 36,0 & & & \\
\hline $07 / 02 / 2006$ & 8,4 & 8,6 & 0,0 & 1,9 & 25,0 & 25,0 & & 32,0 & & & \\
\hline 08/02/2006 & 8,8 & 8,6 & 0,0 & 2,2 & 24,0 & 23,0 & & 32,0 & & & \\
\hline 09/02/2006 & 8,7 & 8,9 & 0,0 & 3,7 & 26,0 & 25,0 & 4,0 & 28,0 & & & \\
\hline $10 / 02 / 2006$ & 8,4 & 8,6 & 0,0 & 7,4 & 25,0 & 24,0 & 4,0 & 30,0 & & & 7,0 \\
\hline $13 / 02 / 2006$ & 8,0 & 8,4 & 0,1 & 6,3 & 25,0 & 25,0 & 4,2 & 36,0 & & & 7,0 \\
\hline $14 / 02 / 2006$ & 8,0 & 8,3 & 0,0 & 3,9 & 24,0 & 23,0 & 4,0 & 30,0 & & & \\
\hline $15 / 02 / 2006$ & 8,1 & 8,4 & 0,0 & 4,1 & 24,0 & 25,0 & 4,0 & 32,0 & & & \\
\hline $16 / 02 / 2006$ & 8,3 & 8,5 & 0,0 & 5,8 & 24,0 & 25,0 & 4,2 & 27,6 & & & 7,0 \\
\hline 20/02/2006 & 8,1 & 8,4 & 0,0 & 5,7 & 25,0 & 24,0 & 4,0 & 30,0 & & & \\
\hline $21 / 02 / 2006$ & 8,1 & 8,4 & 0,0 & 5,6 & 26,0 & 25,0 & 4,0 & 30,0 & & & \\
\hline $22 / 02 / 2006$ & 8,1 & 8,4 & 0,0 & 5,4 & 24,0 & 23,0 & 4,0 & 28,0 & & & \\
\hline 23/02/2006 & 8,1 & 8,4 & 0,0 & 5,6 & 24,0 & 24,0 & 4,2 & 31,2 & & & 7,0 \\
\hline $24 / 02 / 2006$ & 8,1 & 8,4 & 0,0 & 5,8 & 27,0 & 27,0 & 4,4 & 30,0 & & & \\
\hline $02 / 03 / 2006$ & 8,2 & 8,8 & 0,0 & 5,0 & 24,0 & 24,0 & 4,0 & 32,0 & & & 6,9 \\
\hline $03 / 03 / 2006$ & 8,3 & 8,7 & 0,0 & 4,2 & 25,0 & 25,0 & 4,0 & 27,0 & & & \\
\hline $06 / 03 / 2006$ & 8,3 & 8,6 & 0,0 & 4,9 & 25,0 & 25,0 & 4,0 & 48,0 & & & \\
\hline $07 / 03 / 2006$ & 8,1 & 8,3 & 0,0 & 4,5 & 22,0 & 23,0 & 5,0 & 45,4 & & & \\
\hline 08/03/2006 & 8,2 & 8,4 & 0,0 & 4,2 & 23,0 & 24,0 & 5,2 & 44,8 & & & \\
\hline 09/03/2006 & 7,9 & 8,3 & 0,0 & 4,9 & 23,0 & 23,0 & 5,2 & 54,0 & & & \\
\hline $10 / 03 / 2006$ & 7,9 & 8,4 & 0,0 & 3,2 & 26,0 & 24,0 & 5,2 & 36,4 & & & \\
\hline $13 / 03 / 2006$ & 7,9 & 8,4 & 0,0 & 4,0 & 21,0 & 20,0 & 4,4 & 36,0 & & & 7,0 \\
\hline $14 / 03 / 2006$ & 8,1 & 8,5 & 0,0 & 6,9 & 21,0 & 20,0 & 7,8 & 30,0 & & & \\
\hline $15 / 03 / 2006$ & 7,5 & 8,3 & 0,0 & 5,4 & 23,0 & 22,0 & 6,2 & 30,6 & & & \\
\hline
\end{tabular}


Tabela D.1 - Resultados do Monitoramento Diário do Sistema PARCIAL ("P") na $1^{\mathrm{a}}$ Fase na Pesquisa (Conclusão)

\begin{tabular}{|c|c|c|c|c|c|c|c|c|c|c|c|}
\hline Data & $\begin{array}{c}\mathrm{pH} \text { ANOX } \\
\mathrm{P}\end{array}$ & $\begin{array}{c}\mathrm{pH} A E R \\
\mathrm{P}\end{array}$ & $\begin{array}{c}\text { OD ANX } \\
P \\
(\mathrm{mg} / \mathrm{L})\end{array}$ & $\begin{array}{c}\text { OD AER } \\
P \\
(\mathrm{mg} / \mathrm{L})\end{array}$ & $\begin{array}{c}\text { temp } \\
\text { ANOX P } \\
(\mathrm{oC})\end{array}$ & $\begin{array}{c}\text { temp } \\
\text { AER P } \\
\text { (oC) }\end{array}$ & $\begin{array}{c}\text { Qafl P } \\
\text { (mL/min) }\end{array}$ & $\begin{array}{c}\text { Qret P } \\
\text { (mL/min) }\end{array}$ & $\begin{array}{c}\text { Qefl P } \\
\text { (mL/min) }\end{array}$ & $\begin{array}{l}\text { QrecicloP } \\
\text { (mL/min) }\end{array}$ & $\begin{array}{c}\text { Afluente } \\
\mathrm{pH}\end{array}$ \\
\hline $16 / 03 / 2006$ & 7,6 & 8,2 & 0,0 & 5,1 & 24,0 & 26,0 & 6,0 & 30,0 & & & \\
\hline 20/03/2006 & 7,6 & 8,3 & 0,0 & 4,9 & 26,0 & 25,0 & 7,0 & 38,0 & & & \\
\hline 21/03/2006 & 7,9 & 8,4 & 0,0 & 6,9 & 24,0 & 23,0 & 6,0 & 38,4 & & & \\
\hline $22 / 03 / 2006$ & 7,9 & 8,1 & 0,0 & 7,0 & 24,0 & 25,0 & 5,8 & 40,0 & & & \\
\hline 23/03/2006 & 7,7 & 8,2 & 0,0 & 5,8 & 24,0 & 23,0 & 7,6 & 42,0 & & & 7,0 \\
\hline 24/03/2006 & 7,7 & 8,2 & 0,0 & 6,0 & 24,0 & 23,0 & 7,2 & 36,0 & & & \\
\hline $27 / 03 / 2006$ & 7,8 & 8,3 & 0,0 & 5,9 & 22,0 & 21,0 & 7,0 & 36,0 & & & \\
\hline 28/03/2006 & 8,0 & 8,6 & 0,0 & 6,8 & 22,0 & 22,0 & 7,8 & 36,6 & & & \\
\hline 29/03/2006 & 8,1 & 8,5 & 0,0 & 6,9 & 23,0 & 22,0 & 8,0 & 36,0 & & & \\
\hline $30 / 03 / 2006$ & 7,8 & 8,4 & 0,0 & 6,7 & 22,0 & 23,0 & 8,0 & 36,0 & & & 6,9 \\
\hline $31 / 03 / 2006$ & 7,7 & 8,4 & 0,0 & 7,0 & 20,0 & 19,0 & 8,0 & 36,0 & & & \\
\hline 03/04/2006 & 7,7 & 8,3 & 0,0 & 6,8 & 21,0 & 22,0 & 8,4 & 38,0 & & & \\
\hline $04 / 04 / 2006$ & 7,7 & 8,3 & 0,0 & 5,9 & 20,0 & 20,0 & 7,6 & 34,0 & & & \\
\hline 05/04/2006 & 7,7 & 8,3 & 0,0 & 6,9 & 20,0 & 20,0 & 6,8 & 32,8 & & & \\
\hline 06/04/2006 & 7,7 & 8,3 & 0,0 & 6,8 & 23,0 & 22,0 & 7,6 & 32,0 & & & 7,0 \\
\hline $07 / 04 / 2006$ & 7,6 & 8,4 & 0,0 & 5,8 & 23,0 & 21,0 & 7,6 & 36,0 & & & \\
\hline $10 / 04 / 2006$ & 7,8 & 8,3 & 0,0 & 5,4 & 23,0 & 20,0 & 6,8 & 32,0 & & & \\
\hline $11 / 04 / 2006$ & 7,7 & 8,4 & 0,0 & 6,9 & 22,0 & 21,0 & 7,6 & 32,4 & & & \\
\hline $12 / 04 / 2006$ & 7,8 & 8,5 & 0,0 & 5,7 & 21,0 & 20,0 & 7,6 & 33,0 & & & 7,0 \\
\hline $13 / 04 / 2006$ & 7,7 & 8,3 & 0,0 & 6,3 & 21,0 & 20,0 & 7,6 & 30,0 & & & \\
\hline $17 / 04 / 2006$ & 7,4 & 7,2 & 0,0 & 5,7 & 21,0 & 26,0 & 6,8 & 35,0 & & & 7,0 \\
\hline $18 / 04 / 2006$ & 7,4 & 7,0 & 0,0 & 5,4 & 17,0 & 24,0 & & 34,0 & & & \\
\hline $19 / 04 / 2006$ & 7,5 & 8,4 & 0,0 & 6,3 & 20,0 & 24,0 & 6,0 & 34,0 & & & \\
\hline 20/04/2006 & 7,4 & 8,4 & 0,0 & 6,9 & 21,0 & 25,0 & 4,2 & 32,0 & & & 7,0 \\
\hline $24 / 04 / 2006$ & 7,6 & 8,3 & 0,0 & 7,0 & 21,0 & 25,0 & 4,4 & 32,0 & & & \\
\hline $25 / 04 / 2006$ & 7,8 & 8,4 & 0,0 & 6,9 & 22,0 & 26,0 & & 34,0 & & & \\
\hline $26 / 04 / 2006$ & 7,8 & 8,5 & 0,0 & 6,9 & 20,0 & 25,0 & 3,4 & 34,0 & & & \\
\hline $27 / 04 / 2006$ & 7,8 & 8,5 & 0,0 & 6,9 & 22,0 & 26,0 & 7,6 & 30,4 & & & \\
\hline $28 / 04 / 2006$ & 7,7 & 8,3 & 0,0 & 6,9 & 21,0 & 25,0 & 4,0 & 32,0 & & & 7,0 \\
\hline
\end{tabular}


Tabela D.2 - Resultados do Monitoramento Diário do Sistema PARCIAL ("P") na $2^{a}$ Fase na Pesquisa (Continua)

\begin{tabular}{|c|c|c|c|c|c|c|c|c|c|c|c|}
\hline Data & $\begin{array}{c}\mathrm{pH} \\
\text { ANOX P }\end{array}$ & $\begin{array}{c}\mathrm{pH} \text { AER } \\
\mathrm{P}\end{array}$ & $\begin{array}{c}\text { OD } \\
\text { ANX P } \\
(\mathrm{mg} / \mathrm{L}) \\
\end{array}$ & $\begin{array}{c}\text { OD AER } \\
P \\
(\mathrm{mg} / \mathrm{L})\end{array}$ & $\begin{array}{c}\text { temp } \\
\text { ANOX P } \\
(\mathrm{oC})\end{array}$ & $\begin{array}{c}\text { temp } \\
\text { AER P } \\
(\mathrm{oC}) \\
\end{array}$ & $\begin{array}{c}\text { Qafl P } \\
\text { (mL/min) }\end{array}$ & $\begin{array}{c}\text { Qret P } \\
\text { (mL/min) }\end{array}$ & $\begin{array}{c}\text { Qefl P } \\
\text { (mL/min) }\end{array}$ & $\begin{array}{l}\text { QrecicloP } \\
\text { (mL/min) }\end{array}$ & $\begin{array}{c}\text { Afluente } \\
\mathrm{pH}\end{array}$ \\
\hline $02 / 05 / 2006$ & 7,9 & 8,4 & $\overline{0,0}$ & 6,9 & 20,0 & 22,0 & 4,0 & 32,0 & & & \\
\hline 03/05/2006 & 7,8 & 8,3 & 0,0 & 6,9 & 19,0 & 22,0 & 3,0 & 37,0 & & & \\
\hline 04/05/2006 & 8,8 & 8,4 & 0,0 & 6,5 & 20,0 & 22,0 & 4,0 & 30,0 & & & \\
\hline 05/05/2006 & 8,5 & 8,5 & 0,0 & 5,4 & 23,0 & 24,0 & 5,0 & 34,0 & & & 6,9 \\
\hline 09/05/2006 & 8,3 & 8,4 & 0,0 & 0,1 & 20,0 & 27,0 & 5,6 & 30,0 & & & \\
\hline $10 / 05 / 2006$ & 8,5 & 8,7 & 0,0 & 0,1 & 16,0 & 27,0 & 5,2 & 40,0 & & & \\
\hline $11 / 05 / 2006$ & 8,5 & 8,6 & 0,0 & 1,9 & 18,0 & 25,0 & 5,0 & 40,0 & & & \\
\hline $12 / 05 / 2006$ & 8,5 & 8,7 & 0,0 & 3,6 & 18,0 & 24,0 & 5,2 & 37,0 & & & 6,9 \\
\hline $15 / 05 / 2006$ & 8,5 & 8,7 & 0,0 & 2,9 & 27,0 & 25,0 & 5,0 & 36,0 & & & \\
\hline $16 / 05 / 2006$ & 8,4 & 8,5 & 0,0 & 2,8 & 28,0 & 25,0 & 5,0 & 34,0 & & & \\
\hline $17 / 05 / 2006$ & 8,3 & 8,6 & 0,0 & 5,6 & 28,0 & 25,0 & 5,0 & 37,0 & & & \\
\hline 18/05/2006 & 8,1 & 8,4 & 0,0 & 5,9 & 29,0 & 25,0 & 5,8 & 35,0 & & & \\
\hline 19/05/2006 & 7,9 & 8,3 & 0,0 & 5,2 & 28,0 & 25,0 & 5,0 & 35,0 & & & \\
\hline $22 / 05 / 2006$ & 8,2 & 8,5 & 0,0 & 5,2 & 30,0 & 26,0 & 5,2 & 40,0 & & & \\
\hline $24 / 05 / 2006$ & 7,8 & 8,2 & 0,0 & 6,8 & 27,0 & 24,0 & 5,8 & 39,0 & & & 7,0 \\
\hline 25/05/2006 & 7,5 & 7,7 & 0,0 & 5,2 & 28,0 & 25,0 & 5,0 & 38,0 & & & \\
\hline 26/05/2006 & 7,4 & 7,6 & 0,0 & 4,5 & 30,0 & 27,0 & 5,5 & 38,0 & & & \\
\hline $29 / 05 / 2006$ & 7,4 & 7,1 & 0,0 & 1,6 & 31,0 & 28,0 & 5,0 & 43,0 & & & \\
\hline $30 / 05 / 2006$ & 7,6 & 8,0 & 0,0 & 3,5 & 30,0 & 26,5 & 5,4 & 40,0 & & & \\
\hline 31/05/2006 & 7,3 & 7,9 & 0,0 & 5,8 & 30,0 & 27,0 & 5,3 & 40,0 & & & \\
\hline 01/06/2006 & 7,5 & 7,9 & & & 32,0 & 27,0 & 5,2 & 40,0 & & & 5,9 \\
\hline 02/06/2006 & 7,3 & 7,8 & & & 30,0 & 26,0 & 5,5 & 44,0 & & & 7,3 \\
\hline 05/06/2006 & 7,9 & 7,6 & & & 32,0 & 28,0 & 5,2 & 40,0 & & & 7,3 \\
\hline 06/06/2006 & 7,6 & 8,0 & 0,1 & 2,9 & 31,5 & 28,0 & 5,5 & 44,0 & 3,0 & & 7,3 \\
\hline 07/06/2006 & 7,8 & 7,9 & 0,0 & 5,0 & 34,0 & 30,5 & 5,0 & 45,0 & & & \\
\hline 08/06/2006 & 7,7 & 7,8 & & & 31,5 & 28,5 & & 33,0 & 2,0 & & \\
\hline 09/06/2006 & 7,9 & 8,3 & & & 31,0 & 25,0 & 5,4 & 39,0 & & & 7,2 \\
\hline $12 / 06 / 2006$ & 7,8 & 8,2 & & & 30,0 & 27,0 & 5,0 & 42,0 & & & 7,0 \\
\hline $13 / 06 / 2006$ & 7,5 & 8,0 & 0,1 & 4,7 & 31,0 & 27,0 & 6,0 & 47,0 & & & 7,4 \\
\hline $14 / 06 / 2006$ & 7,9 & 8,1 & 0,0 & 4,4 & 29,0 & 25,0 & 5,8 & 41,0 & 16,0 & & 7,0 \\
\hline 19/06/2006 & 7,9 & 8,2 & 0,0 & 5,1 & 29,0 & 24,0 & 5,8 & 44,0 & 68,0 & & 7,0 \\
\hline $20 / 06 / 2006$ & 7,6 & 8,0 & 0,1 & 3,6 & 29,5 & 27,5 & 5,5 & 48,0 & 24,0 & & 7,0 \\
\hline 21/06/2006 & 7,7 & 8,1 & 0,0 & 4,2 & 30,0 & 25,0 & 6,2 & 42,0 & 36,0 & & 6,9 \\
\hline $22 / 06 / 2006$ & 7,7 & 8,0 & 0,1 & 2,9 & 31,0 & 26,0 & 6,2 & 39,0 & 11,0 & & 6,7 \\
\hline 23/06/2006 & 7,7 & 8,1 & 0,0 & 4,0 & 31,0 & 25,0 & 6,0 & 42,0 & 11,0 & & 6,7 \\
\hline 26/06/2006 & 7,8 & 8,2 & 0,0 & 3,6 & 31,0 & 28,0 & 5,8 & 40,0 & 10,0 & & 7,0 \\
\hline 28/06/2006 & 7,7 & 8,2 & 0,0 & 3,3 & 28,0 & 25,0 & 5,8 & 45,0 & 8,0 & & 6,9 \\
\hline 29/06/2006 & 7,6 & 7,9 & 0,0 & 4,7 & 27,0 & 24,0 & 5,5 & 38,0 & & & \\
\hline $30 / 06 / 2006$ & 7,7 & 8,0 & 0,0 & 4,6 & 29,0 & 25,0 & 5,8 & 46,0 & 6,0 & & 6,3 \\
\hline 03/07/2006 & 7,9 & 8,2 & 0,0 & 4,2 & 28,0 & 24,0 & 6,0 & 42,0 & 8,0 & & 6,9 \\
\hline 04/07/2006 & 7,7 & 8,0 & 0,0 & 3,5 & 32,0 & 30,0 & 5,6 & 45,0 & 18,0 & & 6,8 \\
\hline 05/07/2006 & 7,7 & 8,2 & 0,0 & 3,4 & 29,0 & 24,0 & 5,8 & 48,0 & 2,0 & & 6,8 \\
\hline 06/07/2006 & 7,6 & 8,2 & 0,1 & 3,9 & 33,0 & 29,0 & 6,0 & 41,0 & 4,0 & & 7,4 \\
\hline 07/07/2006 & 7,7 & 8,0 & 0,1 & 4,0 & 35,0 & 30,0 & 6,2 & 43,0 & 2,4 & & 7,3 \\
\hline 10/07/2006 & 8,2 & 8,4 & 0,0 & 3,1 & 25,0 & 26,0 & 6,0 & 45,0 & 2,5 & & 7,1 \\
\hline 11/07/2006 & 7,6 & 7,8 & 0,0 & 3,1 & 21,0 & 27,0 & 6,2 & 46,0 & 26,0 & & 7,2 \\
\hline $12 / 07 / 2006$ & 7,8 & 8,1 & 0,0 & 4,5 & 33,0 & 27,0 & 6,0 & 38,0 & 2,0 & & \\
\hline 13/07/2006 & 7,6 & 7,9 & 0,0 & 3,1 & 35,5 & 31,0 & 6,2 & 43,0 & 8,0 & & 7,2 \\
\hline $14 / 07 / 2006$ & 7,6 & 7,8 & 0,0 & 4,4 & 34,0 & 29,0 & 6,2 & 35,0 & & & \\
\hline 17/07/2006 & 7,9 & 8,2 & 0,0 & 4,5 & 28,0 & 25,0 & 5,6 & 46,0 & 6,0 & & \\
\hline 18/07/2006 & 7,6 & 7,9 & 0,1 & 3,9 & 35,0 & 29,5 & 6,0 & 43,0 & 2,5 & & 6,6 \\
\hline 19/07/2006 & 7,6 & 7,8 & 0,0 & 5,2 & 30,0 & 25,0 & 6,0 & 30,0 & 7,0 & & 6,9 \\
\hline 20/07/2006 & 7,6 & 7,7 & 0,1 & 3,5 & 33,5 & 29,5 & 6,2 & 41,0 & 1,0 & & 6,5 \\
\hline 21/07/2006 & 7,6 & 7,9 & 0,1 & 2,1 & 28,0 & 24,0 & 6,0 & 44,0 & & & 7,1 \\
\hline 24/07/2006 & 7,7 & 7,5 & 0,0 & 4,1 & 33,0 & 25,0 & 5,8 & 30,0 & 6,0 & & 6,9 \\
\hline 25/07/2006 & 7,7 & 7,8 & 0,1 & 1,4 & 36,0 & 31,5 & 6,0 & 42,0 & 2,0 & & 6,7 \\
\hline 26/07/2006 & 7,7 & 7,8 & 0,0 & 0,3 & 31,0 & 27,0 & 6,6 & 44,0 & 6,0 & & 6,9 \\
\hline 27/07/2006 & 7,7 & 8,5 & 0,1 & 0,1 & 37,0 & 30,0 & 6,5 & 31,0 & 70,0 & & 6,6 \\
\hline 28/07/2006 & 7,8 & 7,9 & 0,1 & 0,3 & 38,0 & 33,0 & 6,0 & 35,0 & 21,0 & & 7,1 \\
\hline 31/07/2006 & 7,8 & 7,9 & 0,0 & 0,4 & 25,0 & 23,0 & 5,8 & 34,0 & 8,2 & & 7,0 \\
\hline 02/08/2006 & 7,7 & 7,8 & 0,0 & 0,4 & 31,0 & 27,0 & 7,0 & 28,0 & 5,6 & & 7,0 \\
\hline
\end{tabular}


Tabela D.2 - Resultados do Monitoramento Diário do Sistema PARCIAL ("P") na $2^{a}$ Fase na Pesquisa (Continuação)

\begin{tabular}{|c|c|c|c|c|c|c|c|c|c|c|c|}
\hline Data & $\begin{array}{c}\mathrm{pH} \\
\text { ANOX P }\end{array}$ & $\begin{array}{c}\mathrm{pH} \text { AER } \\
\mathrm{P}\end{array}$ & $\begin{array}{l}\text { OD } \\
\text { ANX P } \\
\text { (mg/L) }\end{array}$ & $\begin{array}{c}\text { OD AER } \\
\mathrm{P} \\
(\mathrm{mg} / \mathrm{L})\end{array}$ & $\begin{array}{c}\text { temp } \\
\text { ANOX P } \\
(\mathrm{oC})\end{array}$ & $\begin{array}{c}\text { temp } \\
\text { AER P } \\
\text { (oC) }\end{array}$ & $\begin{array}{l}\text { Qafl P } \\
\text { (mL/min) }\end{array}$ & $\begin{array}{c}\text { Qret P } \\
\text { (mL/min) }\end{array}$ & $\begin{array}{c}\text { Qefl P } \\
\text { (mL/min) }\end{array}$ & $\begin{array}{l}\text { QrecicloP } \\
\text { (mL/min) }\end{array}$ & $\begin{array}{c}\text { Afluente } \\
\mathrm{pH}\end{array}$ \\
\hline $03 / 08 / 2006$ & 7,7 & 7,7 & & 0,4 & 34,0 & 29,5 & 6,4 & 30,0 & 3,0 & & 6,8 \\
\hline 04/08/2006 & 7,7 & 7,7 & 0,0 & 0,4 & 35,0 & 30,0 & 6,0 & 30,0 & 2,0 & & 6,6 \\
\hline 07/08/2006 & 7,7 & 7,9 & 0,0 & 0,3 & 31,0 & 24,0 & 6,0 & 32,0 & 3,5 & & 6,9 \\
\hline 08/08/2006 & 7,6 & 7,7 & 0,1 & 1,3 & 36,0 & 32,0 & 6,0 & 23,0 & & & 6,4 \\
\hline 09/08/2006 & 7,6 & 7,8 & 0,1 & 0,1 & 36,0 & 32,0 & 6,8 & 25,0 & 2,0 & & 7,2 \\
\hline $11 / 08 / 2006$ & 7,7 & 7,8 & 0,1 & 0,1 & 33,0 & 29,5 & 6,5 & 31,0 & 1,0 & & 7,1 \\
\hline $14 / 08 / 2006$ & 7,7 & 7,7 & 0,1 & 0,1 & 37,0 & 33,0 & 6,0 & 29,0 & & & 7,1 \\
\hline $16 / 08 / 2006$ & 7,7 & 7,8 & 0,0 & 0,1 & 35,0 & 30,0 & 6,0 & 30,0 & & & 7,0 \\
\hline $17 / 08 / 2006$ & 7,7 & 7,7 & 0,0 & 0,2 & 35,0 & 31,5 & 6,5 & 30,0 & 0,5 & & 7,4 \\
\hline 18/08/2006 & 7,7 & 7,7 & 0,1 & 0,6 & 36,0 & 31,0 & 6,2 & 30,0 & 8,0 & & 7,2 \\
\hline 21/08/2006 & 7,7 & 7,7 & 0,1 & 1,0 & 30,0 & 24,0 & 6,0 & 29,0 & 7,0 & & 7,2 \\
\hline 22/08/2006 & 7,6 & 7,7 & 0,1 & 1,6 & 30,0 & 22,0 & 6,2 & 30,0 & 7,0 & & 7,2 \\
\hline 23/08/2006 & 7,9 & 8,0 & 0,0 & 1,1 & 31,0 & 27,0 & 6,2 & 32,0 & 7,0 & & 7,1 \\
\hline 24/08/2006 & 7,6 & 7,9 & 0,1 & 1,9 & 38,0 & 30,0 & 7,2 & 29,0 & 6,0 & & 7,4 \\
\hline 25/08/2006 & 7,7 & 7,9 & 0,1 & 1,1 & 40,0 & 33,0 & 7,0 & 28,0 & 2,0 & & 7,4 \\
\hline 28/08/2006 & 7,8 & 8,0 & 0,1 & 0,9 & 31,0 & 27,0 & 7,6 & 30,0 & 6,0 & & 7,1 \\
\hline 29/08/2006 & 7,9 & 7,8 & 0,0 & 1,1 & 29,0 & 26,0 & 7,0 & 30,0 & 2,0 & & 7,1 \\
\hline 30/08/2006 & 7,9 & 7,8 & 0,1 & 1,2 & 27,0 & 25,0 & 6,8 & 28,0 & & & 7,1 \\
\hline $31 / 08 / 2006$ & 7,9 & 7,9 & 0,0 & 1,5 & 30,0 & 25,0 & 8,0 & 30,0 & 9,0 & & 6,7 \\
\hline 01/09/2006 & 7,8 & 7,8 & 0,0 & 1,1 & 33,0 & 30,0 & 7,2 & 28,0 & 8,0 & & 6,9 \\
\hline 04/09/2006 & 7,9 & 7,8 & 0,0 & 1,6 & 30,5 & 25,0 & 7,0 & 27,0 & 4,0 & & 7,2 \\
\hline 05/09/2006 & 7,7 & 7,9 & 0,0 & 1,2 & 26,0 & 23,0 & 7,0 & 31,0 & 11,0 & & 7,2 \\
\hline 06/09/2006 & 7,8 & 7,9 & 0,0 & 1,6 & 26,0 & 20,0 & 7,6 & 30,0 & 5,4 & & 7,1 \\
\hline 11/09/2006 & 7,7 & 7,8 & 0,0 & 0,7 & 34,0 & 28,0 & 7,0 & 28,0 & 7,0 & & 7,1 \\
\hline $12 / 09 / 2006$ & 7,8 & 7,8 & 0,0 & 1,6 & 33,0 & 30,0 & 7,0 & 26,0 & & & 7,0 \\
\hline $13 / 09 / 2006$ & 7,8 & 7,9 & 0,1 & 0,9 & 26,0 & 22,0 & 7,0 & 32,0 & 3,0 & & 7,0 \\
\hline $14 / 09 / 2006$ & 7,8 & 7,9 & 0,0 & 1,6 & 34,0 & 29,0 & 7,0 & 30,0 & 7,0 & & 7,1 \\
\hline 15/09/2006 & 7,7 & 7,7 & 0,0 & 1,7 & 39,0 & 35,5 & 7,0 & 28,0 & & & 7,4 \\
\hline $18 / 09 / 2006$ & 7,7 & 7,1 & 0,0 & 1,8 & 33,0 & 27,0 & 6,8 & 25,0 & 7,0 & & 7,1 \\
\hline 19/09/2006 & 7,6 & 6,7 & & 0,3 & 38,0 & 32,0 & 6,6 & 27,0 & & & 7,2 \\
\hline 20/09/2006 & 7,5 & 6,4 & 0,0 & 1,8 & 37,0 & 31,0 & 7,0 & 28,0 & 7,0 & & \\
\hline $21 / 09 / 2006$ & 7,5 & 7,1 & 0,0 & 1,3 & 35,0 & 30,0 & 7,4 & 28,0 & 3,0 & & 7,0 \\
\hline $22 / 09 / 2006$ & 7,4 & 6,5 & 0,0 & 1,9 & 32,0 & 26,0 & 7,0 & 30,0 & 7,0 & & 7,0 \\
\hline 25/09/2006 & 7,2 & 5,7 & 0,0 & 0,9 & 32,0 & 25,0 & 6,8 & 28,0 & 7,0 & & 7,1 \\
\hline 26/09/2006 & 7,0 & 5,8 & 0,1 & 0,3 & 33,0 & 27,0 & 7,0 & 30,0 & 7,0 & & 6,8 \\
\hline 27/09/2006 & 7,0 & 5,3 & 0,1 & 0,8 & 37,0 & 31,0 & 7,0 & 28,0 & 7,0 & & 6,8 \\
\hline 28/09/2006 & 6,9 & 5,5 & 0,0 & 0,6 & 20,0 & 26,0 & 7,0 & 27,0 & 2,5 & & 6,7 \\
\hline 02/10/2006 & 6,8 & 5,5 & 0,0 & 1,9 & 23,0 & 30,5 & 6,5 & 28,0 & 2,0 & & 6,6 \\
\hline 03/10/2006 & 6,8 & 6,0 & 0,0 & 1,7 & 22,0 & 28,5 & 7,0 & 30,0 & 5,0 & & 6,5 \\
\hline 05/10/2006 & 7,0 & 5,5 & 0,0 & 2,0 & 24,0 & 31,0 & 7,0 & 28,0 & 23,0 & & 7,0 \\
\hline 06/10/2006 & 7,1 & 5,7 & 0,0 & 1,7 & 23,0 & 29,5 & 7,2 & 29,0 & & & 7,4 \\
\hline 09/10/2006 & 7,0 & 5,5 & 0,0 & 1,2 & 21,0 & 28,0 & 6,5 & 28,0 & 2,0 & & 7,3 \\
\hline $10 / 10 / 2006$ & 7,9 & 5,6 & 0,0 & 1,5 & 21,0 & 28,0 & 6,2 & 29,0 & 2,0 & & 7,3 \\
\hline 11/10/2006 & 7,0 & 5,6 & 0,0 & 0,6 & 21,0 & 30,0 & 8,0 & 27,0 & & & 7,4 \\
\hline $16 / 10 / 2006$ & 7,2 & 5,5 & 0,0 & 0,6 & 24,0 & 31,0 & 7,0 & 32,0 & 2,0 & & 7,2 \\
\hline $17 / 10 / 2006$ & 7,2 & 5,5 & 0,0 & 0,8 & 22,0 & 29,0 & 6,5 & 28,0 & 2,0 & & 7,3 \\
\hline $18 / 10 / 2006$ & 7,0 & 5,4 & 0,0 & 1,2 & 20,0 & 28,0 & & 27,0 & 3,0 & & 7,3 \\
\hline 19/10/2006 & 7,2 & 5,6 & 0,0 & 1,5 & 34,0 & 28,5 & 7,0 & 35,0 & & & 7,4 \\
\hline 23/10/2006 & 7,2 & 5,5 & & 0,8 & 34,0 & 30,0 & 7,0 & 32,0 & 1,5 & & 7,1 \\
\hline $24 / 10 / 2006$ & 7,1 & 5,4 & 0,0 & 1,3 & 35,0 & 28,0 & 7,2 & 32,0 & 6,0 & & 6,9 \\
\hline 25/10/2006 & 7,0 & 5,4 & 0,0 & 1,5 & 34,0 & 29,0 & 7,5 & 30,0 & & & 6,6 \\
\hline 26/10/2006 & 7,0 & 5,7 & 0,0 & 0,9 & 30,0 & 31,0 & 7,5 & 30,0 & & & 6,5 \\
\hline 27/10/2006 & 6,9 & 5,8 & 0,0 & 0,9 & 24,0 & 32,0 & 7,0 & 30,0 & & & 6,7 \\
\hline $30 / 10 / 2006$ & 6,6 & 5,4 & 0,0 & 0,7 & 20,0 & 28,0 & 7,0 & 30,0 & 3,0 & & 6,2 \\
\hline $31 / 10 / 2006$ & 6,5 & 5,3 & 0,0 & 0,9 & 22,0 & 30,0 & 7,0 & 34,0 & 7,0 & & 7,9 \\
\hline 01/11/2006 & 6,5 & 5,4 & 0,0 & 0,5 & 23,0 & 31,0 & 8,0 & 40,0 & & & 7,3 \\
\hline 03/11/2006 & 6,8 & 6,2 & 0,0 & 0,7 & 24,0 & 31,0 & 7,0 & 40,0 & 7,0 & & 7,1 \\
\hline 06/11/2006 & 6,7 & 5,4 & 0,0 & 0,3 & 21,0 & 28,4 & 7,5 & 39,0 & 3,0 & & 7,2 \\
\hline 07/11/2006 & 6,7 & 5,4 & 0,0 & 0,5 & 22,5 & 29,0 & 7,5 & 40,0 & 3,0 & & 7,0 \\
\hline 09/11/2006 & 6,8 & 5,3 & 0,0 & 0,7 & 27,0 & 26,0 & 7,0 & 37,0 & 3,0 & & 6,8 \\
\hline $10 / 11 / 2006$ & 6,7 & 8,3 & 0,0 & 0,8 & 27,0 & 19,0 & 7,8 & 44,0 & 2,0 & & 7,1 \\
\hline
\end{tabular}


Tabela D.2 - Resultados do Monitoramento Diário do Sistema PARCIAL ("P") na $2^{a}$ Fase na Pesquisa (Conclusão)

\begin{tabular}{|c|c|c|c|c|c|c|c|c|c|c|c|}
\hline Data & $\begin{array}{c}\mathrm{pH} \\
\text { ANOX P }\end{array}$ & $\begin{array}{c}\mathrm{pH} A E R \\
\mathrm{P}\end{array}$ & $\begin{array}{c}\text { OD } \\
\text { ANX P } \\
(\mathrm{mg} / \mathrm{L})\end{array}$ & $\begin{array}{c}\text { OD AER } \\
\mathrm{P} \\
(\mathrm{mg} / \mathrm{L})\end{array}$ & $\begin{array}{c}\text { temp } \\
\text { ANOX P } \\
(\mathrm{oC})\end{array}$ & $\begin{array}{c}\text { temp } \\
\text { AER P } \\
(\mathrm{oC})\end{array}$ & $\begin{array}{c}\text { Qafl P } \\
\text { (mL/min) }\end{array}$ & $\begin{array}{c}\text { Qret P } \\
\text { (mL/min) }\end{array}$ & $\begin{array}{c}\text { Qefl P } \\
\text { (mL/min) }\end{array}$ & $\begin{array}{l}\text { QrecicloP } \\
\text { (mL/min) }\end{array}$ & $\begin{array}{c}\text { Afluente } \\
\mathrm{pH}\end{array}$ \\
\hline $13 / 11 / 2006$ & 8,0 & 8,2 & 0,0 & 1,8 & 28,0 & 19,0 & 7,0 & 38,0 & & & 6,5 \\
\hline $14 / 11 / 2006$ & 8,1 & 8,2 & 0,0 & 2,6 & 30,0 & 20,0 & 7,0 & 38,0 & & & 6,4 \\
\hline $16 / 11 / 2006$ & 8,1 & 8,1 & 0,0 & 1,0 & 31,0 & 22,0 & 8,0 & 40,0 & 3,0 & & 6,2 \\
\hline $17 / 11 / 2006$ & 8,2 & 8,2 & 0,0 & 0,8 & 32,5 & 22,4 & 8,0 & 40,0 & & & 6,5 \\
\hline $21 / 11 / 2006$ & 8,1 & 8,2 & 0,0 & 1,1 & 33,0 & 21,0 & 7,5 & 40,0 & 60,0 & & 7,2 \\
\hline $22 / 11 / 2006$ & 8,2 & 8,2 & 0,0 & 0,7 & 29,3 & 21,0 & 7,0 & 40,0 & & & 7,2 \\
\hline 23/11/2006 & 8,3 & 8,1 & 0,1 & 0,8 & 31,1 & 21,5 & 7,0 & 40,0 & 3,0 & & 7,1 \\
\hline 24/11/2006 & 8,2 & 8,1 & 0,1 & 0,6 & 35,5 & 25,4 & 7,0 & 40,0 & 8,0 & & 7,1 \\
\hline $27 / 11 / 2006$ & 8,0 & 8,0 & 0,0 & 0,1 & 32,7 & 23,4 & 10,0 & 40,0 & 3,0 & 86,0 & 6,8 \\
\hline $28 / 11 / 2006$ & 8,0 & 8,0 & 0,0 & 0,2 & 29,0 & 24,8 & 8,0 & 40,0 & 3,0 & 140,0 & 6,5 \\
\hline 29/11/2006 & 8,0 & 8,0 & 0,0 & 0,2 & 29,5 & 26,1 & 10,0 & 40,0 & 25,0 & 120,0 & 7,3 \\
\hline $30 / 11 / 2006$ & 8,1 & 8,0 & 0,0 & 0,5 & 31,5 & 25,2 & 10,0 & 40,0 & 3,0 & 50,0 & 7,4 \\
\hline $01 / 12 / 2006$ & 8,0 & 8,0 & 0,0 & 0,3 & 28,2 & 22,1 & 11,0 & 40,0 & 3,0 & 64,0 & 7,3 \\
\hline 04/12/2006 & 8,0 & 7,9 & 0,0 & 0,3 & 31,9 & 25,8 & 10,0 & 40,0 & 5,0 & 70,0 & 7,1 \\
\hline $05 / 12 / 2006$ & 8,0 & 8,0 & 0,0 & 0,6 & 30,2 & 24,2 & 10,0 & 40,0 & 2,0 & 50,0 & 7,0 \\
\hline 07/12/2006 & 7,9 & 8,0 & 0,0 & 0,6 & 29,3 & 24,5 & 10,0 & 40,0 & 2,0 & 70,0 & 6,4 \\
\hline $08 / 12 / 2006$ & 7,9 & 7,9 & 0,0 & 0,4 & 28,4 & 22,6 & 11,5 & 40,0 & & 74,0 & 7,1 \\
\hline $11 / 12 / 2006$ & 8,0 & 8,0 & 0,0 & 0,2 & 27,4 & 23,5 & 10,0 & 44,0 & 3,0 & 140,0 & 6,8 \\
\hline $12 / 12 / 2006$ & 8,0 & 8,2 & 0,0 & 0,5 & 27,5 & 23,4 & 10,0 & 42,0 & 4,0 & 144,0 & 6,8 \\
\hline $13 / 12 / 2006$ & 8,1 & 7,9 & 0,0 & 0,7 & 28,2 & 24,2 & 12,0 & 40,0 & 3,0 & 140,0 & 6,7 \\
\hline $14 / 12 / 2006$ & 8,5 & 8,1 & 0,0 & 0,6 & 29,9 & 25,9 & 12,0 & 40,0 & 1,0 & 140,0 & 6,5 \\
\hline $15 / 12 / 2006$ & & & & & & & 12,0 & 40,0 & & 178,0 & \\
\hline $18 / 12 / 2006$ & 8,3 & 8,4 & 0,0 & 0,4 & 32,7 & 32,6 & 12,0 & 40,0 & 1,5 & 200,0 & 6,9 \\
\hline $19 / 12 / 2006$ & 8,3 & 8,4 & 0,0 & 0,6 & 32,7 & 32,4 & 12,0 & 44,0 & 30,0 & 200,0 & 7,0 \\
\hline $21 / 12 / 2006$ & 8,2 & 8,3 & 0,0 & 0,4 & 32,3 & 32,1 & 12,0 & 40,0 & 6,0 & 200,0 & 6,6 \\
\hline $22 / 12 / 2006$ & 8,2 & 8,3 & 0,0 & 0,3 & 33,5 & 33,2 & 13,0 & 40,0 & 5,0 & 200,0 & 6,6 \\
\hline $26 / 12 / 2006$ & 8,2 & 8,4 & 0,0 & 0,4 & 30,0 & 27,0 & 12,0 & 40,0 & 1,0 & 200,0 & 6,6 \\
\hline 29/12/2006 & 8,3 & 8,3 & 0,0 & 0,2 & 29,1 & 25,9 & 12,0 & 40,0 & 1,0 & 140,0 & 6,5 \\
\hline 02/01/2007 & 8,3 & 8,3 & 0,0 & 0,2 & 29,6 & 26,0 & 13,0 & 40,0 & 5,0 & 145,0 & 6,7 \\
\hline 04/01/2007 & 8,3 & 8,3 & 0,0 & 0,2 & 30,3 & 26,1 & 12,0 & 36,0 & 12,0 & 176,0 & 7,0 \\
\hline 05/01/2007 & 8,2 & 8,3 & 0,0 & 0,2 & 29,6 & 25,9 & 12,0 & 36,0 & 5,0 & 124,0 & 6,8 \\
\hline 08/01/2007 & 8,2 & 8,2 & 0,0 & 0,3 & 31,9 & 28,0 & 12,0 & 40,0 & 6,0 & 150,0 & 6,7 \\
\hline 09/01/2007 & 8,2 & 8,2 & 0,0 & 0,3 & 29,5 & 25,7 & 12,0 & 40,0 & 2,0 & 130,0 & 6,7 \\
\hline $11 / 01 / 2007$ & 8,3 & 8,3 & 0,0 & 0,1 & 28,9 & 25,1 & 13,0 & 35,0 & 2,0 & 130,0 & 6,6 \\
\hline $12 / 01 / 2007$ & 8,3 & 8,3 & 6,6 & 0,1 & 28,2 & 26,4 & 14,0 & 40,0 & 5,0 & 144,0 & 6,6 \\
\hline $15 / 01 / 2007$ & 8,3 & 8,3 & 0,0 & 0,3 & 22,8 & 23,5 & 13,0 & 35,0 & 11,0 & 125,0 & 6,6 \\
\hline $16 / 01 / 2007$ & 8,2 & 8,3 & 0,0 & 0,3 & 21,9 & 23,0 & 13,0 & 35,0 & 13,0 & 115,0 & 6,5 \\
\hline $18 / 01 / 2007$ & 8,1 & 8,2 & 0,0 & 0,2 & 32,7 & 32,8 & 12,0 & 36,0 & & 104,0 & 6,2 \\
\hline 19/01/2007 & 8,1 & 8,2 & 0,0 & 0,2 & 31,9 & 31,9 & 13,0 & 36,0 & 3,0 & 118,0 & 6,4 \\
\hline $22 / 01 / 2007$ & 8,1 & 8,2 & 0,0 & 0,4 & 30,6 & 30,8 & 13,0 & 37,0 & 3,0 & 108,0 & 6,4 \\
\hline 23/01/2007 & 8,1 & 8,2 & 0,0 & 0,4 & 30,7 & 30,1 & 13,0 & 37,0 & 3,0 & 118,0 & 6,3 \\
\hline 24/01/2007 & 8,1 & 8,1 & 0,0 & 0,2 & 27,4 & 28,5 & 12,0 & 38,0 & 5,0 & 110,0 & 6,3 \\
\hline 29/01/2007 & 8,1 & 8,2 & 0,0 & 1,1 & 25,0 & 24,8 & 13,0 & 40,0 & 3,0 & 106,0 & 6,6 \\
\hline $30 / 01 / 2007$ & 8,1 & 8,2 & 0,0 & 1,2 & 24,2 & 24,1 & 13,0 & 40,0 & & 102,0 & 6,7 \\
\hline
\end{tabular}


APÊNDICE E - RESULTADOS DO MONITORAMENTO SEMANAL DO SISTEMA TOTAL 
Tabela E.1 - Resultados do Monitoramento Semanal do Sistema TOTAL ("T") na $1^{\text {a }}$ Fase na Pesquisa (Continua)

\begin{tabular}{|c|c|c|c|c|c|c|c|c|c|c|c|c|}
\hline Mês/Ano & $\begin{array}{c}\text { Fenol afl T } \\
(\mathrm{mg} / \mathrm{L})\end{array}$ & $\begin{array}{c}\text { Fenol anox T pré } \\
(\mathrm{mg} / \mathrm{L})\end{array}$ & $\begin{array}{c}\text { Fenol dec } \mathrm{T} \\
(\mathrm{mg} / \mathrm{L})\end{array}$ & $\begin{array}{c}\mathrm{N} \text {-amon afl T } \\
(\mathrm{mg} / \mathrm{L})\end{array}$ & $\begin{array}{c}\text { N-amon anx T pré } \\
(\mathrm{mg} / \mathrm{L})\end{array}$ & $\begin{array}{c}\mathrm{N} \text {-amon aer } \mathrm{T} \\
(\mathrm{mg} / \mathrm{L})\end{array}$ & $\begin{array}{c}\mathrm{N}-\mathrm{amon}+\operatorname{dec} \mathrm{T} \\
(\mathrm{mg} / \mathrm{L})\end{array}$ & $\begin{array}{c}\text { SSV anox T pré } \\
(\mathrm{mg} / \mathrm{L})\end{array}$ & $\begin{array}{c}\text { SSV aer T } \\
(\mathrm{mg} / \mathrm{L})\end{array}$ & $\begin{array}{c}\text { SSV anox T pós } \\
(\mathrm{mg} / \mathrm{L})\end{array}$ & $\begin{array}{c}\text { SSV dec T } \\
(\mathrm{mg} / \mathrm{L})\end{array}$ & $\begin{array}{c}\text { SSV ret T } \\
(\mathrm{mg} / \mathrm{L})\end{array}$ \\
\hline $\begin{array}{l}\text { set/05 } \\
\text { set/05 }\end{array}$ & 61 & 2,6 & 0,0 & 1008 & 232,4 & 121,5 & 17,4 & 6020 & 1370 & 2680 & 1820 & 11450 \\
\hline set/05 & 472 & 56,8 & 0,0 & & & & & 2260 & 83 & 157 & 36 & 5670 \\
\hline set/05 & & & & & & & & 7200 & 690 & 57 & 20 & 11670 \\
\hline $\begin{array}{l}\text { out/05 } \\
\text { out/05 }\end{array}$ & 692 & 0,0 & 0,08 & & & & & 4310 & 3710 & 3770 & 100 & 4990 \\
\hline out/05 & 807 & 25,6 & 0,0 & 1008 & & & 10,2 & 2530 & 2940 & 3050 & 44 & 3540 \\
\hline $\begin{array}{l}\text { out } / 05 \\
\text { out } / 05\end{array}$ & 898 & 0,0 & 0,0 & 560 & & 7,4 & 10,1 & 2870 & 2890 & 3050 & 67 & 2960 \\
\hline out/05 & 746 & 0,0 & 0,0 & 829 & & 3,6 & 6,4 & 2460 & 3370 & 2860 & 18 & 6820 \\
\hline out/05 & & & & 582 & & 1,8 & 3,9 & & & & & \\
\hline out/05 & 651 & 111,8 & 0,0 & 694 & & 0,4 & 11,3 & 2620 & 2940 & 3190 & 295 & 6000 \\
\hline nov/05 & 772 & 0,0 & 0,04 & 560 & & 0,3 & 3,6 & 2740 & 3000 & 2400 & 260 & 5820 \\
\hline nov/05 & & & & 728 & & 0,0 & 2,7 & & & & & \\
\hline nov/05 & & & & 756 & & 72,6 & 8,2 & & & & & \\
\hline nov/05 & 1126 & 5,2 & 0,3 & 974 & & 0,1 & 47,9 & 1400 & 2150 & 3370 & 1760 & 6740 \\
\hline dez/05 & 1373 & 259,0 & 0,04 & 818 & & 0,2 & 3,2 & 6610 & 3690 & 2910 & 150 & 5430 \\
\hline dez/05 & 818 & 164,7 & 0,0 & 739 & & 20,5 & 9,7 & 2510 & 3040 & 5220 & 90 & 7770 \\
\hline dez/05 & 1016 & 123,2 & 0,3 & 538 & & 0,0 & 14,7 & 2520 & 3070 & 4970 & 73 & 2430 \\
\hline dez/05 & & & & 605 & & 0,3 & 23,5 & & & & & \\
\hline $\mathrm{jan} / 06$ & 498 & 82,9 & 0,1 & 896 & & 0,3 & 8,3 & 2850 & 3460 & 2990 & 235 & 8200 \\
\hline $\mathrm{jan} / 06$ & 909 & 48,7 & 0,13 & 806 & & 0,2 & 1,3 & 2640 & 4220 & 3130 & 47 & 5940 \\
\hline $\mathrm{jan} / 06$ & & & & 728 & & 0,2 & 2,1 & & & & & \\
\hline $\mathrm{jan} / 06$ & 1092 & 0,2 & 0,0 & 717 & & 2,1 & 3,9 & 2270 & 2320 & 2830 & 45 & 7880 \\
\hline $\mathrm{jan} / 06$ & & & & 538 & & 1,1 & 4,0 & & & & & \\
\hline $\mathrm{jan} / 06$ & 772 & 0,0 & 0,0 & 1176 & & 47 & 24,8 & 650 & 5040 & 1070 & 45 & 6440 \\
\hline fev/06 & 890 & 0,0 & 0,0 & 616 & & 61,3 & 24,5 & 2980 & 2190 & 2060 & 1370 & 7830 \\
\hline fev/06 & 799 & 0,0 & 0,0 & 560 & & 3,4 & 14,8 & 2680 & 3200 & 2570 & 40 & 6320 \\
\hline fev/06 & 1263 & 1,4 & 0,0 & 582 & & 2,7 & 2,2 & 3085 & 2325 & 2475 & 60 & 6000 \\
\hline fev/06 & & & & 560 & & 7,4 & 3,8 & & & & & \\
\hline fev/06 & 936 & 16,7 & 0,0 & 605 & & 0,0 & 2,6 & 3350 & 2380 & 2620 & 50 & 7130 \\
\hline fev/06 & & & & 582 & & 2,5 & 0,8 & & & & & \\
\hline mar/06 & & & & & & & & & & & & \\
\hline mar/06 & 936 & 0,0 & 0,0 & 896 & & 18,1 & 2,2 & 2960 & 3270 & 2480 & 10 & 7710 \\
\hline mar/06 & & & & 571 & & 0,0 & 15,9 & & & & & \\
\hline mar/06 & 628 & 0,0 & 0,0 & 470 & & 0,2 & 2,6 & 2530 & 2470 & 2790 & 120 & 8470 \\
\hline mar/06 & 803 & 0,0 & 0,0 & 560 & & 0,0 & 0,3 & 2430 & 2130 & 3030 & 65 & 5960 \\
\hline $\begin{array}{l}\mathrm{mar} / 06 \\
\mathrm{mar} / 06\end{array}$ & 1054 & 4,2 & 0,0 & 538 & & 0,0 & 0,6 & 2100 & 1910 & 2010 & 60 & 2630 \\
\hline abr/06 & 848 & 45,6 & 0,0 & 347 & & 0,0 & 4,5 & 2600 & 2610 & 2470 & 50 & 4170 \\
\hline abr/06 & & & & 504 & & 0,0 & 0,2 & & & & & \\
\hline abr/06 & 860 & 0,2 & 0,0 & 470 & & 0,7 & 0,0 & 1240 & 2970 & 1840 & 20 & 8520 \\
\hline abr/06 & & & & 515 & & 0,0 & 0,0 & & & & & \\
\hline abr/06 & 1442 & 4,8 & 0,0 & 470 & & 11,2 & 9,4 & 2130 & 2530 & 2320 & 65 & 7310 \\
\hline $\mathrm{abr} / 06$ & 761 & 0,0 & 0,04 & 616 & & 21,6 & 9,7 & 1925 & 1935 & 1985 & 215 & 2390 \\
\hline
\end{tabular}


Tabela E.1 - Resultados do Monitoramento Semanal do Sistema TOTAL ("T") na $1^{\text {a }}$ Fase na Pesquisa (Continuação)

\begin{tabular}{|c|c|c|c|c|c|c|c|c|c|c|}
\hline Mês/Ano & $\begin{array}{c}\text { N-NO2- anx T pré } \\
(\mathrm{mg} / \mathrm{L})\end{array}$ & $\begin{array}{c}\text { N-NO2- aer T } \\
(\mathrm{mg} / \mathrm{L})\end{array}$ & $\begin{array}{c}\begin{array}{c}\text { N-NO2- anx T pós } \\
(\mathrm{mg} / \mathrm{L})\end{array} \\
\end{array}$ & $\begin{array}{c}\text { N-NO2- dec T } \\
(\mathrm{mg} / \mathrm{L})\end{array}$ & $\begin{array}{c}\text { N-NO2- ret T } \\
(\mathrm{mg} / \mathrm{L})\end{array}$ & $\begin{array}{c}\text { N-NO3- anx T pré } \\
(\mathrm{mg} / \mathrm{L})\end{array}$ & $\begin{array}{c}\text { N-NO3- aer T } \\
(\mathrm{mg} / \mathrm{L})\end{array}$ & $\begin{array}{c}\text { N-NO3- anx T pós } \\
(\mathrm{mg} / \mathrm{L})\end{array}$ & $\begin{array}{c}\text { N-NO3- dec T } \\
(\mathrm{mg} / \mathrm{L})\end{array}$ & $\begin{array}{c}\text { N-NO3- ret T } \\
(\mathrm{mg} / \mathrm{L})\end{array}$ \\
\hline set/05 & 8,9 & 9,3 & 6,8 & 2,1 & 1,5 & 300 & 490 & 600 & 700 & 490 \\
\hline set/05 & 15,7 & 1,1 & 5,1 & 7,4 & 6,7 & 375 & 540 & 430 & 450 & 430 \\
\hline set/05 & 13,9 & 5,1 & 1,7 & 1,6 & 1,5 & 500 & 710 & 720 & 690 & 710 \\
\hline set/05 & 2,2 & 0,4 & 0,6 & 0,7 & 0,8 & 670 & 740 & 830 & 830 & 740 \\
\hline out/05 & 78,5 & 1,2 & 0,9 & 0,6 & 0,8 & 550 & 790 & 790 & 840 & 840 \\
\hline out/05 & 62,3 & 0,1 & 0,8 & 0,8 & 0,9 & 410 & 590 & 670 & 660 & 730 \\
\hline out/05 & 120,0 & 10,6 & 4,3 & 4,5 & 4,6 & & & & & \\
\hline out/05 & 132,5 & 6,5 & 2,1 & 2,5 & 1,2 & & & & & \\
\hline out/05 & 112,9 & 3,8 & 1,0 & 1,1 & 1,0 & & & & & \\
\hline out/05 & 119,5 & 2,9 & 0,8 & 1,3 & 1,0 & & & & & \\
\hline out/05 & 80,9 & 1,9 & 1,4 & 1,2 & 0,9 & 500 & 770 & 720 & 830 & 790 \\
\hline out/05 & 12,1 & 1,6 & 0,7 & 0,6 & 0,6 & 54 & 250 & 180 & 160 & 180 \\
\hline nov/05 & 79,9 & 0,6 & 1,5 & 1,4 & 1,2 & 14 & 230 & 230 & 240 & 200 \\
\hline nov/05 & 104,1 & 0,5 & 1,1 & 0,8 & 1,6 & 19 & 280 & 250 & 270 & 230 \\
\hline nov/05 & 62,6 & 9,7 & 3,2 & 2,3 & 2,1 & 20 & 250 & 270 & 280 & 200 \\
\hline nov/05 & 56,3 & 0,0 & 4,9 & 8,6 & 6,4 & 190 & 320 & 260 & 280 & 270 \\
\hline dez/05 & 0,0 & 0,6 & 0,0 & 0,0 & 0,1 & 10,7 & 164 & 9,6 & 10,4 & 12,8 \\
\hline dez/05 & 0,0 & 1,4 & 2,4 & 0,5 & 0,1 & 16,2 & 76,1 & 27,2 & 29,9 & 14 \\
\hline dez/05 & 3,1 & 0,1 & 1,1 & 0,6 & 0,6 & 42 & 81 & 35,6 & 30,8 & 21,4 \\
\hline dez/05 & 0,0 & 1,9 & 2,1 & 2,4 & 2,7 & 7,4 & 94,2 & 20,2 & 17,3 & 14,6 \\
\hline jan/06 & 0,5 & 1,7 & 1,8 & 5,2 & 4,6 & 14,9 & 71,2 & 56 & 46,2 & 33,6 \\
\hline jan/06 & 0,0 & 0,1 & 1,8 & 4,4 & 1,4 & 9,4 & 9,3 & 12,5 & 22 & 17 \\
\hline jan/06 & 9,6 & 0,0 & 2,9 & 1,7 & 1,6 & 17,6 & 115,0 & 53,2 & 41 & 34 \\
\hline jan/06 & 36,3 & 2,8 & 2,1 & 3,3 & 2,3 & 37,5 & 108 & 89,8 & 83,1 & 70,1 \\
\hline jan/06 & 40,2 & 3,9 & 1,4 & 2,7 & 1,9 & 67,8 & 137 & 133 & 133 & 116 \\
\hline jan/06 & 59,7 & 29,8 & 19,0 & 17,0 & 13,4 & 25,8 & 49,1 & 81,5 & 88,7 & 90,7 \\
\hline fev/06 & 18,1 & 20,3 & 10,5 & 9,0 & 5,4 & 23 & 51,4 & 132,6 & 176,8 & 143,4 \\
\hline fev/06 & 0,6 & 0,7 & 3,5 & 8,5 & 5,9 & 10,4 & 92,0 & 60,4 & 52,2 & 50,0 \\
\hline fev/06 & 0,2 & 0,7 & 2,3 & 1,1 & 0,7 & 15,8 & 59,8 & 65,0 & 74,5 & 77,4 \\
\hline fev/06 & 1,4 & 1,4 & 1,1 & 1,7 & 1,0 & 14,5 & 65,5 & 43,0 & 38,5 & 48,6 \\
\hline fev/06 & 0,2 & 0,2 & 0,8 & 1,7 & 1,0 & 59,4 & 122,2 & 159 & 138 & 141 \\
\hline fev/06 & 0,4 & 1,3 & 0,7 & 4,9 & 1,4 & 3,5 & 43,0 & 25,2 & 51,2 & 45,4 \\
\hline mar/06 & & & & & & & & & & \\
\hline $\mathrm{mar} / 06$ & 5,9 & 2,9 & 0,8 & 2,7 & 1,4 & 76,6 & 189 & 216 & 190 & 192 \\
\hline $\mathrm{mar} / 06$ & 0,0 & 0,6 & 0,7 & 2,0 & 0,8 & 3,3 & 37,8 & 46,6 & 22,2 & 41,6 \\
\hline $\mathrm{mar} / 06$ & 5,0 & 0,0 & 1,0 & 1,5 & 0,2 & 137 & 219 & 161 & 183 & 149 \\
\hline mar/06 & 23,3 & 1,0 & 0,9 & 2,7 & 1,7 & 120 & 81,6 & 291 & 186 & 175 \\
\hline $\mathrm{mar} / 06$ & 0,5 & 0,3 & 0,2 & 1,2 & 0,4 & 30,7 & 64,7 & 53,8 & 47,5 & 56,0 \\
\hline mar/06 & 0,0 & 0,0 & 0,0 & 0,0 & 0,0 & 24,0 & 39,7 & 43,2 & 33,3 & 30,1 \\
\hline $\mathrm{abr} / 06$ & 1,3 & 0,1 & 0,1 & 1,7 & 0,8 & 14,8 & 61,4 & 62,2 & 105 & 101 \\
\hline $\mathrm{abr} / 06$ & 2,7 & 0,0 & 0,0 & 1,9 & 1,0 & 9,4 & 85,7 & 16,3 & 21,4 & 36,0 \\
\hline $\mathrm{abr} / 06$ & 8,7 & 2,6 & 0,8 & 0,3 & 0,4 & 32,7 & 84,1 & 66,9 & 54,1 & 55,7 \\
\hline $\mathrm{abr} / 06$ & 6,1 & 10,6 & 0,0 & 0,0 & 0,0 & 24,6 & 108 & 21,1 & 18,3 & 22,7 \\
\hline abr/06 & 6,0 & 2,1 & 1,1 & 3,1 & 1,9 & 31,0 & 76,7 & 73,6 & 67,5 & 74,5 \\
\hline $\mathrm{abr} / 06$ & 0,2 & 0,1 & 0,7 & 1,8 & 1,6 & 36,4 & 14,2 & 12,9 & 12,7 & 15,3 \\
\hline
\end{tabular}


Tabela E.1 - Resultados do Monitoramento Semanal do Sistema TOTAL ("T") na $1^{\text {a }}$ Fase na Pesquisa (Conclusão)

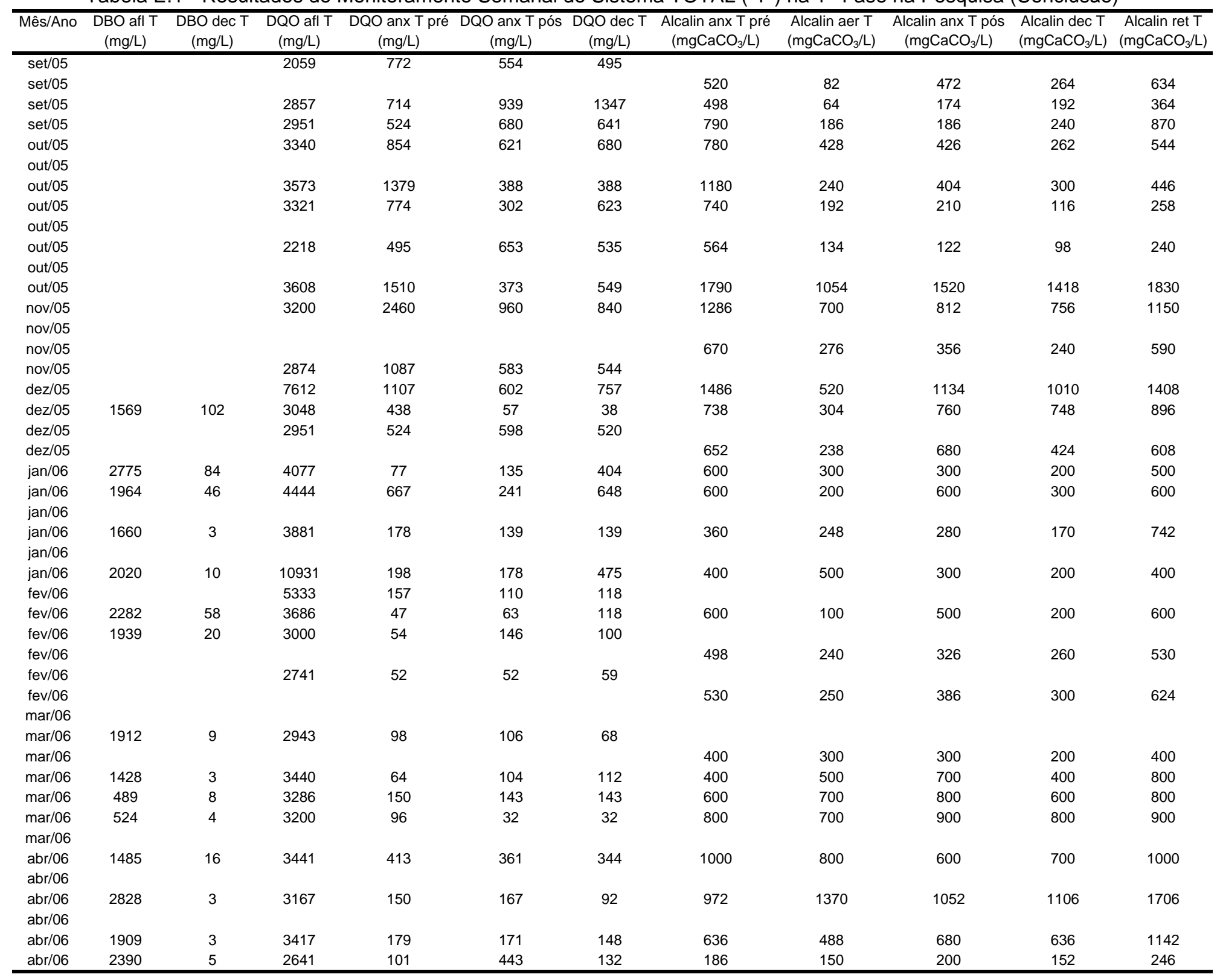


Tabela E.2 - Resultados do Monitoramento Semanal do Sistema TOTAL ("T") na $2^{\mathrm{a}}$ Fase na Pesquisa (Continua)

\begin{tabular}{|c|c|c|c|c|c|c|c|c|c|c|c|c|}
\hline Mês/Ano & $\begin{array}{c}\text { Fenol afl T } \\
(\mathrm{mg} / \mathrm{L})\end{array}$ & $\begin{array}{c}\text { Fenol anox T pré } \\
(\mathrm{mg} / \mathrm{L})\end{array}$ & $\begin{array}{c}\text { Fenol dec T } \\
(\mathrm{mg} / \mathrm{L})\end{array}$ & $\begin{array}{c}\mathrm{N} \text {-amon afl T } \\
(\mathrm{mg} / \mathrm{L})\end{array}$ & $\begin{array}{c}\mathrm{N} \text {-amon anx T pré } \\
(\mathrm{mg} / \mathrm{L})\end{array}$ & $\begin{array}{c}\mathrm{N} \text {-amon aer } \mathrm{T} \\
(\mathrm{mg} / \mathrm{L})\end{array}$ & $\begin{array}{c}\mathrm{N} \text {-amon+ dec T } \\
(\mathrm{mg} / \mathrm{L})\end{array}$ & $\begin{array}{c}\text { SSV anox T pré } \\
(\mathrm{mg} / \mathrm{L})\end{array}$ & $\begin{array}{c}\text { SSV aer T } \\
(\mathrm{mg} / \mathrm{L})\end{array}$ & $\begin{array}{c}\text { SSV anox T pós } \\
(\mathrm{mg} / \mathrm{L})\end{array}$ & $\begin{array}{c}\text { SSV dec T } \\
\text { (mg/L) }\end{array}$ & $\begin{array}{c}\text { SSV ret T } \\
(\mathrm{mg} / \mathrm{L})\end{array}$ \\
\hline mail06 & 902 & 0,0 & 0,0 & 638 & & 7,8 & 4,9 & 1930 & 2530 & 1840 & 35 & 770 \\
\hline mai/06 & 970 & 39,5 & 0,0 & 605 & & 70,3 & 46,0 & 1720 & 1770 & 2760 & 95 & 1420 \\
\hline mai/06 & 1042 & 225,2 & 0,0 & 515 & & 132,8 & & 3860 & 3270 & 2320 & & 5510 \\
\hline mai/06 & 1126 & 0,0 & 0,0 & 571 & & 45,9 & & 3490 & 4030 & 3600 & & 6950 \\
\hline mai/06 & 871 & 0,0 & 0,0 & 683 & & & & & & & & \\
\hline jun/06 & 1016 & 120,9 & 1,1 & 549 & & 23,5 & 2,5 & 2500 & 3140 & 3140 & 65 & 6980 \\
\hline jun/06 & 848 & 0,0 & 0,0 & 650 & & 1,1 & 1,1 & 3760 & 8220 & 3020 & 25 & 6160 \\
\hline jun/06 & 894 & 0,0 & 0,0 & 504 & & 0,0 & 0,0 & 2870 & 2850 & 3230 & 50 & 6760 \\
\hline jun/06 & 833 & 0,0 & 0,0 & 563 & & 0,0 & 0,0 & 2610 & 2980 & 2650 & 0 & 5480 \\
\hline jul/06 & 940 & 12,5 & 0,0 & 549 & & 20,4 & 1,3 & 2620 & 3800 & 3130 & 15 & 650 \\
\hline jul/06 & 1099 & 71,9 & 0,0 & 594 & & 0,0 & 1,7 & 2600 & 2520 & 2420 & 55 & 5080 \\
\hline $\mathrm{jul} / 06$ & 1088 & 0,0 & 0,0 & 549 & & 1,8 & 1,2 & 2020 & 2470 & 2060 & 25 & 4110 \\
\hline $\mathrm{jul} / 06$ & 905 & 17,5 & 0,0 & 549 & & 0,0 & 0,0 & 3110 & 2400 & 2270 & 5 & 1000 \\
\hline jul/06 & 947 & 125,5 & 0,0 & 582 & & 0,0 & 0,0 & 1810 & 2090 & 2770 & 25 & 3760 \\
\hline ago/06 & 864 & 6,9 & 0,0 & 549 & & 15,1 & 0,0 & & & & & \\
\hline ago/06 & 1039 & 32,0 & 0,0 & 661 & & 0,4 & 0,0 & 1920 & 1350 & 1590 & 15 & 3460 \\
\hline ago/06 & 981 & 0,0 & 0,0 & 549 & & 0,9 & 0,0 & 2360 & 1270 & 1160 & 5 & 2340 \\
\hline ago/06 & 1088 & 0,0 & 0,0 & 515 & & 1,2 & 3,5 & 3580 & 1550 & 1470 & 65 & 2360 \\
\hline set/06 & 1061 & 105,4 & 0,0 & 573 & & 3,8 & 0,0 & 3430 & 1990 & 2480 & 105 & 5300 \\
\hline set/06 & 1004 & 43,3 & 0,0 & 560 & & 3,1 & 2,9 & 5080 & 840 & 1870 & 45 & 4810 \\
\hline set/06 & 1225 & 30,8 & 0,0 & 661 & & 2,6 & 0,1 & 3950 & 1190 & 1320 & 35 & 9830 \\
\hline set/06 & 1126 & 28,5 & 0,0 & 470 & & 0,0 & 0,0 & 2430 & 1220 & 2100 & 0 & 7710 \\
\hline out/06 & 962 & 21,3 & 0,0 & 694 & & 0,0 & 1,1 & 5610 & 1940 & 2250 & 20 & 690 \\
\hline out/06 & 761 & 0,0 & 0,0 & 504 & & 5,6 & 5,0 & 6680 & 1390 & 2510 & 44 & 4650 \\
\hline out/06 & 1301 & 73,5 & 0,9 & 616 & & 23,0 & 3,1 & 1160 & 1320 & 4110 & 53 & 14120 \\
\hline out/06 & 974 & 36,2 & 0,0 & 560 & & 21,0 & 5,9 & 1530 & 1610 & 2510 & 54 & 2230 \\
\hline out/06 & 1149 & 2,3 & 0,3 & 644 & & 3,9 & 0,0 & 1550 & 1680 & 1620 & 40 & 1580 \\
\hline nov/06 & 867 & 48,7 & 0,0 & 616 & & 36,4 & 21,0 & 1470 & 1510 & 3170 & 60 & 3620 \\
\hline nov/06 & 1092 & 42,3 & 0,1 & 840 & 71,7 & 43,7 & 27,2 & 1980 & 1720 & 1730 & 62 & 1860 \\
\hline nov/06 & 959 & 0,0 & 0,0 & 532 & 34,7 & 0,8 & 0,0 & 2570 & 1560 & 2320 & 60 & 3720 \\
\hline nov/06 & 1183 & 0,1 & 0,0 & 672 & 60,5 & 0,3 & 0,3 & 1870 & 1600 & 2390 & 56 & 5160 \\
\hline nov/06 & 590 & 0,0 & 0,0 & 420 & 58,2 & 0,3 & 0,0 & & & & & \\
\hline dez/06 & 1084 & 0,0 & 0,0 & 504 & 57,7 & 2,2 & 0,0 & 2610 & 1740 & 1540 & 90 & 6060 \\
\hline dez/06 & 818 & 11,6 & 0,0 & 616 & 83,4 & 3,1 & 0,0 & & & & & \\
\hline dez/06 & 981 & 0,0 & 0,0 & 448 & 35,8 & 2,2 & 0,0 & 2140 & 1760 & 1890 & 90 & 2950 \\
\hline dez/06 & 1004 & 8,6 & 0,0 & 560 & 65,5 & 1,1 & 0,0 & & & & & \\
\hline dez/06 & 959 & 0,0 & 0,0 & 420 & 28,0 & 4,2 & 0,0 & 3330 & 2400 & 2490 & 36 & 3990 \\
\hline dez/06 & 947 & 0,0 & 0,0 & 924 & 79,8 & 5,3 & 0,0 & & & & & \\
\hline jan/07 & 1354 & 0,0 & 0,0 & 1176 & 72,8 & 4,2 & 0,0 & & & & & \\
\hline jan/07 & 1077 & 0,0 & 0,0 & 980 & 68,3 & 4,5 & 1,4 & 5750 & 2880 & 2700 & 40 & 1720 \\
\hline jan/07 & 1058 & 0,0 & 0,0 & 1064 & 75,6 & 4,2 & 0,0 & 3940 & 2810 & 2270 & 30 & 4000 \\
\hline jan/07 & 1210 & 0,0 & 0,3 & 924 & 58,8 & 2,5 & 0,0 & & & & & \\
\hline jan/07 & 1164 & 0,1 & 0,0 & 1008 & 69,4 & 4,2 & 0,6 & 5510 & 3460 & 2860 & 34 & 3860 \\
\hline jan/07 & 943 & 0,0 & 0,0 & 1148 & 76,2 & 2,5 & 0,0 & 5950 & 2070 & 1920 & 30 & 1850 \\
\hline
\end{tabular}


Tabela E.2 - Resultados do Monitoramento Semanal do Sistema TOTAL ("T") na $2^{\text {a }}$ Fase na Pesquisa (Continuação)

\begin{tabular}{|c|c|c|c|c|c|c|c|c|c|c|c|c|}
\hline Mês/Ano & $\begin{array}{c}\text { N-NO2- anx T pré } \\
(\mathrm{mg} / \mathrm{L})\end{array}$ & $\begin{array}{c}\text { N-NO2- aer T } \\
(\mathrm{mg} / \mathrm{L})\end{array}$ & $\begin{array}{c}\text { N-NO2- anx T pós } \\
(\mathrm{mg} / \mathrm{L})\end{array}$ & $\begin{array}{c}\text { N-NO2- dec T } \\
(\mathrm{mg} / \mathrm{L})\end{array}$ & $\begin{array}{c}\text { N-NO2- ret T } \\
(\mathrm{mg} / \mathrm{L})\end{array}$ & $\begin{array}{c}\text { N-NO3- anx T pré } \\
(\mathrm{mg} / \mathrm{L})\end{array}$ & $\begin{array}{c}\text { N-NO3- aer T } \\
(\mathrm{mg} / \mathrm{L})\end{array}$ & $\begin{array}{c}\text { N-NO3- anx T pós } \\
(\mathrm{mg} / \mathrm{L})\end{array}$ & $\begin{array}{c}\text { N-NO3- dec T } \\
(\mathrm{mg} / \mathrm{L})\end{array}$ & $\begin{array}{c}\begin{array}{c}\text { N-NO3- ret T } \\
(\mathrm{mg} / \mathrm{L})\end{array} \\
\end{array}$ & $\begin{array}{c}\text { DBO afl T } \\
(\mathrm{mg} / \mathrm{L})\end{array}$ & $\begin{array}{c}\text { DBO dec T } \\
(\mathrm{mg} / \mathrm{L})\end{array}$ \\
\hline mai/06 & 0,0 & 0,2 & 0,3 & 1,4 & 1,1 & 3,6 & 19,0 & 79,0 & 93,0 & 16,9 & 3969 & 17,0 \\
\hline mai/06 & 0,0 & 7,5 & 1,5 & 3,2 & 2,4 & 113 & 149 & 82 & 79,4 & 68,7 & 2221 & 135 \\
\hline mai/06 & 0,0 & 0,0 & 0,5 & & 0,5 & & & & & & 1694 & \\
\hline mai/06 & 1,3 & 5,7 & 2,4 & & 1,3 & & & & & & 2294 & \\
\hline mai/06 & & & & & & & & & & & 1720 & \\
\hline jun/06 & 0,3 & 0,6 & 0,4 & 7,0 & 5,4 & 17,1 & 139 & 88,4 & 89,2 & 91,9 & 1682 & 4 \\
\hline jun/06 & 4,1 & 0,7 & 0,4 & 4,6 & 0,6 & 30,2 & 104 & 123 & 156 & 114 & 1137 & 28 \\
\hline jun/06 & 5,3 & 0,4 & 0,0 & 0,9 & 0,0 & 21,9 & 79,8 & 89,3 & 81,5 & 71,7 & 1395 & 2 \\
\hline jun/06 & 0,1 & 0,0 & 0,0 & 0,6 & 0,0 & & & & & & 775 & 2 \\
\hline jul/06 & 0,1 & 0,0 & 0,0 & 0,2 & 0,0 & & & & & & 1240 & 1 \\
\hline jul/06 & 0,1 & 0,3 & 0,5 & 0,8 & 0,6 & & & & & & 1683 & 6 \\
\hline jul/06 & 0,3 & 5,1 & 0,4 & 0,7 & 1,6 & & & & & & 1533 & 3 \\
\hline jul/06 & 0,1 & 1,7 & 0,3 & 3,1 & 3,0 & & & & & & 803 & 14 \\
\hline jul/06 & 0,1 & 2,2 & 0,1 & 0,1 & 0,2 & & & & & & 1843 & 28 \\
\hline ago/06 & 0,2 & 0,4 & 0,4 & 0,7 & 0,9 & & & & & & & \\
\hline ago/06 & 0,1 & 0,9 & 0,0 & 0,1 & 0,1 & & & & & & 3230 & 1 \\
\hline ago/06 & 0,1 & 1,3 & 0,3 & 0,5 & 0,4 & 35,6 & 191 & 233 & 243 & 237 & 1160 & 6 \\
\hline ago/06 & 4,7 & 8,9 & 2,2 & 2,1 & 1,7 & 45,5 & 103 & 129 & 132 & 147 & 1041 & 5 \\
\hline set/06 & 0,1 & 7,6 & 11,4 & 15,5 & 8,6 & 22,2 & 125 & 106 & 88,9 & 92,4 & 1148 & 31 \\
\hline set/06 & 0,0 & 6,2 & 7,4 & 8,0 & 5,9 & 22,9 & 149 & 61,9 & 57,7 & 76,6 & 1314 & 24 \\
\hline set/06 & 7,6 & 8,4 & 4,5 & 6,4 & 4,0 & 25,1 & 107 & 96,1 & 70,2 & 63,2 & 148 & 18 \\
\hline set/06 & 0,0 & 7,6 & 9,2 & 8,4 & 5,5 & 16,4 & 68,3 & 47,3 & 46,1 & 57,5 & 438 & 8 \\
\hline out/06 & 0,1 & 0,7 & 4,7 & 5,8 & 4,9 & 14,7 & 81,9 & 48,2 & 48,8 & 47,0 & 1253 & 21 \\
\hline out/06 & 9,2 & 3,1 & 5,9 & 5,5 & 4,5 & 27,4 & 111 & 70,8 & 69,6 & 63,4 & & \\
\hline out/06 & 0,0 & 7,0 & 0,1 & 0,0 & 0,0 & 15,5 & 101 & 14,7 & 16,4 & 14,8 & & \\
\hline out/06 & 11,7 & 4,1 & 3,8 & 1,8 & 1,5 & 30,2 & 58,2 & 43,7 & 45,0 & 39,6 & 659 & 17 \\
\hline out/06 & 2,2 & 0,3 & 0,9 & 0,5 & 0,4 & 47,3 & 55,4 & 52,2 & 50,2 & 54,0 & & \\
\hline nov/06 & 0,0 & 3,0 & 0,0 & 0,0 & 0,0 & 11,6 & 8,9 & 10,7 & 10,0 & 8,6 & 605 & 83 \\
\hline nov/06 & 0,1 & 4,1 & 0,5 & 0,4 & 0,5 & 11,6 & 23,2 & 20,6 & 21,7 & 18,8 & 1409 & 36 \\
\hline nov/06 & 13,0 & 3,2 & 2,1 & 4,7 & 3,9 & 93,2 & 133 & 128 & 124 & 130 & 1041 & 76 \\
\hline nov/06 & 12,3 & 0,1 & 0,5 & 0,3 & 0,2 & 30,4 & 149 & 139 & 140 & 115 & 1040 & 85 \\
\hline nov/06 & 10,1 & 0,0 & 0,3 & 0,3 & 0,5 & 36,4 & 120 & 103 & 103 & 101 & & \\
\hline dez/06 & 12,7 & 0,0 & 0,1 & 0,1 & 0,2 & 16,6 & 38,8 & 45 & 46,6 & 51,6 & 756 & 12 \\
\hline dez/06 & 0,0 & 0,1 & 0,0 & 0,2 & 0,0 & 21,5 & 104 & 120 & 110 & 112 & & \\
\hline dez/06 & 1,6 & 0,0 & 0,0 & 0,1 & 0,0 & 25,8 & 60,9 & 63,1 & 64,4 & 60,3 & 793 & 41 \\
\hline dez/06 & 0,0 & 0,0 & 0,0 & 0,1 & 0,0 & 14,2 & 80,5 & 68,9 & 78,7 & 54,5 & & \\
\hline dez/06 & 0,9 & 0,0 & 0,1 & 0,1 & 0,1 & 53,1 & 89,8 & 89,4 & 89,4 & 58,3 & & \\
\hline dez/06 & 1,4 & 0,1 & 0,1 & 0,2 & 0,1 & 14,8 & 118 & 98,7 & 109,2 & 114 & & \\
\hline $\mathrm{jan} / 07$ & 2,1 & 0,0 & 0,0 & 0,1 & 0,0 & 124 & 239 & 230 & 217 & 161 & & \\
\hline $\mathrm{jan} / 07$ & 0,9 & 0,0 & 0,1 & 0,1 & 0,1 & 56,0 & 80,2 & 76,0 & 79,0 & 74,4 & 1197 & 18 \\
\hline $\mathrm{jan} / 07$ & 3,0 & 0,1 & 0,0 & 0,1 & 0,0 & 167 & 241 & 224 & 221 & 221 & 2923 & 144 \\
\hline $\mathrm{jan} / 07$ & 0,1 & 0,0 & 0,0 & 0,1 & 0,1 & 129 & 154 & 178 & 167 & 169 & & \\
\hline $\mathrm{jan} / 07$ & 0,7 & 0,0 & 0,1 & 0,1 & 0,1 & 86,2 & 118 & 112 & 50,8 & 44,2 & & \\
\hline $\mathrm{jan} / 07$ & 0,0 & 0,0 & 0,0 & 0,0 & 0,0 & 62,8 & 98,4 & 87,2 & 84 & 85,2 & & \\
\hline
\end{tabular}


Tabela E.2 - Resultados do Monitoramento Semanal do Sistema TOTAL ("T") na 2 ${ }^{\text {a }}$ Fase na Pesquisa (Conclusão)

\begin{tabular}{|c|c|c|c|c|c|c|c|c|c|}
\hline Mês/Ano & $\begin{array}{c}\text { DQO afl T } \\
(\mathrm{mg} / \mathrm{L})\end{array}$ & $\begin{array}{c}\text { DQO anx T pré } \\
(\mathrm{mg} / \mathrm{L})\end{array}$ & $\begin{array}{c}\text { DQO anx T pós } \\
(\mathrm{mg} / \mathrm{L})\end{array}$ & $\begin{array}{c}\text { DQO dec T } \\
(\mathrm{mg} / \mathrm{L})\end{array}$ & $\begin{array}{c}\text { Alcalin anx T pré } \\
\left(\mathrm{mgCaCO}_{3} / \mathrm{L}\right)\end{array}$ & $\begin{array}{l}\text { Alcalin aer T } \\
\left(\mathrm{mgCaCO}_{3} / \mathrm{L}\right)\end{array}$ & $\begin{array}{c}\text { Alcalin anx T pós } \\
\left(\mathrm{mgCaCO}_{3} / \mathrm{L}\right)\end{array}$ & $\begin{array}{l}\text { Alcalin dec T } \\
\left(\mathrm{mgCaCO}_{3} / \mathrm{L}\right)\end{array}$ & $\begin{array}{c}\text { Alcalin ret T } \\
\left(\mathrm{mgCaCO}_{3} / \mathrm{L}\right)\end{array}$ \\
\hline mai/06 & 3048 & 107 & 76 & 46 & 210 & 50 & 136 & 170 & 160 \\
\hline mai/06 & 5053 & 362 & 168 & 152 & 950 & 852 & 994 & 796 & 950 \\
\hline mai/06 & 2133 & 324 & 152 & & 680 & 660 & 764 & & 864 \\
\hline mai/06 & 2943 & 181 & 204 & & 370 & 194 & 272 & & 250 \\
\hline mai/06 & 4400 & & & & & & & & \\
\hline jun/06 & 3010 & 372 & 158 & 135 & 686 & 160 & 344 & 190 & 538 \\
\hline jun/06 & 2718 & 109 & 85 & 70 & 414 & 134 & 116 & 70 & 284 \\
\hline jun/06 & 1724 & 76 & 83 & 62 & 378 & 262 & 148 & 118 & 210 \\
\hline jun/06 & 2692 & 77 & 62 & 69 & 388 & 232 & 136 & 86 & 226 \\
\hline $\mathrm{jul} / 06$ & 2902 & 110 & 102 & 31 & 474 & 166 & 162 & 78 & 88 \\
\hline $\mathrm{jul} / 06$ & 2538 & 192 & 69 & 77 & 618 & 250 & 166 & 130 & 242 \\
\hline jul/06 & 2766 & 52 & 30 & 45 & 464 & 184 & 130 & 94 & 112 \\
\hline jul/06 & 2593 & 296 & 393 & 422 & 822 & 570 & 852 & 762 & 790 \\
\hline \multicolumn{10}{|l|}{ ago/06 } \\
\hline ago/06 & 3170 & 189 & 113 & 98 & 504 & 112 & 94 & 56 & 118 \\
\hline ago/06 & 3168 & 48 & 135 & 297 & 532 & 104 & 82 & 58 & 116 \\
\hline ago/06 & 3686 & 98 & 133 & 102 & 350 & 82 & 148 & 110 & 156 \\
\hline set/06 & 3615 & 327 & 154 & 77 & 564 & 146 & 514 & 536 & 628 \\
\hline set/06 & 2951 & 184 & 117 & 78 & 406 & 98 & 228 & 218 & 356 \\
\hline set/06 & 2308 & 115 & 62 & 23 & 346 & 74 & 168 & 112 & 276 \\
\hline set/06 & 4038 & 124 & 46 & 122 & 250 & 198 & 168 & 116 & 282 \\
\hline out/06 & 3089 & 129 & 127 & 143 & 362 & 110 & 194 & 146 & 148 \\
\hline out/06 & 1613 & 169 & 105 & 81 & 376 & 86 & 198 & 166 & 224 \\
\hline out/06 & 3010 & 307 & 475 & 475 & 432 & 102 & 540 & 384 & 778 \\
\hline out/06 & 2097 & 311 & 311 & 97 & 398 & 230 & 276 & 290 & 292 \\
\hline out/06 & 3728 & 233 & 214 & 179 & 138 & 164 & 104 & 68 & 90 \\
\hline nov/06 & 2308 & 337 & 346 & 58 & 142 & 70 & 178 & 128 & 182 \\
\hline nov/06 & 2535 & 139 & 89 & 59 & 152 & 590 & 92 & 42 & 82 \\
\hline nov/06 & 2535 & 158 & 149 & 129 & 224 & 88 & 116 & 92 & 156 \\
\hline \multicolumn{10}{|l|}{ nov/06 } \\
\hline $\begin{array}{l}\mathrm{dez} / 06 \\
\mathrm{dez} / 06\end{array}$ & \multicolumn{8}{|c|}{ dez/06 } & 142 \\
\hline dez/06 & 2415 & 128 & 226 & 128 & 224 & 170 & 110 & 94 & 134 \\
\hline \multicolumn{10}{|l|}{$\mathrm{dez} / 06$} \\
\hline \multicolumn{10}{|l|}{ dez/06 } \\
\hline jan/07 & & & & & 274 & 124 & 120 & 90 & 114 \\
\hline jan/07 & & & & & 282 & 150 & 128 & 86 & 216 \\
\hline \multicolumn{10}{|l|}{$\mathrm{jan} / 07$} \\
\hline \multicolumn{10}{|l|}{ jan/07 } \\
\hline $\mathrm{jan} / 07$ & & & & & 274 & 112 & 134 & 124 & 182 \\
\hline $\mathrm{jan} / 07$ & & & & & 314 & 98 & 150 & 110 & 148 \\
\hline
\end{tabular}


APÊNDICE F - RESULTADOS DO MONITORAMENTO SEMANAL DO SISTEMA PARCIAL 
Tabela F.1 - Resultados do Monitoramento Semanal do Sistema PARCIAL ("P") na $1^{\text {a }}$ Fase na Pesquisa (Continua)

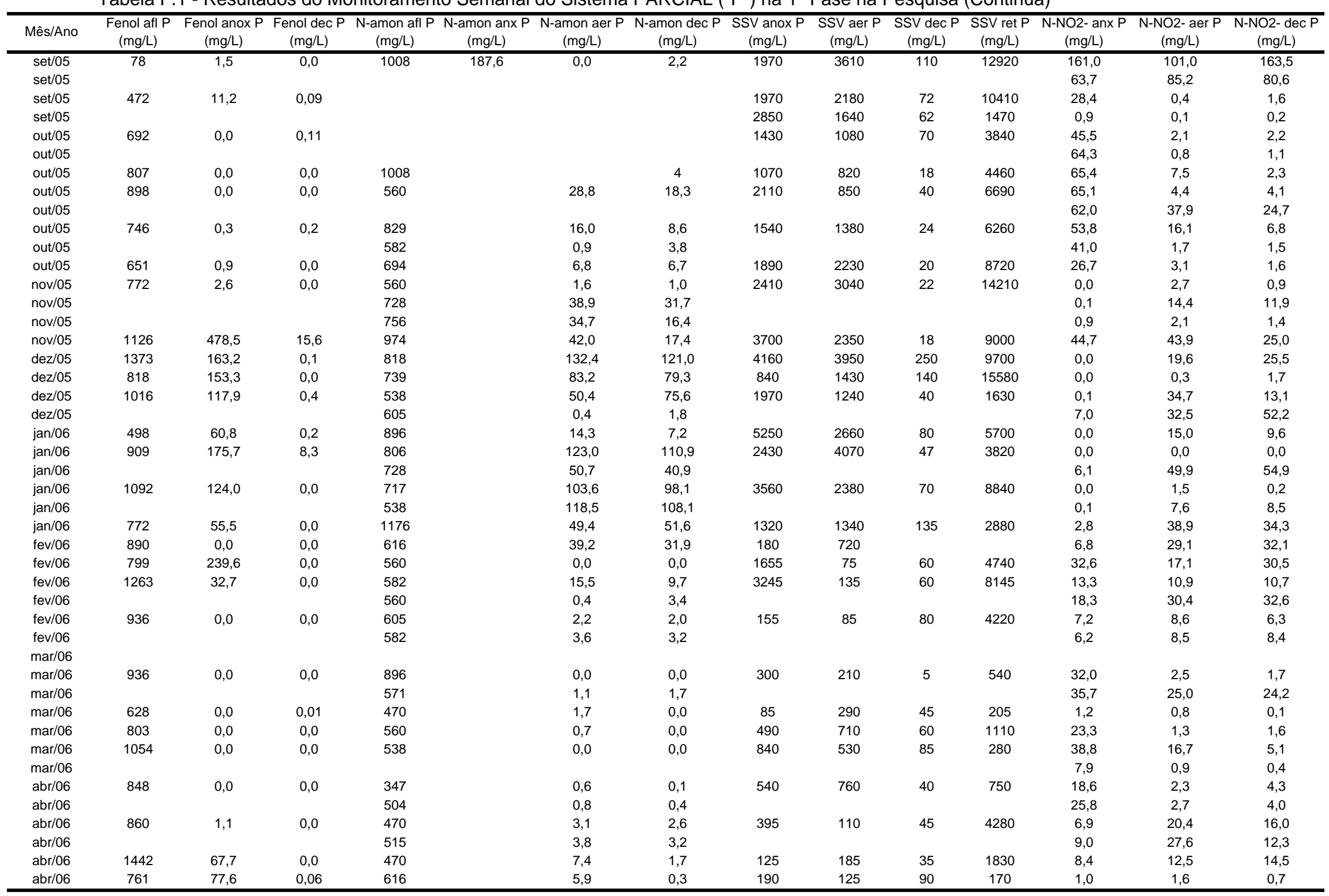


Tabela F.1 - Resultados do Monitoramento Semanal do Sistema PARCIAL ("P") na $1^{\mathrm{a}}$ Fase na Pesquisa (Conclusão)

\begin{tabular}{|c|c|c|c|c|c|c|c|c|c|c|c|c|c|c|}
\hline Mês/Ano & $\begin{array}{c}\text { N-NO2- ret P } \\
(\mathrm{mg} / \mathrm{L})\end{array}$ & $\begin{array}{c}\begin{array}{c}\text { N-NO3- anx } \\
(m g / L)\end{array} \\
\end{array}$ & $\begin{array}{c}\text { N-NO3- aer P } \\
(\mathrm{mg} / \mathrm{L})\end{array}$ & $\begin{array}{c}\text { N-NO3- dec P } \\
(\mathrm{mg} / \mathrm{L})\end{array}$ & $\begin{array}{c}\mathrm{N}-\mathrm{NO}-\text { ret P } \\
(\mathrm{mg} / \mathrm{L})\end{array}$ & $\begin{array}{c}\text { DBO afl P } \\
(\mathrm{mg} / \mathrm{L})\end{array}$ & $\begin{array}{c}\text { DBO dec } \mathrm{P} \\
(\mathrm{mg} / \mathrm{L})\end{array}$ & $\begin{array}{c}\text { DQO afl P } \\
(\mathrm{mg} / \mathrm{L})\end{array}$ & $\begin{array}{c}\text { DQO anx P } \\
(\mathrm{mg} / \mathrm{L})\end{array}$ & $\begin{array}{c}\text { DQO dec P } \\
(\mathrm{mg} / \mathrm{L})\end{array}$ & $\begin{array}{l}\text { Alcalin anx P } \\
\left(\mathrm{mgCaCO}_{3} / \mathrm{L}\right)\end{array}$ & $\begin{array}{c}\text { Alcalin aer } \mathrm{P} \\
\left(\mathrm{mgCaCO}_{3} / \mathrm{L}\right)\end{array}$ & $\begin{array}{l}\text { Alcalin dec P } \\
\left(\mathrm{mgCaCO}_{3} / \mathrm{L}\right)\end{array}$ & $\begin{array}{c}\text { Alcalin ret P } \\
\left(\mathrm{mgCaCO}_{3} / \mathrm{L}\right)\end{array}$ \\
\hline set/05 & 154,4 & 110 & 310 & 200 & 150 & & & 2059 & 931 & 1109 & & & & \\
\hline set/05 & 55,3 & 215 & 470 & 430 & 280 & & & & & & 704 & 546 & 408 & 1196 \\
\hline set/05 & 0,5 & 380 & 650 & 640 & 530 & & & 2857 & 2163 & 3082 & 504 & 320 & 246 & 786 \\
\hline set/05 & 0,6 & 470 & 610 & 620 & 570 & & & 2951 & 796 & 583 & 390 & 352 & 250 & 508 \\
\hline out/05 & 0,4 & 410 & 590 & 580 & 690 & & & 3340 & 2602 & 1165 & 838 & 546 & 454 & 730 \\
\hline out/05 & 0,9 & 420 & 520 & 420 & 370 & & & & & & & & & \\
\hline out/05 & 2,5 & & & & & & & 3573 & 1786 & 136 & 1196 & 626 & 600 & 972 \\
\hline out/05 & 3,1 & & & & & & & 3321 & 453 & 321 & 912 & 254 & 260 & 736 \\
\hline out/05 & 11,5 & & & & & & & & & & & & & \\
\hline out/05 & 8,6 & & & & & & & 2218 & 356 & 386 & 566 & 156 & 88 & 230 \\
\hline out/05 & 3,6 & 70 & 250 & 670 & 270 & & & & & & & & & \\
\hline out/05 & 4,9 & 21 & 170 & 180 & 170 & & & 3608 & 314 & 78 & 1150 & 808 & 648 & 1330 \\
\hline nov/05 & 8,0 & 8 & 148 & 148 & 128 & & & 3200 & 480 & 440 & 1568 & 964 & 840 & 1582 \\
\hline nov/05 & 12,9 & 6,6 & 88 & 104 & 104 & & & & & & & & & \\
\hline nov/05 & 1,8 & 5,2 & 192 & 220 & 240 & & & & & & 1284 & 1136 & 1086 & 1858 \\
\hline nov/05 & 19,5 & 70 & 150 & 195 & 180 & & & 2874 & 1282 & 466 & & & & \\
\hline dez/05 & 16,8 & 14,4 & 12,92 & 33 & 75 & & & 7612 & 544 & 369 & 3022 & 2958 & 2726 & 3102 \\
\hline dez/05 & 0,4 & 13 & 12,5 & 11,7 & 12,4 & 1569 & 13 & 3048 & 400 & 114 & 2420 & 2684 & 2684 & 3660 \\
\hline dez/05 & 13,1 & 13,8 & 19 & 14,6 & 14,6 & & & 2951 & 447 & 660 & & & & \\
\hline dez/05 & 40,7 & 13,9 & 43,9 & 66,6 & 54,6 & & & & & & 2566 & 2600 & 2440 & 2646 \\
\hline $\mathrm{jan} / 06$ & 6,2 & 13,7 & 72,6 & 102,6 & 78,2 & 2775 & 36 & 4077 & 115 & 288 & 2500 & 2000 & 1700 & 2100 \\
\hline $\mathrm{jan} / 06$ & 1,8 & 23,3 & 15,7 & 13,9 & 11,8 & 1964 & 64 & 4444 & 685 & 352 & 2500 & 2500 & 2500 & 2500 \\
\hline $\mathrm{jan} / 06$ & 33,3 & 14,1 & 24,4 & 34,3 & 30,6 & & & & & & & & & \\
\hline $\mathrm{jan} / 06$ & 0,7 & 33,9 & 41,6 & 40,8 & 40,6 & 1660 & 37 & 3881 & 297 & 139 & 1900 & 2400 & 2300 & 3000 \\
\hline $\mathrm{jan} / 06$ & 0,7 & 35,9 & 27,1 & 32,1 & 31,0 & & & & & & & & & \\
\hline $\mathrm{jan} / 06$ & 18,9 & 20,6 & 27,6 & 27,4 & 26,3 & 2020 & 16 & 10931 & 238 & 386 & 2400 & 2400 & 2400 & 2500 \\
\hline fev/06 & 28,3 & 18,9 & 21,2 & 32,3 & 30,3 & & & 5333 & & & & & & \\
\hline fev/06 & 27,4 & 19,7 & 40,8 & 30,4 & 30,0 & 2282 & 79 & 3686 & 118 & 94 & 1100 & 1000 & 1000 & 1500 \\
\hline fev/06 & 11,4 & 43,0 & 60,8 & 99,8 & 78,9 & 1939 & 37 & 3000 & 231 & 54 & & & & \\
\hline fev/06 & 13,5 & 30,2 & 64,0 & 82,3 & 59,6 & & & & & & 1520 & 1246 & 1180 & 2146 \\
\hline fev/06 & 6,0 & 65,5 & 135 & 162 & 116 & & & 2741 & 111 & 81 & & & & \\
\hline fev/06 & 8,5 & 12,9 & 60,2 & 58,2 & 31,2 & & & & & & 1472 & 1434 & 1414 & 1700 \\
\hline mar/06 & & & & & & & & & & & & & & \\
\hline mar/06 & 1,4 & 88,6 & 272 & 254 & 264 & 1912 & 0 & 2943 & 106 & 83 & & & & \\
\hline mar/06 & 25,7 & 37,0 & 122 & 106 & 66,8 & & & & & & 700 & 600 & 900 & 800 \\
\hline mar/06 & 0,1 & 160 & 217 & 242 & 202 & 1428 & 5 & 3440 & 48 & 48 & 600 & 500 & 600 & 400 \\
\hline mar/06 & 1,0 & 96,6 & 99,8 & 347 & 106 & 489 & 3 & 3286 & 121 & 79 & 800 & 600 & 600 & 600 \\
\hline mar/06 & 10,0 & 56,2 & 96,4 & 167 & 17,0 & 524 & 3 & 3200 & 141 & 32 & 600 & 500 & 700 & 600 \\
\hline mar/06 & 0,3 & 103 & 114 & 173 & 152 & & & & & & & & & \\
\hline abr/06 & 2,9 & 6,0 & 35,2 & 41,6 & 33,8 & 1485 & 6 & 3441 & 387 & 344 & 600 & 500 & 600 & 600 \\
\hline abr/06 & 5,1 & 6,7 & 48,6 & 36,2 & 44,6 & & & & & & & & & \\
\hline abr/06 & 18,1 & 40,1 & 74,6 & 146 & 80,8 & 2828 & 5 & 3167 & 142 & 108 & 838 & 700 & 710 & 1032 \\
\hline abr/06 & 16,1 & 76,2 & 84,1 & 86,3 & 97,4 & & & & & & & & & \\
\hline abr/06 & 12,3 & 56,2 & 60,2 & 145,6 & 54,6 & 1909 & 9 & 3417 & 249 & 171 & 380 & 134 & 140 & 240 \\
\hline abr/06 & 0,6 & 22,9 & 80,9 & 149 & 102 & 2390 & 9 & 2641 & 93 & 78 & 640 & 472 & 454 & 450 \\
\hline
\end{tabular}


Tabela F.2 - Resultados do Monitoramento Semanal do Sistema PARCIAL ("P") na $2^{\mathrm{a}}$ Fase na Pesquisa (Continua)

\begin{tabular}{|c|c|c|c|c|c|c|c|c|c|c|c|c|c|c|}
\hline Mês/Ano & $\begin{array}{c}\text { Fenol afl P } \\
(\mathrm{mg} / \mathrm{L})\end{array}$ & $\begin{array}{c}\text { Fenol anox } \mathrm{P} \\
(\mathrm{mg} / \mathrm{L})\end{array}$ & $\begin{array}{c}\text { Fenol dec P } \\
(\mathrm{mg} / \mathrm{L})\end{array}$ & $\begin{array}{c}\mathrm{N} \text {-amon afl } \mathrm{P} \\
(\mathrm{mg} / \mathrm{L})\end{array}$ & $\begin{array}{c}\mathrm{N} \text {-amon anx } \mathrm{P} \\
(\mathrm{mg} / \mathrm{L})\end{array}$ & $\begin{array}{c}\mathrm{N} \text {-amon aer } \mathrm{P} \\
(\mathrm{mg} / \mathrm{L})\end{array}$ & $\begin{array}{c}\mathrm{N} \text {-amon dec } \mathrm{P} \\
(\mathrm{mg} / \mathrm{L})\end{array}$ & $\begin{array}{c}\text { SSV anox P } \\
(\mathrm{mg} / \mathrm{L})\end{array}$ & $\begin{array}{c}\text { SSV aer } \mathrm{P} \\
(\mathrm{mg} / \mathrm{L})\end{array}$ & $\begin{array}{c}\text { SSV dec P } \\
(\mathrm{mg} / \mathrm{L})\end{array}$ & $\begin{array}{c}\text { SSV ret P } \\
\text { (mg/L) }\end{array}$ & $\begin{array}{c}\text { N-NO2- anx P } \\
(\mathrm{mg} / \mathrm{L})\end{array}$ & $\begin{array}{c}\text { N-NO2- aer P } \\
(\mathrm{mg} / \mathrm{L})\end{array}$ & $\begin{array}{c}\text { N-NO2- dec P } \\
(\mathrm{mg} / \mathrm{L})\end{array}$ \\
\hline mai/06 & 902 & 0,0 & 0,0 & 638 & & 0,0 & 0,0 & 380 & 60 & $\overline{5}$ & 1100 & 0,6 & 1,3 & 0,4 \\
\hline mai/06 & 970 & 93,6 & 0,0 & 605 & & 65,5 & 53,4 & 1290 & 695 & 75 & 400 & 0,2 & 0,3 & 0,5 \\
\hline mai/06 & 1042 & 113,3 & 0,0 & 515 & & 0,0 & 0,0 & 3270 & 1840 & 65 & 1360 & 0,0 & 1,1 & 0,8 \\
\hline mai/06 & 1126 & 0,0 & 0,0 & 571 & & 0,0 & 0,0 & 1410 & 1010 & 50 & 3690 & 2,2 & 0,7 & 0,4 \\
\hline mai/06 & 871 & 0,0 & 0,0 & 683 & & 4,0 & 2,9 & 1000 & 530 & 15 & 4340 & 0,0 & 9,5 & 12,3 \\
\hline jun/06 & 1016 & 168,9 & 1,3 & 549 & & 4,0 & 2,9 & 930 & 230 & 15 & 5210 & 0,2 & 1,0 & 0,5 \\
\hline jun/06 & 848 & 0,0 & 0,0 & 650 & & 0,2 & 0,0 & 730 & 550 & 35 & 4720 & 22,1 & 12,6 & 0,4 \\
\hline jun/06 & 894 & 0,0 & 0,0 & 504 & & 0,1 & 0,0 & 2870 & 450 & 35 & 3150 & 0,5 & 4,1 & 4,5 \\
\hline jun/06 & 833 & 0,0 & 0,01 & 563 & & 1,0 & 0,0 & 800 & 760 & 40 & 1440 & 0,3 & 1,1 & 0,1 \\
\hline jul/06 & 940 & 11,0 & 0,0 & 549 & & 1,7 & 0,0 & 560 & 380 & 35 & 390 & 2,4 & 2,8 & 1,5 \\
\hline jul/06 & 1099 & 76,8 & 0,0 & 594 & & 0,0 & 0,0 & 1150 & 1560 & 30 & 6920 & 0,0 & 0,0 & 0,0 \\
\hline jul/06 & 1088 & 0,0 & 0,0 & 549 & & 0,0 & 0,0 & 1320 & 1450 & 30 & 810 & 0,5 & 0,5 & 0,1 \\
\hline $\mathrm{jul} / 06$ & 905 & 119,4 & 0,0 & 549 & & 2,5 & 12,3 & 1520 & 1500 & 55 & 3020 & 0,0 & 0,4 & 0,6 \\
\hline jul/06 & 947 & 156,7 & 0,0 & 582 & & 0,1 & 0,0 & 1590 & 1500 & 15 & 4880 & 0,9 & 1,3 & 0,5 \\
\hline ago/06 & 864 & 66,2 & 0,0 & 549 & & 3,5 & 0,0 & & & & & 0,1 & 0,1 & 0,3 \\
\hline ago/06 & 1039 & 57,8 & 0,0 & 661 & & 49,7 & 42,9 & 1680 & 1950 & 5 & 6520 & 0,5 & 0,4 & 0,7 \\
\hline ago/06 & 981 & 0,0 & 0,0 & 549 & & 0,0 & 0,0 & 2050 & 1780 & 15 & 3130 & 0,6 & 0,9 & 0,3 \\
\hline ago/06 & 1088 & 11,0 & 0,0 & 515 & & 0,0 & 0,0 & 3420 & 2060 & 55 & 5370 & 1,4 & 0,8 & 0,1 \\
\hline set/06 & 1061 & 82,0 & 0,0 & 573 & & 0,4 & 0,0 & 2580 & 1890 & 140 & 4260 & 0,4 & 2,1 & 0,3 \\
\hline set/06 & 1004 & 37,6 & 0,0 & 560 & & 0,9 & 0,0 & 2080 & 1580 & 0 & 7160 & 0,1 & 0,2 & 0,1 \\
\hline set/06 & 1225 & 46,1 & 0,0 & 661 & & 1,5 & 0,0 & 2530 & 1730 & 40 & 5210 & 0,0 & 0,5 & 0,1 \\
\hline set/06 & 1126 & 41,4 & 0,1 & 470 & & 0,0 & 0,0 & 1320 & 1540 & 7 & 3790 & 0,0 & 0,8 & 0,2 \\
\hline out/06 & 962 & 21,7 & 0,0 & 694 & & 25,3 & 17,9 & 2730 & 2580 & 30 & 370 & 13,6 & 3,7 & 2,6 \\
\hline out/06 & 761 & 0,0 & 0,0 & 504 & & 7,0 & 3,9 & 1790 & 2150 & 14 & 6990 & 10,3 & 1,0 & 1,0 \\
\hline out/06 & 1301 & 93,2 & 0,0 & 616 & & 5,6 & 0,8 & 1990 & 1980 & 50 & 6500 & 0,0 & 4,9 & 2,3 \\
\hline out/06 & 974 & 77,6 & 0,1 & 560 & & 30,0 & 15,7 & 1700 & 1410 & 18 & 1610 & 0,1 & 21,3 & 21,2 \\
\hline out/06 & 1149 & 13,4 & 0,0 & 644 & & 55,7 & 43,1 & 1360 & 1780 & 24 & 2600 & 0,0 & 3,5 & 5,7 \\
\hline nov/06 & 867 & 80,9 & 0,0 & 616 & & 94,1 & 82,3 & 1630 & 1210 & 20 & 4730 & 0,0 & 4,3 & 3,5 \\
\hline nov/06 & 1092 & 82,0 & 0,6 & 840 & 170,2 & 79,8 & 71,7 & 1430 & 2130 & 34 & 2990 & 0,1 & 48,9 & 50,9 \\
\hline nov/06 & 959 & 1,4 & 0,0 & 532 & 105,3 & 8,4 & 0,0 & 2110 & 1670 & 14 & 5030 & 1,8 & 77,3 & 83,0 \\
\hline nov/06 & 1183 & 0,0 & 0,0 & 672 & 35,8 & 9,0 & 0,0 & 1940 & 1950 & 14 & 5350 & 42,1 & 56,5 & 57,8 \\
\hline nov/06 & 590 & 0,0 & 0,0 & 420 & 46,5 & 7,6 & 0,0 & & & & & 19,6 & 31,1 & 43,6 \\
\hline dez/06 & 1084 & 0,1 & 0,1 & 504 & 43,1 & 7,0 & 0,0 & 1850 & 1840 & 90 & 450 & 17,7 & 24,3 & 26,0 \\
\hline dez/06 & 818 & 0,0 & 0,0 & 616 & 30,8 & 6,7 & 0,0 & & & & & 24,3 & 20,3 & 17,2 \\
\hline dez/06 & 981 & 0,0 & 0,0 & 448 & 24,1 & 0,0 & 0,0 & 1100 & 1320 & 14 & 2530 & 1,7 & 5,6 & 4,9 \\
\hline dez/06 & 1004 & 3,2 & 0,0 & 560 & 28,6 & 0,0 & 0,0 & & & & & 0,4 & 9,1 & 7,1 \\
\hline dez/06 & 959 & 12,7 & 0,0 & 420 & 29,4 & 0,0 & 0,0 & 1860 & 2300 & 18 & 4010 & 12,1 & 12,0 & 9,3 \\
\hline dez/06 & 947 & 0,9 & 0,0 & 924 & 37,5 & 2,8 & 0,0 & & & & & 32,6 & 39,6 & 33,5 \\
\hline jan/07 & 1354 & 0,1 & 0,1 & 1176 & 44,8 & 0,6 & 0,0 & & & & & 3,0 & 17,8 & 17,6 \\
\hline jan/07 & 1077 & 0,0 & 0,0 & 980 & 48,2 & 0,0 & 0,0 & 1450 & 1390 & 70 & 2930 & 3,9 & 15,6 & 18,4 \\
\hline jan/07 & 1058 & 0,0 & 0,0 & 1064 & 58,8 & 0,8 & 0,0 & 1830 & 2140 & 47 & 5010 & 0,7 & 27,2 & 25,9 \\
\hline jan/07 & 1210 & 0,0 & 0,0 & 924 & 57,7 & 2,5 & 0,0 & & & & & 1,9 & 15,7 & 14,9 \\
\hline jan/07 & 1164 & 0,1 & 0,1 & 1008 & 65,0 & 1,1 & 0,0 & 2540 & 1530 & 22 & 6300 & 1,3 & 23,5 & 23,3 \\
\hline jan/07 & 943 & 0,0 & 0,0 & 1148 & 57,1 & 0,0 & 0,0 & 1370 & 1400 & 32 & 5670 & 1,7 & 2,1 & 4,4 \\
\hline
\end{tabular}


Tabela F.2 - Resultados do Monitoramento Semanal do Sistema PARCIAL ("P") na 2 ${ }^{\mathrm{a}}$ Fase na Pesquisa (Conclusão)

\begin{tabular}{|c|c|c|c|c|c|c|c|c|c|c|c|c|c|c|}
\hline Mês/Ano & $\begin{array}{c}\text { N-NO2- ret P } \\
(\mathrm{mg} / \mathrm{L})\end{array}$ & $\begin{array}{c}\text { N-NO3- anx P } \\
(\mathrm{mg} / \mathrm{L})\end{array}$ & $\begin{array}{c}\text { N-NO3- aer P } \\
(\mathrm{mg} / \mathrm{L})\end{array}$ & $\begin{array}{c}\text { N-NO3- dec P } \\
(\mathrm{mg} / \mathrm{L})\end{array}$ & $\begin{array}{c}\text { N-NO3- ret P } \\
(\mathrm{mg} / \mathrm{L})\end{array}$ & $\begin{array}{c}\text { DBO afl P } \\
(\mathrm{mg} / \mathrm{L})\end{array}$ & $\begin{array}{c}\text { DBO dec P } \\
(\mathrm{mg} / \mathrm{L})\end{array}$ & $\begin{array}{c}\text { DQO afl P } \\
(\mathrm{mg} / \mathrm{L})\end{array}$ & $\begin{array}{c}\text { DQO anx P } \\
(\mathrm{mg} / \mathrm{L})\end{array}$ & $\begin{array}{c}\text { DQO dec P } \\
(\mathrm{mg} / \mathrm{L})\end{array}$ & $\begin{array}{l}\text { Alcalin anx P } \\
\left(\mathrm{mgCaCO}_{3} / \mathrm{L}\right)\end{array}$ & $\begin{array}{l}\text { Alcalin aer P } \\
\left(\mathrm{mgCaCO}_{3} / \mathrm{L}\right)\end{array}$ & $\begin{array}{l}\text { Alcalin dec P } \\
\left(\mathrm{mgCaCO}_{3} / \mathrm{L}\right)\end{array}$ & $\begin{array}{c}\text { Alcalin ret P } \\
\left(\mathrm{mgCaCO}_{3} / \mathrm{L}\right)\end{array}$ \\
\hline mai/06 & 0,4 & 125 & 94,1 & 184 & 100 & 3969 & 5 & 3048 & 190 & 145 & 340 & 230 & 258 & 330 \\
\hline mai/06 & 0,9 & 69,4 & 42,4 & 111 & 101 & 2221 & 104 & 5053 & 371 & 152 & 2850 & 3130 & 2960 & 3330 \\
\hline mai/06 & 0,9 & & & & & 1694 & 3 & 2133 & 366 & 168 & 1908 & 1690 & 1616 & 1764 \\
\hline mai/06 & 0,3 & & & & & 2294 & 11 & 2943 & 196 & 219 & 990 & 688 & 658 & 944 \\
\hline mai/06 & 5,8 & 19,2 & 111 & 128 & 112 & 1720 & 8 & 4400 & 140 & 147 & 504 & 294 & 240 & 510 \\
\hline jun/06 & 0,7 & 54,3 & 124 & 170 & 110 & 1682 & 9 & 3010 & 491 & 253 & 756 & 446 & 528 & 766 \\
\hline jun/06 & 0,3 & 36,0 & 115 & 183 & 136 & 1137 & 28 & 2718 & 155 & 163 & 784 & 540 & 500 & 846 \\
\hline jun/06 & 3,4 & 24,5 & 69,9 & 73,6 & 73,6 & 1395 & 4 & 1724 & 90 & 103 & 824 & 598 & 522 & 678 \\
\hline jun/06 & 0,2 & & & & & 775 & 7 & 2692 & 54 & 85 & 704 & 670 & 590 & 644 \\
\hline jul/06 & 0,9 & & & & & 1240 & 2 & 2902 & 141 & 63 & 752 & 710 & 702 & 670 \\
\hline jul/06 & 0,0 & & & & & 1683 & 12 & 2538 & 115 & 100 & 864 & 690 & 510 & 960 \\
\hline jul/06 & 0,2 & & & & & 1533 & 1 & 2766 & 67 & 60 & 644 & 538 & 380 & 410 \\
\hline jul/06 & 1,0 & & & & & 803 & 8 & 2593 & 800 & 393 & 796 & 1020 & 768 & 872 \\
\hline jul/06 & 0,1 & & & & & 1843 & 26 & 2667 & 244 & 99 & 1036 & 1052 & 822 & 1060 \\
\hline ago/06 & 0,3 & & & & & & & & & & & & & \\
\hline ago/06 & 0,7 & & & & & 3230 & 3 & 3170 & 255 & 121 & 966 & 834 & 706 & 1054 \\
\hline ago/06 & 1,2 & 68,2 & 268 & 273 & 267,1 & 1160 & 12 & 3168 & 119 & 131 & 1062 & 1020 & 798 & 840 \\
\hline ago/06 & 0,0 & 48,9 & 175 & 195 & 201 & 1041 & 4 & 3686 & 167 & 94 & 1330 & 1076 & 930 & 1178 \\
\hline set/06 & 0,1 & 42,9 & 206 & 210 & 119 & 1148 & 15 & 3615 & 269 & 292 & 1064 & 858 & 814 & 972 \\
\hline set/06 & 0,8 & 34,5 & 67,2 & 239 & 171 & 1314 & 11 & 2951 & 194 & 101 & 1032 & 686 & 650 & 934 \\
\hline set/06 & 0,0 & 36,4 & 261 & 271 & 278 & 148 & 17 & 2308 & 154 & 100 & 746 & 152 & 136 & 328 \\
\hline set/06 & 0,3 & 31,6 & 124 & 222 & 153 & 438 & 9 & 4038 & 86 & 30 & 410 & 58 & 10 & 60 \\
\hline out/06 & 2,5 & 24,2 & 208 & 244 & 228 & 1253 & 7 & 3089 & 307 & 95 & 500 & 96 & 32 & 34 \\
\hline out/06 & 0,9 & 23,5 & 182 & 183 & 175 & & & 1613 & 137 & 137 & 446 & 18 & 22 & 36 \\
\hline out/06 & 1,9 & 21,5 & 152 & 152 & 160 & & & 3010 & 337 & 178 & 686 & 30 & 20 & 88 \\
\hline out/06 & 15,5 & 23,7 & 85 & 93,1 & 85 & 659 & 3 & 2097 & 252 & 350 & 420 & 28 & 24 & 28 \\
\hline out/06 & 6,0 & 18,4 & 57,8 & 61,6 & 57,3 & & & 3728 & 282 & 186 & 168 & 30 & 16 & 44 \\
\hline nov/06 & 2,9 & 17,9 & 45,4 & 48,2 & 44,2 & 605 & 4 & 2308 & 385 & 260 & 210 & 16 & 18 & 64 \\
\hline nov/06 & 48,1 & 17,9 & 33,0 & 35,2 & 22,9 & 1409 & 34 & 2535 & 307 & 158 & 1788 & 1866 & 1728 & 1980 \\
\hline nov/06 & 77,1 & 22,3 & 59,4 & 61,6 & 58,5 & 1041 & 40 & 2535 & 198 & 228 & 1710 & 1580 & 1470 & 1780 \\
\hline nov/06 & 42,9 & 27,9 & 61,9 & 77,7 & 69,5 & 1040 & 33 & 3960 & 248 & 178 & 1290 & 1290 & 1160 & 1510 \\
\hline nov/06 & 37,9 & 20,1 & 61,0 & 49,4 & 54,1 & & & & & & & & & \\
\hline dez/06 & 21,3 & 12,9 & 38,5 & 46,2 & 42,4 & 756 & 7 & 3029 & 466 & 233 & 1480 & 1378 & 1236 & 1250 \\
\hline dez/06 & 13,2 & 39,2 & 84,7 & 95,7 & 92,5 & & & & & & & & & \\
\hline dez/06 & 4,1 & 14,6 & 31,2 & 33,7 & 27,6 & 793 & 38 & 2415 & 170 & 158 & 1186 & 1212 & 1118 & 1228 \\
\hline dez/06 & 2,0 & 15,5 & 39,6 & 41,7 & 48,8 & & & & & & & & & \\
\hline dez/06 & 6,3 & 39,0 & 85,2 & 72,8 & 51,4 & & & & & & & & & \\
\hline dez/06 & 25,0 & 26,0 & 79,2 & 84,7 & 73,7 & & & & & & & & & \\
\hline jan/07 & 9,3 & 32,6 & 59 & 70,5 & 46,6 & & & & & & 2486 & 2434 & 2400 & 2592 \\
\hline $\mathrm{jan} / 07$ & 11,2 & 8,6 & 28,3 & 28,6 & 26,8 & 1197 & 35 & & & & & & & \\
\hline $\mathrm{jan} / 07$ & 20,3 & 21,6 & 52,6 & 53,5 & 51,3 & 2923 & 78 & & & & 2500 & 2200 & 2300 & 2600 \\
\hline jan/07 & 13,5 & 32,4 & 81,9 & 74,9 & 88,8 & & & & & & & & & \\
\hline $\mathrm{jan} / 07$ & 19,8 & 64,3 & 54,2 & 80,9 & 93,8 & & & & & & 2000 & 1800 & 1700 & 2200 \\
\hline $\mathrm{jan} / 07$ & 0,6 & 40,4 & 69,2 & 79,7 & 78,2 & & & & & & 2000 & 1800 & 1500 & 2300 \\
\hline
\end{tabular}

